\title{
Evaluation of the AASHTO Mechanistic Empirical Pavement Design Guide: An Experimental and Analytical Investigation of the Performance of Flexible Roads
}

\author{
by \\ Omran Maadani \\ MSc. (Civil Engineering)
}

A thesis submitted to the Faculty of Graduate and Postdoctoral Affairs in partial fulfillment of the requirements for the degree of

Doctor of Philosophy

Carleton University

Ottawa, Ontario

(C) 2015, Omran Maadani 


\begin{abstract}
The M-EPDG represents a significant attempt to change the approach to engineering design of road structures. It reflects a shift from total reliance on empirical methods to a combination of mechanistic and empirical methods. Three instrumented road sections were used to capture the impact of local conditions. The measurements indicated that opening roads prematurely to traffic, immediately after construction, may result in high stresses and strains causing excessive deformations in both the asphaltic and unbound layers. Further, controlled truck tests confirmed the vulnerability of roads to premature and excessive distresses under low speed traffic and frequent stopping. The mechanistic characterization of road materials in the laboratory showed that the dynamic modulus is capable of capturing the effect of binder grade, temperature and frequency on the behaviour of asphaltic materials. Moreover, the findings confirmed that the resilient modulus accurately reflects the state of unbound materials in terms of moisture and density changes. The evaluation of the M-EPDG and its ability to model and predict the behaviour observed in the field showed that it is sensitive to binder performance grades as well as to climatic zones. However, the M-EPDG showed limited sensitivity to the state of unbound materials where permanent deformation showed negligible changes between wet, dry, and optimum conditions. The M-EPDG predicted rutting performances reflecting sufficient sensitivity compared to the field performance at the three different sites. The model predictions and actual field results were in good agreement and the deviations were within the margin of error. However, the M-EPDG falls short of
\end{abstract}


modeling the thermal cracking which is a prevalent cause of permanent deterioration in asphalt pavements in cold regions. 


\section{ACKNOWLEDGMENTS}

The author wishes to express his appreciation to his thesis supervisor, Prof. A.O. Abd El Halim, Department of Civil and Environmental Engineering, Carleton University, for his suggestion of the thesis topic and for the support, encouragement and guidance throughout the course of this work.

Special thanks go to the following staff of NRC, Construction portfolio: to Dr.

Jim Boudeoin, Dr. Morched Zeghal, Mr. Jim Margerson, and to the late Dr. Mostaf Nofal for their advice, suggestions and editing assistance.

The author is also grateful to the National Research Council of Canada and Natural Sciences and Engineering Research Council of Canada for their financial support and guidance.

Finally, I wish to thank my family, friends and NRC staff for their patience and support and understanding throughout the course of this research work. 
Table of contents

\section{Page}

$\begin{array}{lc}\text { Abstract } & \text { ii } \\ \text { Acknowledgment } & \text { iv } \\ \text { Table of Contents } & \mathrm{v} \\ \text { List of Tables } & \text { xi } \\ \text { List of Figures } & \text { xiii } \\ \text { List of Symbols } & \text { xxii }\end{array}$

Table of contents

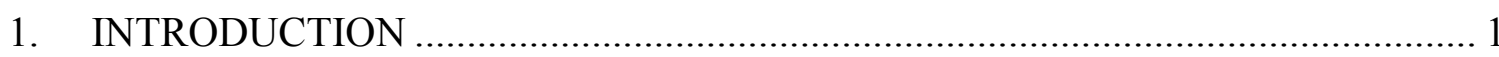

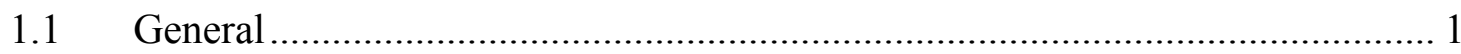

1.2 Problem definition ........................................................................... 3

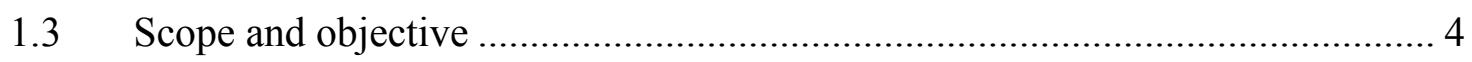

1.4 Organization of the thesis ....................................................................... 5

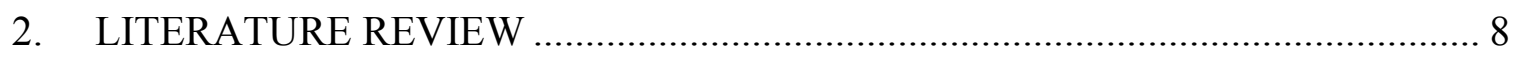

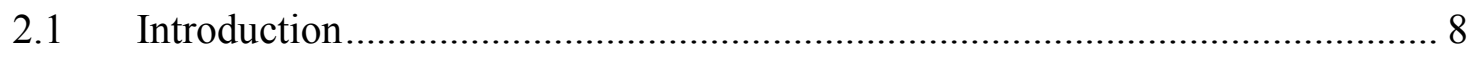

2.2 AASHTO flexible pavement design guides............................................ 9

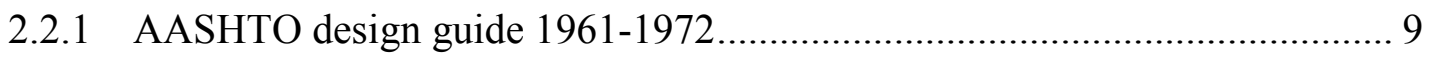

2.2.1.1 Design principles: ................................................................ 9

2.2.1.2 Design input factors: ............................................................ 11

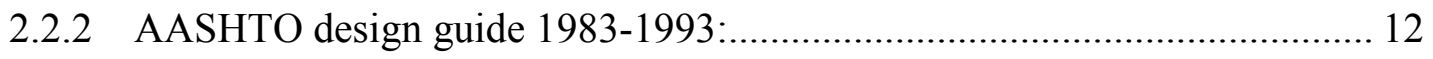

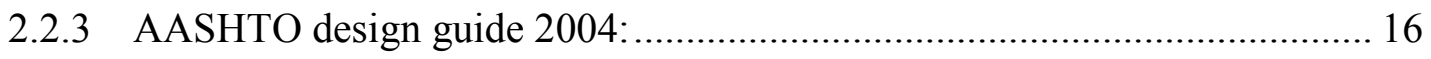

2.2.3.1 Resilient Modulus ................................................................... 18

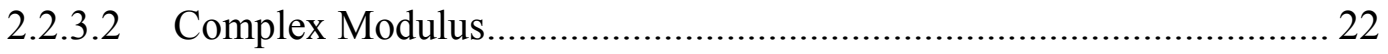




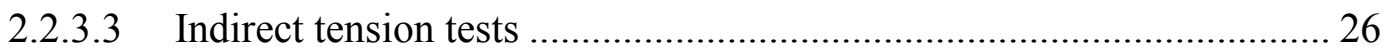

2.2.4 Loading concept of AASHTO design guides ............................................. 27

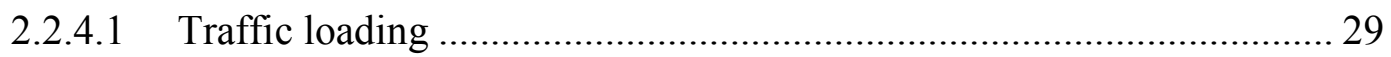

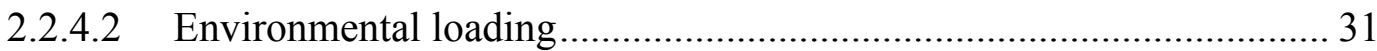

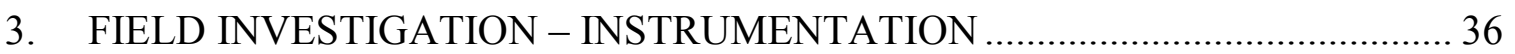

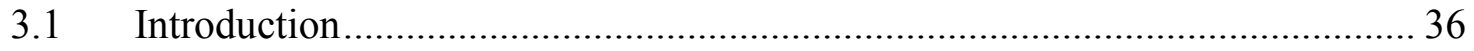

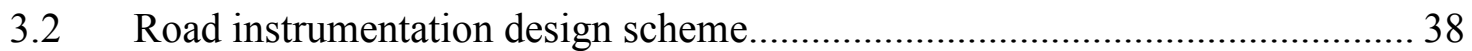

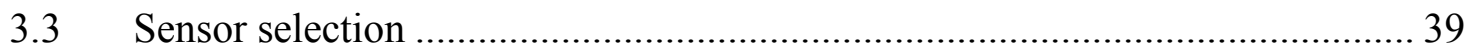

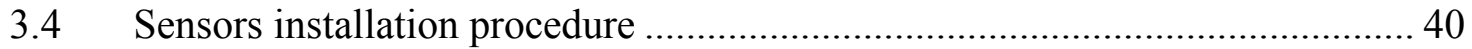

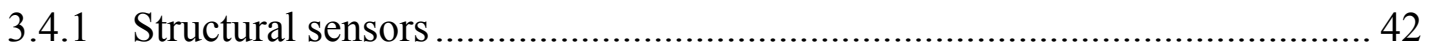

3.4.1.1 Asphalt concrete strain.................................................................... 42

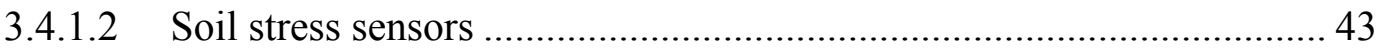

3.4.1.3 EMU Soil deformation sensor (strain) .............................................. 45

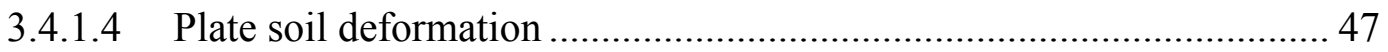

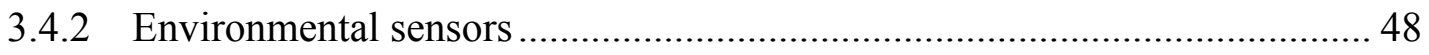

3.4.2.1 Temperature sensor ...................................................................... 48

3.4.2.2 Moisture content sensor .................................................................. 49

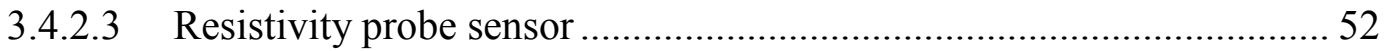

3.5 Data acquisition system ……………………........................................... 53

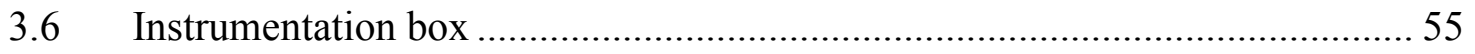

3.7 Data categories and collection methods....................................................... 57

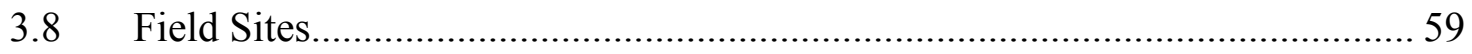

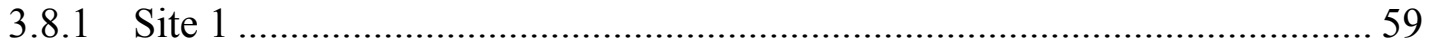




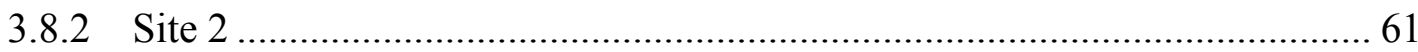

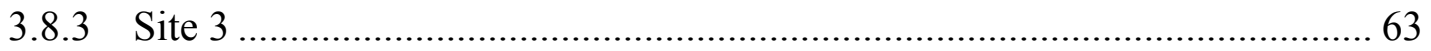

4. FIELD INVESTIGATION - RESULTS AND ANLYSIS ……….............................. 65

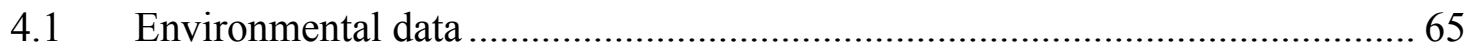

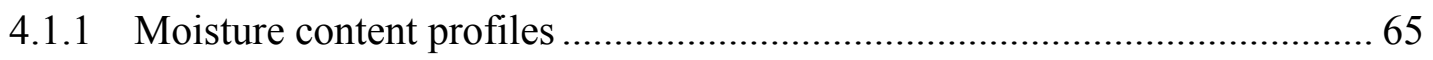

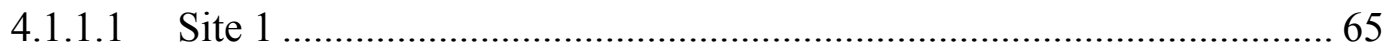

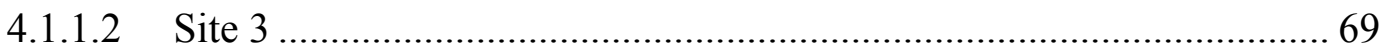

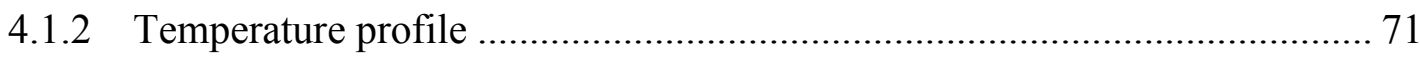

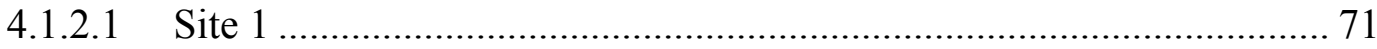

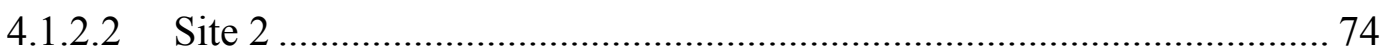

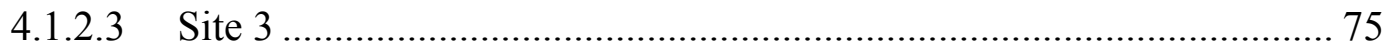

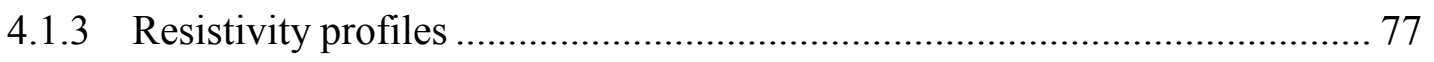

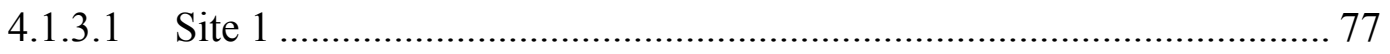

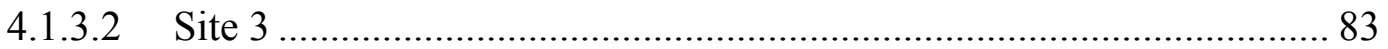

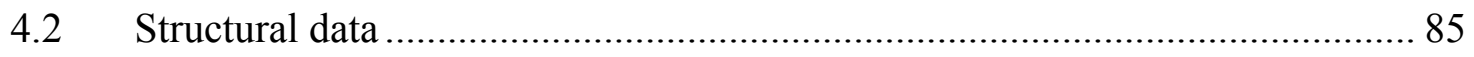

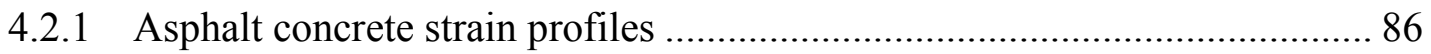

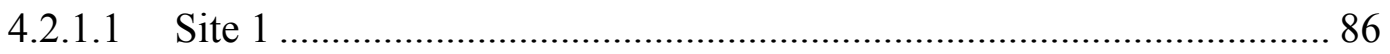

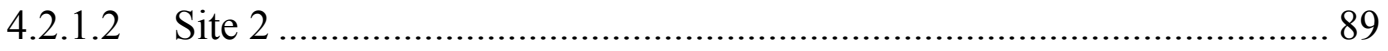

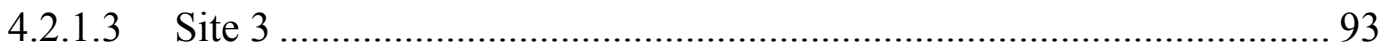

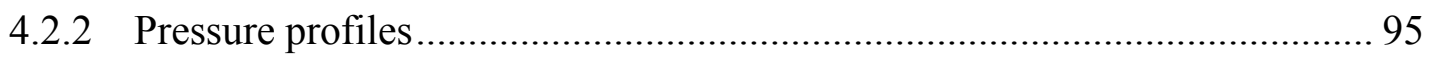

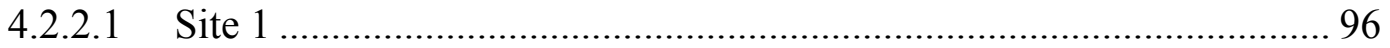

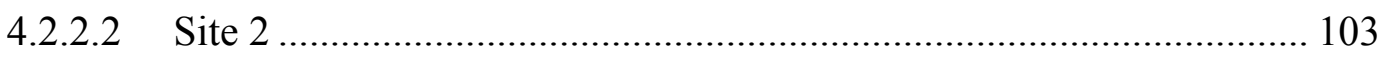

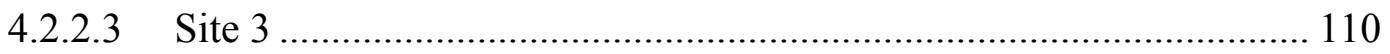


4.2.3 Deformation profiles of bound and unbound materials .......................... 116

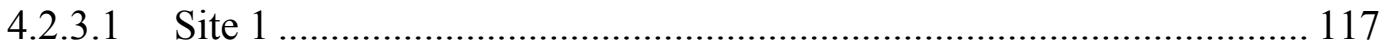

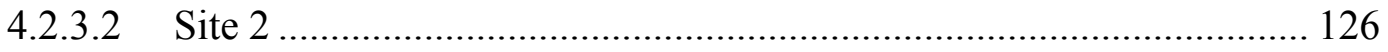

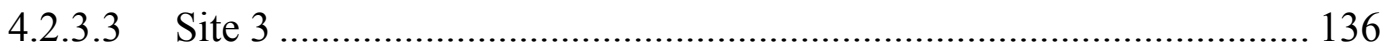

4.3 Impact of loading speed and asphalt concrete temperature on structural data 146

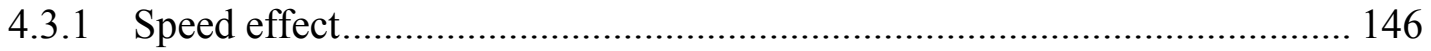

4.3.2 Asphalt concrete temperature effect .................................................. 152

5. LABORATORY INVESTIGATION - RESULTS AND ANALYSIS................. 163

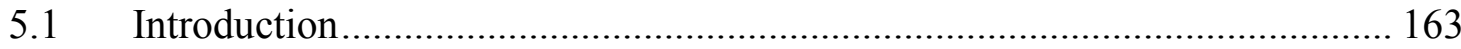

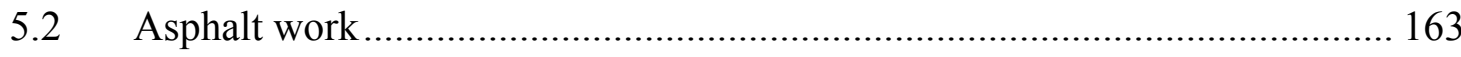

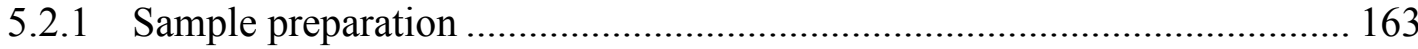

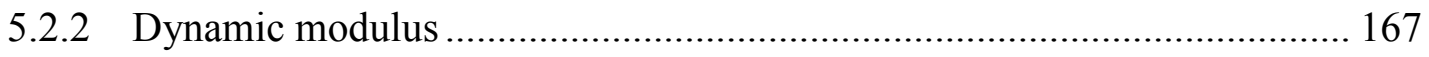

5.2.3 Creep compliance and tensile strength ............................................. 172

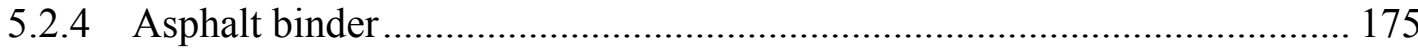

5.3 Unbound and sub-grade materials ..................................................... 177

5.3.1 Sieve analysis and Atterberg limits................................................... 177

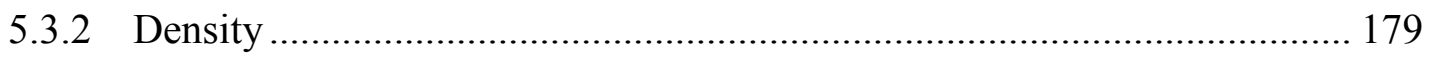

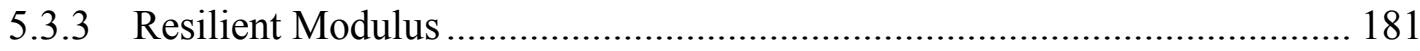

6. THICKNESS DESIGN OF FLEXIBLE PAVEMENT .................................... 183

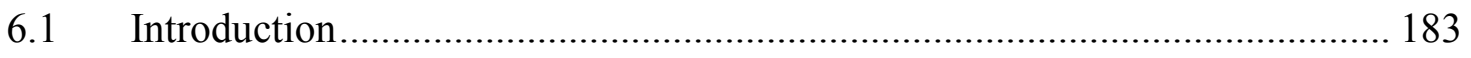

6.2 Computation of the design ESAL .............................................................. 184

6.3 Computation of pavement structure layer thicknesses............................. 186

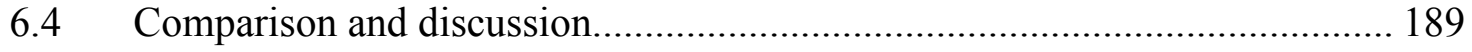


7. EVALUATION OF THE M-EPDG

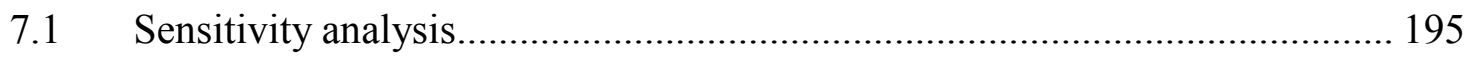

7.1.1 Effect of M-EPDG layer thickness limitation on permanent deformation . 197

7.1.2 Effect of climate on M-EPDG model performances.................................. 199

7.1.2.1 Permanent deformation ..................................................................... 199

7.1.2.2 Surface down fatigue (longitudinal) cracking.................................... 200

7.1.2.3 Bottom up fatigue (alligator) cracking ............................................... 201

7.1.2.4 Thermal cracking .......................................................................... 202

7.1.2.5 International Roughness Index (IRI) .............................................. 203

7.1.3 Effect of binder type and soil condition on M-EPDG model performances204

7.1.3.1 Asphalt concrete permanent deformation ........................................... 204

7.1.3.2 Unbound material permanent deformation ........................................ 206

7.1.3.3 Surface down fatigue (longitudinal) cracking..................................... 208

7.1.3.4 Bottom up fatigue (alligator) cracking ............................................... 212

7.1.3.5 International Roughness Index (IRI) ............................................... 214

7.1.4 Effect of traffic speed on M-EPDG model performances ........................... 214

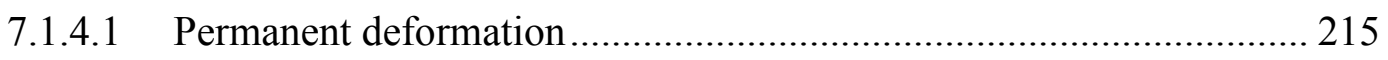

7.1.4.2 Surface down fatigue (longitudinal) cracking.................................... 218

7.1.4.3 Bottom up fatigue (alligator) cracking ............................................... 220

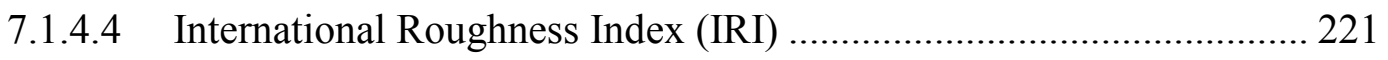

7.1.5 Effect of traffic capacity on M-EPDG model performances ...................... 221

7.1.5.1 Permanent deformation .................................................................. 222

7.1.5.2 Surface down fatigue (longitudinal) cracking.................................... 223 
7.1.5.3 Bottom up fatigue (alligator) cracking ........................................ 224

7.1.5.4 International Roughness Index (IRI) ........................................ 225

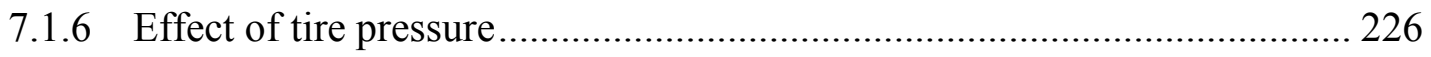

7.1.6.1 Permanent deformation ................................................................. 226

7.1.6.2 Surface down fatigue (longitudinal) cracking............................... 229

7.1.6.3 Bottom up fatigue (alligator) cracking...................................... 231

7.1.6.4 International Roughness Index (IRI) ......................................... 232

7.2 Pavement management system ............................................................ 233

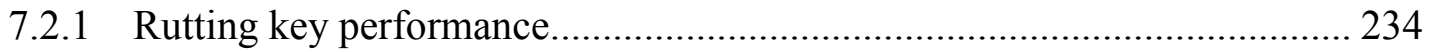

7.2.2 Longitudinal cracking key performance ......................................... 236

7.2.3 Alligator cracking key performance ................................................ 237

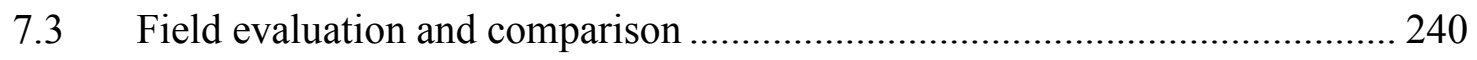

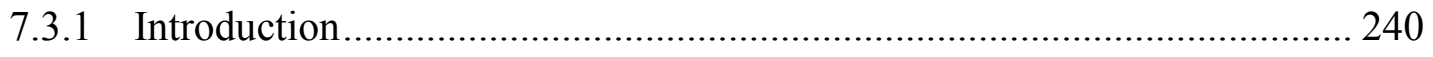

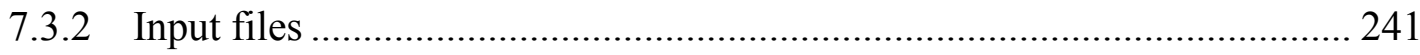

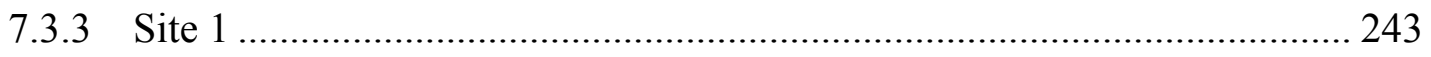

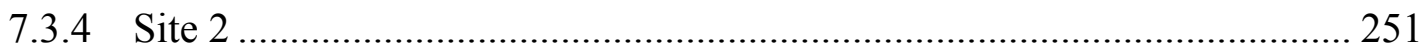

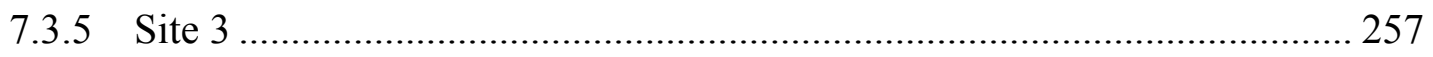

8. SUMMARY, CONCLUSIONS AND RECOMMENDATIONS ......................... 267

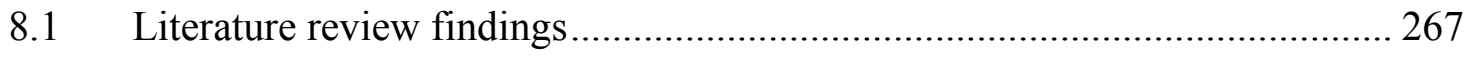

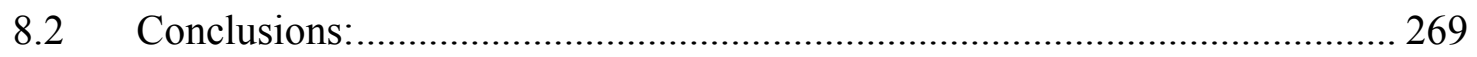

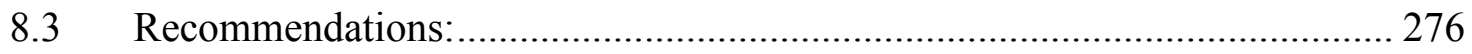

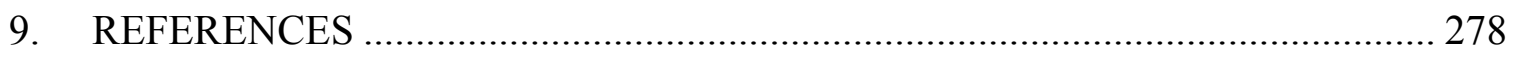




\section{List of tables}

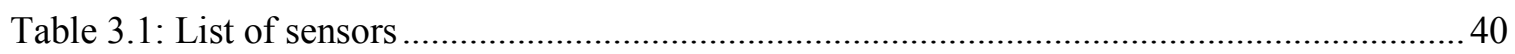

Table 5.1: Hot Mix Asphalt requirements for the aggregate control point................................ 165

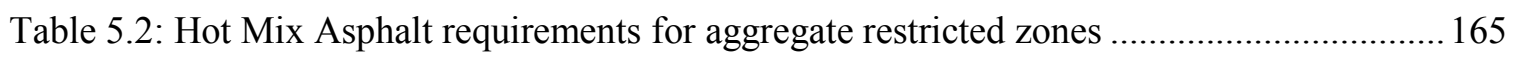

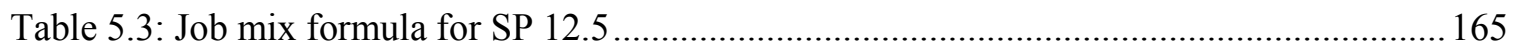

Table 5.4: Aggregate gradation for Hot Mix Asphalt-OPSS ................................................... 166

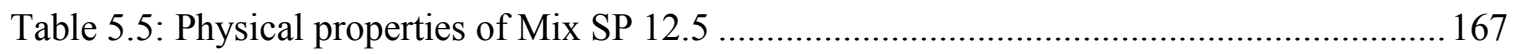

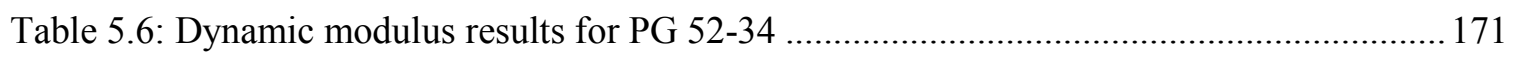

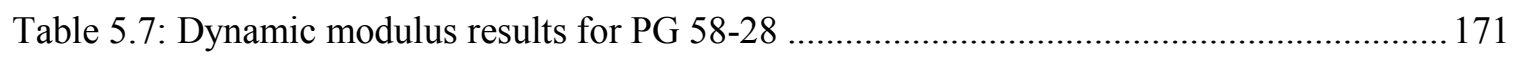

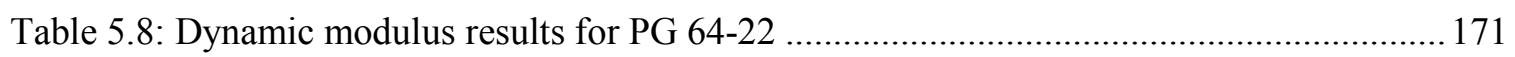

Table 5.9: Creep compliance results for PG 52-34 …......................................................... 174

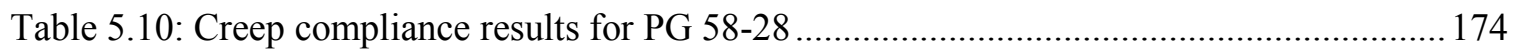

Table 5.11: Creep compliance results for PG 64-34 …........................................................ 175

Table 5.12: Recommended A and VTS parameters based on asphalt PG grades ....................... 176

Table 5.13: Binders complex shear modulus and phase angle ................................................ 177

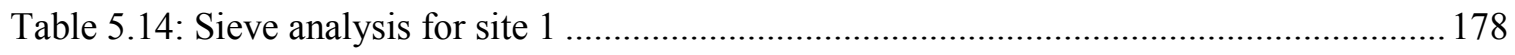

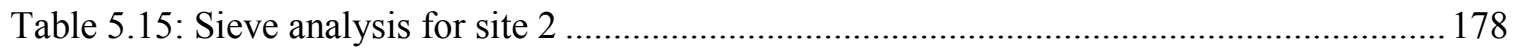

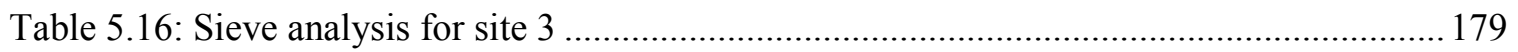

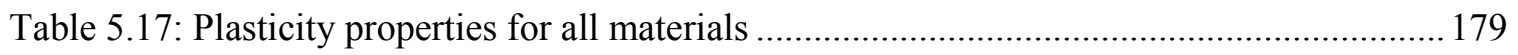

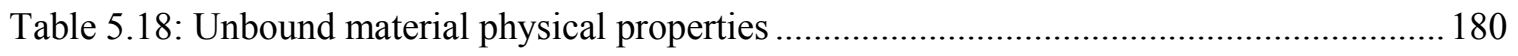

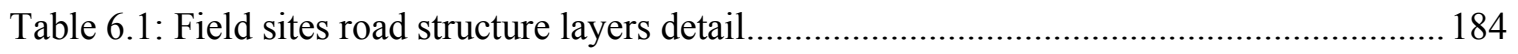

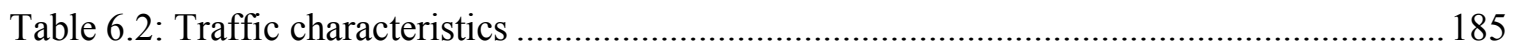

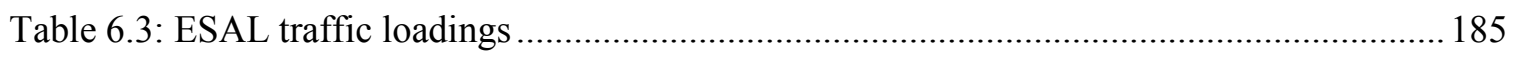

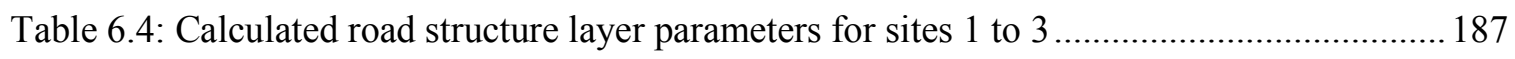

Table 6.5: AASHTO recommended minimum thickness of highway layers............................. 188 
Table 6.6: Calculated, designed and constructed road structure layers for sites 1 to 3

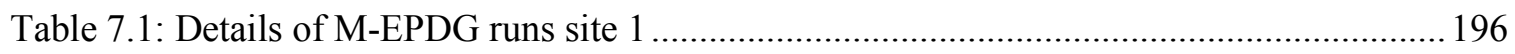

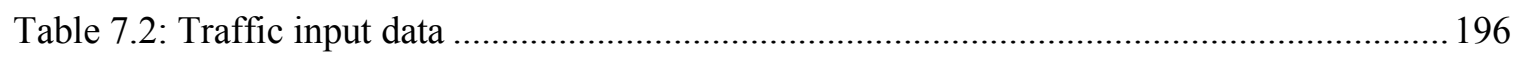

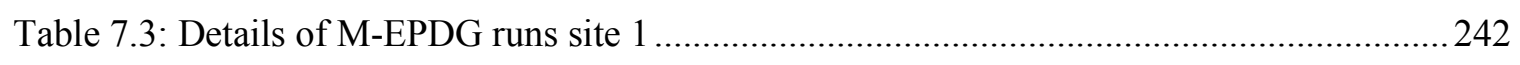

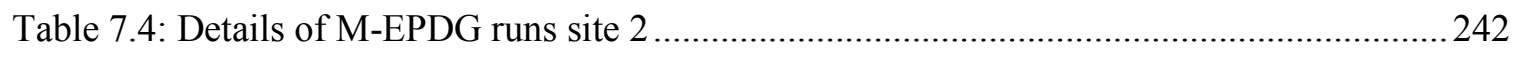

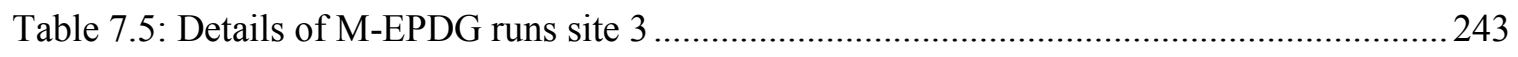

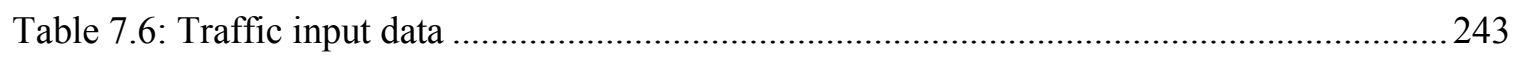




\section{List of figures}

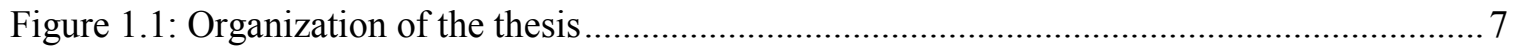

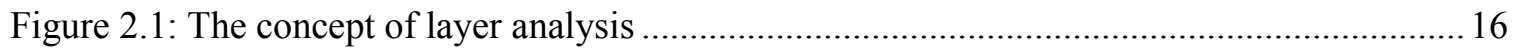

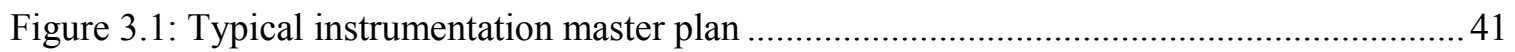

Figure 3.2: Installation of the AC strain gauges in the overlay in both directions........................ 43

Figure 3.3: Sanding underneath the pressure cell during site installation in case of granular

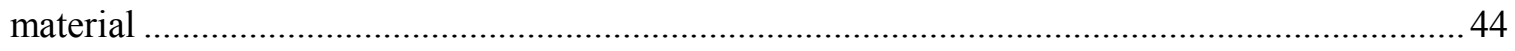

Figure 3.4: Installing and surveying the location of a pressure cell......................................... 45

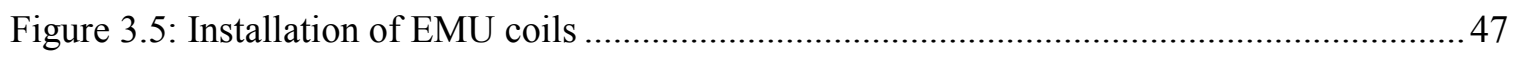

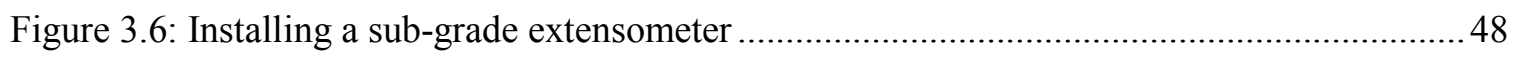

Figure 3.7: Typical installation of a thermocouple ................................................................. 49

Figure 3.8: Installation of the water content reflectometer ................................................... 51

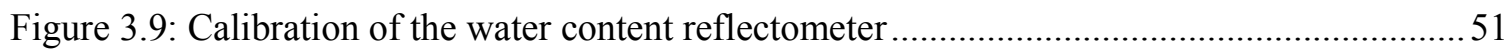

Figure 3.10: Installation of CRREL resistivity probe …......................................................... 52

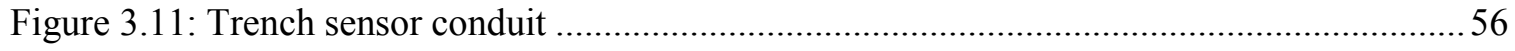

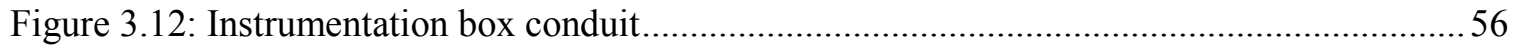

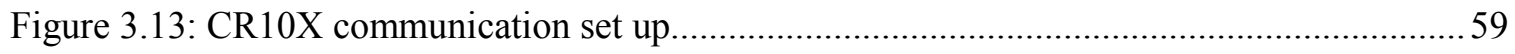

Figure 3.14: Vertical distribution of environmental and structural sensors-site 1 ....................... 61

Figure 3.15: Vertical distribution of environmental and structural sensors-site 2 .......................63

Figure 3.16: Vertical distribution of environmental and structural sensors-site 3 ....................... 64

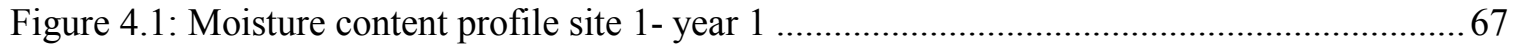

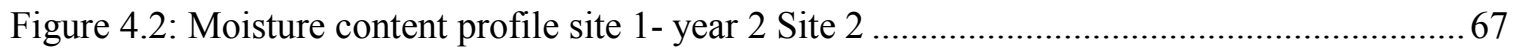

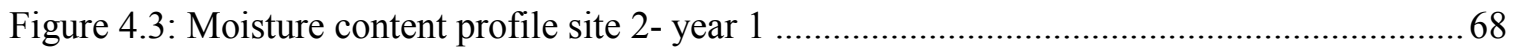

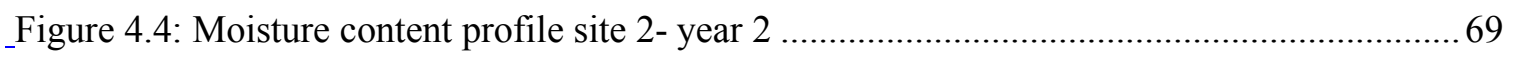

Figure 4.5: Moisture content profile site 3- year 1 ............................................................... 70

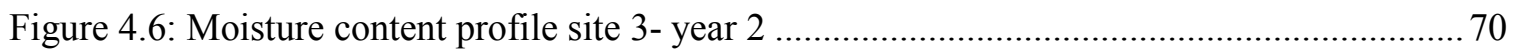




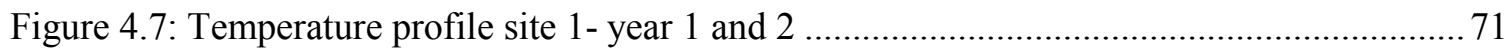

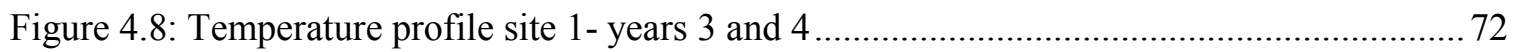

Figure 4.9: Site 1 freeze and thaw cycle for years 1 and 2 using thermocouple sensors .............. 73

Figure 4.10: Site 1 freeze and thaw cycle for years 3 and 4 using thermocouple sensors ............ 74

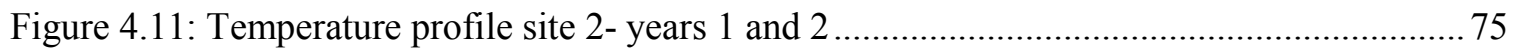

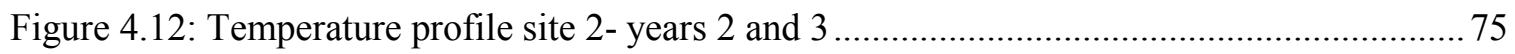

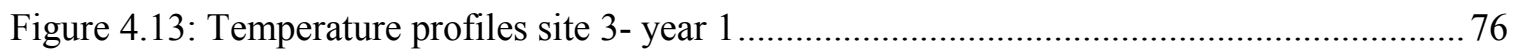

Figure 4.14: Site 3 freeze and thaw cycle for years 1 and 2 using thermocouple sensors ............. 77

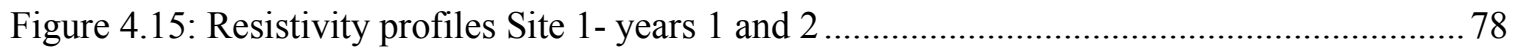

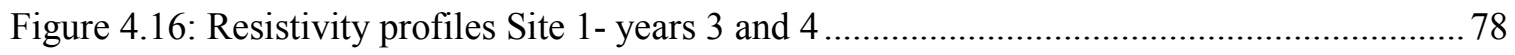

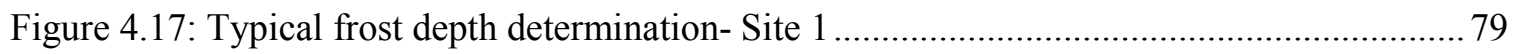

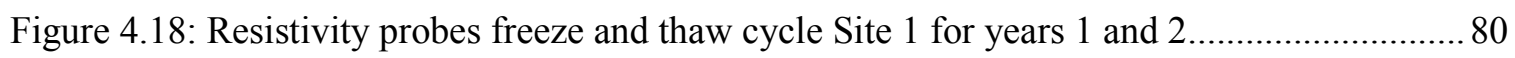

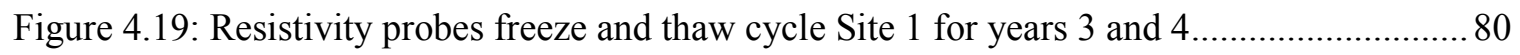

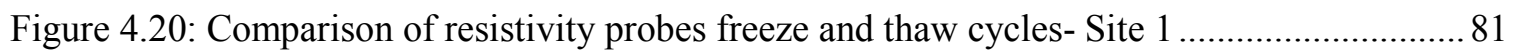

Figure 4.21: Comparison of freeze and thaw cycle using thermocouple and resistivity probes Site

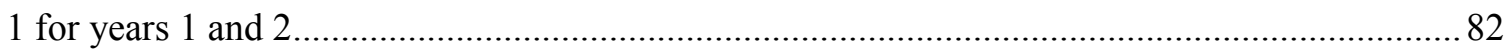

Figure 4.22: Comparison of freeze and thaw cycle using thermocouple and resistivity ............... 82

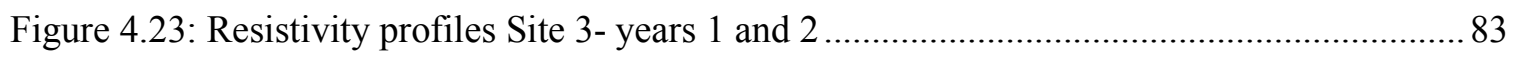

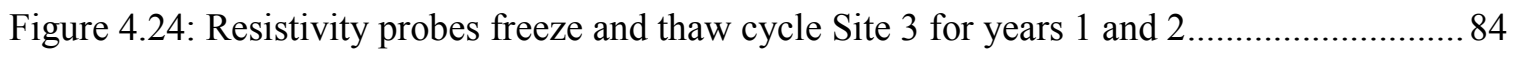

Figure 4.25: Comparison of freeze and thaw cycle using thermocouple and resistivity ............... 85

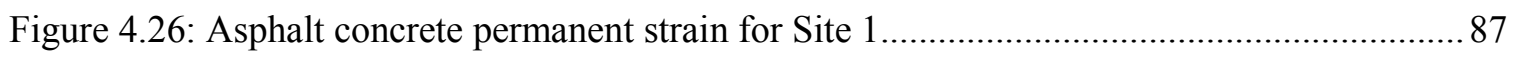

Figure 4.27: Truck impact on asphalt concrete strain gauge in the $\mathrm{x}$-direction for Site 1 ............88

Figure 4.28: Truck impact on asphalt concrete strain gauge in the y-direction for Site 1 ............88

Figure 4.29: Asphalt concrete permanent strain-x direction for Site 2 ..................................... 89

Figure 4.30: Asphalt concrete permanent strain- y direction for Site 1 ..................................... 90

Figure 4.31: Truck impact on asphalt concrete strain measurements in the $\mathrm{x}$-direction for ..........91 
Figure 4.32: Truck impact on asphalt concrete strain measurements in the y-direction for..... 91

Figure 4.33: Truck impact on asphalt concrete strain measurements in the x-direction for Site 2-

( 9 months after construction) 92

Figure 4.34: Truck impact on asphalt concrete strain measurements in the y-direction for 93

Figure 4.35: Asphalt concrete permanent strain- x-direction for Site 3 ...................................... 94

Figure 4.36: Asphalt concrete permanent strain- y-direction for Site 3 ...................................... 94

Figure 4.37: Truck impact on asphalt concrete strain measurements in the y-direction for ..........95

Figure 4.38: Overburden pressure at $400 \mathrm{~mm}$ below the surface .............................................. 96

Figure 4.39: Overburden pressure at $640 \mathrm{~mm}$ below the surface ............................................. 97

Figure 4.40: Overburden pressure at $1510 \mathrm{~mm}$ below the surface ............................................. 97

Figure 4.41: Overburden pressure at $2570 \mathrm{~mm}$ below the surface- Site 1 .................................. 98

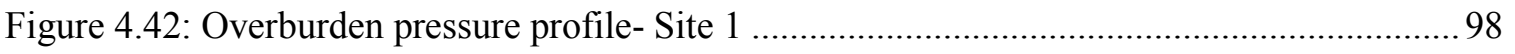

Figure 4.43: Vertical pressure records for truck impact in year 1- Site 1 .................................... 99

Figure 4.44: Vertical pressure records for truck impact in year 1- Site 1 .................................. 100

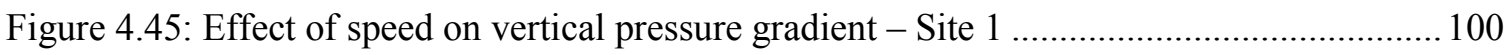

Figure 4.46: Vertical pressure records for truck impact in September, year 2- Site 1 ................ 101

Figure 4.47: Comparison of the vertical pressure records for truck impact in years 1 and 2- Site 1

Figure 4.48: Decay of vertical pressure due to truck impact- Site 1 .......................................... 102

Figure 4.49: Overburden pressure at $290 \mathrm{~mm}$ below the surface- Site 2 .................................. 103

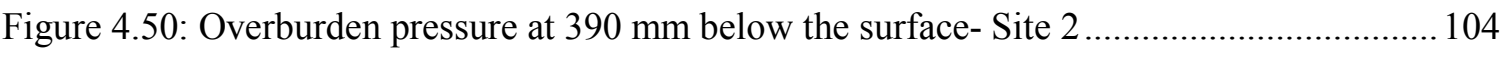

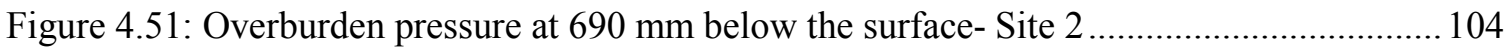

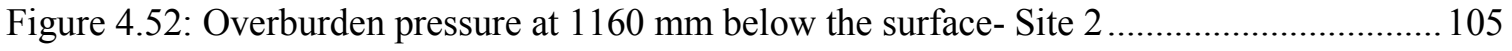

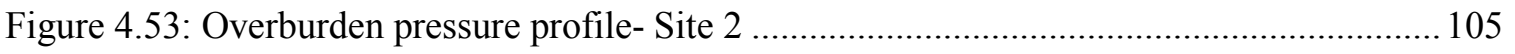

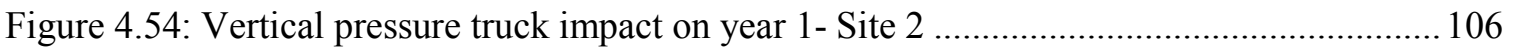

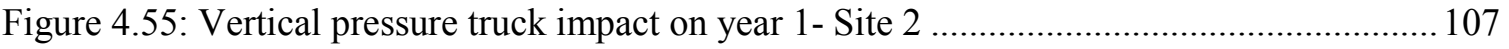




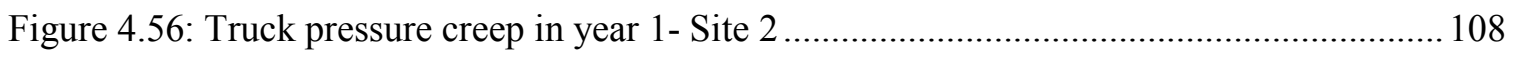

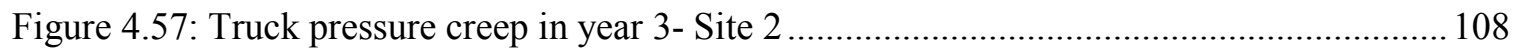

Figure 4.58: Vertical pressure truck impact at speed of $3 \mathrm{~km} / \mathrm{h}$ in year 3- Site $2 \ldots \ldots \ldots \ldots \ldots \ldots \ldots \ldots . . . . . . . . .109$

Figure 4.59: Vertical pressure truck impact at speed of $20 \mathrm{~km} / \mathrm{h}$ in year 3- Site $2 \ldots \ldots \ldots \ldots \ldots \ldots \ldots . . . . . . . .109$

Figure 4.60: Vertical pressure truck impact at speed $25 \mathrm{~km} / \mathrm{h}$ in year 3- Site 2 ....................... 110

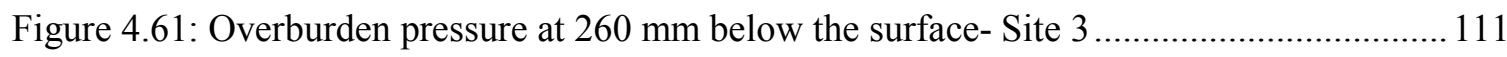

Figure 4.62: Overburden pressure at $465 \mathrm{~mm}$ below the surface- Site 3 .................................. 111

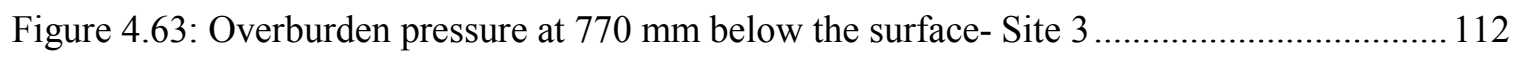

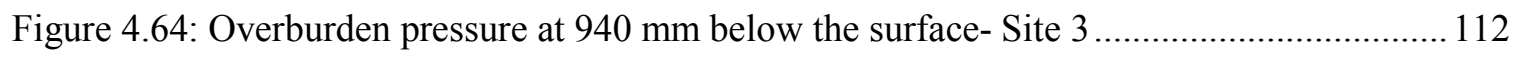

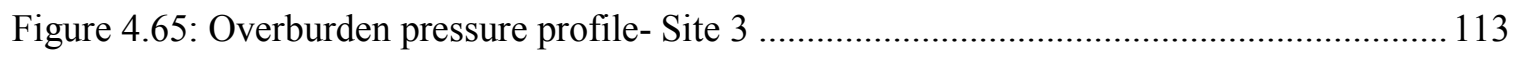

Figure 4.66: Comparison of overburden pressure profile measured using static and .................. 114

Figure 4.67: Vertical pressure truck impact at speed of $45 \mathrm{~km} / \mathrm{h}$ in year 1 - Site $3 \ldots \ldots \ldots \ldots \ldots \ldots \ldots . . . . . . . .115$

Figure 4.68: Vertical pressure truck impact at speed of $35 \mathrm{~km} / \mathrm{h}$ in year 2- Site $3 \ldots \ldots \ldots \ldots \ldots \ldots \ldots . . . . .116$

Figure 4.69: Vertical pressure truck impact at speed of $2 \mathrm{~km} / \mathrm{h}$ in year 2- Site $3 \ldots \ldots \ldots \ldots \ldots \ldots \ldots \ldots . . . . .116$

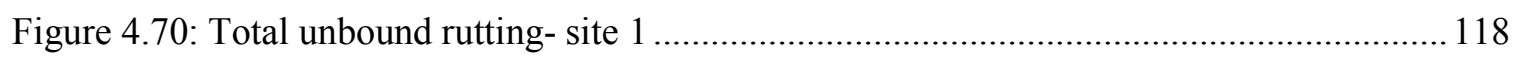

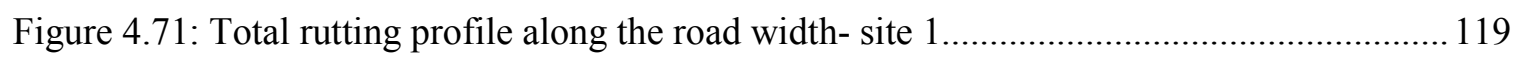

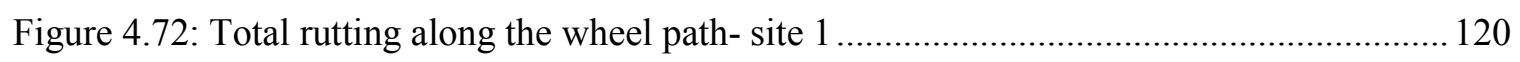

Figure 4.73: Asphalt concrete rutting along the wheel path- site 1 ........................................ 120

Figure 4.74: Vertical strain truck impact at a speed of $15 \mathrm{~km} / \mathrm{h}$ and a depth of $400 \mathrm{~mm}$, year 2-

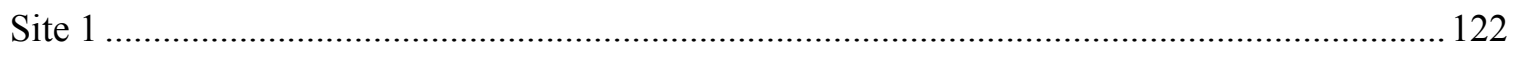

Figure 4.75: Vertical strain truck impact at a speed of $15 \mathrm{~km} / \mathrm{h}$ and a depth of $700 \mathrm{~mm}, \ldots \ldots \ldots . .122$

Figure 4.76: Vertical strain truck impact at a speed of $15 \mathrm{~km} / \mathrm{h}$ and a depth of $1450 \mathrm{~mm}, \ldots \ldots \ldots 123$

Figure 4.77: Vertical strain truck impact at a speed of $15 \mathrm{~km} / \mathrm{h}$ and a depth of $2500 \mathrm{~mm}, \ldots \ldots \ldots 123$

Figure 4.78: Vertical strain truck impact at a speed of $15 \mathrm{~km} / \mathrm{h}$ and a depth of $400 \mathrm{~mm}, \ldots \ldots \ldots . .124$

Figure 4.79: Vertical strain truck impact at a speed of $15 \mathrm{~km} / \mathrm{h}$ and a depth of $700 \mathrm{~mm}$ year 3- site 1. 125 
Figure 4.80: Vertical strain truck impact at a speed of $15 \mathrm{~km} / \mathrm{h}$ and a depth of $1450 \mathrm{~mm}$ 125

Figure 4.81: Comparison of vertical truck impact strain profile in year 2 and year 3- Site $1 \ldots . . .126$

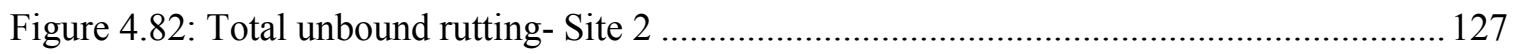

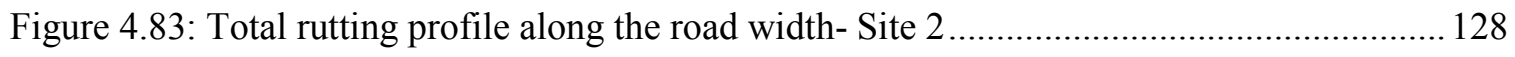

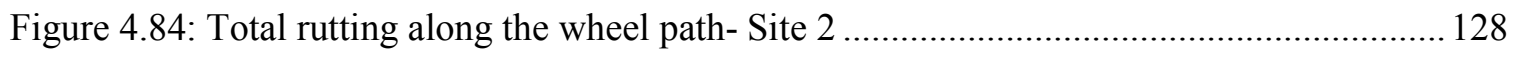

Figure 4.85: Asphalt concrete rutting along the wheel path- Site 2 ........................................ 129

Figure 4.86: Vertical strain truck impact at a speed of $15 \mathrm{~km} / \mathrm{h}$ and a depth of $290 \mathrm{~mm}, \ldots \ldots \ldots . .130$

Figure 4.87: Vertical strain truck impact at a speed of $15 \mathrm{~km} / \mathrm{h}$ and a depth of $390 \mathrm{~mm}, \ldots \ldots \ldots . .131$

Figure 4.88: Vertical strain truck impact at a speed of $15 \mathrm{~km} / \mathrm{h}$ and a depth of $690 \mathrm{~mm}, \ldots \ldots \ldots . .131$

Figure 4.89: Vertical strain truck impact at a speed of $15 \mathrm{~km} / \mathrm{h}$ and a depth of $990 \mathrm{~mm}, \ldots \ldots \ldots . .132$

Figure 4.90: Vertical strain truck impact at a speed of $35 \mathrm{~km} / \mathrm{h}$ and a depth of $390 \mathrm{~mm}, \ldots \ldots \ldots . .132$

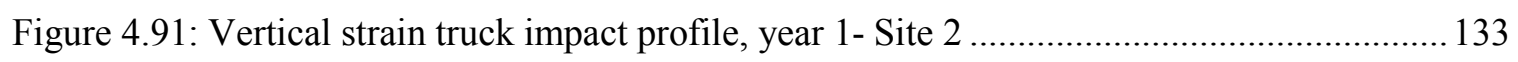

Figure 4.92: Vertical strain truck impact at a speed of $15 \mathrm{~km} / \mathrm{h}$ and a depth of $290 \mathrm{~mm}, \ldots \ldots \ldots . .134$

Figure 4.93: Vertical strain truck impact at a speed of $15 \mathrm{~km} / \mathrm{h}$ and a depth of $390 \mathrm{~mm}, \ldots \ldots \ldots . .134$

Figure 4.94: Vertical strain truck impact at a speed of $15 \mathrm{~km} / \mathrm{h}$ and a depth of $690 \mathrm{~mm}, \ldots \ldots \ldots . .135$

Figure 4.95: Vertical strain truck impact at a speed of $15 \mathrm{~km} / \mathrm{h}$ and a depth of $990 \mathrm{~mm}, \ldots \ldots \ldots . .135$

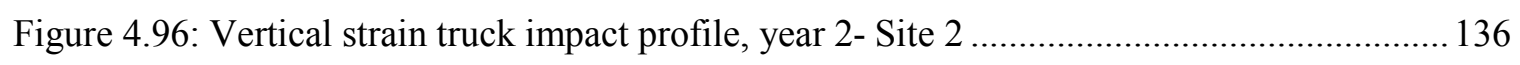

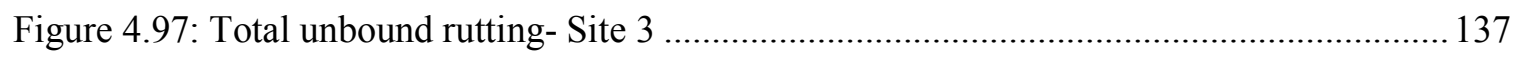

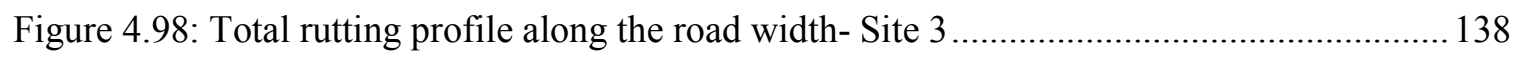

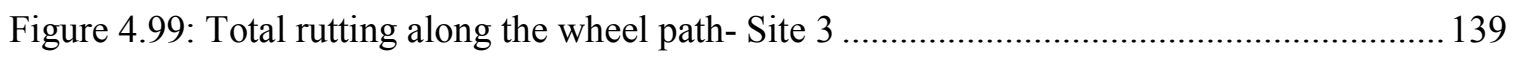

Figure 4.100: Asphalt concrete rutting along the wheel path- Site 3 ....................................... 139

Figure 4.101: Vertical strain truck impact at a depth of $260 \mathrm{~mm}$, year 1- Site 3....................... 141

Figure 4.102: Vertical strain truck impact at a depth of $410 \mathrm{~mm}$, year 1- Site 3 ....................... 141

Figure 4.103: Vertical strain truck impact at a depth of $710 \mathrm{~mm}$, year 1- Site 3 ....................... 142

Figure 4.104: Vertical strain truck impact at a depth of $860 \mathrm{~mm}$, year 1- Site 3 ........................ 142

Figure 4.105: Vertical strain truck impact profile, year 1- Site 3 ........................................... 143 
Figure 4.106: Vertical strain truck impact at a depth of $260 \mathrm{~mm}$, year 2- Site 3. 144

Figure 4.107: Vertical strain truck impact at a depth of $410 \mathrm{~mm}$, year 2- Site 3....................... 144

Figure 4.108: Vertical strain truck impact at a depth of $710 \mathrm{~mm}$, year 2- Site 3........................ 145

Figure 4.109: Vertical strain truck impact at a depth of $860 \mathrm{~mm}$, year 2- Site 3........................ 145

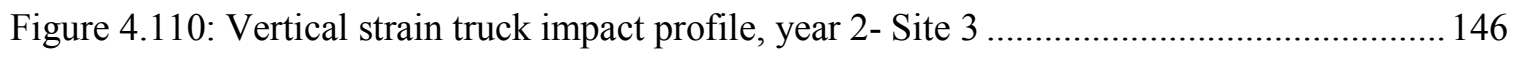

Figure 4.111: Effect of speed on the top pressure cell at a depth of $290 \mathrm{~mm}$, year 1- Site 2...... 148

Figure 4.112: Speed effect on truck strain impact at a depth of $390 \mathrm{~mm}$, year 1- Site 2 ............ 148

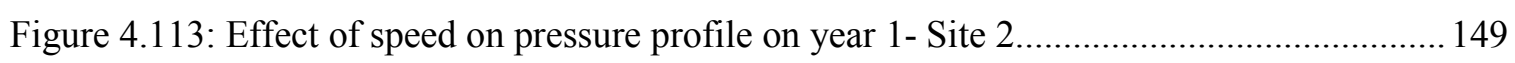

Figure 4.114: Effect of speed on the top pressure cell at depth $290 \mathrm{~mm}$ year 3- Site 2.............. 149

Figure 4.115: Effect of speed on the truck impact pressure profile year 3- Site 2 $2 \ldots \ldots \ldots \ldots \ldots \ldots \ldots \ldots . . . . . .150$

Figure 4.116: Truck impact pressure and speed profile at depth $290 \mathrm{~mm}$ year 3- Site 2............ 150

Figure 4.117: Speed effect on the top pressure cell at a depth of $260 \mathrm{~mm}$, year 2- Site 3.......... 151

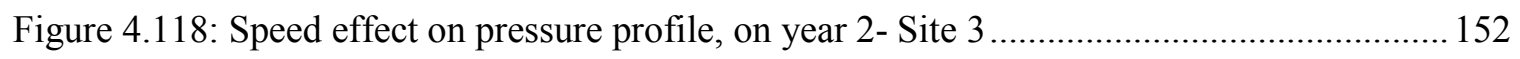

Figure 4.119: Effect of temperature on the top pressure cell at a depth of $290 \mathrm{~mm}$ - Site $2 \ldots \ldots . .156$

Figure 4.120: Effect of temperature on truck pressure impact profile- Site 2 ............................ 156

Figure 4.121: Temperature effect on truck pressure creep at a depth of $290 \mathrm{~mm}$ - Site 2 .......... 157

Figure 4.122: Temperature effect on truck pressure creep profile- Site 2 ................................. 157

Figure 4.123: Temperature effect on the top pressure cell at a depth of $260 \mathrm{~mm}$ - Site $3 \ldots \ldots \ldots \ldots 158$

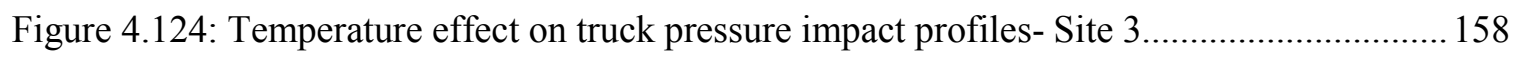

Figure 4.125: Temperature effect on the top EMU coil gauges at a depth of $390 \mathrm{~mm}$ - Site $2 \ldots 160$

Figure 4.126: Effect of temperature on truck strain impact profile- Site 2 ............................... 160

Figure 4.127: Temperature effect on the EMU coil at a depth of $260 \mathrm{~mm}$ - Site 3 ..................... 161

Figure 4.128: Temperature effect on truck strain impact profiles- Site 3 ................................. 161

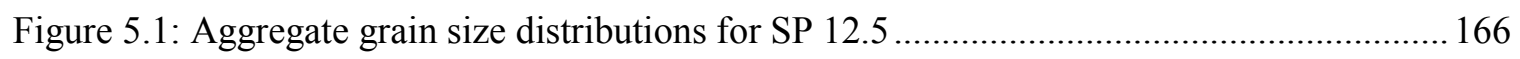

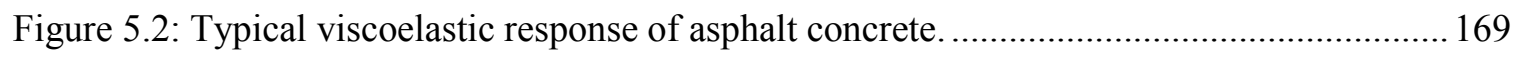

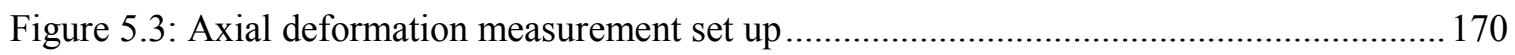


Figure 5.4: Dynamic modulus of SP 12.5 asphalt concrete mixes. 172

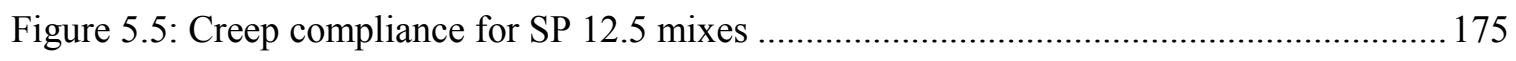

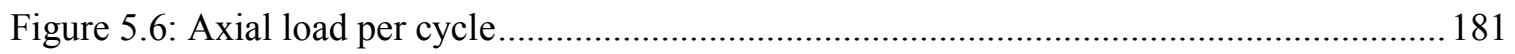

Figure 6.1: AASHTO design guide chart for flexible pavement ............................................ 187

Figure 6.2: Comparison of asphalt concrete layers- ESALs versus constructed ......................... 190

Figure 6.3: Comparison of base course layers- ESALs versus constructed............................... 191

Figure 6.4: Comparison of sub-base course layers- ESALs versus constructed ........................... 191

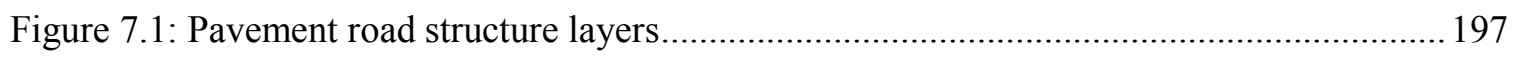

Figure 7.2: Sections considered investigating thickness limitation in the MEPDG ................... 198

Figure 7.3: Effect of software upper limit on permanent deformation ..................................... 199

Figure 7.4: Effect of environment on asphalt concrete rutting ............................................... 200

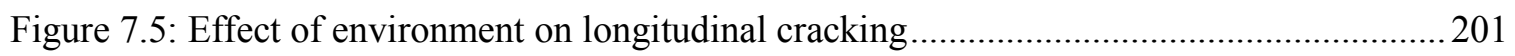

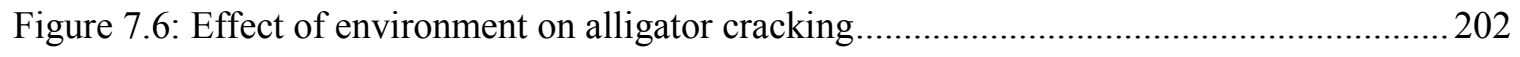

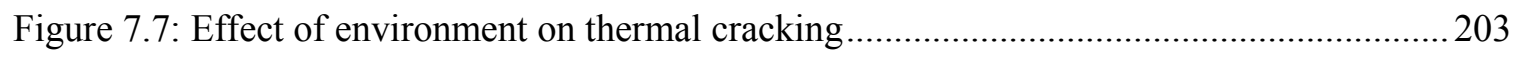

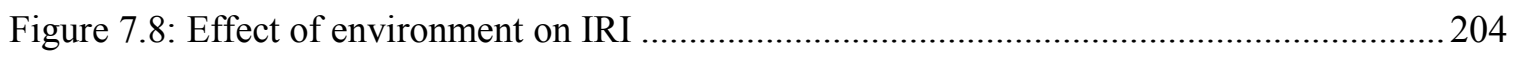

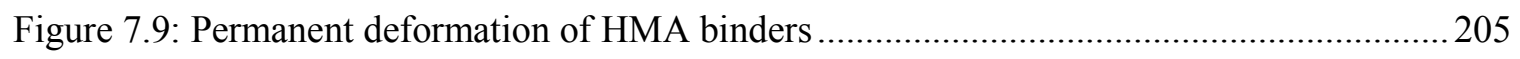

Figure 7.10: Permanent deformation of HMA binders at optimum .......................................... 206

Figure 7.11: Total permanent deformation for bound and unbound material............................ 207

Figure 7.12: Total permanent deformation for bound and unbound material at optimum........... 208

Figure 7.13: Super grade binders effect on longitudinal cracking for the dry soil condition ...... 210

Figure 7.14: Super grade binders' effect on longitudinal cracking for the optimum soil condition

Figure 7.15: Super grade binders' effect on longitudinal cracking for the wet soil condition..... 211

Figure 7.16: Effect of soil condition on the behaviour of super grade binders.......................... 211

Figure 7.17: Super grade binder effect and soil condition on alligator cracking ........................ 213

Figure 7.18: Super grade binder effect on alligator cracking for the optimum soil condition..... 213 
Figure 7.19: Effect of binders and soil condition on IRI 214

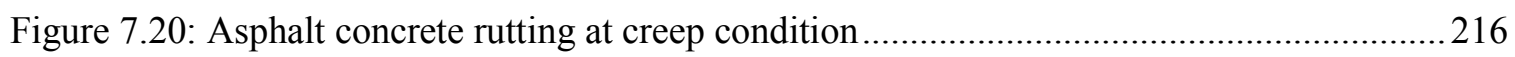

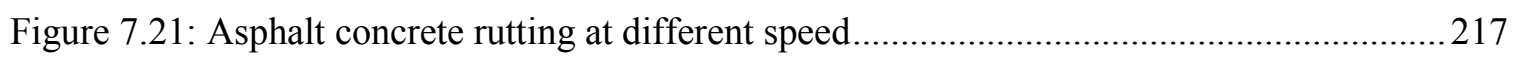

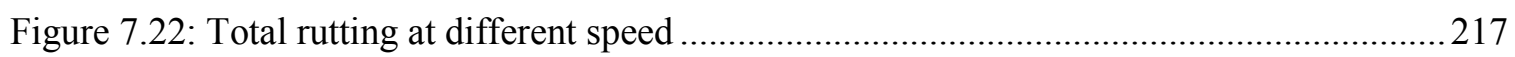

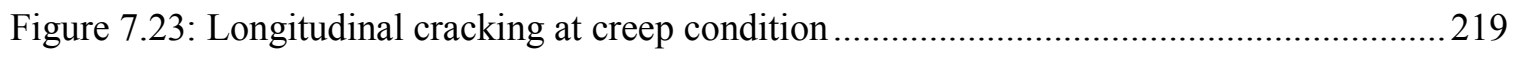

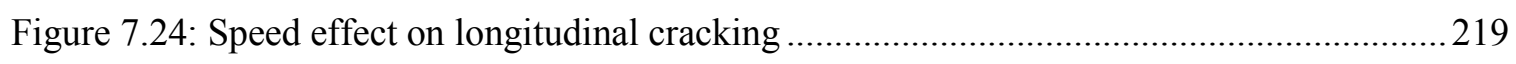

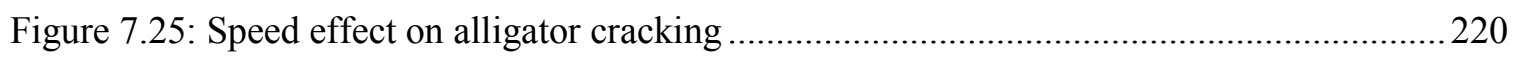

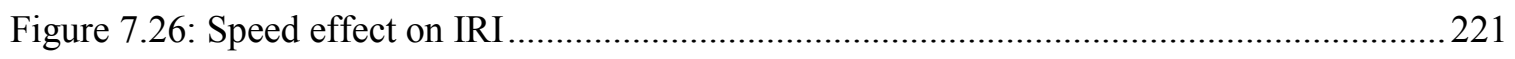

Figure 7.27: Asphalt concrete rutting at different traffic capacity ...........................................222

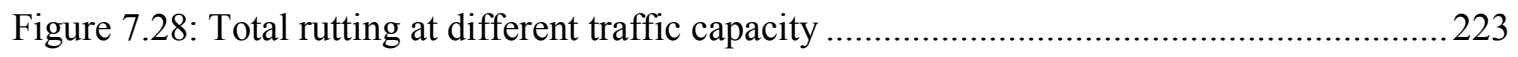

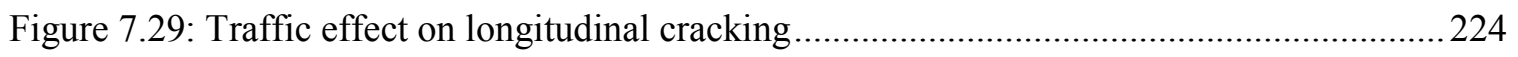

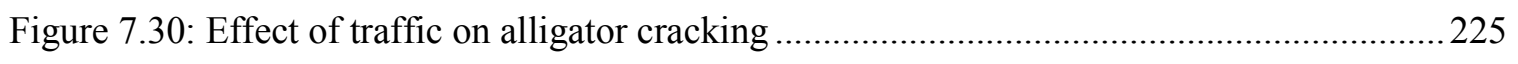

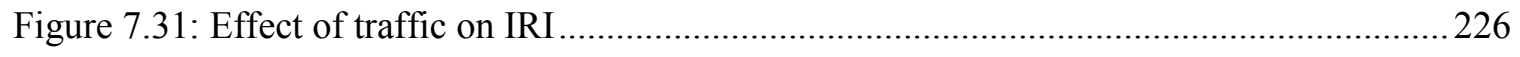

Figure 7.32: Asphalt concrete rutting at different tire pressures..............................................22

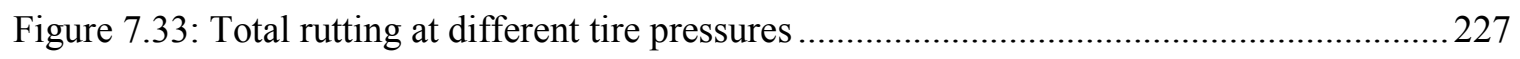

Figure 7.34: Determined asphalt concrete rutting versus tire pressure .....................................229

Figure 7.35: Effect of tire pressures on longitudinal cracking ................................................2 230

Figure 7.36: Tire pressures effect on pavement service life using longitudinal crack ................231

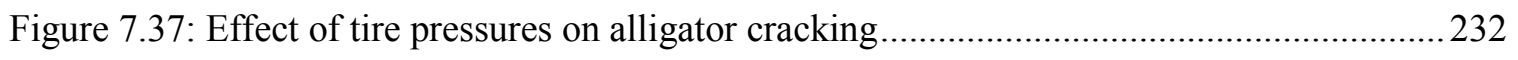

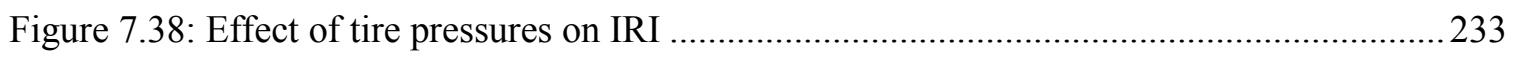

Figure 7.39: Traffic effect on pavement service life using asphalt concrete rutting...................2235

Figure 7.40: Traffic effect on pavement service life using total rutting .....................................235

Figure 7.41: Traffic effect on pavement service life using longitudinal crack ..........................237

Figure 7.42: Traffic effect on pavement service life using alligator cracking as key parameters 238

Figure 7.43: AADT failure limit of road key performance indicators ......................................239

Figure 7.44: Comparison of road design life key performance indicators..................................240 
Figure 7.45: Asphalt concrete rutting - Site 1

Figure 7.46: Asphalt concrete rutting at the optimum soil condition - Site 1 245

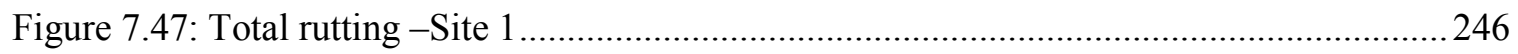

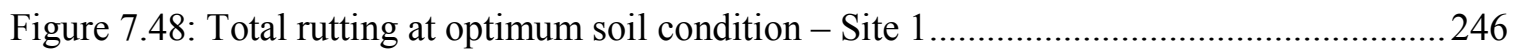

Figure 7.49: Effect of asphalt concrete rutting on road service life - Site 1..............................247

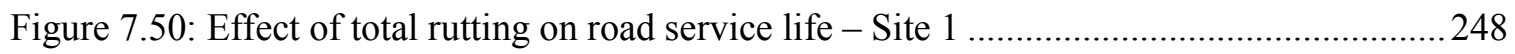

Figure 7.51: Comparison between field and M-EPDG asphalt concrete rutting - site 1 .............250

Figure 7.52: Comparison between field and M-EPDG total rutting - site 1 ................................250

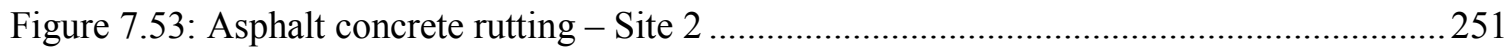

Figure 7.54: Asphalt concrete rutting at optimum soil condition - Site 2 .................................252

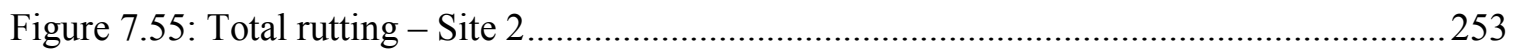

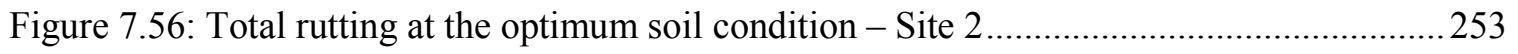

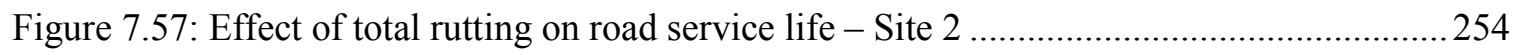

Figure 7.58: Comparison between field and M-EPDG asphalt concrete rutting - Site 2 ...........256

Figure 7.59: Comparison between field and M-EPDG total rutting - Site 2 ..............................257

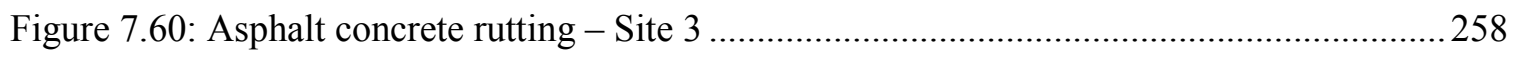

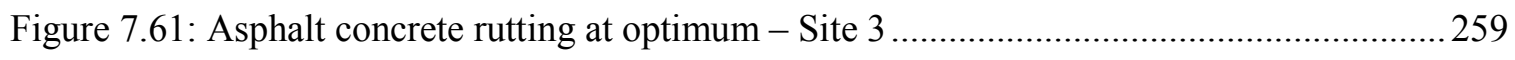

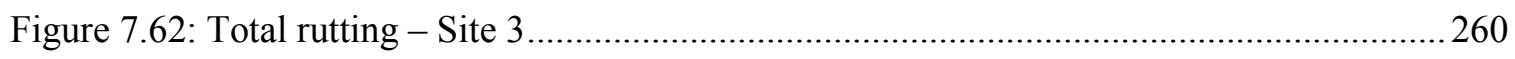

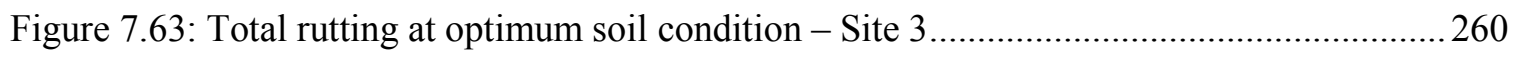

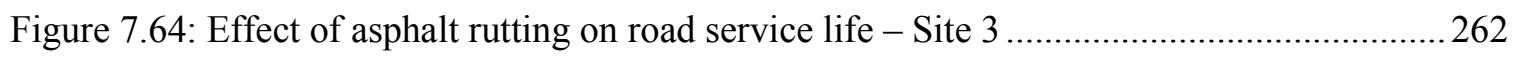

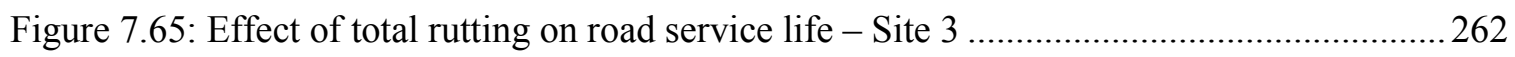

Figure 7.66: Comparison between field and M-EPDG asphalt concrete rutting - Site 3 ............264

Figure 7.67: Comparison between field and M-EPDG total rutting - Site 3 ............................. 265 


\section{List of Symbols}

Symbol

AASHTO

AASHO

M-EPDG

NCHRP

PSR

$\mathrm{W}_{\mathrm{t} 18}$

$\mathrm{R}$

$\mathrm{p}_{\mathrm{t}}$

SN

$\mathrm{D}_{\mathrm{i}}$

$a_{1}, a_{2}, a_{3}$

$\mathrm{S}_{\mathrm{i}}$

$\mathrm{M}_{\mathrm{R}}$

$\mathrm{Z}_{R}$

$\mathrm{S}_{o}$

$\mathrm{p}_{\mathrm{o}}$

$\triangle P S I$

CBR

$\mathrm{H}$

DCP

$\mathrm{E}_{\mathrm{FWD}}$

$\mathrm{P}$

$\mathrm{d}_{\mathrm{r}}$

$\mathrm{u}_{\mathrm{f}}$

$\mathrm{C}_{1}$ and $\mathrm{C}_{2}$
Definition

American Association of State Transportation Officials

American Association of State Highway Officials

Mechanistic-Empirical Pavement Design Guide

National Cooperative Highway Research Program

Present Serviceability Rating

Number of 18-kip single axle load applications to time, $\mathrm{t}$

Regional climatic factor

Serviceability at end of time, $\mathrm{t}$

Structural Number of pavement

Thickness of the ith layer

Coefficients of surface, base, and sub-base respectively

Soil support value

Resilient modulus

Standard normal deviate

Combined standard error

Initial design serviceability

Difference between the initial design serviceability index, $p_{o}$, and the design terminal serviceability index, $p_{t}$

California Bearing Ratio test

Hveem value

Dynamic cone penetration

Sub-grade modulus

Applied load

Deflection measured at a radial distance, $r$

Relative damage

Constants as defined in equation 2.8 


\begin{tabular}{|c|c|}
\hline$m_{i}$ & Drainage coefficient for the ith layer \\
\hline$\theta$ & Bulk stress \\
\hline $\mathrm{E}$ & Young modulus \\
\hline$\sigma_{1}$ & Total axial stress (major principal stress) \\
\hline$\sigma_{3}$ & Confining pressure (minor principal stress, and $\sigma_{2}=\sigma_{3}$ ) \\
\hline$\sigma_{\mathrm{d}}$ & Deviator stress \\
\hline $\mathrm{p}_{\mathrm{a}}$ & Atmospheric pressure \\
\hline $\mathrm{k}_{\mathrm{i}}=\mathrm{i}=1$ to 3 & Regression constant as defined in equation 2.9 \\
\hline$(\mathrm{ESAL})_{\mathrm{o}}$ & Initial Equivalent Single Axle Loads \\
\hline$(\mathrm{ESAL})_{\mathrm{T}}$ & Total Equivalent Single Axle Loads \\
\hline$f_{D}$ & Directional split factor \\
\hline$f_{L}$ & Lane-use distribution factor \\
\hline $\mathrm{r}$ & Annual traffic growth \\
\hline PSI & Present serviceability index \\
\hline CRREL & Cold Regions Research and Engineering Laboratory \\
\hline EMU & $\varepsilon$-Measuring Unit \\
\hline TDR & Time Domain Reflectometery \\
\hline AADT & Annual Average Daily Traffic \\
\hline CABII & Coarse Aggregate Backfill type II \\
\hline DGABC & Dense Granular Aggregate Base Course \\
\hline EICM & Enhanced Integrated Climatic Model \\
\hline Superpave & SUperior PERforming Asphalt PAVEments \\
\hline HMA & Hot Mix Asphalt \\
\hline VMA & Percent voids in mineral aggregate \\
\hline VFA & Percent voids filled with asphalt \\
\hline $\mathrm{G}_{\mathrm{mm}}$ & Theoretical maximum relative density \\
\hline $\mathrm{G}_{\mathrm{mb}}$ & Bulk relative density \\
\hline $\mathrm{N}_{\text {initial }}$ & Initial number of gyration \\
\hline
\end{tabular}




$\begin{array}{ll}\mathrm{N}_{\text {design }} & \text { Design number of gyration } \\ \sigma_{0} & \text { Stress amplitude } \\ \varepsilon_{0} & \text { Strain amplitude } \\ \omega & \text { Angular velocity } \\ \mathrm{f} & \text { Frequency } \\ \mathrm{A} & \text { Cross sectional area } \\ \mathrm{F} & \text { Axial force } \\ \Delta \mathrm{h} & \text { Deformation } \\ \mathrm{GL} & \text { Gauge length } \\ \phi & \text { Phase lag between the strain and the stress signal } \\ \mathrm{E} & \text { Complex modulus } \\ \left|E^{*}\right| & \text { Dynamic modulus } \\ T_{i} & \text { Time lag between the stress and strain cycles } \\ T_{p} & \text { Average time for a stress cycle } \\ \mathrm{D}_{(\mathrm{t})} & \text { Creep compliance } \\ \mathrm{X} & \text { Horizontal deformation } \\ \mathrm{Y} & \text { Vertical deformation } \\ \mathrm{t} & \text { Thickness of specimen } \\ \mathrm{D} & \text { Diameter of specimen } \\ \sigma_{\mathrm{t}} & \text { Tensile strength } \\ \mathrm{P}_{\mathrm{f}} & \text { Tensile strength at failure } \\ \mathrm{G}^{*} & \text { Binder complex shear modulus } \\ \mathrm{V} & \text { Viscosity } \\ \eta & \mathrm{TR}\end{array}$

A Regression intercept as defined in equation 5.17

VTS Regression slope of viscosity temperature as defined in equation 5.17 


$\begin{array}{ll}\text { LL } & \text { Liquid Limit } \\ \text { PI } & \text { Plasticity Index } \\ \text { CPC } & \text { Optimum Content } \\ \delta & \text { Binder phase angle } \\ \text { IRI } & \text { International roughness index } \\ t_{\mathrm{p}} & \text { Tire pressure }\end{array}$




\section{INTRODUCTION}

\subsection{General}

In view of the substantial annual investments in maintenance and rehabilitation of roads, it is necessary to link pavement materials characterization and structural design to produce durable structures. One such improvement may target linking the pavement response, influenced by environmental and traffic loading, to a given performance quantified according to a specific criterion.

Pavements are composed of complex structural materials that have different engineering properties. The current structural flexible pavement design approach is empirical in nature and uses some established relationships to estimate the strength of different materials. However, the limitations of the empirical approach are becoming obvious with developments in transportation systems as well as increased knowledge in the fields of pavement mechanics and materials science. Despite researchers' efforts in the last several decades to enhance the mechanistic part of the design, the results have not been satisfactory. Premature failures of flexible pavement, one year after construction, highlight the need to develop a more comprehensive design tool that incorporates both the mechanistic and empirical approaches.

Mechanistic characterization techniques of road materials represent one of the major improvements introduced in the Mechanistic-Empirical Pavement Design Guide (M-EPDG). This necessitates accounting for the impact of seasonal variations in moisture and temperature conditions on the behaviour of road materials. However, pavement analysis tools, including the M-EPDG, are based primarily on multilayered linear elastic analysis, whereby the thickness of the different layers is determined by applying failure 
criteria (in the form of stresses or strains) obtained from experimental studies. This approach limits the possibility of exploring the impact of the wide range of existing materials and road conditions on pavement performance, as it requires undertaking many experimental studies to establish the failure criteria. Furthermore, current performance specifications, which address several deformation mechanisms, are not defined in terms of engineering parameters such as stress or strain.

Analytical models can provide the support engineers need to make informed decisions for the design of new pavement structures or the repair of existing roads. These models offer performance-based design strategies such as setting the extent of a certain distress type at a maximum acceptable limit. The models also allow the application of design strategies to a preferred choice or the evaluation of the performance from a variety of construction alternatives and rehabilitation techniques to select a cost-effective solution. However, engineers managing roads are faced with a lack of effective tools to support their decision to adopt one solution or another. Shortened service life and premature road failures are becoming more common in all regions, and subsequently there is a need for a more responsive analytical tool to support engineers' decisions. Moreover, the selection of the optimum rehabilitation method for a road requires the calculation of the total costs that will be incurred throughout the life cycle of the pavement for all repair options. Life cycle cost analysis requires reliable information and data on the service life of the different rehabilitation alternatives. A monitoring system where data collected from sensors installed in the pavement structure could be used to calibrate and benchmark the design and analysis models. 
Data provided from field experiments and laboratory work is critical to assess the ability of pavement models to accurately predict performance of different roads exposed to different environments. Data is also instrumental in evaluating the sensitivity of these models.

\subsection{Problem definition}

The current structural design approach to flexible pavement is empirical and based on the results of limited experimental studies that were conducted between 1956 and 1961 in Ottawa, Illinois, USA. The experimental results from the Illinois study were used to produce design equations that reflect the observed loss of serviceability for specified pavement thicknesses and traffic. Furthermore, these design equations reflected the conditions of the American Association of State Highway Officials (AASHO) road test. The limitations of AASHO road test can be attributed to:

$\square \quad$ The duration of the accelerated test was only two years rather than the typical expected life of in-service pavements.

$\square \quad$ The maximum load applied was less than road structures currently experience.

$\square \quad$ The distributions of axle loads and configurations were simple and do not conform to those experienced today. The trucking industry has succeeded in increasing legal truckloads.

$\square \quad$ The materials used and construction practices represented those available in the 1950s.

$\square \quad$ Only one climatic condition was assessed. 
The continuous developments of materials and demand for improved road structure performance have far exceeded the capabilities of the empirical approach. The 1993 American Association of State Highway and Transportation Officials (AASHTO) design practice does not accurately account for the speed of the passing traffic. Traffic volume and development of cities across North America resulted in slower traffic speeds and more frequent stoppages, especially during peak hours. These conditions resulted in high occurrence of rutting damage. However, it should be noted this damage can also be the result of inadequate mix design and roadway usages such as intersections and bus stops, where we often observe greater rutting damage compared to other parts of road systems.

Research work in the last decade has acknowledged premature (in some cases even within a few months of construction) failures of pavement structures. The attempts to understand the underlying causes of these failures indicated that there is room for improving the knowledge of how to account for the ways in which local conditions, materials, construction quality, traffic characteristics as well as the seasonal variations of moisture and temperature of pavement layers have an effect on pavement response.

As a result of the issues described above, there is urgent need for more comprehensive mechanistic pavement design models.

\subsection{Scope and objective}

The scope of this thesis is to address and analyze the flexible pavement performance with the objective of validating and identifying weaknesses of the M-EPDG to design and subsequently analyze flexible pavement roads and area for improvement. This was achieved by: 
$\square$ Designing and developing a field instrumentation scheme capable of capturing the silent response due to mechanical and environmental loadings.

$\square \quad$ Implementing the developed instrumentation scheme to measure and monitor over a period of two to three years the environmental and structural response of flexible pavement roads, covering three different local environmental conditions, traffic and load characteristics.

Establishing laboratory mechanistic characterization protocols for unbound granular materials and asphalt concrete materials.

$\square$ Employing the laboratory protocols to determine the mechanistic properties of road materials encountered and used in the field experiments.

- Conducting an analytical investigation, using generic data, to evaluate the sensitivity of the new M-EPDG model to the variety of materials and loading conditions used and encountered in flexible pavement roads.

$\square \quad$ Assessing the potential of using the M-EPDG as a decision-making tool for pavement management systems.

$\square \quad$ Using the M-EPDG, modelling and analyzing the instrumented field experiments and contrasting their modeled performance with those measured in the field.

\section{$1.4 \quad$ Organization of the thesis}

The thesis contains eight chapters as shown in Figure 1.1:

Chapter 1 gives a general background of the topic, defines the problem and sets out the scope and objective of the research. 
Chapter 2 provides an extensive literature review. It identifies the gaps in knowledge and the field for existing flexible pavement design guides and the Mechanistic-Empirical Pavement Design Guide (M-EPDG).

Chapter 3 presents the designing and developing of a field instrumentation scheme that is capable of capturing the pavement structural response under mechanical and environmental loadings.

Chapter 4 presents environmental and structural responses of flexible pavement roads measured over a period of two to four years, covering three different environmental conditions, traffic, and load characteristics.

Chapter 5 describes the use of the environmental and structural data obtained from fieldwork to carry out the laboratory work. It describes the laboratory protocols that have been established to mechanically characterize unbound granular materials and asphalt concrete materials encountered and used in the field experiments.

Chapter 6 discusses the assessment of the three constructed sites based on road structure pavement layers using the existing 1993 AASHTO design guide.

Chapter 7 evaluates the sensitivity of the M-EPDG to the variety of materials and loading conditions used and encountered in flexible pavement roads using generic data. It also presents the results of modeling and analyzing, using the M-EPDG, the instrumented field experiments and contrasting their modeled performance with those measured in the field.

Chapter 8 includes the summary and conclusions of this research work. It also presents recommendations for future work/investigation. 


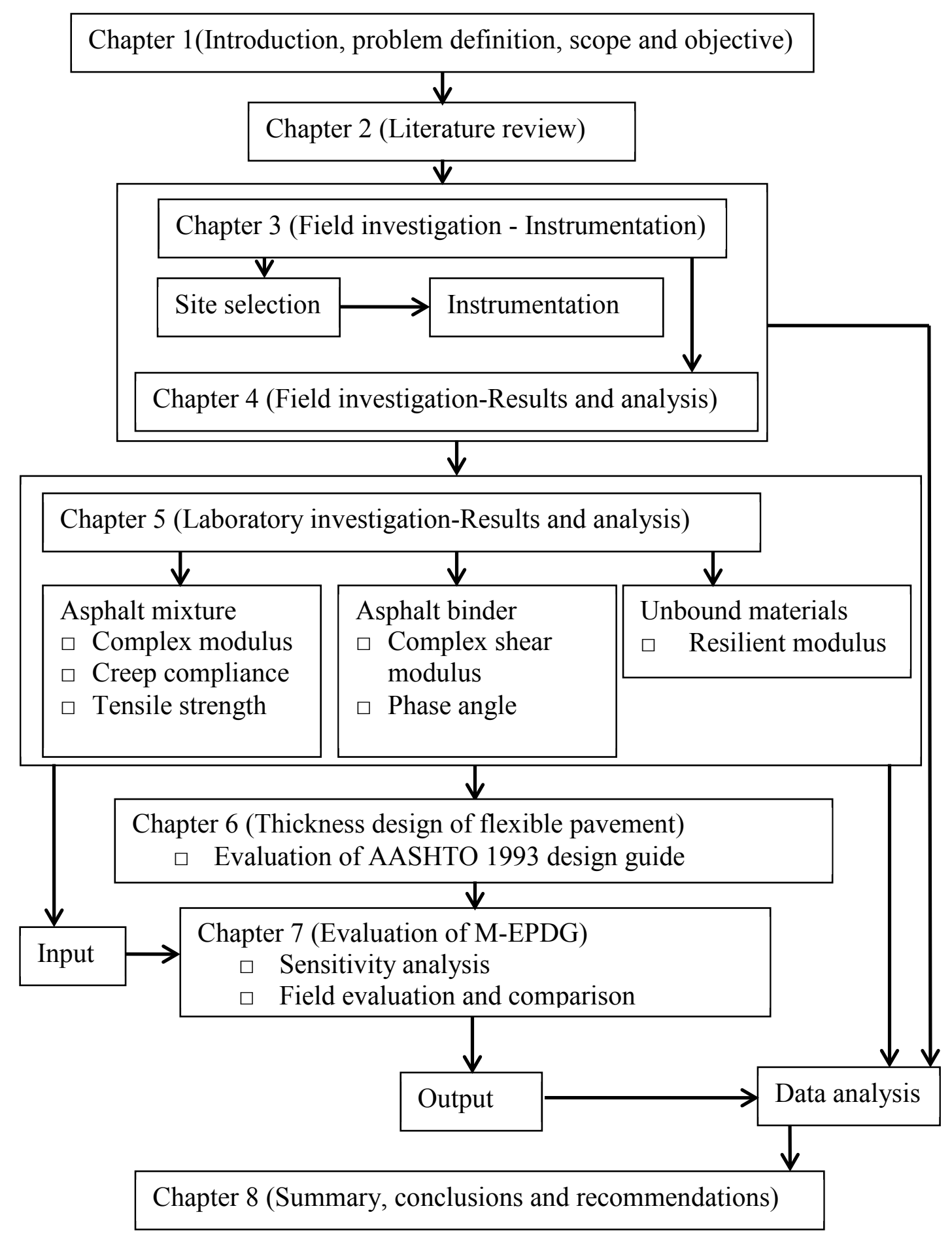

Figure 1.1: Organization of the thesis 


\section{LITERATURE REVIEW}

\section{$2.1 \quad$ Introduction}

Pavement researchers and engineers continue to develop an effective and reliable analytical tool to assist in the analysis and design of pavement structures while taking into account the service conditions of the road. The existing pavement design procedures are based mainly on both semi-analytical and empirical approaches, or one or the other. For example, the results from the AASHO road test were used to develop a pavement design guide. The test was comprised of experiments carried out by the AASHO to determine how traffic loading, physical properties of pavement materials and environmental conditions contribute to the structural deterioration of highway pavements. This guide was first issued in 1961 as the AASHO interim guide for the design of flexible pavement, and again issued in 1962 for rigid pavement, with major updates issued in 1972.

A number of empirical design methods are in use today, such as the Asphalt Institute Thickness Design method (1991) and the AASHTO design guide (1972). The most commonly used method of pavement design follows the AASHTO design guides (1986 and 1993). The original AASHO design procedure (1961) has been modified several times over the last 50 years in an attempt to improve the procedure and to incorporate new findings. In 1986, the reliability concept was introduced into the AASHO design guide to allow for uncertainties associated with design variables such as material properties and traffic. In 1993, a major shift was introduced to the design guide to replace the pavement support value by resilient modulus and drainage coefficients. The 
improved design guide also eliminated the use of empirical values reflecting regional factors.

At this juncture, it should be mentioned that worldwide transportation systems have been under pressure to sustain an incredible increase of heavy traffic volumes to meet the demands of moving people and goods. The dramatic increases of traffic volume and loads have accelerated the rate and amount of damage to roadways. Statistics Canada (2003) reported that at least 8 billion dollars is spent annually for the rehabilitation of urban roads using the overlay technique has been recognized as one of the most common practices. The next section summarizes research findings over the past 50 years.

\subsection{AASHTO flexible pavement design guides}

\subsubsection{AASHTO design guide 1961-1972}

The AASHTO pavement design method has undergone frequent revisions. Upon completion of the AASHO Road Test in late 1950s and early 1960s in Ottawa, Illinois, the AASHO interim guide for the design of flexible pavement (AASHO design guide, 1961) and rigid pavement (AASHO design guide, 1962) were developed and circulated. Based on the test results, pavement design criteria and design procedures were developed. After several years of continuous research and verification work, the AASHTO interim guide for the design of pavement structures was published (AASHTO design guide, 1972).

\subsubsection{Design principles:}

The function of any road is to safely and smoothly carry vehicular traffic. In order to quantify this, two main concepts were introduced in the AASHTO guide: serviceability, and performance. Serviceability was defined as the ability of a pavement 
to serve the traffic for which it was designed. Performance was defined as the ability of the pavement to serve traffic over a period of time. From these definitions, performance could be interpreted as the change of serviceability with time. According to the AASHO Road Test, performance was determined by the serviceability at the time of construction as well as at different times after construction. Ratings from 0 to 5 for serviceability were obtained by taking the mean ratings performed by a group of raters. A 0 rating indicates a very poor pavement, while 5 indicates an excellent pavement. The Present Serviceability Rating (PSR) was introduced as a measure of serviceability (Van Til et al, 1972). PSR was statistically correlated to various physical measurements of the pavement and it is referred to as the Present Serviceability Index.

The basic equation developed from the AASHO Road Test for flexible pavements design was:

$$
\log \mathrm{W}_{\mathrm{t} 18}=9.36\left(\log \log \frac{1}{\mathrm{R}}+1\right)-0.2+\frac{\log \left[\left(4.2-\mathrm{p}_{\mathrm{t}}\right) /(2.7)\right]}{0.4+\left[1094 /(\mathrm{SN}+1)^{5.19}\right]}
$$

Where; $\mathrm{W}_{\mathrm{t} 18}$ is the number of 18-kip single axle load applications at time $\mathrm{t} ; \mathrm{P}_{\mathrm{t}}=$ serviceability at end of time $\mathrm{t} ; \mathrm{SN}=$ Structural Number of the pavement,

Equation 2.1, however, was not applicable for different climatic conditions and various types of soils. It was therefore modified to relate the number of 18-kip single-axle repetitions $\left(\mathrm{W}_{\mathrm{t} 18}\right)$ required to reach a predefined terminal serviceability level $\left(\mathrm{p}_{\mathrm{t}}\right)$ for any given pavement structure $(\mathrm{SN})$, regional climatic factor $(\mathrm{R})$, and soil support value $\left(\mathrm{S}_{\mathrm{i}}\right)$. These modifications are included in Equation 2.2. 
$\log \mathrm{W}_{\mathrm{t} 18}=9.36 \log (\mathrm{SN}+1)-0.2+\frac{\log [(4.2-\mathrm{pt}) /(2.7)]}{0.4+\left[1094 /(\mathrm{SN}+1)^{5.19}\right]}+\log \frac{1}{\mathrm{R}}+0.372\left(\mathrm{~S}_{\mathrm{i}}-3\right)$

\subsubsection{Design input factors:}

The following input parameters were used in AASHTO Design as identified in equation 2.2 above.

Terminal Serviceability $\left(p_{t}\right)$ : Serviceability index that can be tolerated by users of roadway. 2.5 is recommended for major highways and 2.0 is for low-volume roads (AASHTO design guide, 1972).

Equivalent Wheel Load Repetitions ( $\left.\mathrm{W}_{t 18}\right)$ : Traffic could be equated to daily 18- kip load applications if a common 20-year traffic analysis period is selected, or it can be expressed as the total 18-kip load applications within the traffic analysis period.

Regional Climatic Factor (R): represents the climatic environment effect.

Structural Number $(S N)$ : Is an index number derived from an analysis of traffic, roadbed soil condition, and regional factor. SN can be converted to thickness of various layers of flexible pavement using suitable coefficients related to the type of material being used in each layer. $\mathrm{SN}$ is given by equation 2.3 :

$$
\mathrm{SN}=\mathrm{a}_{1} \mathrm{D}_{1}+\mathrm{a}_{2} \mathrm{D}_{2}+\mathrm{a}_{3} \mathrm{D}_{3}
$$

Where; $\mathrm{D}_{\mathrm{i}}$ is the thickness of the $i$ th layer, and $a_{1}, a_{2}, a_{3}$ represent the coefficients of the surface, base, and sub-base respectively.

Soil Support Value (S): Represents the soil sub-grade condition. 


\subsubsection{AASHTO design guide 1983-1993:}

In 1983, an evaluation of the Guide was made to incorporate information developed since 1972. Based on research completed during the 20 years after the road test was introduced, several changes were made in the revised version of AASHTO Guide in 1983. The soil support value $\left(\mathrm{S}_{\mathrm{i}}\right)$ had been replaced with the resilient modulus $\left(M_{R}\right)$, a material property that was incorporated in the design method. However, $M_{R}$ served only the unbound material properties and neglected the asphalt concrete surface layer properties. Accordingly, the design equations 2.1 and 2.2 for flexible pavement were modified. The new formula generated was as follows:

$$
\begin{gathered}
\log \mathrm{W}_{\mathrm{t} 18}=\mathrm{Z}_{\mathrm{R}} \times \mathrm{S}_{\mathrm{o}}+9.36 \log (\mathrm{SN}+1)-0.2+ \\
\frac{\log [(\Delta \mathrm{PSI} / 2.7)]}{0.4+\left[1094 /(\mathrm{SN}+1)^{5.19}\right]}+2.32 \times \log \mathrm{M}_{\mathrm{R}}-8.07
\end{gathered}
$$

Where; $\mathrm{W}_{\mathrm{t} 18}=$ Predicted number of 18-kip equivalent single axle load applications; $\mathrm{Z}_{R}=$ Standard normal deviate; $\mathrm{S}_{o}=$ Combined standard error of the traffic prediction and performance prediction; $\triangle P S I=$ Difference between the initial design serviceability index, $\mathrm{p}_{\mathrm{o}}$, and the design terminal serviceability index, $\mathrm{p}_{\mathrm{t}} ; \mathrm{M}_{R}=$ Resilient modulus, psi; $\mathrm{SN}=$ is the structural number indicative of the total pavement thickness.

It is important to note that the modified equations are predictors of the amount of traffic that can be sustained before the road deteriorates to some terminal levels of serviceability.

Pavements are made of complex structural materials that have different properties. Flexible pavement design procedures have been empirical as described in the AASHTO design guide (1993), which recommended the use of the strength of the sub- 
grade to measure the thickness of base, sub-base and surface layers. The soil strength parameters expressed in terms of California Bearing Ratio test (CBR), Hveem value $(\mathrm{H})$ and soil support value $\left(\mathrm{S}_{\mathrm{i}}\right)$, are often used in pavement design. All these parameters are derived from the results of laboratory tests on soil specimens.

Flexible pavements rarely fail by sub-grade failures during their design life (Huang, Y.H., 1993). Failures occur by either excessive rutting of the supporting pavement layers or cracking of the asphalt mat, as a result of fatigue due to environmental effects (Barksdale, R. D., 1972; Brown, S. F., 1974, 1996). The concept of soil resilient modulus, $M_{R}$ was introduced in the 1993 design guide. The resilient modulus is a measure of the mechanical property of soil, recognizing its permanent deformation to repetitive dynamic loading (AASHTO design guide, 1993). The total pavement thickness requirements are assumed to be a function of the sub-grade resilient modulus $\left(M_{R}\right)$ determined by the AASHTO test method (T294, 1992). This was the first attempt at implementing a mechanistic property in a pavement design. It should be noted that the AASHTO guide empirical model (AASHTO design guide, 1993) is sensitive to variation in the resilient modulus. It is recommended by AASHTO design guide (1993) that the resilient modulus test be performed in the laboratory using site condition stress levels and the corresponding moisture conditions. It is common practice in case of lack of availability of testing facility for determining $\mathrm{M}_{\mathrm{R}}$ to use some empirical correlation with other soil properties such as $\mathrm{CBR}$ and/or $\mathrm{H}$ values.

$\mathrm{M}_{\mathrm{R}}$ (in MPa) for fine grained soils with soaked CBR of 10 or less (Heukelom, W., Klomp, A. J. G., 1964), is given by:

$$
M_{R}=10.3 \times C B R
$$


For other types of soil, some correlations were established to estimate the resilient modulus (Van Til et al., 1972). However, designers do not use those correlations because they produce inconsistent results. Several researchers (Salgado, R.; Yoon, S., 2002 and Amini, F., 2003), have developed relationships between stiffness of sub-grades and bases and Dynamic Cone Penetration (DCP).

The strength of unbound road materials (resilient modulus) is greatly affected by the moisture content, and one single value of resilient modulus will not be representative for the material. Seasonal variations in volumetric water content and temperature were explored and a formula for estimating these as a function of the time of the year was established (Heydinger, A.G., 2003). Typically, an increase in sub-grade water content results in a decreased resilient modulus that leads to increased deflections in the pavement, leading to a decrease in pavement service life. Guidelines for estimating the decrease in sub-grade resilient modulus with a known increase in the degree of saturation or post compaction and water content have been proposed (Drumm et al., 1997)

For existing roads, Choubane and McNamara (2000) proposed the use of the back calculation method to estimate the stiffness of sub-grades and base and sub-base materials using deflection measurements obtained with the Falling Weight Deflectometer (FWD) for pavement design. The relationships between modulus, load and deflection are given by equation 2.6 .

$$
E_{F W D}=0.00147 \times\left(\frac{P}{d_{r}}\right)
$$

Where; $\mathrm{E}_{\mathrm{FWD}}=$ Sub-grade modulus, $\mathrm{MPa} ; \mathrm{P}=$ applied load, $\mathrm{N}$ and $\mathrm{d}_{\mathrm{r}}=$ deflection measured at a radial distance, $\mathrm{r}$, of $0.9 \mathrm{~m}$. 
The current AASHTO design guide (1993) recommends dividing the year into 12 or 24 periods to take care of the influence of moisture variation on the resilient modulus. Each period is assigned a resilient modulus value based on the expected water content, which is then used to determine a relative damage or reduction factor.

Equation 2.7 is used to estimate the relative damage corresponding to each season, then all seasons' damage values are summed and divided by number of seasons. The mean of the relative damage factor is then used in the same Equation 2.7 to obtain a single value for the resilient modulus, known as the "effective roadbed soil resilient modulus". It is noted that the AASHTO design (1993) relies on physical properties to characterize pavement structure materials except the native soil (sub-grade soil).

$$
\mathrm{u}_{\mathrm{f}}=9.488 \times 10^{16} \times \mathrm{M}_{\mathrm{R}}^{-2.32}
$$

Where; $\mathrm{M}_{\mathrm{R}}=$ Resilient modulus, $\mathrm{MPa} ; \mathrm{u}_{\mathrm{f}}=$ Relative damage, $\mathrm{mm}$.

A drainage coefficient was added to determine the layer coefficients representing the various unbound layer materials related to the resilient modulus. The bound material may be tested by procedures described in ASTM standard (D4123, 1999). By knowing the elastic modulus at $25^{\circ} \mathrm{C}$, asphalt structural layer coefficient $\left(a_{1}\right)$ can be determined from the chart used by the AASHTO design guide (1993). The coefficient of the materials base $\left(a_{2}\right)$ and sub-base $\left(a_{3}\right)$ can be determined using the following correlations given by equation 2.8 :

$$
\mathrm{a}_{\mathrm{i}}=\mathrm{C}_{1}\left(\log _{10} \mathrm{M}_{\mathrm{R}}\right)-\mathrm{C}_{2}
$$

When $\mathrm{i}=2, \mathrm{C}_{1}$ and $\mathrm{C}_{2}$ are 0.481 and 0.977 respectively, and when $\mathrm{i}=3, \mathrm{C}_{1}$ and $\mathrm{C}_{2}$ are 0.478 and 0.839 respectively. $\mathrm{M}_{\mathrm{R}}=$ Resilient modulus, $\mathrm{MPa}$ 
It is clear from equation 2.8 that the test results of the laboratory resilient modulus can significantly influence the predicted layer coefficient. The AASHTO design guide (1993) expresses the relationship between structural layer coefficient, which is a measure of the relative ability of the material to function as a structural element of the pavement, structural number (SN), thickness (D) and drainage coefficient for the layer (m). These relationships describing the concept of layer thickness are depicted in Figure 2.1. The 1993 AASHTO design guide relied heavily on characterizing materials using elastic modulus.

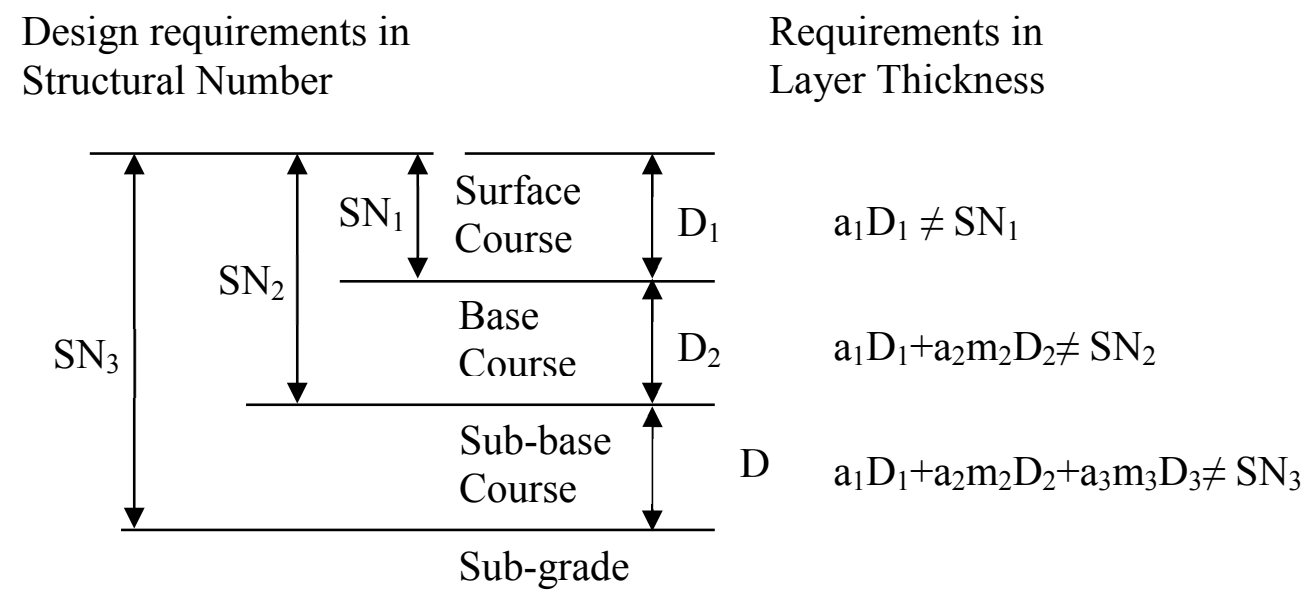

Figure 2.1: The concept of layer analysis

\subsubsection{AASHTO design guide 2004:}

The design guide (NCHRP, 2004) has adopted new material characterization techniques as design parameters. One of them is the Resilient Modulus to characterize the mechanistic response of the unbound granular materials, and the other is the complex modulus, creep compliance and tensile strength to characterize the mechanistic response of the asphalt concrete materials. This approach is expected to improve pavement design processes. The advanced design level recommends using actual laboratory test data of the 
dynamic and resilient modulus determined under simulated environmental and traffic loading conditions.

Based on mechanics theory, the 1993 AASHTO design guide incorporated the use Young modulus (E) to characterize pavement structures, assuming the pavement as an elastic material. However, this is not wholly accurate because asphalt concrete materials do not behave purely in an elastic manner. They are in fact viscoelastic, and subsequently, it is important to account for their viscoelastic characteristics to estimate the behaviour of such materials. The new design guide (M-EPDG) is considering this behaviour by adopting the complex modulus for asphalt concrete materials characterization.

One must consider the following service conditions as indicated by: stress state (associated with loading), environmental condition (temperature), and construction condition (binder content) to define pavement materials response properly. The stiffness characteristics of asphalt mixtures are dependent on the time of loading and temperature. At temperatures above $25^{\circ} \mathrm{C}$, it is most likely that the stress has an influence on the stiffness characteristics as the binder becomes less stiff. At temperatures above $40^{\circ} \mathrm{C}$ asphalt mixtures can no longer treated as linear viscoelastic, (Monismith, C.L., 1992; Johanneck, L. and Khazanovich, L., 2010). At low temperatures, the behaviour of asphalt concrete is considered as a combination of both elastic and little linear viscoelastic behaviour. This behaviour can be considered purely elastic and viscoelastic at low strain amplitude measurement (Di Benedetto and De La Roche, 1998).

The new design guide (NCHRP, 2004) provides three levels of input depending on the importance of the project, the sensitivity of the pavement performance to a given 
input, the resources available to the designer, and the availability of input information at the time of the design.

Level 1: Physical testing for hot mix asphalt (dynamic modulus, creep compliance and indirect tensile strength) and unbound materials (resilient modulus) are required.

Level 2: The accuracy of this level is considered to be intermediate. The required inputs are determined using established correlations in the model. For example, the dynamic modulus could be estimated based on results of tests performed on binders, aggregate gradation and mix properties.

Level 3: The outcome design of this level has the lowest accuracy level. Inputs are typically national or regional default values; such as the physical properties and type of binder used to characterize the asphalt concrete mixes.

Road engineers and practitioners anticipated the release of the new version of AASHTO design guide (NCHRP, 2004) to incorporate the mechanistic approach to the experimental approach M-EPDG model. The efforts of calibrating the design guide are not yet completed. Level 1 analysis of unbound materials in the M-EPDG model involves measuring the resilient modulus of the unbound granular materials, complex modulus, creep compliance and indirect tensile strength for hot mix asphalt.

\subsubsection{Resilient Modulus}

The resilient modulus parameter was adopted for the characterization of unbound materials in the proposed new design guide (NCHRP, 2004). The resilient modulus along with Poisson's ratio is used in the pavement response model to quantify the stress dependent stiffness of unbound material layers. This resilient modulus is determined from laboratory testing of representative material samples. Two standard test methods are 
recommended in the guide (NCHRP 1-28A, 1997; AASHTO 307, 2003). Results of the laboratory tests are used to determine the non-linear elastic coefficients and exponents of classical universal model in equation 2.9, but unfortunately the non-linear part of the design guide is not operational yet working, and therefore the design is still linear in the case of unbound materials (Uzan, J., 1985).

$$
\mathrm{M}_{\mathrm{R}}=\mathrm{k}_{1}\left(\frac{\theta}{\mathrm{p}_{\mathrm{a}}}\right)^{\mathrm{k}_{2}}\left(\frac{\sigma_{\mathrm{d}}}{\mathrm{p}_{\mathrm{a}}}\right)^{\mathrm{k}_{3}}
$$

Where; $\theta$ (bulk stress) $=\sigma_{1}+\sigma_{2}+\sigma_{3}(\mathrm{kPa}) ; \sigma_{\mathrm{d}}=\sigma_{1}-\sigma_{3}(\mathrm{kPa}) ; \mathrm{p}_{\mathrm{a}}=$ Atmospheric pressure, $\mathrm{kPa} ; \sigma_{1}=$ Total axial stress (major principal stress), $\mathrm{kPa} ; \sigma_{3}=$ Confining pressure (minor principal stress, and $\sigma_{2}=\sigma_{3}$ ), $\mathrm{kPa} ; \sigma_{\mathrm{d}}=$ Deviator stress, $\mathrm{kPa} ; \theta=$ Bulk stress, $\mathrm{kPa} ; \mathrm{k}_{\mathrm{i}}=\mathrm{i}=1$ to 3 (Regression constant)

The complexity of the response of unbound road layers, which depends on the state of the material (density and moisture condition) and the level of applied stress, dictates that pavement response models be calibrated to achieve accurate performance prediction capabilities. The effectiveness of the approach of using physical properties as indicators of the expected mechanical response of unbound materials was evaluated by Zeghal et al. (2005) and revealed that the measured resilient modulus of the two studied materials (Granular A and B) were found to be outside the proposed range. It has been concluded that reliance on AASHTO classification to estimate the resilient modulus, as suggested in the proposed guide may underestimate or overestimate base rutting as well as fatigue cracking. These inaccuracies of the predictive equation proposed by the new AASHTO design guide (NCHRP, 2004) for estimation of the resilient modulus was also confirmed by ElHussein et al. (2006). 
When granular material is subjected to external loading, it exhibits both recoverable (elastic) and non-recoverable (permanent or plastic) deformations. Recoverable deformation may be attributed to the elastic response of the solid particles forming part of the material structure, whereas the plastic deformation may be attributed to rearrangement occurring within the material internal structure due to particle sliding and rotation as the external load is applied. Much of the research work completed to date on granular material behaviour focuses on the recoverable (or resilient) characterization of these materials. Limited effort was exerted to understand the material permanent deformation behaviour and its link to the overall pavement structure performance. The relationships between the induced deformation and the externally applied load are usually referred to as the material constitutive models. The accurate determination of such relationships constitutes the backbone of any analytical procedure. In the case of granular materials, there are several factors that tend to influence the mechanical response of these materials as reported by Martin and Qingli (2005), and the most notable factors are:

- The fact that granular material is a particulate material by nature. This means that its behaviour under load is largely governed by its structural makeup at the particle level.

$\square \quad$ The non-isotropic nature of the material, which implies that the mechanistic properties of the material are not the same in all directions.

$\square \quad$ The material response to load in any direction is highly non-linear and it is stress dependent.

$\square \quad$ The percentage of fineness in the granular material, which greatly influences the way these materials behave under load.

The amount of moisture present in the material. 
$\square \quad$ The mineralogy of the aggregate fractions, which controls the crushing properties of aggregates.

It is now well understood that the granular material elastic response, as characterized by the resilient modulus parameter, exhibits a non-linear relationship with the applied deviator stress. The resilient modulus tends to increase as the level of the applied stress is increased. The confining pressure also appears to have a strengthening effect on the material, i.e. as the level of confinement increases, so does the resilient modulus (Martin and Qingli, 2005).

Therefore, the mechanistic properties of materials used in the different pavement layers are needed to develop effective material models for road structures. Further to this, environmental factors such as temperature and moisture influence these properties and must be considered in the material model and, hence, its strength, durability and load carrying capacity. The quality of construction also has an impact on the mechanistic response of construction materials and should be accounted for in modeling them. Inservice conditions associated with aging (asphalt concrete surface) or densification (unbound aggregate layers) also affect the structural response of a pavement. In-service conditions may also include cracking, where an unfavourable response to external loading in the form of crack propagation may occur. The M-EPDG incorporated the Enhanced Integrated Climatic Model (EICM) to simulate changes in the behaviour and characteristics of pavement and sub-grade materials that concur with climatic conditions over the design period. Johanneck and Khazanovich (2010) and Johanneck et al. (2011) conducted a comprehensive sensitivity study of the effect of different climates on the M- 
EPDG performance model's prediction. They found that different climatic conditions have a significant impact on the M-EPDG predicted performances.

\subsubsection{Complex Modulus}

The behaviour of asphalt concrete mixture, similar to its binder, depends on temperature and load frequency. Viscoelastic properties of asphaltic materials are generally determined within the linear viscoelastic domain where the material is subjected to sinusoidal loading at different frequencies at small values of strain to keep it within the linear zone. The modulus value of asphalt concrete materials can rise during the cold winter months by a factor of 20 compared to its value during the hot summer months (Clyne et al., 2003).

Studies of Uzan, (1996), Perl et al., (1983), Sides et al., (1985), Kim and Daniel (1997), Wright and Zheng (1994), and Lu and Wright (1998) demonstrated that the asphalt concrete behaviour has four distinct responses, i.e. elastic, viscoelastic, viscoplastic and plastic behaviour depending on loading and temperature. However, Di Benedetto and De La Roche (1998) considered the behaviour of asphalt concrete as complex viscoelastoplastic, and this type of behaviour can be considered purely elastic and viscoelastic at low strain amplitude measurement. At low temperature, the asphalt concrete behaviour is a combination of both elastic and a little linear viscoelastic behaviour. For the case of lower loading rates and high temperature, the behaviour is non-linear viscoelastic, viscoplastic and plastic. Schapery and Park (1999) applied viscoeleastic theory to modelling asphalt concrete using uniaxial monotonic loading. Lee (1996), Kim and Daniel (1997) and Lee and Kim (1998) used cyclic loading to apply this theory to modelling asphalt concrete. Relaxation modulus, creep compliance and 
complex modulus tests can be used to characterize the actual linear viscoelastic behaviour of asphalt concrete through interconversion methods based on the theory of viscoelasticity provided by Schapery and Park (1999). However, the viscoelastic behaviour is influenced also by the speed of loading (frequency); thus it is incorrect to use a value for the modulus of a viscoelastic material without knowing the corresponding values of temperature and frequency. This leads to the principle of using a Master curve (time-temperature equivalence). Tests needed for model development are conducted at several temperatures instead of measuring the behaviour at just a single temperature, and model parameters are determined for a reference temperature. A single curve called a Master curve is obtained. Hopman (1996) produced VEROAD software that uses the Cole et Cole curve and Black diagram to determine the parameters of the Huet Sayegh model, thus providing a good estimation of the complex modulus for the different temperatures and frequencies (loading rate).

Currently the concept of layer analysis as employed by the AASHTO (1993) uses the modulus of elasticity to determine the asphalt concrete thickness, without accounting for the temperature and aging effects. Di Benedetto and Di La Roche (1998) used a simplified linear viscoelastic approach, which can be considered satisfactory at low strain amplitude of pavement deformation. Characterization of pavement materials in the new mechanistic-empirical pavement design guide (2004) level 1, involves application of the dynamic modulus technique for asphalt concrete and the resilient modulus for unbound materials as discussed earlier. The dynamic modulus, the true component of the complex modulus, has been adopted as the stiffness property in the M-EPDG model and is determined following AASHTO TP62 (2003) test specifications. Because the material 
response depends on mix composition, type of material, aging characteristics, asphalt concrete temperature, rate of loading and is influenced by the prevailing unique local conditions, it also requires calibration of performance models incorporated in the new design guide (NCHRP, 2004). In the proposed AASHTO design guide (NCHRP, 2004) the temperature and loading rate are determined from a master curve constructed using a $21^{\circ} \mathrm{C}$ reference temperature. Sayegh (1967) reported that the complex modulus testing approach focuses on capturing the viscoelastic response of AC materials where traffic loading is simulated in the laboratory with a sinusoidal load. The response of the material is also sinusoidal in nature but with a phase lag. The dynamic modulus is the only component of complex modulus that has been implemented in the AASHTO design guide (NCHRP, 2004). The structural response model of the guide is based on linear elasticity, and hence, the phase angle is not being considered in the analysis. Further development in mechanics may make it possible to incorporate the effect of the phase angle in the structural response model. Direct measurement in the laboratory remains the most accurate method for determining the dynamic modulus due to the complexity of the response. But due to the fact that the majority of users do not yet have the necessary laboratory testing capabilities, the financial resources to cover high costs and lack the trained personnel to conduct the test, material development has been hampered. Thus, there has not been establishment of an effective laboratory characterization technique leading to the use of predictive equations adopted by new design guide (NCHRP, 2004) as in the cases of levels 2 and 3. Witczak and Fonseca (1996) summarized the most important asphalt concrete complex models developed since 1967 and reported that all have several limitations. They proposed a new predictive equation for estimating the 
dynamic modulus of AC materials based on a statistical study conducted on a data consisting of 1429 points from 49 separate AC mixes. Their equation has shown some improvement over the previous models because it accounts for the aging effect for both short and long-term loading and extreme temperature conditions. This predictive model by Witczak and Fonseca (1996) represents the latest and most accurate models to date and has been adopted by the new design guide (NCHRP, 2004). However, Zeghal and ElHussein (2008) assessed the NCHRP (2004) improved version of the 1996 formula developed by Witczak and Fonseca (1996) and noted that errors are high in the case of higher temperatures as well as in the case of engineered binders. Subsequently, Zeghal and ElHussein (2008) proposed establishing a database to provide users of the new design guide with an estimate of dynamic modulus.

The stiffness characteristics of asphalt mixtures are dependent on the time of loading and temperature. It is most likely that the stress has an influence on the stiffness characteristics as the binder becomes less stiff at temperature above $25^{\circ} \mathrm{C}$. Mixtures can no longer treated as linear viscoelastic at temperature above $40^{\circ} \mathrm{C}$, (Monismith, C.L., 1992).

The dynamic modulus, the true component of the complex modulus, has been adopted as the stiffness property in the M-EPDG and is determined following AASHTO procedure $(\mathrm{TP} 62,2003)$ test specifications. Since the material response depends on mix composition, type of material and aging characteristics, asphalt concrete temperature and the rate of loading are influenced by prevailing unique local conditions, and also requires calibration of performance models incorporated in the new design guide (NCHRP, 2004). The recommended test series consists of five test temperatures $\left(-10,0,20,30\right.$, and $\left.40^{\circ} \mathrm{C}\right)$ 
and six loading frequencies $(0.1,0.3,1.0,5,10$, and $20 \mathrm{~Hz}$.) Each specimen should be tested for the 30 combinations of temperature and frequency starting with the lowest temperature and proceeding to the highest. Testing at a given temperature should begin with the highest frequency of loading and proceed to the lowest.

The complex modulus testing approach has reported on capturing the viscoelastic response of AC materials where traffic loading is simulated in the laboratory with a sinusoidal load. The response of the material is also sinusoidal in nature, but with a phase lag (Sayegh, G., 1967). The dynamic modulus is the only component of the complex modulus that has been implemented in the new design guide (NCHRP, 2004). The structural response model of the guide is based on linear elasticity and hence, the phase angle is not being considered in the analysis. Further development in mechanics may make it possible to incorporate the effect of the phase angle in the structural response model.

\subsubsection{Indirect tension tests}

In the new design guide, creep compliance and tensile strength tests are considered the most promising for predicting the low-temperature performance of asphalt concrete mixtures. The creep compliance is determined by applying a static compressive load of fixed magnitude along the diametric axis of a specimen for duration of 100 seconds. The measured horizontal and vertical deformations are used to calculate the creep compliance. The recommended test series consists of three-test temperatures -20, 10 and $0^{\circ} \mathrm{C}$. The indirect tensile strength is measured by applying load on the HMA specimen along its diametric axis at constant rate until failure. The test is always performed at a temperature of $-10^{\circ} \mathrm{C}(\mathrm{AASHTO} \mathrm{T} 322,2003)$. 
This type of pavement failure is the result of tensile stress caused by sudden temperature drops in combination with the embrittlement of asphalt concrete at low temperature. Thermal cracking continues to be a prevalent cause of permanent deterioration in asphalt pavement throughout the world. Thermal cracking can develop early in pavement life thereby contributing to loss of pavement serviceability. Thermal cracks permit the ingress of water into underlying layers if left untreated. This causes additional pavement deterioration.

\subsubsection{Loading concept of AASHTO design guides}

Repeated traffic loading is the one of the major causes of distress in asphalt concrete pavement. Accurate modeling of asphalt performance necessitates understanding the behaviour of asphalt concrete under traffic conditions. Kim and Little (1990) and Lee and Kim (1997) reported that the hysteretic behaviour of asphalt concrete under traffic loading involves three major mechanisms: damage growth; relaxation of stresses in the pavement structure due to the viscoelastic behaviour of asphalt concrete; and micro crack healing. So far, most of the attempts made to predict the mechanistic response of pavement mixtures have been developed based on applying dynamic or quasi-static loads that produces elastic (linear) response. In reality, the majority of the materials used in pavement structures are loaded with repetitive and cyclic loads. However, Schapery (1984) concluded that constitutive models for some viscoelastic media are similar to those for the elastic models.

The accurate determination of stress and the resulting strain in roads under traffic has been a question of major concern for the understanding of most pavement distress problems such as rutting, fatigue and cracking. According to Heck et al. (1998), such 
understanding will greatly help road authorities and designers to evaluate accurately the mechanistic performance of pavement materials.

Monismith and Finn (1977) concluded that to define pavement material response properly, one must consider the following service condition; the stress state associated with loading, environmental condition (temperature), and construction condition (binder content).

Developing procedures to define the requisite materials' characteristics is fundamental to establishing analytical based methods. For example, pavement analysis depends on solutions for stresses and strains, and such analysis requires a measure of the stiffness characteristics of the various pavement components.

Most of the existing pavement design procedures do not provide materials parameters in a form that can be used in analysis methods. Certainly the California Bearing Ratio (CBR), the Hveem value $(\mathrm{H})$ and soil support value $\left(\mathrm{S}_{\mathrm{i}}\right)$, and the Marshall stability are not compatible with analytically based procedures. Fortunately, there are efforts that have been pursued to remedy the shortcomings of these over-simplifications. One such simplification has been to describe the materials response in terms of the relationship between applied stress and recoverable strain measured in a repeated load test. This was known as Resilient Modulus and it was first incorporated into the 1983 version of AASHTO design guide of pavement structures. This same concept has been adopted to describe the pavement materials response in the latter additions of the design guide. It is also known as the dynamic modulus. 


\subsubsection{Traffic loading}

Traffic, being one of the external loading components, must also be accurately applied to improve pavement analysis. There are two aspects of traffic loading in the AASHTO design guide (1993): the number of load applications and the magnitude of each load type. The current AASHTO design guide (1993) is based on the $80 \mathrm{kN}$ single axle load. The single axle load of $80 \mathrm{kN}$ was arbitrarily chosen in the AASHO road test as the standard axle with a unity damaging effect. The concept of the relative damage is not quantifiable and is based on empirical results of the 1950 ASSHO road test. The combined loading effects of the repetitive application of different axle types on pavements have been converted using equivalency factors to equivalent passes of an 80 $\mathrm{kN}$ single axle load (ESAL). The AASHTO design guide (1993) contains ESAL factors for different thickness of pavement structures in terms of structural number ( $\mathrm{SN}$ ) and with respect to a terminal serviceability index of 2.5. ElHussein and Nofal (1997) concluded that the superposition adopted in the current AASHTO design guide (1993) ignored the actual response; hence the combined effect of all axles presented in ESAL will not determine the actual stress and strain state due to the effect of numbers of axles and their distribution. The ultimate aim of traffic analysis for pavement design is to determine the magnitude of the wheel loads and the number of times each of these loads will be applied on the pavement during its useful design operational life.

The AASHTO design guide (1993) summarized the basic computation steps for the design of traffic loading for highway pavement as: estimation of expected initial year traffic volume; estimation of expected annual traffic growth; estimation of traffic stream composition; computation of traffic loads; estimation of directional split of design traffic loads; and estimation of design lane traffic loads. 
Assuming all of this information is known, equation 2.10 can be used to compute the loading of a design lane for the design life of a roadway.

$$
(E S A L)_{T}=(E S A L)_{o} \frac{(1+0.01 r)^{n}-1}{0.01 r} f_{D} f_{L}
$$

Where; $(\mathrm{ESAL})_{\mathrm{T}}=$ total design lane ESAL for $\mathrm{n}$ years, $(\mathrm{ESAL})_{\mathrm{o}}=$ initial year design lane ESAL, $r=$ annual traffic growth of ESAL in percent, $f_{D}=$ directional split factor, $\mathrm{f}_{\mathrm{L}}=$ lane-use distribution factor

It is a normal practice to assign 50\% flow of the traffic to each direction but in some situations, uneven splits occur. The AASHTO design guide (1993) recommended that based on number of lanes the $\%$ ESAL in the design lane varies from 100 to $50 \%$ in case of 1 to 4 lanes respectively.

The AASHTO design guide (1993) defined pavement performance in terms of the Present Serviceability Index (PSI), which varies from 0 to 5 . The PSI for newly constructed flexible and rigid pavements was found to be 4.2 and 4.5 respectively. A serviceability index of 2.5 for a highway is considered as being terminal or end of road life. The structural number can be determined using AASHTO monograph by knowing the reliability, standard deviation, ESAL, Roadbed resilient modulus and serviceability index. The AASHTO guide incorporates in the design the reliability factor to account for uncertainties in traffic prediction and pavement performance with overall standard deviations of 0.45 and 0.35 for flexible and rigid pavements, respectively.

One of the major changes in the new design guide is the improvement of traffic related variables. The new AASHTO design guide (NCHRP, 2004) considers the tire pressure, axle load and distribution, where in case of current design guide the only parameter is the equivalent standard axle load. It should be mentioned that in the past, the 
stress and strain-based design model proved to be unreliable. Currently, the performance model has been implemented. It is more effective for road engineers to determine when the rehabilitation activities will be anticipated. Road engineers and municipalities are encouraged to use the new design guide (NCHRP, 2004). However, examination and calibration of the new design guide are required before implementing it. Current forms of load models are not adequate and cannot be effectively used to evaluate traffic impact on pavement performance. Vehicle weight characteristics responsible for known forms of pavement damage are neither well understood nor identified. Different road corridors are exposed to different traffic volumes and mixtures. The traffic mix involves vehicles with different weight characteristics (e.g., wheel base, tire inflation pressure and stiffness, axle load/configuration and unsprung weight). These weight characteristics are responsible for different forms of damage and their impact cannot be captured using a standard vehicle or its equivalent. Another traffic load component, which is unique to urban roads, relates to vehicle manoeuvres such as braking, turning and stoppage at traffic lights. These manoeuvres may increase substantially stresses and strains in the pavement structure and should be considered in the analysis. Measured pavement response to a given vehicle type will further the development of models geared towards an appropriate application of traffic loading.

\subsubsection{Environmental loading}

Soil is compacted to improve its load carrying capacity and to minimize differential settlement (rutting) under traffic loading. High soil strength is usually associated with a high degree of compaction and optimum moisture conditions. However, attaining and maintaining a desired strength in soils is contingent upon the water content 
at the time of construction and throughout the period of use. Some basic moisture content density relations for cohesive and non-cohesive materials are determined according to AASHTO T99 (2015).

It is necessary to account for the effect of seasonal variations in moisture and temperature condition on the behaviour of the road materials. Brown (1977) concluded that there are advantages of considering resilient modulus as a close simulation to the insitu conditions of traffic and environmental loading. Section 2.2.2 in this report summarized AASHTO design guide (1993) procedures for dealing with the influence of moisture variation on the resilient modulus.

Heydinger (2003) explored seasonal variations in volumetric water content and temperature and developed a formula for estimating the ambient temperature and volumetric water content as a function of the time of the year. Typically, an increase in sub-grade water content results in a decreased resilient modulus that leads to increased deflections in the pavement leading to a decrease in pavement design life. Drumm et al. (1997) proposed guidelines for estimating the decrease in sub-grade resilient modulus with a known increase in the degree of saturation or post compaction and water content.

Tarefder and Zaman (2003), reported that the resilient modulus of asphalt concrete decreases with an increase in temperature by several orders of magnitude. However, these should not be interpreted as meaning that at higher temperatures traffic loads have a more detrimental effect to the fatigue failure of an actual pavement. In fact, it is at low temperatures, not at high temperatures, that an asphalt pavement is more susceptible to fatigue failure. Rather, asphalt concrete is more susceptible to plastic deformation or rutting at higher temperatures. 
The current design guide and its predecessors were largely based on design equations empirically derived from the observations AASHTO's predecessor made during road performance tests completed in 1959-60. Several transportation experts such as Hajek (1994) have criticized the empirical data as outdated and inadequate for today's highway and urban road systems. Additionally, in March 1994, the DOT office of the inspector general report concluded that the design guide was outdated and that pavement design information relied on could not be supported and validated with systematic comparisons to actual results of pavement response.

The performance of a pavement structure under traffic and/or environmental load depends to a large degree on the stress-strain relationships of the various pavement materials from which it is made. The response also depends on the intended use of these material layers and on the mechanism by which the load is transferred from one layer to another. In general, these stress-strain relations are defined by the mechanistic properties of the road material in addition to the currently adopted physical ones such as density level. Therefore, the mechanistic properties of materials used in the different pavement layers are needed to develop effective material models for road structures. Furthermore, environmental factors such as temperature and moisture influence these properties and must be considered in the material model. The quality of construction also has an impact on the mechanistic response of construction materials and should be accounted for in modeling them. In-service conditions associated with aging (asphalt concrete surface) or densification (unbound aggregate layers), also have an effect on the structural response of a pavement. In-service conditions may also include cracking, where an unfavourable response to external loading in the form of crack propagation may occur. The response 
may also involve other forms of deformation such as shear flow, which leads to shoving resulting in uneven road surfaces. An uneven road surface creates critical traffic loading conditions and magnifies the impact of the load adding to the severity of damage. The ability of any model to capture such responses is critical for carrying out effective analysis leading to accurate performance prediction.

An overall review of the current design guide in this study revealed that AASHTO design guide (1993) is used across Canada and United States. However, this guide is based on very limited and dated experimental work. The qualifying experiments were carried out on a single native soil and road construction material within single environmental and traffic conditions. All of these limitations of AASHTO road design guide are motivating researchers to improve the design procedures by a developing mechanistic-based design approach. Today's advances in analytical modeling and proper constitutive relationships reflect the silent behaviour of road materials. This is leading potentially to the linking of the mechanistic behaviour and the measured performance of pavements.

The new approach considered the historical development of AASHTO design guides (1961-1972 and 1983-1993) and the new design guide (NCHRP, 2004). The literature review showed a shift from total reliance on an empirical method in the AASHTO design guide (1993) to a combination of mechanistic and empirical methods in the new design guide (NCHRP, 2004).

The use of a practical pavement instrumentation system to produce necessary performance based data is discussed in this thesis. The data is valuable on its own in that it is beneficial to have knowledge of the actual value of stress and strain and their 
correspondence to environmental conditions under a certain loading scheme. The proposed system is simple and the majority of data could be retrieved by remote interrogation of data loggers connected directly to the installed sensors.

This proposed road installation scheme is simple yet effective in generating data needed for evaluating the new AASHTO design guide (NCHRP, 2004).

The mechanistic empirical pavement design guide employs more efficient and sophisticated analytical tools and structural analysis models. It is recommended in this study to use actual laboratory test data of the complex modulus, creep compliance and indirect tensile strength for asphalt concrete and resilient modulus for unbound materials determined under simulated measured environmental parameters and traffic loading conditions in order to evaluate the advance design level. It is well known that climatic changes are the major factor in pavement deterioration. Seasonal variations and their impact on the road performance are considered to be very important. This study focuses on sensitivity analysis to examine the ability of the model to account for the impact of seasonal variations, namely temperature and moisture content. These two parameters must be incorporated in the new design guide particularly in cold regions where pavement is expected to heave during the winter and lose part of its resilient modulus during spring thaw. 


\section{FIELD INVESTIGATION - INSTRUMENTATION}

\subsection{Introduction}

The field experiments in this study included a number of variables associated with the type of road structure, construction materials and traffic. The structures of the road were different in the three sites according to the design methods adopted locally by road authorities. Each of the three sites included some unique features compared to the two conventional flexible pavements involving AC surface layers on top of layers constructed with different unbound materials.

The three sites were chosen based on their different structure, unique traffic patterns and weather conditions. The monitoring of seasonal variations helped in establishing a fundamental understanding of the magnitude and impact of these variations in the pavement response to different loading conditions. A monitoring program was planned before installation of the instruments began. Installation of sensors depends on the road construction process. In newly constructed areas, sensors were positioned following the progress of material lying in the different pavement layers. In reconstruction and overlaying projects, the existing damaged base was dug to position some sensors in unbound layers and then restored by placing back the same material and compacting it to local specifications. The instruments for seasonal parameters were installed at the inner wheel path while the instruments for the structural response were installed at the outer wheel path. The backfill was constructed in layers of approximately $150 \mathrm{~mm}$ to allow for the installation of the different sensors and better compaction quality. The state of stresses and strains associated with these layers was monitored with sensors installed during construction using pressure cells and strain gauges. Because of the 
impact of seasonal variations in moisture and temperature conditions on the mechanical properties of road materials, moisture gauges and thermocouples were installed to establish changes in the gradients associated with the two environmental parameters. Frost depth at all sites (if necessary) was monitored using resistivity probes.

The fieldwork plan was customized to the features of each site to capture the effect of different parameters related to the environment, traffic, foundation materials and borrowed backfill materials. Types of data collected include those necessary for capturing the response of the pavement under dynamic loading conditions that involves high-speed data collection rates. Test truck runs commenced immediately after construction in some test sections and in others after the mat temperature dropped. Wheels of the test truck were aligned with the wheel path already marked on the road surface to assist the truck operator. Each pass was used to capture a combination of signals from specific numbers of buried sensors. The need to capture the impact of traffic speed on the pavement response necessitated that test truck runs were repeated to cover the targeted speed range.

The other data type involved static readings associated with build-up of permanent deformation with time and under the action of traffic loading. The data type also involved measuring temperature and moisture conditions four times a day to support analysis sensitive to changes in these parameters (temperature sensitivity of asphalt concrete and $\mathrm{M}_{\mathrm{R}}$ dependency on moisture state). The part of the instrumentation plan involving the distribution of sensors was developed while considering the site layout plan and geometry of the cuts (width, length and depth). At this juncture, it should be mentioned that this current study developed and implemented the pavement monitoring system of existing roads. The plan was also developed taking into consideration the 
configuration of the cuts and their locations with respect to the road geometry and traffic flow.

The summary of the instrumentation part of the field investigation work was published as a source and guidance of a cost effective and reliable pavement instrumentation and monitoring system (Maadani et al., 2014).

\subsection{Road instrumentation design scheme}

To design an effective and economical pavement monitoring system, one must consider both the structural and environmental data to be collected. The type and arrangement of the layout of the different layers of the pavement should also be considered in determining the type of instrumentation to be used. The adopted system should also be able to capture the impact of seasonal variations in moisture and temperature conditions on the mechanical properties and behaviour of road materials. The implemented system should utilize moisture gauges and thermocouples to establish changes in the gradients associated with the environmental parameters. The proposed instrumentation system also determined the frost depth of all sites using resistivity probes and compared with thermocouple sensors.

The selected sensors and data acquisition system should be capable of capturing the response of the pavement under dynamic loading conditions. It should also be capable of taking static readings associated with the build-up of permanent deformation with time, and under the action of traffic loading. The design of the system of the current study used measurements of temperature and moisture conditions four times a day to conduct sensitivity analyses of changes in these parameters (i.e., the temperature sensitivity of the 
load response of the asphalt concrete and unbound soil materials at various moisture states). The structural response was measured and recorded on a daily basis.

Instrumenting a new road is ideal as the sensors can be installed during construction. However, instrumenting existing roadways can be somewhat more difficult because it is typically done during road repair or utility repair and/or replacement. Precautions need to be taken to ensure that the performance of the instrumented section does not dramatically deviate from the surrounding or existing road structures.

\subsection{Sensor selection}

In implementing the proposed pavement monitoring system it is important to remember that the selection of sensors, their distribution within the different road layers, and the design of the data acquisition system should be based on the objectives of the proposed study and locally prevailing conditions. Site condition assessment information obtained prior to construction using general survey, cores and boreholes, or data collected from construction records proved useful in this study in the selection of sensors. The design of road instrumentation depends on the type of construction; whether it is new construction, repairs, or reconstruction. There are many factors that should be considered in the selection of sensors. Obviously, the sensor should be capable of capturing the intended property or response. Successful instrumentation design requires adequate knowledge of; (a) the type of sensor output (the majority of the sensors have voltage output), (b) the sensor measurement range, (c) the sensor's operating mechanism, necessary for determining its compatibility with the data acquisition system, (d) the life expectancy of the sensor, and (e) other limitations related to the surrounding magnetic environment. Finally, manufacturer's specifications related to output and capacity must 
be examined and considered in the selection process and respected during installation.

Sensors selection and their manufacturers for this study are listed in Table 3.1.

Table 3.1: List of sensors

\begin{tabular}{|l|l|l|}
\hline Sensor type & Measured response & Manufacturer \\
\hline Pressure cells & Pressure & $\begin{array}{l}\text { RST instruments LTD. British } \\
\text { Columbia, Canada }\end{array}$ \\
\hline $\begin{array}{l}\text { PAST II Asphalt concrete } \\
\text { strain gauges }\end{array}$ & Strain & Denmark \\
\hline $\begin{array}{l}\text { Water content } \\
\text { reflectometer (TDR) }\end{array}$ & $\begin{array}{l}\text { Volumetric water } \\
\text { content }\end{array}$ & $\begin{array}{l}\text { Campbell scientific Inc. } \\
\text { Logan/Utah, USA }\end{array}$ \\
\hline Thermocouple & Temperature & $\begin{array}{l}\text { Thermo-electric wire\& cable, } \\
\text { LLC, Saddle Brook, NJ, USA }\end{array}$ \\
\hline Extensometer & $\begin{array}{l}\text { Unbound } \\
\text { Settlement }\end{array}$ & $\begin{array}{l}\text { RST instruments LTD. British } \\
\text { Columbia, Canada }\end{array}$ \\
\hline Emu coils (3 pairs each) & $\begin{array}{l}\text { Unbound } \\
\text { Settlement }\end{array}$ & US army corps of engineers \\
\hline Resistivity probe & Frost depth & US army corps of engineers \\
\hline
\end{tabular}

\subsection{Sensors installation procedure}

In order to obtain an effective road instrumentation system for a given application, pre-construction activities must be conducted in preparation for installation. The pre-construction activities involve taking non-destructive deflection basin measurements on the existing road structure, coring samples from the road and survey work. These activities establish the type of materials that exist within a road structure which play a major role in the road design as well as the selection of sensors for each road layer. Figure 3.1 shows a block diagram of the master plan and communication links that should be prepared prior to the beginning of construction. The following describes the selection procedure for sensors suitable for the different road materials and provides 
the installation process of each sensor. In general, the sensors measure either the structural response (i.e., pressure and deformation) or the hydrothermal conditions (i.e., temperature, and moisture content) of road layers.

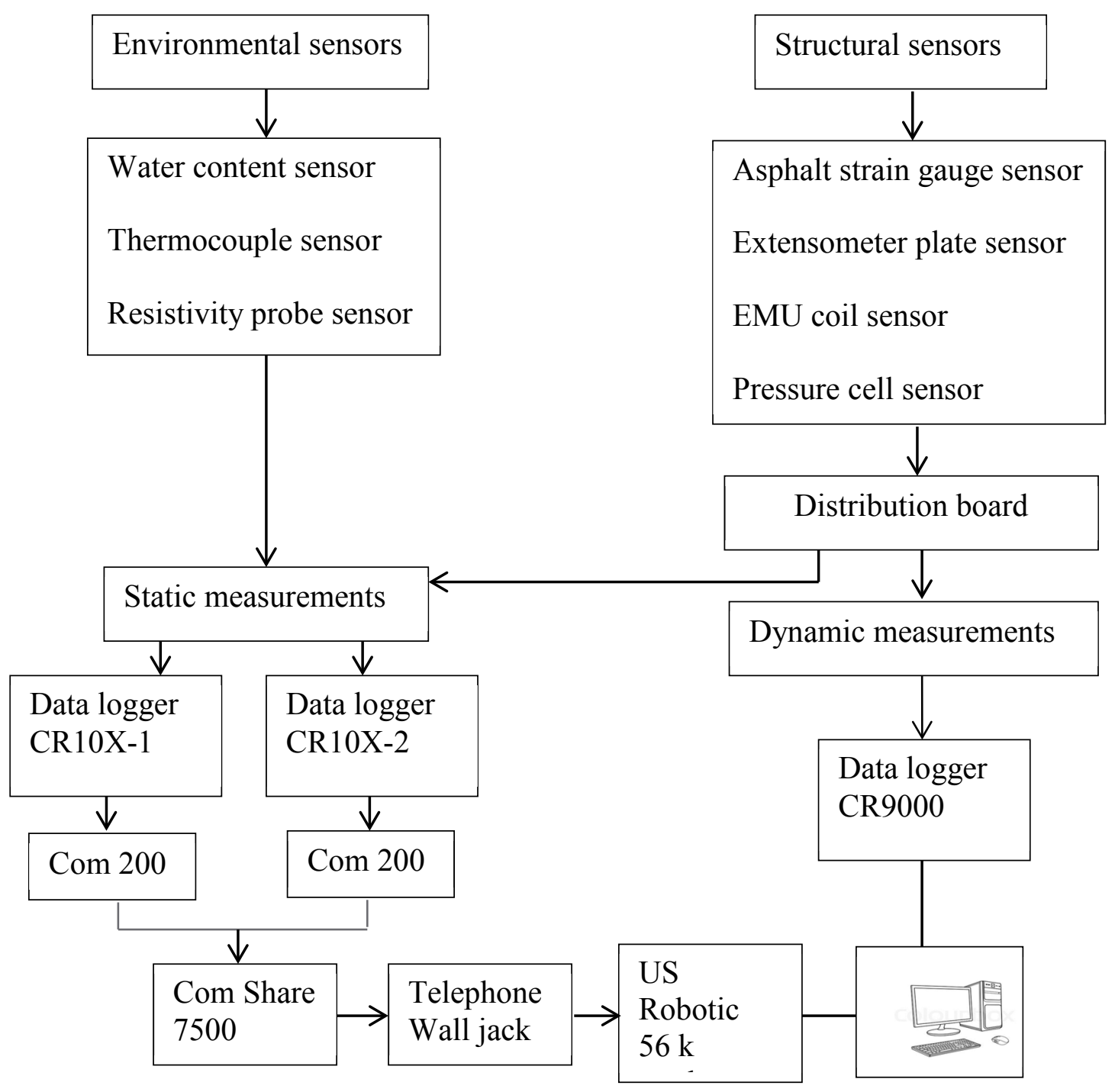

Figure 3.1: Typical instrumentation master plan 


\subsubsection{Structural sensors}

\subsubsection{Asphalt concrete strain}

Asphalt strains were measured using Dynatest Past IIA strain gauges. Strain gauges were positioned within the asphalt concrete (AC) layer, to measure strain in the transverse and longitudinal directions with respect to the traffic flow. In this study, the gauges were installed close to the bottom of the lower AC layer. The Dynatest past strain gauge is an $\mathrm{H}$ shaped precision transducer specifically manufactured to measure strain in asphalt concrete. However, to ensure optimum results, the following steps were followed:

$\square \quad$ Application of a thin layer of bitumen primer (if not already done) within the area, where the transducer is to be placed and left to cure.

$\square \quad$ Placement of a thin layer of 3 to $4 \mathrm{~mm}$ sand bitumen mix on the cured bitumen primer. Pressing of the anchor bars of the transducers into the sand/bitumen mix, until contact between the strain gauge bar and the sand bitumen mix was established. It was cured for at least one hour.

$\square \quad$ Protection when possible of the sensor cable by burying it into the unbound materials to a depth of at least $40 \mathrm{~mm}$.

Application of some hot asphalt from the paver on the transducer. Removal of the biggest stones. Place a 20 to $30 \mathrm{~mm}$ thick layer on the transducer to cover it.

$\square \quad$ Compaction of the hot asphalt material by applying a static pressure using a steel plate.

$\square$ Rolling of the hot asphalt in the direction of the anchor bars (rolling pin parallel to the transducer bar). Figure 3.2 shows the position of asphalt strain gauges in the $x-y$ 
directions after the completion of compaction using a solid metal roller with $100 \mathrm{~mm}$ diameter and a width of $200 \mathrm{~mm}$ ) (rolling pin type).

$\square \quad$ Placement of the asphalt with the paver and compact using a non-vibrating pneumatic tire roller.

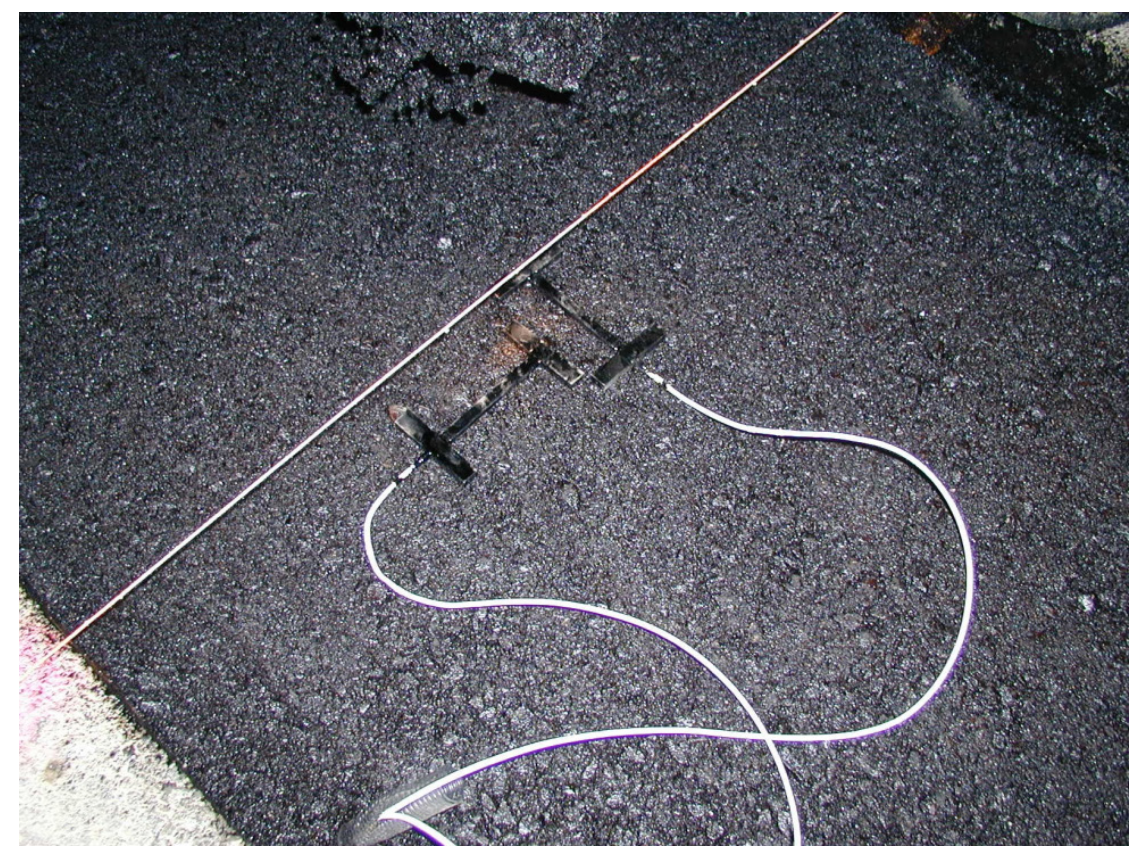

Figure 3.2: Installation of the AC strain gauges in the overlay in both directions

\subsubsection{Soil stress sensors}

The soil pressure sensors models TP-101-9-9-S, manufactured by RST instruments, were installed directly beneath the asphalt layer. These sensors monitored the amount of pressure applied by traffic, which was transmitted to each soil layer including the granular base and other unbound layers. This sensor has a transducer encased in a cylindrical tube attached to a flat pancake-type loading plate via a slender tube. 
The loading plate should be in direct contact with the unbound material. To ensure this, a very thin layer of fine sand (silica) was spread over the area under the loading plate (see Figure 3.3). The load plate area was then carefully seated by hand in the fine sand (slight twisting, with down ward pressure) until full contact was achieved (see Figure 3.4). These sensors can also be placed directly on the crown of a buried utility (pipe) to find the exact amount of load applied by soil and traffic loading on the buried pipe. Finally, the connecting tube and transducer portion of the sensors were covered with base material to prevent direct contact with the asphalt slab.

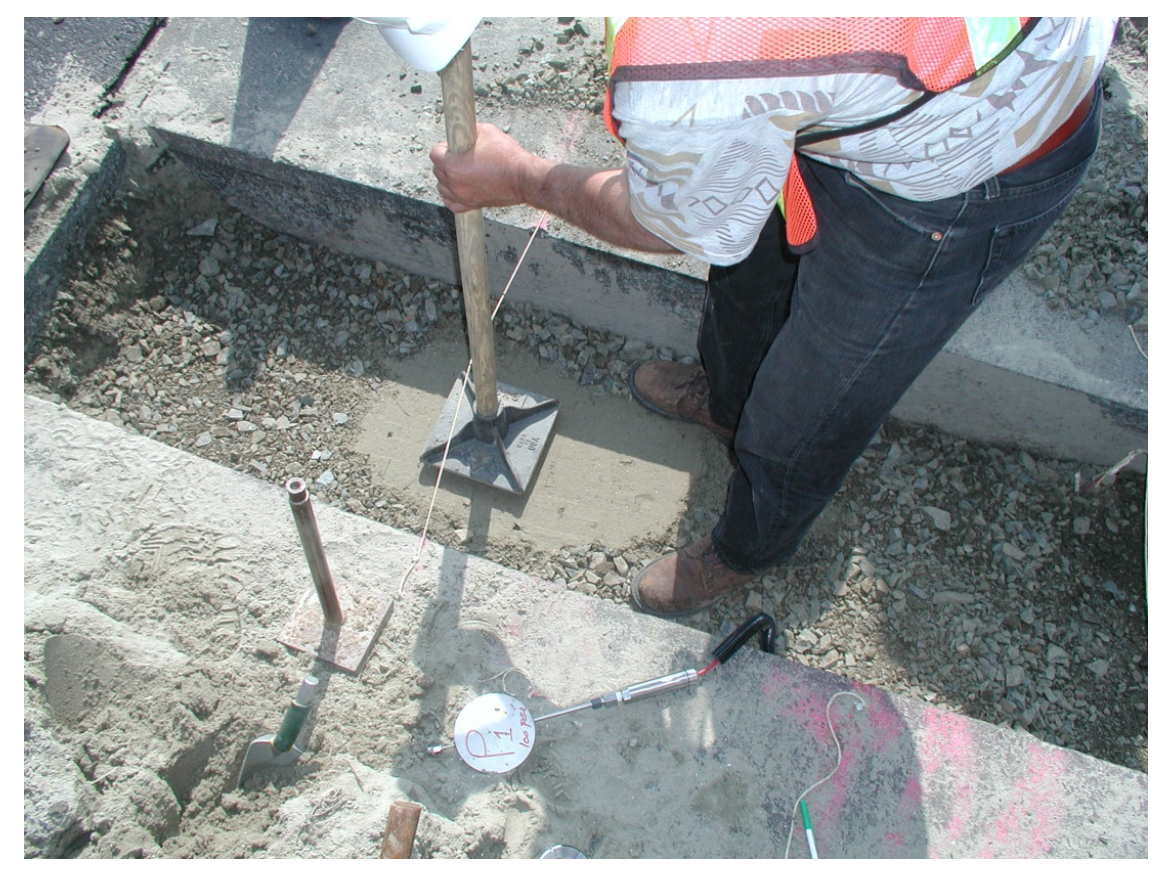

Figure 3.3: Sanding underneath the pressure cell during site installation in case of granular material 


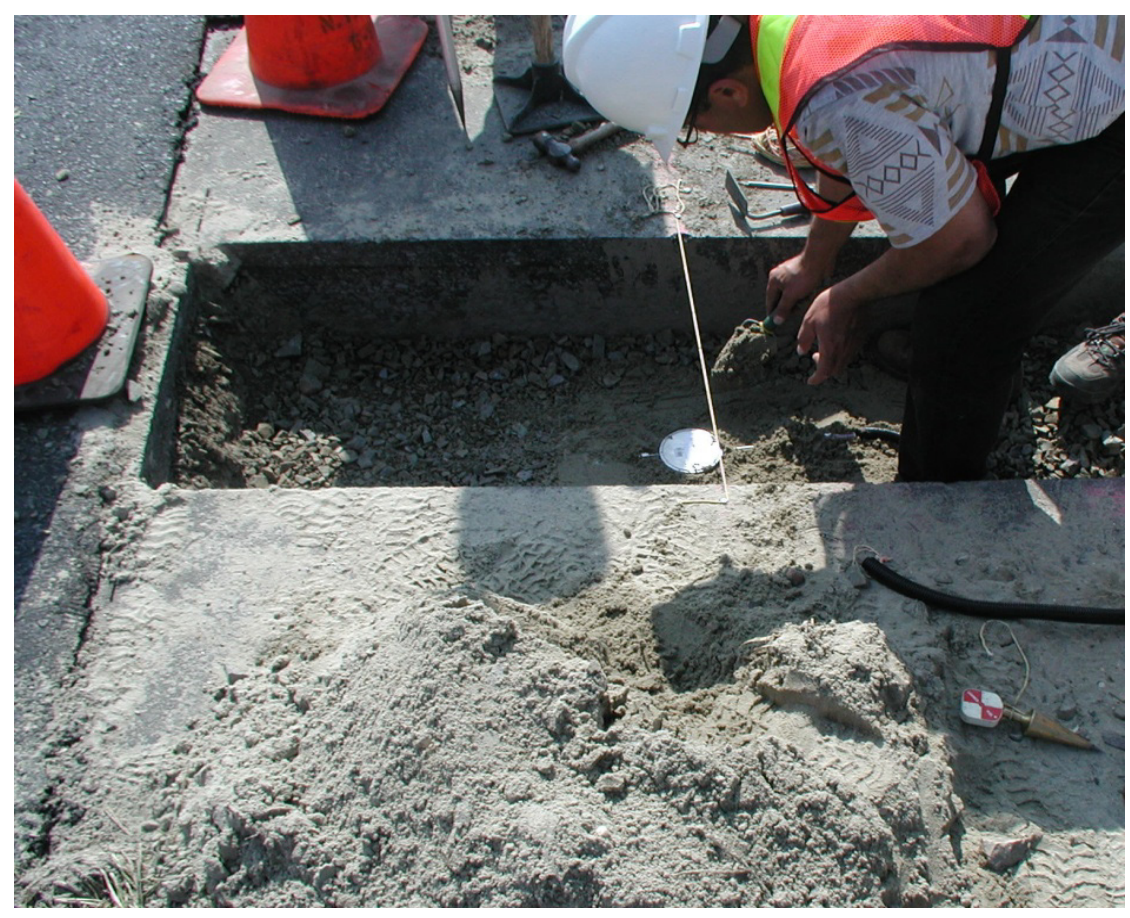

Figure 3.4: Installing and surveying the location of a pressure cell

\subsubsection{EMU Soil deformation sensor (strain)}

Sub-grade strain measurements were made with the $\varepsilon$-Measuring Unit (EMU) soil strain measuring system, an induction coil technology (Dawson, A.R., 1994) developed at Nottingham University which was later refined and enhanced (Dawson et al., 1999) at the Cold Regions Research and Engineering Laboratory (CRREL) of the US Army Corps of Engineers. An alternating current is passed through one coil, generating an electromagnetic field around it. Three receiving coils can detect this field. The strength of the detected electrical field is a function of the distance between the transmitting and receiving coils. Both dynamic (elastic) and permanent (plastic) strain can be measured by the coil system. The coils were installed in columnar stacks at the studied depth, starting at $150 \mathrm{~mm}$ below the asphalt layer, and the nominal centre-to-centre spacing was 150 
$\mathrm{mm}$. The strain measurements are made using the inductive coil system called the EMUCRREL system. These sets of $100 \mathrm{~mm}$ diameter coil sensors were manufactured by CRREL. Again, coil sensors measure vertical displacements in the vertical direction (designated as the $\mathrm{Z}$ direction) and in two perpendicular horizontal directions ( $\mathrm{X}$ and $\mathrm{Y}$ directions). The $\mathrm{Z}$ direction coils are coaxial, which the $\mathrm{X}$ and $\mathrm{Y}$ direction coils are coplanar. The $\mathrm{X}$ direction is parallel to wheel path, and Y direction is perpendicular to it. It is recommended that the thickness of underlying compacted lift should be measured. This is because a small amount of trimming is necessary if the lift is too thick, and a small amount of shimming with soil is done if the lift is too thin. After the coil is aligned and levelled, it is covered with about $5 \mathrm{~cm}$ of soil, which is lightly tamped. Sets of three $100 \mathrm{~mm}$ diameter EMU coils per layer are used to measure strain in the longitudinal, lateral and vertical directions (see Figure 3.5). Measurements from two sets are necessary for determining vertical strain within an unbound pavement layer. 


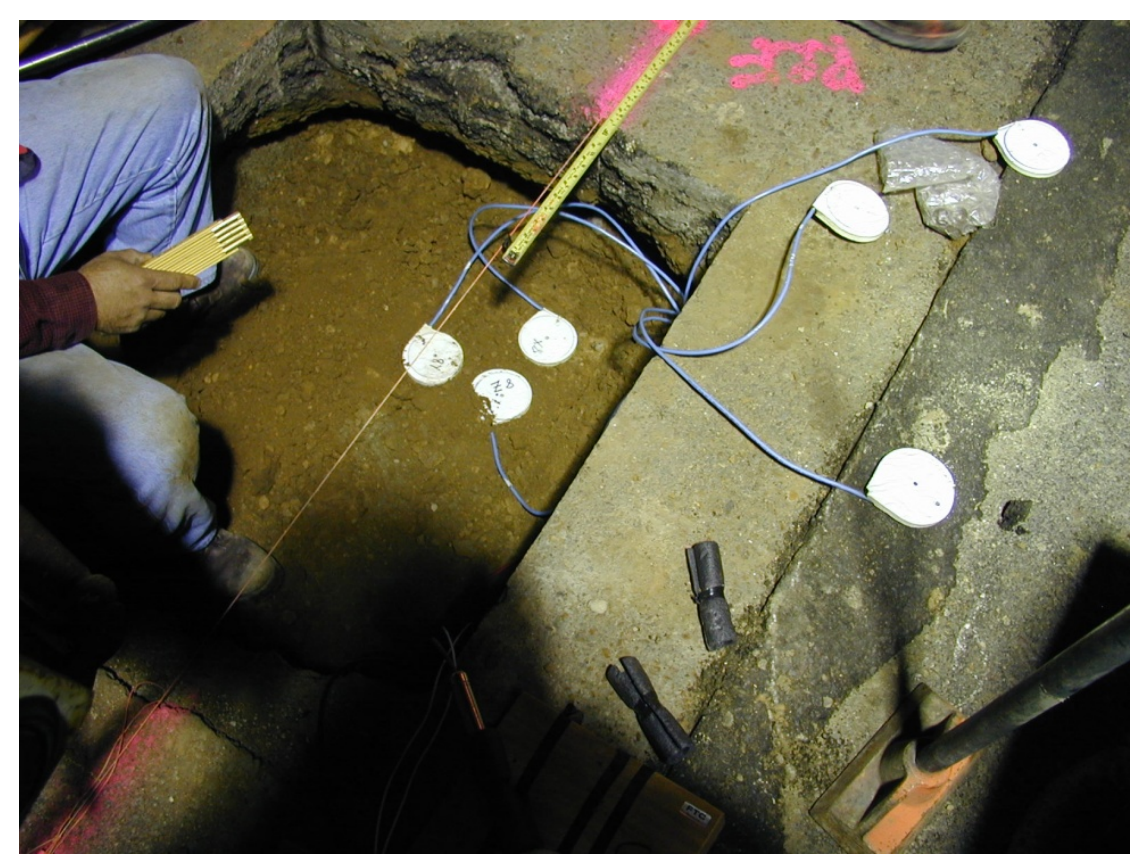

Figure 3.5: Installation of EMU coils

\subsubsection{Plate soil deformation}

Conventional settlement plates such as those manufactured by RST instruments, model EXF 0191A, were adopted in this study to quantify permanent deformations accumulating in the unbound road layers. These sensors contain a rod extensometer which monitors changes in the distance between one or more down hole anchors. Deformation of the unbound layers was determined by measuring the reference head. Any change in distance found by comparing the current measurement to the initial measurement indicates that movement has occurred. The rod extensometers are made of stainless steel with bottom and top caps which are the displacement surfaces with reference to the collar tube. The image in Figure 3.6 shows the initial step in the installation of the extensometer as stabilizing the bottom cap on a rigid area, such as a block of concrete positioned in the sub-grade material. The unbound materials are 
compacted around the bottom cap and backfilled up to the tube end, followed by screwing on the top cap. The initial measurements are taken and used as the baseline data after these installation steps.

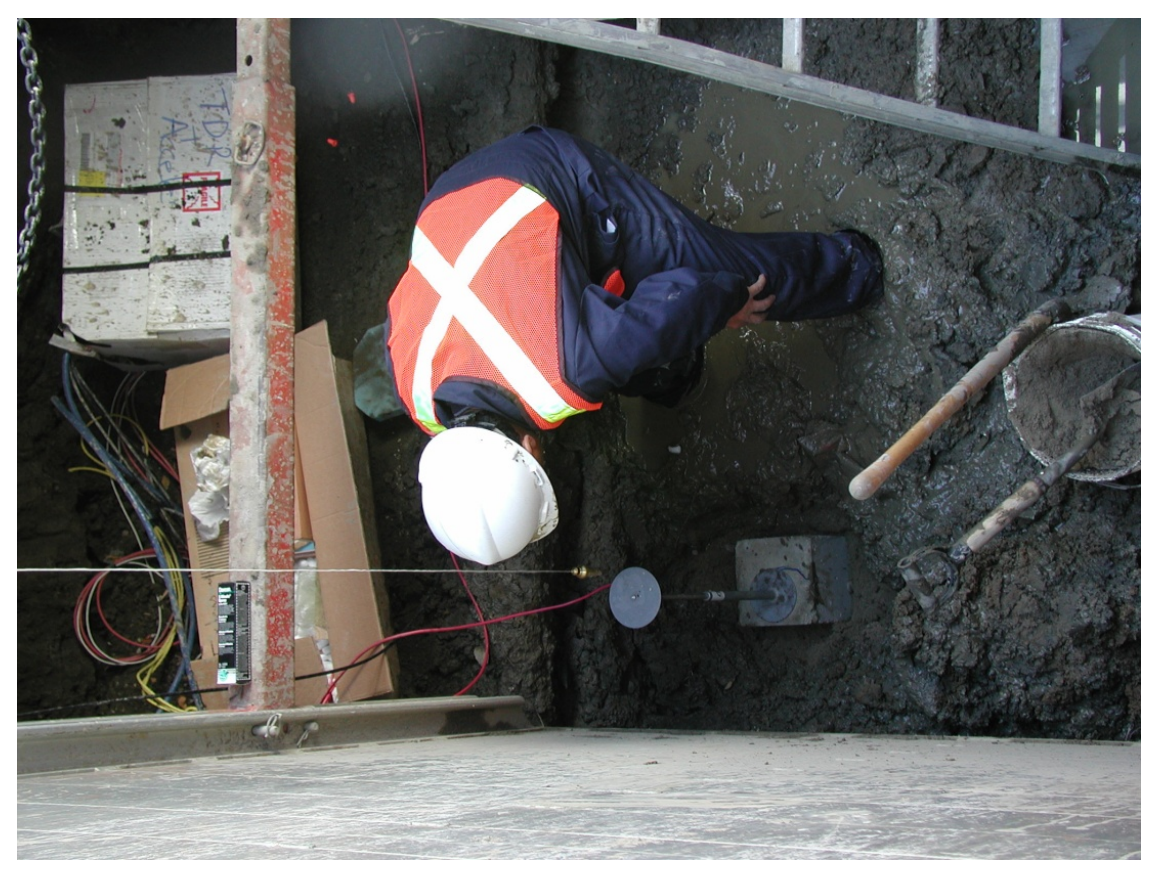

Figure 3.6: Installing a sub-grade extensometer

\subsubsection{Environmental sensors}

\subsubsection{Temperature sensor}

Copper-constantan (Type T) thermocouple probes were used to determine the temperature profile of the soil layers and within the pavement structure. Type T thermocouples can measure temperatures in any condition with an accuracy of $\pm 0.5^{\circ} \mathrm{C}$. For this study, temperatures were measured at 3 or 4 different depths in the pavement surface, depending on the thickness of the asphalt layer. Temperature was measured every $100 \mathrm{~mm}$ in the other soil layers starting at $25 \mathrm{~mm}$ below the asphalt concrete layer. The thermocouple cable used in this study had twelve 20-gauge copper-constantan wire 
pairs. The sensor junction was formed at one end by: a) stripping the outer insulation at least $12 \mathrm{~mm}, \mathrm{~b}$ ) twisting both ends together, c) soldering the twisted end, d) trimming the end, and e) covering the junction using heat-shrink tubing filed with silicon. A piece of wood was used to fix the thermocouple in place for a particular position as shown in Figure 3.7 .

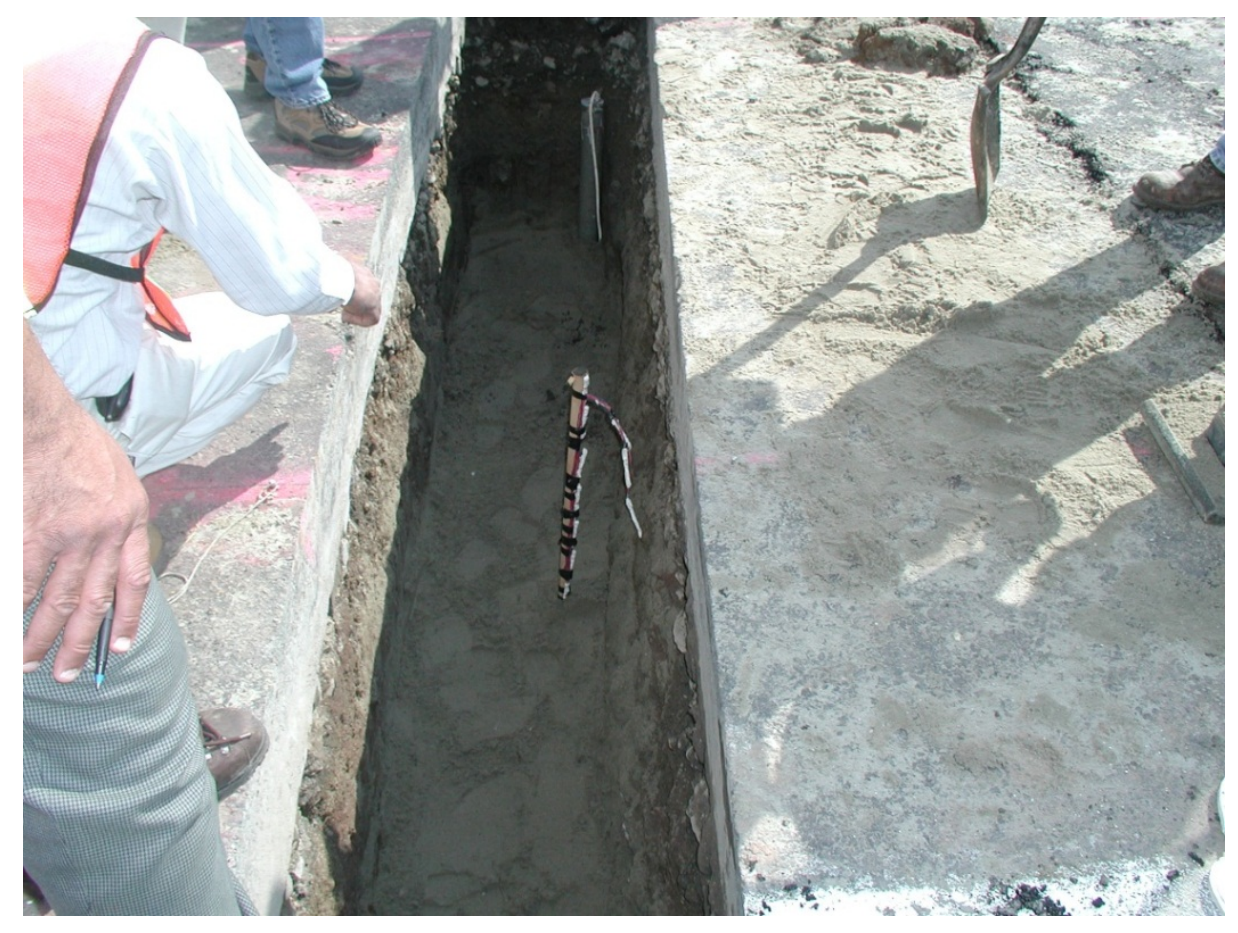

Figure 3.7: Typical installation of a thermocouple

\subsubsection{Moisture content sensor}

Variations in moisture content through the depth of unbound layers were monitored using water content reflectometer sensors model CS615 or CS616, manufactured by Campbell Scientific INC. These water content reflectometers consisted of two stainless steel rods connected to a printed circuit board. In this study, the two rods were maintained at a constant distance apart by using a piece of wood in between to 
eliminate the effect of unparalleled and unequal distance between them, as shown in Figure 3.8. The CS615 or CS616 sensors should be installed on a levelled surface and in the horizontal direction. A shielded four-conductor cable is connected to the circuit board to supply power, enable the probe, and monitor the pulse output. The CS615 and CS616 provide an indirect measurement of soil water content by using the effect of changing dielectric constant on applied electromagnetic waves. The probe rods act as a wave-guide and the material surrounding the rods (soil) varies in dielectric constant with the amount of water present in the material. Changes in the dielectric constant of the soil system can be attributed to changes in water content. The water content reflectometer sensors utilize the principles of time domain reflectometry (TDR) to measure the unfrozen volumetric water content present within the soil mass. The time domain reflectometry method of monitoring sub-grade water was introduced to pavement engineering by Neiber and Baker (1989). For this study, the reflectometers were connected to a Campbell Scientific CR10X and an AM416 relay multiplexer. The measured period of wave propagation was converted to gravimetric water content using standard calibration values for a given soil material as shown in Figure 3.9. 


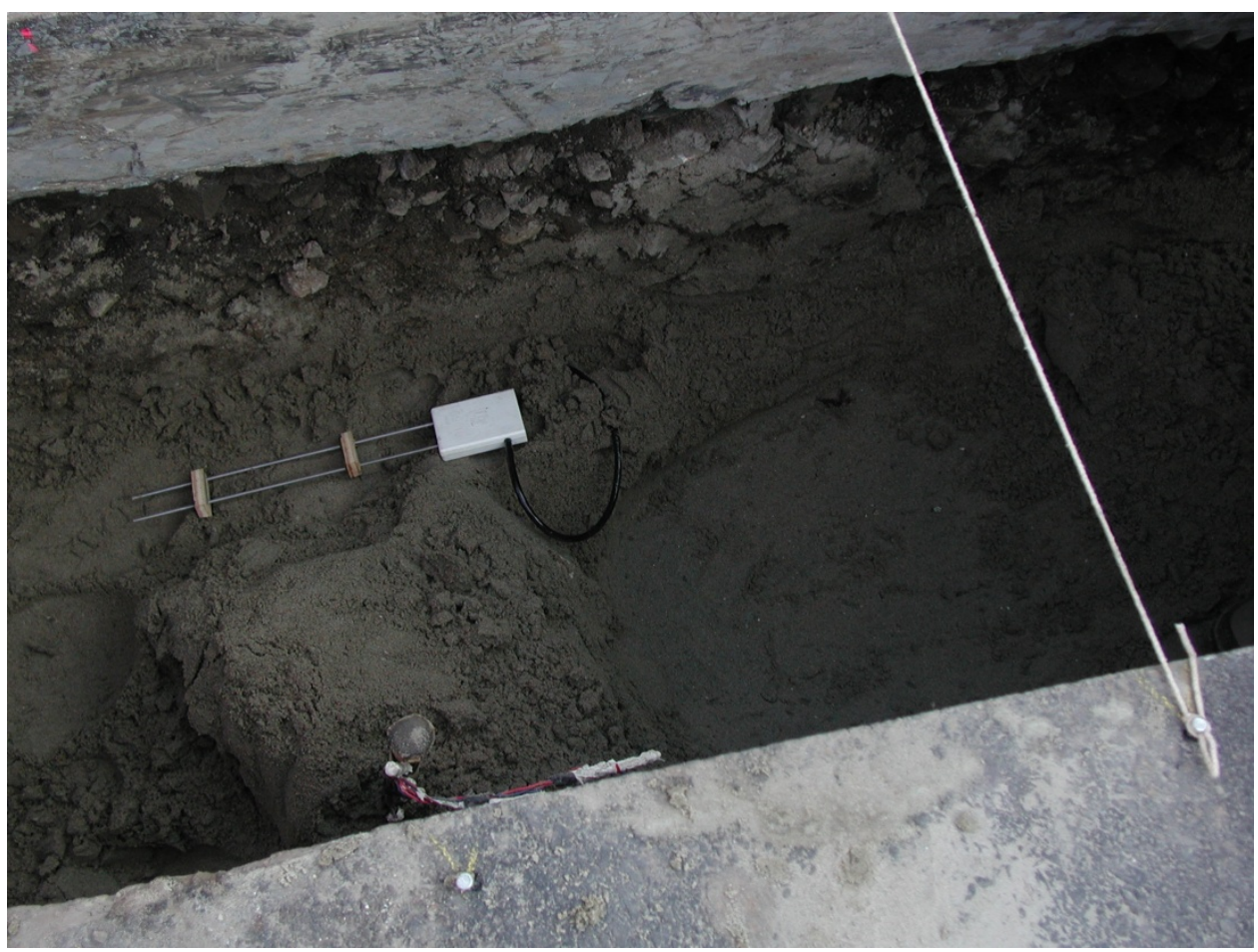

Figure 3.8: Installation of the water content reflectometer

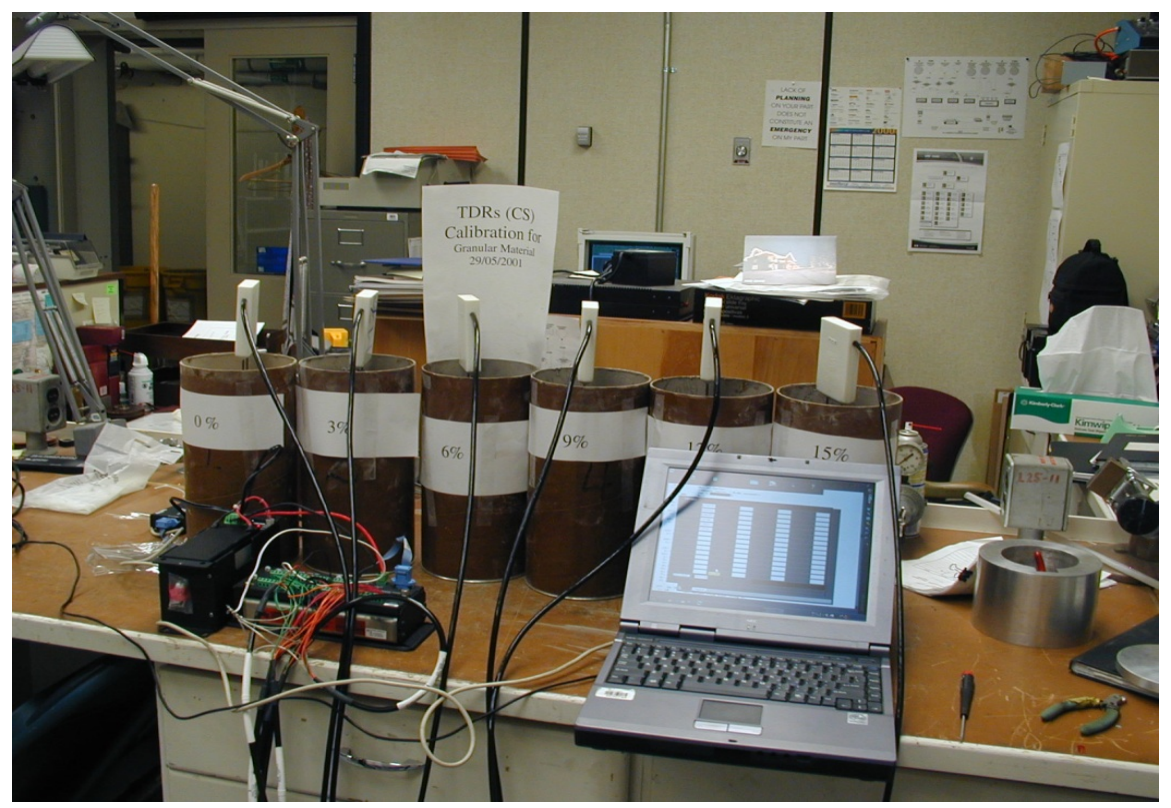

Figure 3.9: Calibration of the water content reflectometer 


\subsubsection{Resistivity probe sensor}

The CRREL frost tube (Knuth, 2001), was used to monitor frost depths in the soil materials. These probes can be quite reliable when used in granular materials. The probe consists of 36 metal (rings) wire electrodes, spaced $51 \mathrm{~mm}$ apart, and mounted on a solid PVC rod (installation shown in Figure 3.10). The resistivity probe measures the electrical resistance of the soil mass to identify points of change in the resistance field within the material. Such changes are induced by changes in the physical nature of the water contained in the soil as water undergoes a phase change from the liquid stage to the solid stage within the soil. The CRREL frost tubes were found to be compatible with the data logger (Campbell Scientific CR10X) used in this study.

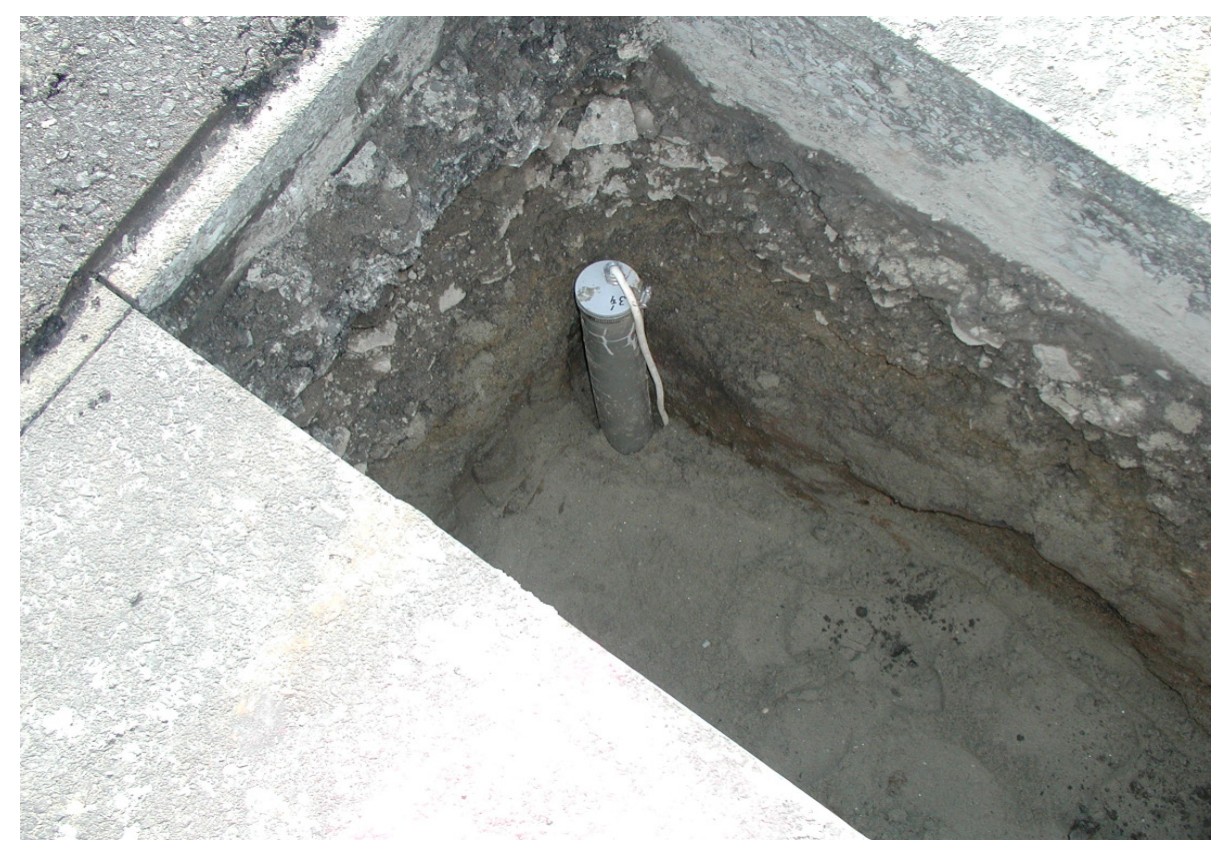

Figure 3.10: Installation of CRREL resistivity probe 


\subsection{Data acquisition system}

The quality of the captured pavement response associated with traffic loading is influenced by the ability of the data acquisition system to match the vehicle speed. The pavement response is dynamic and necessitates the use of a high sampling rate at high vehicle speeds. The structural response starts to build up when a vehicle approaches the location of the sensor and diminishes after it passes that location. That location experiences an increase in vertical stress and strain until a peak is reached when the wheel is directly above it and then decreases as the vehicle moves away. This causes a bell shaped stress and strain pulse and necessitates acquiring a large number of readings to capture the peak response. Accordingly, a sampling rate representative of traffic speed on the road should be calculated in advance to guarantee capturing the necessary information. The stress pulse duration for a vehicle traveling at speed of $60 \mathrm{~km} / \mathrm{hr}$ (Akram et al., 1992) is 120 milliseconds requiring a rate of 8 samples/sec to capture the peak. An attempt was made to combine sensors that were under the same vehicle pass. This was intended to read the strain corresponding to traffic induced stresses to facilitate quantification of the material elastic modulus. In this study, an initial attempt to measure the peak of the signal was missed at a sampling rate of 200 samples/sec when the capacity of the data loggers and the number of occupied channels were not considered in the design. Therefore, it is important to determine the rate after determining the combination of sensors involved in each reading and the capacity of the data logger. Experience gained in this study indicates that for a signal to capture the peak value, the rate should not be less than 1000 samples/second for any combination of sensors. These details should be utilized in programming the data loggers. Major guidelines for designing a data acquisition system include: 
$\square \quad$ Identification of each sensor type and anticipated output range to determine whether it should be supported by either a slow or fast system.

$\square \quad$ Determination the reading frequency, i.e. how many times a day and for how long should the data retrieval mode is maintained.

$\square \quad$ Satisfying the objective of the investigation related to collection of dynamic response data to determine the optimum scanning intervals. As mentioned earlier, the number of sensors attached to the data logger and subsequent processing will limit the sampling rate per channel. Limited system capacity may force sampling different sensors for different events (vehicle passes). For pragmatic reasons, combinations of different sensors should be tested until the desired sampling rate is achieved.

$\square \quad$ Selection of data loggers and communication devices that are suitable to assemble a data acquisition system. In this study, in order to meet operational requirements of the system, two types of Campbell scientific data loggers were used:

(a) Model CR10X was used to acquire (static) data. It is a durable and batteryoperated programmable device that operates over a wide temperature range. The CR10X is equipped with three or four AM416 multiplexers to accommodate all of the sensors. The rate of sampling of the CR10X is ideal to monitor thermocouples, full bridge strain gauges, and water content reflectometers.

(b) Model CR9000 was used to record dynamic readings (traffic impact) for monitoring stress and strain (عmu coil gauges). It is a faster data logger, which is required to collect data for recording structural responses due to moving vehicles. The Campbell Scientific CR9000 is also a fast, durable, battery-operated, stand-alone and 
programmable data logger that operates over a wide temperature range. It can measure up to 100,000 samples per second and accommodate up to nine $\mathrm{I} / \mathrm{O}$ modules.

\subsection{Instrumentation box}

The sensors, with different functions, were buried in the road structures to capture the structural and environmental response of the pavement. A data acquisition system was installed at the testing site to collect data from these sensors and these were remotely interrogated to download the data to a central laboratory. Accordingly, a system of conduits was required to connect the sensors in the three sites to the data loggers. In addition, a system for housing data loggers and communication devices was assembled to protect these devices throughout the life of the experiment as shown in Figures 3.11 and 3.12. PVC pipes were used to protect wires not embedded in the pavement structure. Additional requirements at each site included $110 \mathrm{VAC} / 60 \mathrm{~Hz}$ power supply and two standard telephone lines for communication. 


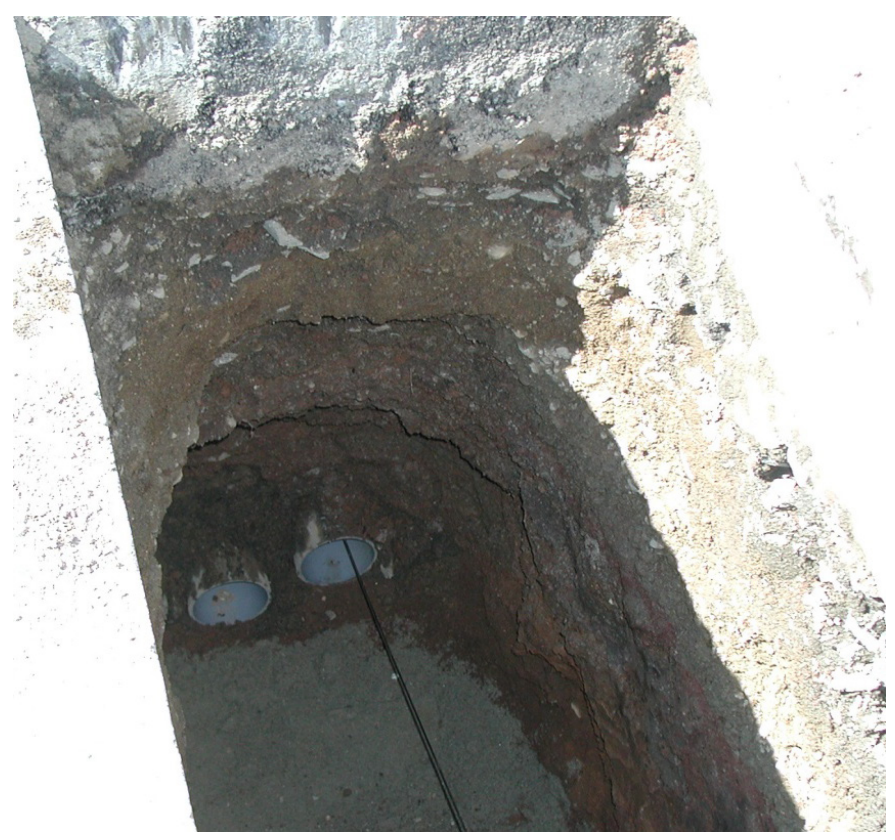

Figure 3.11: Trench sensor conduit

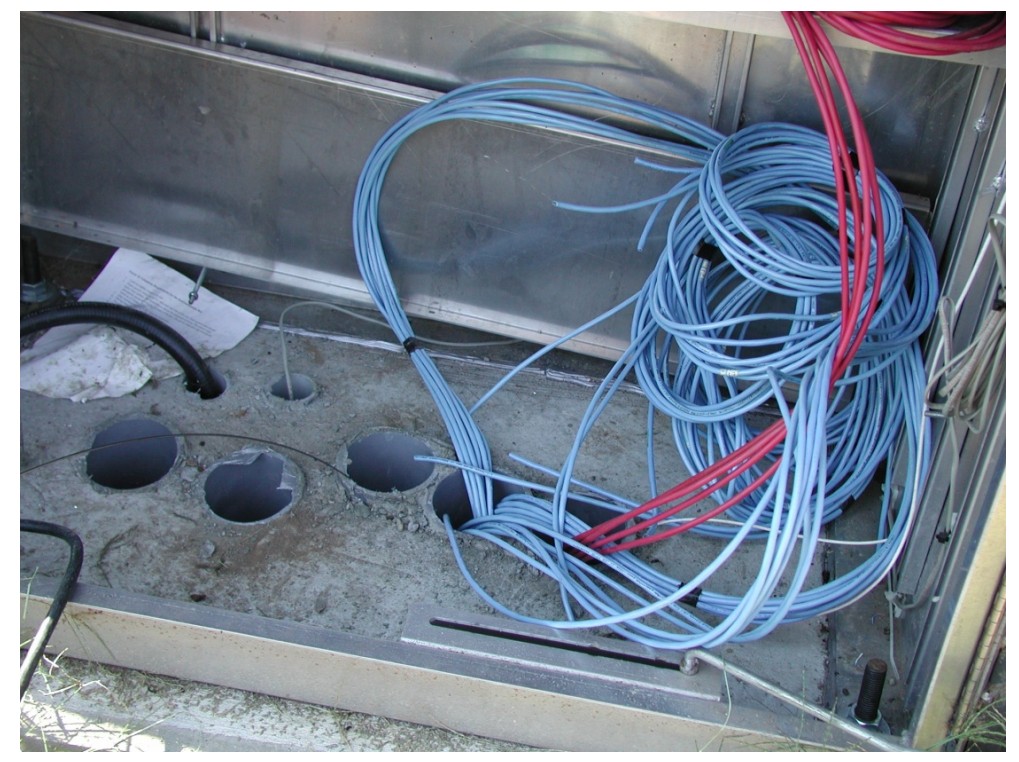

Figure 3.12: Instrumentation box conduit 


\subsection{Data categories and collection methods}

In road testing, the data that is to be collected can be broadly divided into two categories. The first type of data is obtained during the passage of a given heavy vehicle over the tested road section. This type of testing and monitoring is usually done once or twice per year. It is preferable to conduct this testing to measure such response during the freeze-thaw season and/or after a major rainstorm. It is referred herein to this data as the dynamic data. The collection of this data requires the presence of an engineer or qualified personnel at the site and involves high-speed data collection rates. The other data type is collected throughout the year and is called static data. The static data readings are associated with build-up of permanent deformation over time and under the cumulative action of traffic loading. It also involves measuring temperature and moisture conditions to conduct sensitivity analyses of changes in these parameters (i.e., the temperature sensitivity of the load response of the asphalt concrete and unbound soil materials at various moisture states).

Similar to other components of the monitoring system, data collection techniques should be designed to satisfy the objectives of the experiments. The main steps of the procedure adopted to meet the objectives of this research are given below:

$\square \quad$ Data was collected frequently using a programmed data acquisition system and retrieved remotely via a modem on weekly basis. The communication systems designed for this study were the CR10X data loggers, depicted in Figure 3.13.

$\square$ Collection of stresses and strains during the passage of test trucks requires the engineer to be present at the site. Any number of truck categories common to the specific road corridor may be examined depending on the budget. 
․ Relationships established between the performance data and factors such as road geometry, construction quality and environmental condition, should be analyzed to guide the model calibration process.

$\square \quad$ Data collected from multiple visits were needed to capture the impact of changes in the pavement materials related to aging of the binder and densification of unbound material.

$\square \quad$ Temperature and moisture data were collected a number of times every day throughout the life of the experiment to support analysis.

$\square \quad$ The sampling rate was determined according to data category.

Vehicles traveling at speeds as high as 60 kilometres per hour resulted in a loading period that was less than $1 / 100$ of a second. This condition necessitates a high sampling rate. The CR9000 data acquisition system proved suitable for this high sampling rate (1000 to 2500 samples/sec.). Capturing environmental data at specified intervals does not require a high sampling rate and a CR10X system produced adequate data quality.

The master plan of the instrumentation scheme developed in this study, covering sensors, data loggers and communication devices, is shown in Figure 3.7. Data types referred to as "static measurements", which included temperature, water content, pressure, frost depth and permanent deformations, were acquired using the CR10X data logger. On the other hand, "dynamic data" included pressure and strain, and were acquired using the CR9000 data logger. In the assembled data acquisition system, consideration was given to the type and number of sensors fitted in the various pavement 
layers (asphalt concrete, granular base and native soil). Sampling rates computed in this study were incorporated in the computer programs of the data logger, taking into account anticipated traffic characteristics and the capacity of the system.

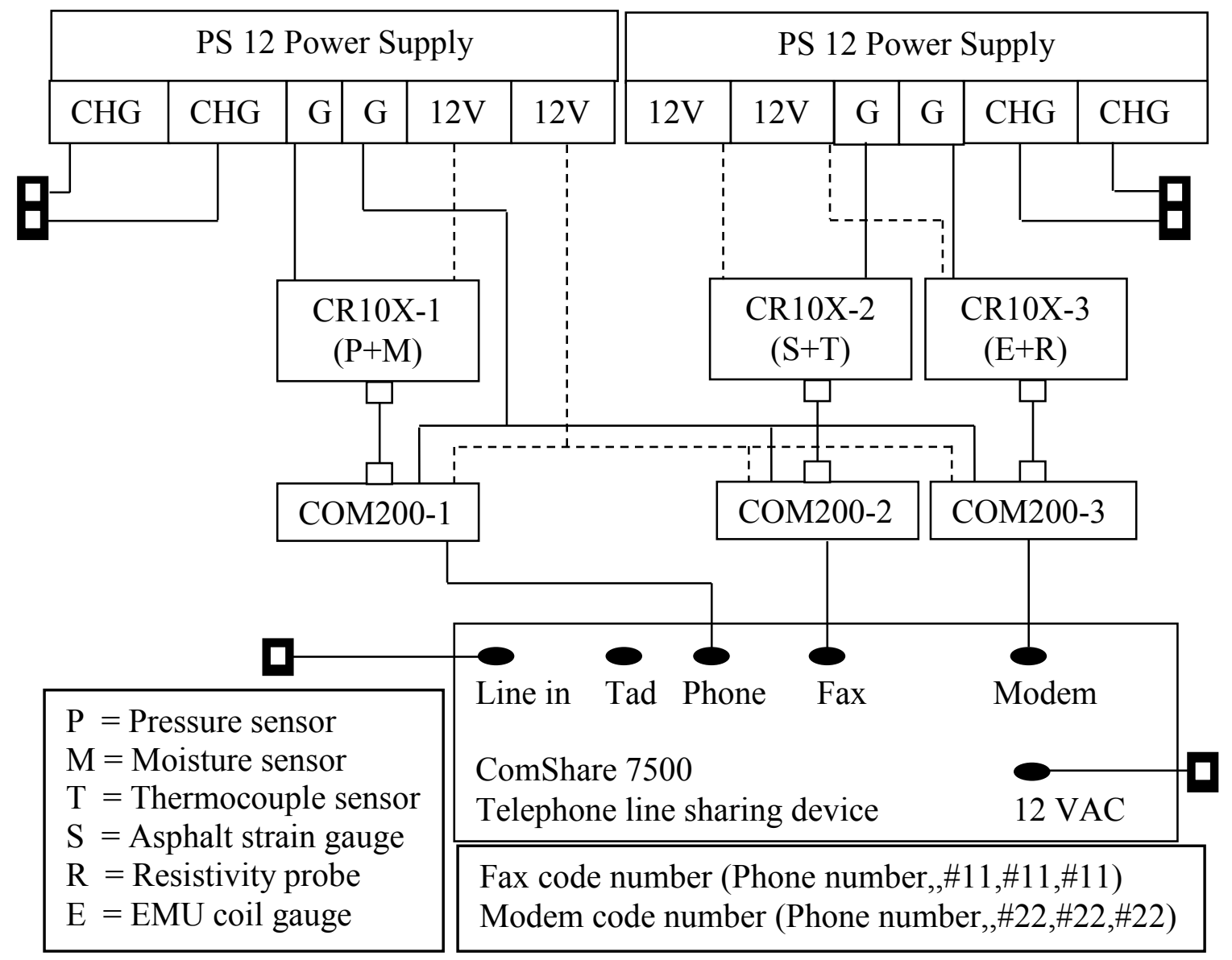

Figure 3.13: CR10X communication set up

\section{8 $\quad$ Field Sites}

\subsubsection{Site 1}

Site 1 field experiment is one of three sites selected to represent a wide range of structure practices and environmental conditions with the objective of generating information to support the research leading to the evaluation of the new design guide (NCHRP, 2004). The instrumentation at site 1 utilizes a deep and wide cut of the road 
structure and provided an opportunity to study the behaviour of road structures in a relatively cold region. The pavement section at this site is composed of $200 \mathrm{~mm}$ asphalt concrete layer and filled with $2320 \mathrm{~mm}$ of granular A material (base), resting on silty sand sub-grade materials. Site 1, which is North-South bound, has a 4-lane divided road (two lanes in each traffic direction) with a space for a proposed bicycle lane extending along the southbound traffic lanes. The existing road was in fair condition with minimum transverse and longitudinal cracks. Existing cracks were all sealed as per practice of the municipality responsible for site 1 . The recent Annual Average Daily Traffic (AADT) reported was 7000 . Figure 3.14 shows the details of installed sensors including the thicknesses of the layers built in Ottawa, Canada.

Data were collected for at least two years covering a wide range of engineering parameters and environmental conditions. Stresses and strains in asphalt concrete, granular base and native soil were measured under static and dynamic loading modes. The data were complemented with performance data including those obtained from visual damage assessment and profile surveys. Data were analyzed and the full results will be given and discussed later on.

Site 1 experiences below freezing temperature during winter months. Accordingly, a resistivity probe was installed in the road to determine frost penetration depth. Variations in moisture and temperature condition in various pavements, is captured using water content reflectometers and thermocouples respectively. 


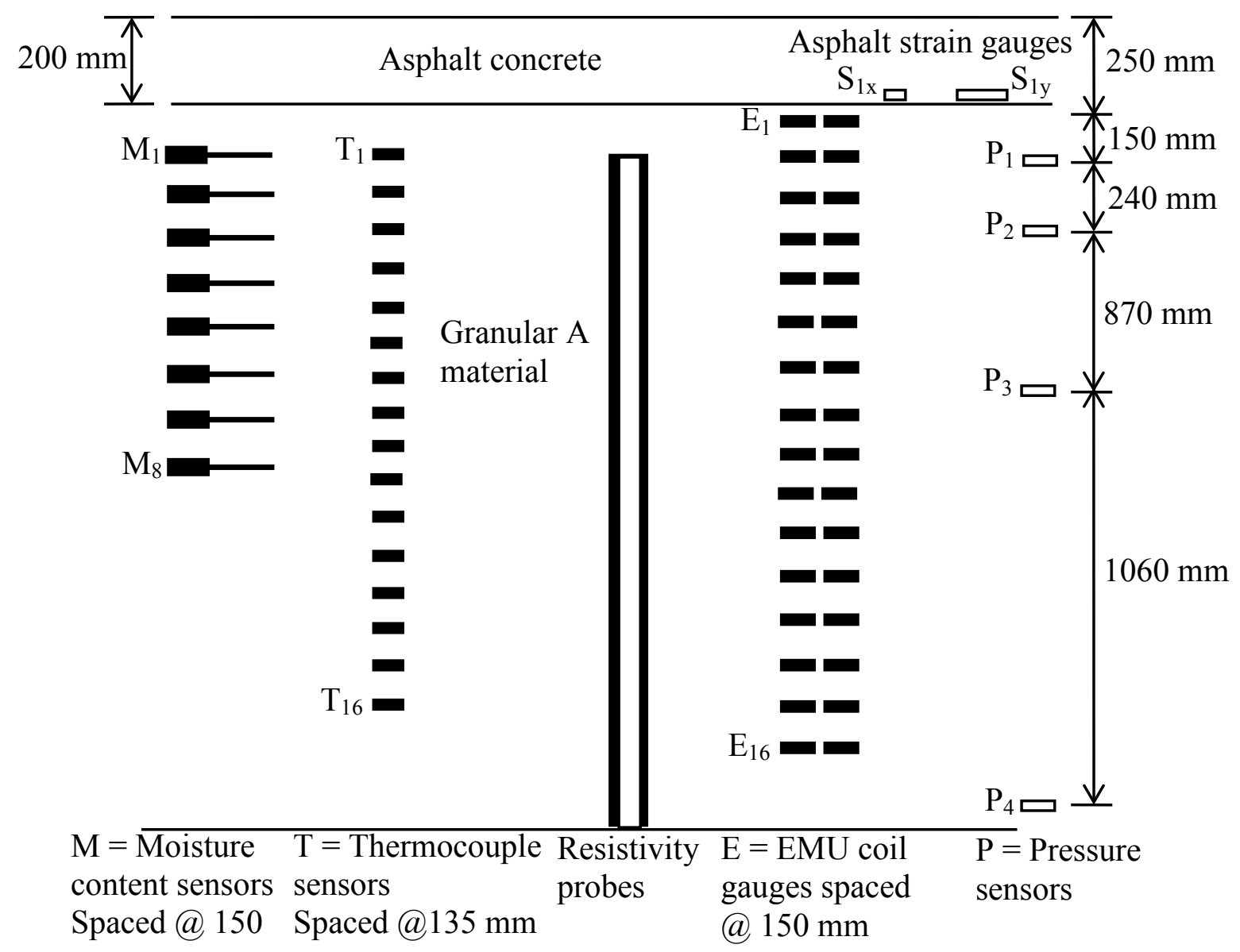

Figure 3.14: Vertical distribution of environmental and structural sensors-site 1

\subsubsection{Site 2}

Site 2 provided an opportunity to study the behaviour of road structures in a relatively dry, warm region. The experiment site was fitted with sensors and the data were analyzed to examine the characteristic behaviour of roads built in this kind of environment. The site 2 road is an eight-lane urban street (4 lanes in each traffic direction). Data collected prior to construction included details related to the road structure, its condition, and geotechnical information. Road condition assessments performed on site 2 indicated that the road was in fair condition. Based on information obtained from the pavement cores and boreholes, the existing road structure within Lane 
3 rests on a native plastic silty clay sub-grade. The pavement structure is composed of an asphalt concrete surface of $230 \mathrm{~mm}$, an aggregate granular base of $110 \mathrm{~mm}$ (CAB II), a select granular backfill material sub-base of $870 \mathrm{~mm}$, and silty clay as sub-grade material. Annual Average Daily Traffic (AADT) was 2000.

A number of sensors, with different functions, were buried in the trench to capture the structural response of the pavement as well as the environmental changes within the road layers.

Variations in moisture and temperature conditions, which influence the structural response of foundation materials, were captured using thermocouples and water content reflectometers. Strains and permanent deformations were measured in asphalt concrete and different road layers. The road layers were also instrumented to capture stresses. The stresses and strains were measured under static (permanent deformation) and dynamic loading. Figure 3.15 shows the distribution of all sensor types with different layers built in Los Angeles, USA. Sensors for measuring stress and strain under vehicular loading were positioned along the wheel path. 


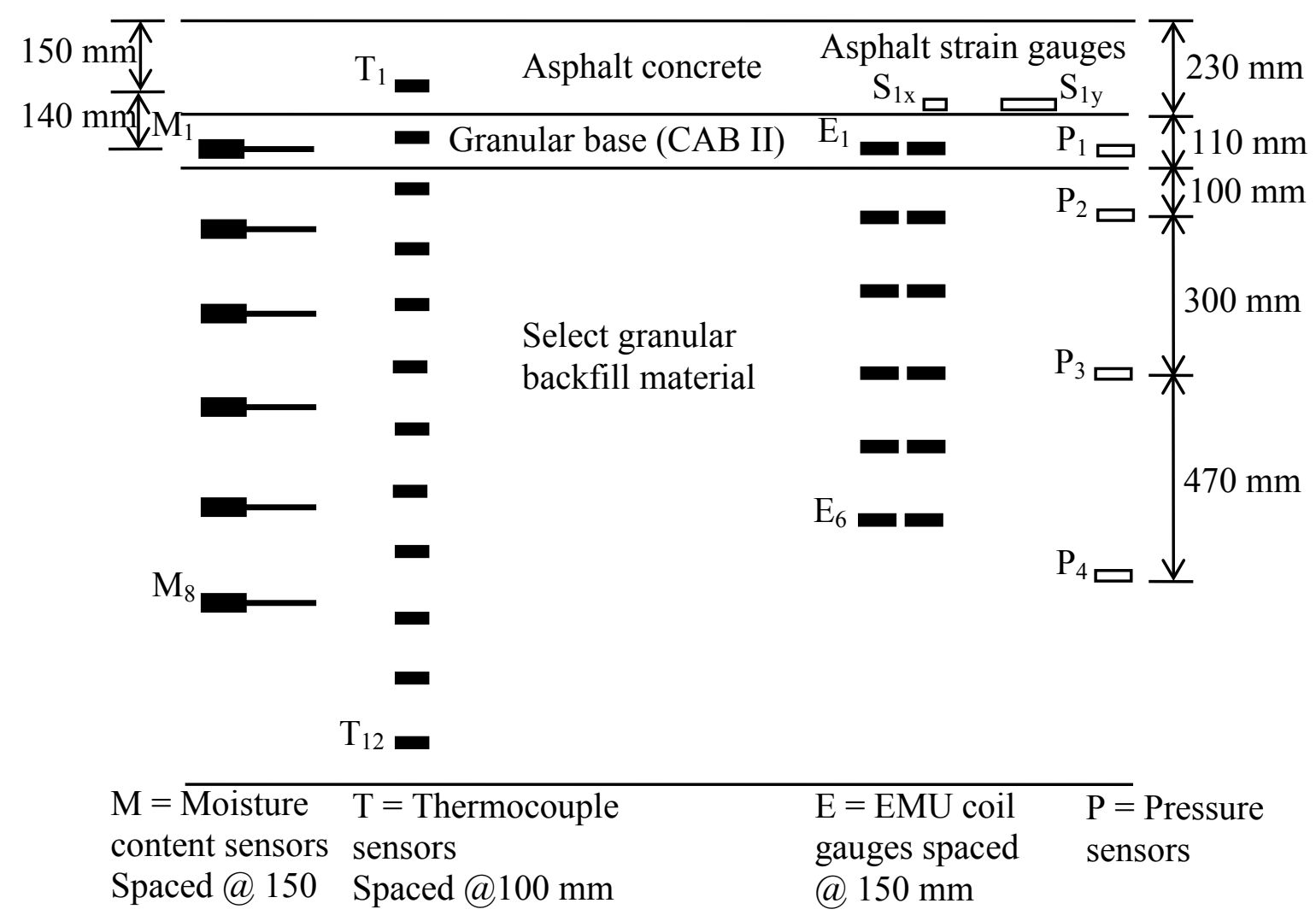

Figure 3.15: Vertical distribution of environmental and structural sensors-site 2

\subsubsection{Site 3}

The site 3 road is four lane urban streets ( 2 lanes in each traffic direction) and provided an opportunity to study the behaviour of road structures in a relatively cold region. Based on information obtained from the pavement cores and boreholes, the existing road structure rests on a native clay sub-grade. The pavement structure is composed of an asphalt concrete surface of $240 \mathrm{~mm}$, a Dense Granular Aggregate BaseCoarse of $225 \mathrm{~mm}$ (DGABC) and a sand material sub-base of $1100 \mathrm{~mm}$. Annual Average Daily Traffic (AADT) was 33000.

The state of stresses, strains and permanent deformations in these material layers were monitored with sensors installed during construction using pressure cells and strain gauges. Determination of the stresses, strains and permanent deformations in each 
pavement layer was necessary for evaluating the impact of traffic on the performance of the road and the contribution of each of its layers. Variations in moisture and temperature conditions within various layers, which influence material condition and structural response of the layers built with these materials, were captured using thermocouples and water content reflectometers. Frost depth at the site was also monitored using a resistivity probe. Figure 3.16 is a vertical distribution of all sensor types, structural sensors were positioned along the two wheel path and built in New Jersey, USA.

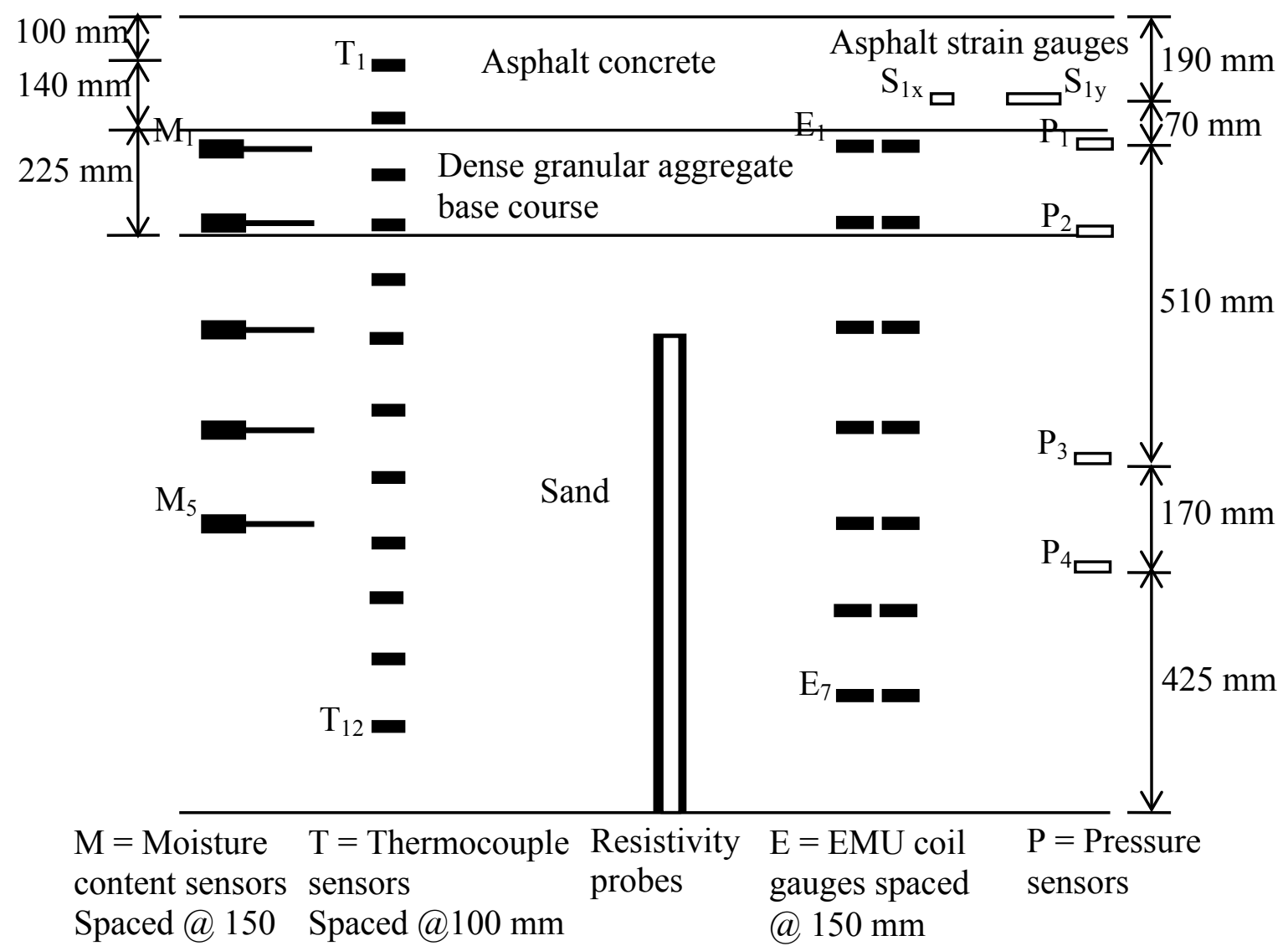

Figure 3.16: Vertical distribution of environmental and structural sensors-site 3 


\section{FIELD INVESTIGATION - RESULTS AND ANLYSIS}

\subsection{Environmental data}

Capturing the impact of variations in temperature and moisture condition in the response of the different layers forming the road structure was one of the elements included in the scope of this study. The temperature and moisture gradients were monitored throughout the road depth using regular measurements of thermocouple and water content. Sites located within regions that experience the build-up of frost were instrumented with a resistivity probe to monitor frost depth.

\subsubsection{Moisture content profiles}

The water content reflectometer utilizes the principles of time domain reflectometry to measure unfrozen volumetric water content present within the soil mass. Recorded measurements were converted to gravimetric water contents via a calibration procedure, which was explained earlier.

\subsubsection{Site 1}

Moisture profiles of gravimetric water content collected during the two-year period of the experiment are displayed in Figures 4.1 and 4.2.

Significant seasonal variations in the moisture profile were recorded during the life of the experiment. The maximum envelope with which moisture variations took place changed from one year to the next. In the first year, the range oscillated between 2.4 and $12.8 \%$ whereas for second year, the corresponding ranges oscillated between $2.8-$ 16.3\%. Based on Modified Proctor characteristics of the Granular materials A used as backfill at site 1 , the measured optimum moisture content is $5.2 \%$ (see Table 3.19 ). These 
ranges represent a change in moisture condition from 3\% dry of optimum to more than 6 $\%$ wet of optimum.

The moisture profile also exhibited more changes within the bottom portion of the backfill than at the upper portion of the backfill. This trend, which was consistent for the first two years, can be attributed to two mechanisms working concurrently. The first one is the ingress of water from the pavement surface (through existing or newly developed cracks) into the road/cut structure. Due to the granular nature of the backfill material and the fact that less than adequate densities were achieved during construction, the water percolates deeper into the backfill causing an accumulation of moisture at this location. Since the bottom of the cut rests on a native silty sand sub-grade with low permeability, the water from the surface will remain stagnant for a long period of time. The second mechanism involved the freezing of water within the soil mass at sub-zero temperatures. This mechanism works over the entire depth of the backfill, causing the amount of measured unfrozen water to decrease as the season changes from spring to winter. 
Gravimetric moisture content, \%

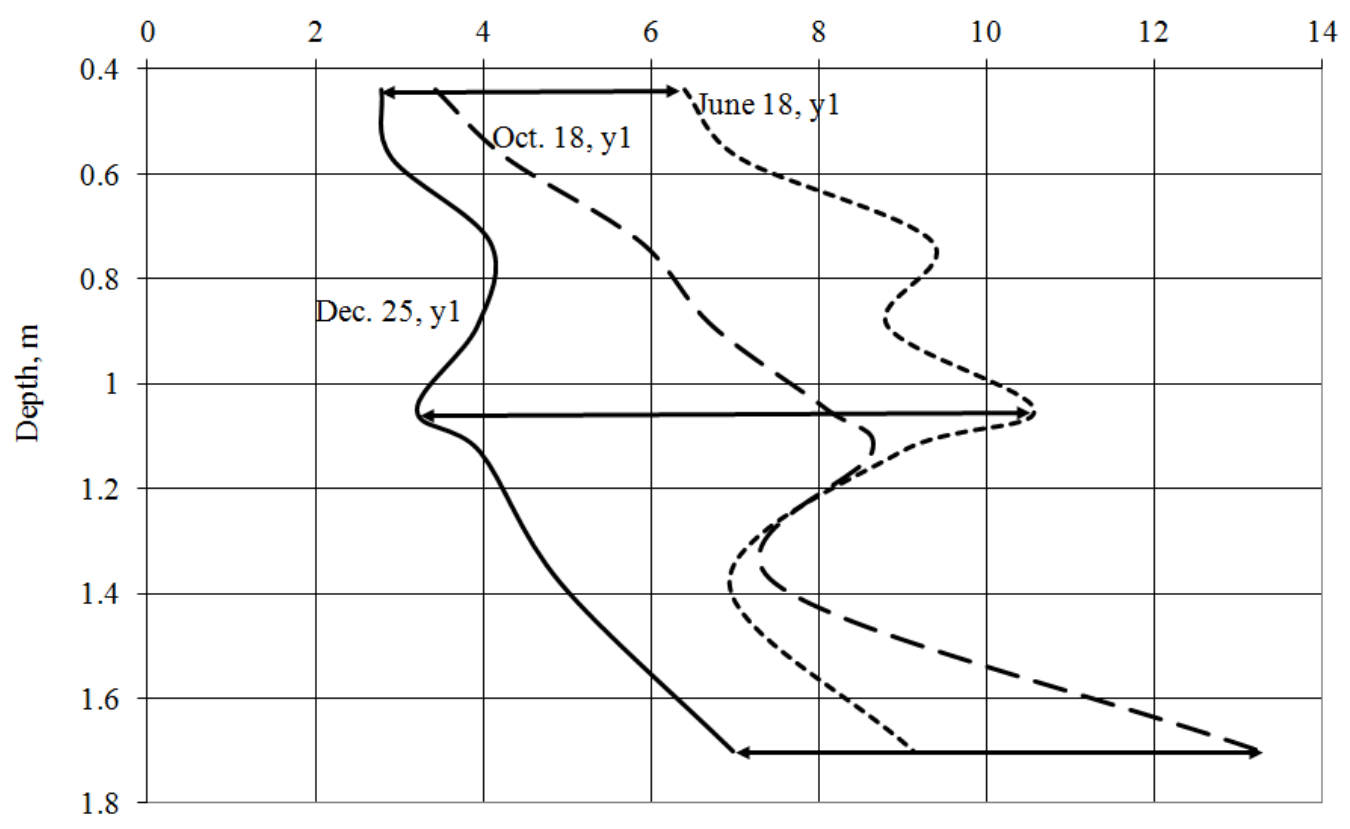

Figure 4.1: Moisture content profile site 1- year 1

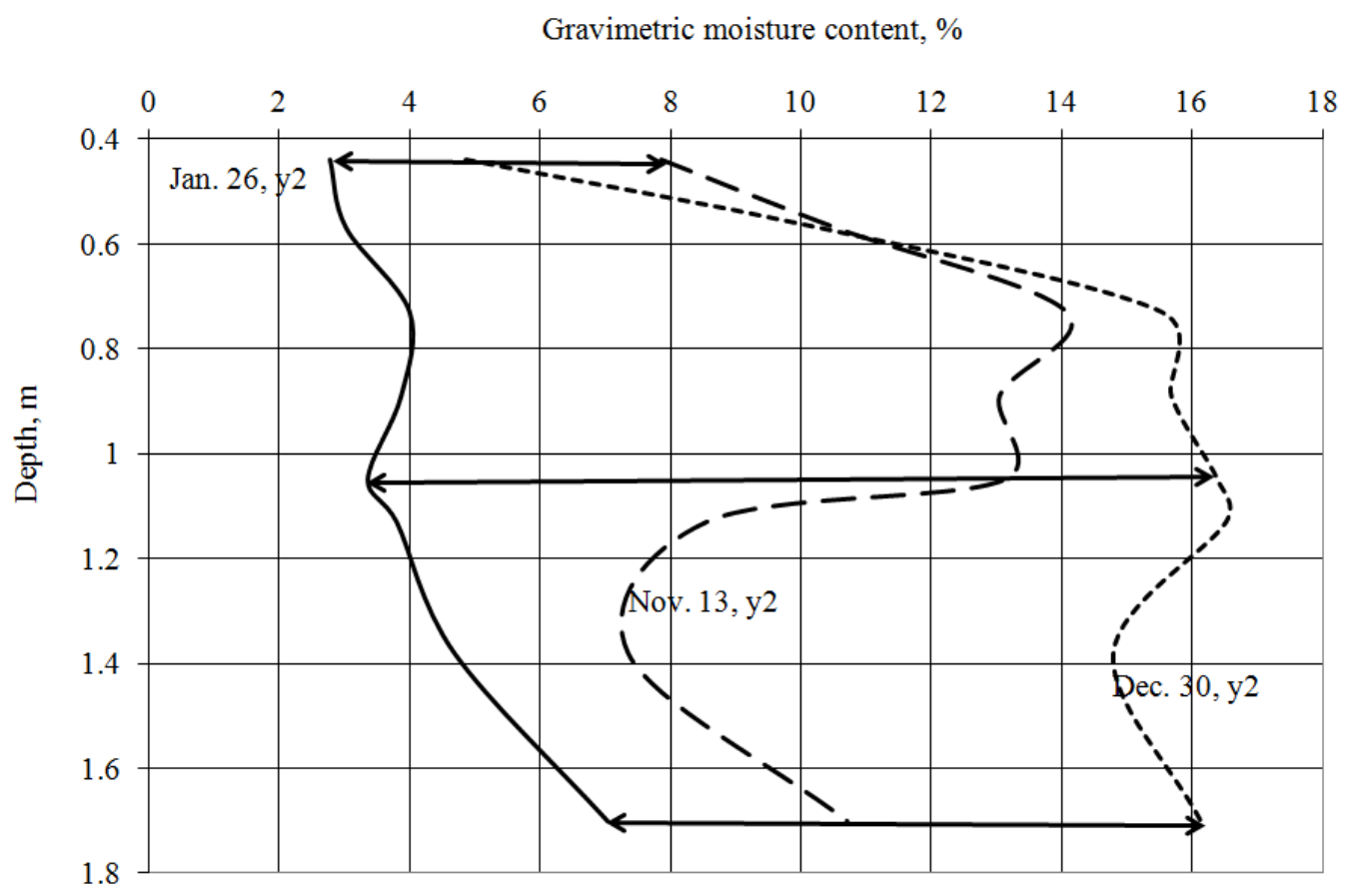

Figure 4.2: Moisture content profile site 1- year 2 Site 2

Both Figures 4.3 and 4.4 of gravimetric moisture profiles recorded during the two-year period of the life of the experiment show typical behaviour within the range of 6 
to $14 \%$. These profiles are considered representative of the environmental regime at the warm and rainy experimental site. Due to the granular nature of the backfill material and the fact that adequate densities were expected and achieved during construction, the ingress of water from the pavement surface into the road structure remained stagnant for a long period of time. Since the bottom of the road rests on a native silty clay sub-grade with low permeability, the water from the surface will remain.

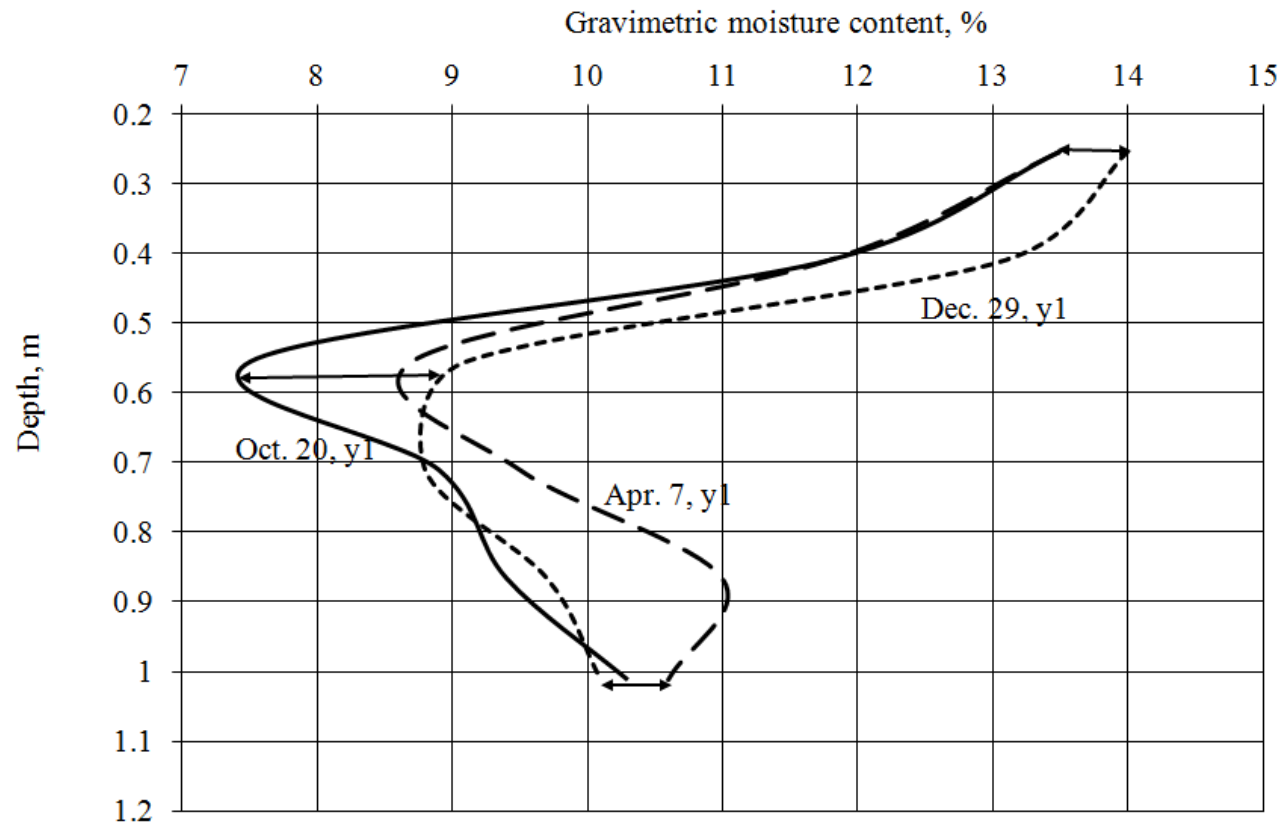

Figure 4.3: Moisture content profile site 2- year 1 


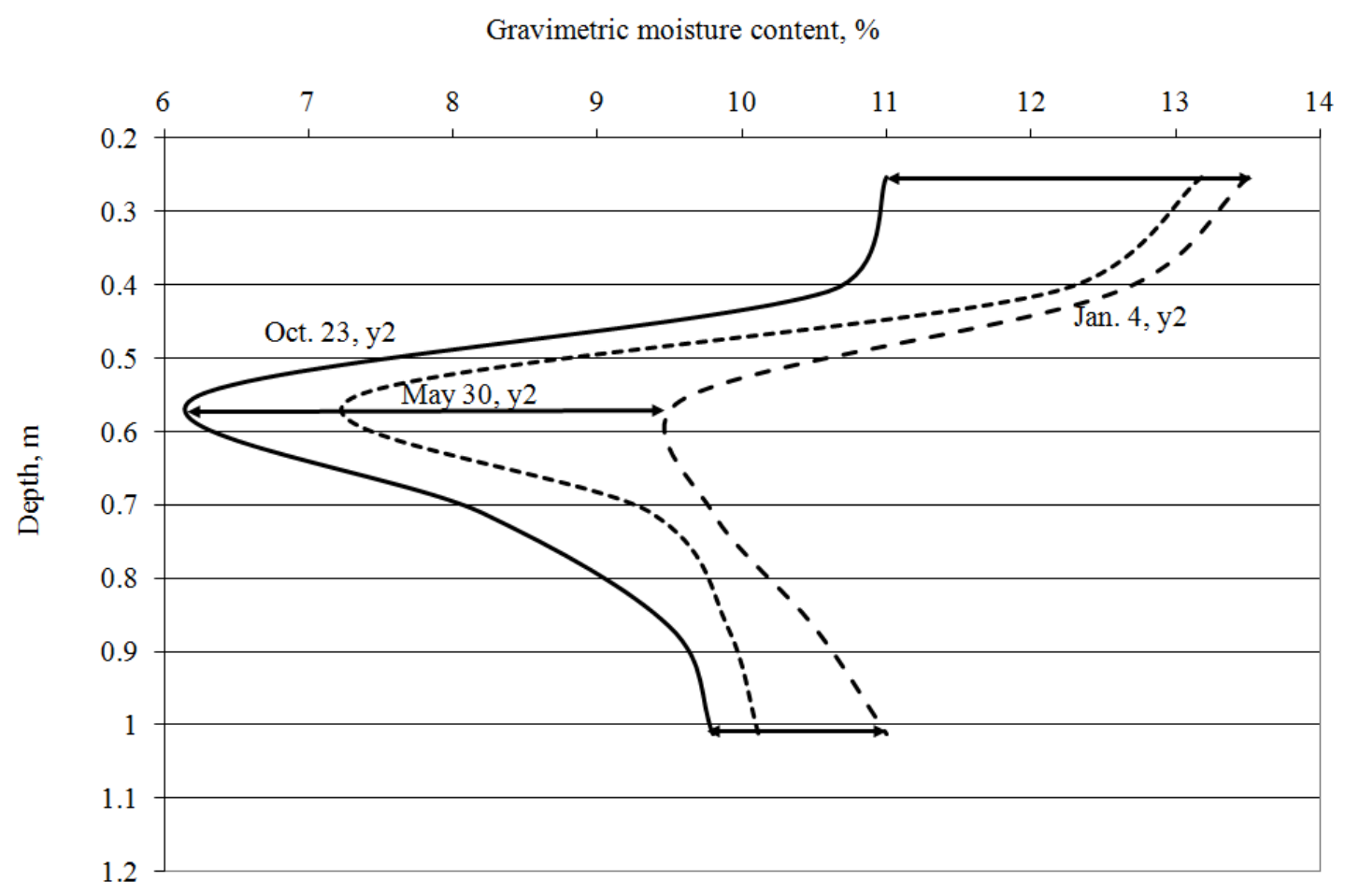

Figure 4.4: Moisture content profile site 2- year 2

\subsubsection{Site 3}

The gravimetric moisture profiles recorded during the two-year period of the life of the experiment are shown in Figures 4.5 and 4.6. The trend moisture envelope is similar for both years and within the range of 3 to $22 \%$. 


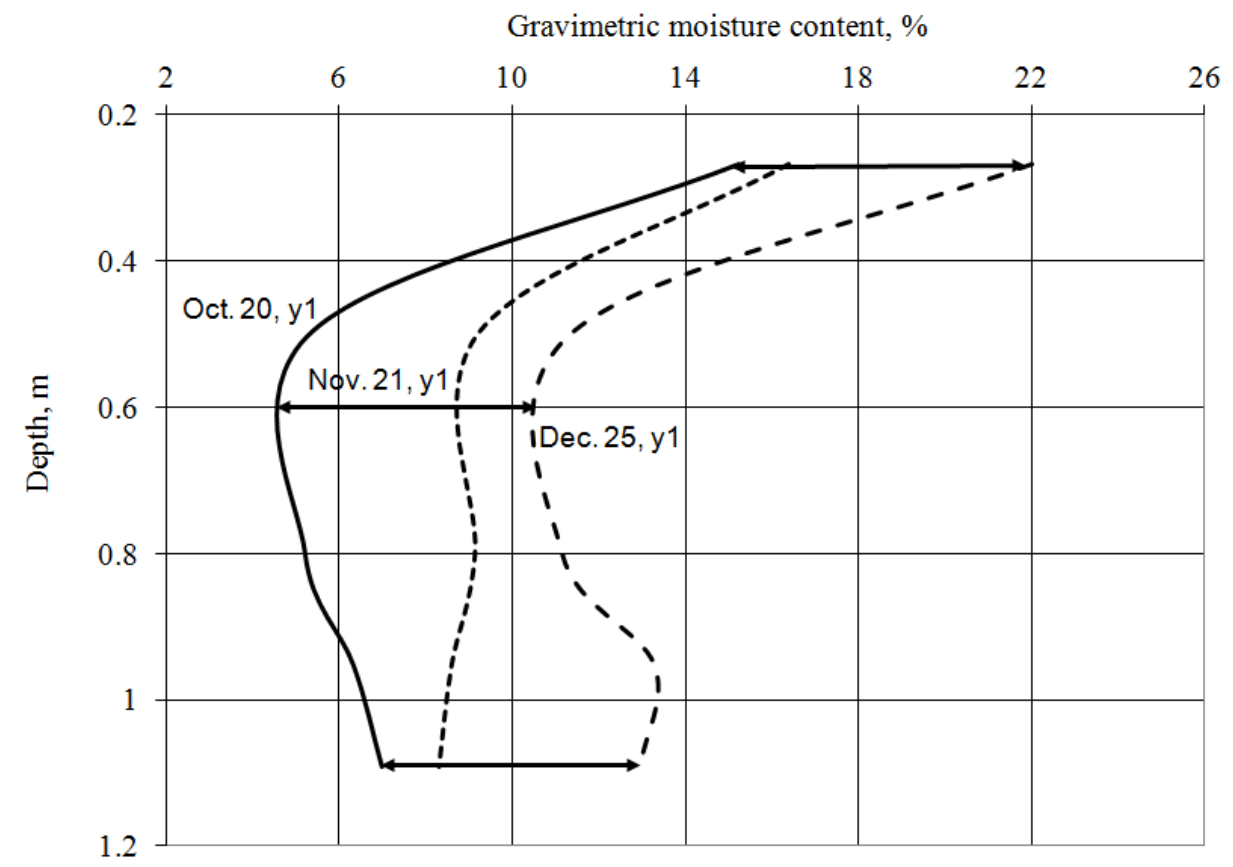

Figure 4.5: Moisture content profile site 3- year 1

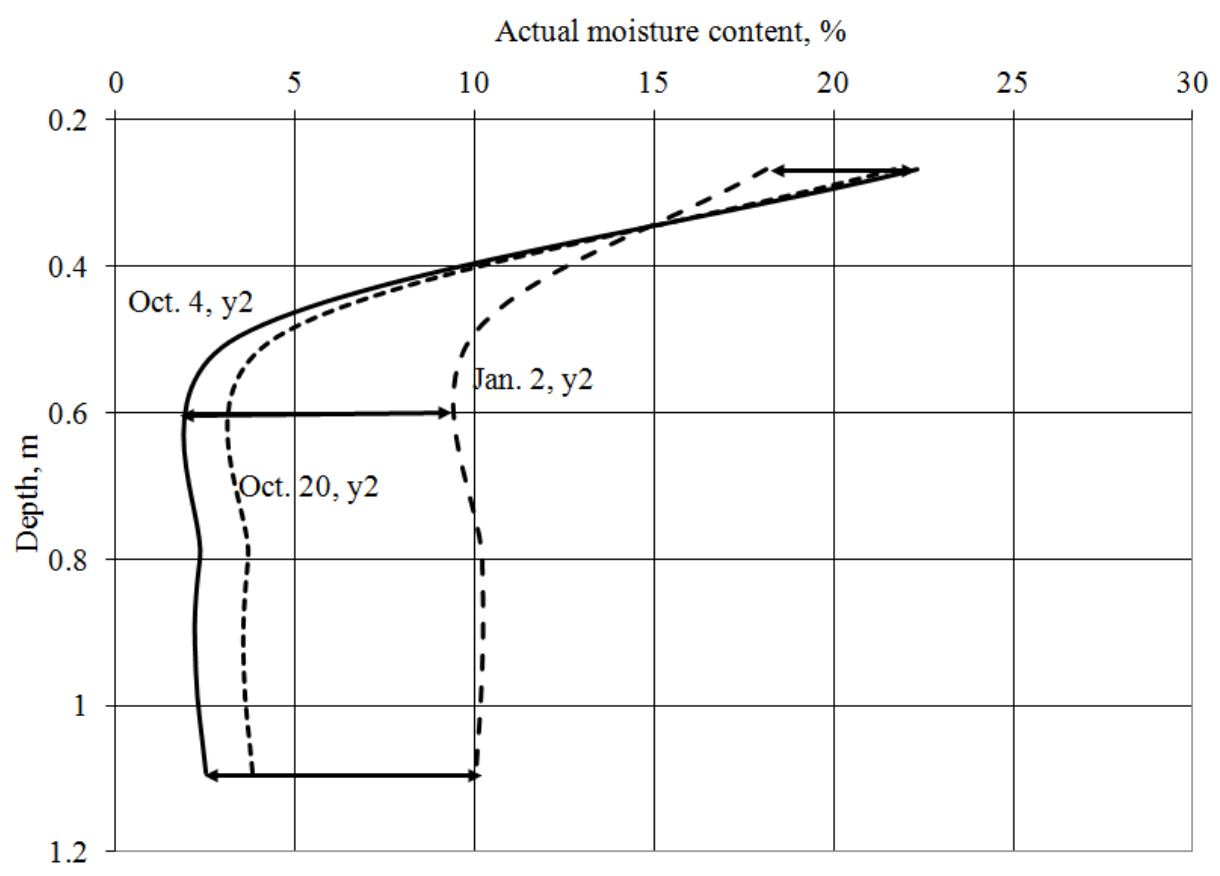

Figure 4.6: Moisture content profile site 3- year 2 


\subsubsection{Temperature profile}

\subsubsection{Site 1}

Temperature data were collected on daily basis throughout the life of the experiment (Four years). Records of representative temperature of unbound materials of road structure layers records are shown in Figures 4.7 and 4.8. Both profiles show similar temperature gradients throughout the road structure layers.

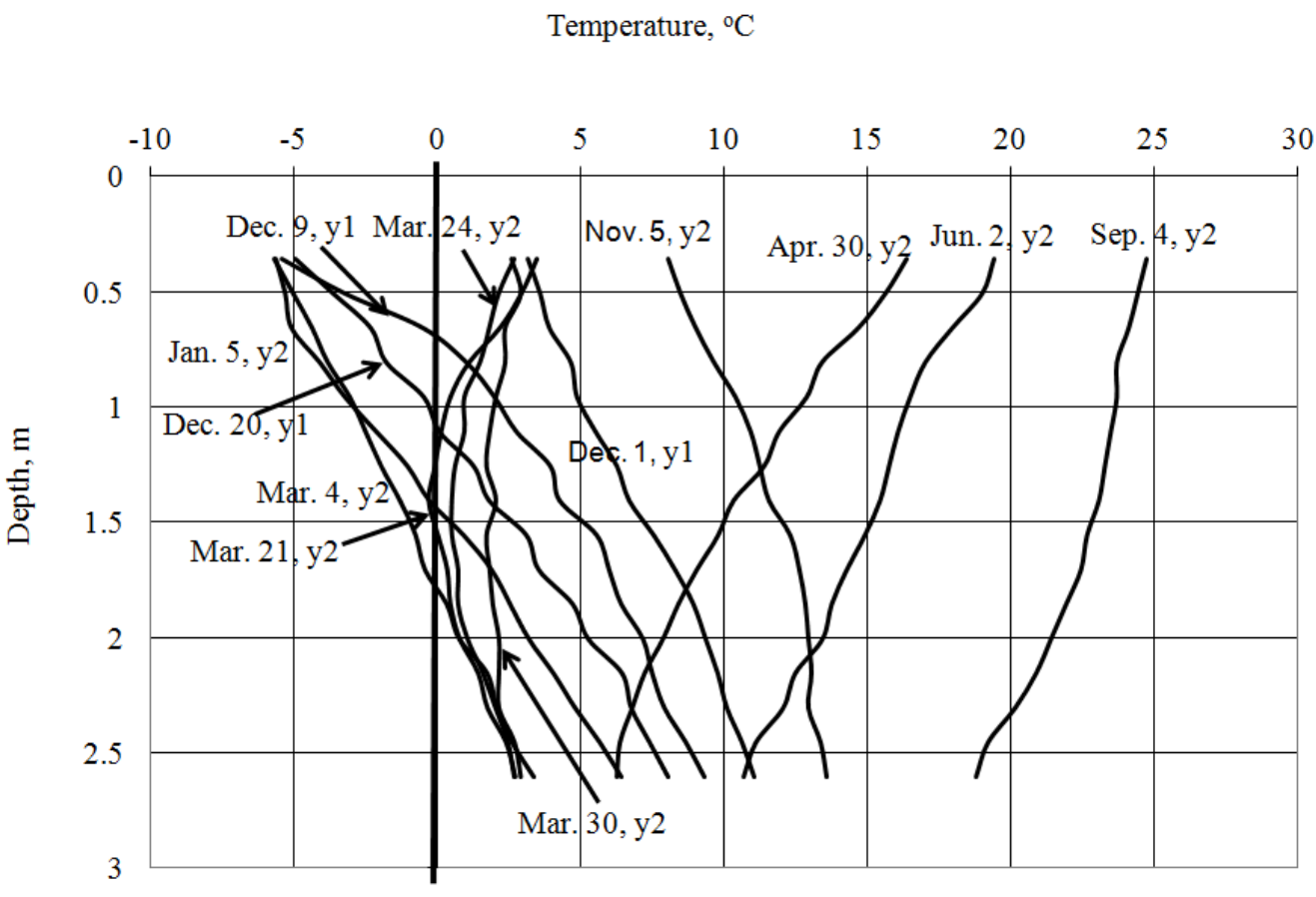

Figure 4.7: Temperature profile site 1- year 1 and 2 
Temperature, ${ }^{\circ} \mathrm{C}$

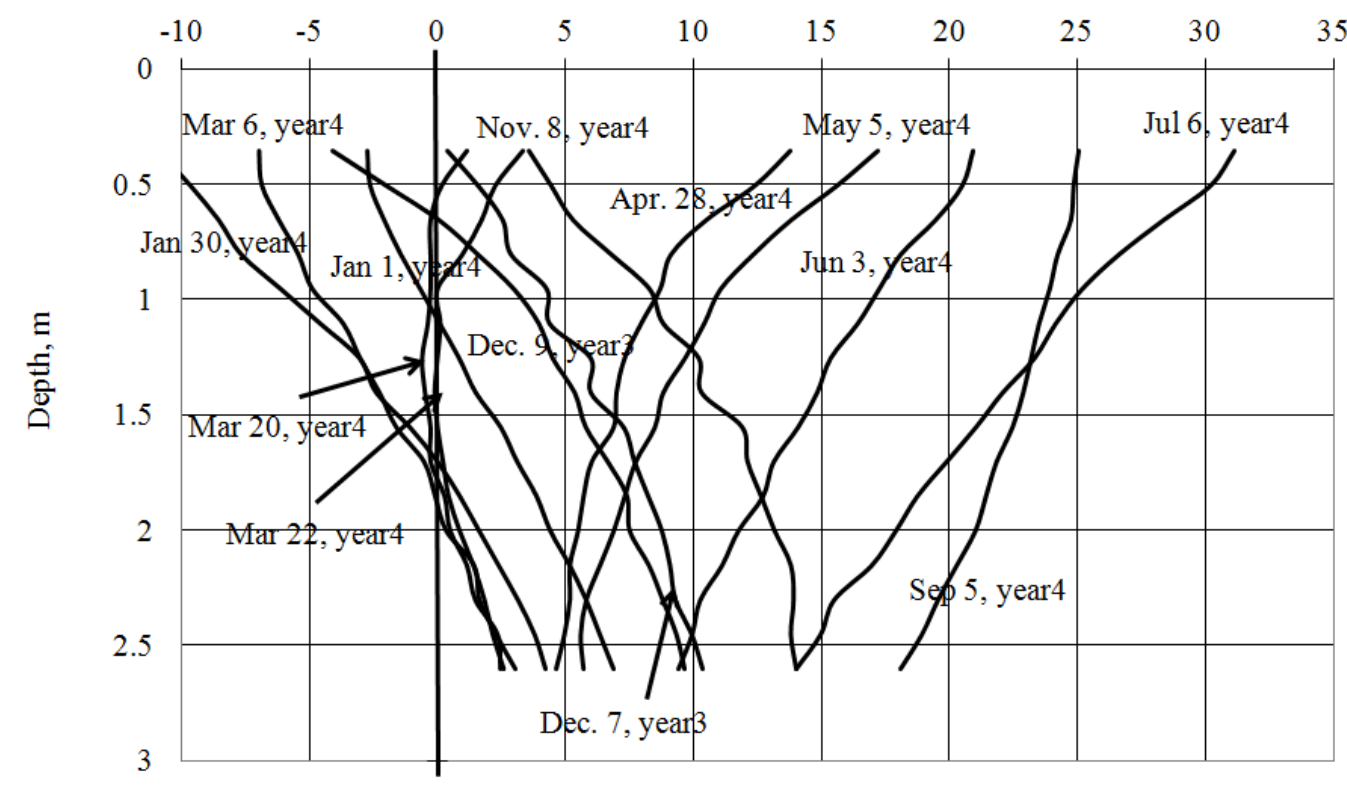

Figure 4.8: Temperature profile site 1- years 3 and 4

These temperature profiles established with data obtained from sensors in this study shown together earlier with ambient temperature could be used to calibrate the climatic part of the M-EPDG model. Temperature profiles established in this study reflected a difference of $5^{\circ} \mathrm{C}$ between the pavement surface and the bottom of the cut with this difference increasing to $15^{\circ} \mathrm{C}$ in summer months. This finding suggests that the progress of the freezing front during winter months will be rapid, which will be confirmed and discussed later in the resistivity probe data section.

An attempt was made in this study to construct the freeze and thaw diagram using thermocouple sensors. The results will also be compared later with the resistivity probe profiles. When data registered by the temperature profile starts crossing the zero temperature line, this point will be taken as the one corresponding to the start of freezing at the top of the backfill. By repeating this process for every calendar day thereafter, the 
progress of the freezing front was determined and plotted versus depth as shown in Figures 4.9 and 4.10 for years 1 and 2 and years 3 and 4 respectively. Both cycles registered typical cold region frost depths for a frost period of almost 108 days.

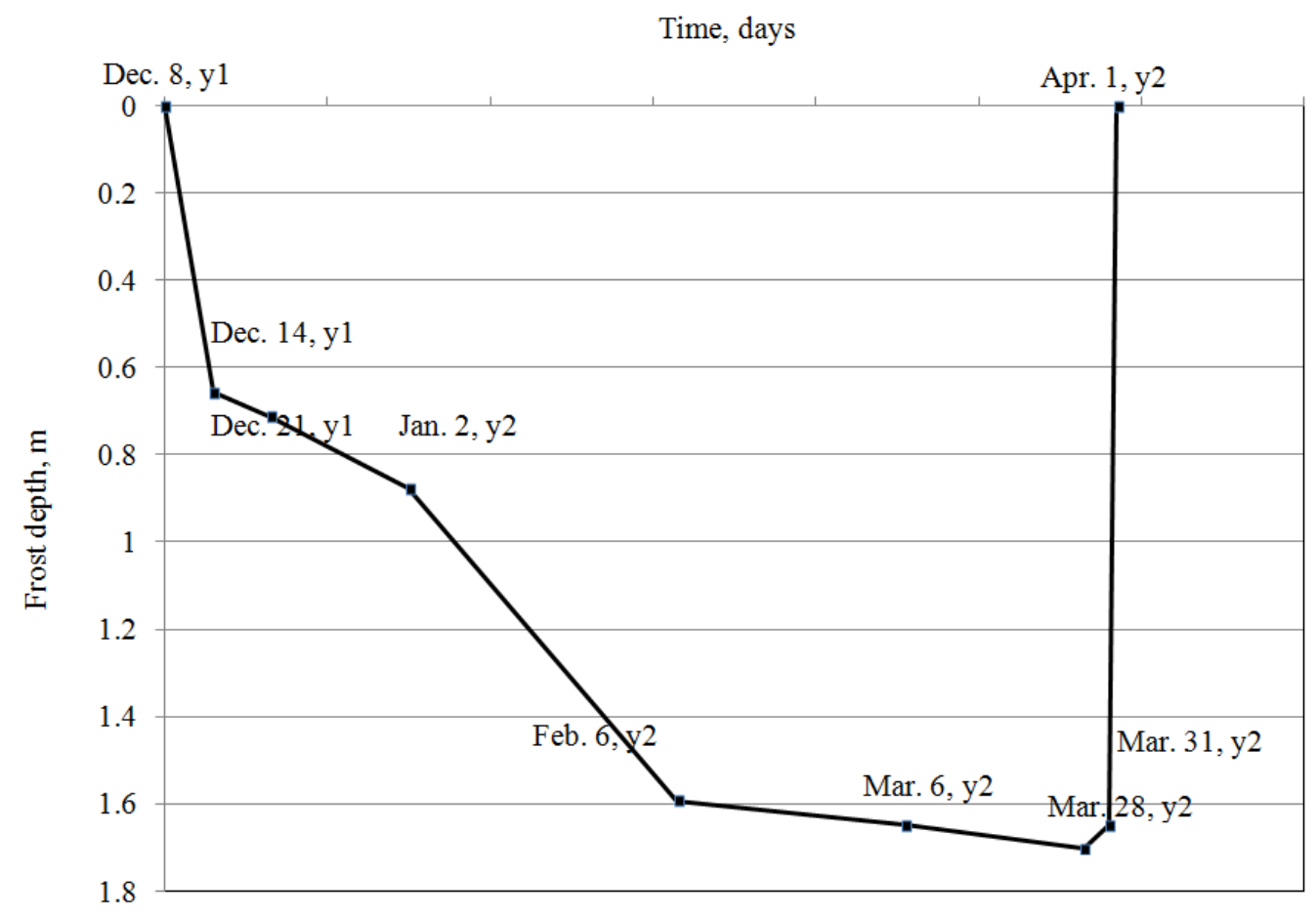

Figure 4.9: Site 1 freeze and thaw cycle for years 1 and 2 using thermocouple sensors 


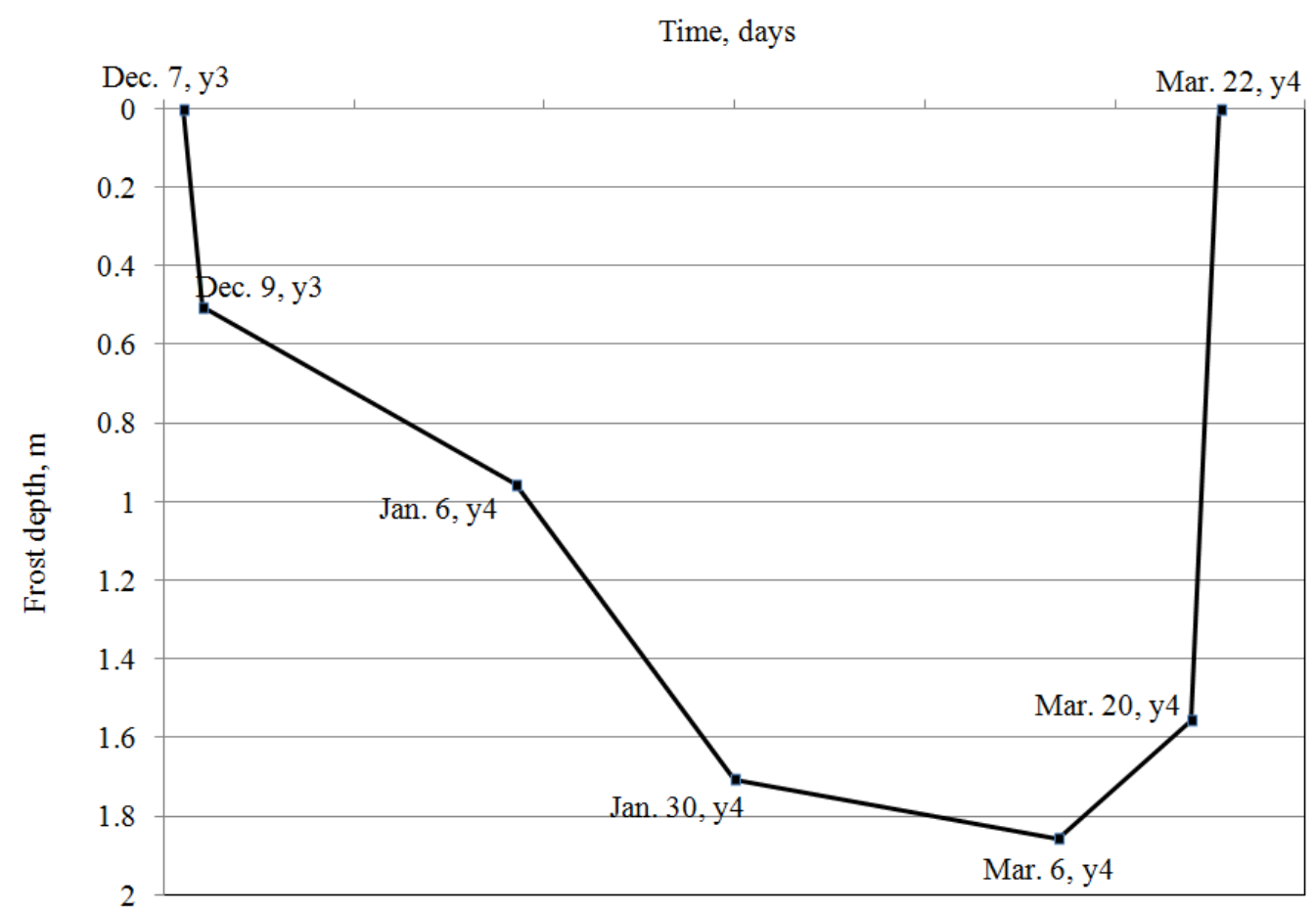

Figure 4.10: Site 1 freeze and thaw cycle for years 3 and 4 using thermocouple sensors

\subsubsection{Site 2}

Temperature data were collected on a daily basis throughout the life of the experiment (three years). Representative temperature records of asphalt and unbound material for road structure layers are shown in Figures 4.11 and 4.12. Those two profiles showed identical temperature behaviour and they represent typical hot weather in the Los Angeles region. 


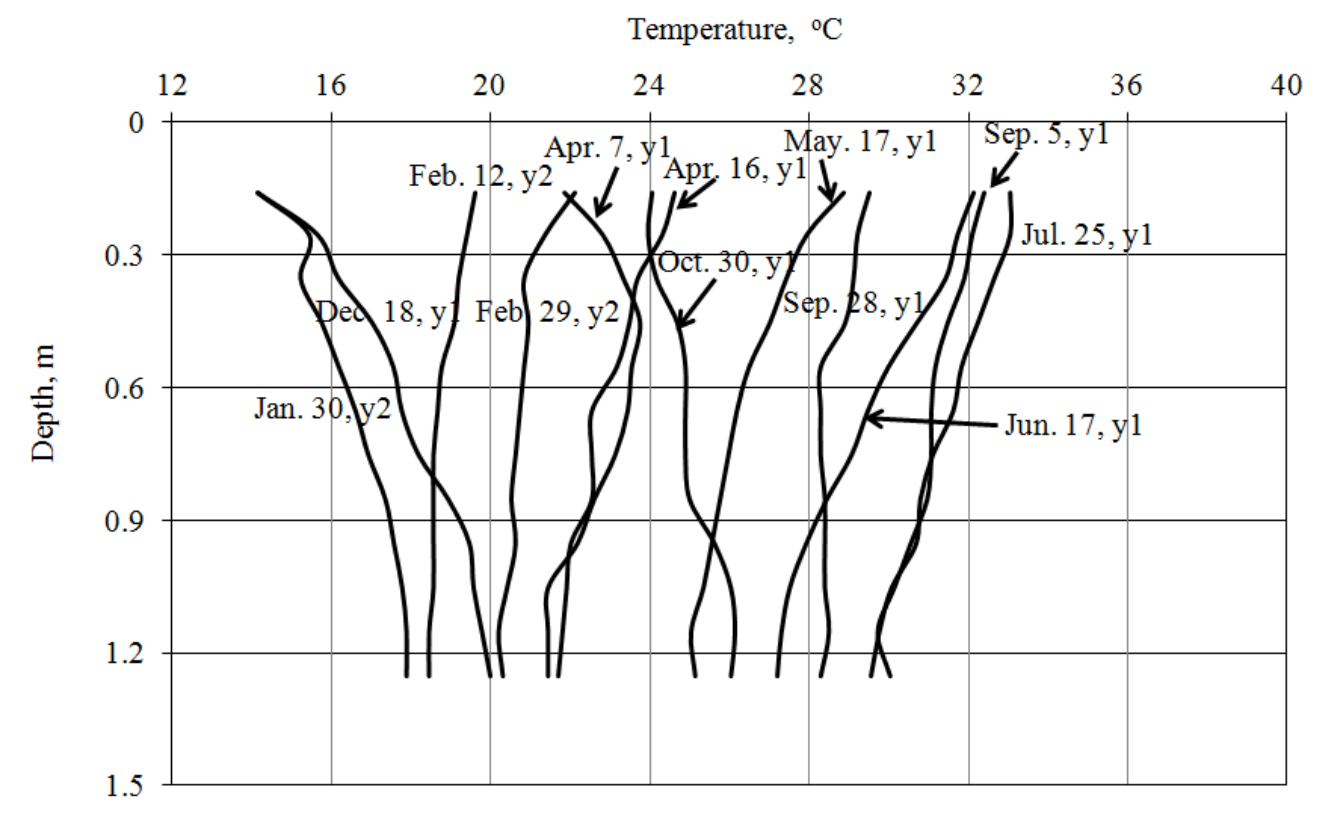

Figure 4.11: Temperature profile site 2- years 1 and 2

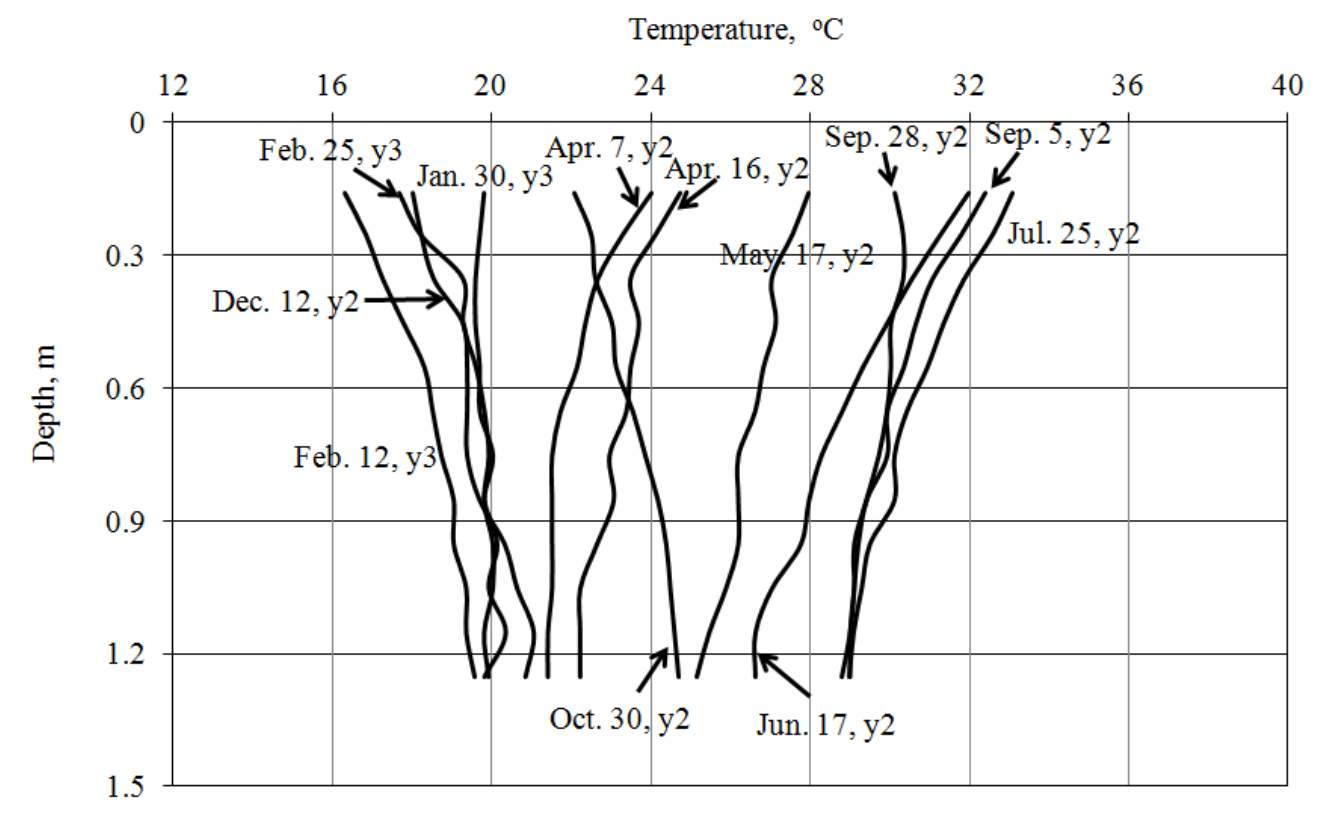

Figure 4.12: Temperature profile site 2- years 2 and 3

\subsubsection{Site 3}

Temperature data were collected on a daily basis throughout the life of the experiment (two years). Representative temperature records of asphalt and unbound 
material for road structure layers are shown in Figure 4.13. The two-year profiles represent typical cold weather in the New Jersey region. Due to malfunction of sensors buried in the Site 3 after almost one year, limited analysis was done. Therefore the behaviour of one year is shown.

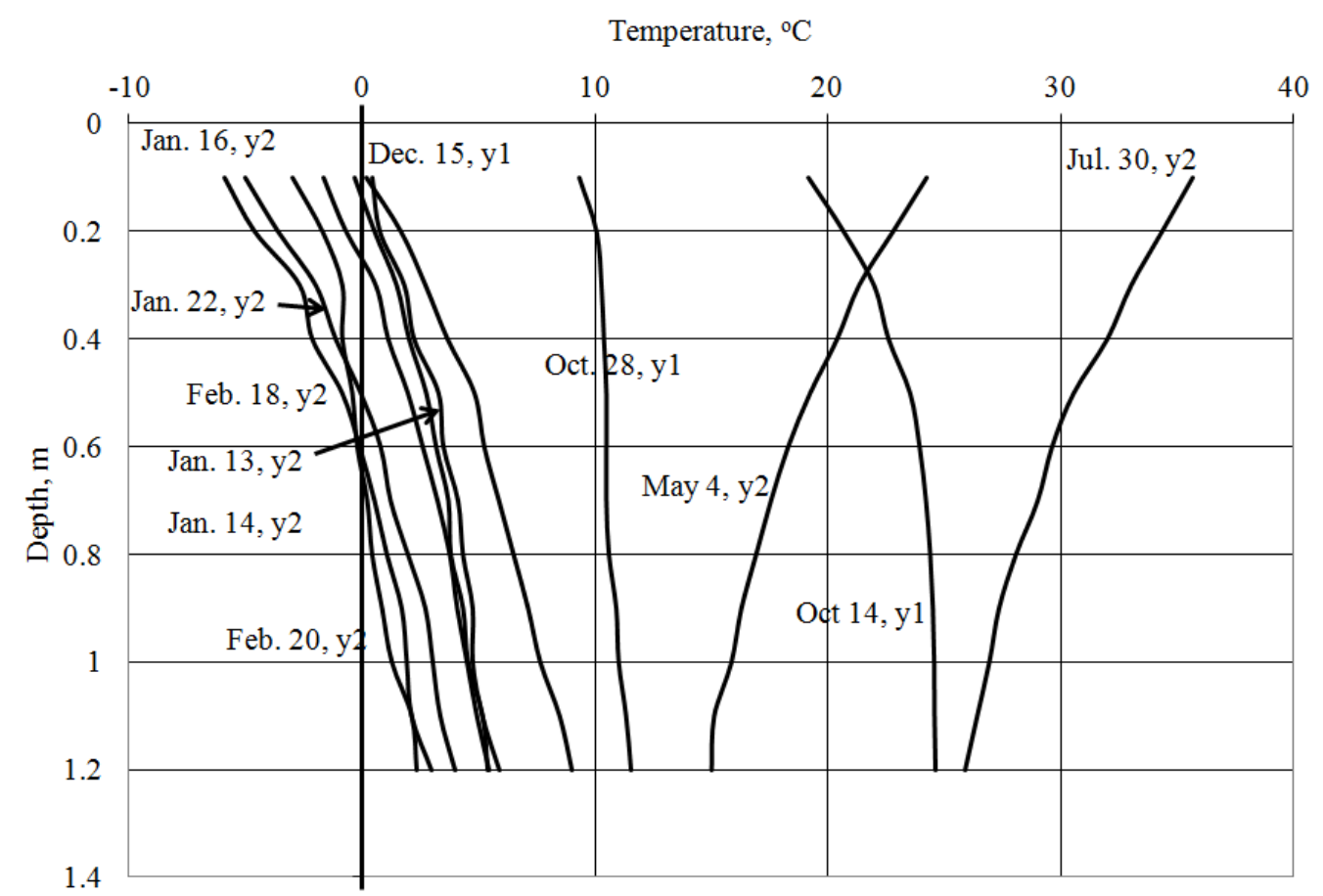

Figure 4.13: Temperature profiles site 3- year 1

Figure 4.14 was constructed following the same method used at site 1 to determine the freeze and thaw diagram. It shows the frost behaviour of site 3 , that represents a mild weather region. It is noted that the Site 3 frost period was very short (38 days) compared to site 1 (108 days). 
Time, days

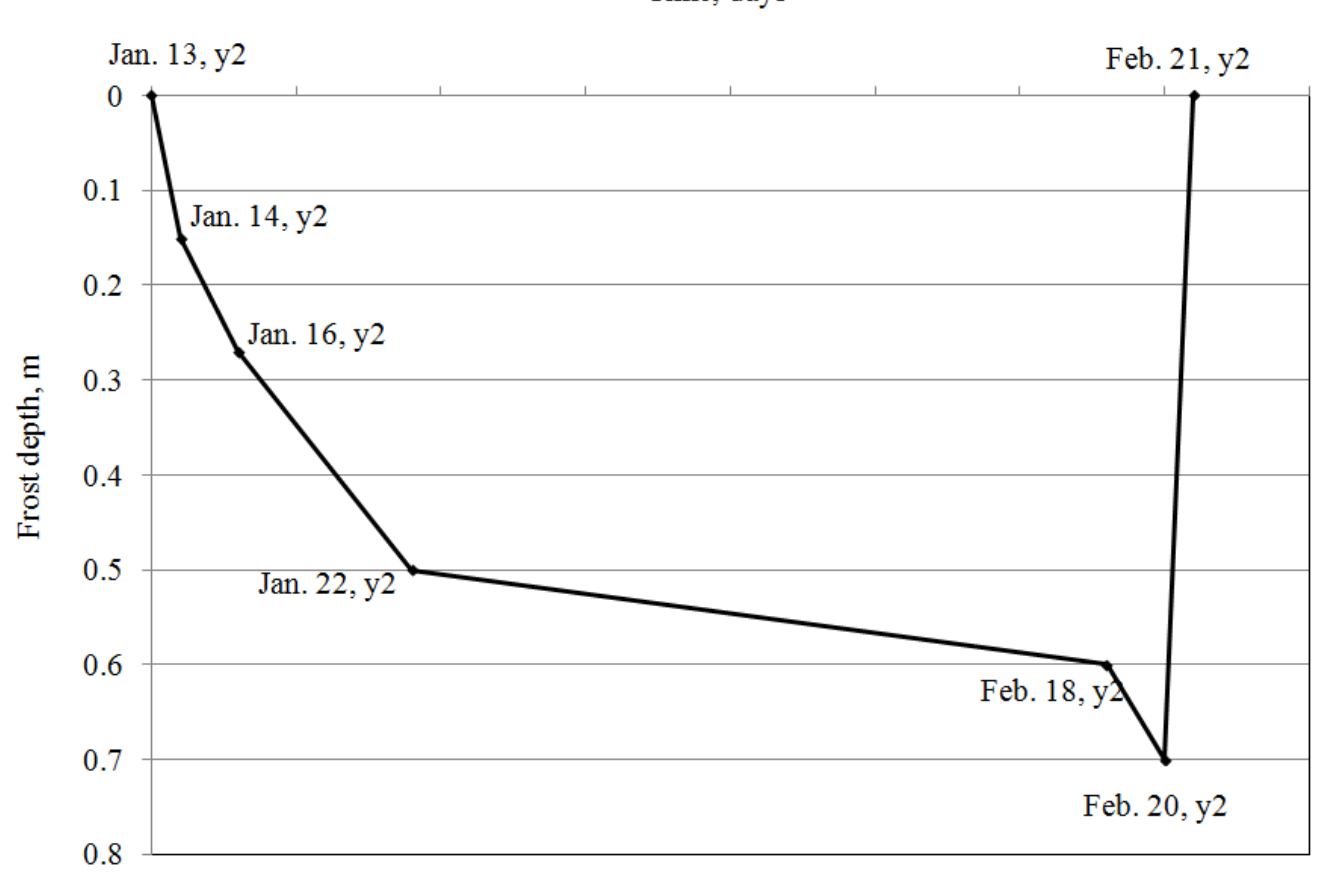

Figure 4.14: Site 3 freeze and thaw cycle for years 1 and 2 using thermocouple sensors

\subsubsection{Resistivity profiles}

Road structure layers in cold regions are expected to freeze and thaw, therefore resistivity probes were installed at both sites 1 and 3 . The resistivity probe uses the principle of electrical resistance change for the water in the soil. Water in the soil changes from a liquid stage during summer to a frozen stage during winter. These changes are associated with changes in the shape of resistivity probe signal and represent the start of the freezing in the top road structure layers.

\subsubsection{Site 1}

Resistivity probe measurements of frost penetration depth for the unbound materials of the road structure layers are shown in Figures 4.15 and 4.16. 
Resistivity, mvolt

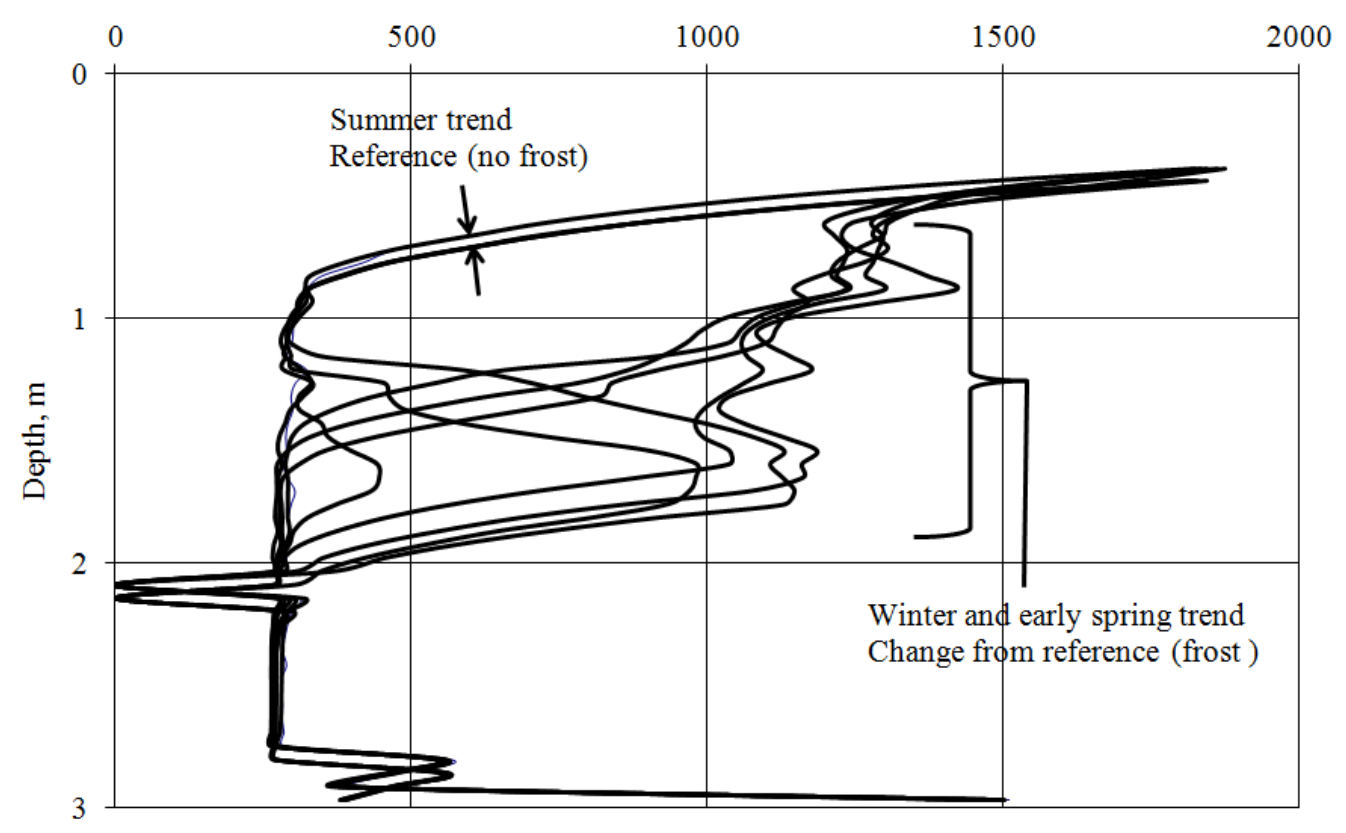

Figure 4.15: Resistivity profiles Site 1- years 1 and 2

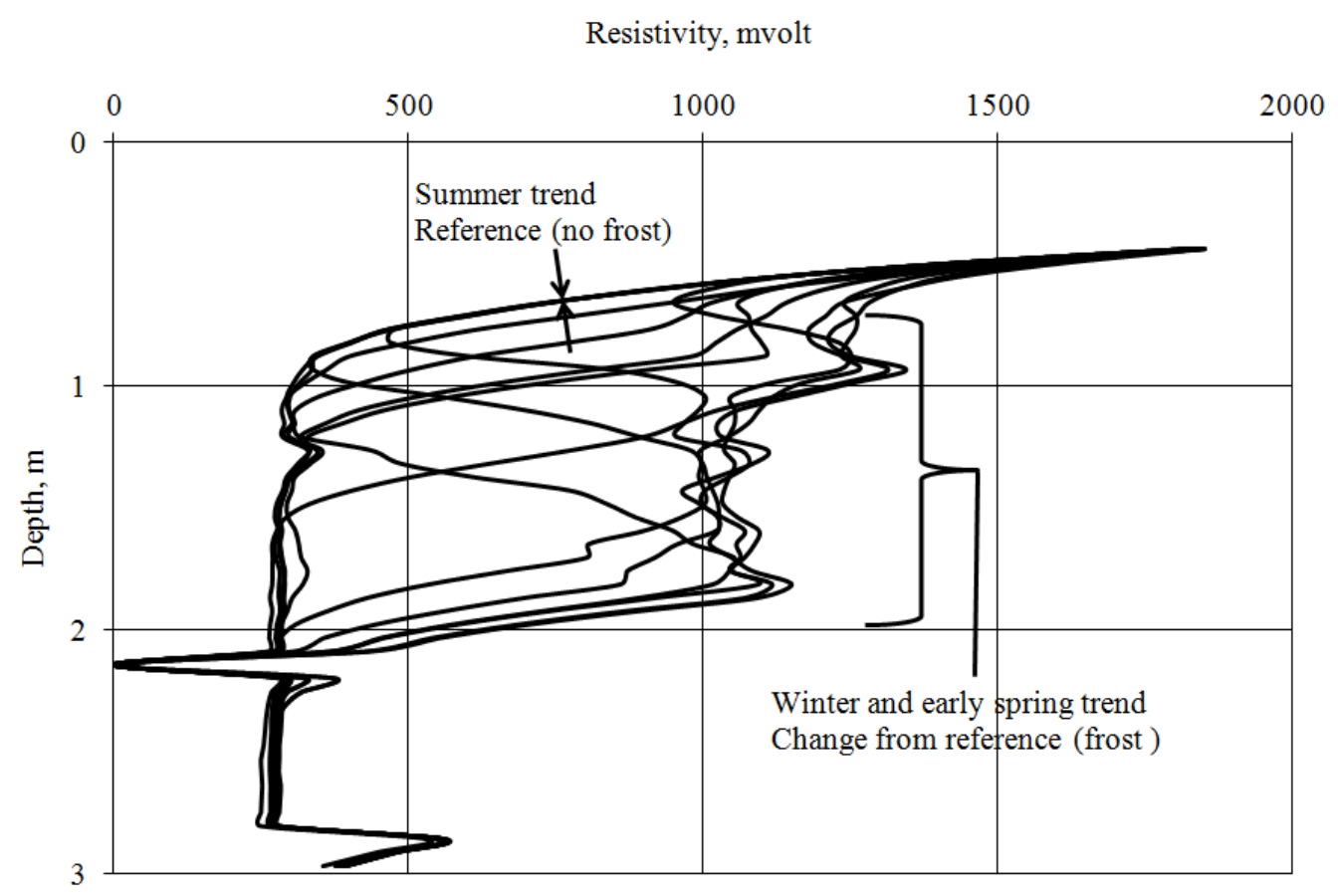

Figure 4.16: Resistivity profiles Site 1- years 3 and 4 
Typical reference behaviour in Figure 4.17 shows that the unbound materials still are not in a frozen state, where March behaviour in the curve shows change in the shape of the resistivity probe response. This point will be taken as the one corresponding to the start of freezing at the top of the backfill. By repeating this process for every calendar day thereafter, the progress of the freezing front was determined and plotted versus depth for two cycles from year 1 to year 4 as shown in Figures 4.18 and 4.19.

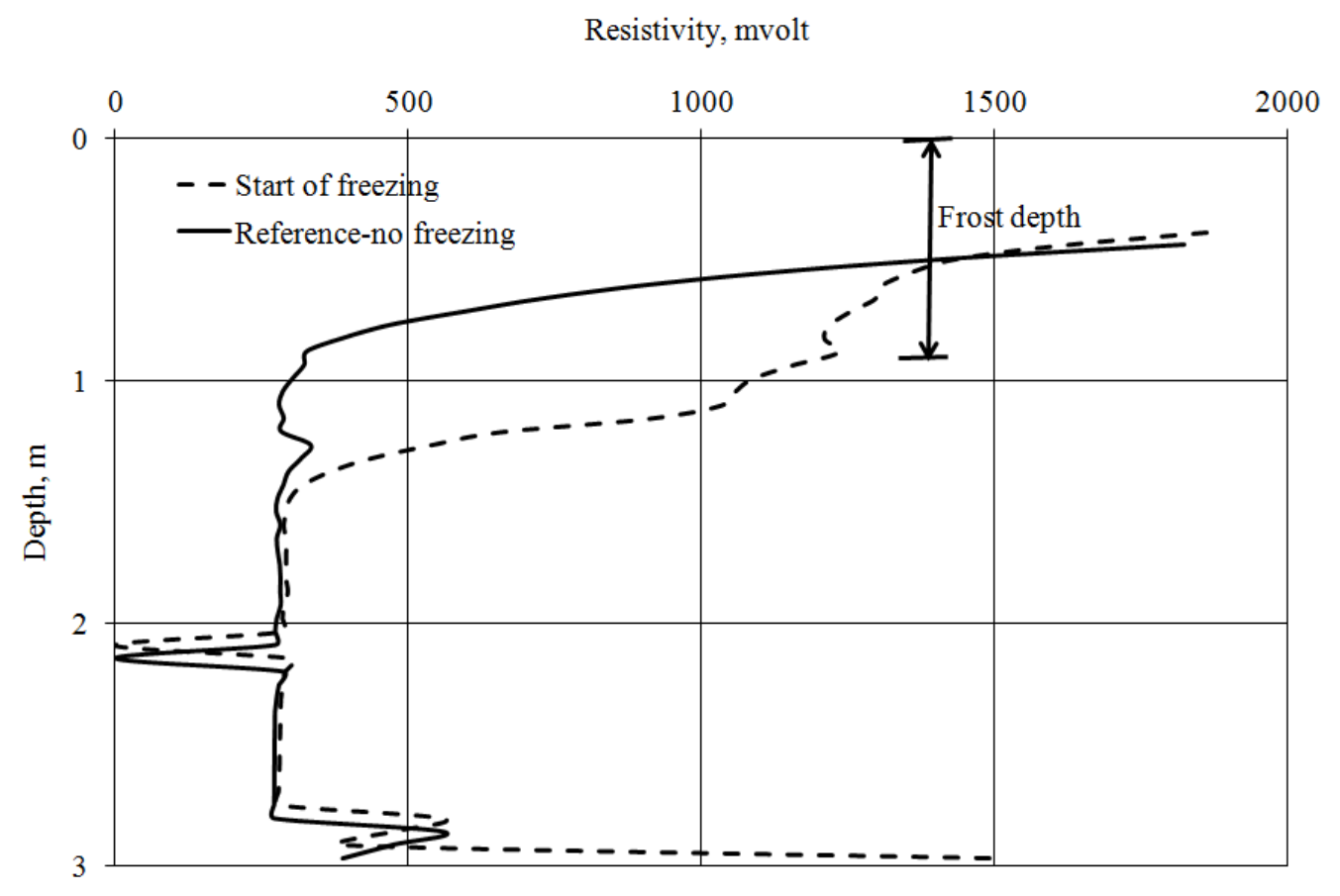

Figure 4.17: Typical frost depth determination- Site 1 


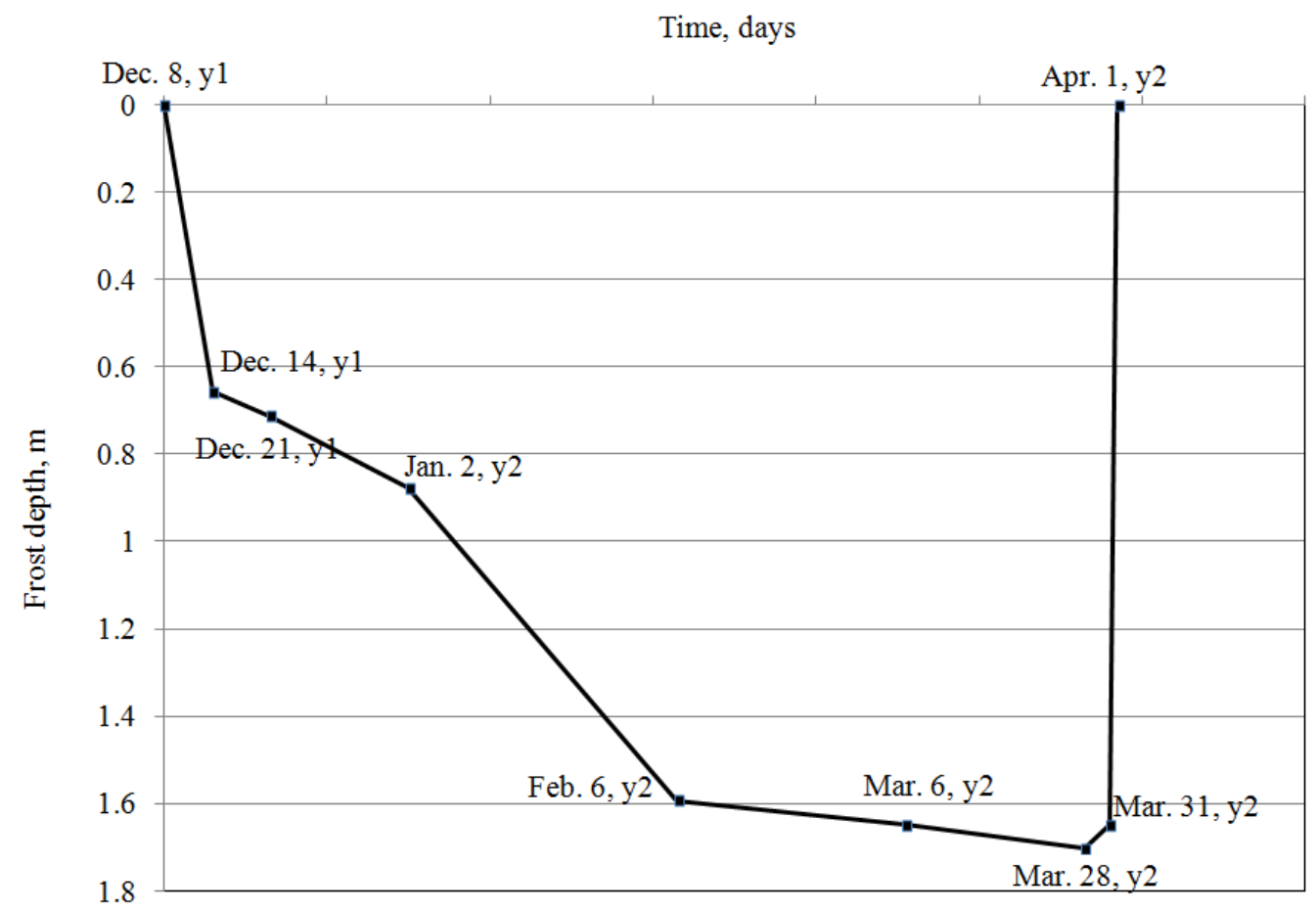

Figure 4.18: Resistivity probes freeze and thaw cycle Site 1 for years 1 and 2

Time, days

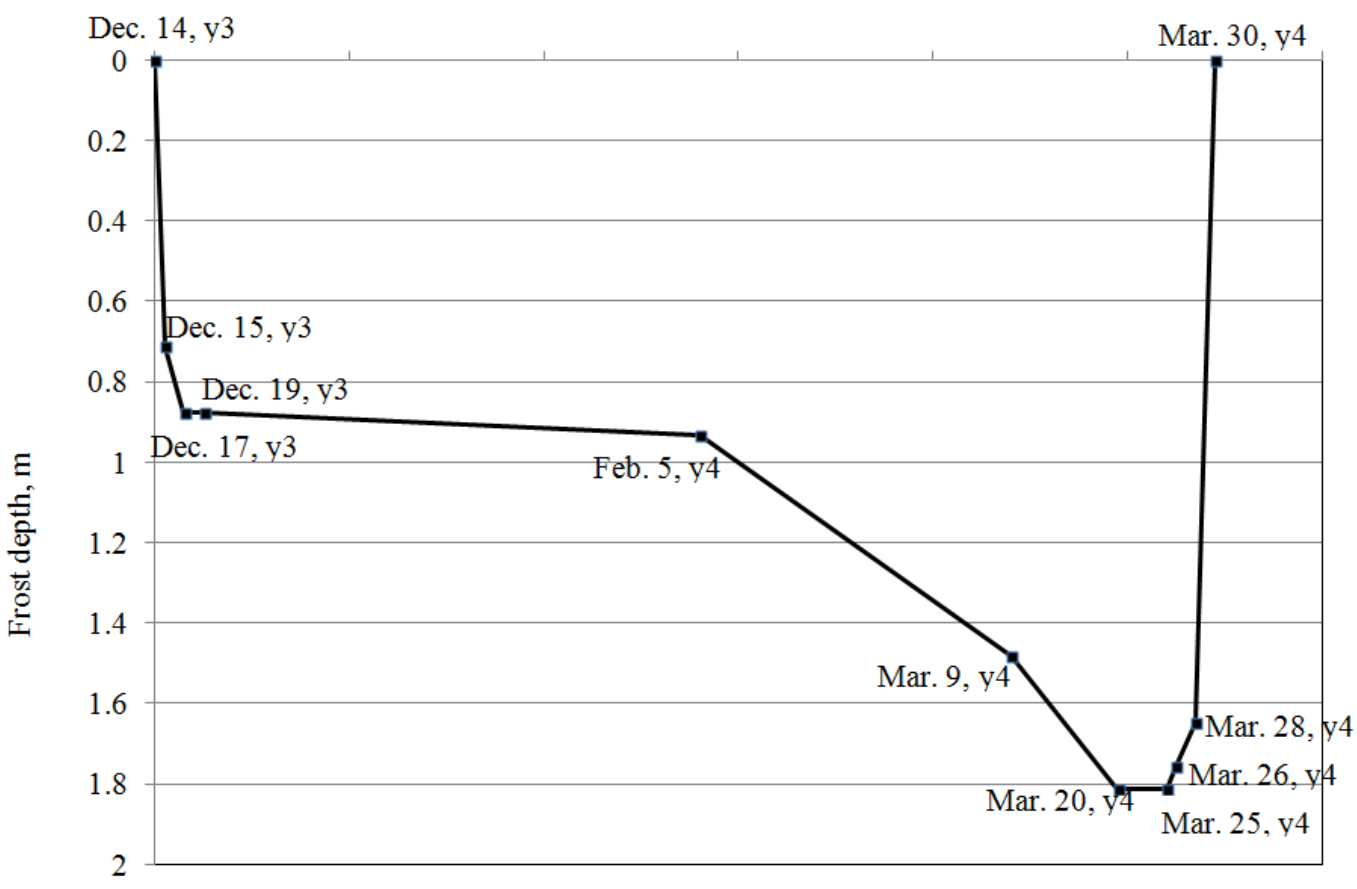

Figure 4.19: Resistivity probes freeze and thaw cycle Site 1 for years 3 and 4 
Further comparison between the two cycles as shown in Figure 4.20, obtained during the first monitoring period (years 1 and 2) the freezing front reached a depth of 1.7 $\mathrm{m}$ compared to $1.82 \mathrm{~m}$ in the second monitoring period (years 3 and 4). This represents a typical winter in the experiment where sub-zero temperatures prevail for a prolonged period (at least 108 days) of time.

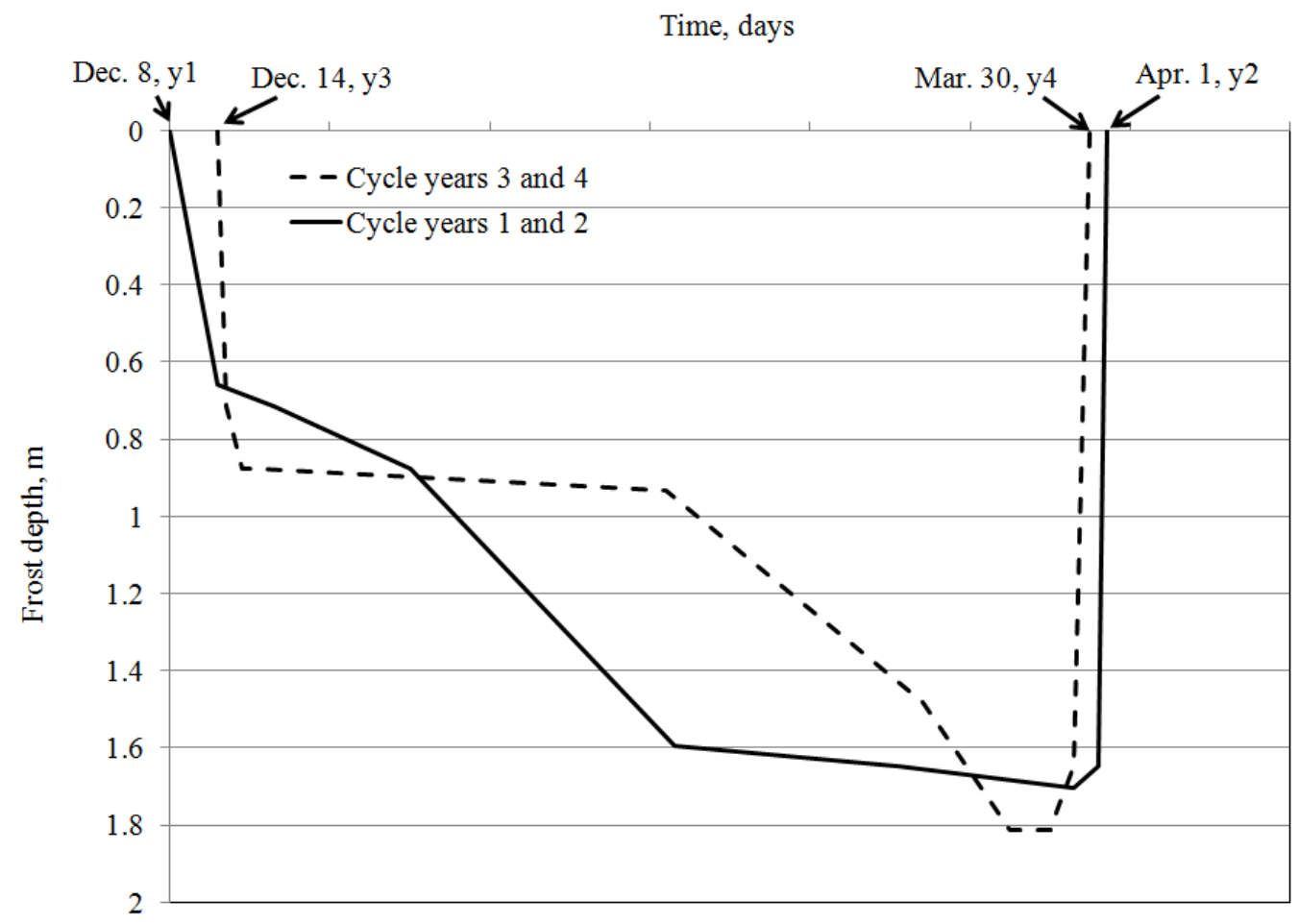

Figure 4.20: Comparison of resistivity probes freeze and thaw cycles- Site 1

A typical freeze and thaw diagram constructed using thermocouple data was established to compare it with results of the resistivity probe for the same site and cycles. Comparisons in Figures 4.21 and 4.22 generally show a very close trend. This provides an opportunity to use practical and inexpensive thermocouple measurements to establish the freeze and thaw diagrams. 


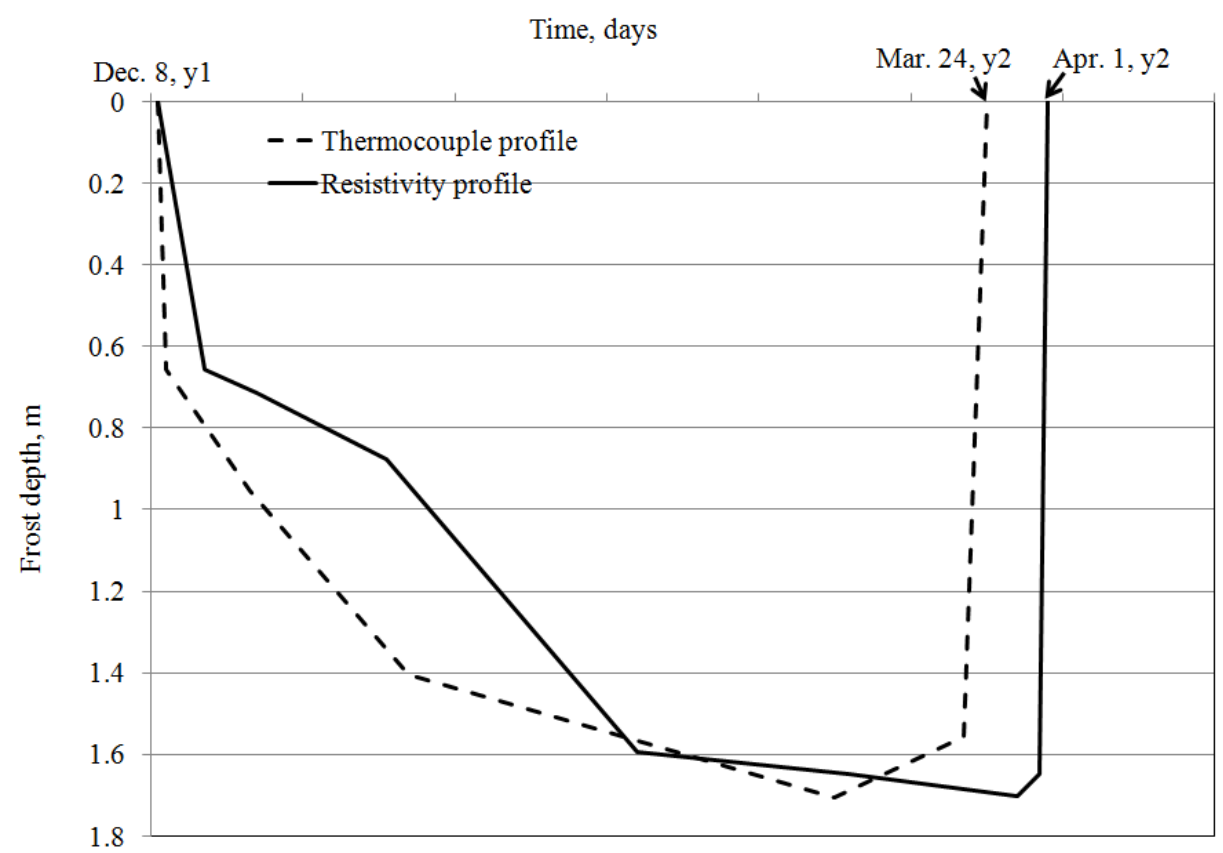

Figure 4.21: Comparison of freeze and thaw cycle using thermocouple and resistivity probes Site 1 for years 1 and 2

Time, days

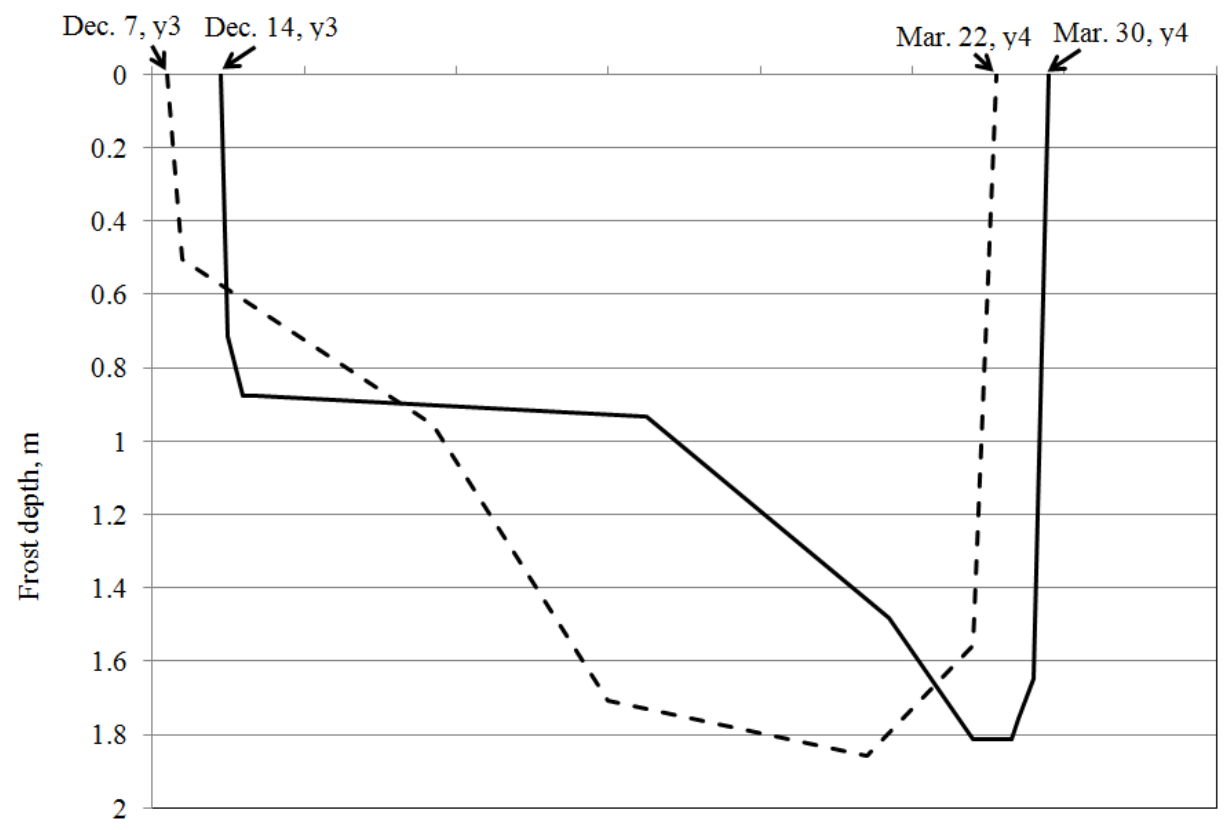

Figure 4.22: Comparison of freeze and thaw cycle using thermocouple and resistivity probes Site 1 years 3 and 4 


\subsubsection{Site 3}

Resistivity probe measurements of frost penetration depth for the unbound materials of the road structure layers are shown in Figures 4.23. Due to sensor malfunction, the resistivity signals were recorded for just one cycle. The same procedure as explained in details for site 1 was used to establish the freeze and thaw diagram for site 3 (see Figure 4.24).

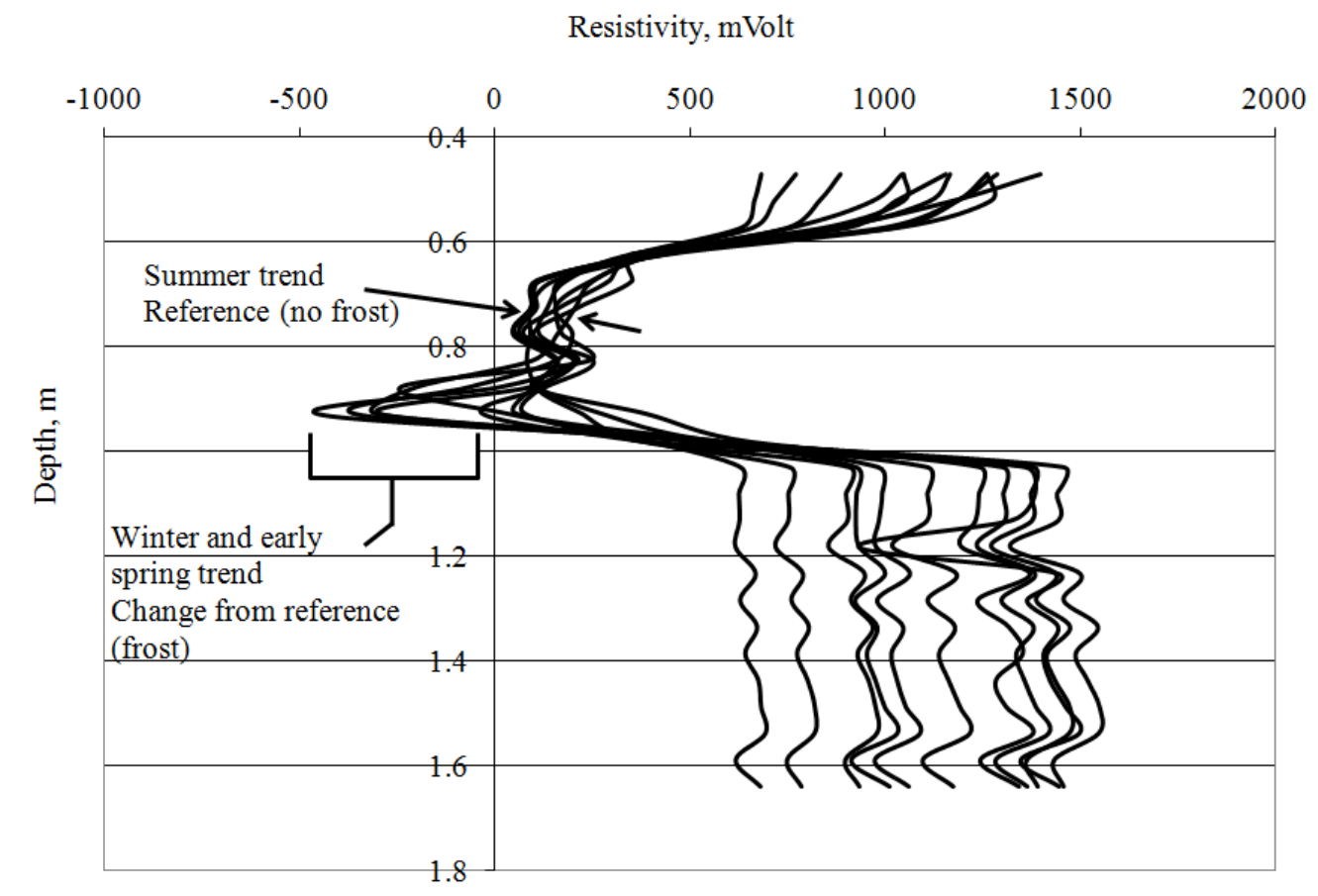

Figure 4.23: Resistivity profiles Site 3 - years 1 and 2 


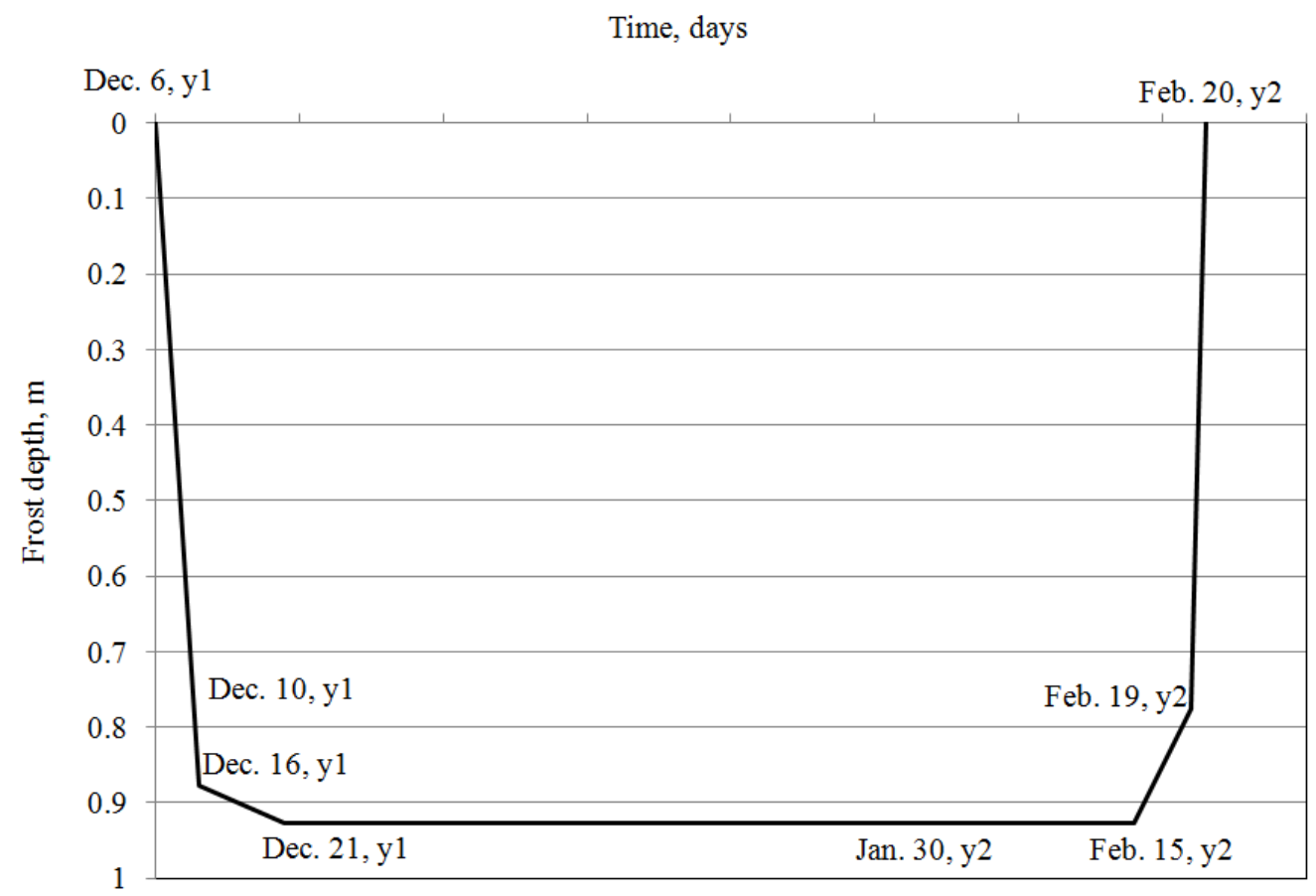

Figure 4.24: Resistivity probes freeze and thaw cycle Site 3 for years 1 and 2

Freeze and thaw diagrams were constructed using thermocouple data to compare it with results of the resistivity probe for the same site and cycles. Comparisons in Figure 4.25 show different trends that may be caused by malfunction of the data acquisition system within a certain period of time in the first year of construction. 


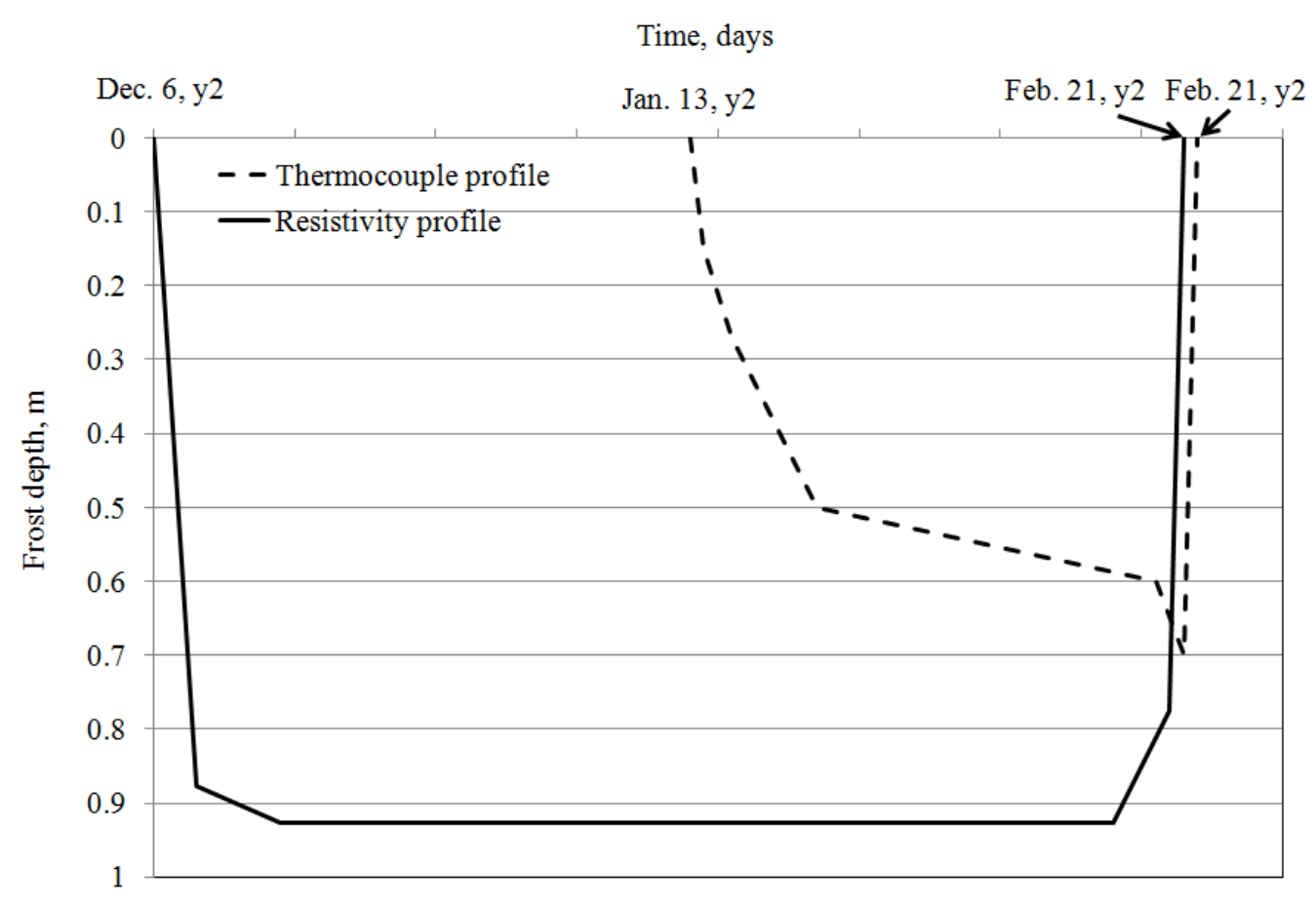

Figure 4.25: Comparison of freeze and thaw cycle using thermocouple and resistivity probes Site 3 years 1 and 2

\subsection{Structural data}

This study was designed to improve the ability of the M-EPDG model to predict the state of stress and strain in the pavement layers and also to quantify performance. Measurement of the actual structural behaviour in terms of stress and strain is a means to evaluate the effectiveness of the 2004 AASHTO design guide. Subsequently, this is an opportunity to introduce necessary modifications that will help accurately predict the MEPDG model performance. Both permanent and dynamic structural behaviour was monitored for all sites. The literature associated with conventional road practices does not include a reference to field data or analytical simulations at such high levels of stress. Site 2 was the first in which such a high stress level has been recorded. This finding necessitated monitoring the dynamic behaviour at same time, as the road was open to traffic. During early research work on site 1 , the structural behaviour was obtained a few 
days after finishing construction during normal asphalt mat temperature. However, no attempts were made to record the same behaviour after the road was opened to traffic immediately after construction. Details of the behaviour will be discussed in the following sections.

\subsubsection{Asphalt concrete strain profiles}

Data collection was focused on measuring permanent deformation accumulating with time under the action of general traffic loading and dynamic impact caused by known truckloads. Permanent deformation data were collected on a daily basis using a programmed static data acquisition system while dynamic impact required a high-speed data acquisition system.

\subsubsection{Site 1}

Permanent deformation of asphalt concrete was monitored in both directions $\mathrm{x}$ (perpendicular to traffic) and y (parallel to traffic) at a depth of $190 \mathrm{~mm}$ from the top of the asphalt concrete surface as shown previously in Figure 3.14. Strain records established using data collected from the site on a daily basis using a programmed static data acquisition system is shown in Figure 4.26. Figure 4.26 revealed that high rates of strain (within the first 6 months) occur, supporting observations documented in the literature. This suggests that the majority of poor performance incidents occur at an early stage in the service life. 


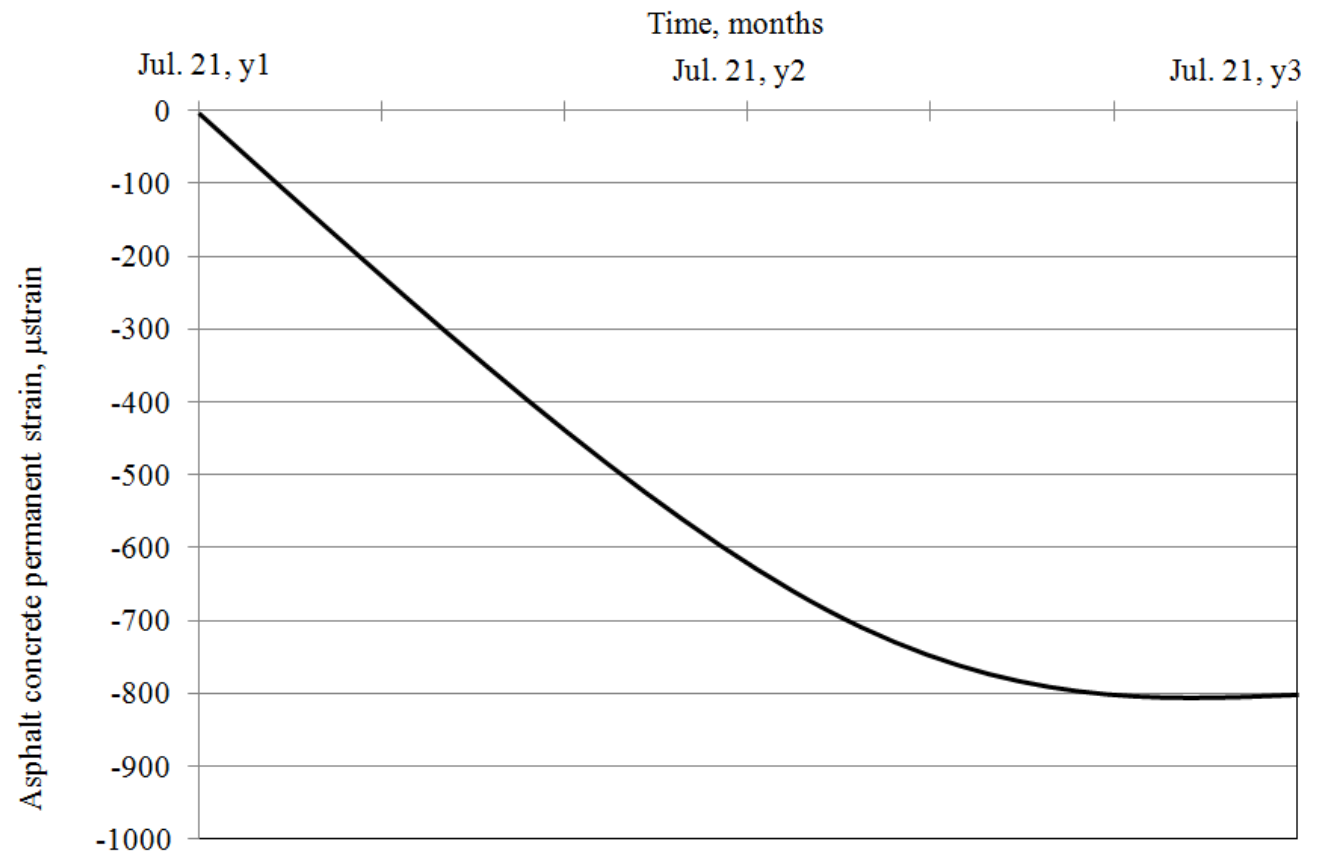

Figure 4.26: Asphalt concrete permanent strain for Site 1

One single and two twin axle test trucks, each weighing 48.8, 174.82 and 169.79 $\mathrm{kN}$ from front to back respectively, were operated 30 days after construction (asphalt mat temperature was $21.6^{\circ} \mathrm{C}$ ) on asphalt concrete. Strain gauge data in both directions $\mathrm{x}$ (perpendicular to traffic) and y (parallel to traffic) using the dynamic data acquisition system as explained earlier were obtained. Both signals are shown in Figures 4.27 and 4.28 respectively. A maximum strain of $290 \mu$ strain was registered. 
Time, sec

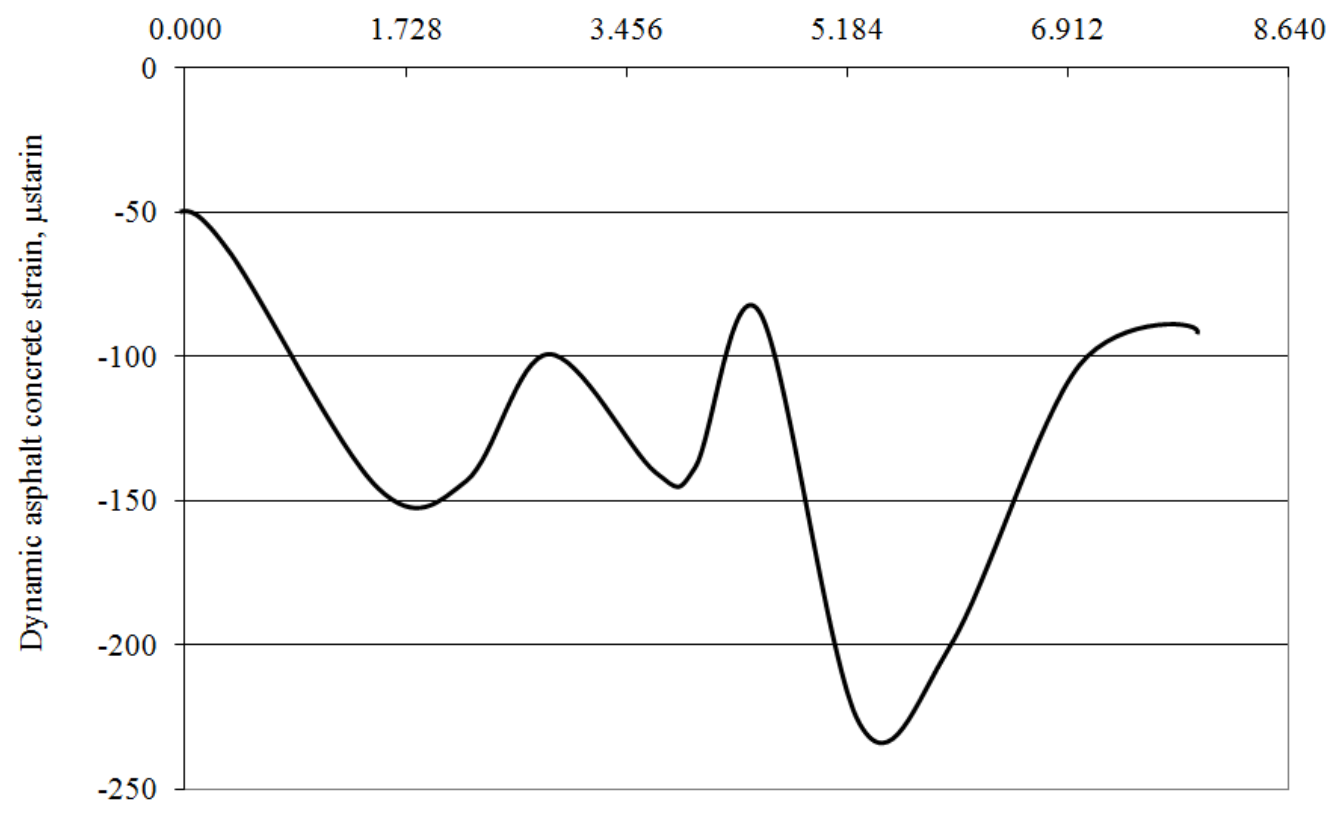

Figure 4.27: Truck impact on asphalt concrete strain gauge in the x-direction for Site 1

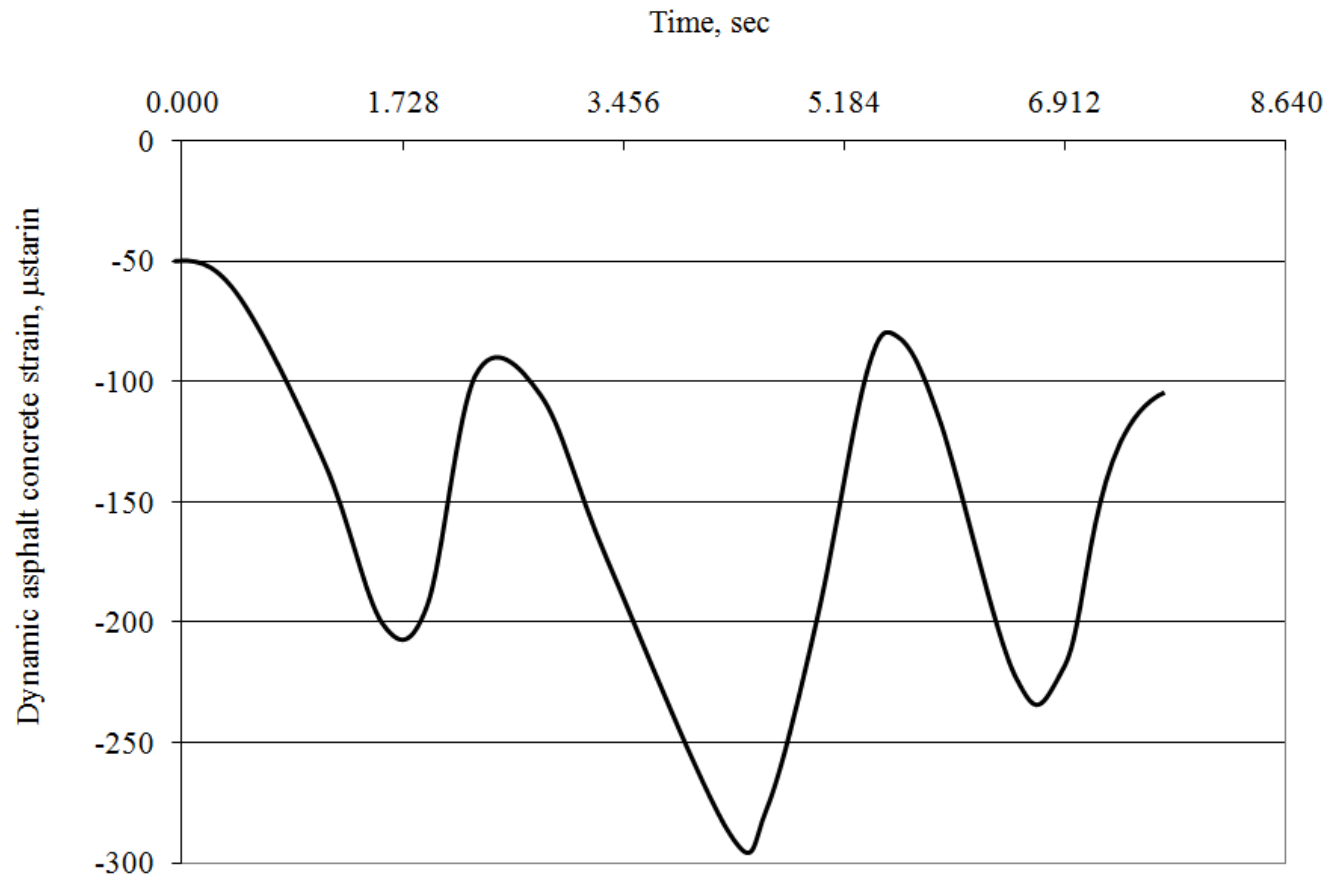

Figure 4.28: Truck impact on asphalt concrete strain gauge in the y-direction for Site 1 


\subsubsection{Site 2}

Permanent deformation of asphalt concrete was monitored at a depth of $230 \mathrm{~mm}$ from the top of the asphalt concrete surface as shown previously in Figure 3.15. Strain records were established for data collected from the site on a daily basis using a programmed static data acquisition system in both directions $\mathrm{x}$ (perpendicular to traffic) and y (parallel to traffic). The records are shown in Figures 4.29 and 4.30, respectively. Figures 4.29 and 4.30 reveal that high rates of strain occurred within the first 9 months, supporting observations documented in the literature and the findings in this study for site 1. This subsequently supports the view that the majority of poor performance incidents occur at an early stage in the service life. However, permanent strain results in the direction of traffic (y-direction) showed higher values by about $15 \%$ than the direction perpendicular to traffic (x-direction).

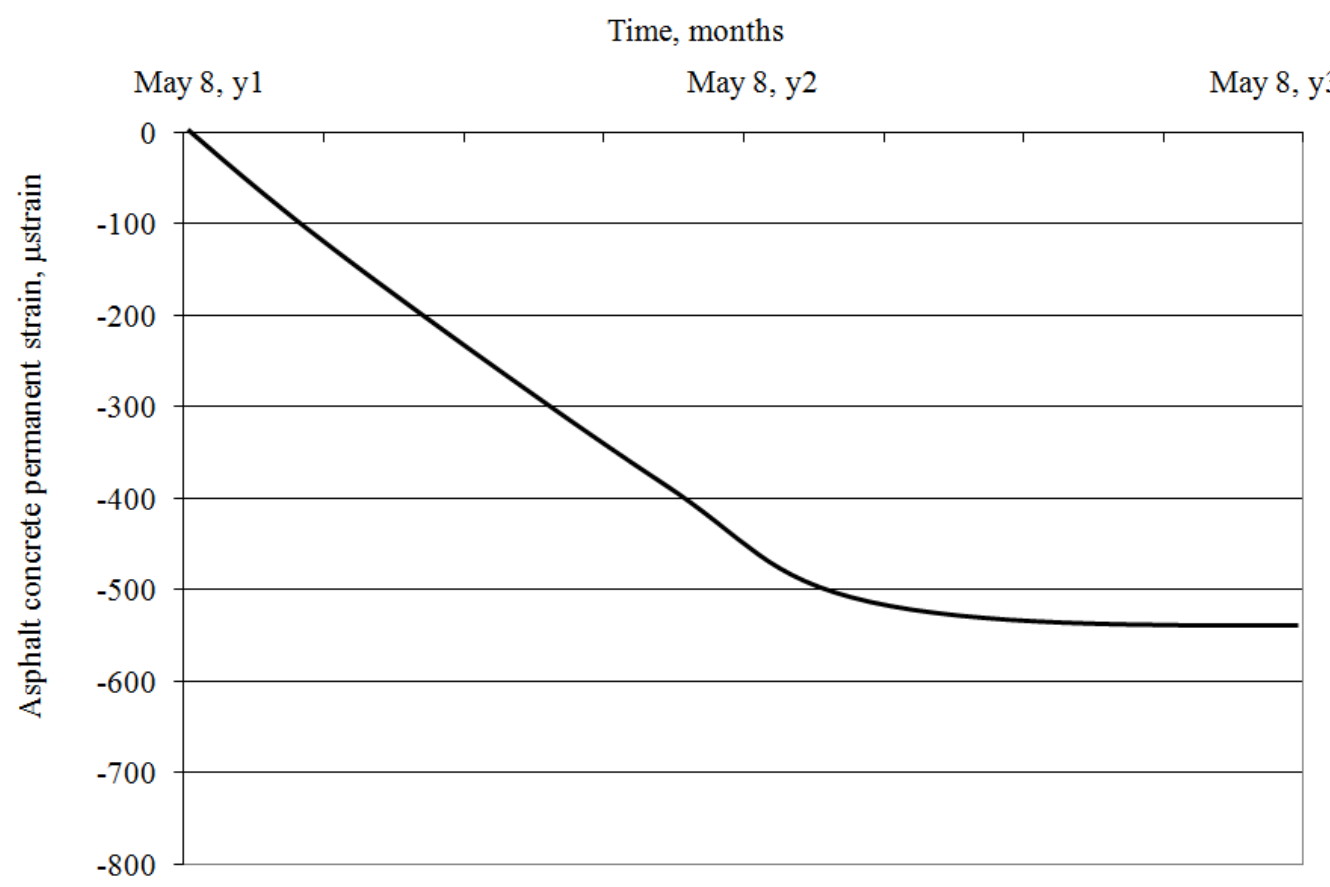

Figure 4.29: Asphalt concrete permanent strain-x direction for Site 2 


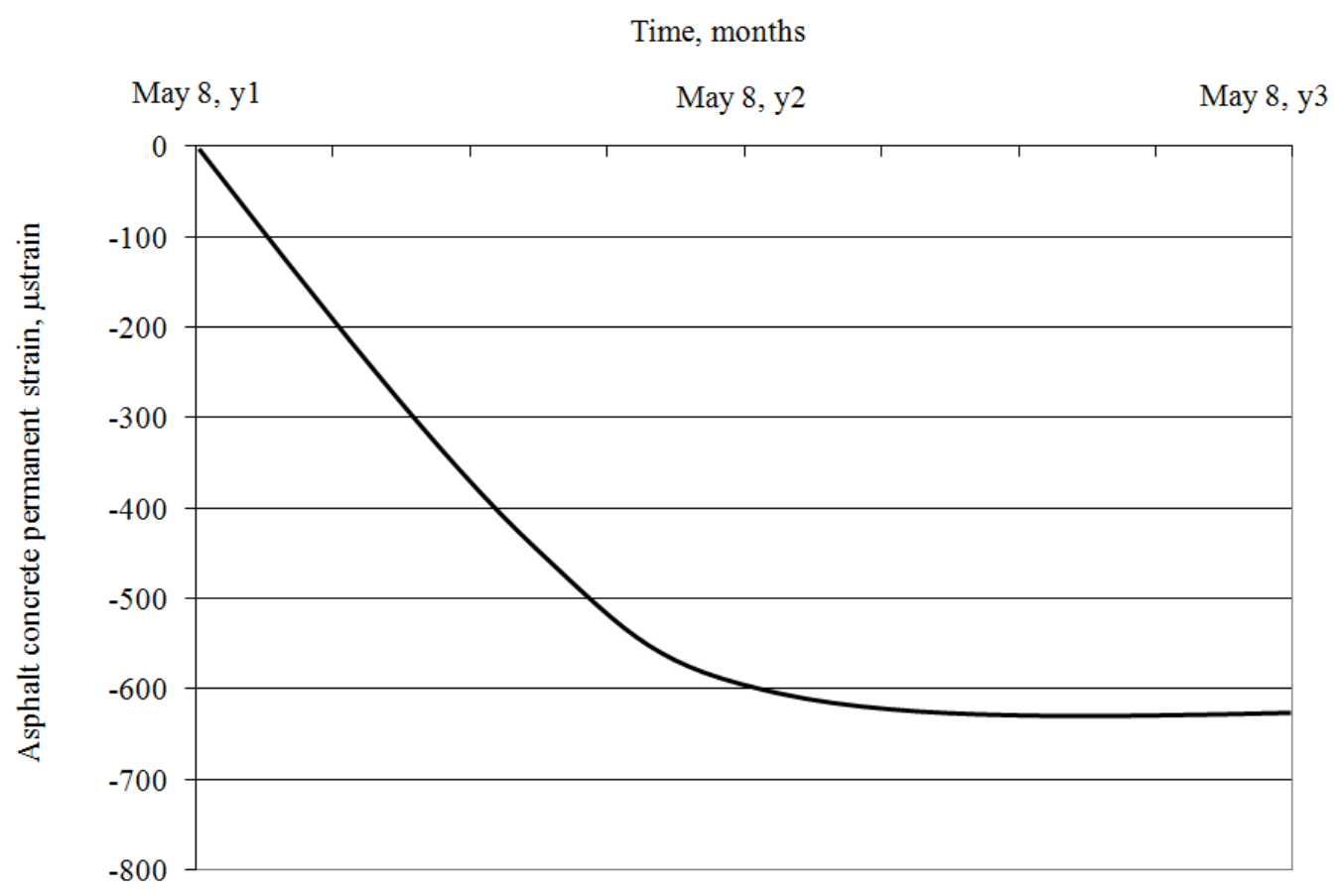

Figure 4.30: Asphalt concrete permanent strain- y direction for Site 1

A two axle test truck with axle loads of 57.83 and $83.18 \mathrm{kN}$ respectively from front to back, was operated immediately after construction (asphalt mat temperature was $50^{\circ} \mathrm{C}$ ). Strain data was obtained from asphalt concrete strain gauges in both directions $\mathrm{x}$ (perpendicular to traffic) and y (parallel to traffic) using a dynamic data acquisition system revealing an extraordinarily high level of strain as shown in Figures 4.31 and 4.32. A maximum strain of 3200 and $4100 \mu$ strain were registered for the $\mathrm{x}$ and $\mathrm{y}$ directions respectively. Data analysis revealed that the asphalt concrete temperature when these strain levels were recorded was higher than normal road operating temperatures. The temperature recorded at the bottom of the asphalt concrete layer was $50^{\circ} \mathrm{C}$ during the truck test. 
Time, sec

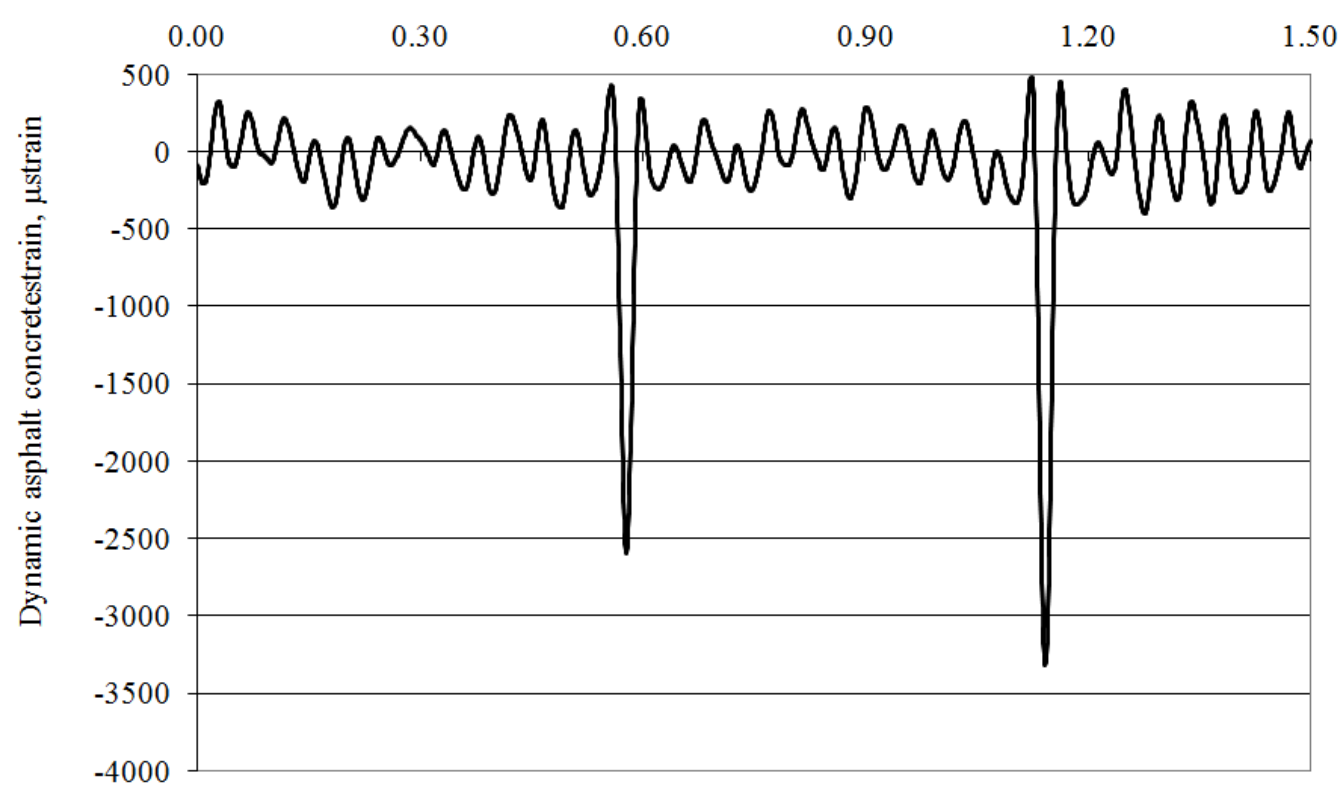

Figure 4.31: Truck impact on asphalt concrete strain measurements in the x-direction for Site 2

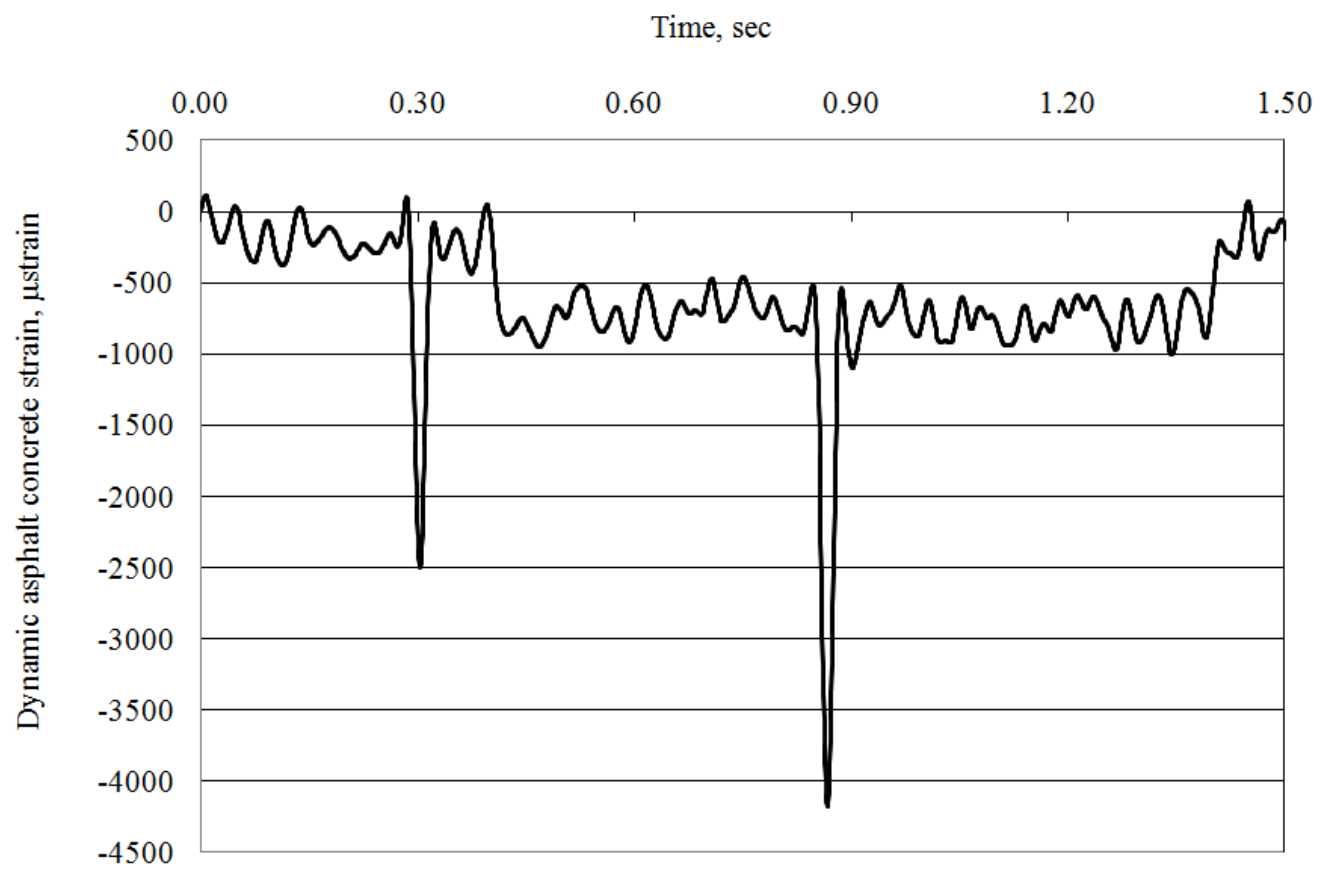

Figure 4.32: Truck impact on asphalt concrete strain measurements in the y-direction for Site 2-(immediately after construction) 
The strain induced at the bottom of the asphalt concrete layer, however, significantly dropped by $75 \%$ for both $\mathrm{x}$ and $\mathrm{y}$ directions when the temperature of asphalt concrete cooled to $25^{\circ} \mathrm{C}$ (9 months after construction) as shown in Figures 4.33 and 4.34 of the same truck impact test in $\mathrm{x}$ and $\mathrm{y}$ directions respectively.

Time, sec

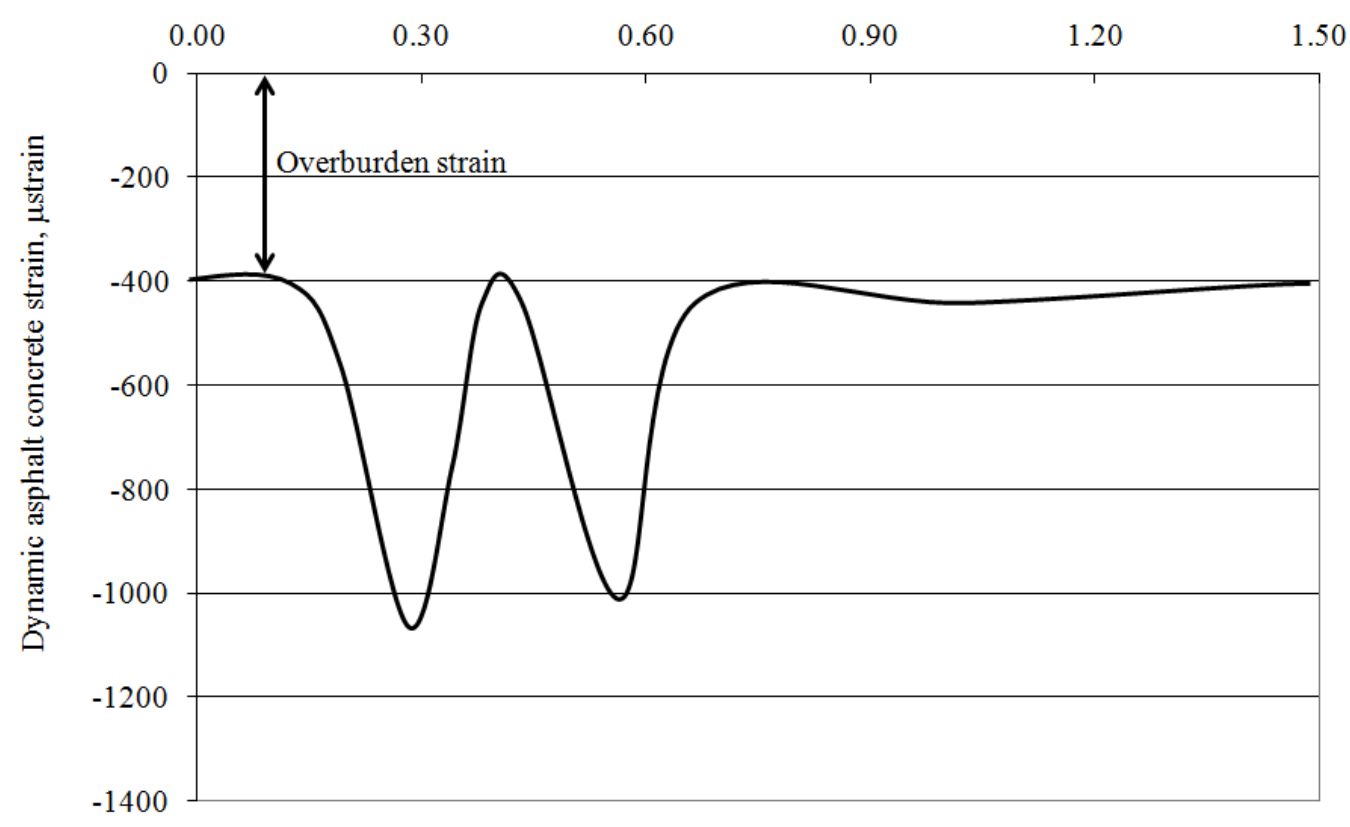

Figure 4.33: Truck impact on asphalt concrete strain measurements in the x-direction for Site 2- ( 9 months after construction) 


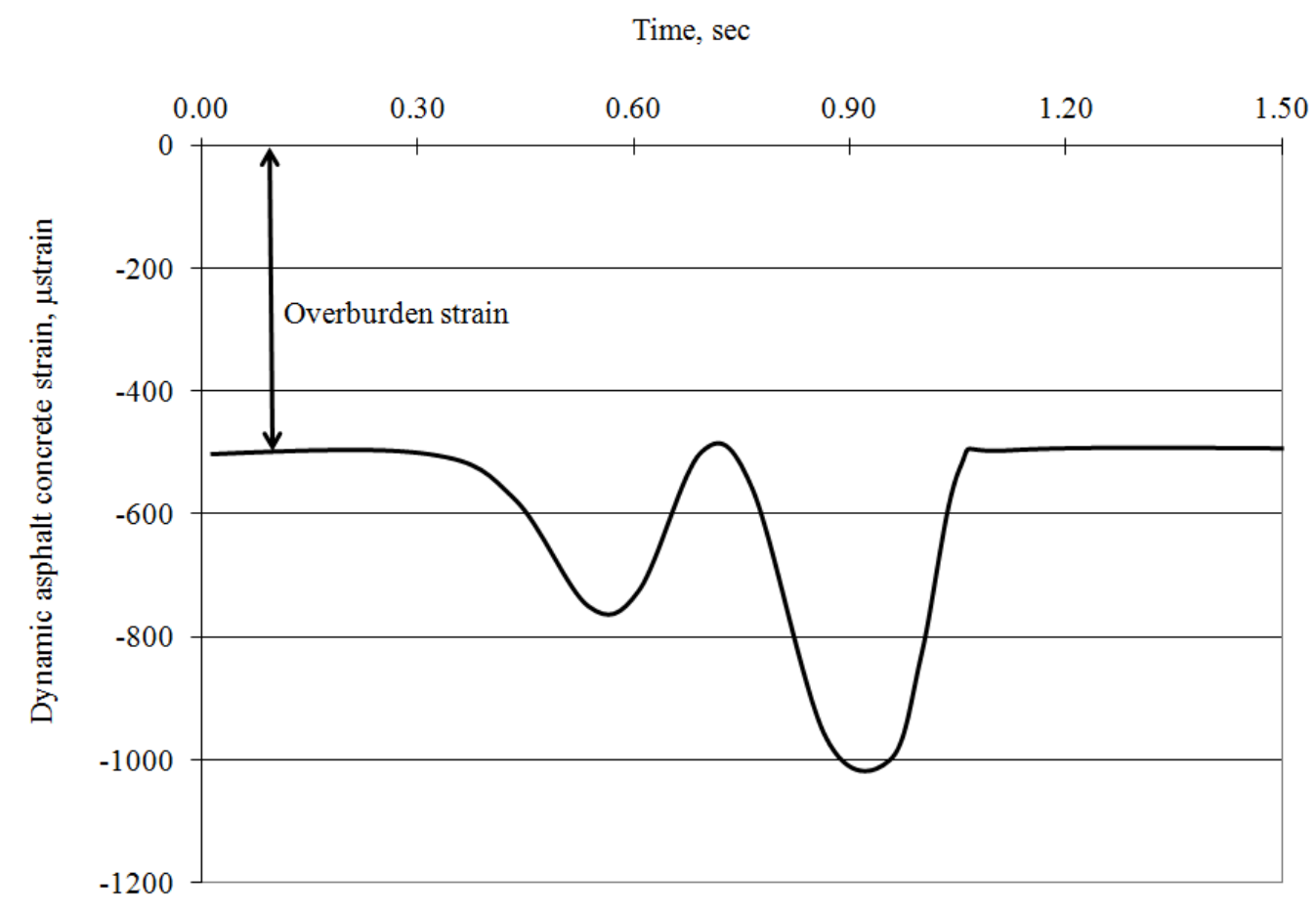

Figure 4.34: Truck impact on asphalt concrete strain measurements in the y-direction for Site 2- (9 months after construction)

\subsubsection{Site 3}

Permanent deformation of asphalt concrete was monitored in both directions $\mathrm{x}$ (perpendicular to traffic) and y (parallel to traffic) at a depth of $190 \mathrm{~mm}$ from the top of the asphalt concrete surface as shown previously in Figure 3.16. Strain records established using data collected from the site on a daily basis using a programmed static data acquisition system is shown in Figures 4.35 and 4.36. Both profiles revealed that high rates of strain (within the first 6 months) occurred in both directions. The permanent strain profiles were very similar. 


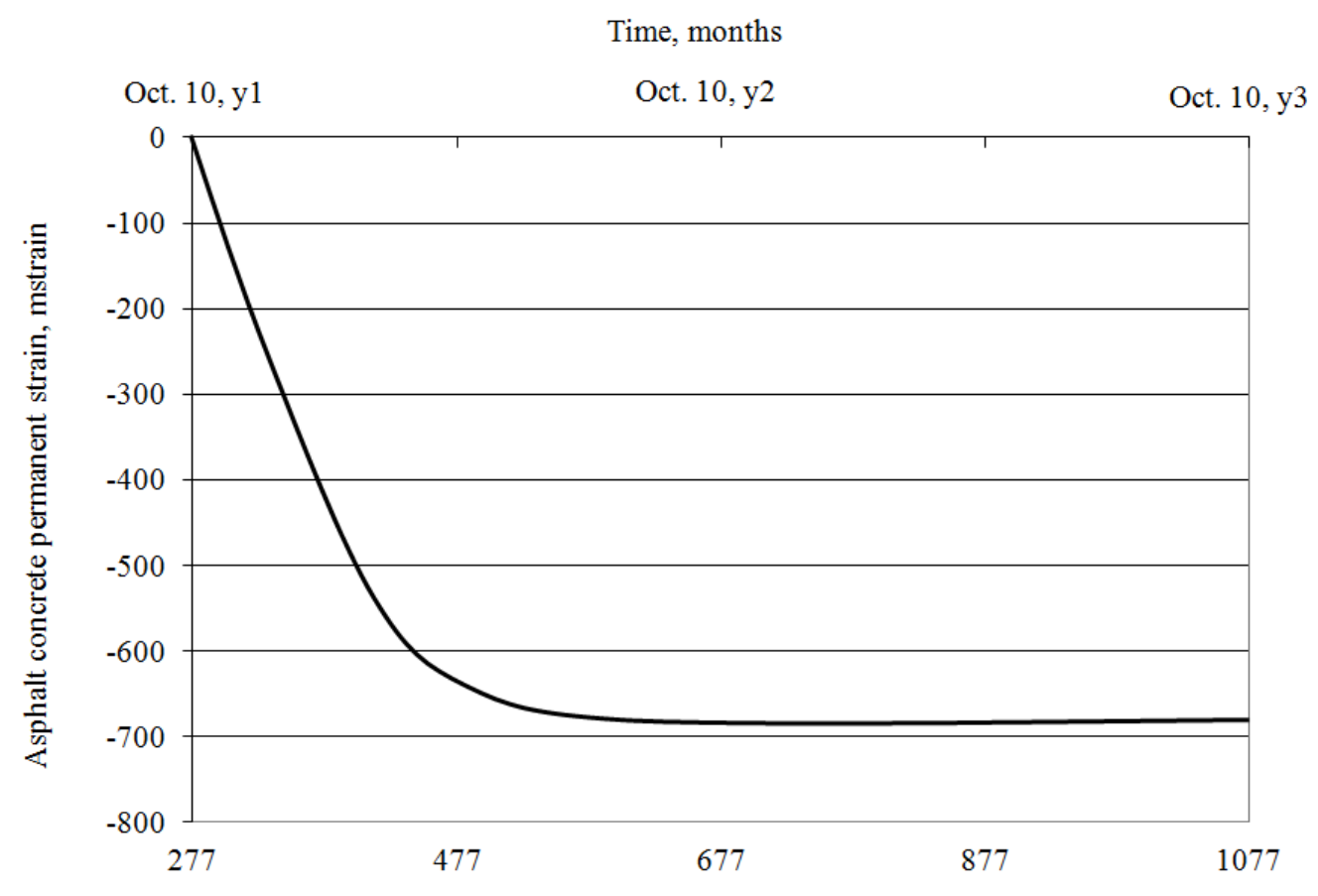

Figure 4.35: Asphalt concrete permanent strain- x-direction for Site 3

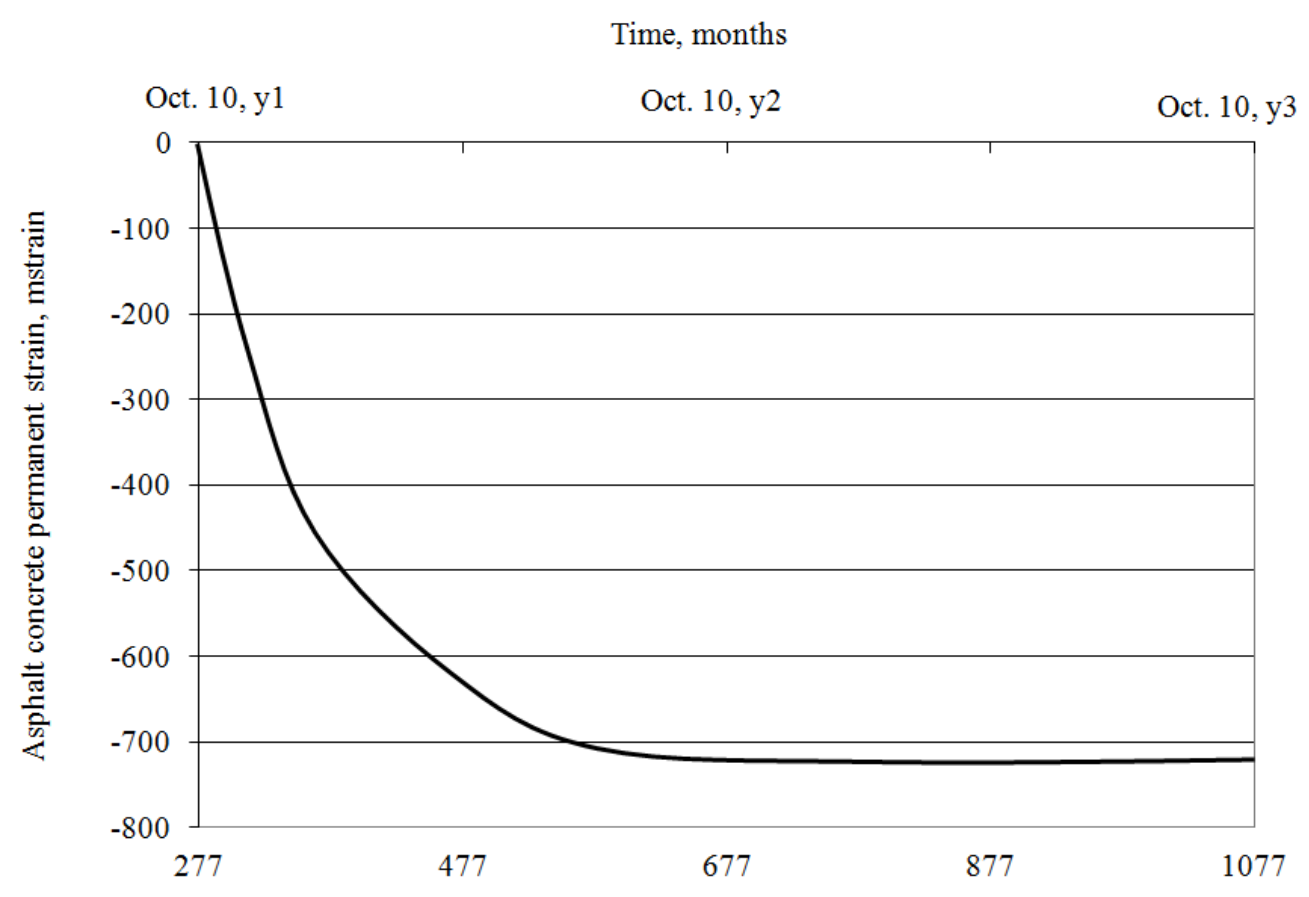

Figure 4.36: Asphalt concrete permanent strain- y-direction for Site 3

A three-axle test truck, with axle loads of $43.24,86.65$ and $85.85 \mathrm{kN}$ respectively from front to back, was operated immediately after construction (the asphalt mat 
temperature was $81.5^{\circ} \mathrm{C}$ ). Strain data was collected in both directions $\mathrm{x}$ (perpendicular to traffic) and y (parallel to traffic) using a dynamic data acquisition system revealing an extraordinarily high level of strain as shown in Figures 4.37. A registered maximum strain of $5200 \mu$ strain in the y directions was obtained. The sensor data in the $\mathrm{x}$-direction were last. Data analysis revealed that the road was opened to traffic when the asphalt concrete temperature was still very high $\left(81.5^{\circ} \mathrm{C}\right)$ compared with the other sites. In summary, the analysis revealed that low asphalt concrete stiffness is responsible for the majority of strains exceeding those encountered under normal road operating conditions.

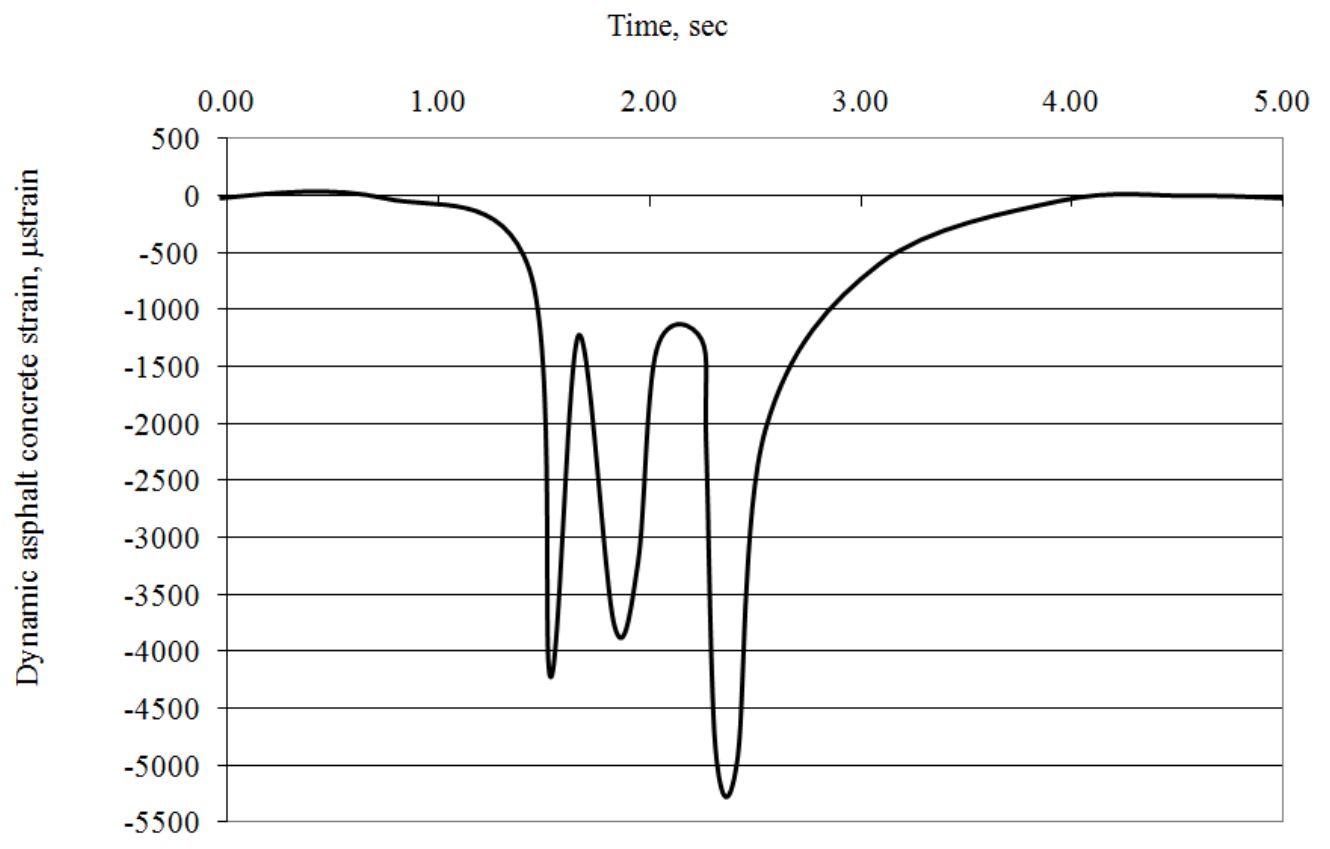

Figure 4.37: Truck impact on asphalt concrete strain measurements in the y-direction for Site 3- (immediately after construction)

\subsubsection{Pressure profiles}

Data collection was focused on measuring overburden pressure accumulating with time under the action of general traffic loading and dynamic impact caused by a known 
test truck. Overburden pressure data were collected on a daily basis using a programmed static data acquisition system while dynamic impact required a high- speed data acquisition system.

\subsubsection{Site 1}

Overburden pressure was monitored at different depth levels (400, 640, 1510 and $2570 \mathrm{~mm}$ ) as shown previously in Figure 3.14. Overburden pressure records were established using data collected from the site on a daily basis using a programmed static data acquisition system shown in Figures 4.38 to 4.41 . The difference profiles types were observed. Figure 4.42 shows that overburden pressure increases with depth.

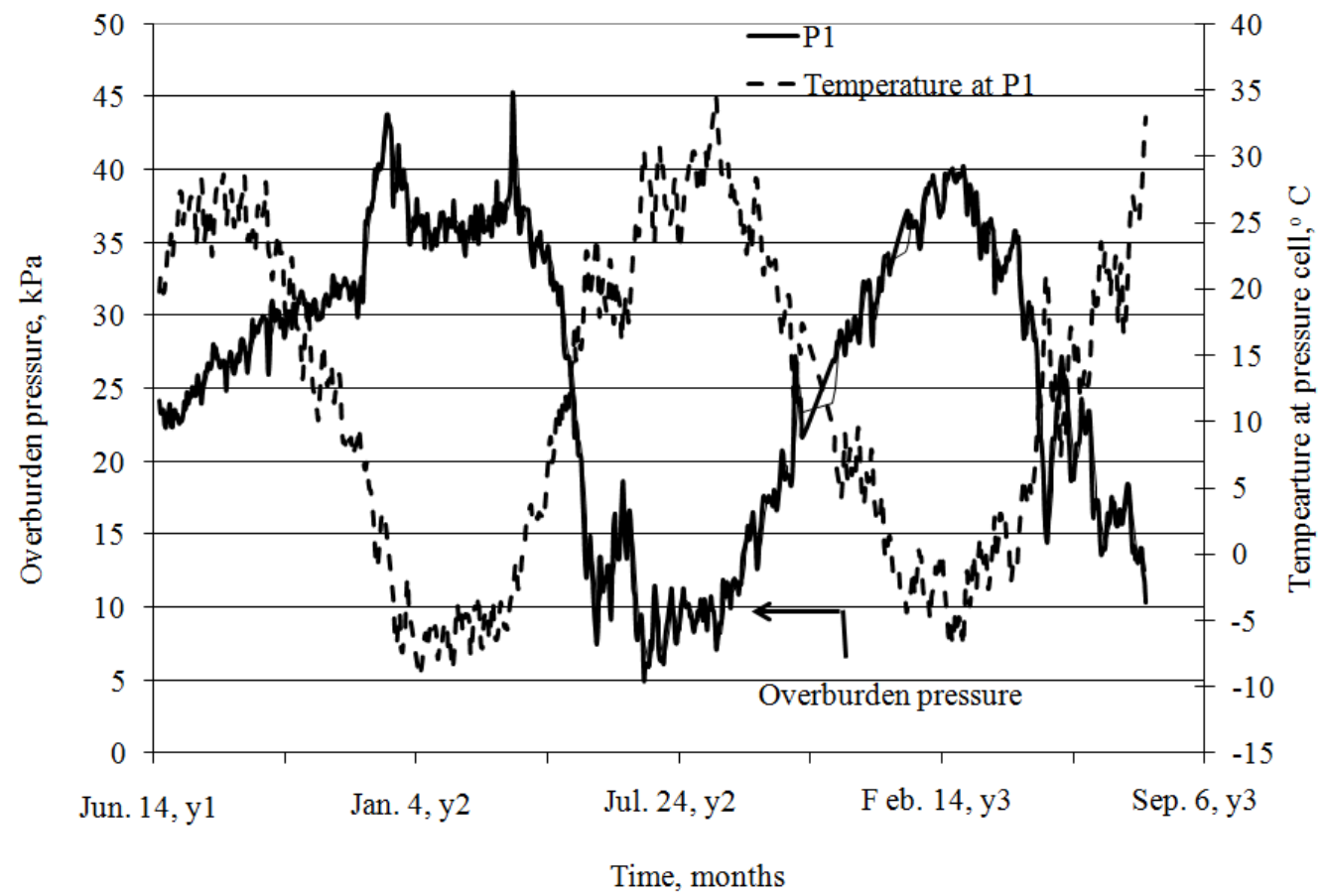

Figure 4.38: Overburden pressure at $400 \mathrm{~mm}$ below the surface 


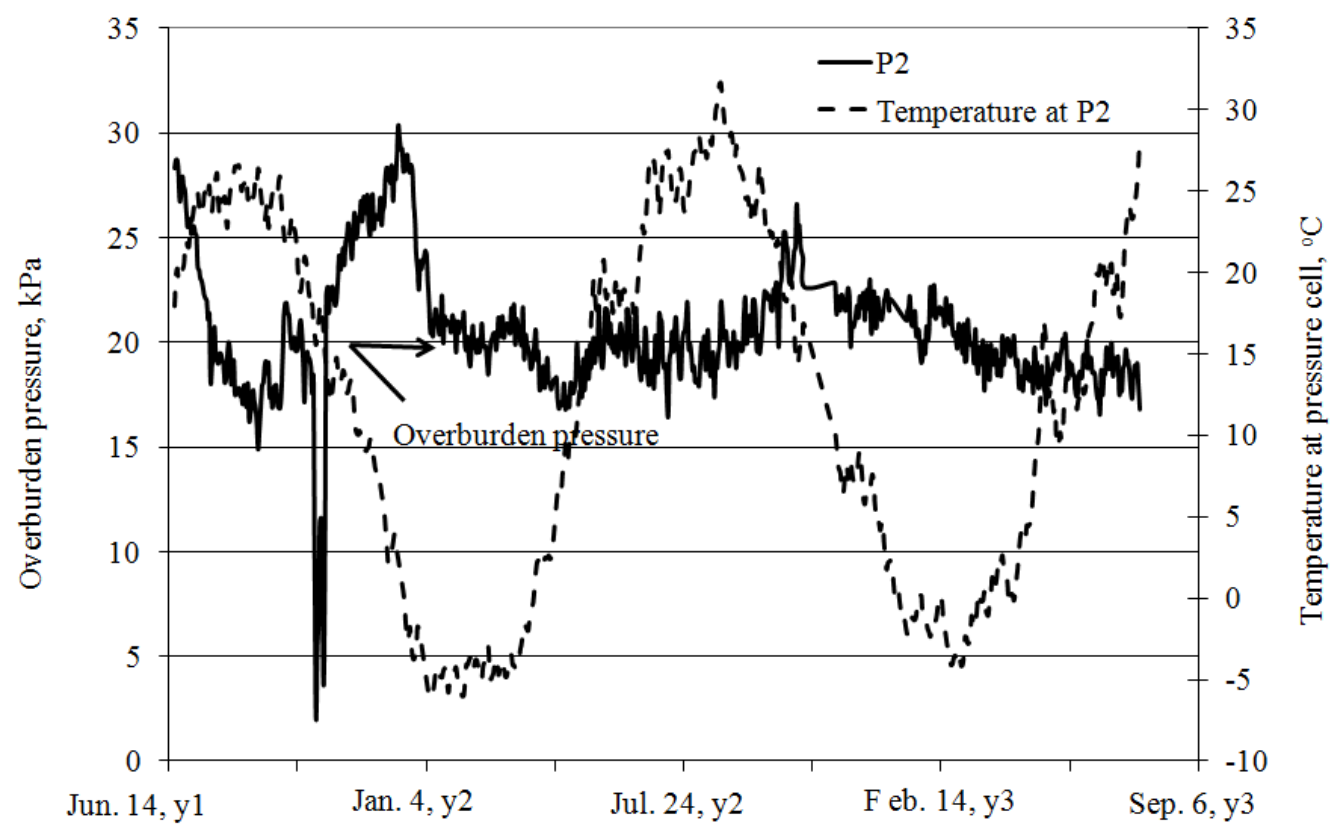

Time, months

Figure 4.39: Overburden pressure at $640 \mathrm{~mm}$ below the surface

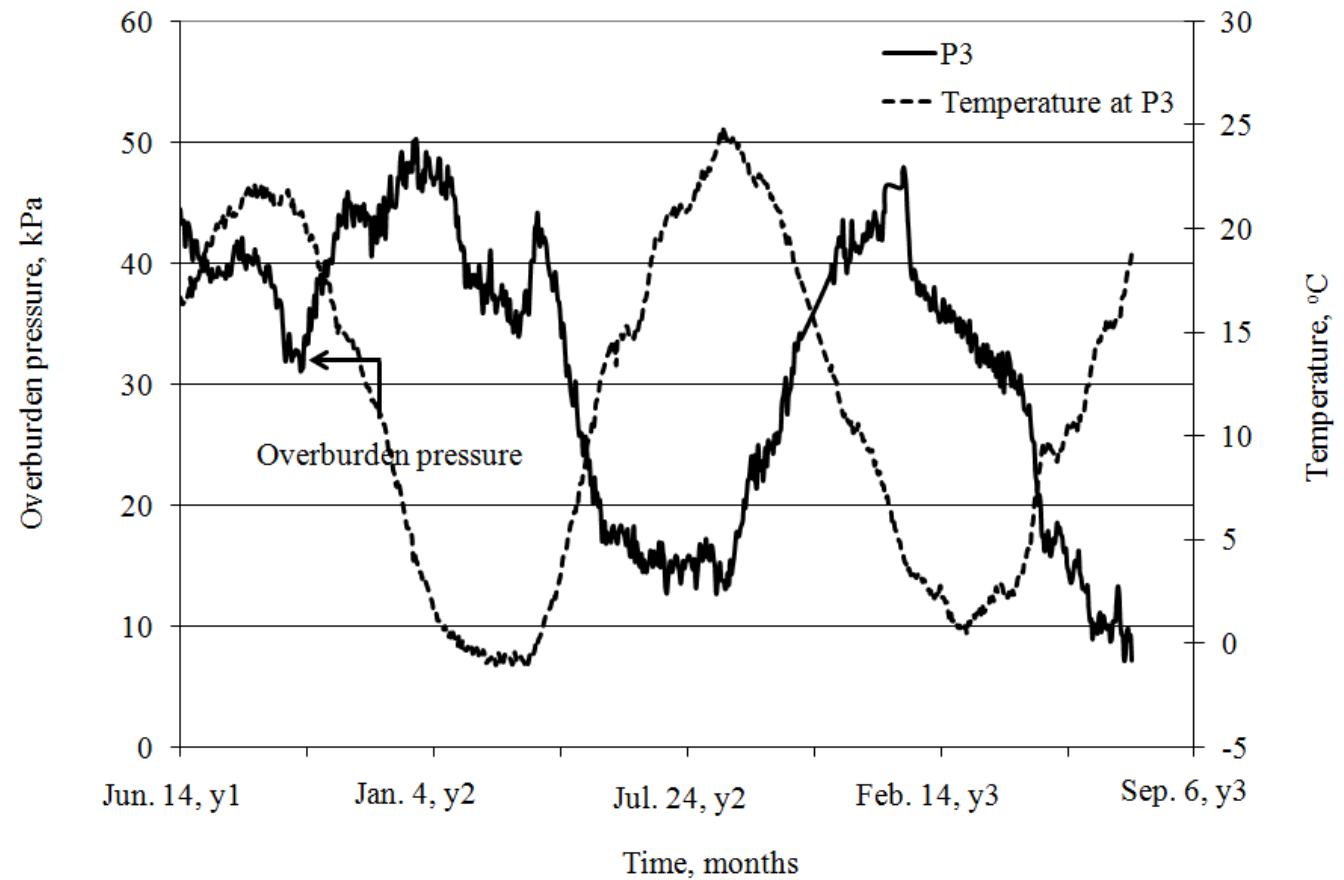

Figure 4.40: Overburden pressure at $1510 \mathrm{~mm}$ below the surface 


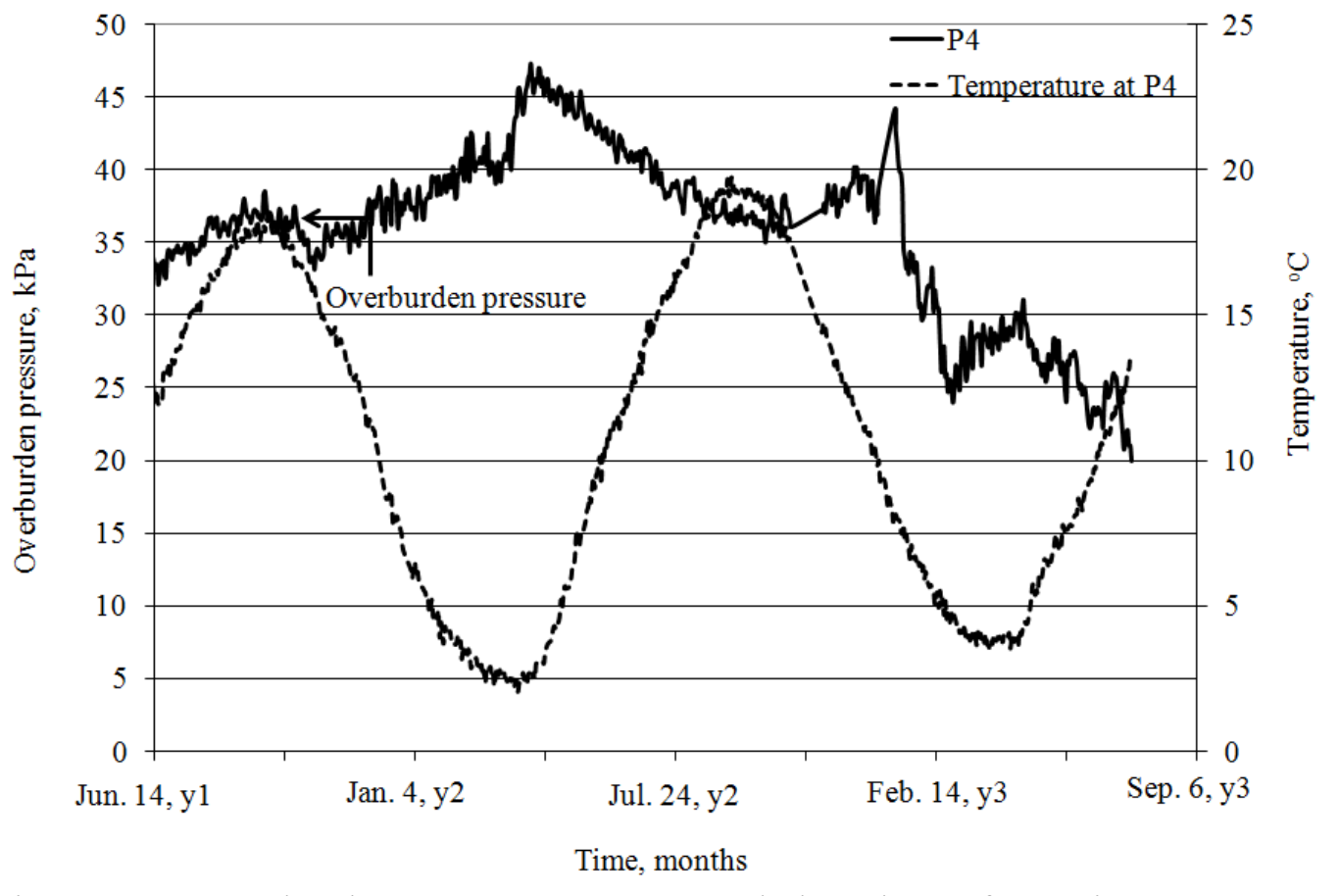

Figure 4.41: Overburden pressure at $2570 \mathrm{~mm}$ below the surface- Site 1

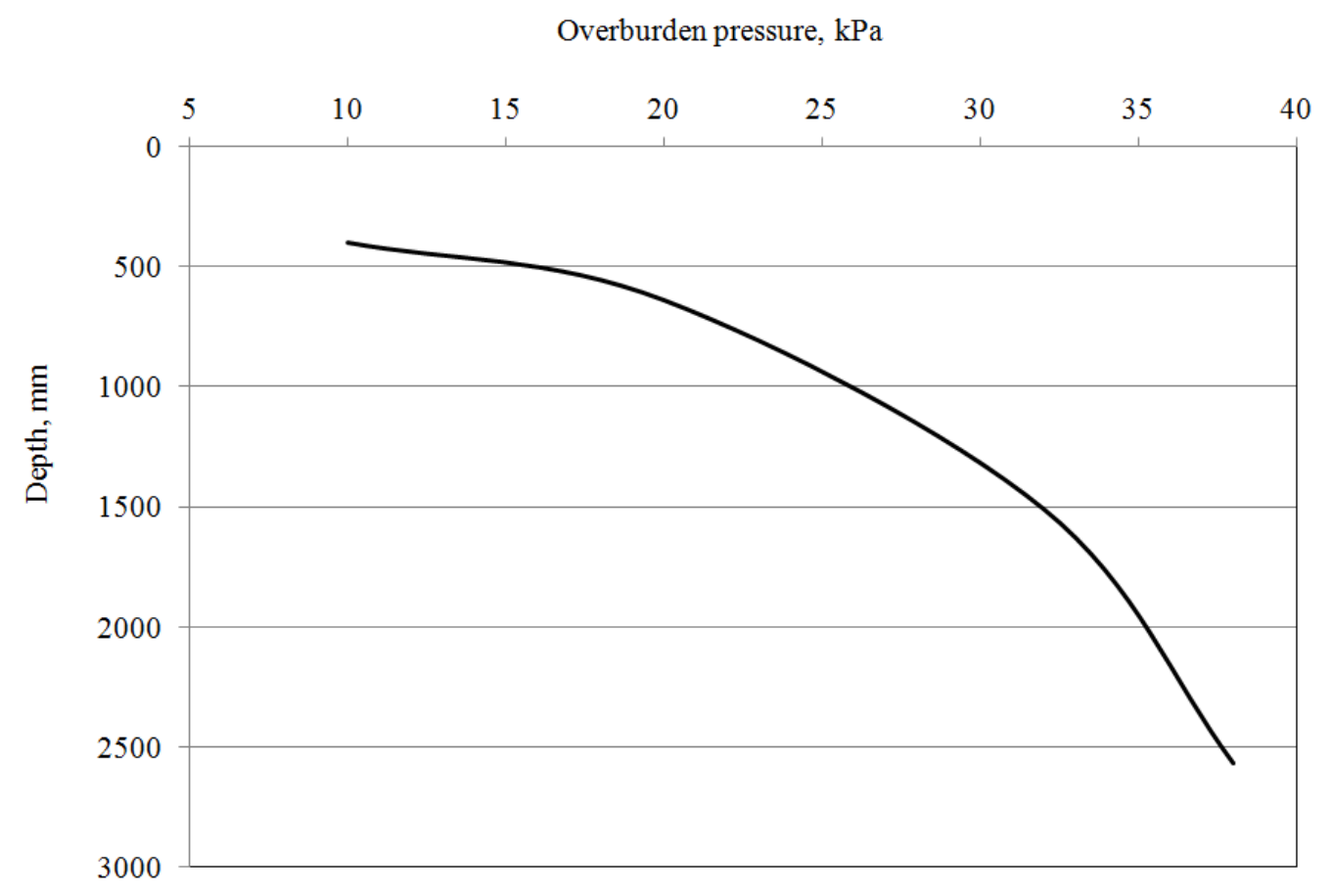

Figure 4.42: Overburden pressure profile- Site 1

One single axle and two twin axle test truck with axle loads of 48.8, 174.8 and $169.8 \mathrm{kN}$ respectively from front to back, were utilized few days after construction (the 
asphalt mat temperature was $21.5^{\circ} \mathrm{C}$ ). Pressure cells were buried in the road unbound materials and located at four different levels (400,640, 1510 and $2570 \mathrm{~mm}$ ) as shown previously in Figure 3.14. Dynamic data was collected using a dynamic data acquisition system revealing a high level of pressure after a few days of construction as shown in Figures 4.43 and 4.44 for 45 and $15 \mathrm{~km} / \mathrm{h}$ truck speed respectively. Data analysis revealed that the closer the pressure cells to the road surface, the more truck pressure impact registered. The effect of truck speed variation between 15 to $45 \mathrm{~km} / \mathrm{h}$ is negligible below the road surface of $500 \mathrm{~mm}$ as shown in Figure 4.45 .

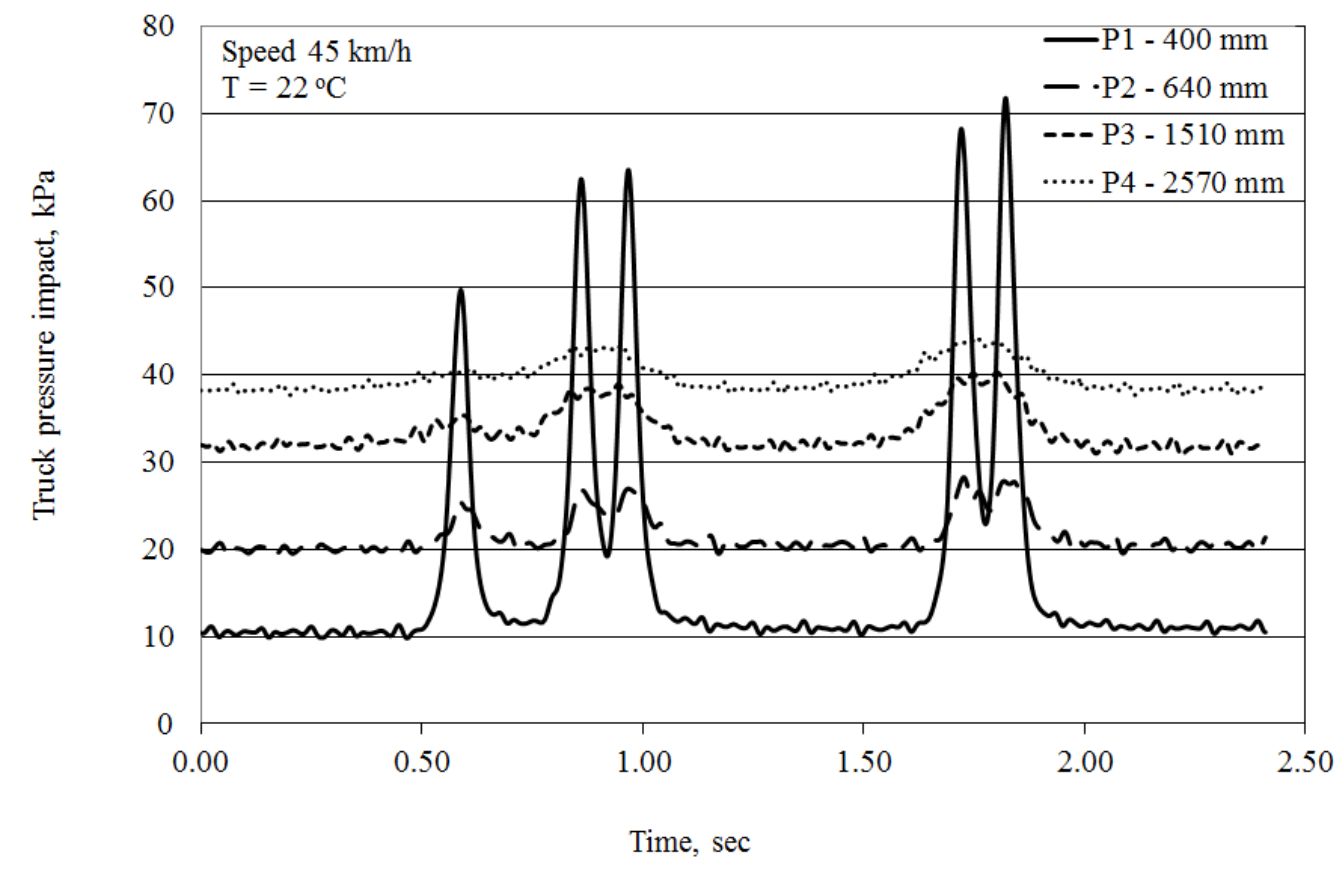

Figure 4.43: Vertical pressure records for truck impact in year 1- Site 1 


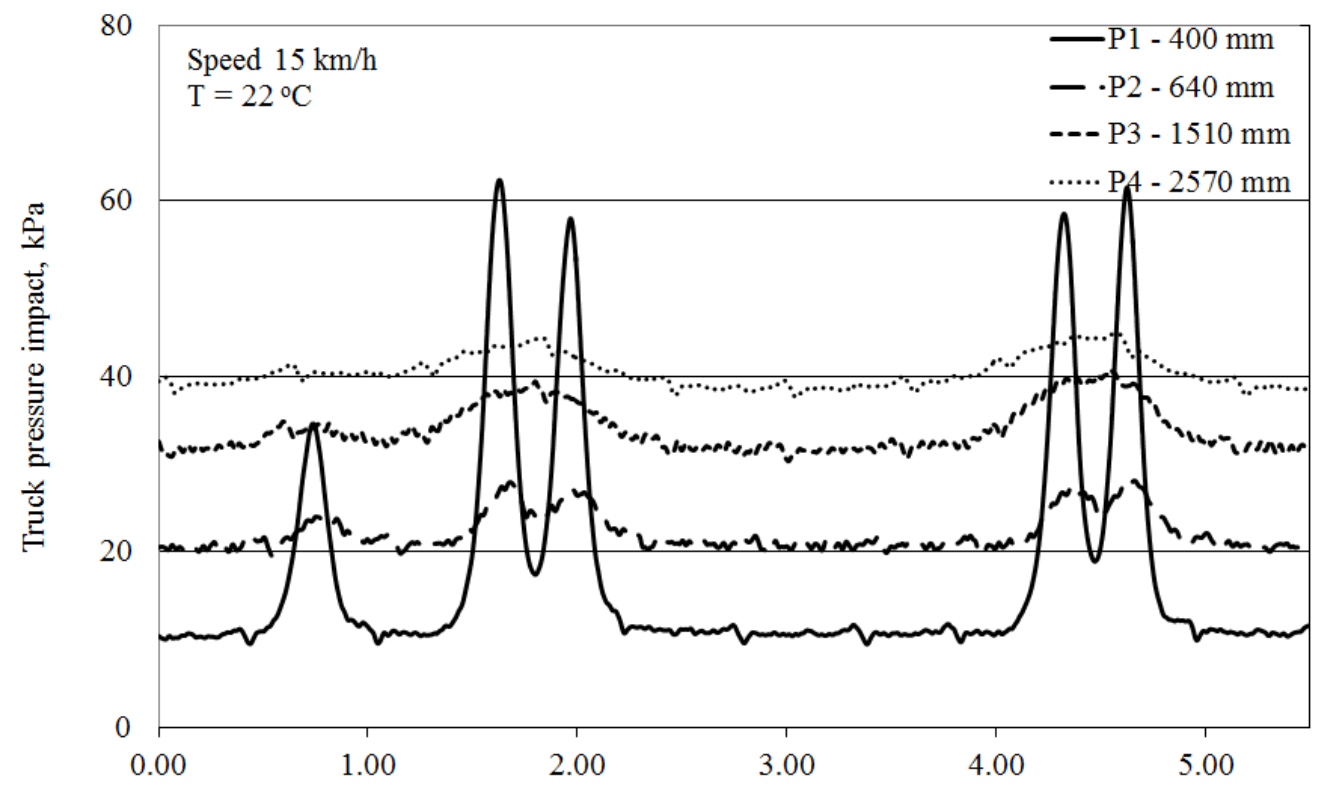

Time, sec

Figure 4.44: Vertical pressure records for truck impact in year 1- Site 1

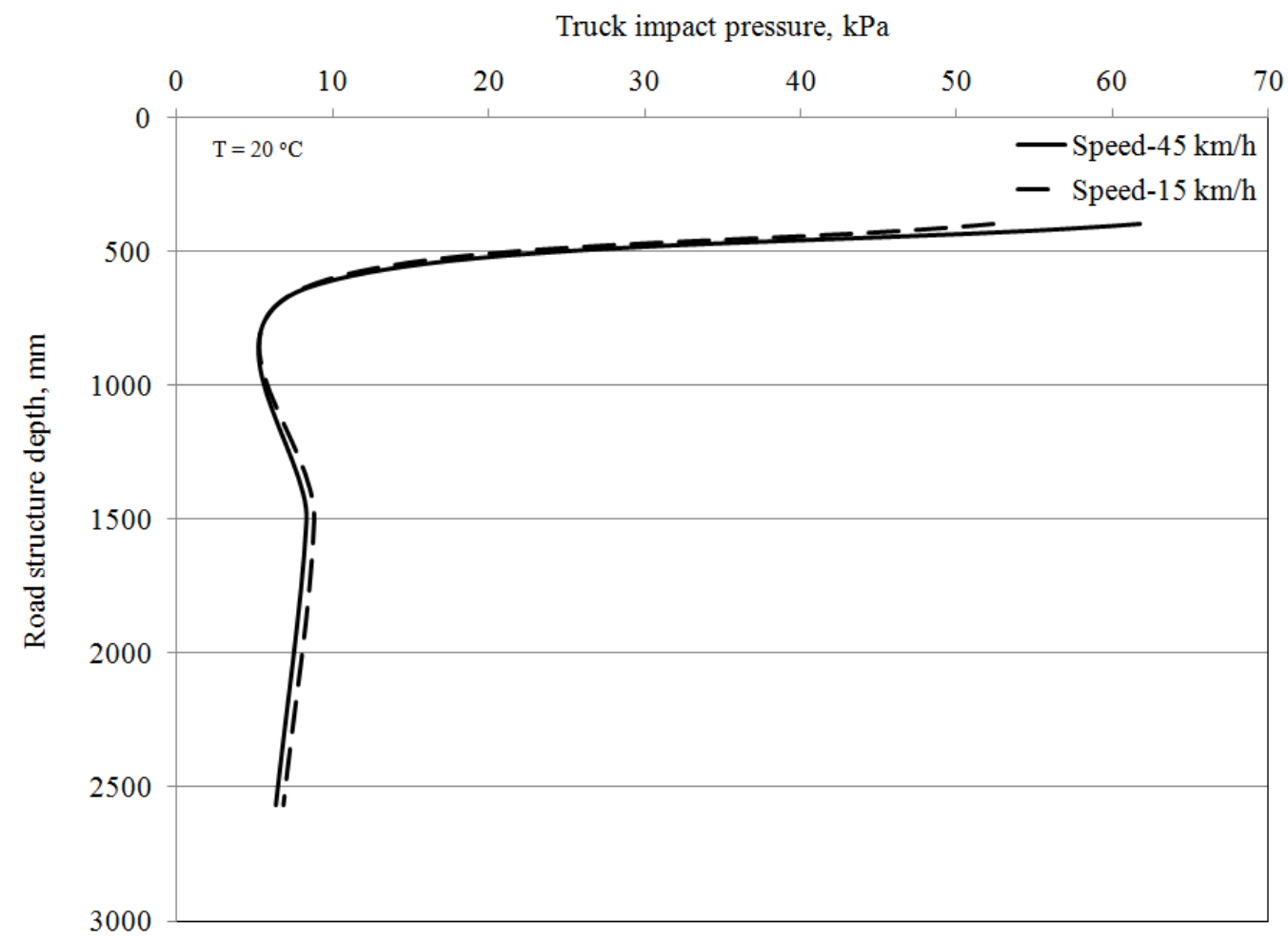

Figure 4.45: Effect of speed on vertical pressure gradient - Site 1 
Figure 4.46 shows the records for the impact of the same truck pressure signals in year 2 . The results revealed that the one-year pressure signal dropped tremendously. Additional evaluations were made on the pressure cell close to the surface at a depth of $400 \mathrm{~mm}$ as shown in Figure 4.47. The truck impact pressure gradients (without overburden) for the same conditions are shown in Figure 4.48. The impact dropped to 85 and $82 \%$ at depths of 400 and $1510 \mathrm{~mm}$, respectively.

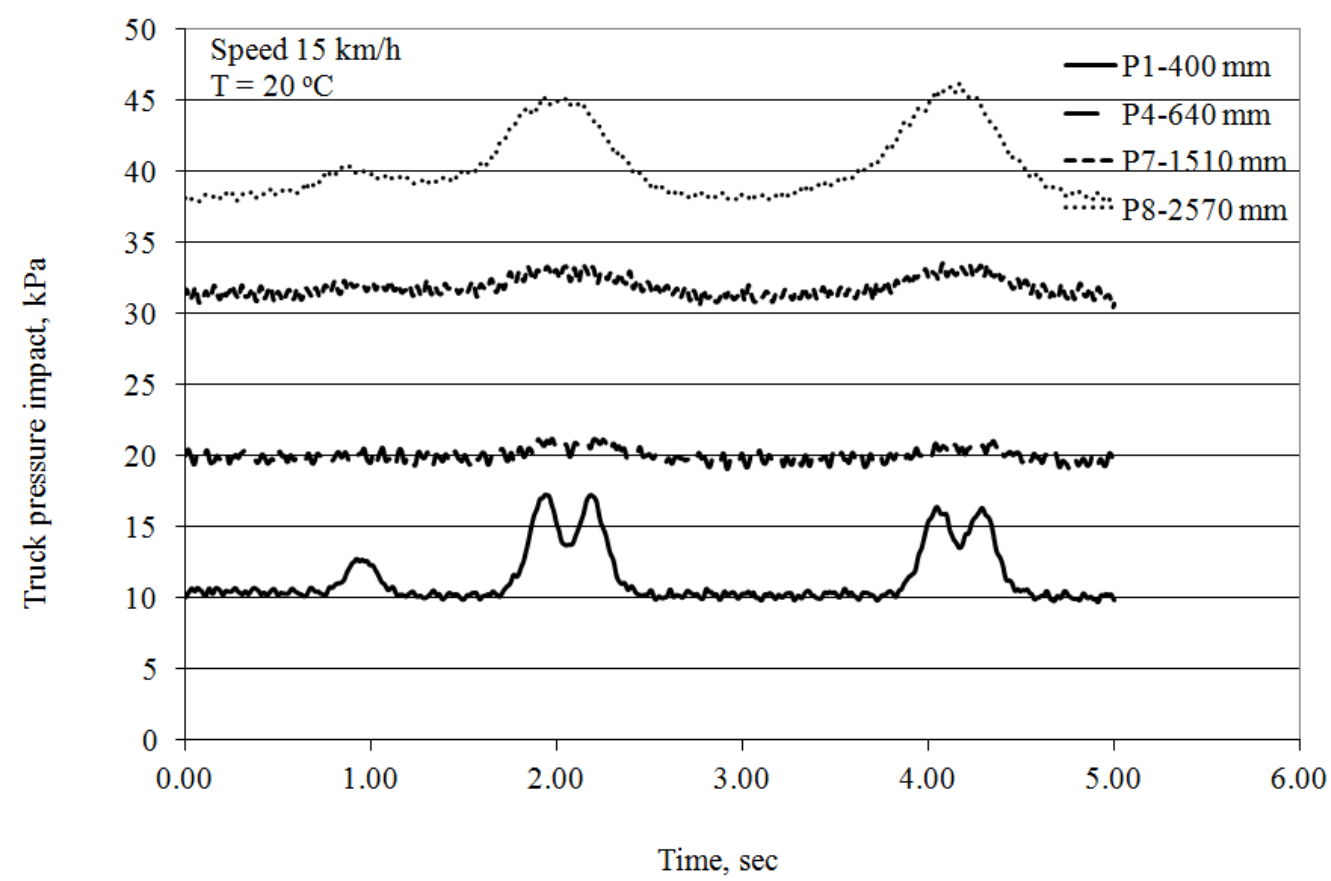

Figure 4.46: Vertical pressure records for truck impact in September, year 2- Site 1 


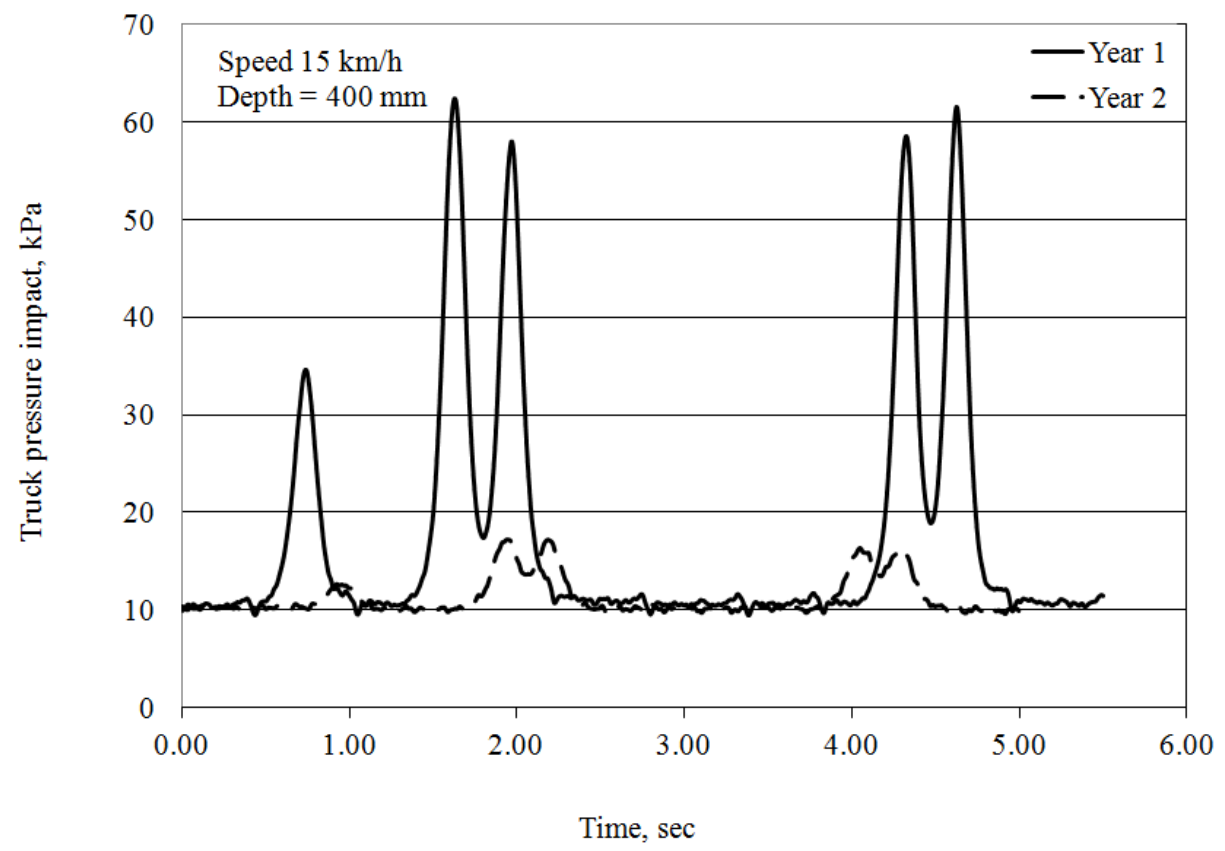

Figure 4.47: Comparison of the vertical pressure records for truck impact in years 1 and 2- Site 1

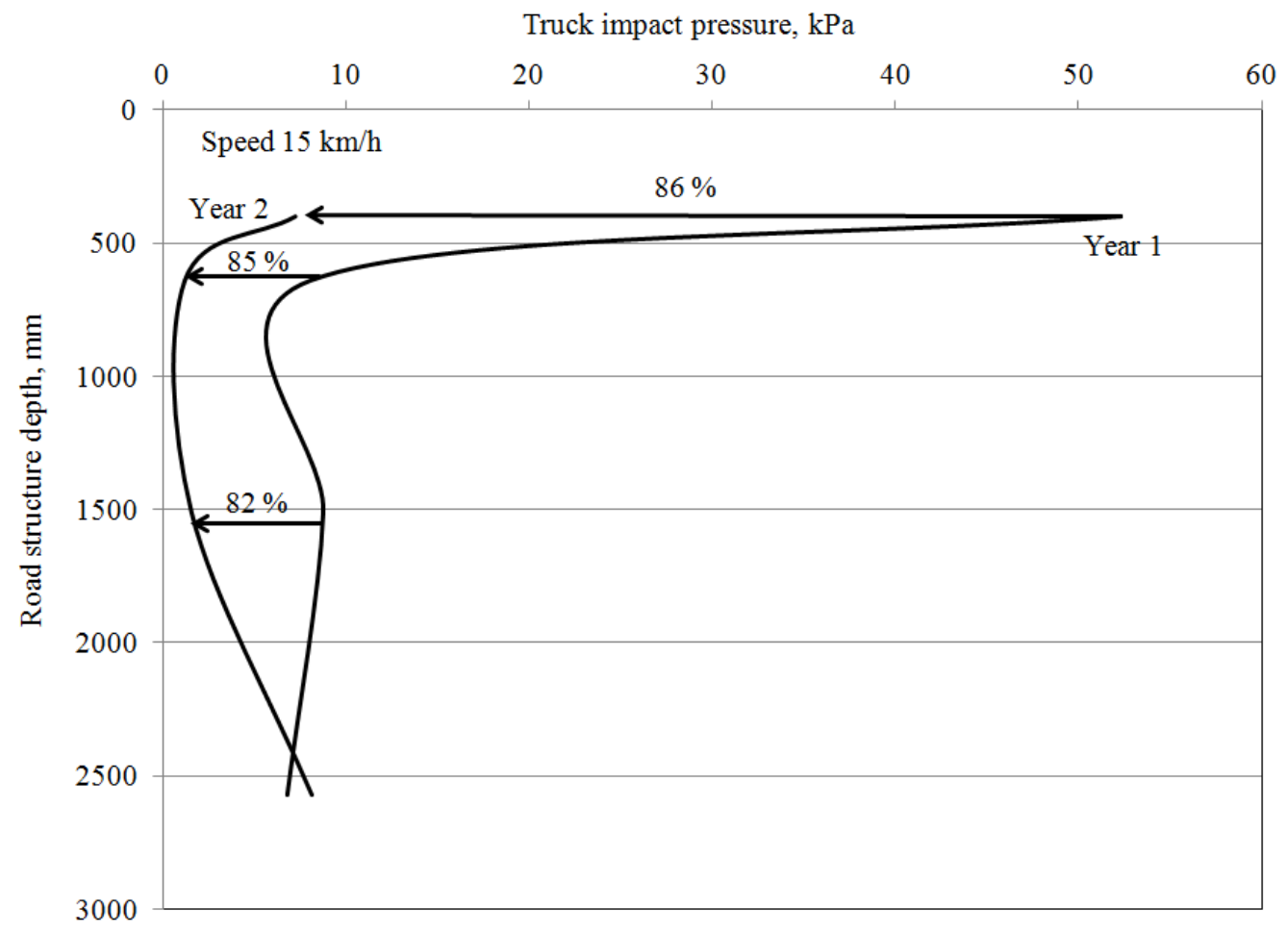

Figure 4.48: Decay of vertical pressure due to truck impact- Site 1 


\subsubsection{Site 2}

Overburden pressure was monitored at different depth levels $(290,390,690$ and $1160 \mathrm{~mm}$ ) as shown previously in Figure 3.15. Overburden pressure records were established from data collected at the site on a daily basis using a programmed static data acquisition system as shown in Figures 4.49 and 4.52. Profiles revealed that two different rates of profiles, where the highest rate occurred when the depth was less than $400 \mathrm{~mm}$ and the lowest rate occurred when the depth was higher than $400 \mathrm{~mm}$ as illustrated in Figure 4.53 .

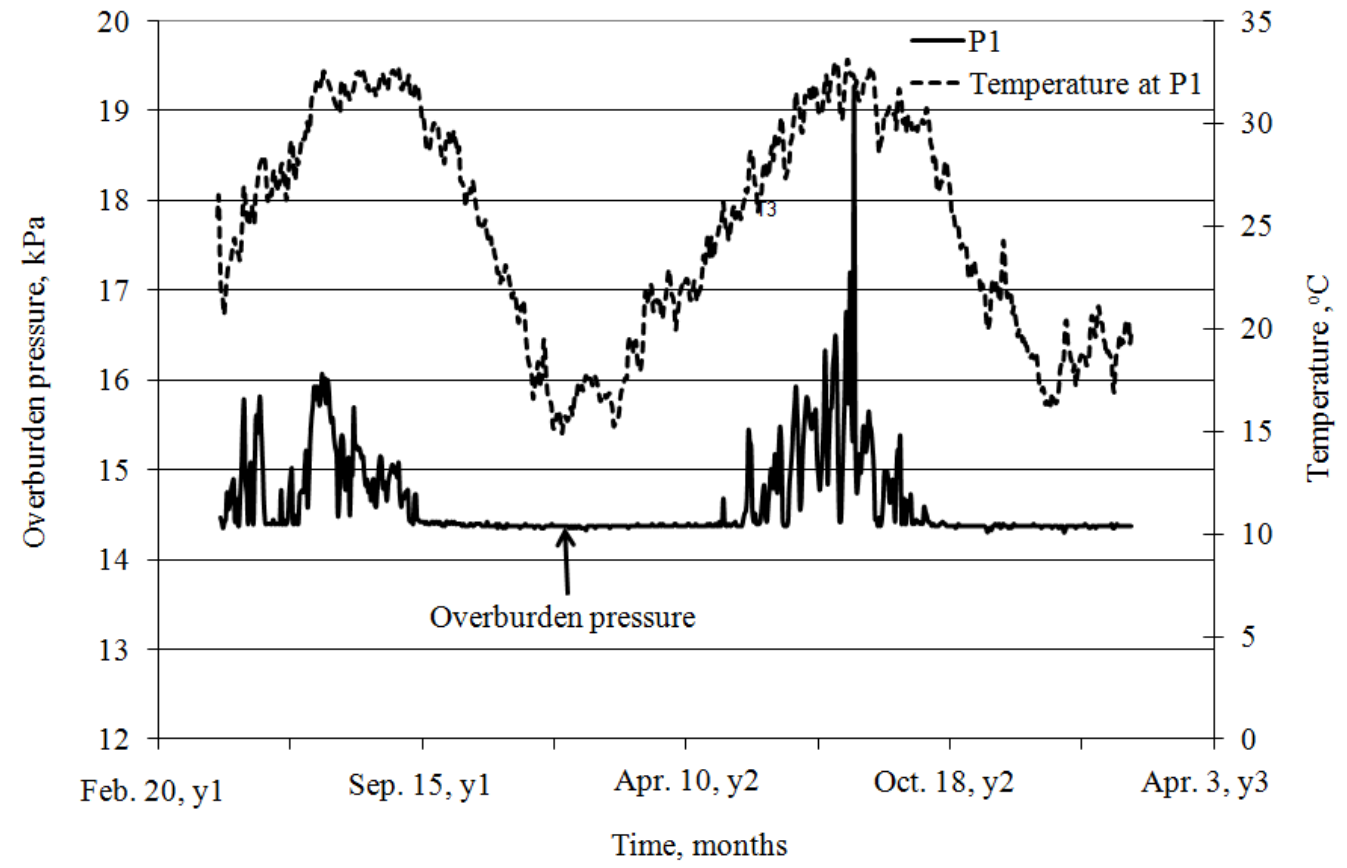

Figure 4.49: Overburden pressure at $290 \mathrm{~mm}$ below the surface- Site 2 


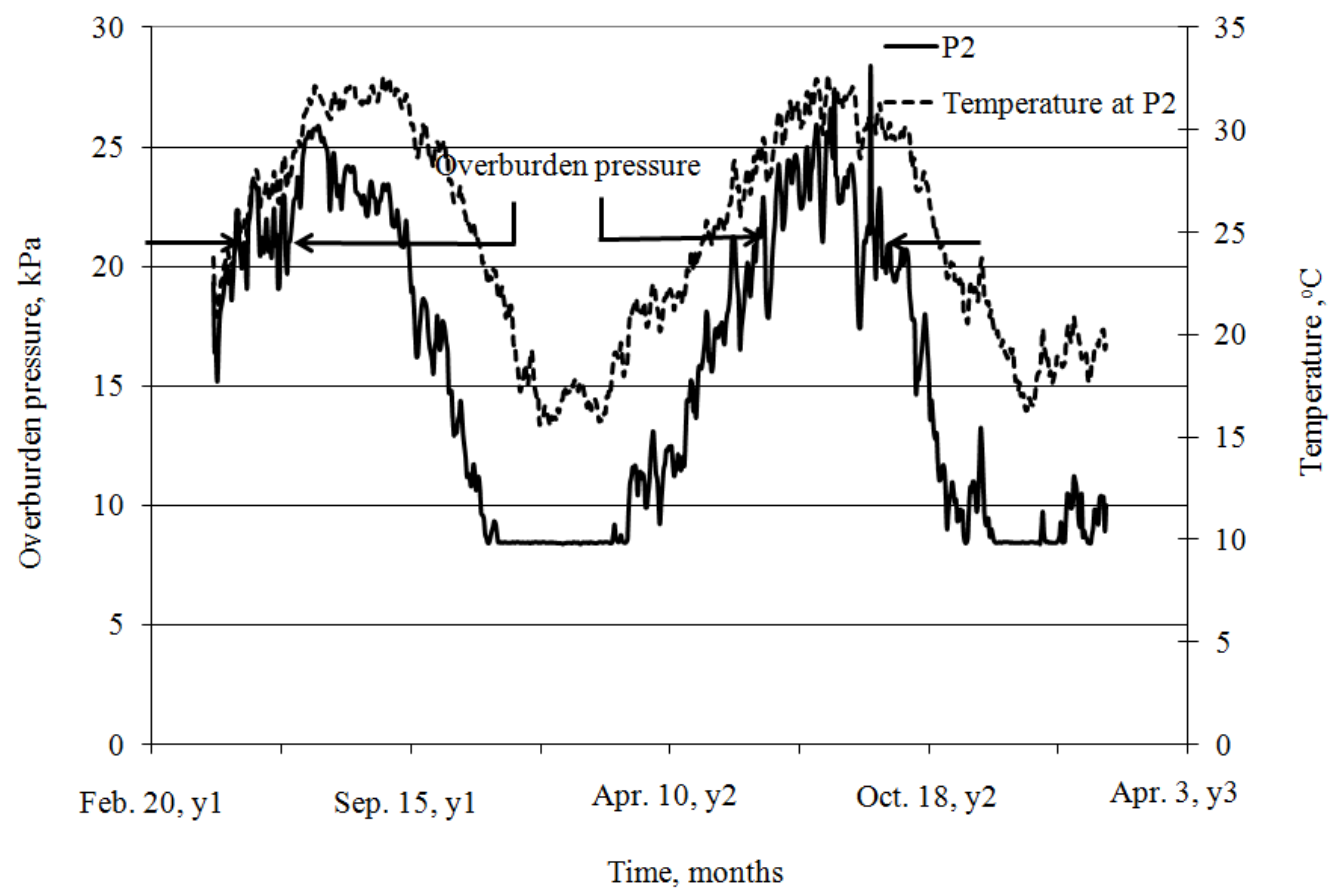

Figure 4.50: Overburden pressure at $390 \mathrm{~mm}$ below the surface- Site 2

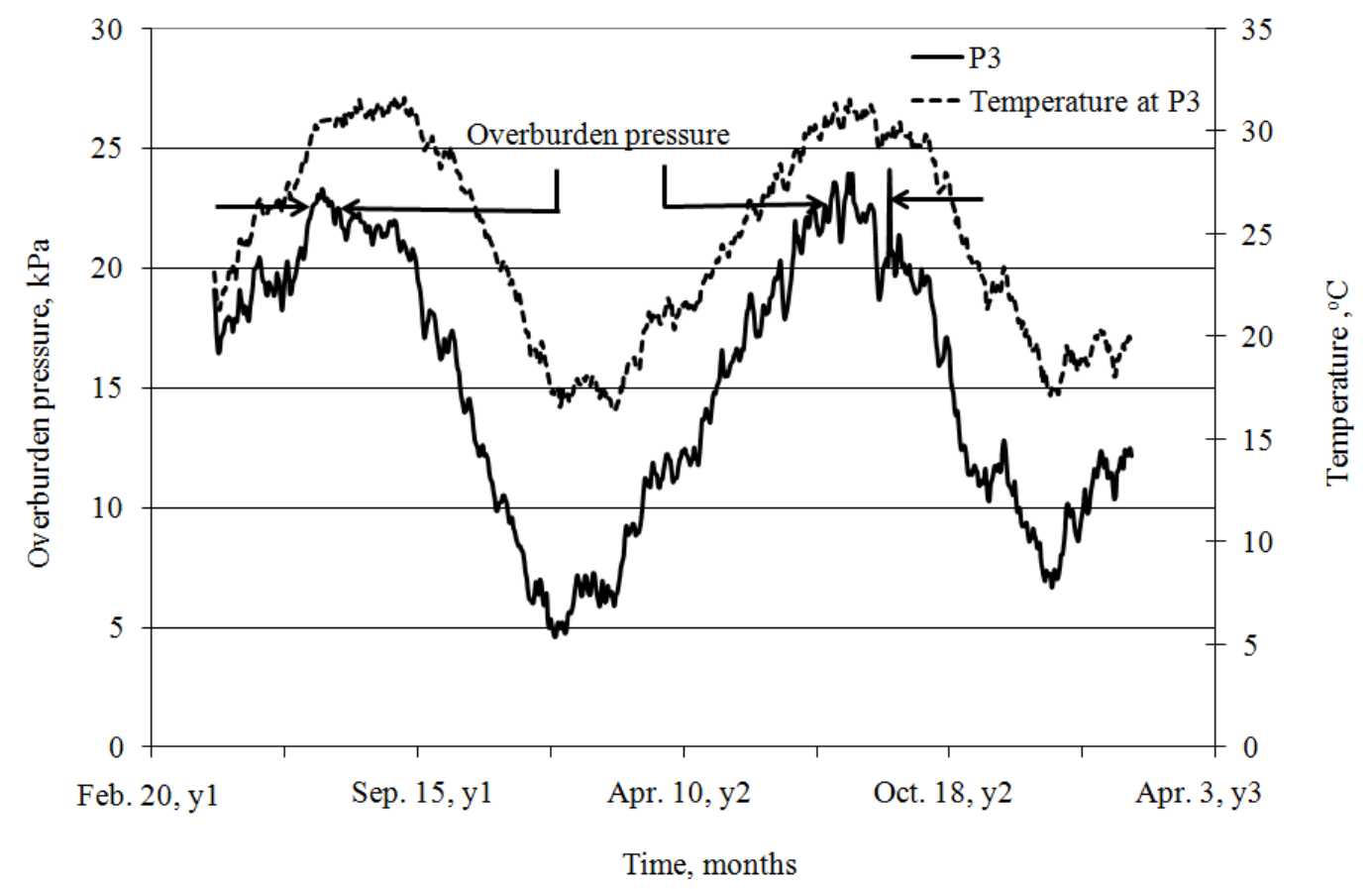

Figure 4.51: Overburden pressure at $690 \mathrm{~mm}$ below the surface- Site 2 


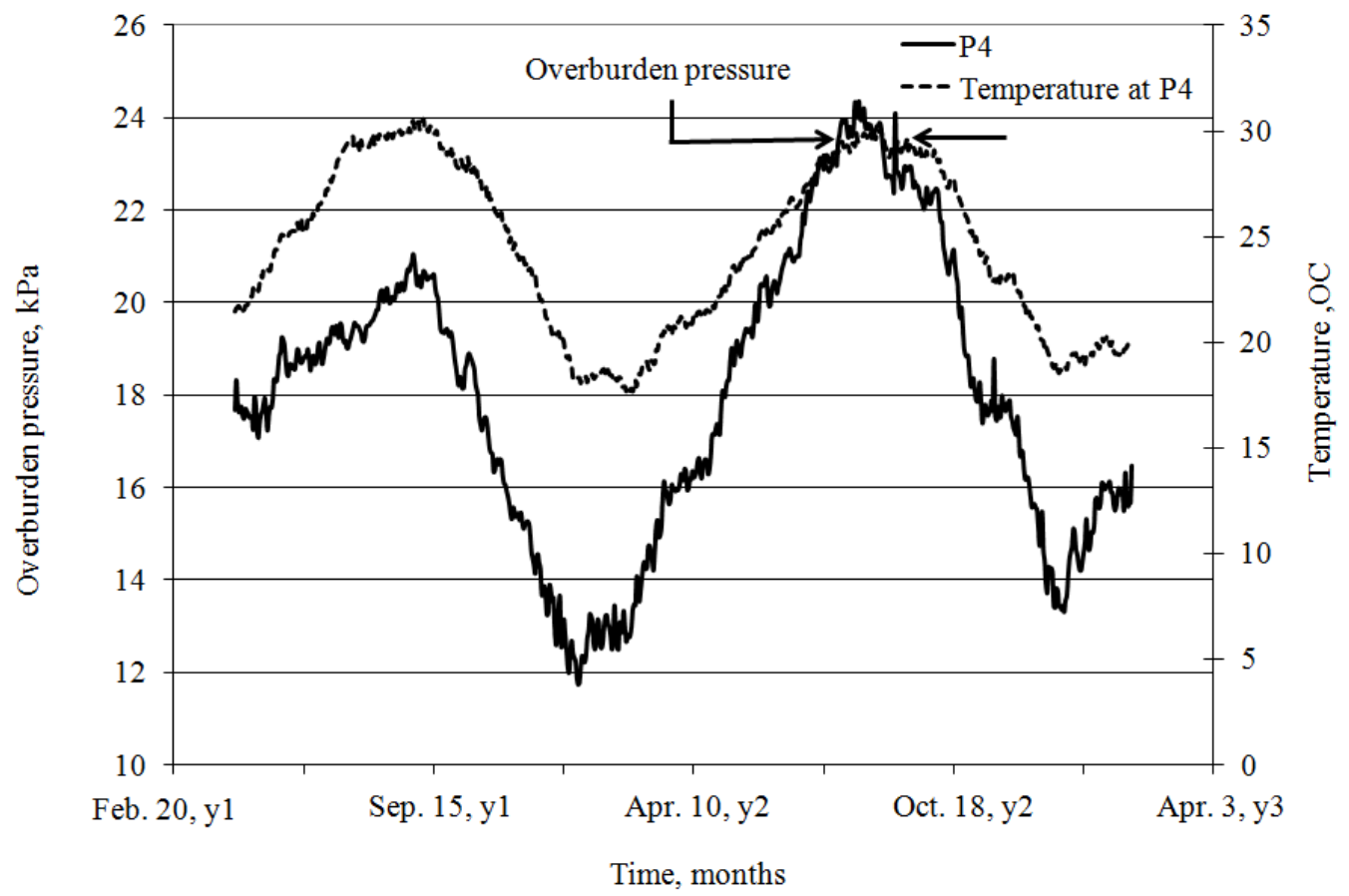

Figure 4.52: Overburden pressure at $1160 \mathrm{~mm}$ below the surface- Site 2

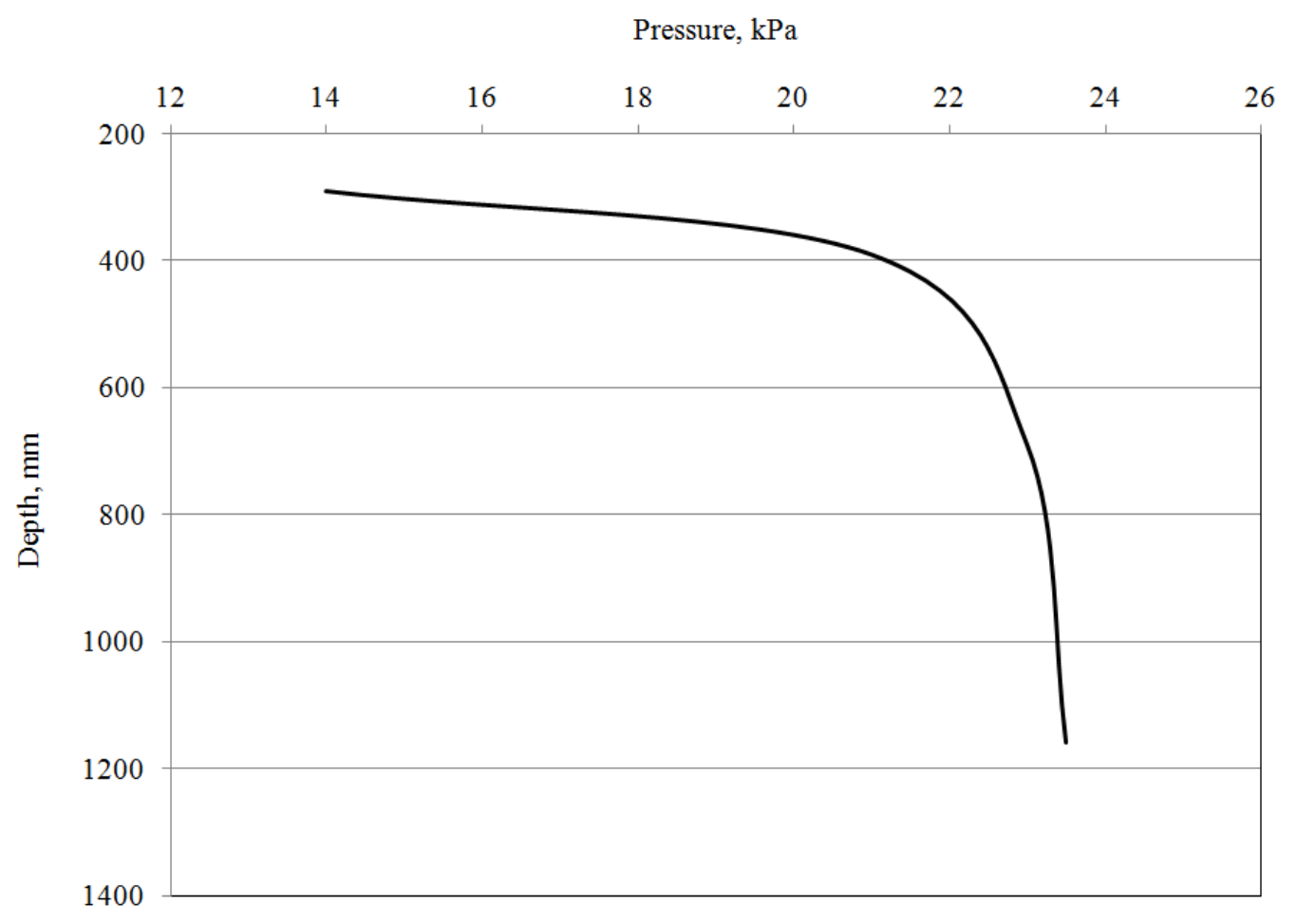

Figure 4.53: Overburden pressure profile- Site 2 
Dynamically, a two axle test truck, 57.83 and $83.18 \mathrm{kN}$ from front to back respectively, was operated immediately after construction (the asphalt mat temperature was $\left.51^{\circ} \mathrm{C}\right)$ over pressure cells located at four different depth levels $(290,390,690$ and $1160 \mathrm{~mm}$ ) as shown previously in Figure 3.15. Recorded vertical pressure impacts were collected using the dynamic data acquisition system revealing an extraordinarily high level of pressure as shown in Figures 4.54 and 4.55 compared with the values reported in the literature (Robin, M. A.; Wei, Z., 1997 and Gancalves et al, 2003). Registered maximum pressures of 290 and $240 \mathrm{kPa}$ were determined for 20 and $35 \mathrm{~km} / \mathrm{h}$ truck speed, respectively. When these pressure levels were recorded, data analysis revealed that the asphalt concrete temperature was higher than normal road operating temperatures.

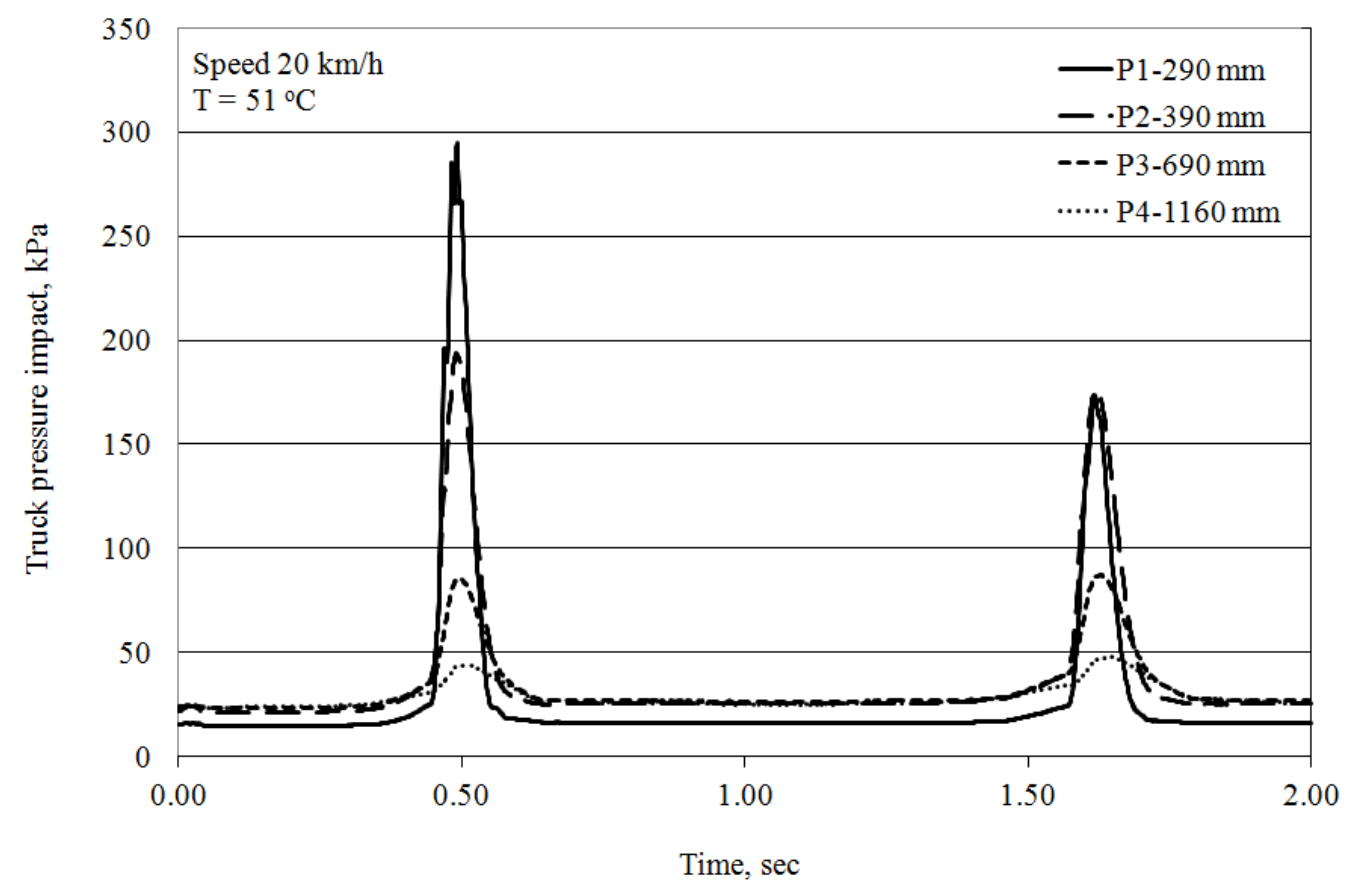

Figure 4.54: Vertical pressure truck impact on year 1- Site 2 


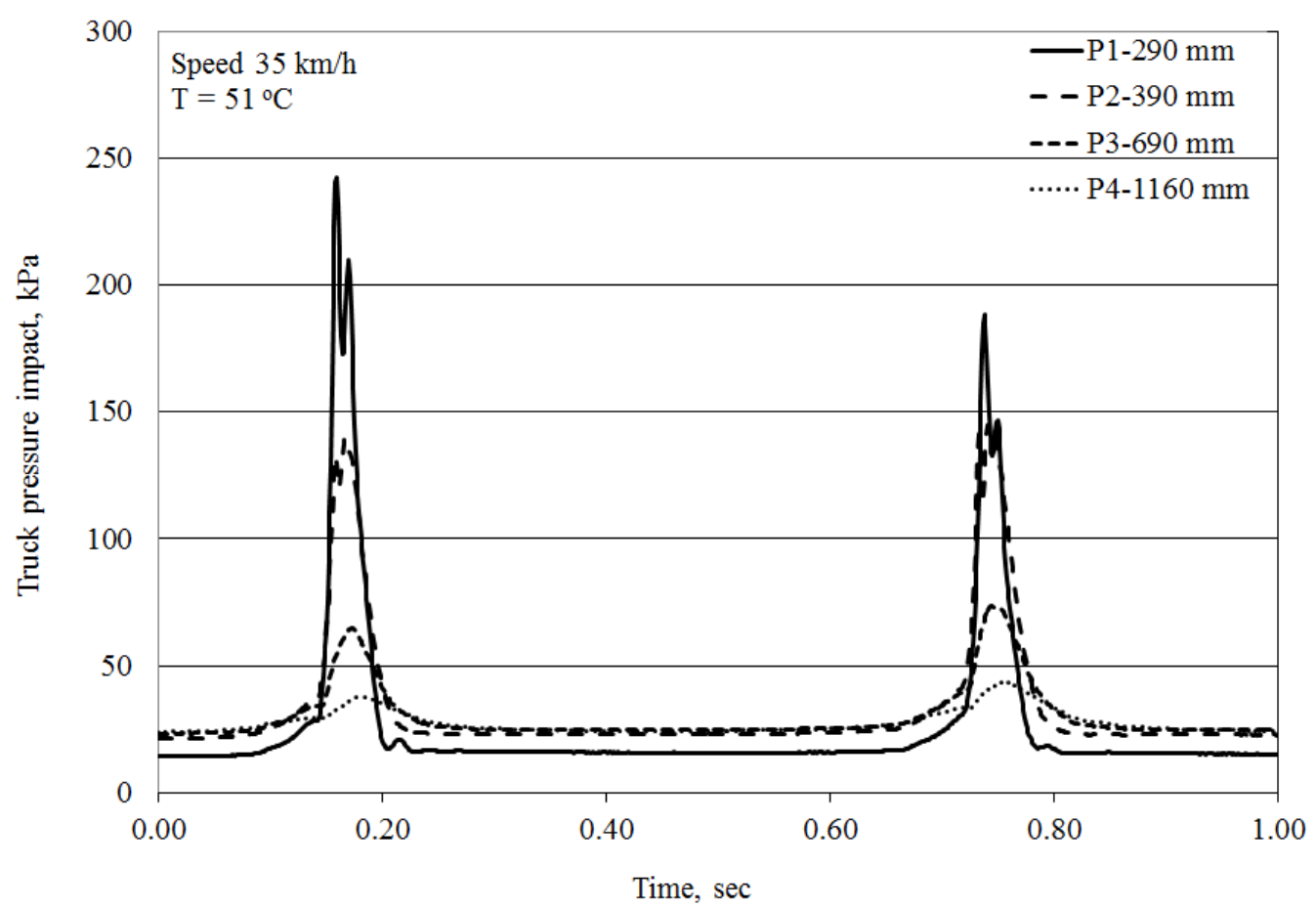

Figure 4.55: Vertical pressure truck impact on year 1- Site 2

Truck impact at a speed of $0 \mathrm{~km} / \mathrm{h}$ (creep) was made immediately after construction (the asphalt mat temperature was $44^{\circ} \mathrm{C}$ ) and after 1 year (asphalt mat temperature was $\left.20^{\circ} \mathrm{C}\right)$ over pressure cells located at four different depth levels (290, 390, 690 and $1160 \mathrm{~mm}$ ) as shown previously in Figure 3.15. Recorded vertical pressure impacts were shown in Figures 4.56 and 4.57 respectively. Figures 4.58 to 4.60 show the same truck impact after one year over same pressure cells at 3, 20 and $25 \mathrm{~km} / \mathrm{h}$. The maximum percentage of truck pressure impact decreased by $62 \%$ as truck speed increased from 0 to $25 \mathrm{~km} / \mathrm{h}$ at same asphalt mat temperature. The results revealed that the one-year pressure signal dropped tremendously. 


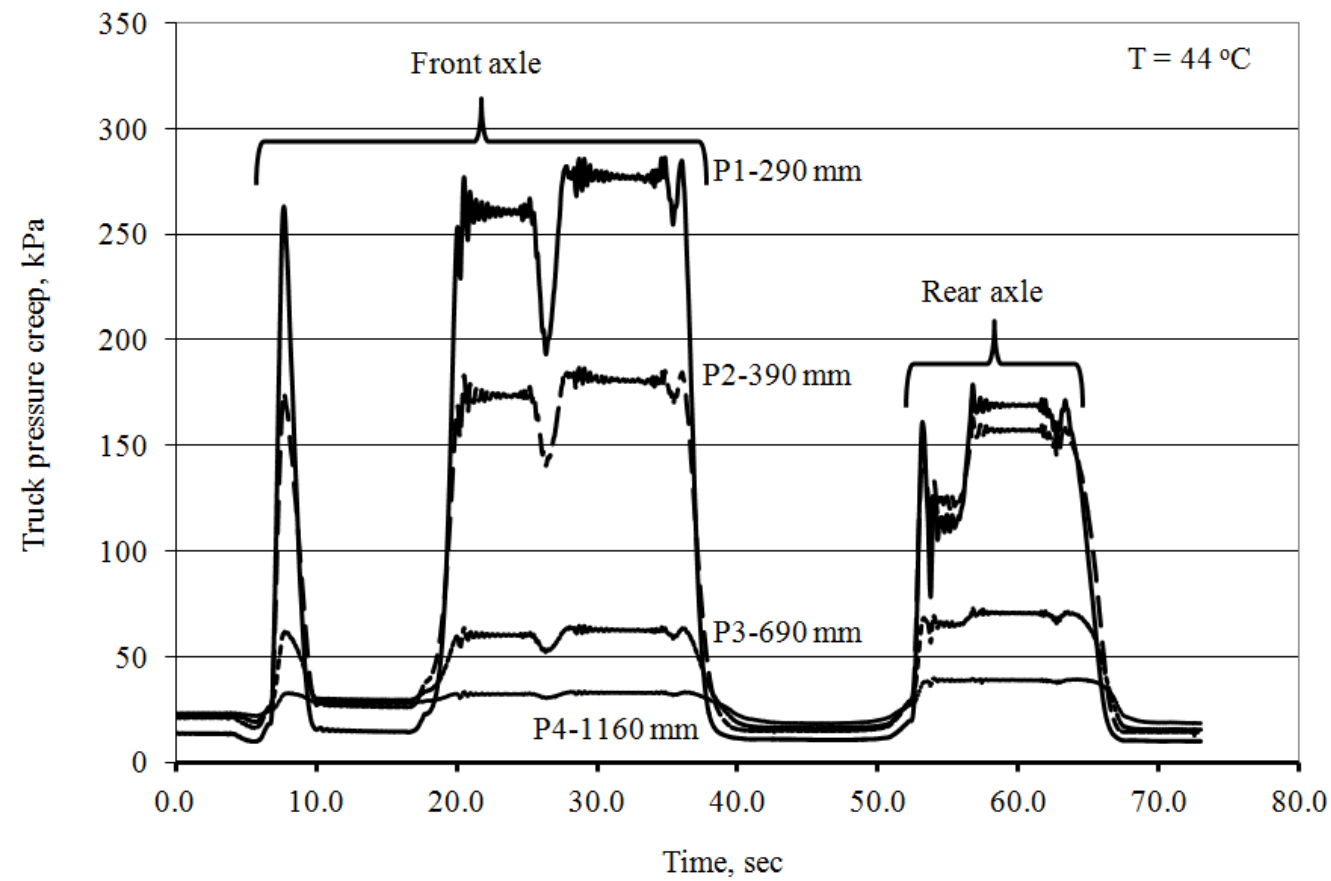

Figure 4.56: Truck pressure creep in year 1- Site 2

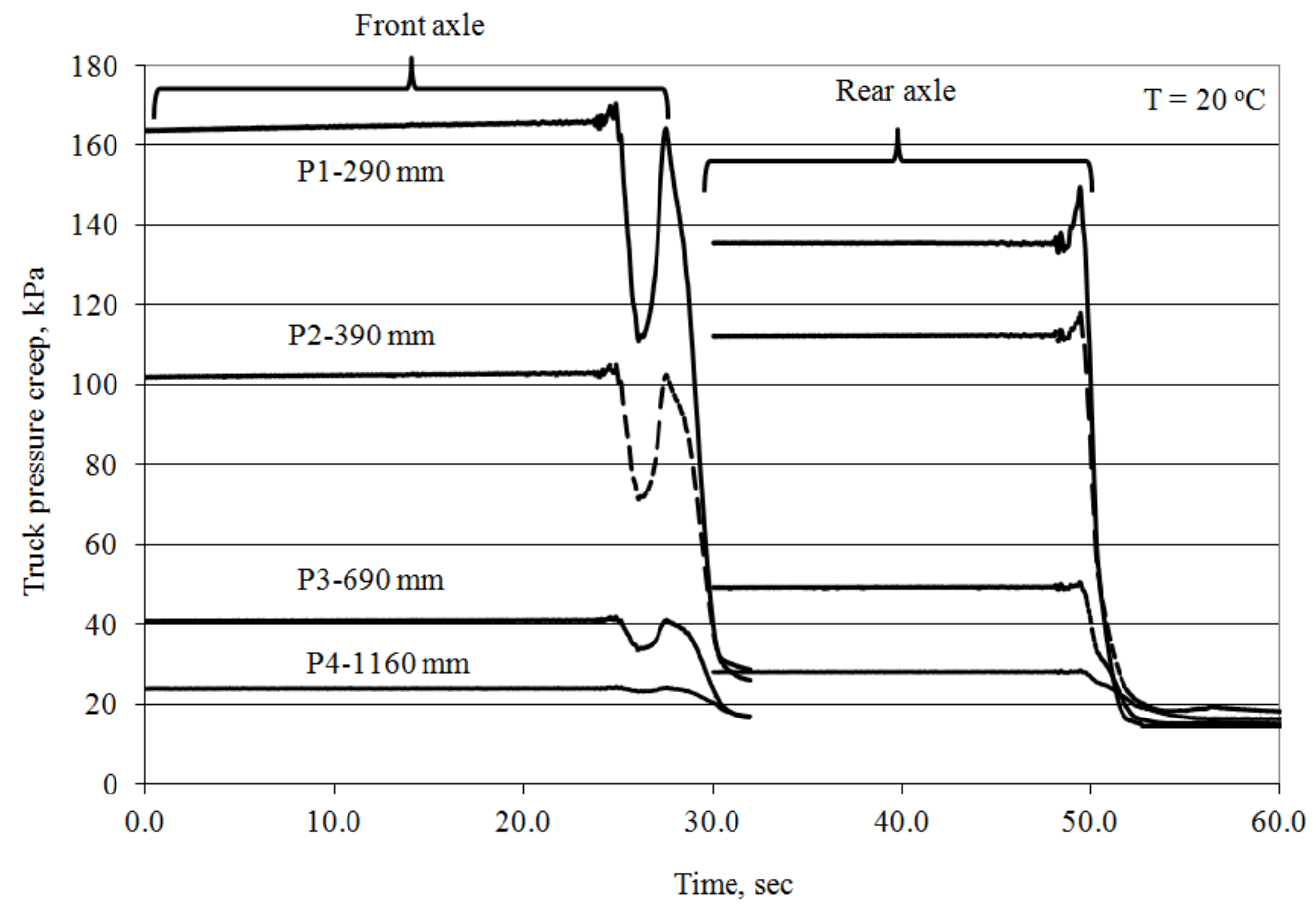

Figure 4.57: Truck pressure creep in year 3- Site 2 


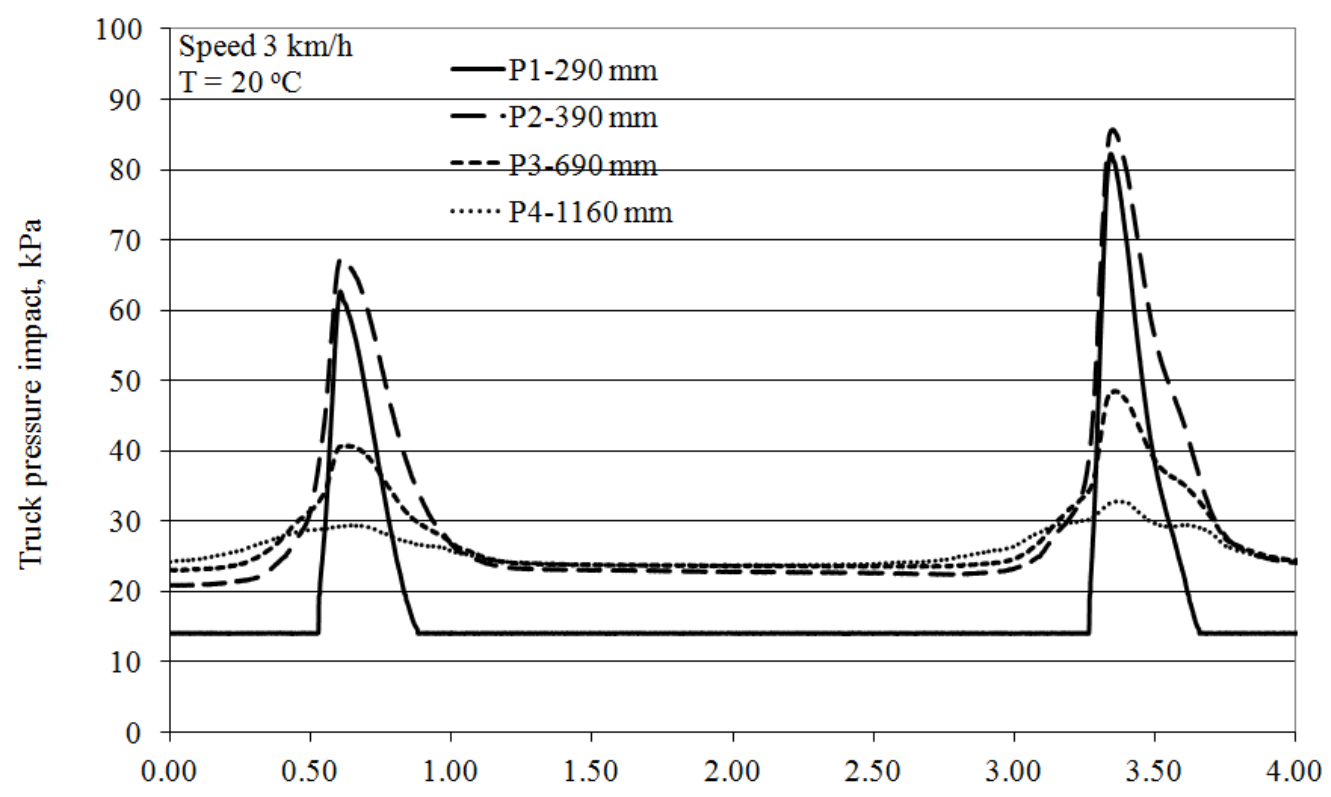

Time, sec

Figure 4.58: Vertical pressure truck impact at speed of $3 \mathrm{~km} / \mathrm{h}$ in year 3 - Site 2

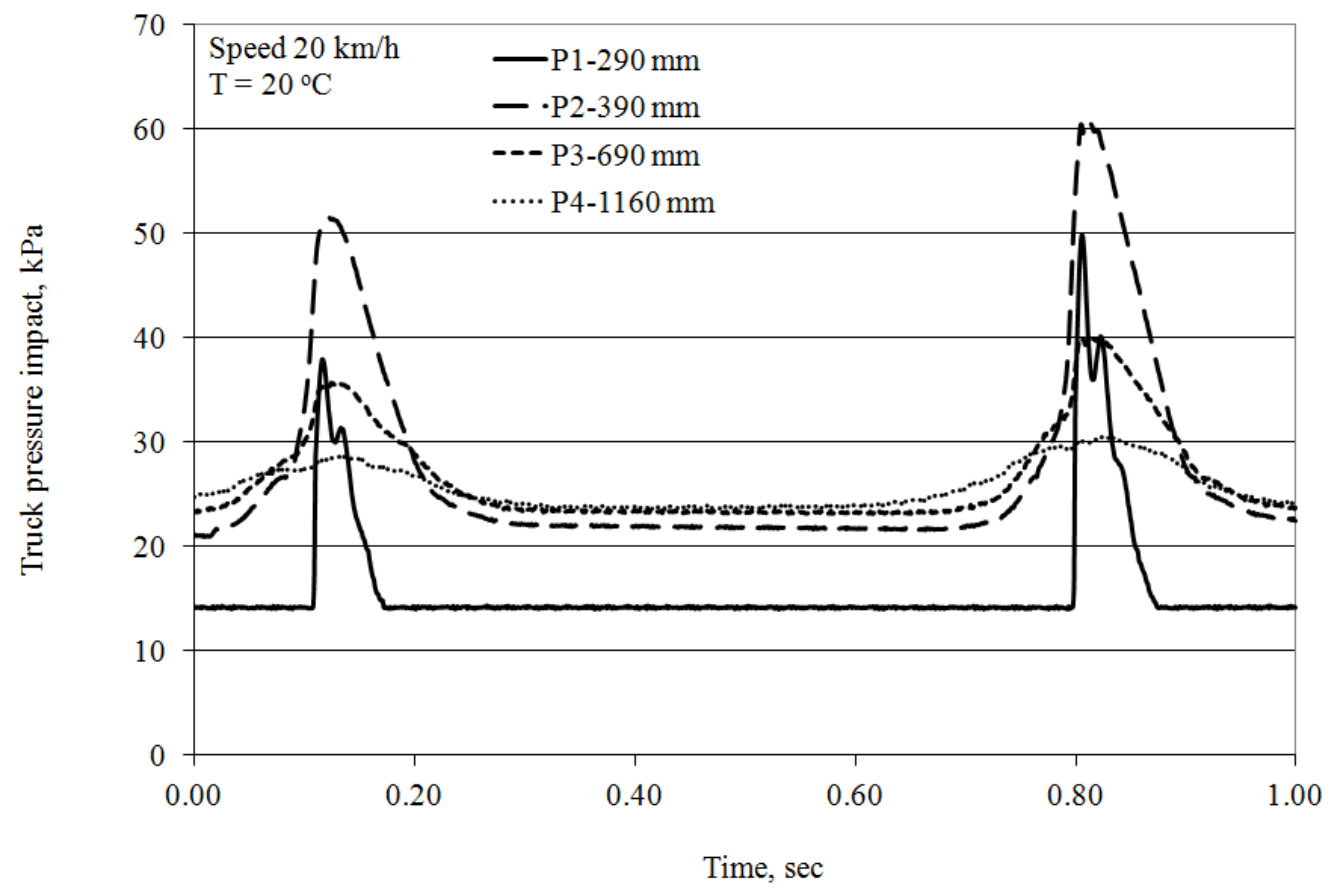

Figure 4.59: Vertical pressure truck impact at speed of $20 \mathrm{~km} / \mathrm{h}$ in year 3- Site 2 


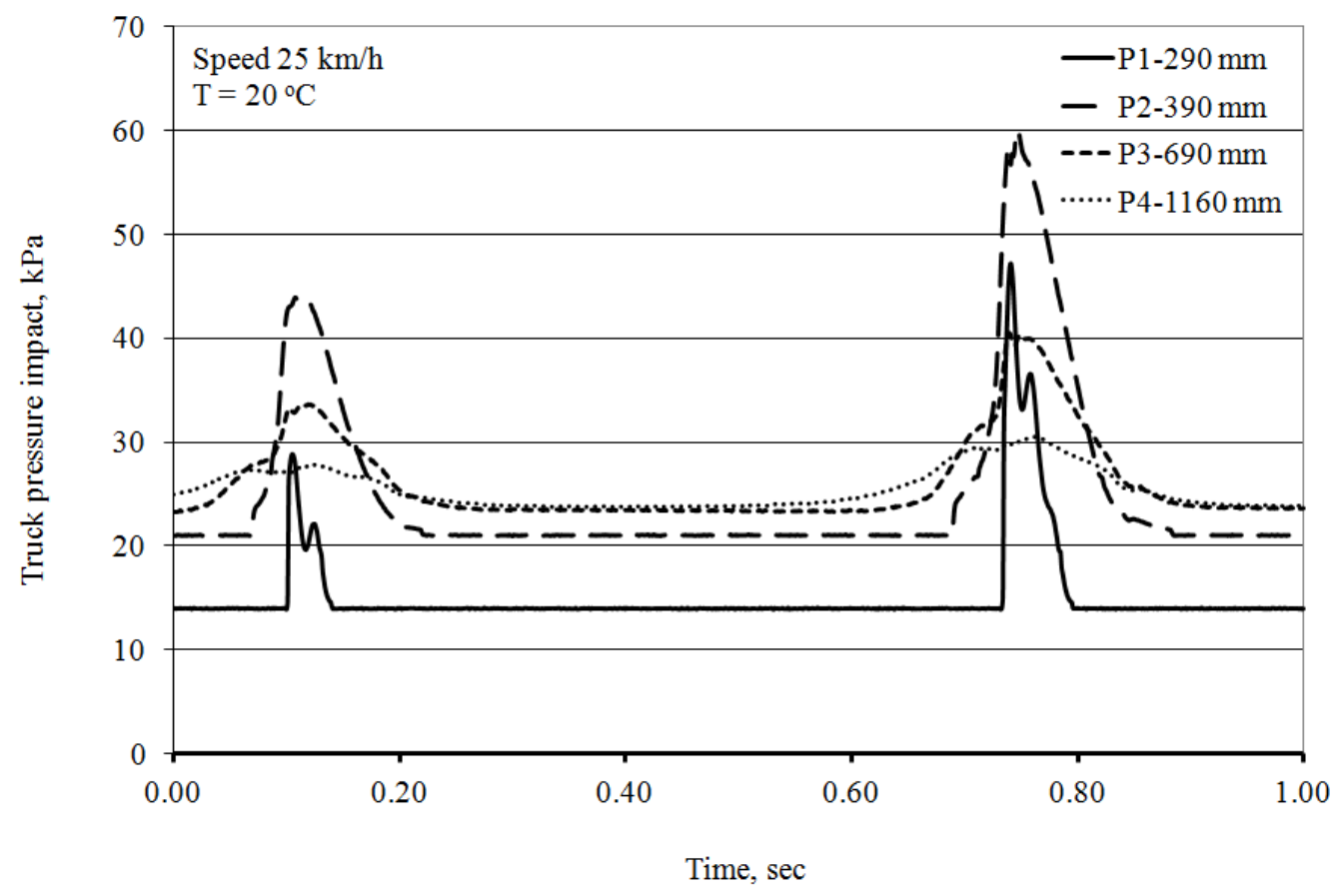

Figure 4.60: Vertical pressure truck impact at speed $25 \mathrm{~km} / \mathrm{h}$ in year 3- Site 2

\subsubsection{Site 3}

The overburden pressure was monitored at different depth levels $(260,465,770$ and $940 \mathrm{~mm}$ ) as shown previously in Figure 3.16. Overburden pressure records were established from data collected at the site on a daily basis using a programmed static data acquisition system as shown in Figures 4.61 to 4.64. Road structure depth pressures revealed an unexpected pressure profile as shown on Figure 4.65. This profile will be compared later on with overburden road structure pressure profile collected using the dynamic data acquisition system. 


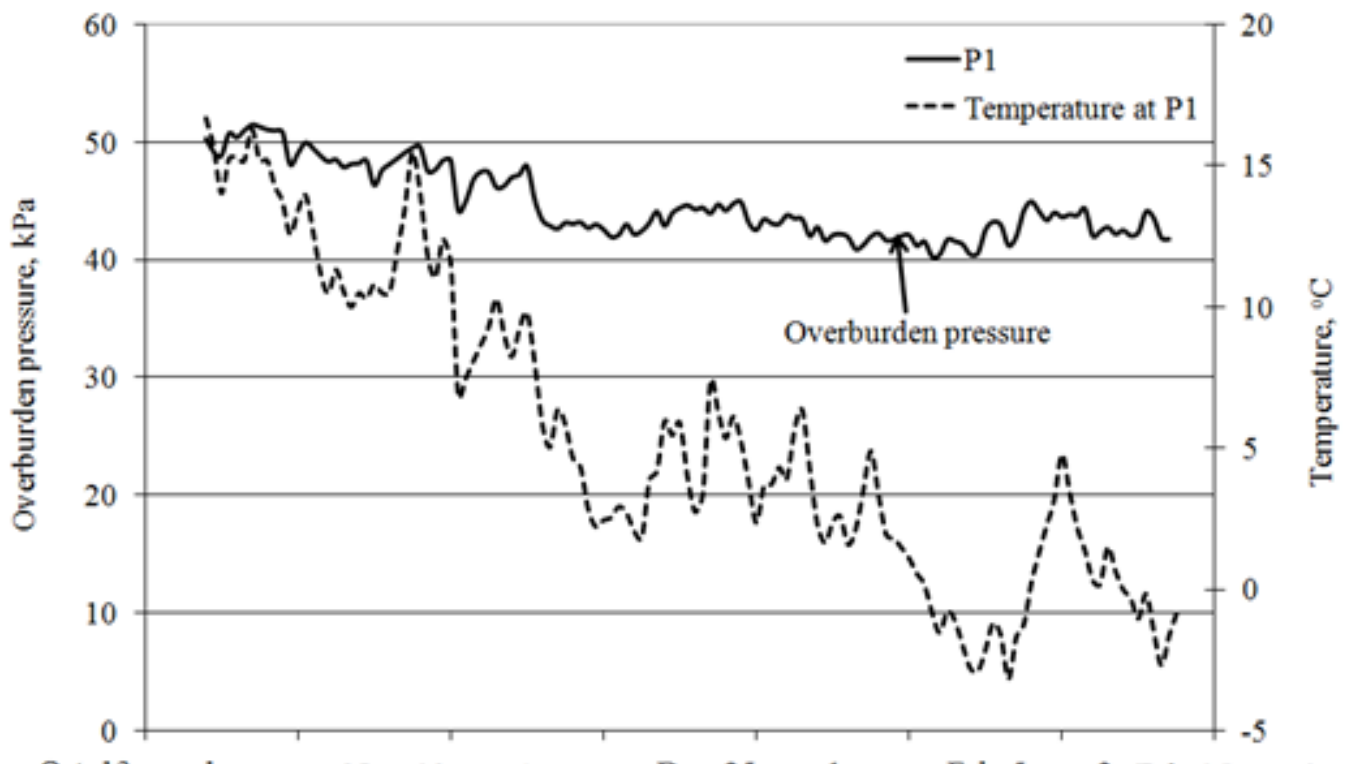

Oct. 13, year1 Nov. 23, year1 Dec. 25, year1 Feb. 5, year2 Feb. 25, year2

Time, months

Figure 4.61: Overburden pressure at $260 \mathrm{~mm}$ below the surface- Site 3

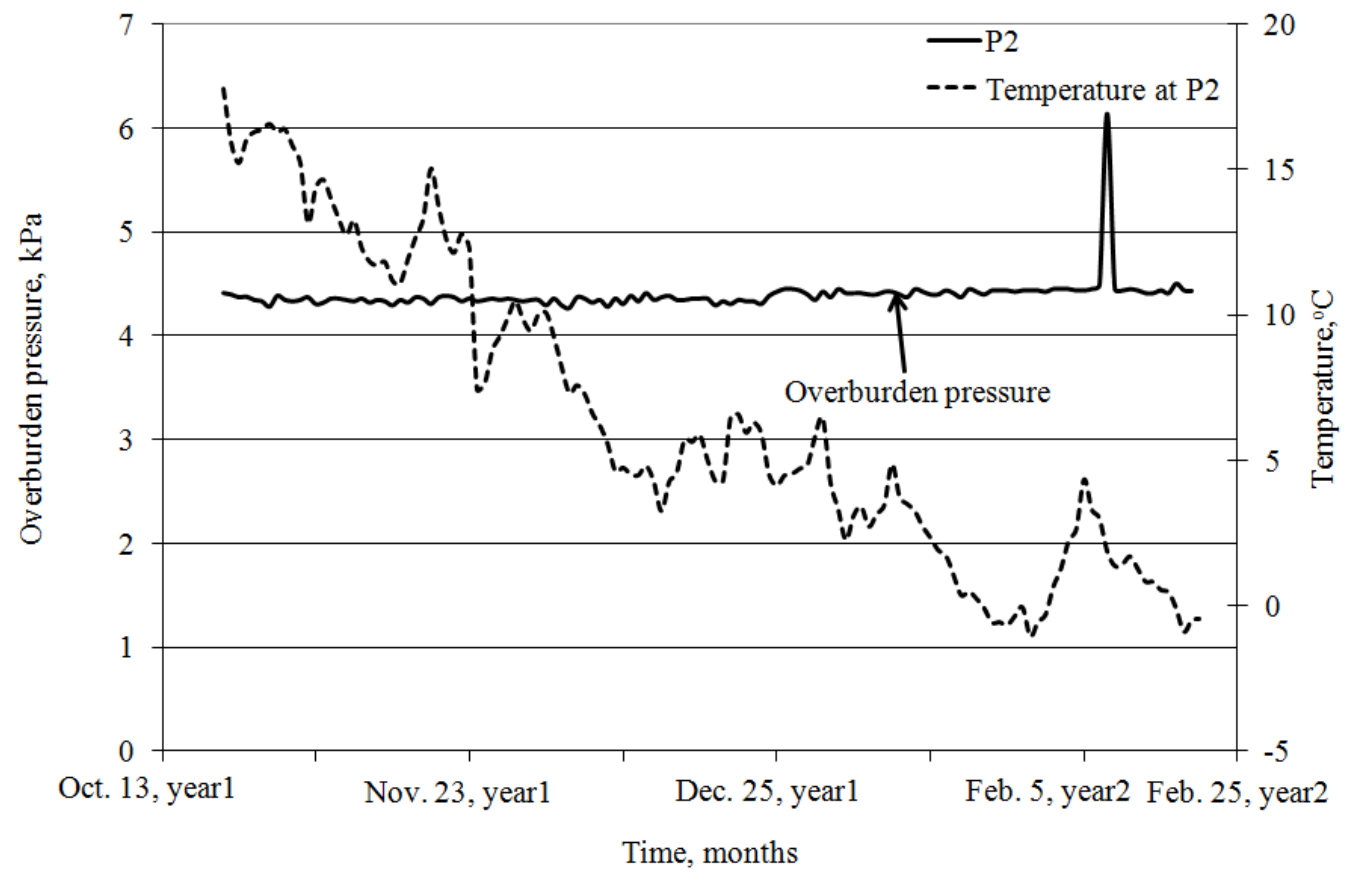

Figure 4.62: Overburden pressure at $465 \mathrm{~mm}$ below the surface- Site 3 


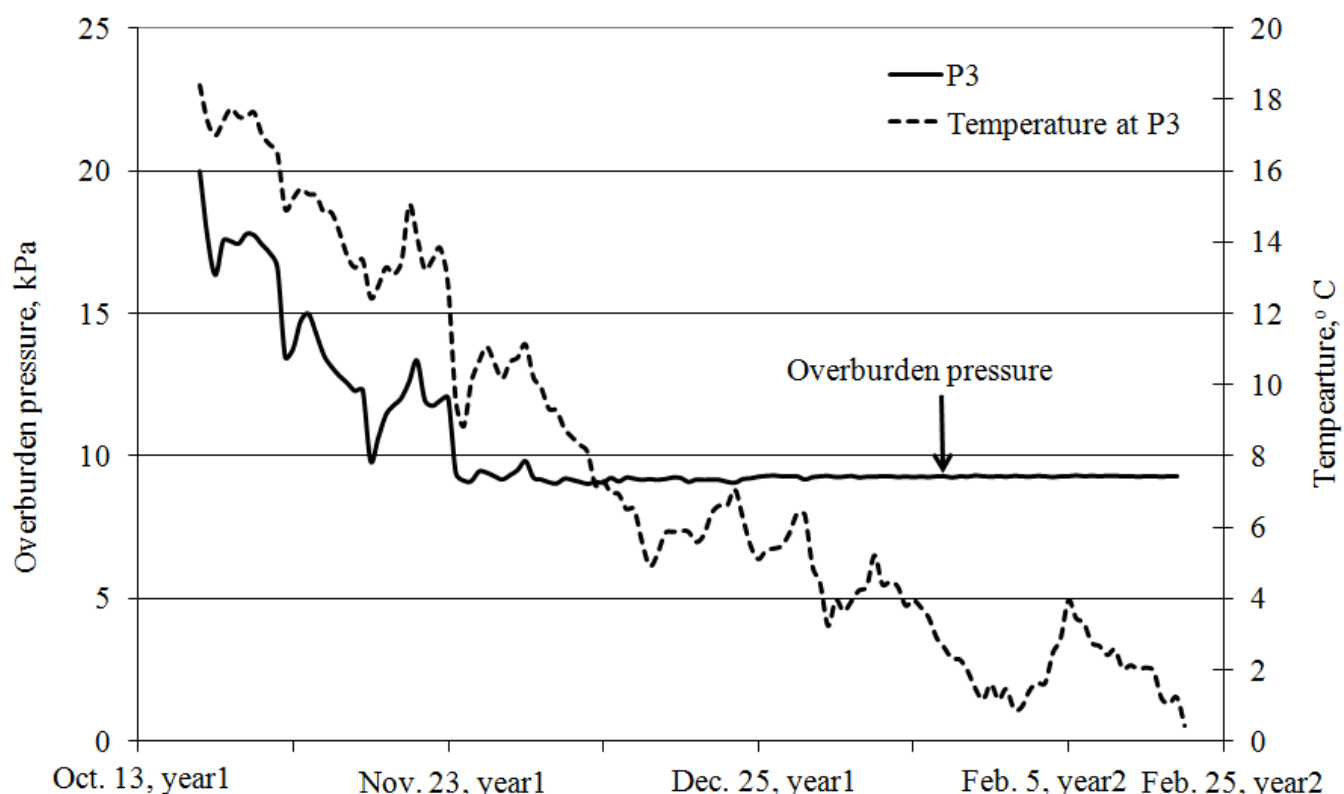

Time, months

Figure 4.63: Overburden pressure at $770 \mathrm{~mm}$ below the surface- Site 3

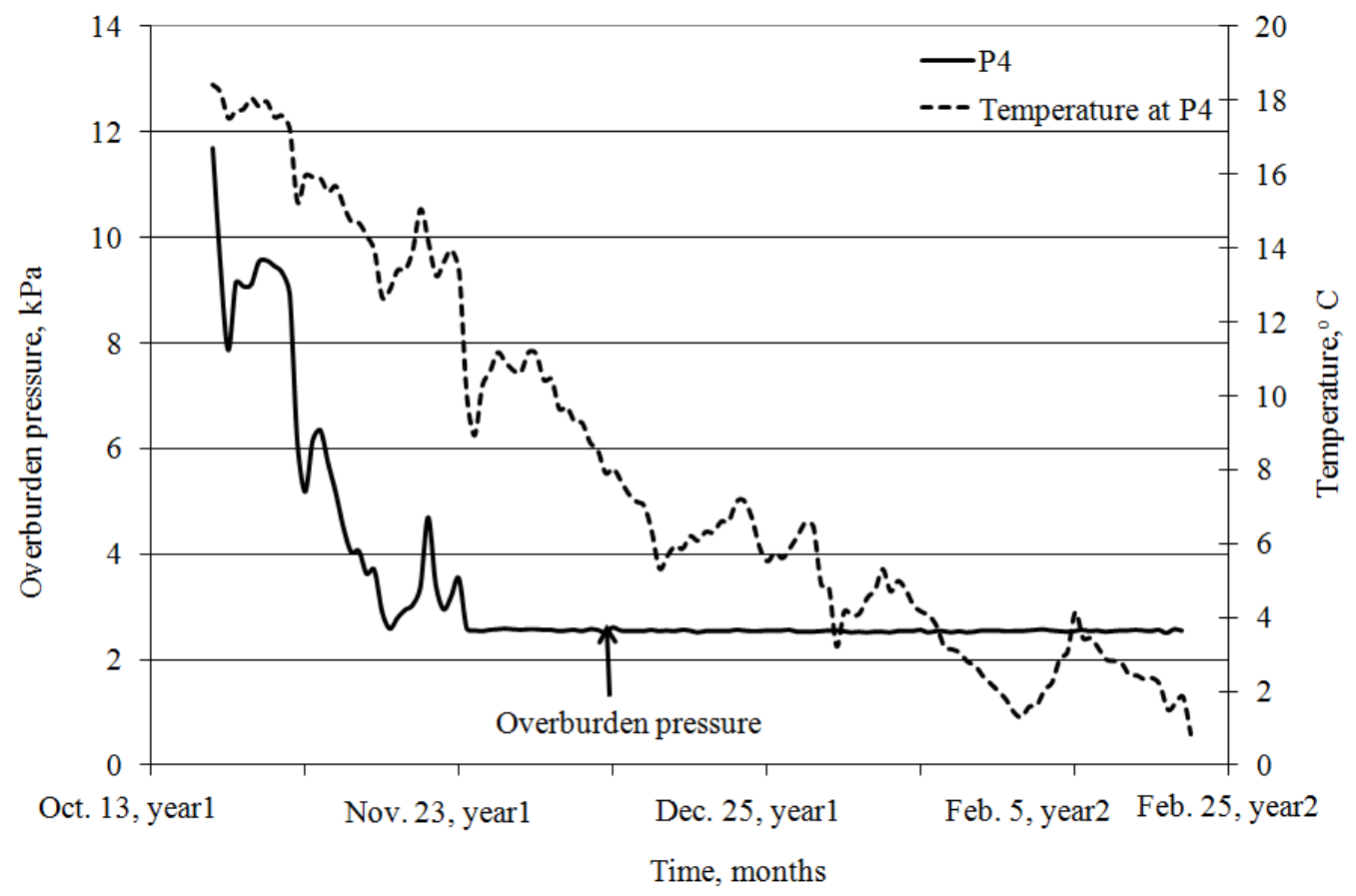

Figure 4.64: Overburden pressure at $940 \mathrm{~mm}$ below the surface- Site 3 


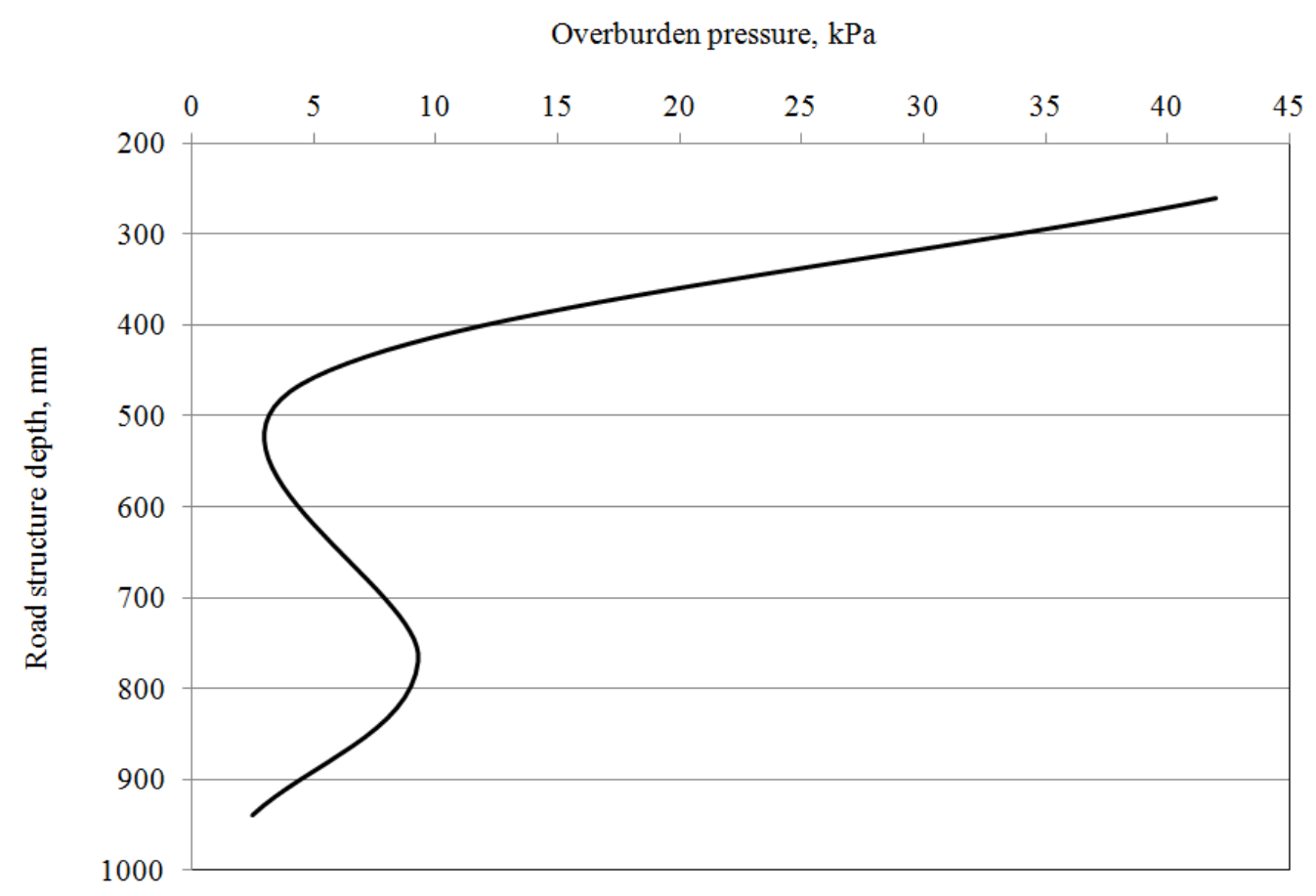

Figure 4.65: Overburden pressure profile- Site 3

A road structure overburden pressure profile was collected using the dynamic data acquisition system right after construction (open to traffic) when the asphalt concrete temperature was still high $\left(81^{\circ} \mathrm{C}\right)$ and after 1 year (year 2$)$. The profile was compared in Figure 4.66 with the static case illustrated previously in Figure 4.65. Overburden pressure dropped $50 \%$ when the temperature decreased from 81 to $20^{\circ} \mathrm{C}$ for the pressure cell located close to the asphalt concrete layer. It is noted in site 3 only that the overburden pressure profile is higher closer to the surface, and decreases away from the surface due to densification that occurs on top of the sensitive side of pressure cells. 


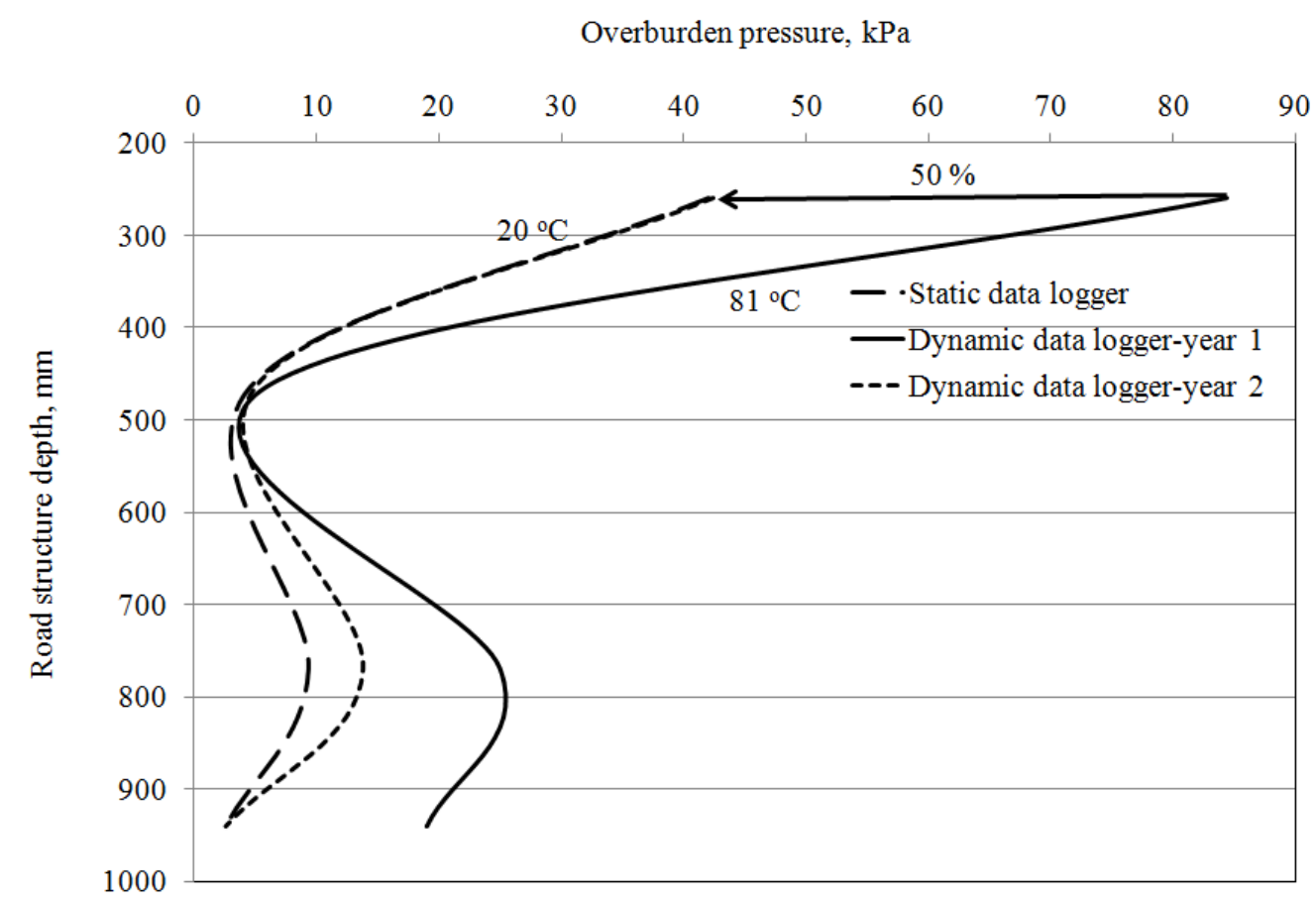

Figure 4.66: Comparison of overburden pressure profile measured using static and dynamic data loggers- Site 3

Dynamically, a three axle test truck, $43.24,86.65$ and $85.85 \mathrm{kN}$ from front to back respectively, was operated immediately after construction (asphalt mat temperature was $\left.81^{\circ} \mathrm{C}\right)$ on pressure cells located at four different depth levels $(260,465,770$ and $940 \mathrm{~mm})$ as shown previously in Figure 3.16. Recorded vertical pressure impacts were collected using dynamic data acquisition system revealing an extraordinarily high level (320 $\mathrm{kPa})$ of pressure as shown in Figure 4.67. Data analysis revealed that the asphalt concrete temperature when these pressure levels were recorded was higher than normal road operating temperatures.

Figure 4.68 shows the recorded pressure signals of the test impact of the same truck. The results revealed that after one year when the temperature of the asphalt concrete layer dropped to $20^{\circ} \mathrm{C}$, the pressure signal dropped to a maximum of $103 \mathrm{kPa}$, 
about $70 \%$ lower than the signal recorded during the road opening time when the asphalt concrete layer temperature was $81{ }^{\circ} \mathrm{C}$. Figure 4.69 shows the recorded signal of the truck pressure impact at a speed of $2 \mathrm{~km} / \mathrm{h}$. Further analysis of the impact of two different speeds revealed that when the speed decreased from 35 to $2 \mathrm{~km} / \mathrm{h}$, the maximum pressure impact increased by 37 to $10 \%$ from the top pressure cell (at depth $260 \mathrm{~mm}$ ) to the bottom level pressure cell (at a depth $940 \mathrm{~mm}$ ), respectively.

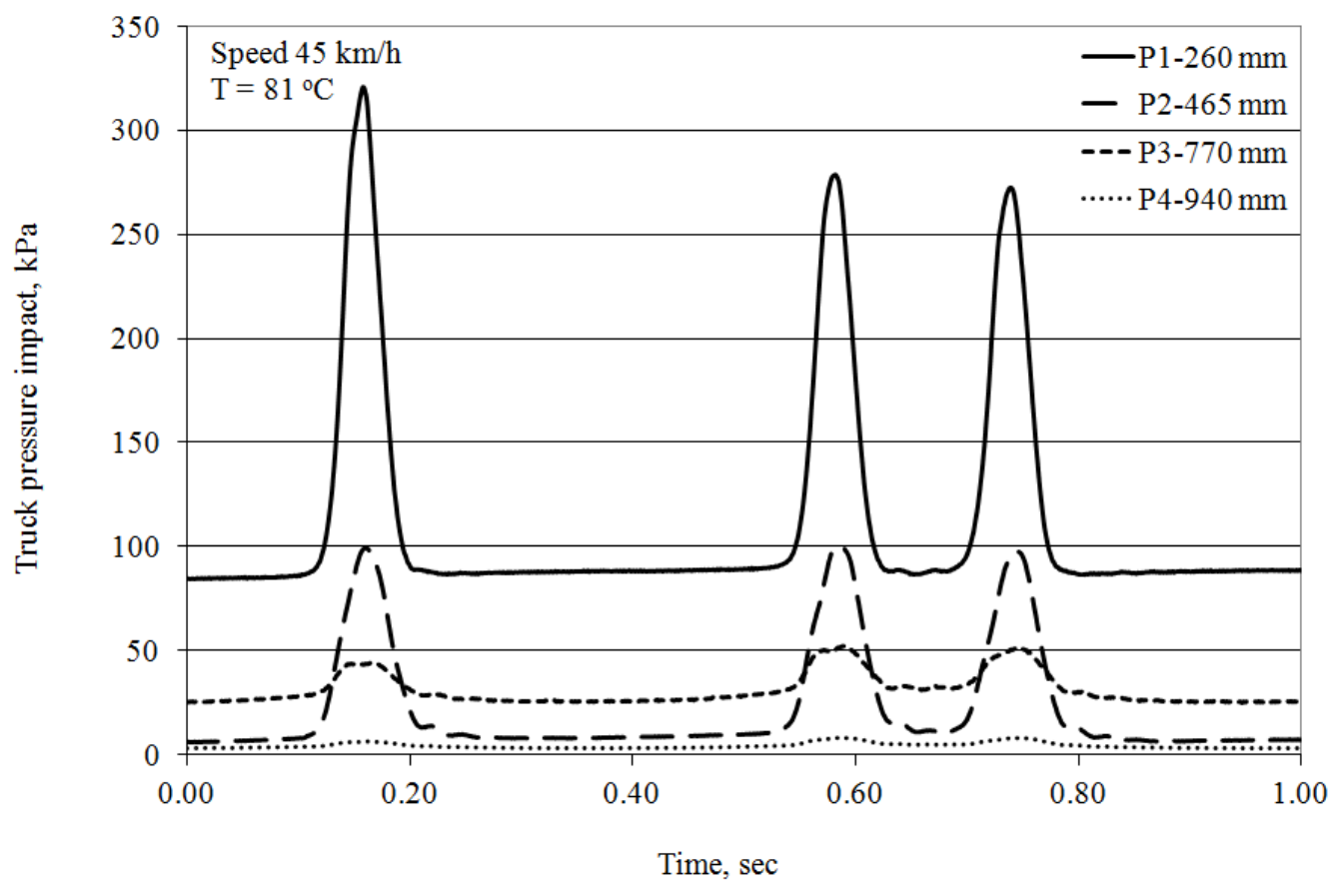

Figure 4.67: Vertical pressure truck impact at speed of $45 \mathrm{~km} / \mathrm{h}$ in year 1 - Site 3 


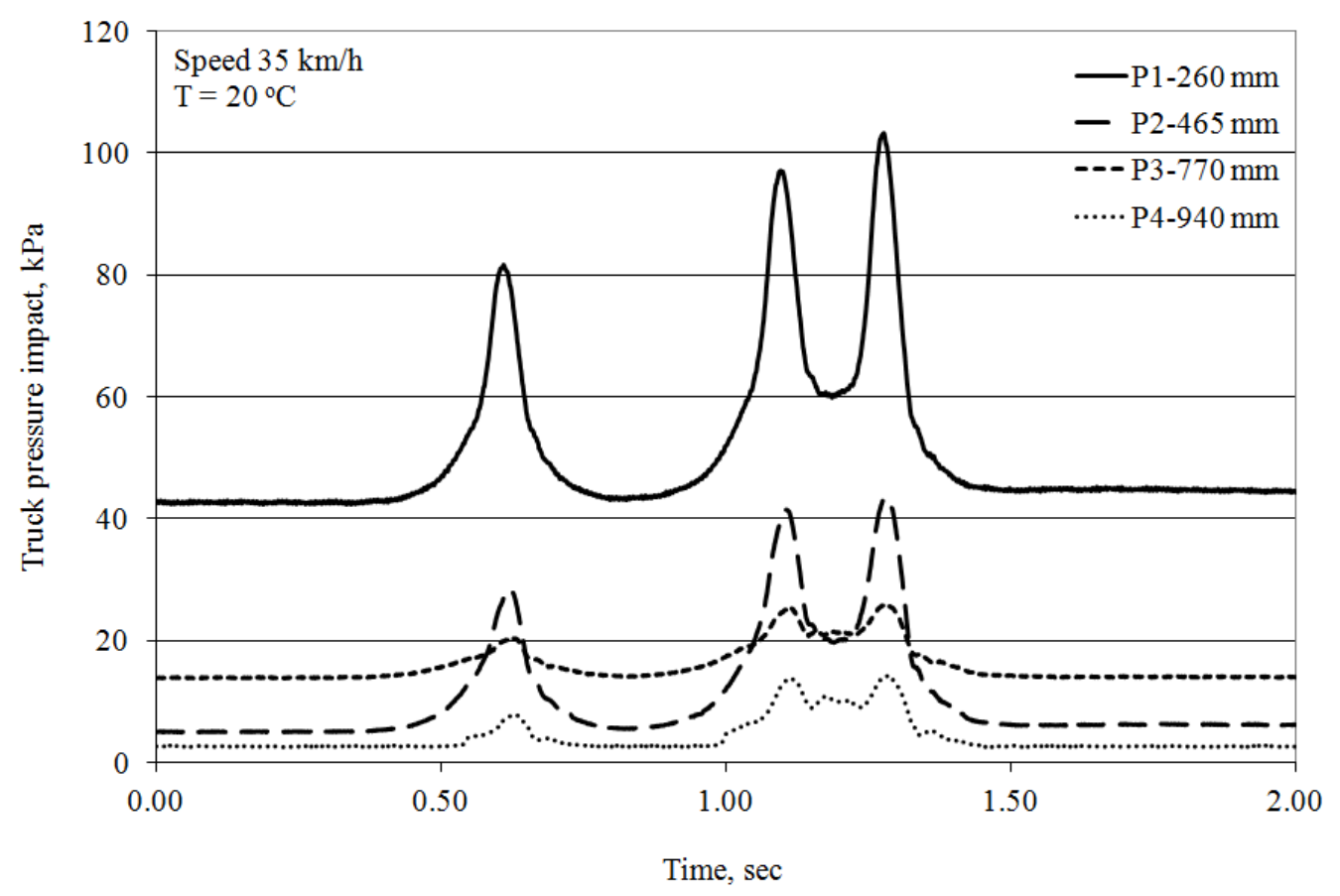

Figure 4.68: Vertical pressure truck impact at speed of $35 \mathrm{~km} / \mathrm{h}$ in year 2- Site 3

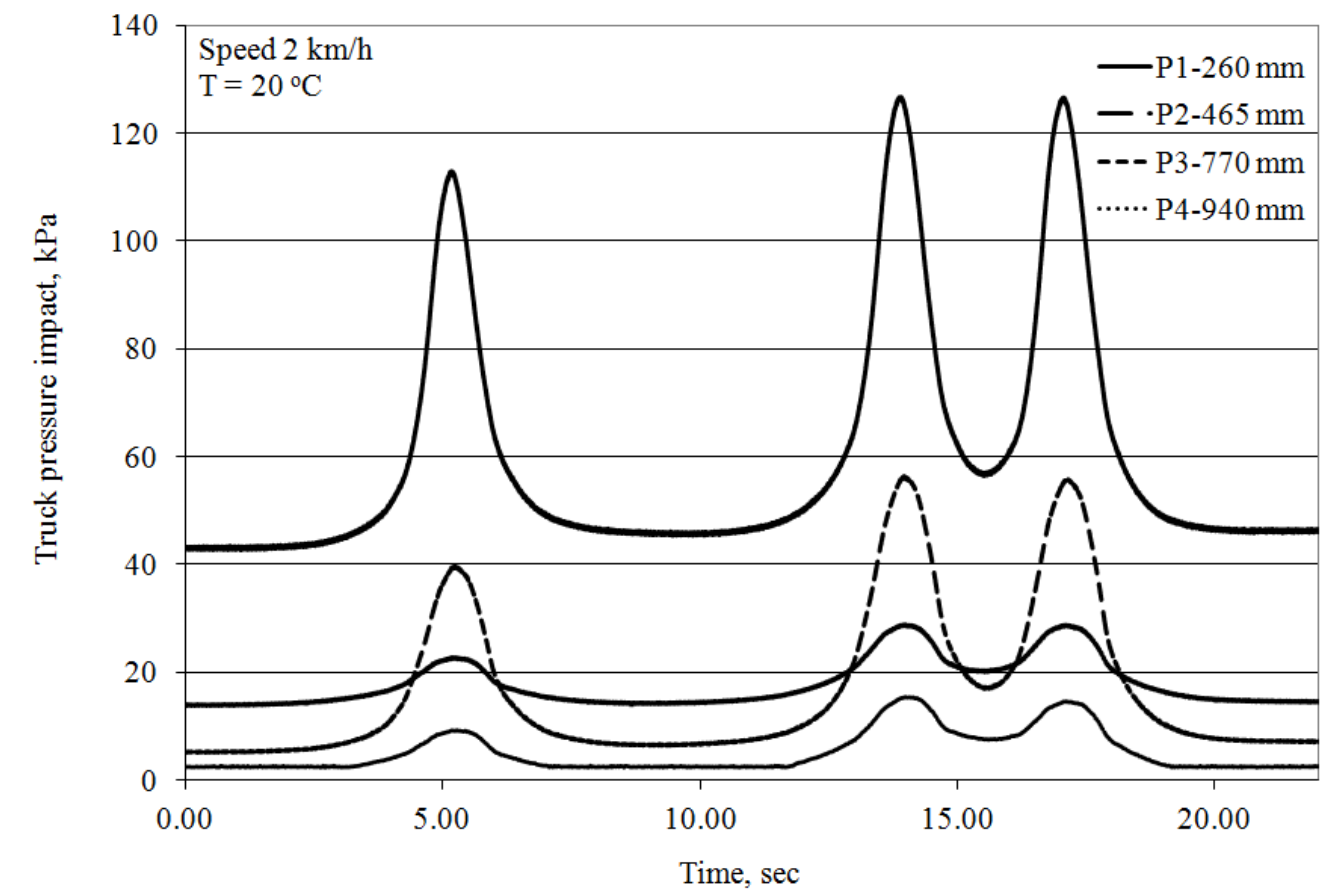

Figure 4.69: Vertical pressure truck impact at speed of $2 \mathrm{~km} / \mathrm{h}$ in year 2- Site 3

\subsubsection{Deformation profiles of bound and unbound materials}

Total unbound rutting for road structure was monitored at different levels along the road structure depth. Total unbound rutting records were established from data 
collected at the three sites on a daily basis using a programmed static data acquisition system. Total rutting (bound and unbound materials) was monitored for the three sites by surveying the road profiles at the location where all the sensors were buried in the road.

The total unbound rutting and total rutting profiles from the three sites will be compared with the output of the M-EPDG model performances.

Truck strain impact profiles while included in this thesis for the three sites, are recommended to be used to evaluate the strain predictions made using the M-EPDG model while comparing the model predictions with the actual data collected from the three sites.

\subsubsection{Site 1}

Figure 4.70 shows the total unbound rutting for the road structure profile. The profile revealed that high rates of deformation occurred within the first 6 months, supporting observations documented in the literature, which suggest that the majority of poor performance incidents occur at an early stage in the service life.

Deviations from optimum conditions as showed previously in Figures 4.1 and 4.2, lead to excessive permanent deformation $(27.5 \mathrm{~mm})$ and inferior resilience, which contribute to poor performance. 


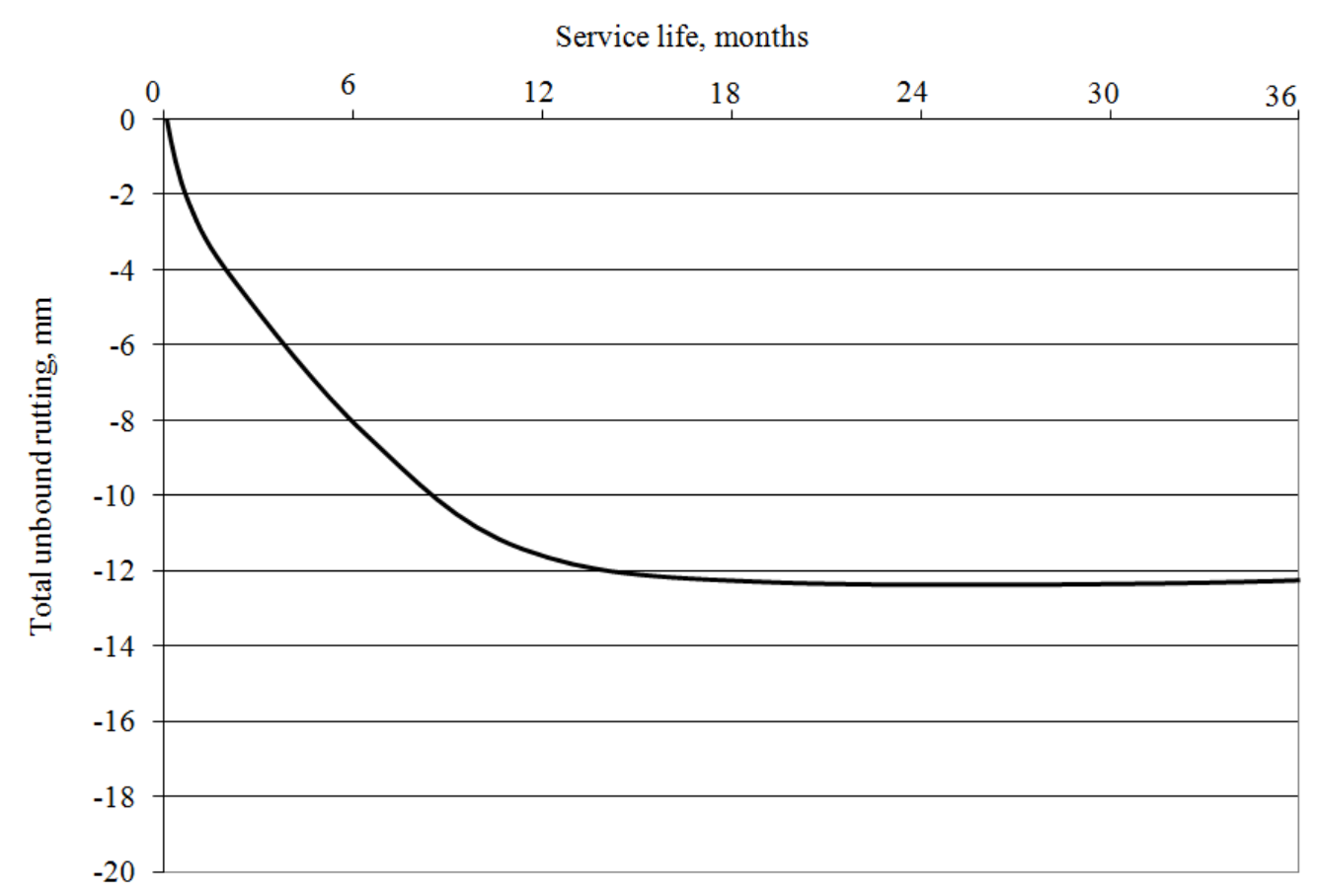

Figure 4.70: Total unbound rutting- Site 1

The survey profile total rutting was taken perpendicular to the direction of the traffic (along the road width). Figure 4.70, shows the three survey profiles at 6,14 and 53 months at the location where all the sensors were buried in the road. As can be seen in Figure 4.71, the road surface profile dropped after 6 months to about $56 \%$ from the total rutting that was observed after 53 months. The deformation sensors (EMU coils) were buried in the design lane where heavy traffic and transit buses were expected to go through. Further analyses of the data in Figure 4.71, leads to the establishment of the total rutting with respect to road age as shown in Figure 4.72. This profile represents the total rutting at the same point where the deformation sensors were buried. The rutting contributed by the asphalt concrete layer as shown in Figure 4.73 can be obtained by subtracting the total rutting caused by unbound material shown in Figure 4.70 from the total rutting shown in Figure 4.72. 
Total rutting and rutting caused by unbound and asphalt concrete will be used in this study to validate the M-EPDG output for this site.

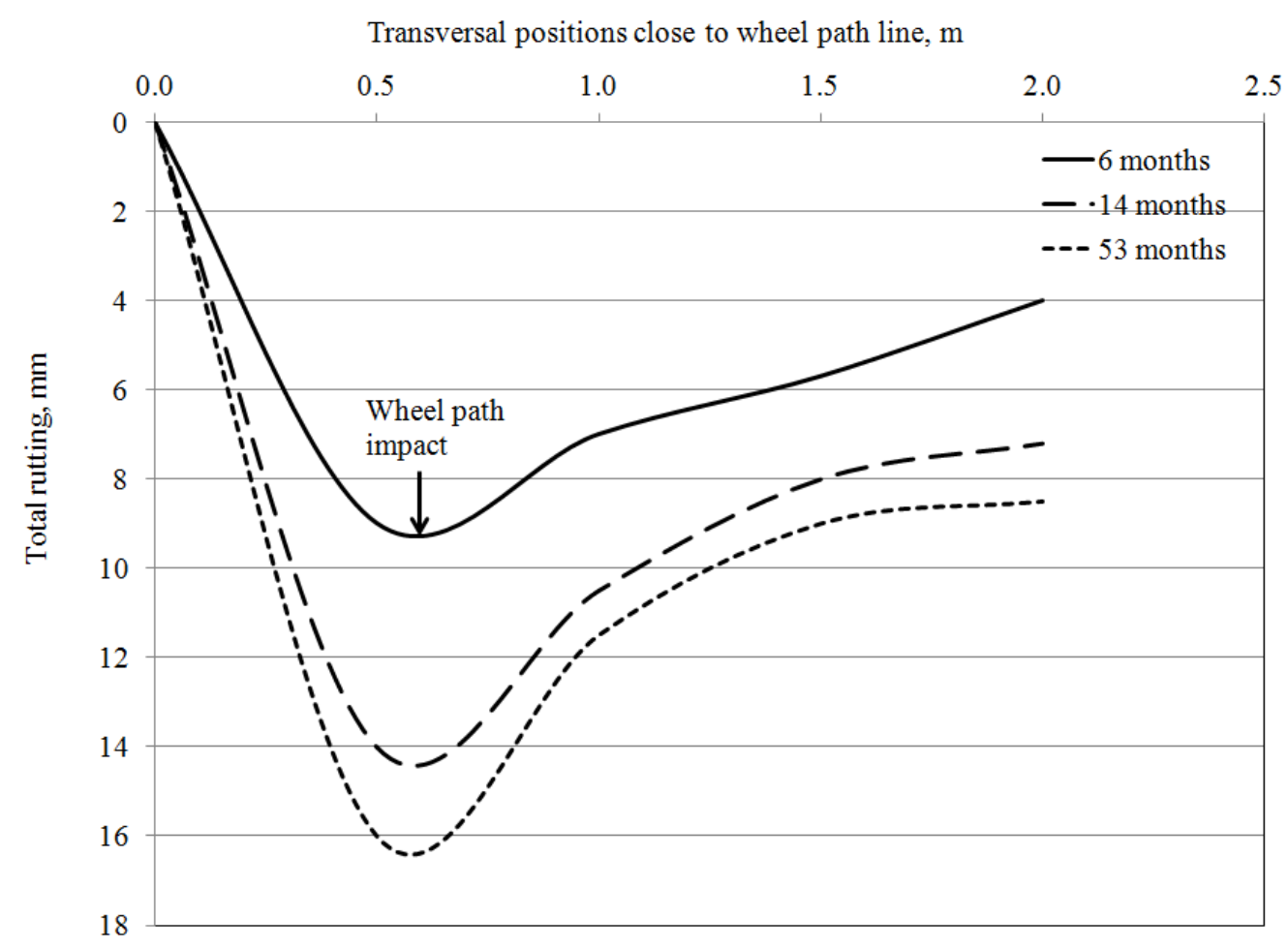

Figure 4.71: Total rutting profile along the road width- Site 1 


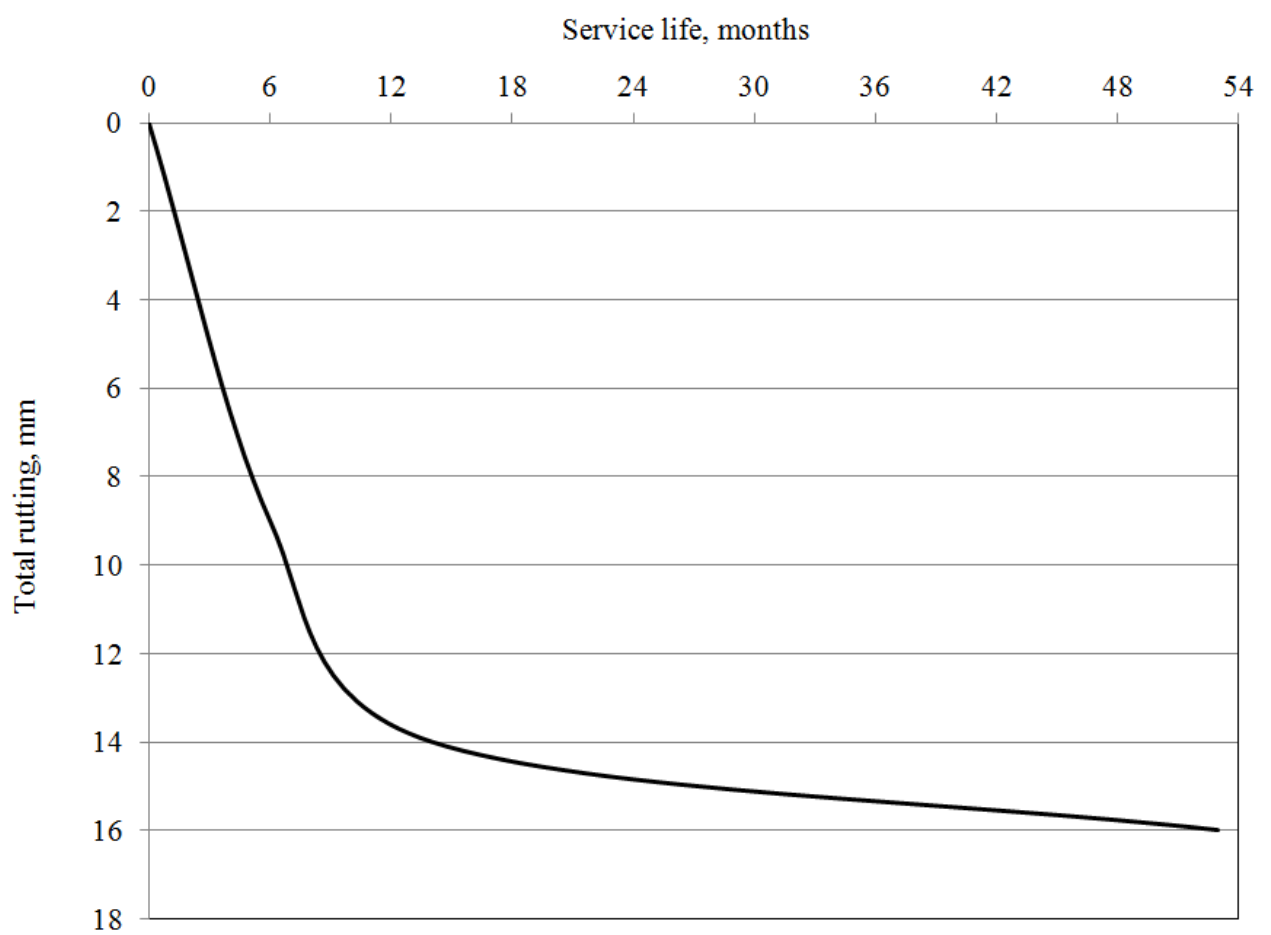

Figure 4.72: Total rutting along the wheel path- Site 1

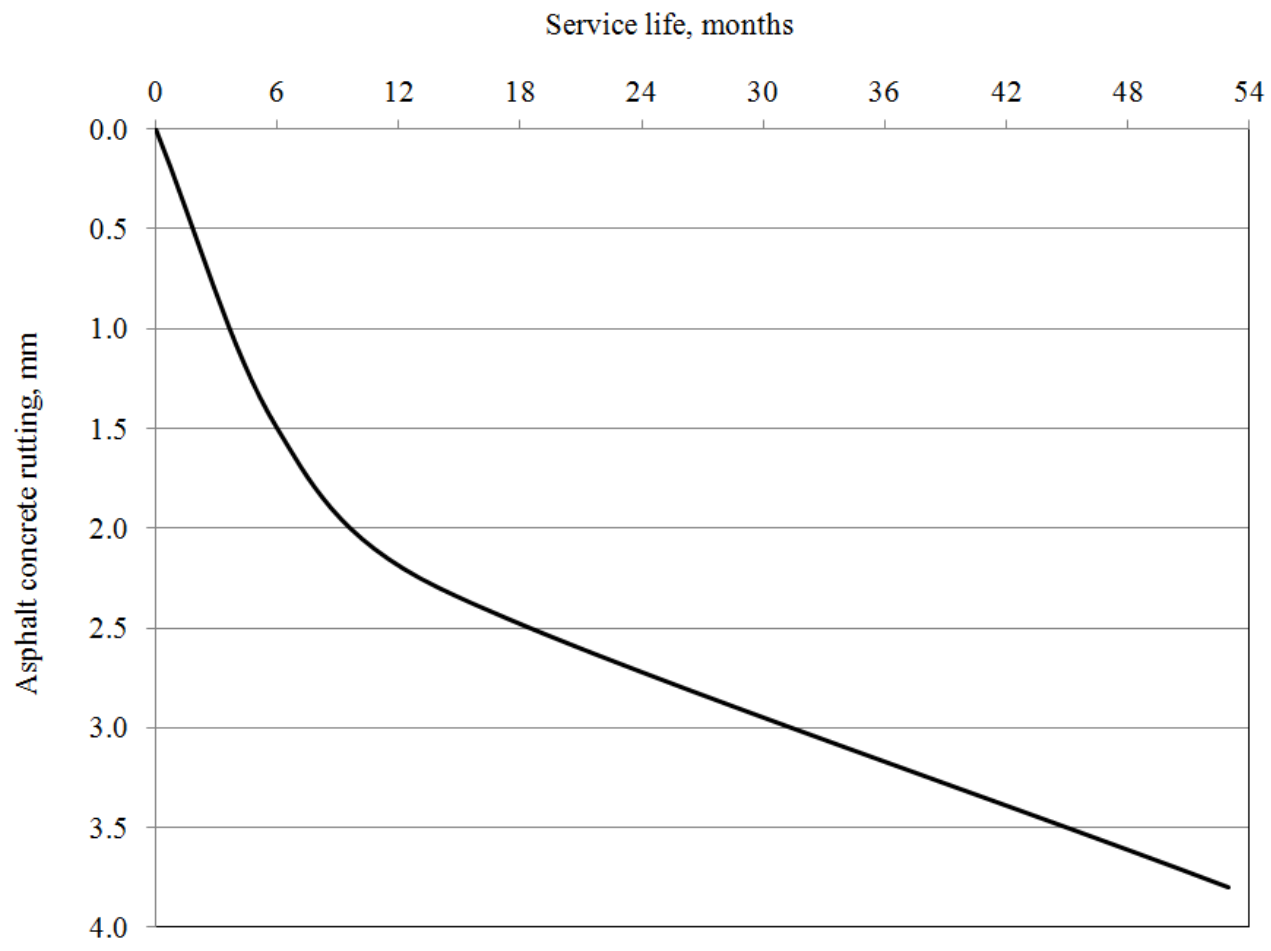

Figure 4.73: Asphalt concrete rutting along the wheel path- Site 1 
The dynamic system of the EMU coil gauges was not working correctly after construction, so the dynamic data during the opening of the site during the impact of the hot asphalt mat temperature was not collected. THE EMU coils were operational for the second and third year only. One single axle and two twin axle test trucks with axle loads of $48.8,174.8$ and $169.8 \mathrm{kN}$ from front to back respectively, were operated when the asphalt mat temperature was 20 and $21^{\circ} \mathrm{C}$ for year 2 and year 3 . The speed of the truck was about $15 \mathrm{~km} / \mathrm{h}$. The EMU coils were buried in the road, with unbound materials and located at four different levels near the pressure cells buried in the same site $(400,700$, 1450 and $2500 \mathrm{~mm}$ ) as shown previously in Figure 3.14. Dynamic data was collected using the dynamic data acquisition system revealing a low level of strain due to the mat asphalt temperature and densification caused by 1 and 2 years of traffic as shown in Figures 4.74 to 4.77 . Data analysis revealed that the closer the EMU coils were to the road surface the greater the truck strain impact (1146 $\mu$ strain) compared to the lower EMU coils (467 $\mu$ strain). 


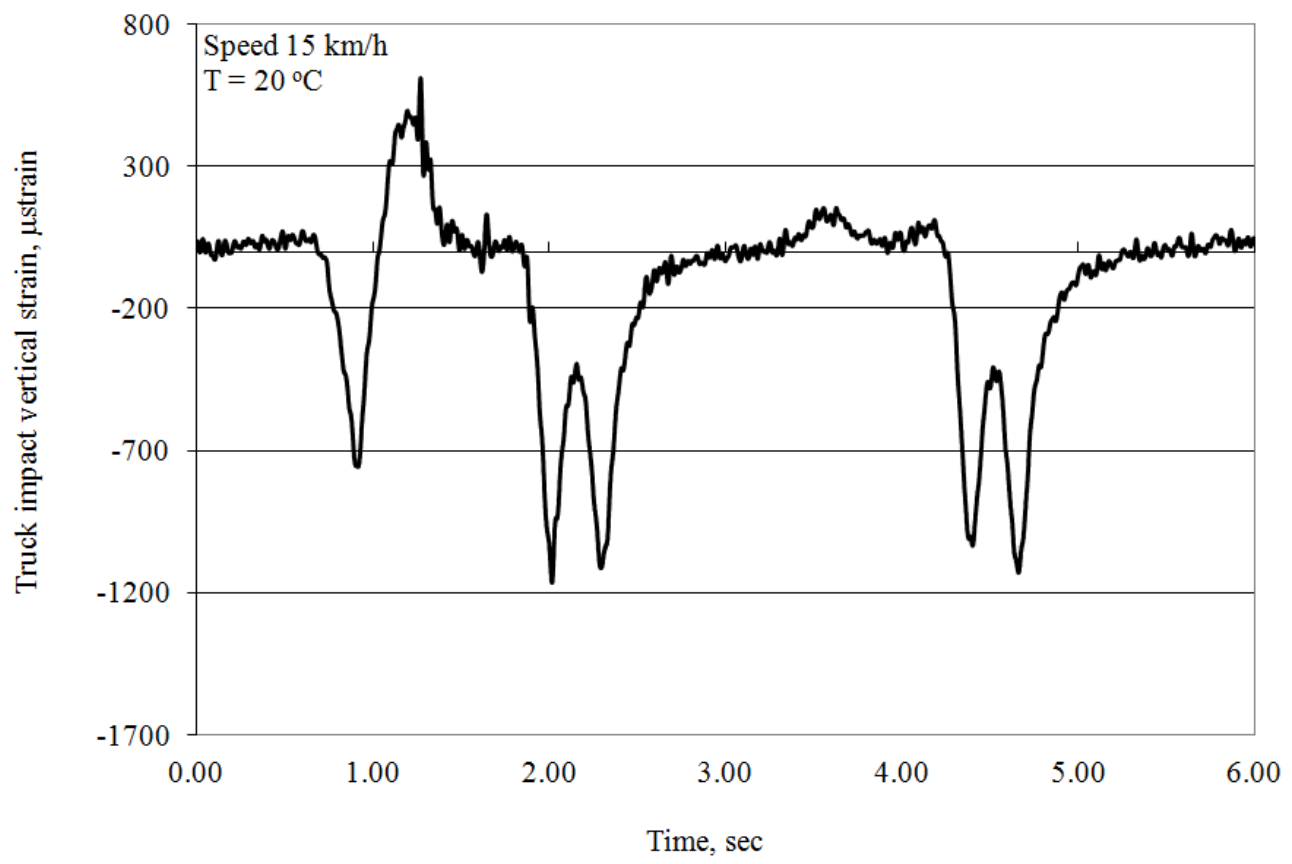

Figure 4.74: Vertical strain truck impact at a speed of $15 \mathrm{~km} / \mathrm{h}$ and a depth of $400 \mathrm{~mm}$, year 2- Site 1

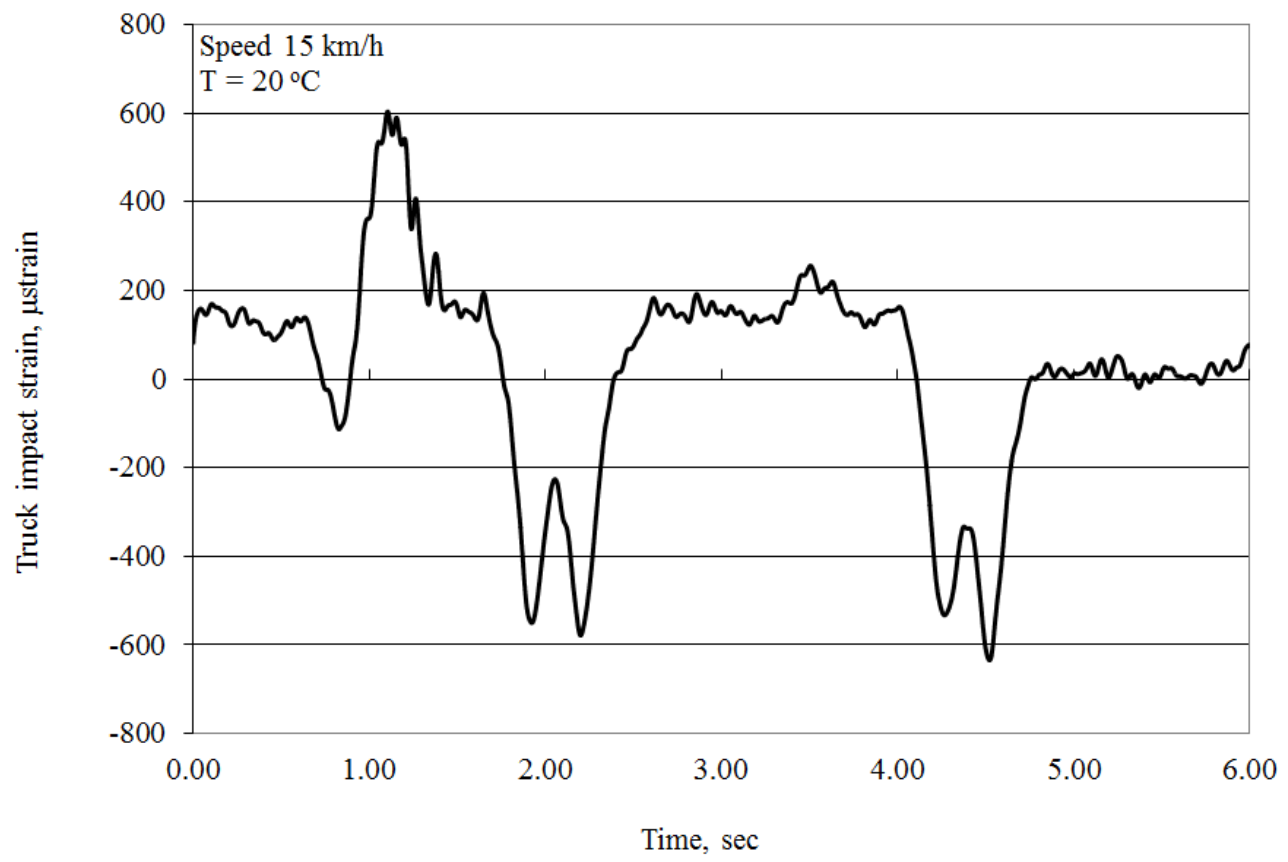

Figure 4.75: Vertical strain truck impact at a speed of $15 \mathrm{~km} / \mathrm{h}$ and a depth of $700 \mathrm{~mm}$, year 2- Site 1 


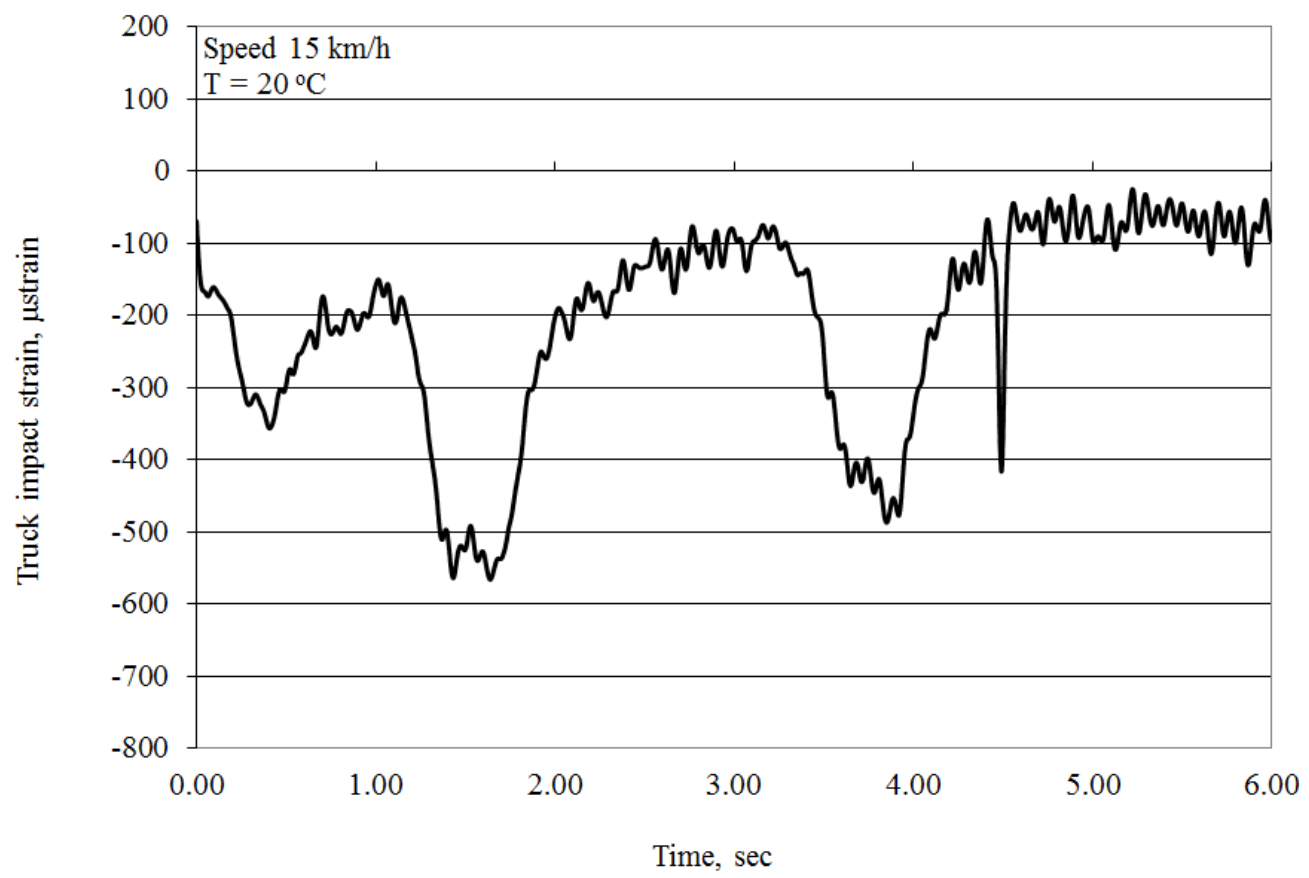

Figure 4.76: Vertical strain truck impact at a speed of $15 \mathrm{~km} / \mathrm{h}$ and a depth of $1450 \mathrm{~mm}$, year 2-Site 1

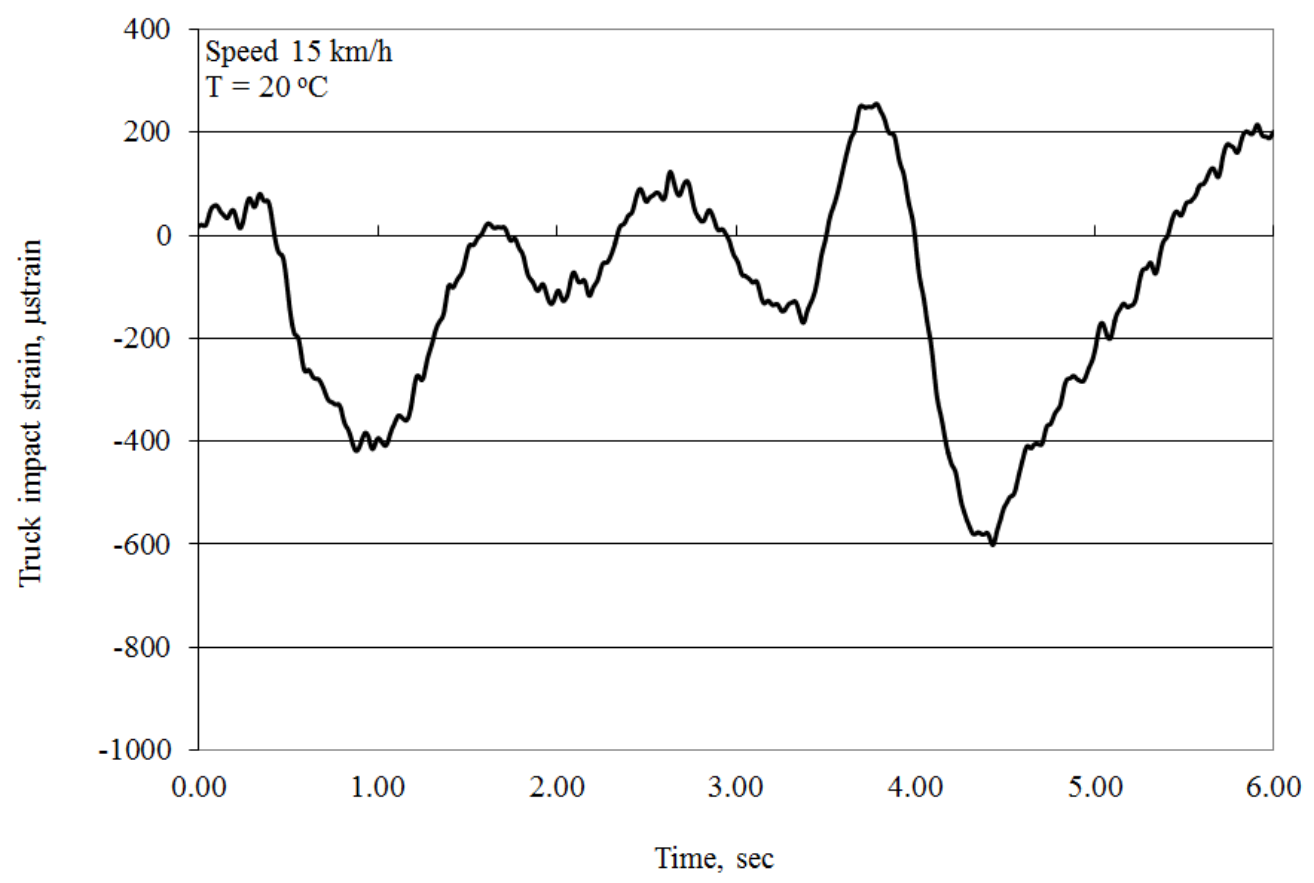

Figure 4.77: Vertical strain truck impact at a speed of $15 \mathrm{~km} / \mathrm{h}$ and a depth of $2500 \mathrm{~mm}$, year 2- Site 1 
Similarly, impact of the same truck on the EMU coils was operated at a speed of $15 \mathrm{~km} / \mathrm{h}$ at year 3. The recorded data is displayed on Figures 4.78 to 4.80 . Comparison of the peak truck impact strain between the year 2 and year 3 is shown in Figure 4.81. The strain dropped by 13, 41, 77 and $100 \%$ at depths of 400, 700, 1450 and $2500 \mathrm{~mm}$ respectively.

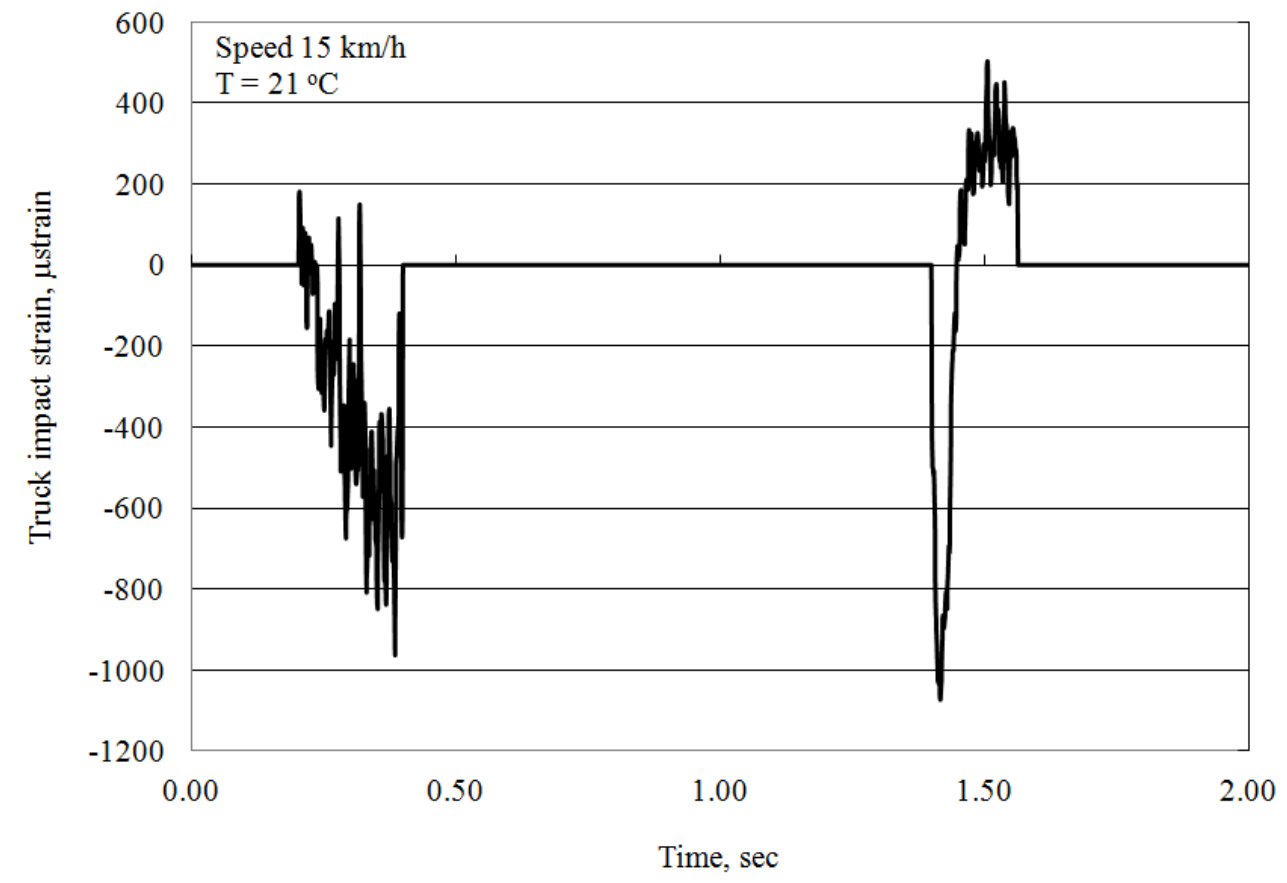

Figure 4.78: Vertical strain truck impact at a speed of $15 \mathrm{~km} / \mathrm{h}$ and a depth of $400 \mathrm{~mm}$, year 3- Site 1 


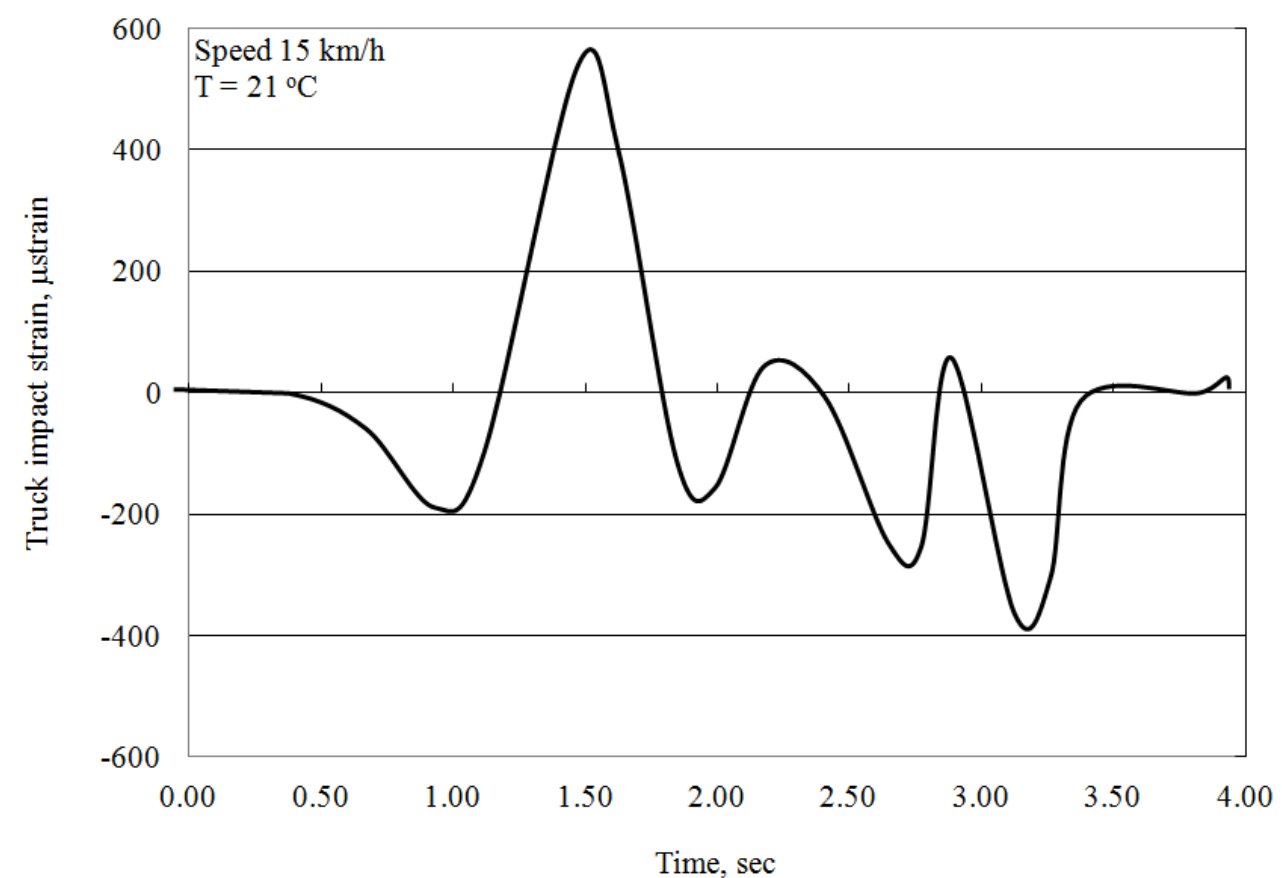

Figure 4.79: Vertical strain truck impact at a speed of $15 \mathrm{~km} / \mathrm{h}$ and a depth of $700 \mathrm{~mm}$ year 3- Site 1

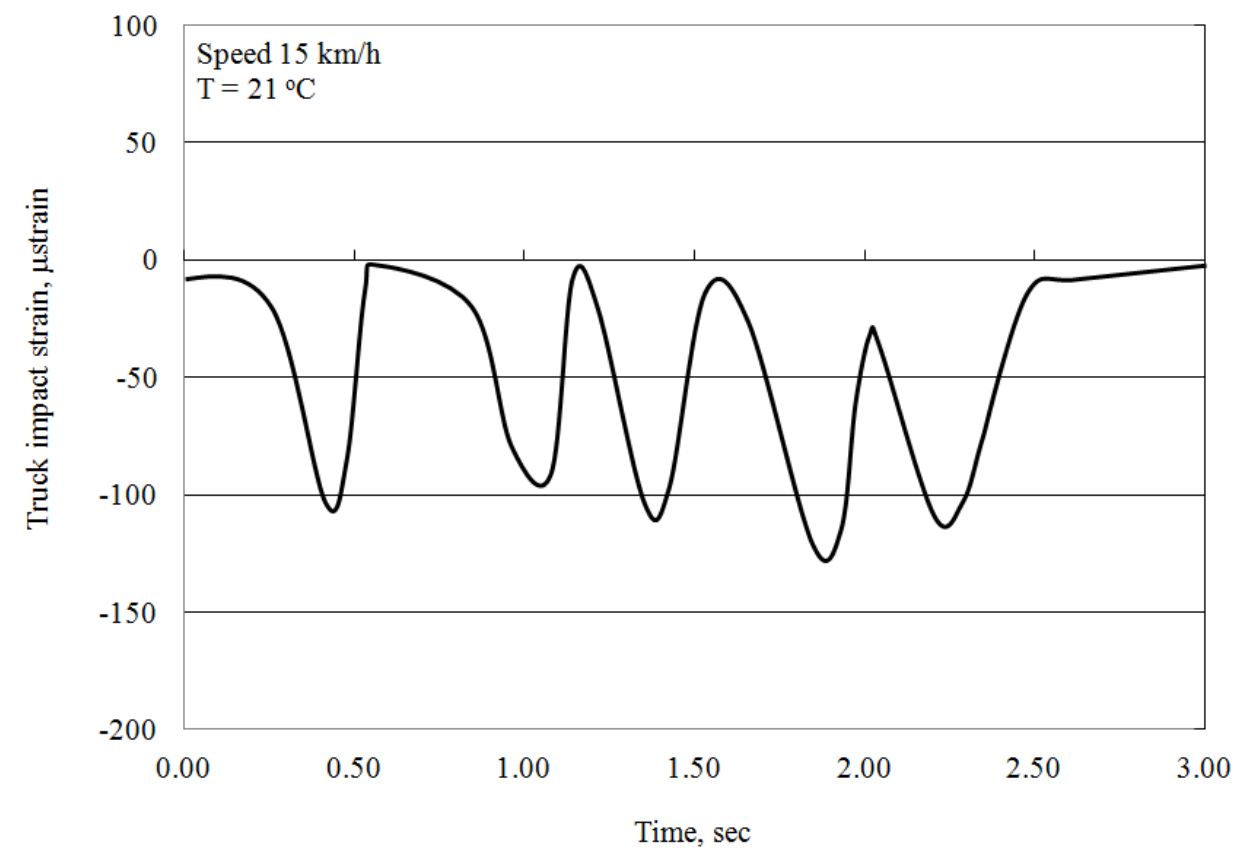

Figure 4.80: Vertical strain truck impact at a speed of $15 \mathrm{~km} / \mathrm{h}$ and a depth of $1450 \mathrm{~mm}$ year 3- Site 1 


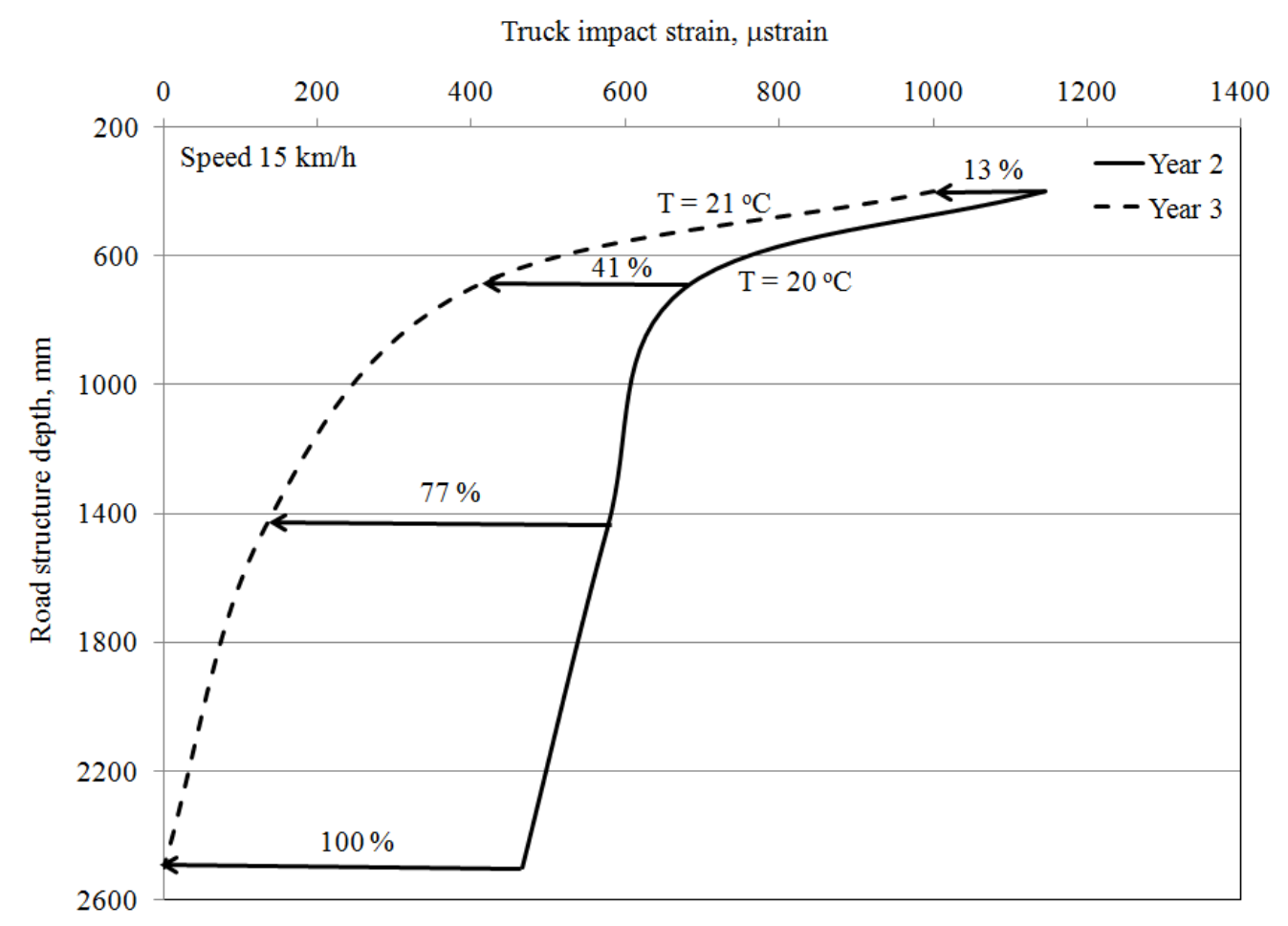

Figure 4.81: Comparison of vertical truck impact strain profile in year 2 and year 3- Site 1

\subsubsection{Site 2}

Permanent deformation of unbound materials in the road structure at site 2 is shown in Figure 4.82. The profile revealed that $91 \%$ of the total unbound rutting $(7.5$ $\mathrm{mm}$ ) occurred within the first 4 months after construction. The data for site 2 once again support observations documented in the literature, which suggest that the majority of poor performance incidents occur at an early stage in the service life. 


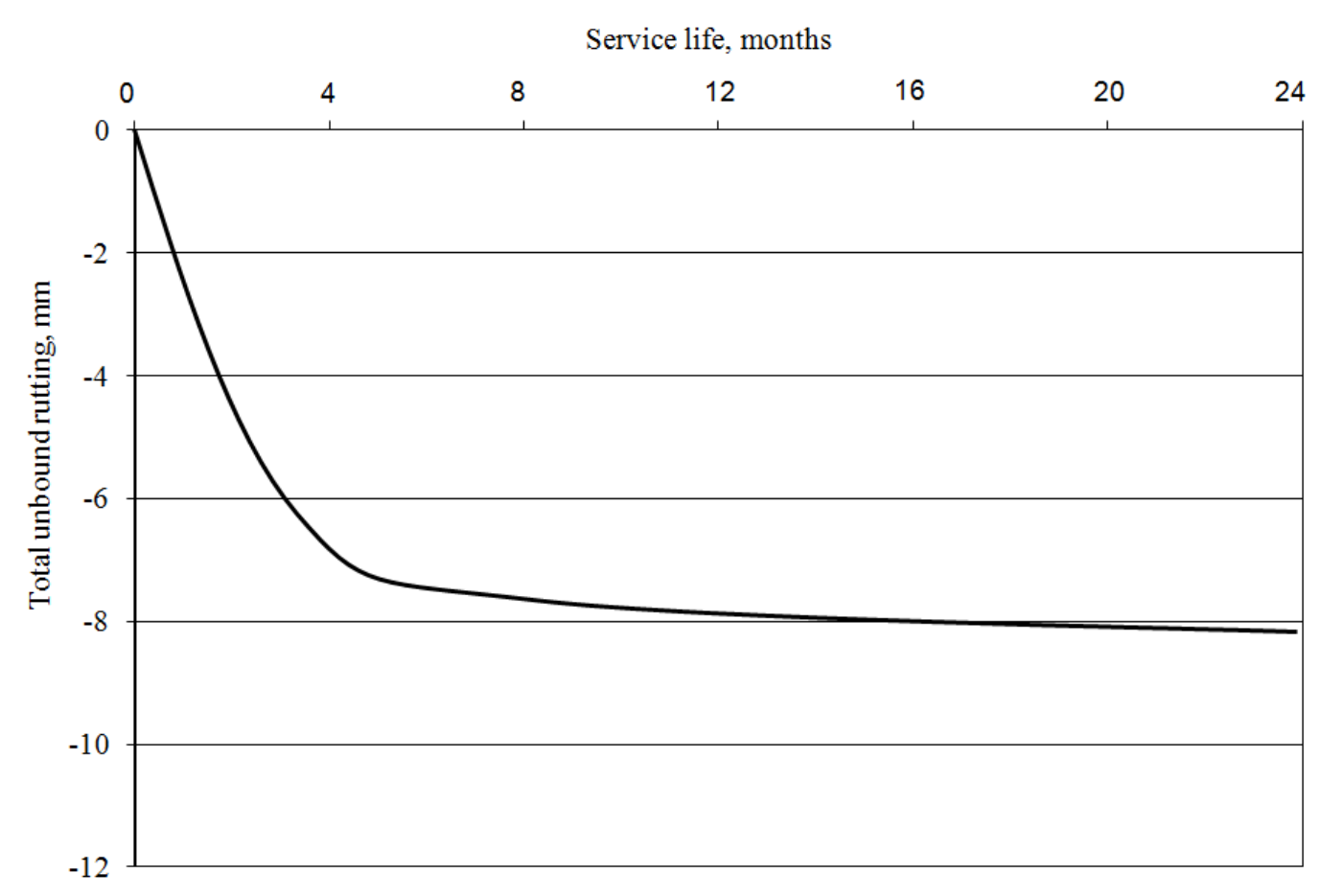

Figure 4.82: Total unbound rutting- Site 2

The survey profile for total rutting was taken perpendicular to the direction of the traffic (along the road width). Figure 4.83, shows the three survey profiles at 8, 23 and 53 months at the location where all the sensors were buried in the road. As can be seen in Figure 4.83 , the road surface profile dropped and after 8 months it was about $68 \%$ from the total rutting surveyed after 53 months. The deformation sensors (EMU coils) were buried in the design lane where heavy traffic and transit buses were expected to go through. Further analyses of the data in Figure 4.83, leads to the establishment of total rutting with respect to road age as shown in Figure 4.84. This profile represents the total rutting at the same point where the deformation sensors were buried. By subtracting the total rutting caused by unbound material shown in Figure 4.82 from the total rutting shown in Figure 4.84, it is possible to determine the rutting contributed by the asphalt concrete layer as shown in Figure 4.85. 
Total rutting and rutting caused by unbound and asphalt concrete will be used in this study to evaluate the M-EPDG.

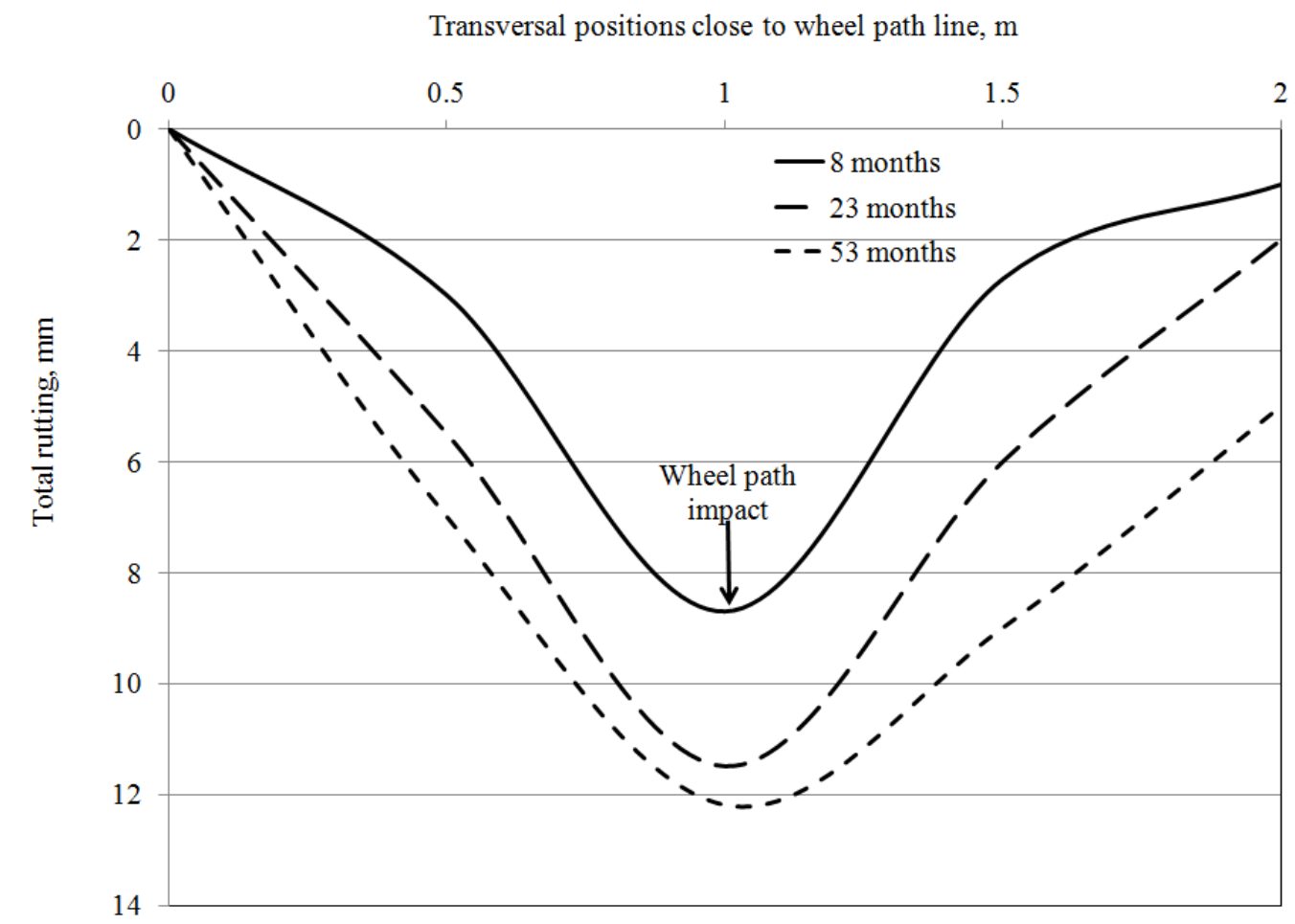

Figure 4.83: Total rutting profile along the road width- Site 2

Service life, months

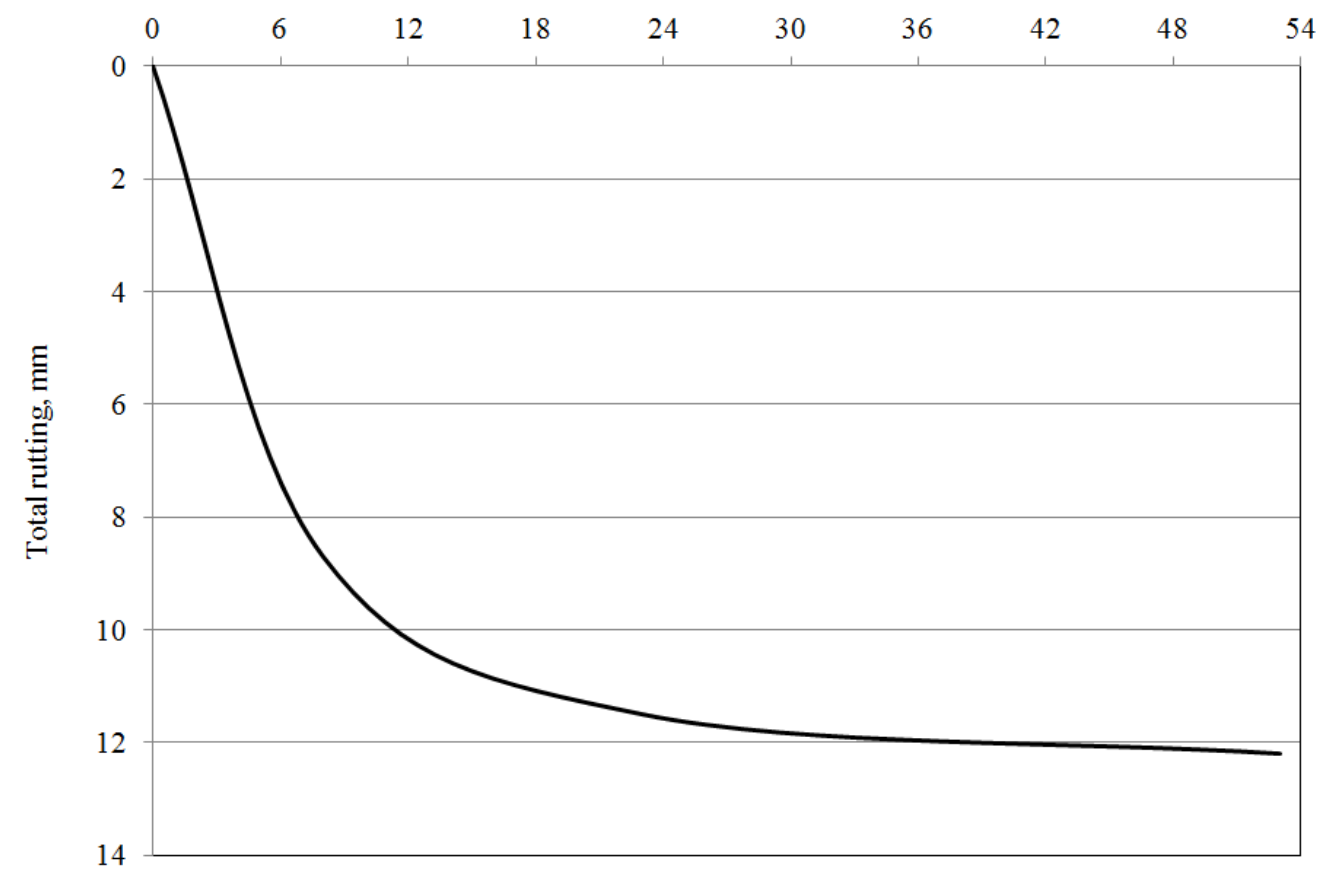

Figure 4.84: Total rutting along the wheel path- Site 2 


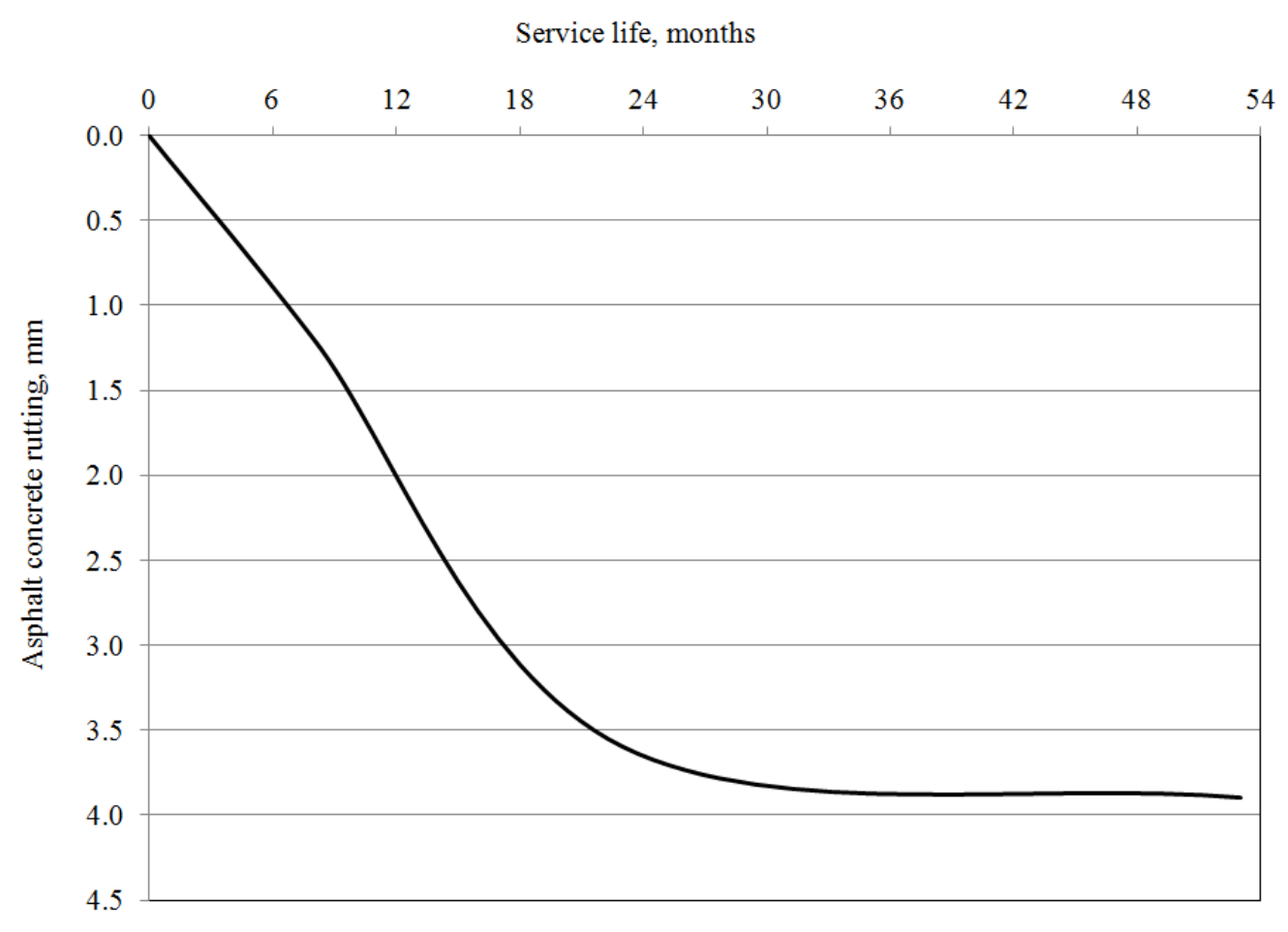

Figure 4.85: Asphalt concrete rutting along the wheel path- Site 2

Comparing the total permanent deformation for both sites 1 (Figure 4.72) and 2 (Figure 4.84) in cold and warm weather respectively, demonstrates that freeze and thaw cycles have a significant impact on the permanent deformation values.

Dynamically, a two axle test truck, with axle loads of 57.83 and $83.18 \mathrm{kN}$ from front to back respectively, was operated immediately after construction (the asphalt mat temperature was $51^{\circ} \mathrm{C}$ ) over deformation sensors (EMU coils) located at the same location or very close to the pressure sensors level at depths shown previously in Figure 3.15. The recorded vertical truck strain impacts were collected using a dynamic data acquisition system revealing an extraordinarily high level of strain as shown in Figures 4.86 to 4.89 . 
Registered maximum strains of 3589, 5200, 820 and $677 \mu$ strain at depths of 290, 390, 690 and $990 \mathrm{~mm}$, respectively for truck impact strain at speed of $15 \mathrm{~km} / \mathrm{h}$ were recorded. Further, Figure 4.90 shows the signal of the truck impact strain at the $390 \mathrm{~mm}$ level for a speed of $35 \mathrm{~km} / \mathrm{h}$. Further analysis showed that the truck impact strain at a speed of $35 \mathrm{~km} / \mathrm{h}$ was lessened by about $37 \%$ than the truck speed at $15 \mathrm{~km} / \mathrm{h}$. Data analysis revealed that the asphalt concrete temperature when these strain levels were recorded was higher than the normal road operating temperatures. The temperature recorded at the bottom of the asphalt concrete layer was $51{ }^{\circ} \mathrm{C}$ during the truck test.

Figure 4.91 shows the truck impact vertical strain profile along the road structure layers. The strain dropped by about $87 \%$ at a depth $1 \mathrm{~m}$ below the asphalt concrete surface.

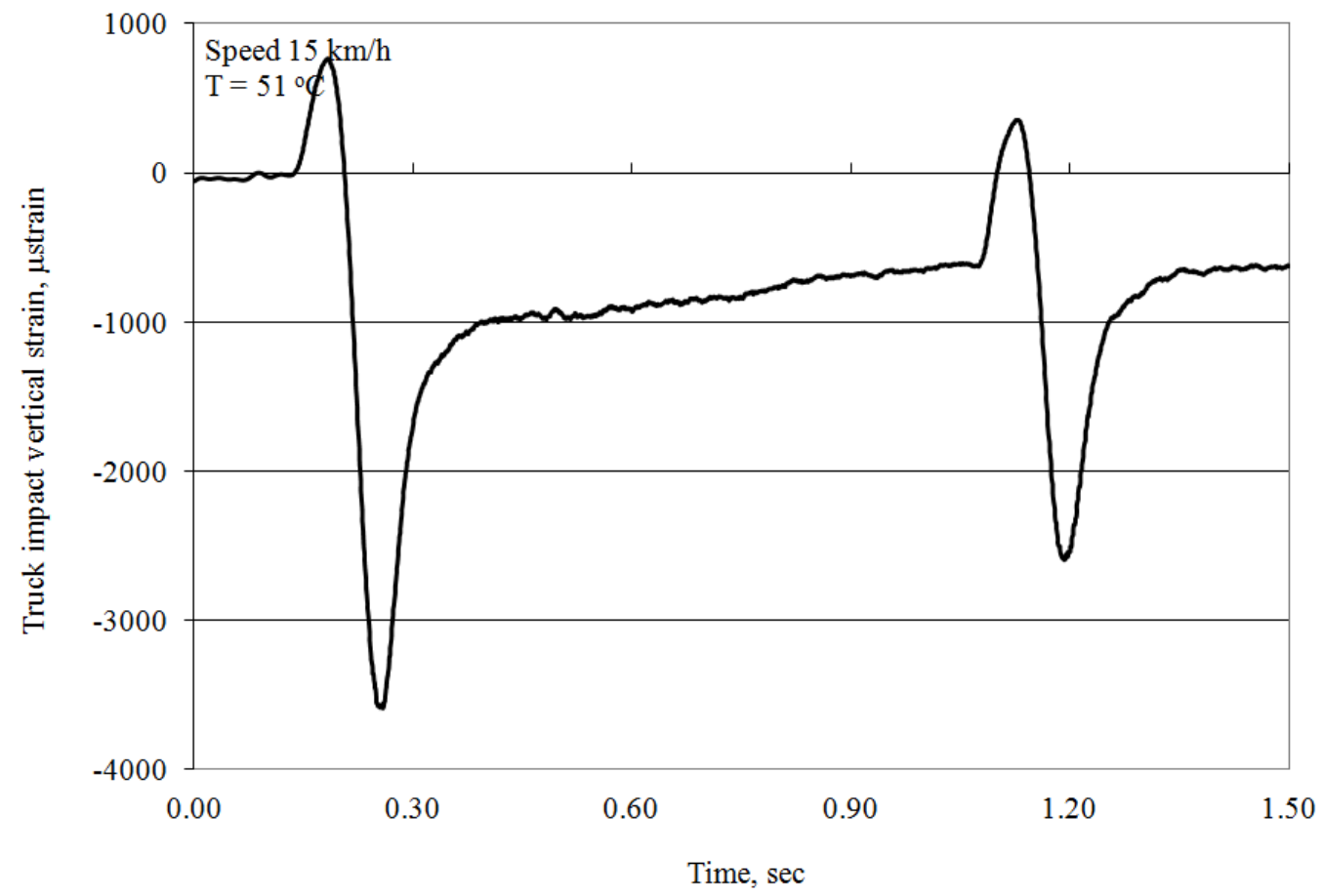

Figure 4.86: Vertical strain truck impact at a speed of $15 \mathrm{~km} / \mathrm{h}$ and a depth of $290 \mathrm{~mm}$, year 1- Site 2 


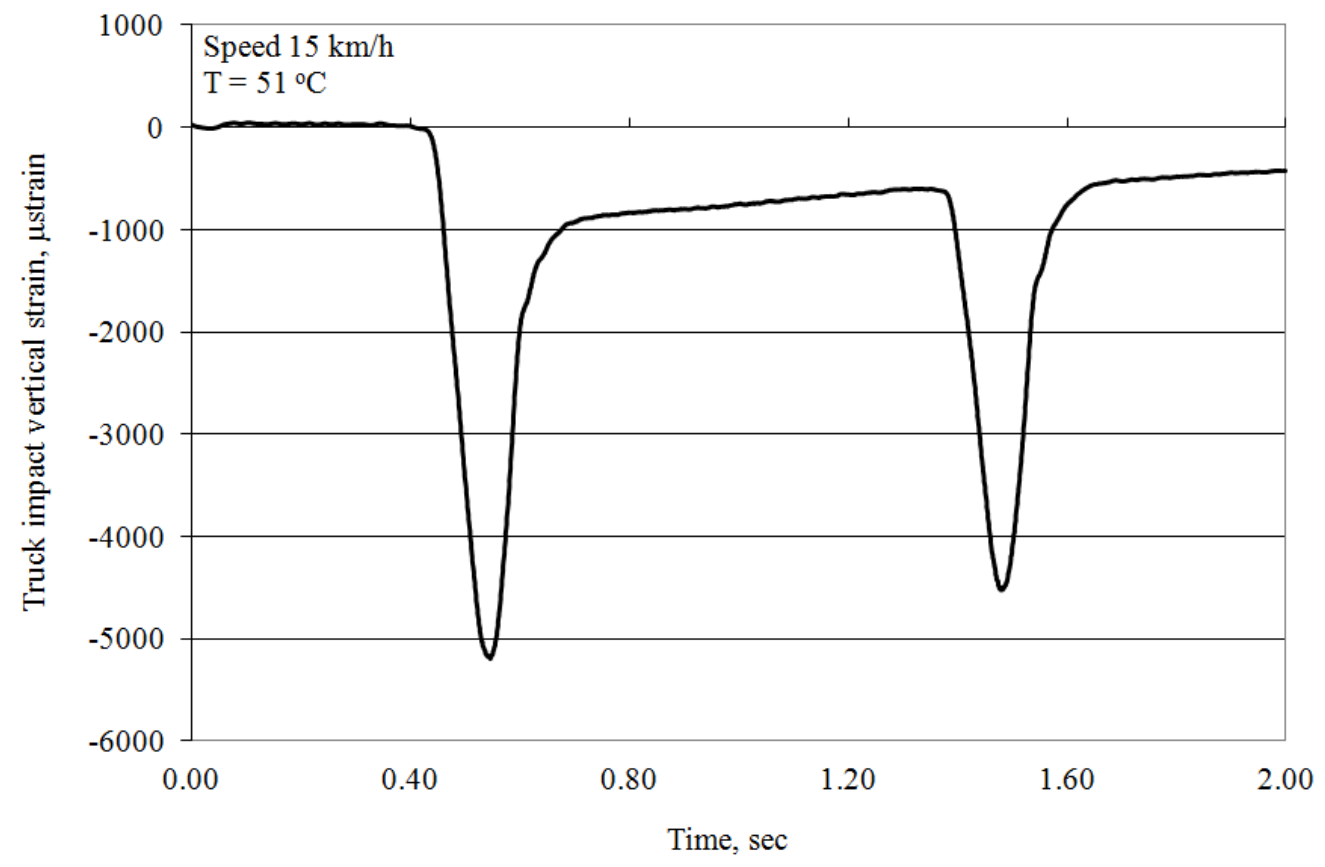

Figure 4.87: Vertical strain truck impact at a speed of $15 \mathrm{~km} / \mathrm{h}$ and a depth of $390 \mathrm{~mm}$, year 1- Site 2

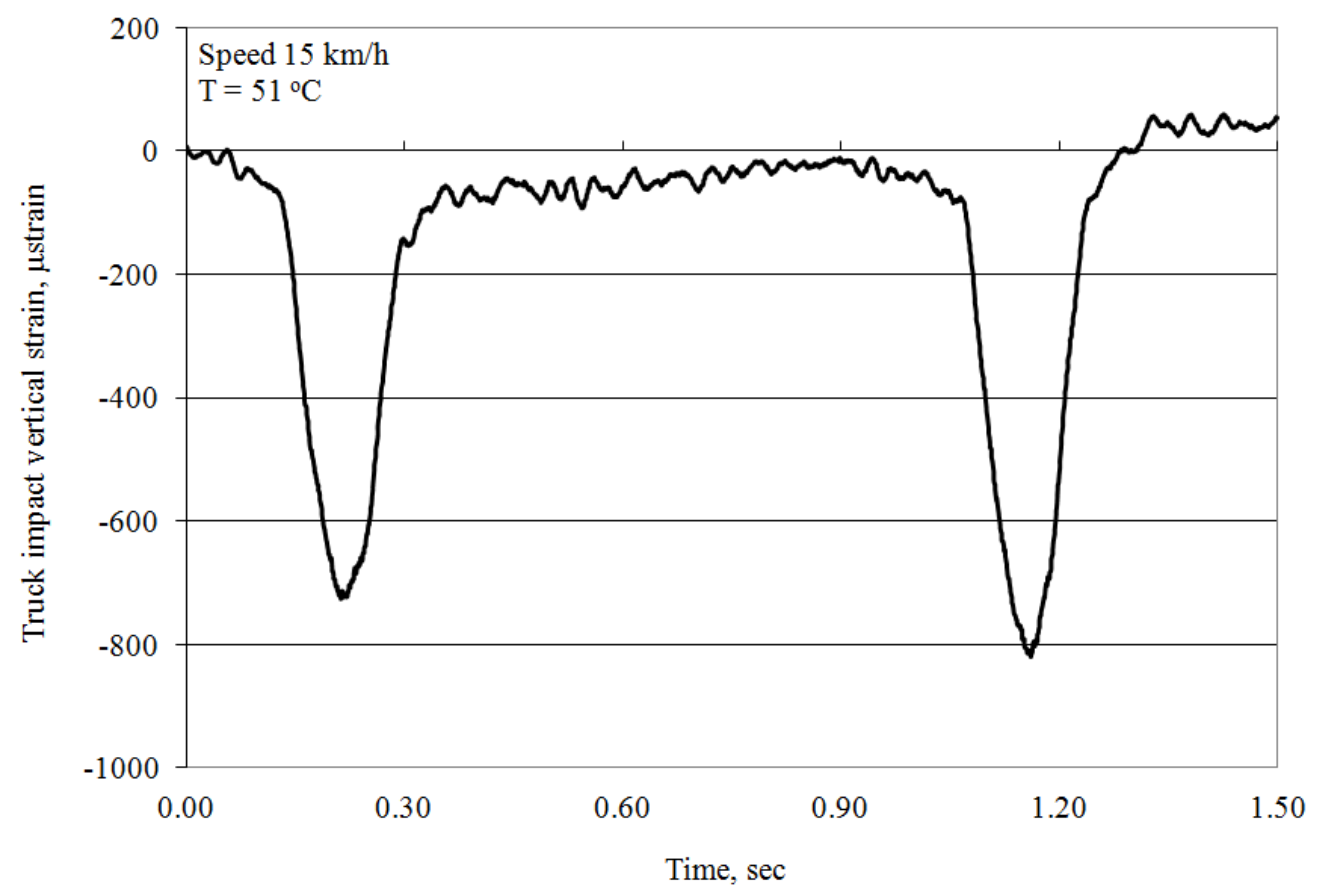

Figure 4.88: Vertical strain truck impact at a speed of $15 \mathrm{~km} / \mathrm{h}$ and a depth of $690 \mathrm{~mm}$, year 1- Site 2 


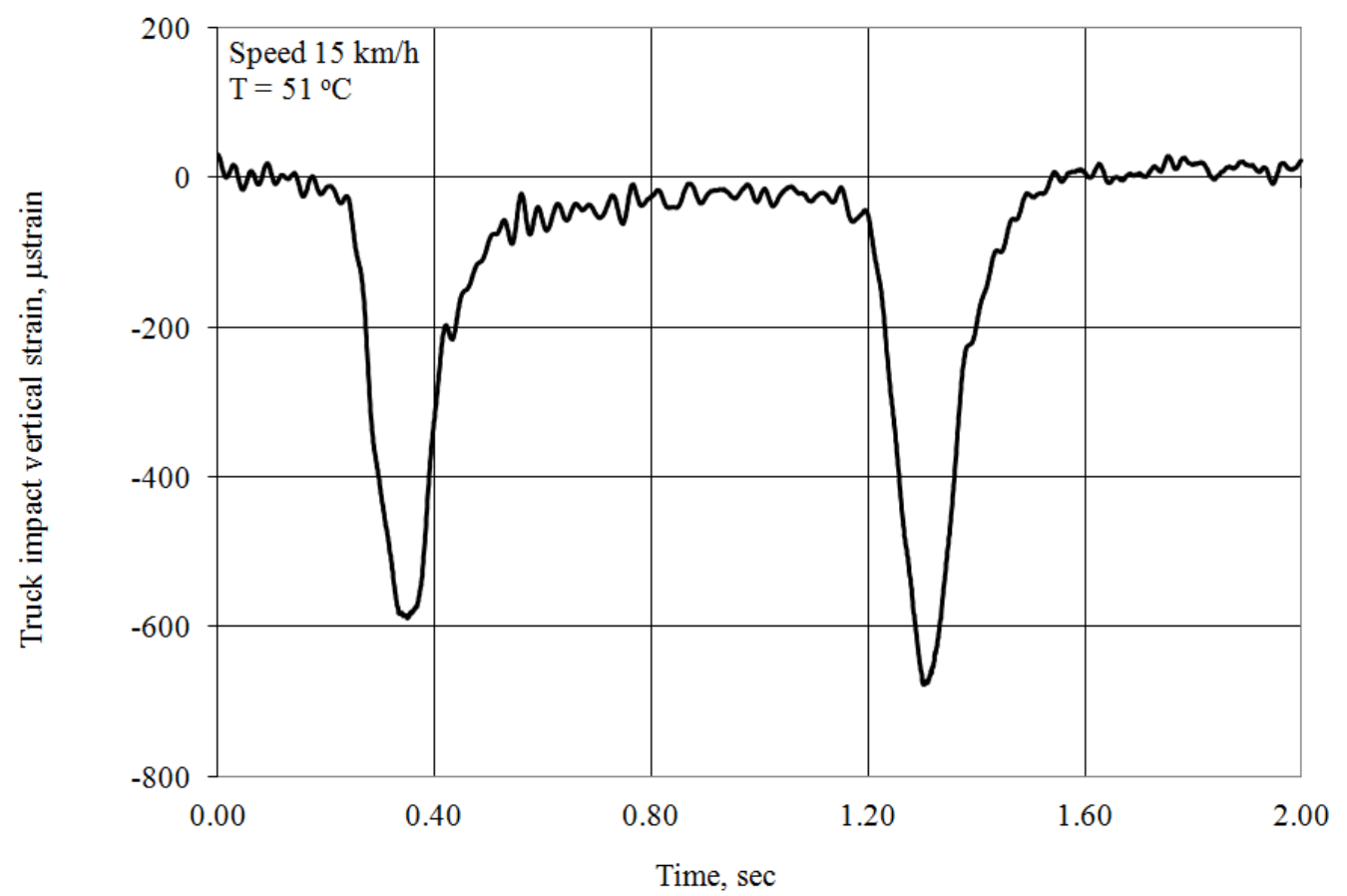

Figure 4.89: Vertical strain truck impact at a speed of $15 \mathrm{~km} / \mathrm{h}$ and a depth of $990 \mathrm{~mm}$, year 1 - Site 2

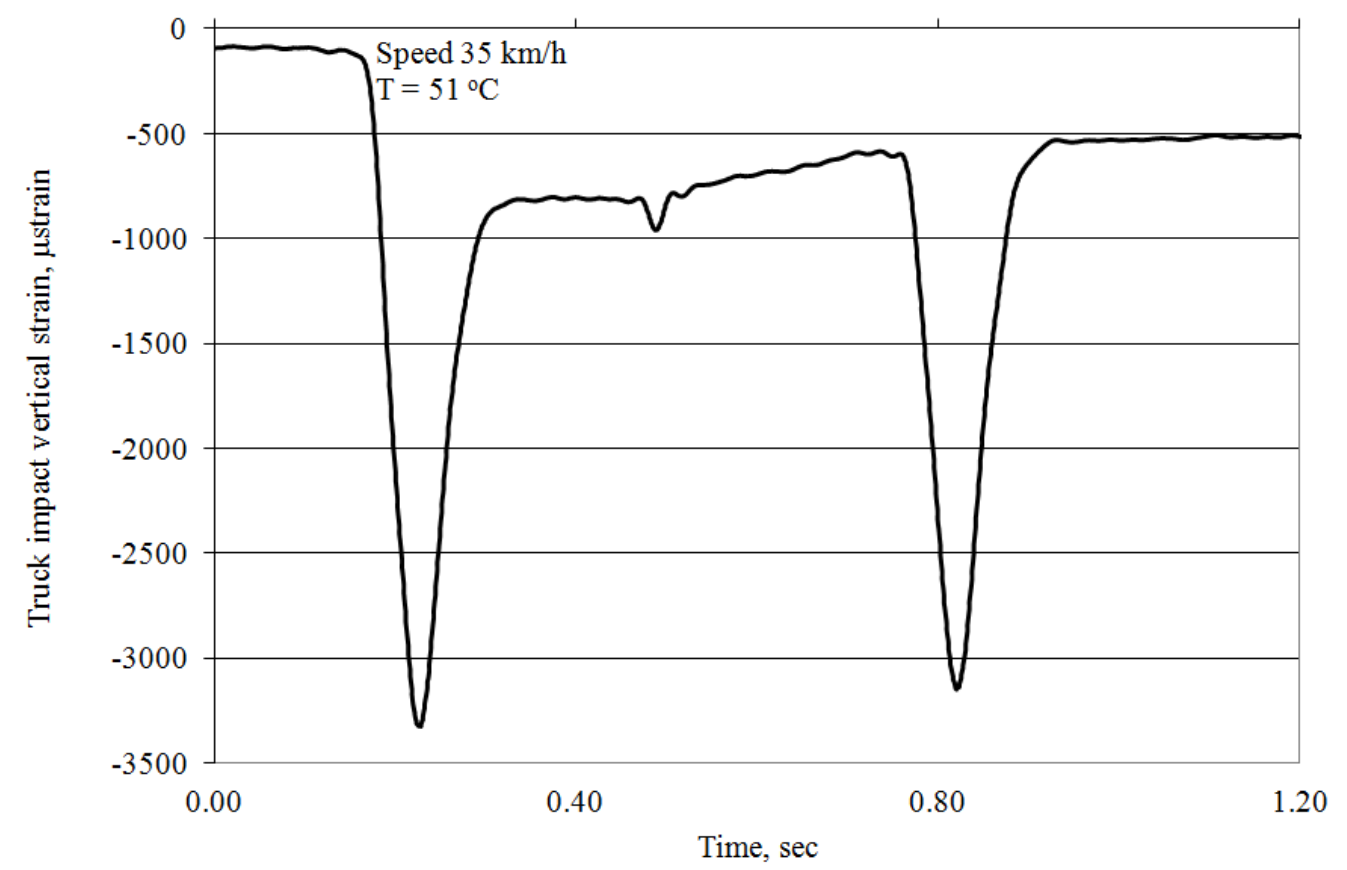

Figure 4.90: Vertical strain truck impact at a speed of $35 \mathrm{~km} / \mathrm{h}$ and a depth of $390 \mathrm{~mm}$, year 1- Site 2 


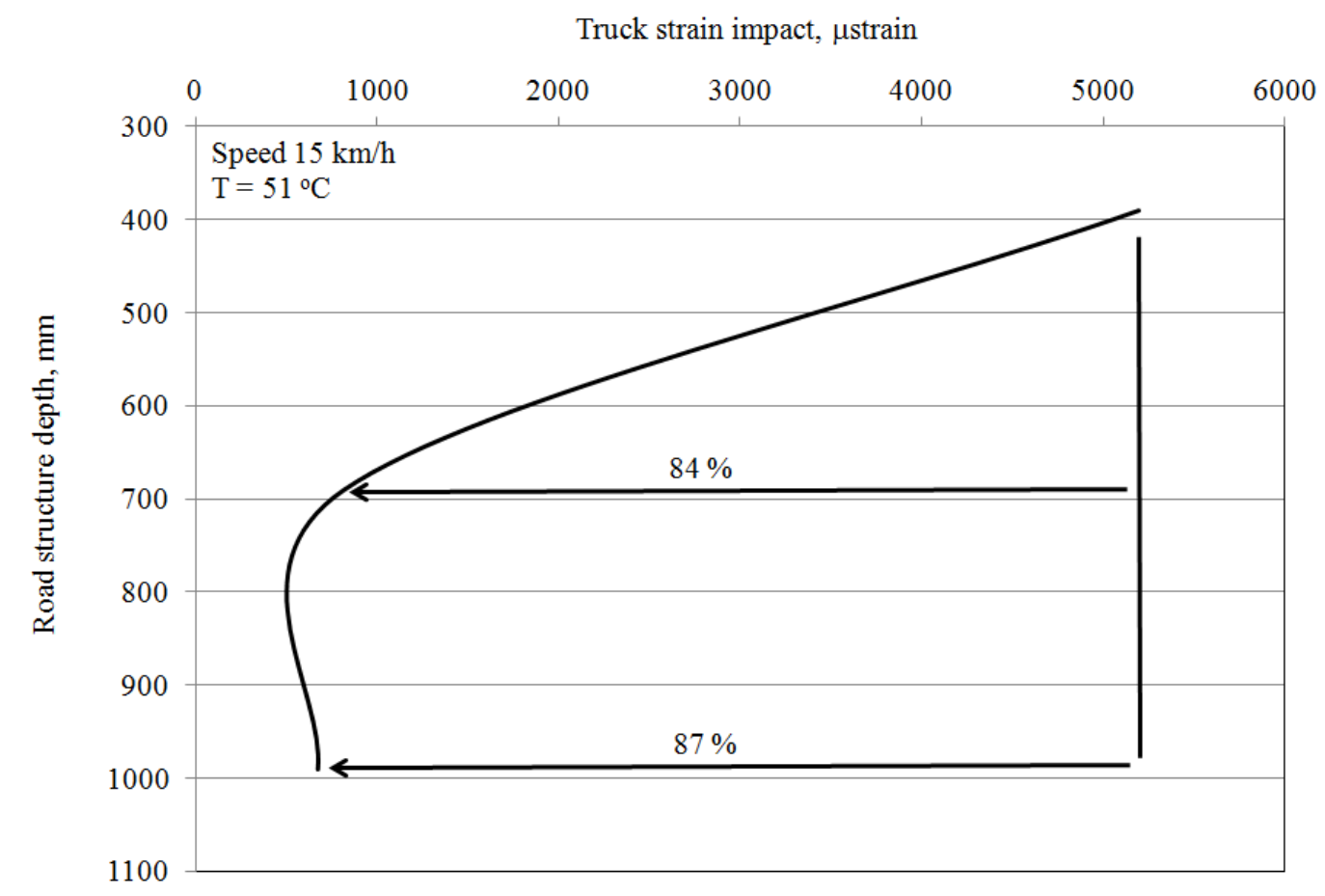

Figure 4.91: Vertical strain truck impact profile, year 1- Site 2

Similarly, the impact of the same truck operated at a speed of $15 \mathrm{~km} / \mathrm{h}$ on the EMU coils at year 2 with an asphalt concrete mat temperature of $20^{\circ} \mathrm{C}$ was determined. The recorded data is displayed in Figures 4.92 to 4.95 . The peak truck impact strains are 419, 439, 294 and $245 \mu$ strain and the percentage of the strain drops from year 1 (immediately after construction) to year 2, with 88, 92, 64 and $64 \%$ at depth levels of 290, 390, 690 and $990 \mathrm{~mm}$ respectively. Decreased strains were caused by the nature of the unbound materials that densified due to traffic. The temperature at year 1 was also high when the road was open to traffic.

Figure 4.96 shows the truck impact vertical strain profile along the road structure layers. The strain dropped less (i.e. by $44 \%$ at a depth of $1 \mathrm{~m}$ below the asphalt concrete 
surface) on year 2 . The asphalt mat temperature was $20^{\circ} \mathrm{C}$ and complete densification of the road below the asphalt concrete surface occurred.

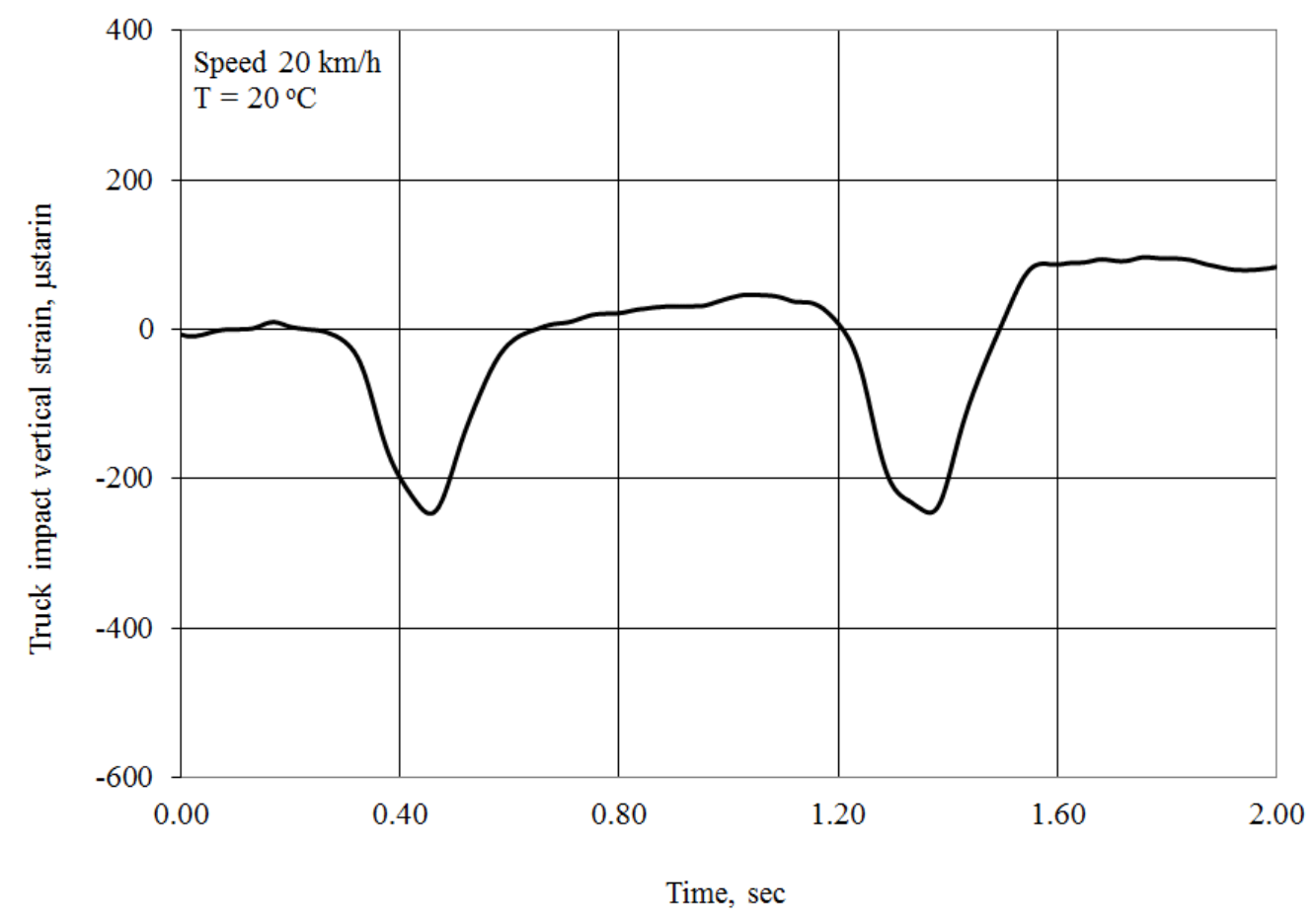

Figure 4.92: Vertical strain truck impact at a speed of $15 \mathrm{~km} / \mathrm{h}$ and a depth of $290 \mathrm{~mm}$, year 2- Site 2

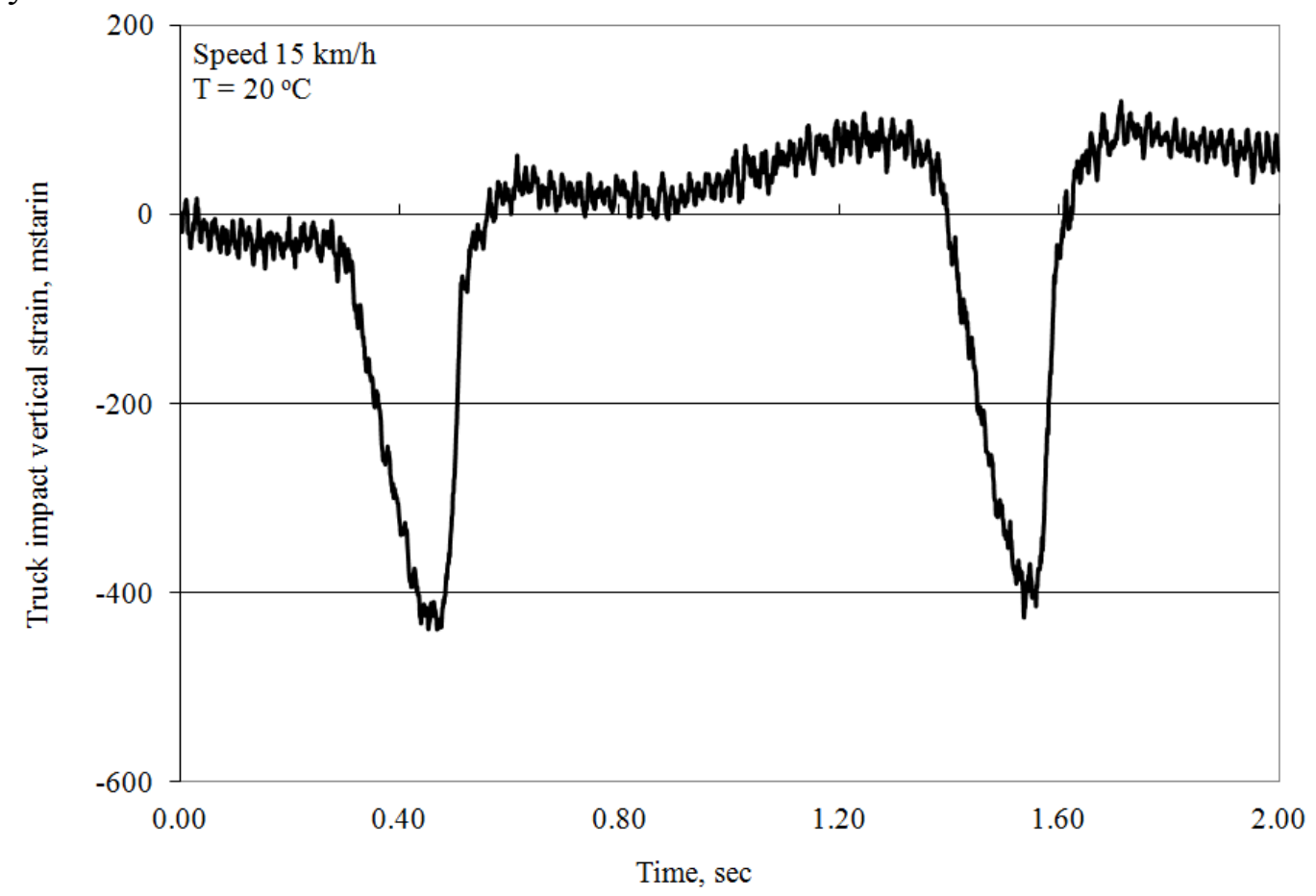

Figure 4.93: Vertical strain truck impact at a speed of $15 \mathrm{~km} / \mathrm{h}$ and a depth of $390 \mathrm{~mm}$, year 2- Site 2 


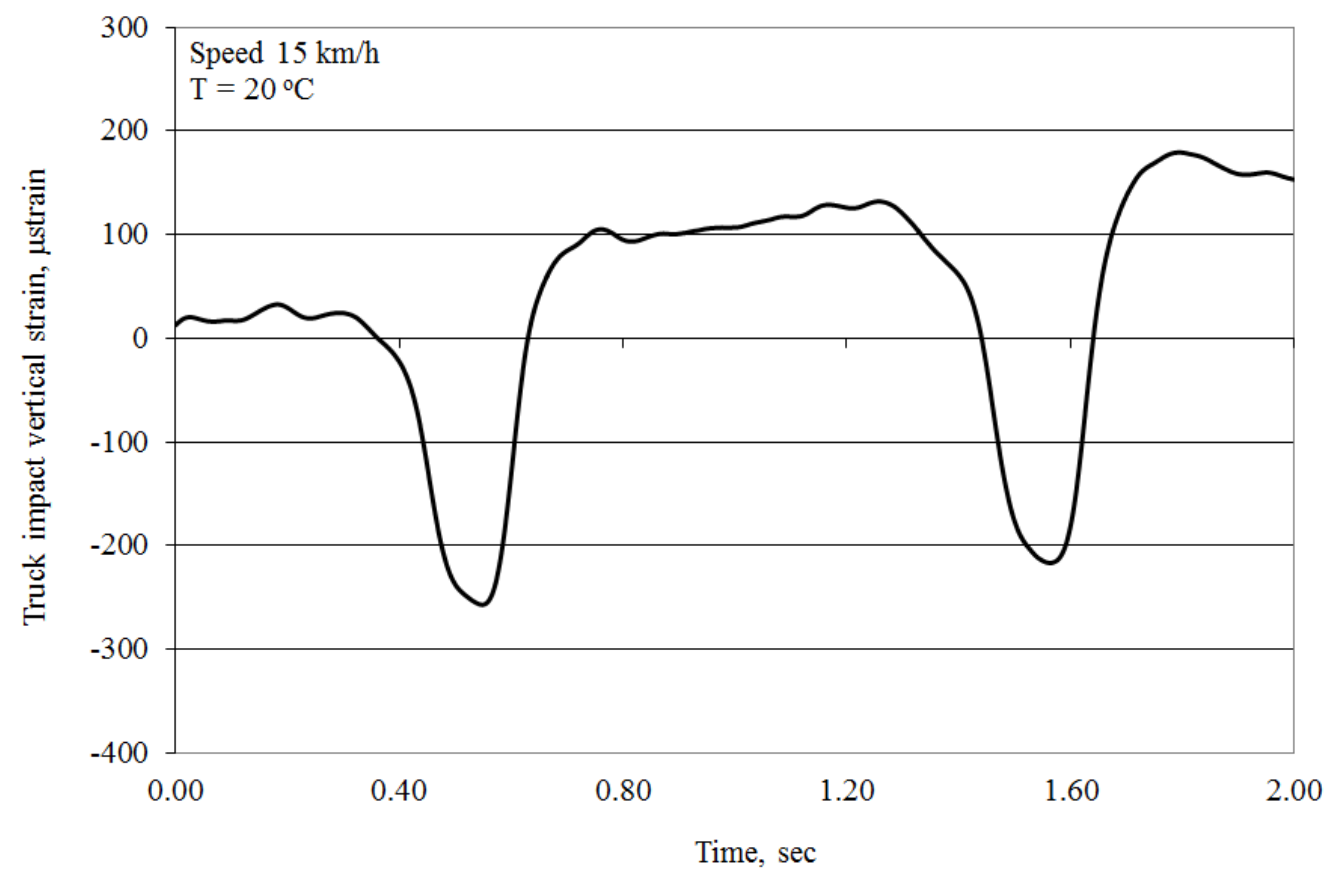

Figure 4.94: Vertical strain truck impact at a speed of $15 \mathrm{~km} / \mathrm{h}$ and a depth of $690 \mathrm{~mm}$, year 2- Site 2

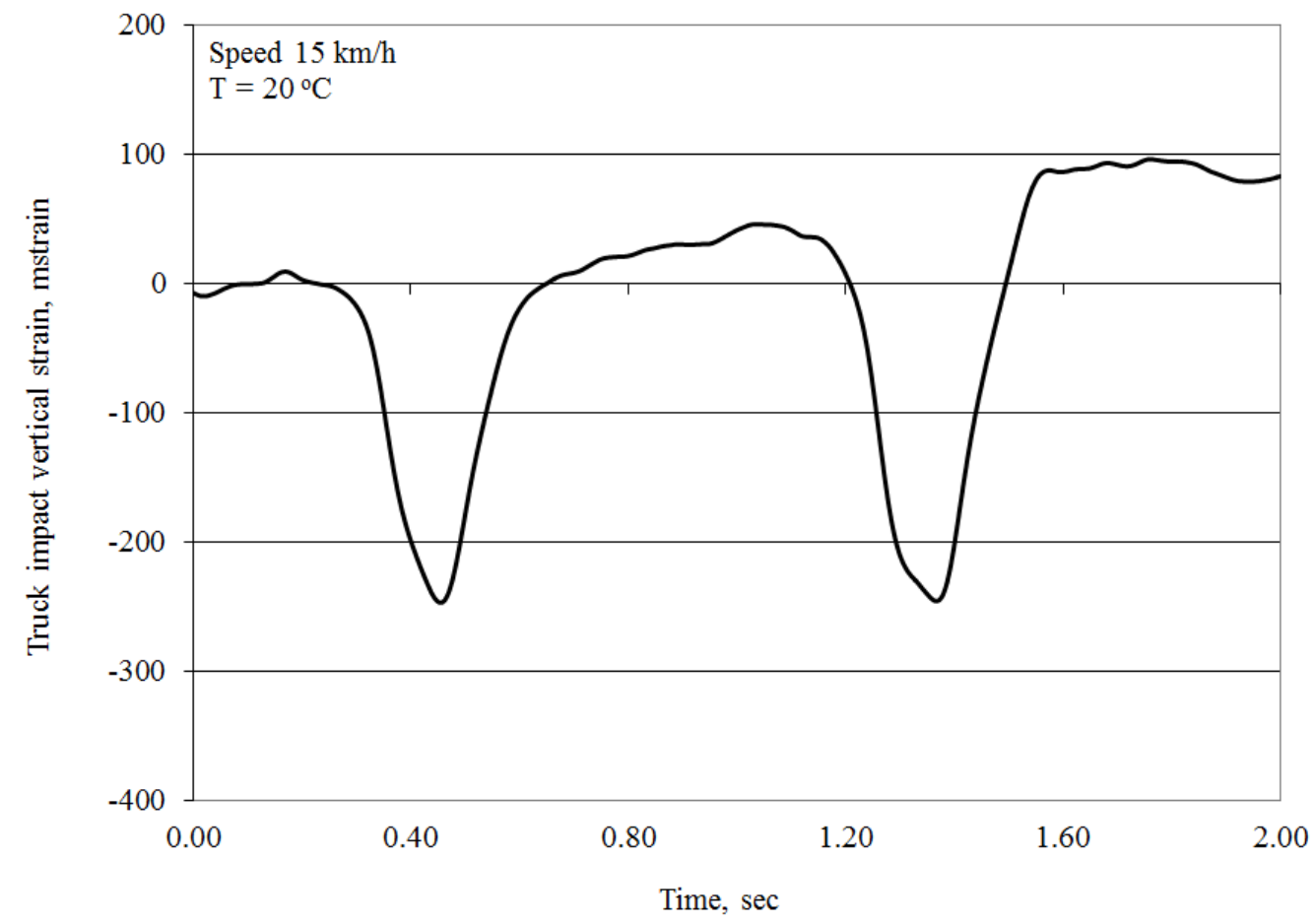

Figure 4.95: Vertical strain truck impact at a speed of $15 \mathrm{~km} / \mathrm{h}$ and a depth of $990 \mathrm{~mm}$, year 2- Site 2 


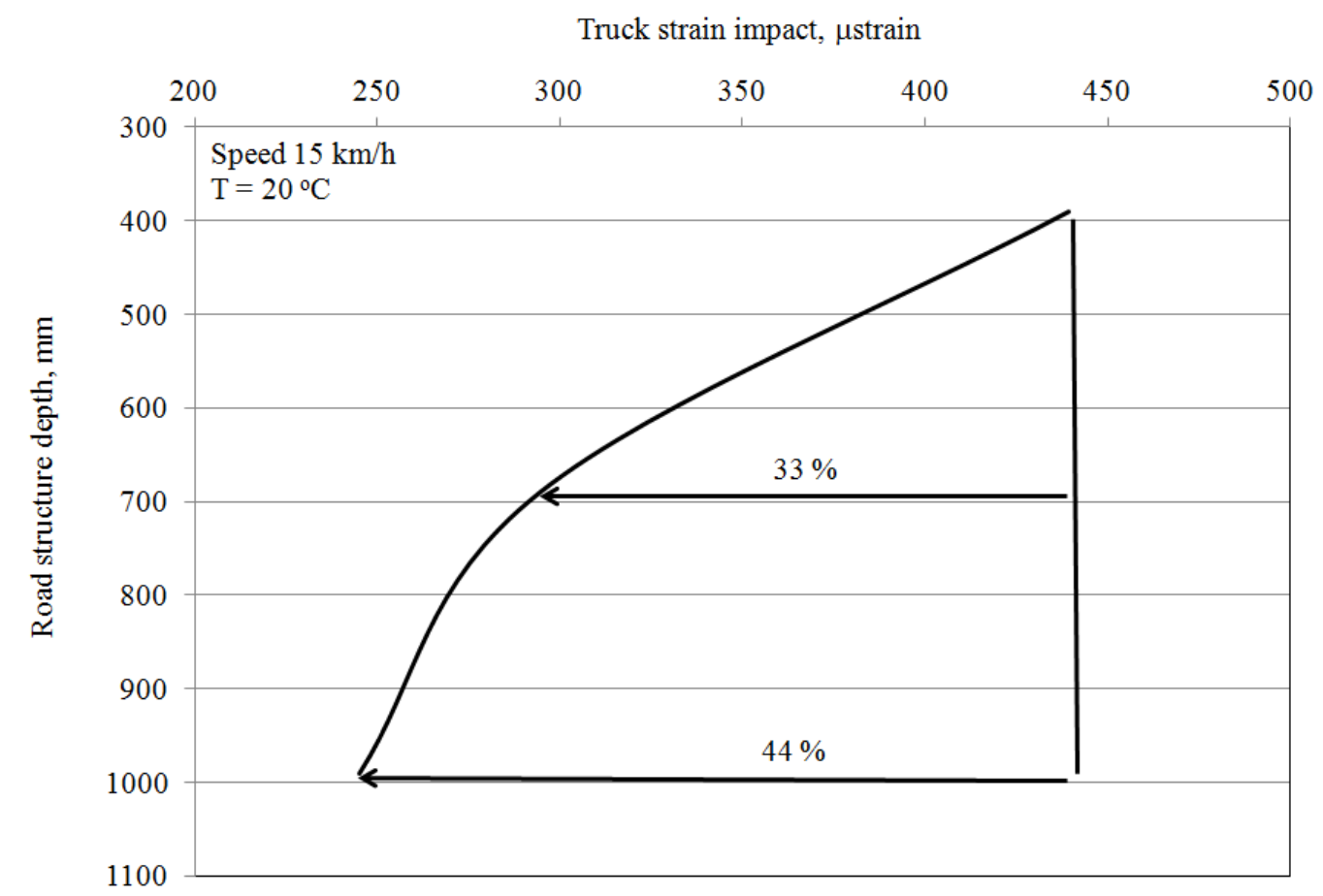

Figure 4.96: Vertical strain truck impact profile, year 2- Site 2

\subsubsection{Site 3}

Total unbound rutting of the road structure at site 3 is shown in Figure 4.97. The profile revealed that $91 \%$ of the total unbound rutting $(7.5 \mathrm{~mm})$ occurred within the first 4 months after construction. Once again the data for site 3 supported observations documented in the literature, which suggest that the majority of poor performance incidents occur at an early stage in the service life. 


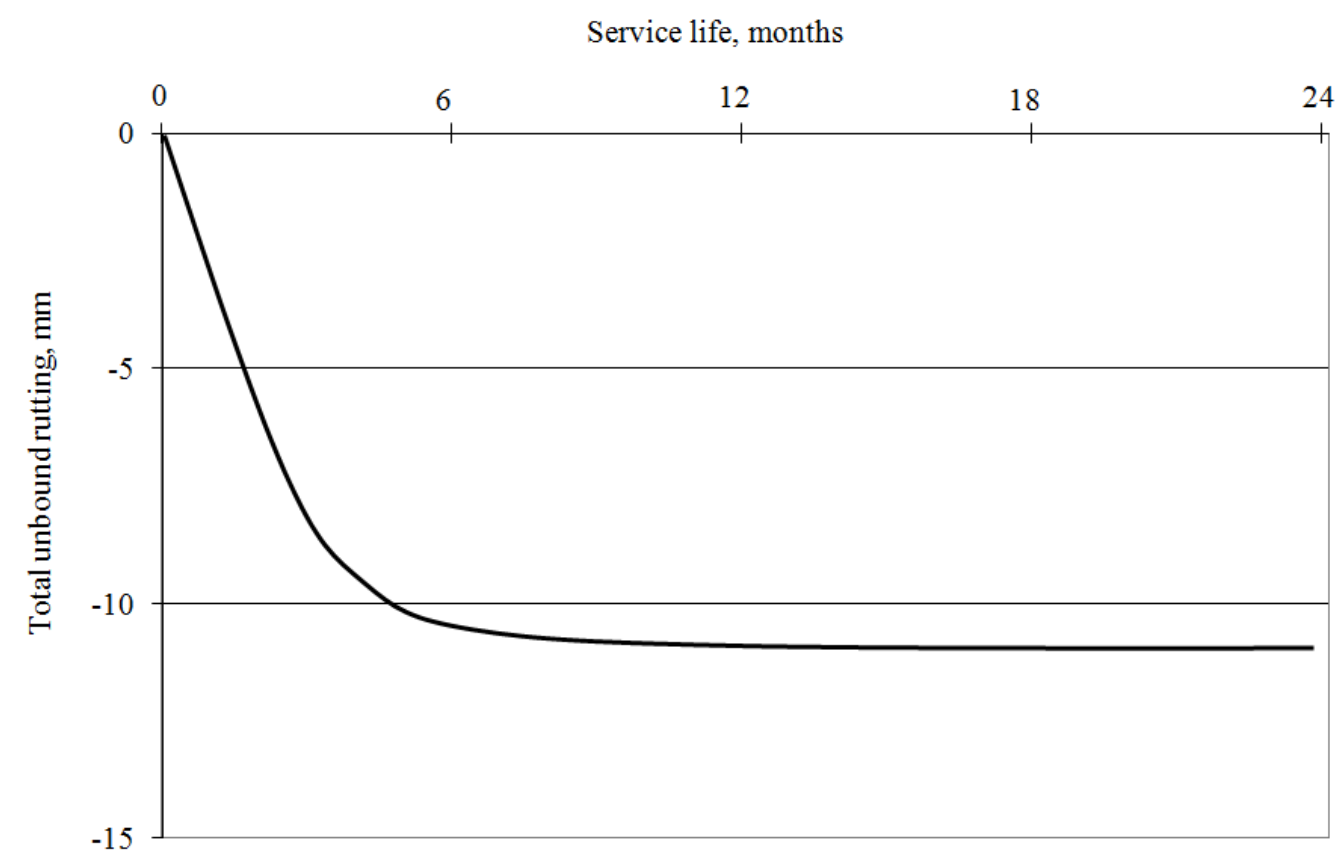

Figure 4.97: Total unbound rutting- Site 3

The survey profile for total rutting was taken perpendicular to the direction of the traffic (along the road width). Figure 4.98, shows the three survey profiles at 7, 14 and 24 months at the location where all the sensors were buried in the road. The road surface profile after 7 months was about $84 \%$ of the total rutting surveyed after 24 months. The deformation sensors (EMU coils) were buried in the design lane where heavy traffic and transit buses were expected to go through. Further analyses to Figure 4.98 leads to the establishment of total rutting with respect to road age as shown in Figure 4.99. This profile represents the total rutting at the same point where the deformation sensors were buried. By subtracting the total rutting caused by the unbound material shown in Figure 4.97 from the total rutting shown in Figure 4.99, the rutting contributed by the asphalt concrete layer was determined as shown in Figure 4.100. 
Total rutting and rutting caused by unbound and asphalt concrete will be used in this study to validate the M-EPDG output for this site.

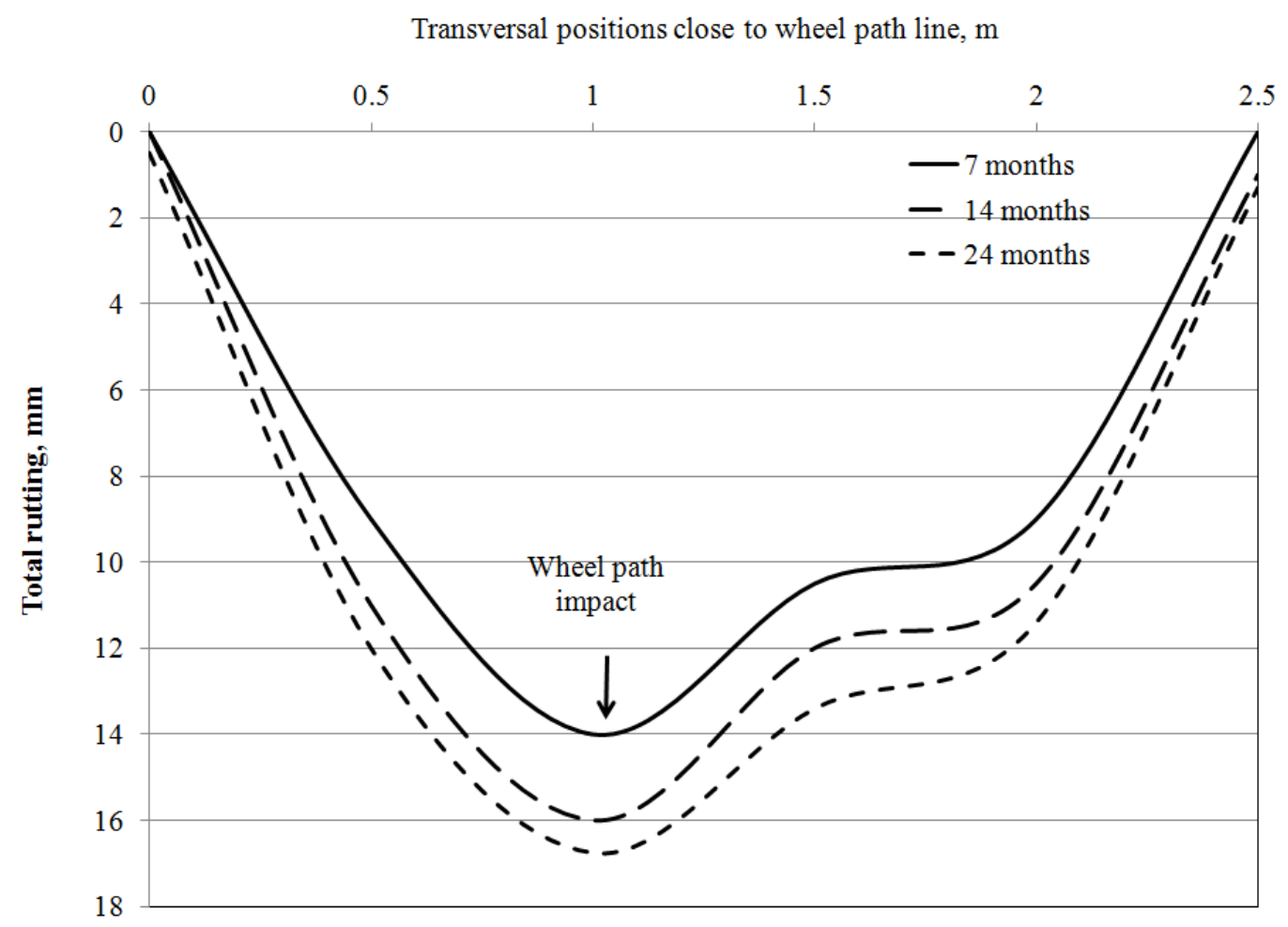

Figure 4.98: Total rutting profile along the road width- Site 3

Comparison of the total rutting at both site 2 (Figure 4.84) and site 3 (Figure 4.99) in warm and cold weather respectively, indicates that freeze and thaw cycles has significant impact on the total rutting values. 
Service life, months

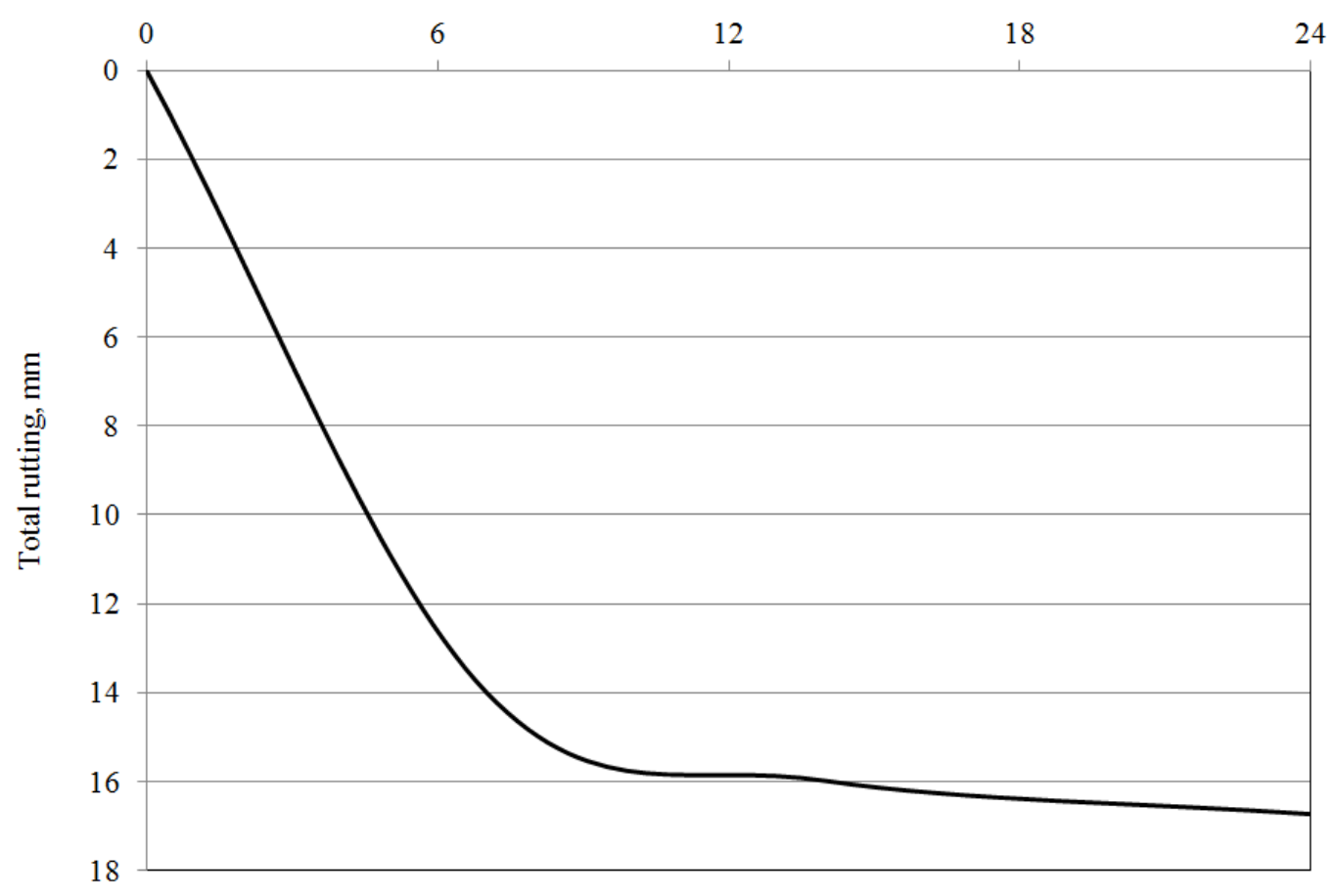

Figure 4.99: Total rutting along the wheel path- Site 3

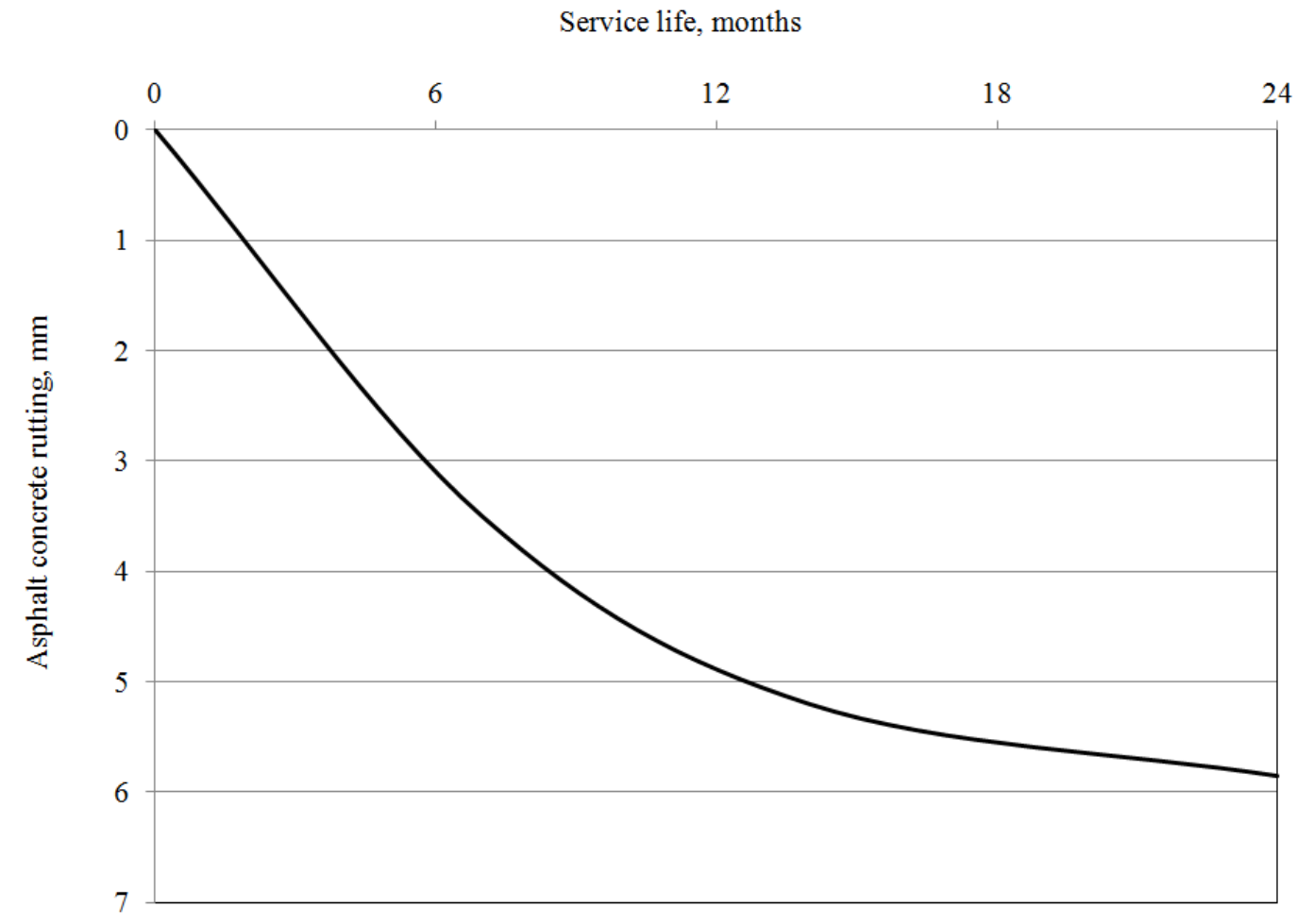

Figure 4.100: Asphalt concrete rutting along the wheel path- Site 3 
Dynamically, a three axle test truck, with axle loads of $43.24,86.65$ and $85.85 \mathrm{kN}$ from front to back respectively, was operated immediately after construction (the asphalt mat temperature was $81^{\circ} \mathrm{C}$ ) over the EMU coil gauges located at four different depth levels $(260,410,710$ and $860 \mathrm{~mm})$ as shown previously in Figure 3.16. Recorded vertical truck impact strains were collected using a dynamic data acquisition system revealing an extraordinarily high level of strain as shown in Figures 4.101 to 4.104. Maximum strains of $1518,812,457$ and $327 \mu$ strain, at depths of $260,410,710$ and $860 \mathrm{~mm}$ respectively for truck impact strain at a speed of $45 \mathrm{~km} / \mathrm{h}$ were recorded.

Data analysis revealed that the asphalt concrete temperature when these pressure levels were recorded was higher than normal road operating temperatures.

Figure 4.105 shows the truck impact vertical strain profile along the road structure layers, where the strain dropped by about $79 \%$ at a depth of $1 \mathrm{~m}$ below the asphalt concrete surface. 


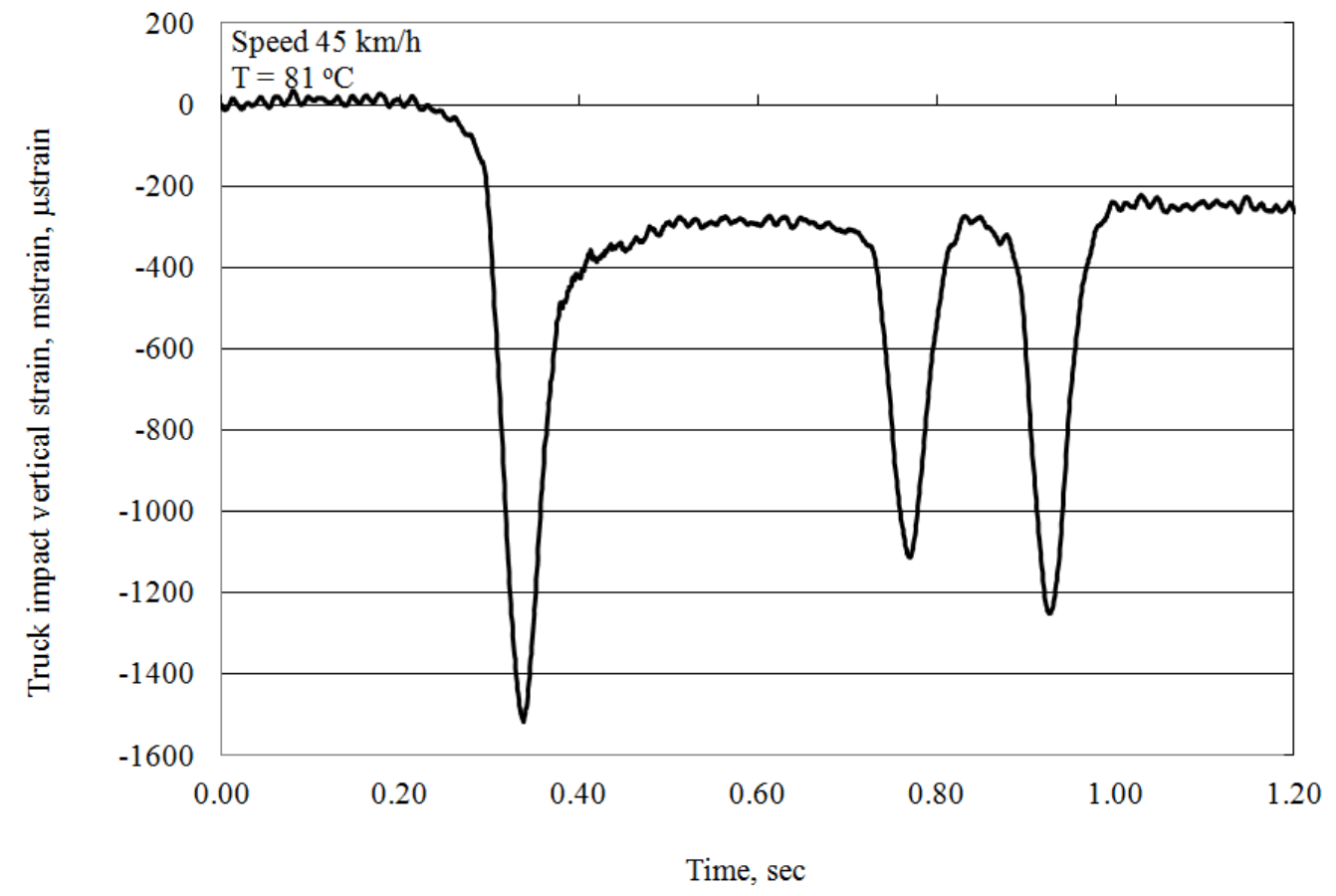

Figure 4.101: Vertical strain truck impact at a depth of $260 \mathrm{~mm}$, year 1- Site 3

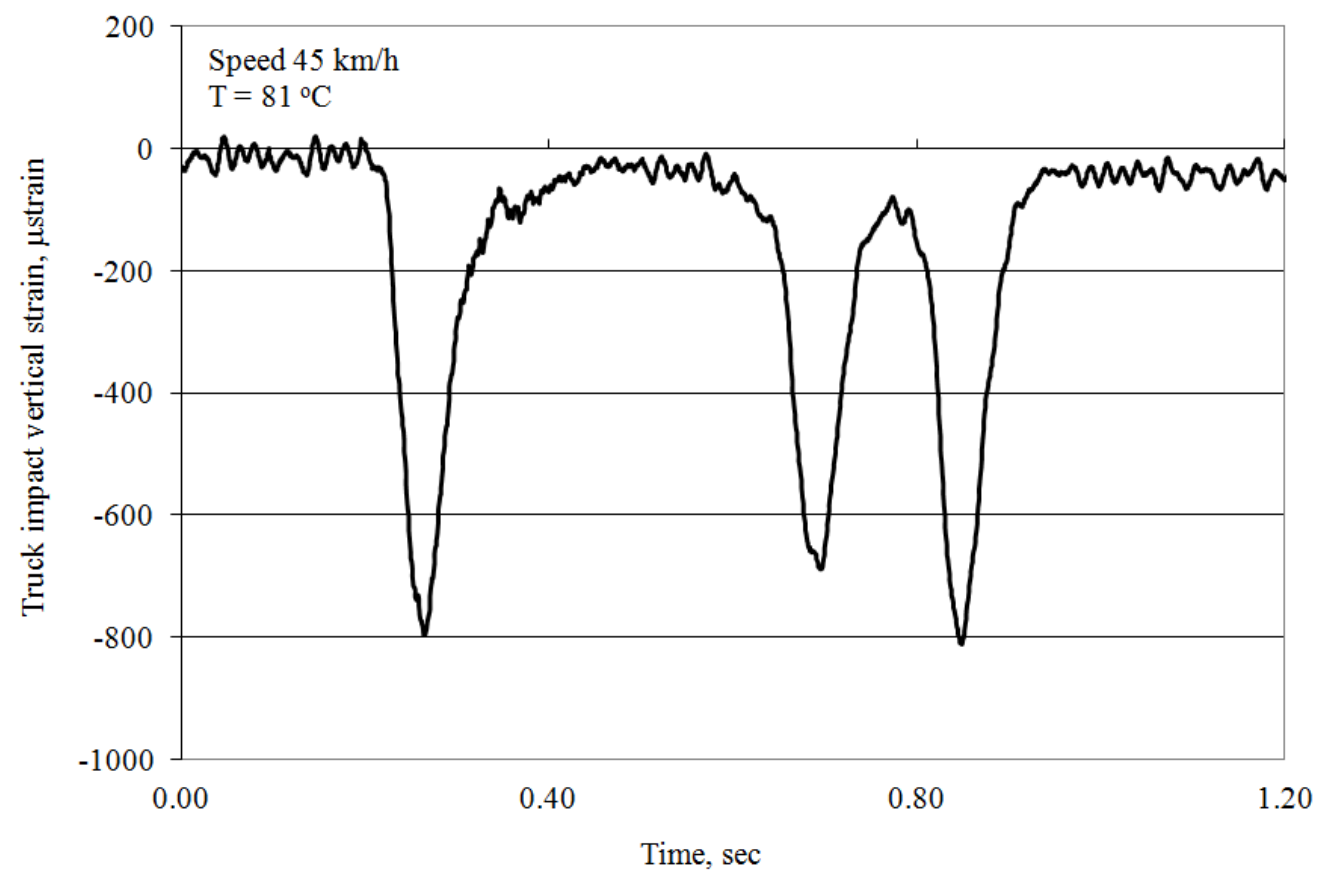

Figure 4.102: Vertical strain truck impact at a depth of $410 \mathrm{~mm}$, year 1- Site 3 


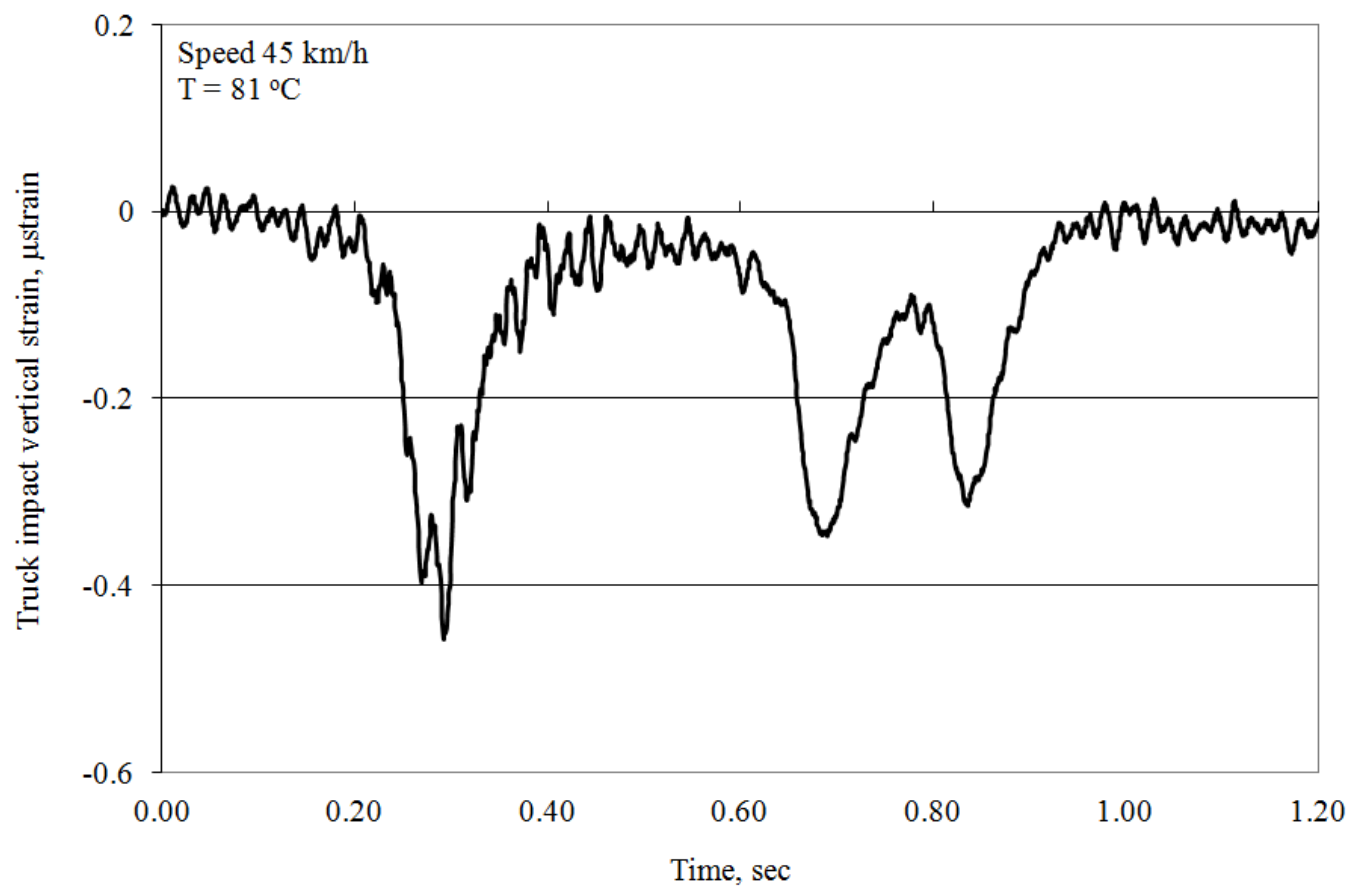

Figure 4.103: Vertical strain truck impact at a depth of $710 \mathrm{~mm}$, year 1- Site 3

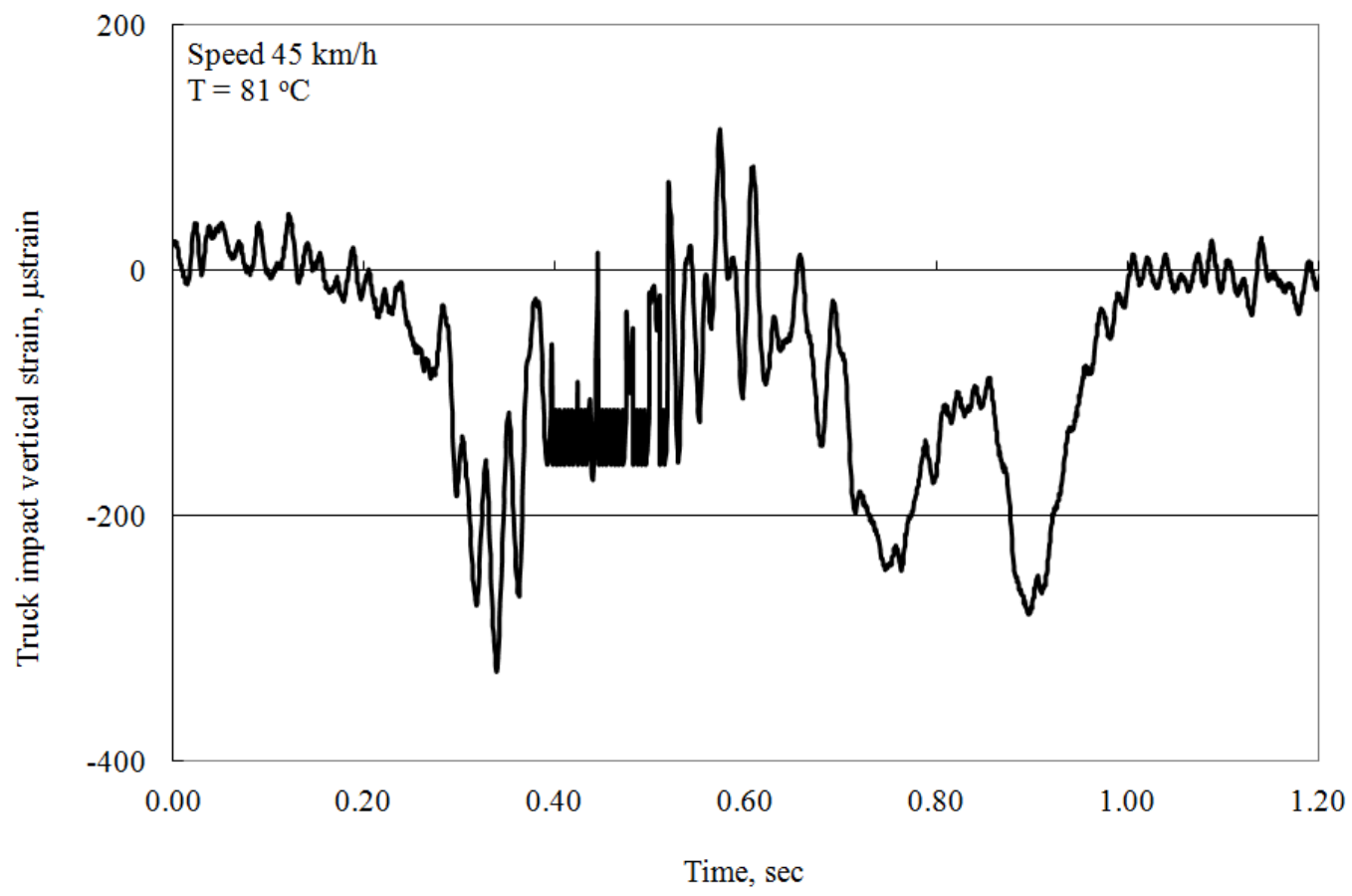

Figure 4.104: Vertical strain truck impact at a depth of $860 \mathrm{~mm}$, year 1- Site 3 


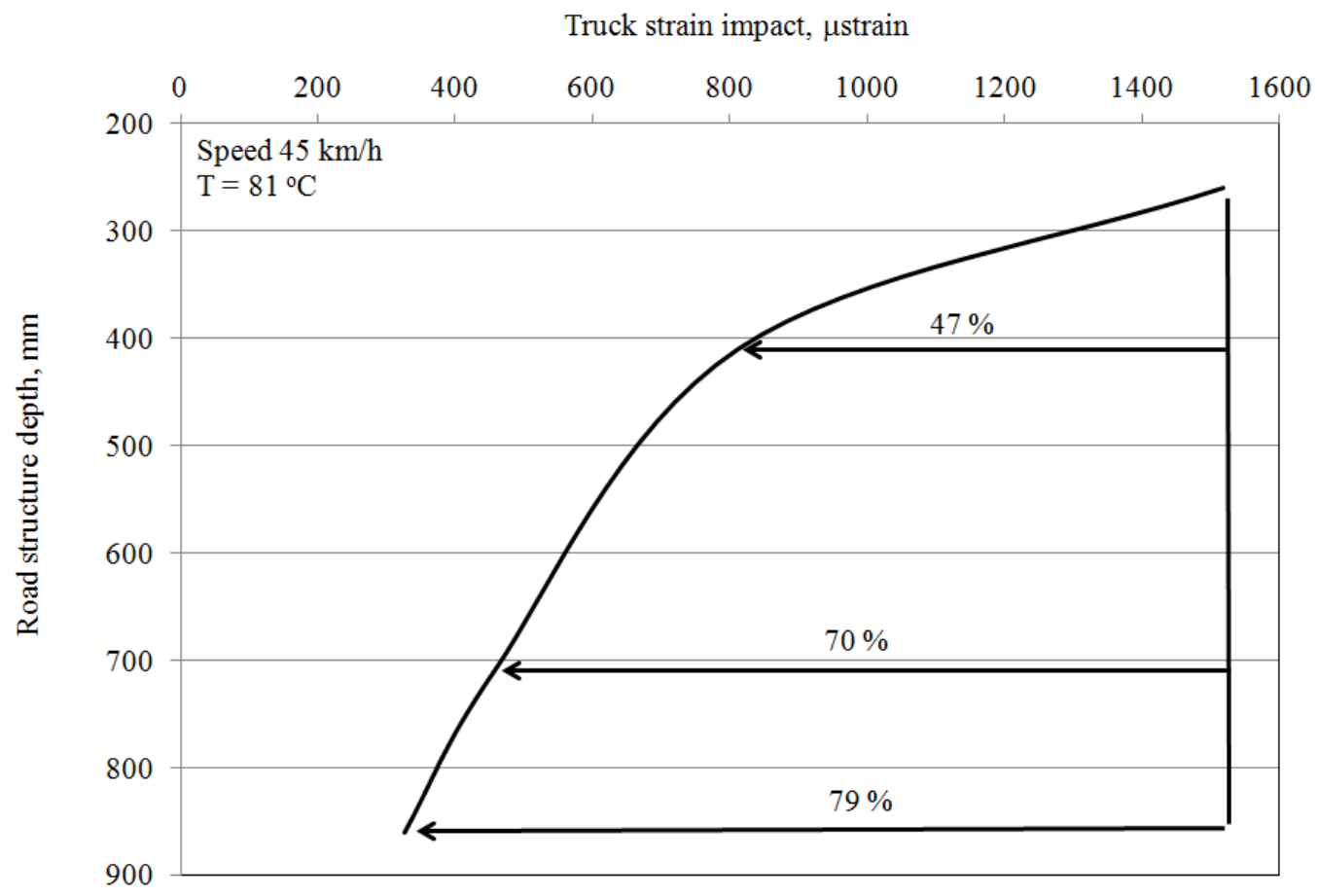

Figure 4.105: Vertical strain truck impact profile, year 1- Site 3

One year after the first truck impact strain test, the same truck was operated again over the EMU coil gauges at asphalt concrete mat temperature of $20{ }^{0} \mathrm{C}$. Figures 4.106 to 4.109 show the recorded strain signals of the test impact of the same truck. The peak truck impact strains on year 2 (second visit) are 436, 294, 226 and $150 \mu$ strain and the percentage of the strain drops are $71,64,51$ and $54 \%$ at depth levels of 260, 410, 710 and $860 \mathrm{~mm}$ respectively from year 1 to year 2 . Dropped strains were caused by the nature of unbound materials that densified due to traffic as well as the temperature at year 1 was high when the road was open to traffic.

Figure 4.110 shows the truck impact vertical strain profile along the road structure layers, the strain dropped less at year 2 . When the asphalt mat temperature was $20^{\circ} \mathrm{C}$ and 
complete densification of the road occurred the drop was $66 \%$ at a depth of $1 \mathrm{~m}$ below the asphalt concrete surface, compared to the top level (at $260 \mathrm{~mm}$ ).

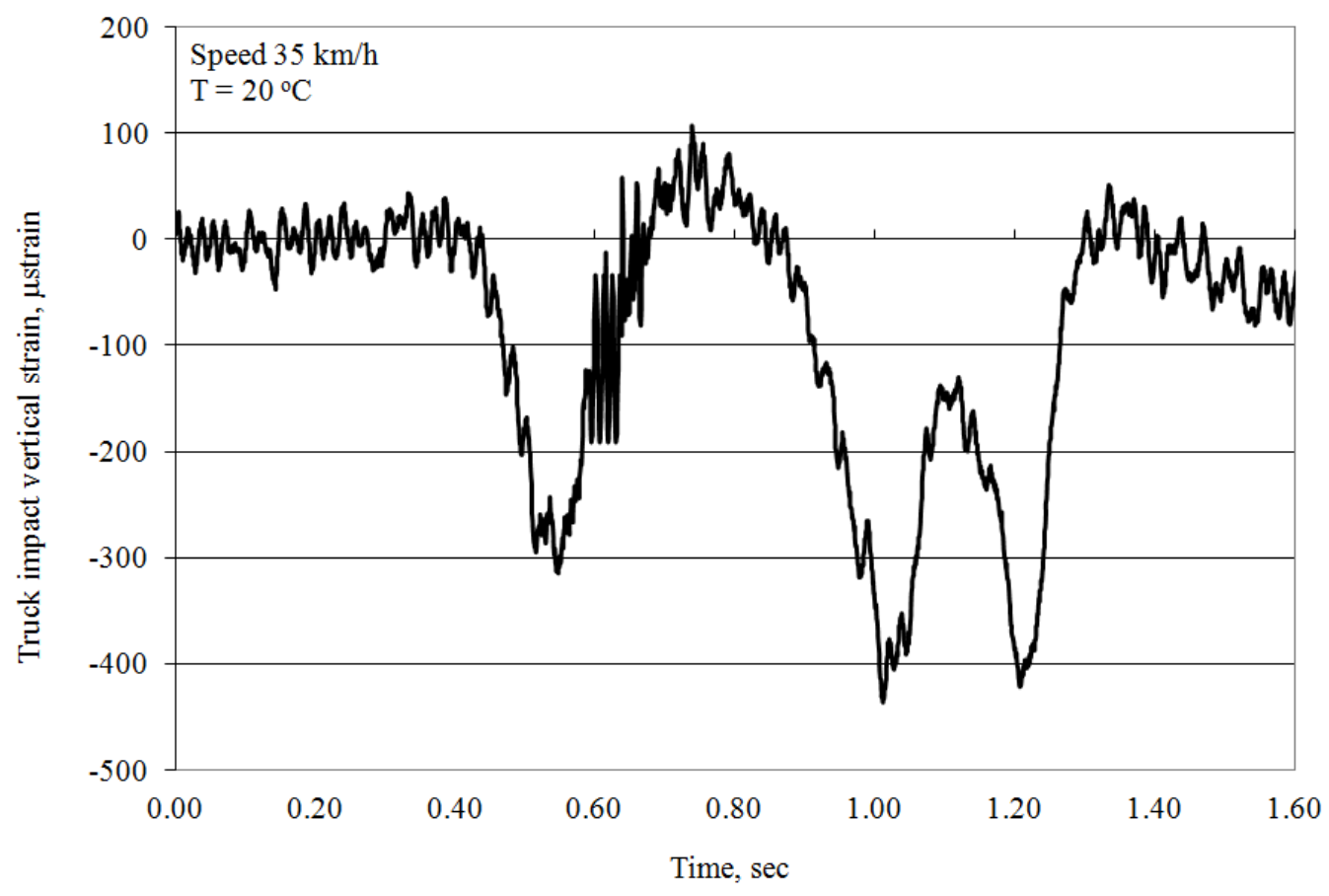

Figure 4.106: Vertical strain truck impact at a depth of $260 \mathrm{~mm}$, year 2- Site 3

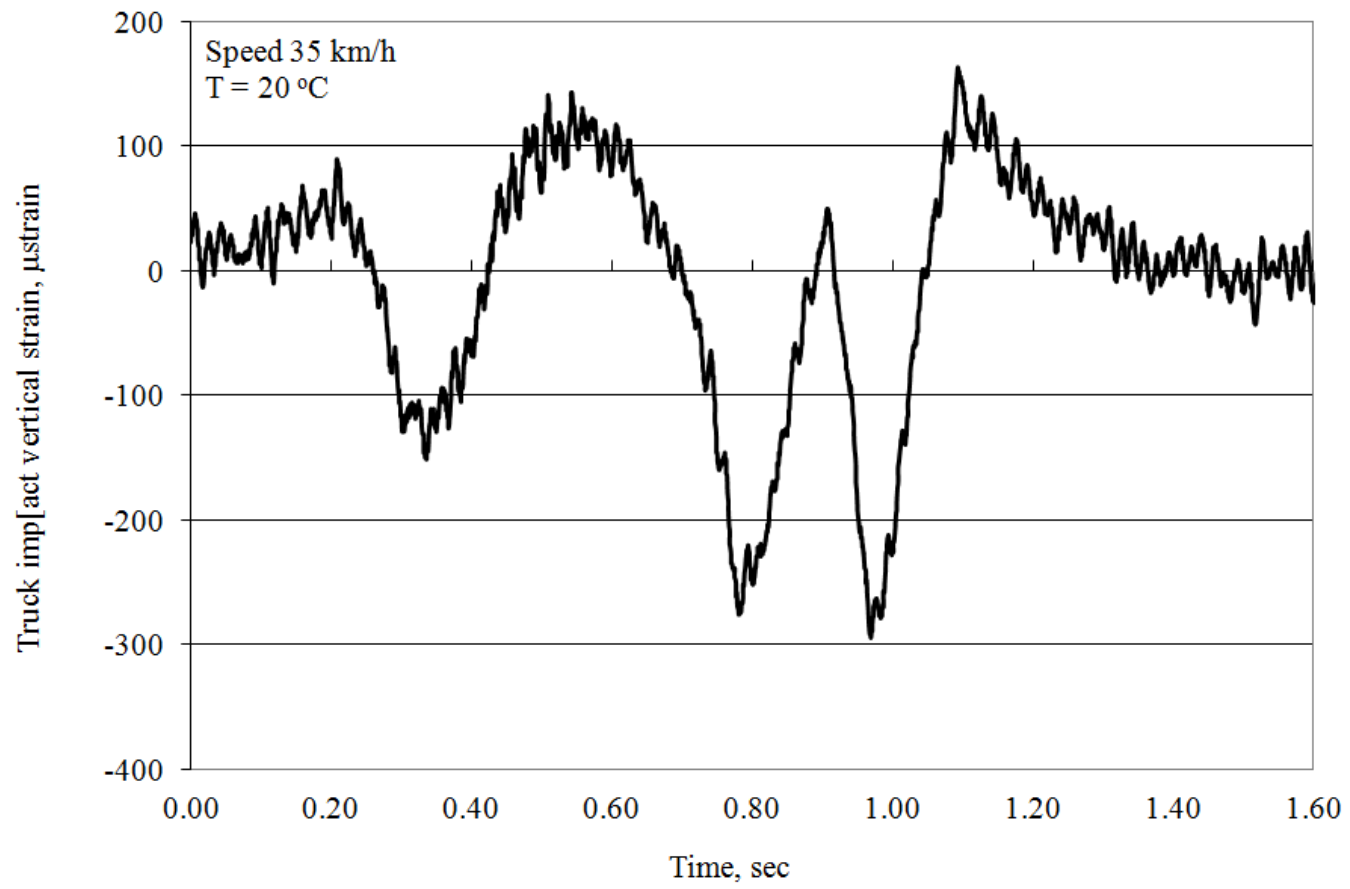

Figure 4.107: Vertical strain truck impact at a depth of $410 \mathrm{~mm}$, year 2- Site 3 


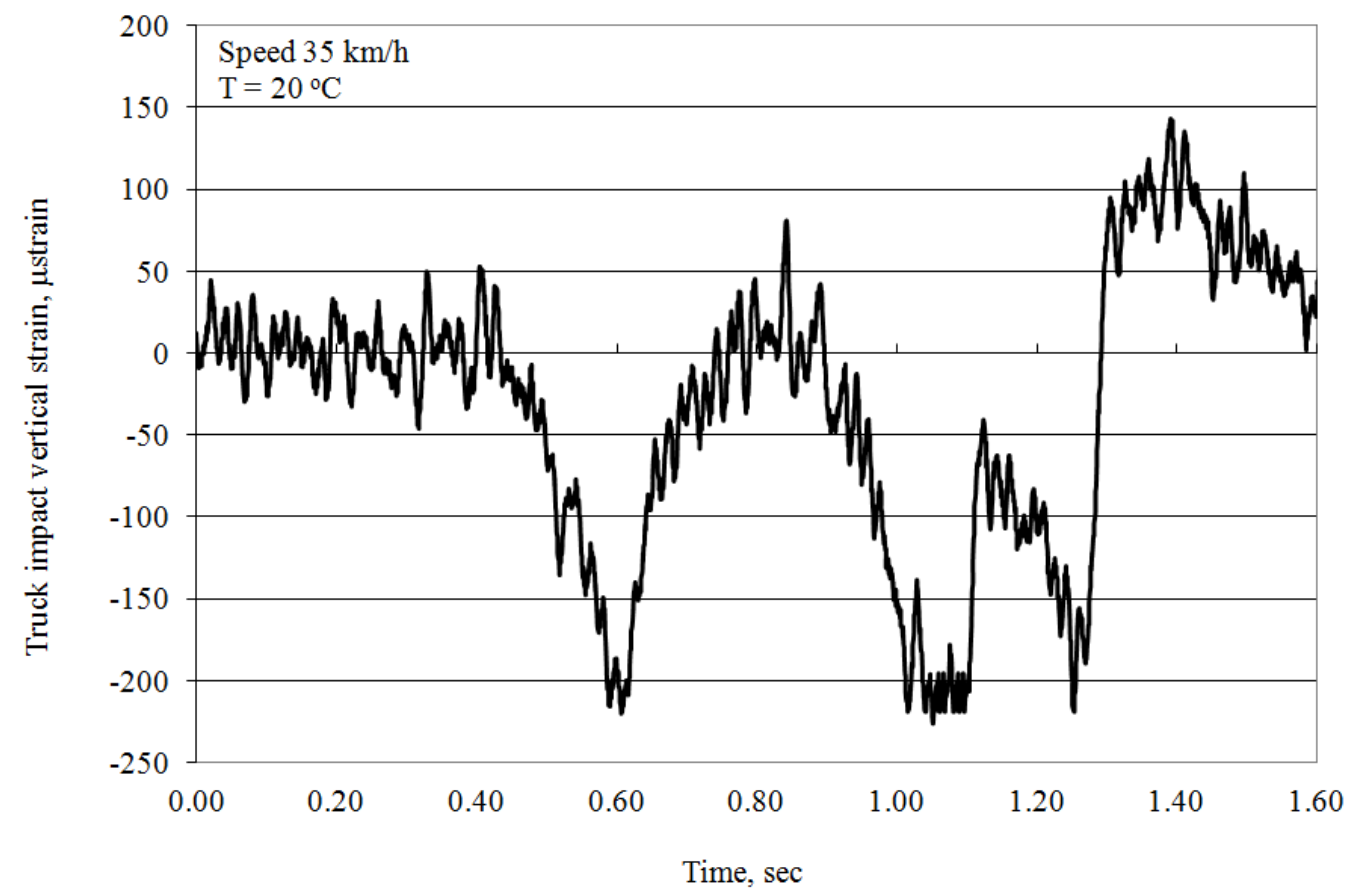

Figure 4.108: Vertical strain truck impact at a depth of $710 \mathrm{~mm}$, year 2- Site 3

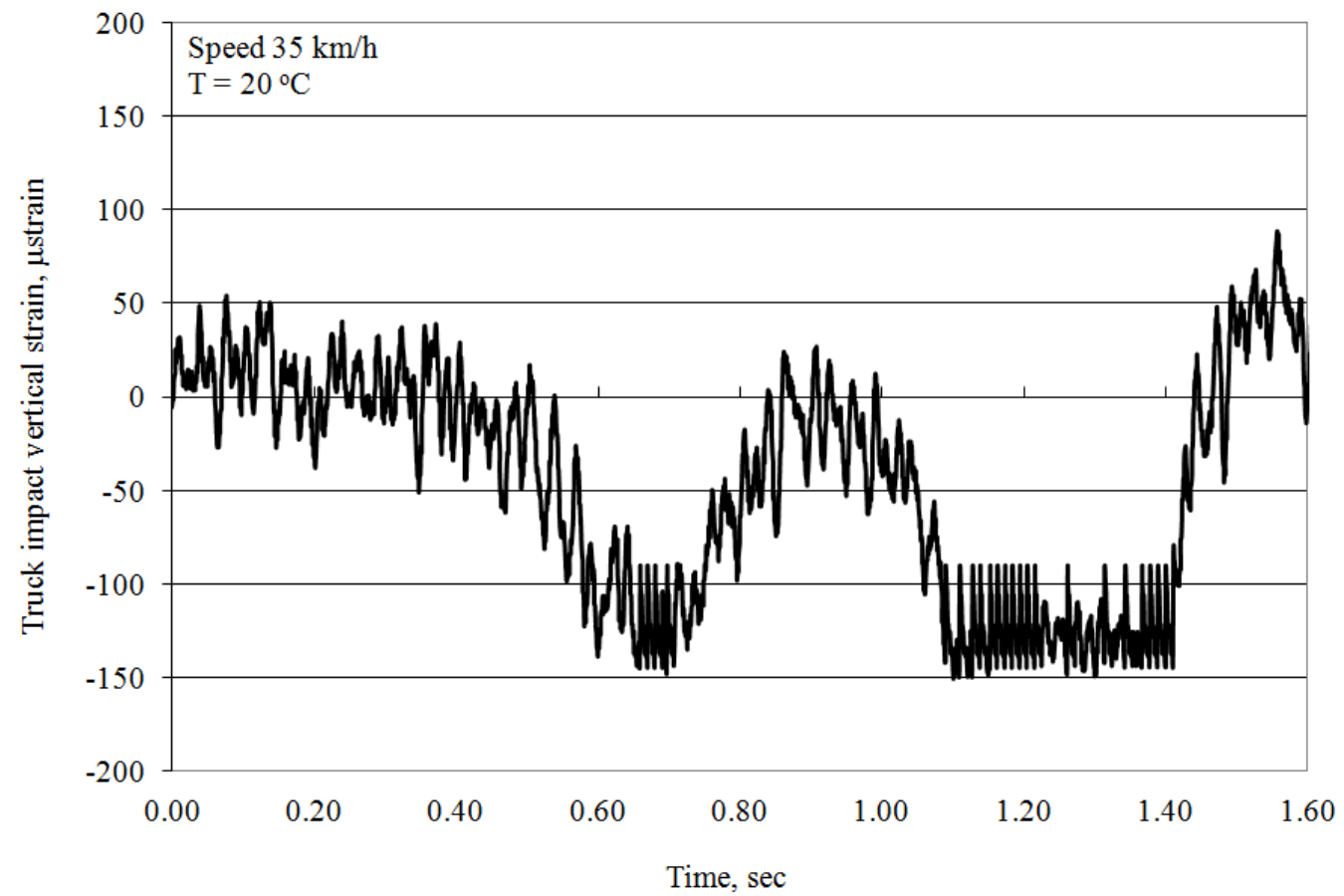

Figure 4.109: Vertical strain truck impact at a depth of $860 \mathrm{~mm}$, year 2- Site 3 


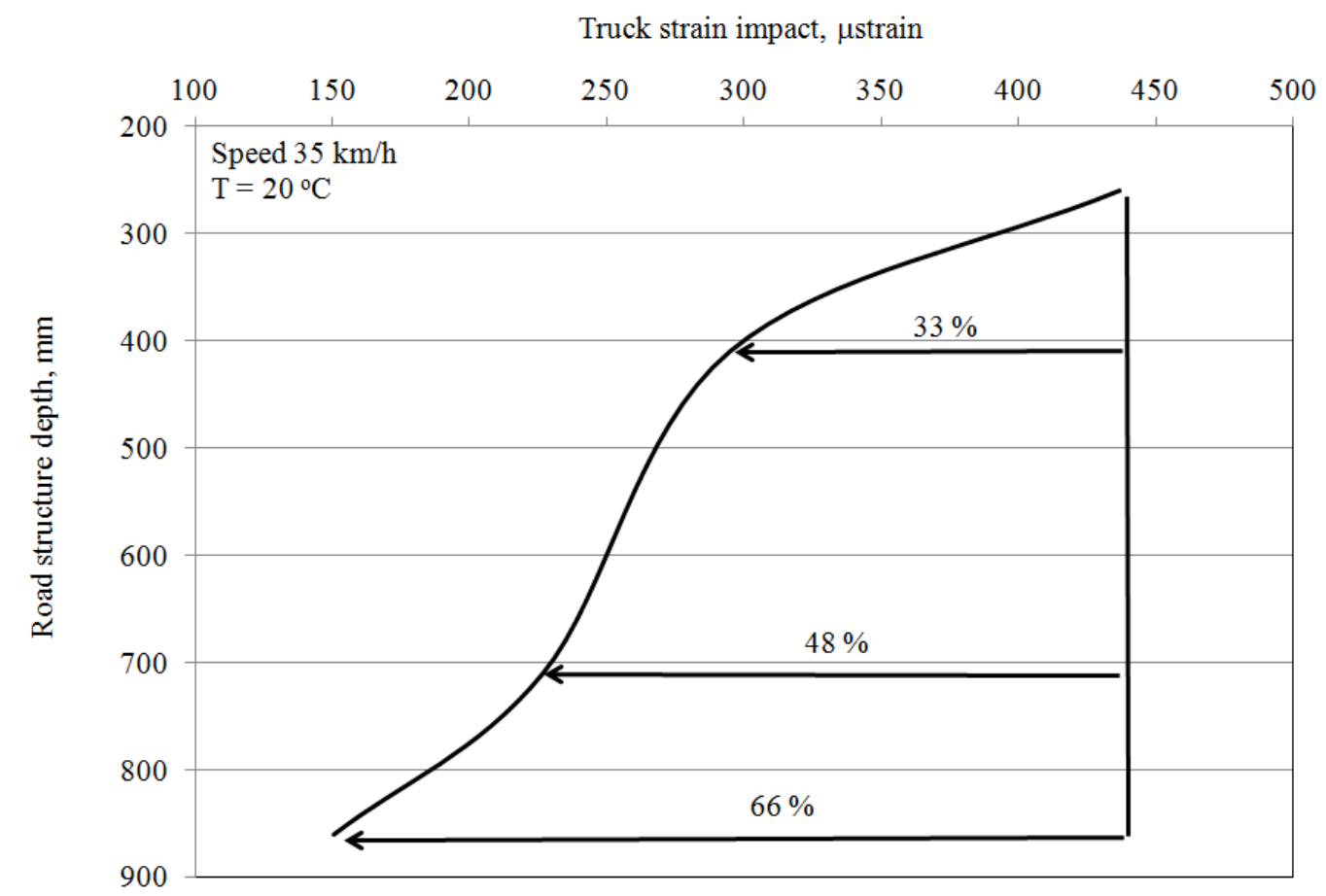

Figure 4.110: Vertical strain truck impact profile, year 2- Site 3

\subsection{Impact of loading speed and asphalt concrete temperature on structural data}

\subsubsection{Speed effect}

One of the new capabilities of the M-EPDG is to consider the effect of speed on pavement performance. Therefore, the field speed effect was studied to determine the impact of known trucks on top of asphalt strain gauges, unbound pressure cells and unbound EMU coil gauges throughout the road structure layers at sites 2 and 3 . The MEPDG sensitivity analysis of the speed effect on pavement performance will be discussed further later.

As a tire rolls over the roadway, it applies then removes a load. This induces a strain on the asphaltic concrete and strain and pressure on unbound materials. Typically, it is assumed that the asphaltic concrete and unbound materials behaviour is purely elastic and the strain that is induced is completely recovered. While this is true for the majority 
of the strain, some is not recovered and leads to plastic deformation and compaction of the asphaltic concrete. While the tire will apply the same loading on the asphaltic concrete when the speed of traffic is increased, it will spend less time in contact with the road. The result of less contact time with asphaltic concrete is less compaction, and therefore less rutting will occur.

Figure 4.111 shows the relationship of pressure impact at a depth of $290 \mathrm{~mm}$ with truck speeds of 20 and $35 \mathrm{~km} / \mathrm{h}$ at site 2 . The speed increase of $75 \%$ leads to a decrease in the pressure impact of $19 \%$. In the case of truck strain impact when the speed increased from $15 \mathrm{~km} / \mathrm{h}$ to $35 \mathrm{~km} / \mathrm{h}$ (a $133 \%$ increase), it resulted in a strain decrease of $37 \%$ as shown in Figure 4.112. Moreover, the pressure impact gradient throughout the depth for those two speeds was plotted in Figure 4.113. It is noted that the average drop in pressure is about $20 \%$ along the road structure layer when speed is increased by $75 \%$.

Typical truck impact pressures at different speeds on the top pressure cell are shown in Figure 4.114. A speed increase from 3 to 20 and $25 \mathrm{~km} / \mathrm{h}$ resulted in a decrease of pressure by 39 and $43 \%$, respectively.

A creep truck impact study at a speed of $0 \mathrm{~km} / \mathrm{h}$ was made and resulted in a very high truck pressure impact. Figure 4.115 shows the pure pressure gradient (no overburden) throughout the road structure layer at speed of $0,3,20$ and $25 \mathrm{~km} / \mathrm{h}$. The maximum percentage of truck pressure impact decreased by $80 \%$ as truck speed increased 0 to $25 \mathrm{~km} / \mathrm{h}$.

Most of the pavement performance problems occurred at locations where buses stop close to a traffic signal. This finding highlights the importance of traffic speed. MEPDG is considering this parameter and will be evaluating the sensitivity of it in this 
study. Further analysis of the results is plotted in Figure 4.116. It shows truck speed up to the range of $5 \mathrm{~km} / \mathrm{h}$ has great impact on the asphalt road layer structure.

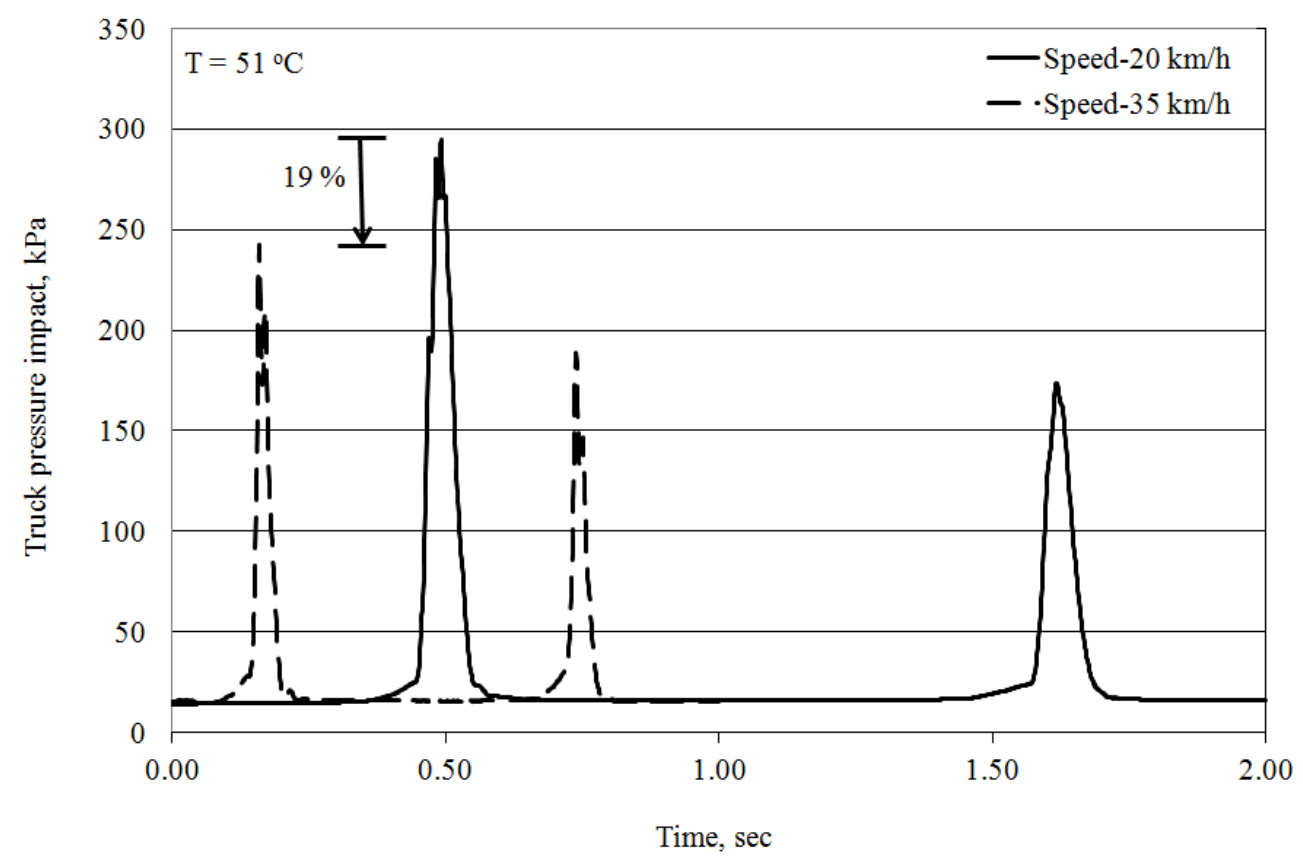

Figure 4.111: Effect of speed on the top pressure cell at a depth of $290 \mathrm{~mm}$, year 1- Site 2

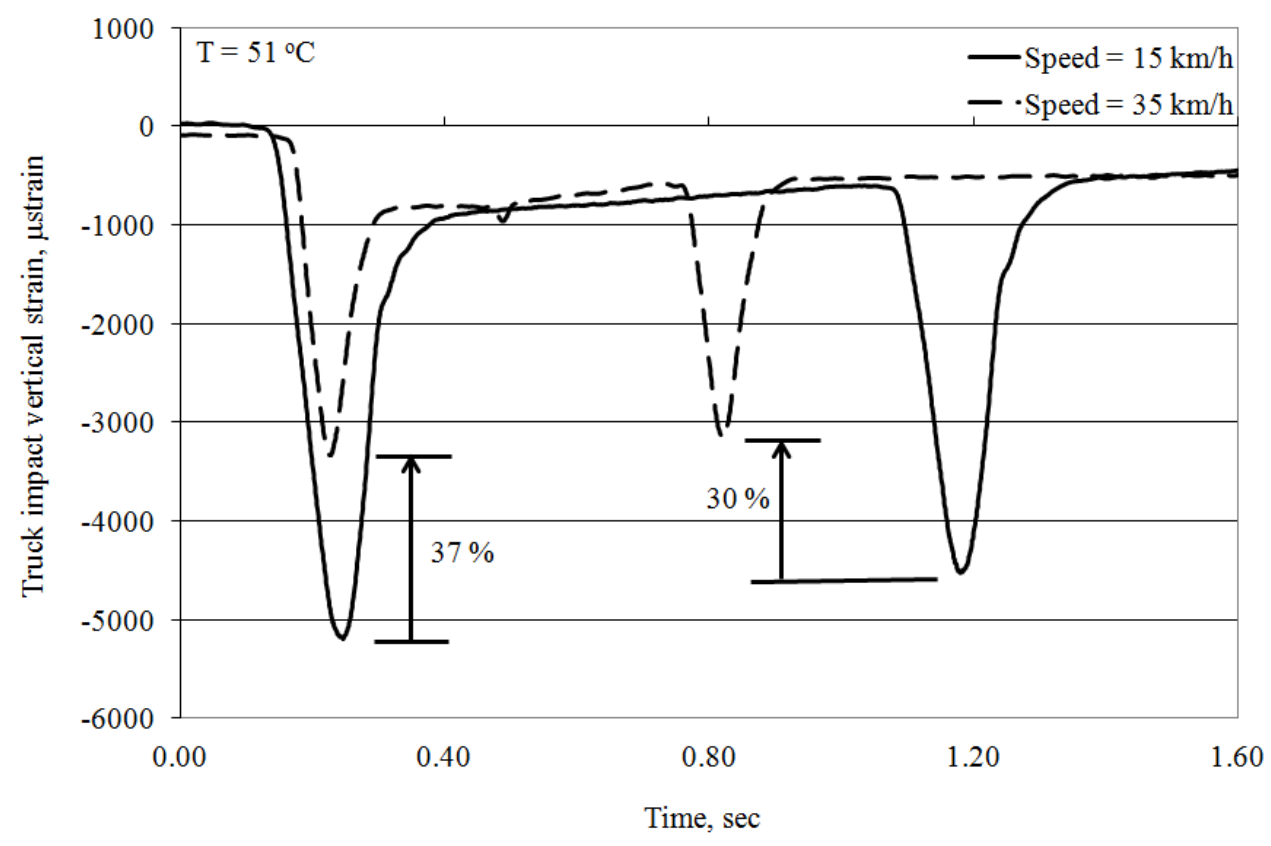

Figure 4.112: Speed effect on truck strain impact at a depth of $390 \mathrm{~mm}$, year 1- Site 2 
Truck impact pressure, $\mathrm{kPa}$

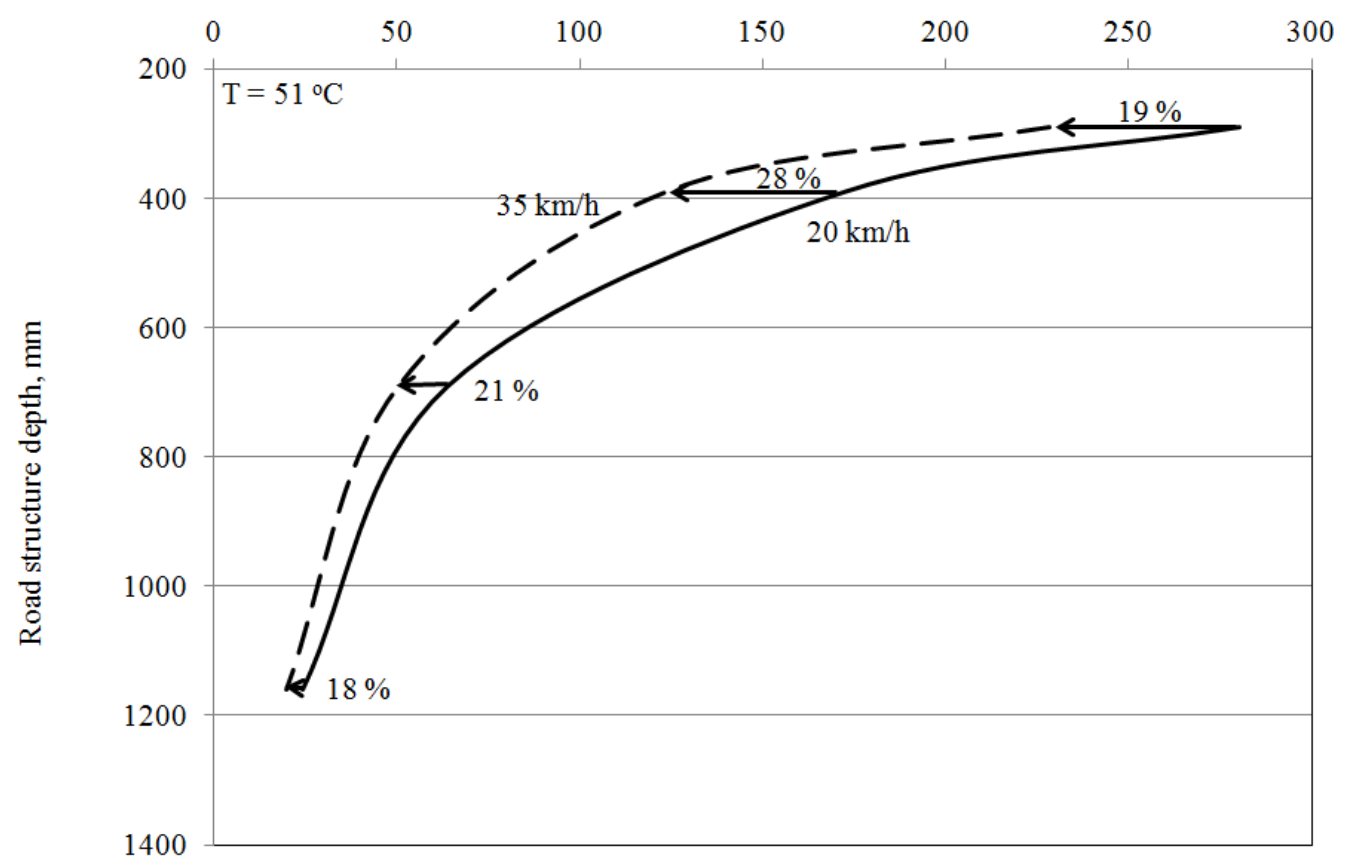

Figure 4.113: Effect of speed on pressure profile on year 1- Site 2

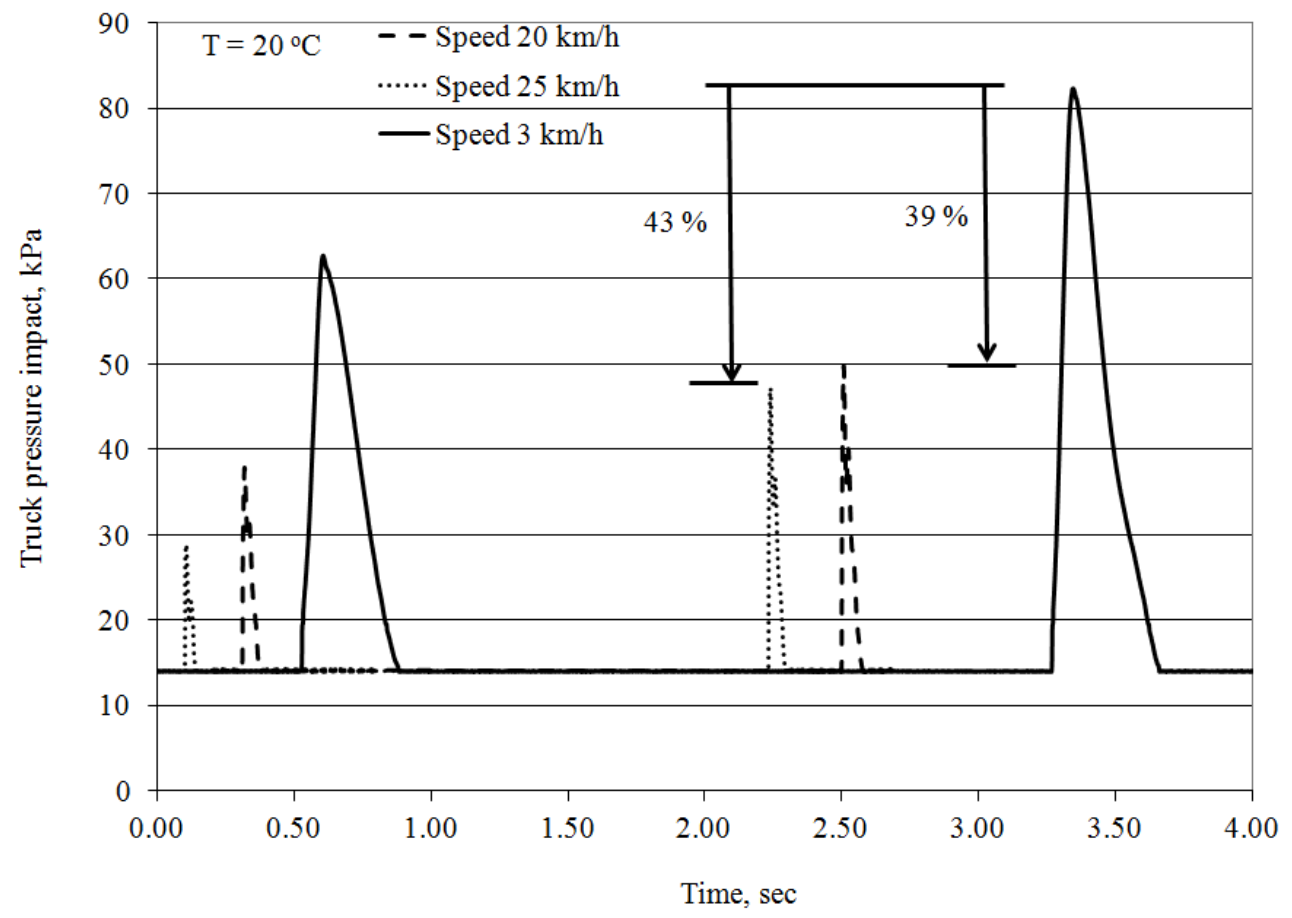

Figure 4.114: Effect of speed on the top pressure cell at depth $290 \mathrm{~mm}$ year 3- Site 2 


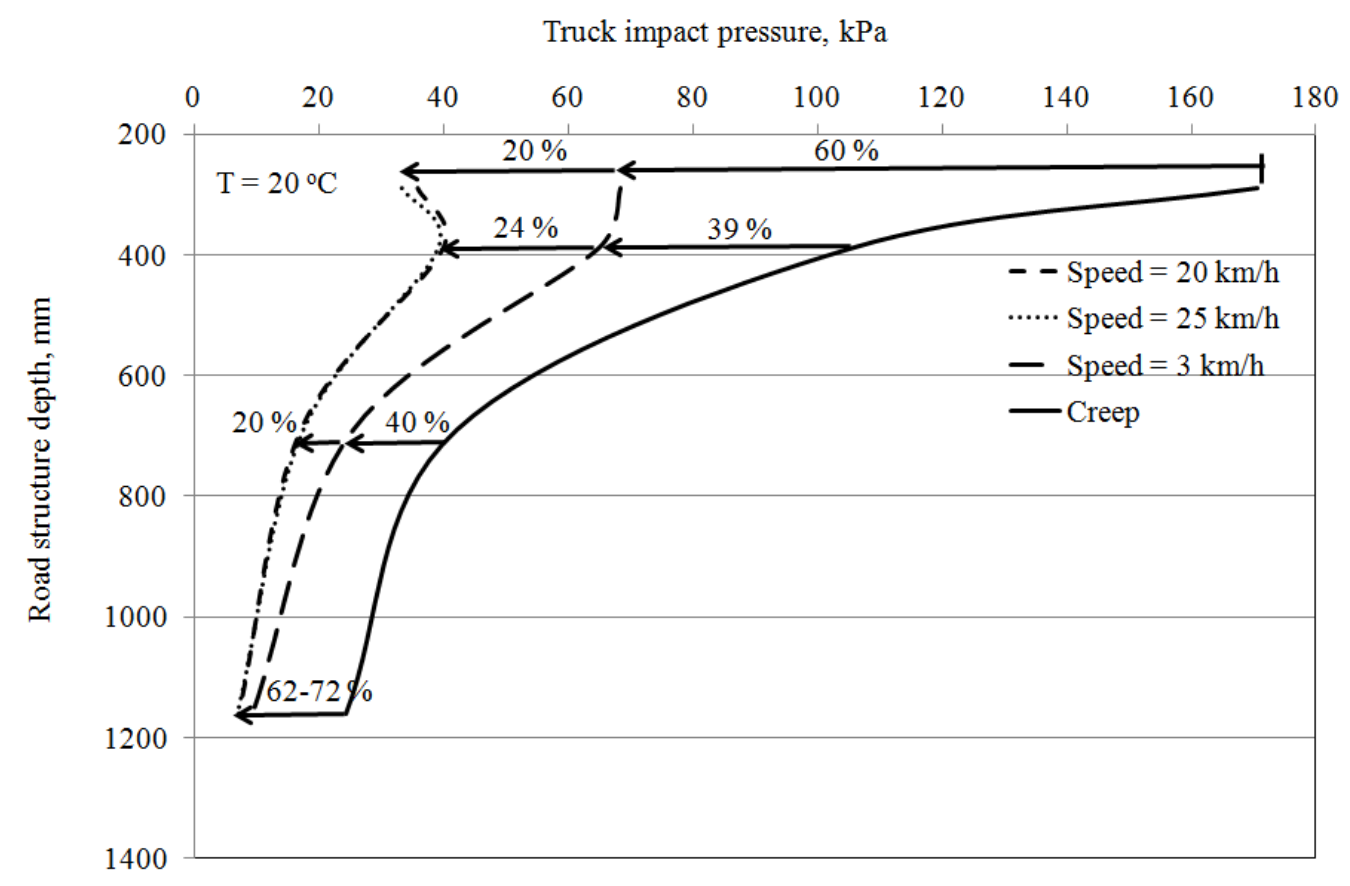

Figure 4.115: Effect of speed on the truck impact pressure profile year 3- Site 2

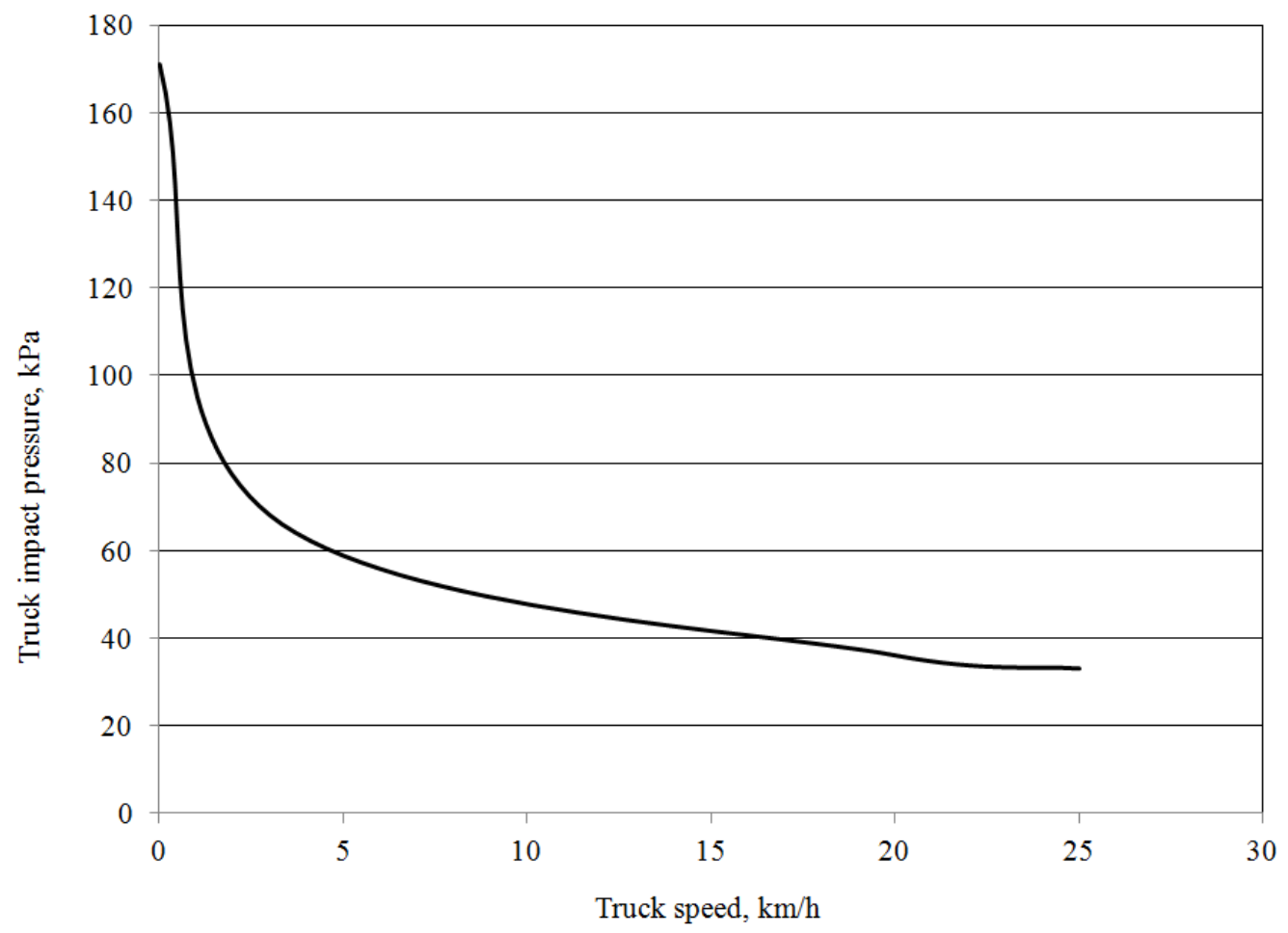

Figure 4.116: Truck impact pressure and speed profile at depth $290 \mathrm{~mm}$ year 3- Site 2

The relationship of pressure impact at a depth of $260 \mathrm{~mm}$ of truck speed of 2 and $35 \mathrm{~km} / \mathrm{h}$ for site 3 is shown in Figure 4.117 . The truck pressure impact dropped by 23 and 
$28 \%$ when the speed increased to $35 \mathrm{~km} / \mathrm{h}$. Moreover, the pressure impact gradient throughout the depth (no overburden) for those two speeds is plotted in Figure 4.118. It is noted that the average drop in pressure is about $27 \%$ close to the surface and $9 \%$ at a 1 $m$ depth below the surface.

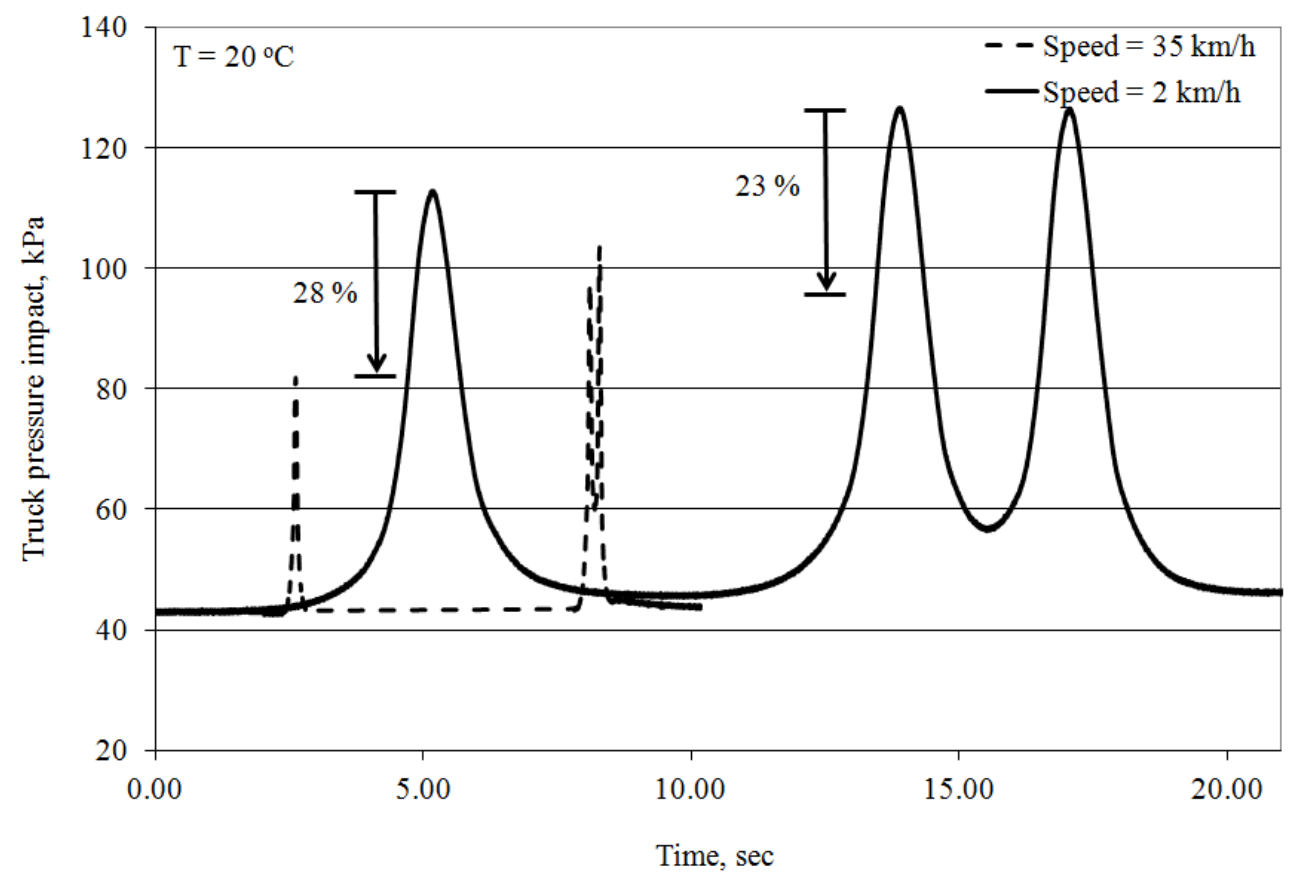

Figure 4.117: Speed effect on the top pressure cell at a depth of $260 \mathrm{~mm}$, year 2- Site 3 


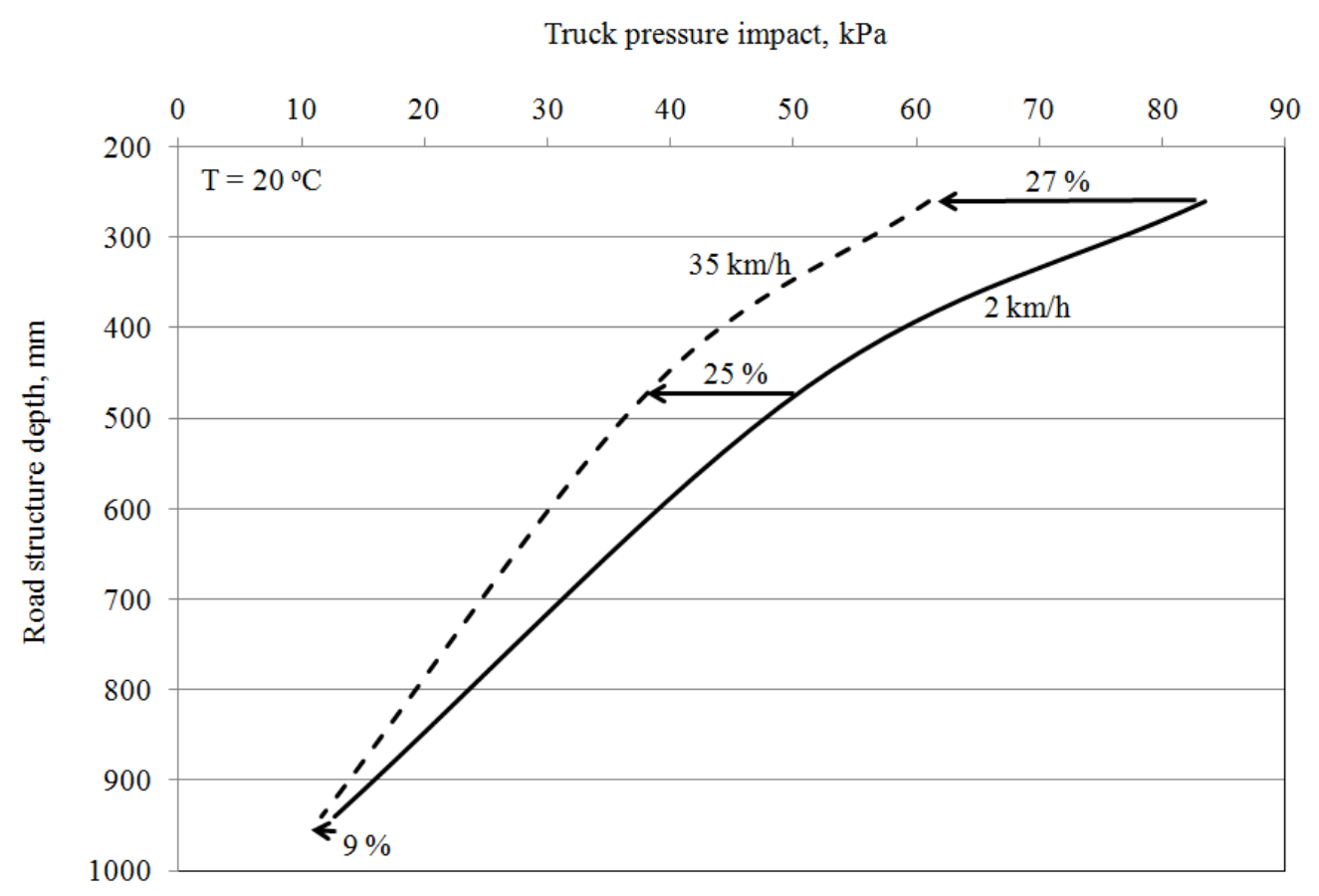

Figure 4.118: Speed effect on pressure profile, on year 2- Site 3

\subsubsection{Asphalt concrete temperature effect}

The behaviour of an asphalt concrete mixture, similar to its binder, depends on temperature and load frequency and is reflected in its stiffness characteristics.

Viscoelastic properties of asphalt materials are generally determined within the linear viscoelastic domain when the material is subjected to sinusoidal loading at different frequencies at small values of strain. However, when temperatures are above $40^{\circ} \mathrm{C}$, the mixtures can no longer be treated as linear viscoelastic. At low temperatures, the behaviour of asphalt concrete is considered to be a combination of both elastic and little linear viscoelastic. This behaviour can be considered purely elastic and viscoelastic under measurements are obtained with low strain amplitude. The modulus value of asphalt concrete materials can rise during the cold winter months by a factor of 20 compared to 
its value during the hot summer months. The modulus values are dependent on the time of loading and temperature.

The value of the dynamic modulus reflects the stiffness of the mixture and its resistance to deformation at a designated frequency and temperature. Creep compliance and tensile strength tests are considered to be the most promising for predicting the lowtemperature performance of asphalt concrete mixtures.

Characterization of pavement materials in the proposed M-EPDG level 1 involves an application of the dynamic modulus technique and creep compliance determinations for asphalt concrete. The M-EPDG also incorporated the Enhanced Integrated Climatic Model (EICM) to simulate changes in the behaviour and characteristics of pavement and sub-grade materials that concur with climatic conditions over the design period.

Based on the above discussion and the field results presented in this study, it appears that investigating the impact of high temperature on the pressure and strain transmitted through the asphalt concrete layer to the unbound materials road structure layers is of high importance.

A study was performed to evaluate the impact of asphalt concrete temperature on the distribution of stresses and strains within the pavement structure. The high stress and strain was registered when the road was opened to traffic (test truck operation). The asphalt concrete temperature was still relatively high and the fresh mix exhibited a low modulus compared with that at normal road operating temperatures. The results were needed to support the development and importance of evaluating the sensitivity of MEPDG with respect to different climatic conditions and to support of consideration of the including the effect of temperature on the asphalt material stiffness. 
Truck loading tests conducted immediately after the construction (asphalt concrete temperature of $51^{\circ} \mathrm{C}$ ) indicated that extremely high stresses were transferred to the backfill layers of the road structure layers. These are unprecedented levels of stress, reaching as high as $290 \mathrm{kPa}$. This suggests that the high stress levels have a significant impact on the response of the asphalt concrete layer and underlying backfill layers. The low asphalt concrete stiffness associated with high temperatures (above normal operating temperatures) reduces the material's ability to function properly as a surface layer responsible for distributing surface loads and minimizes the effectiveness of lower layers. The high stresses detected during the initial service life at the site 2 are alarming and are expected to affect the performance of the backfill layers below the asphalt concrete layer. Figure 4.119 shows the relationship of pressure impact at depth of $290 \mathrm{~mm}$ for a truck speed of $20 \mathrm{~km} / \mathrm{h}$ at asphalt concrete temperatures of 51 and $20^{\circ} \mathrm{C}$. Cooling the asphalt concrete from $51^{\circ} \mathrm{C}$, (open to traffic) to $20^{\circ} \mathrm{C}$ (normal operating temperature) and asphalt concrete road aging ( 2 years) resulted in a 71 to $87 \%$ decrease in the truck pressure impact.

The truck impact pressure gradient for a road structure layer at asphalt concrete temperatures of $51^{\circ} \mathrm{C}$ (representing open to traffic) and $20^{\circ} \mathrm{C}$ (representing both 2 years pavement aging and normal operating temperature) is shown in Figure 4.120. A drop in pressure of about 87 and $71 \%$ occurred of the depth increased from 290 to $1170 \mathrm{~mm}$. This drop is believed to be due to the temperature and densification of the backfill material under the action of general traffic.

Additionally, creep truck impact tests were performed for both conditions, i.e. for open to traffic just after construction when the asphalt concrete temperature was about 
$44^{\circ} \mathrm{C}$, and after 2 years of in-service road pavement at $20^{\circ} \mathrm{C}$. The tests were carried out at a pressure cell depth of $390 \mathrm{~mm}$ which resulted in a very high truck pressure impact of $280 \mathrm{kPa}$ compared to $170 \mathrm{KPa}$, in year 3 ( Figure 4.121). Further analysis of the data in Figure 4.121, indicated that the creep impact after 2 years of construction was still very high. This finding was not reported in the literature associated with conventional road practices and it does not include a reference to field data or analytical simulations at such high levels of stress as well as this type of test.

Figure 4.122 shows the pure creep gradient (no overburden) throughout the road structure layer at the same conditions mentioned above. The pressure gradient was measured for the open to traffic condition (at $44^{\circ} \mathrm{C}$ asphalt concrete temperature) and 2 years after the construction condition (aging and $20^{\circ} \mathrm{C}$ asphalt concrete temperature) and was found to decrease by 39 and $26 \%$ at depths of $390 \mathrm{~mm}$ and $1160 \mathrm{~mm}$, respectively.

This creep test mimics the effect of bus stoppages and general traffic impact at a light signal. Once again, this finding highlights the importance of considering the traffic creep impact and the role of this impact in the M-EPDG.

The site 3 truck impact tests were carried out right after construction finished (open to traffic) at an asphalt concrete temperature of $81^{\circ} \mathrm{C}$ and after 1 year of construction, which represented the aging effect as well as a normal operating asphalt concrete temperature at $20^{\circ} \mathrm{C}$. The results confirmed the unprecedented high stress level caused by low asphalt stiffness. Figure 4.123 shows typical results of truck impact pressure at a depth of $260 \mathrm{~mm}$. Further analysis of the results showed that the maximum impact decreased by $75 \%$ when the asphalt concrete temperature dropped from 81 to $20^{\circ} \mathrm{C}$ and the 2 year aging effect was considered. The truck impact pressure gradients 
(without overburden) for the same conditions are shown in Figure 4.124. The impact dropped to 75 and $67 \%$ at depths of 260 and $940 \mathrm{~mm}$, respectively.

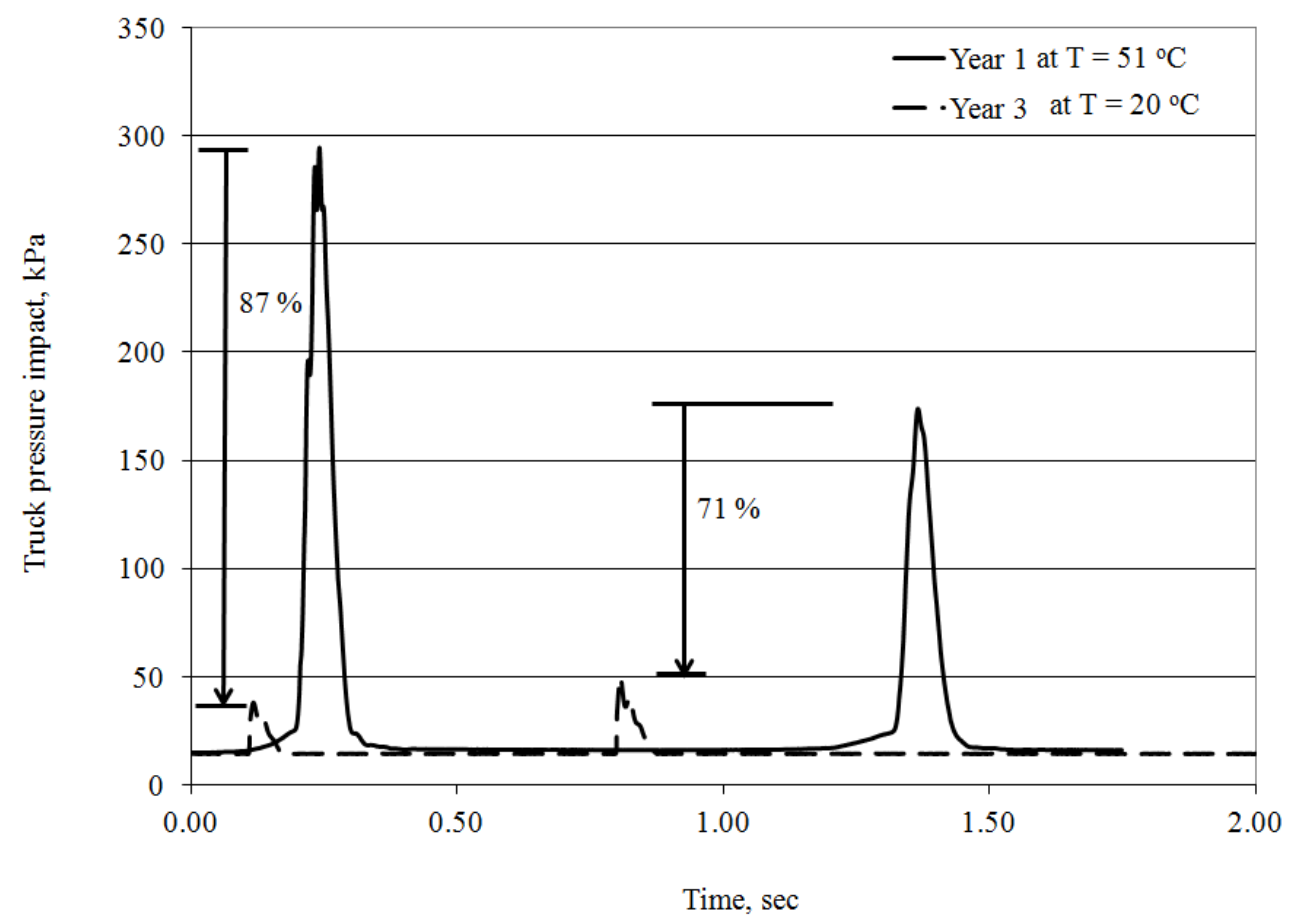

Figure 4.119: Effect of temperature on the top pressure cell at a depth of $290 \mathrm{~mm}$ - Site 2 Truck impact pressure, $\mathrm{kPa}$

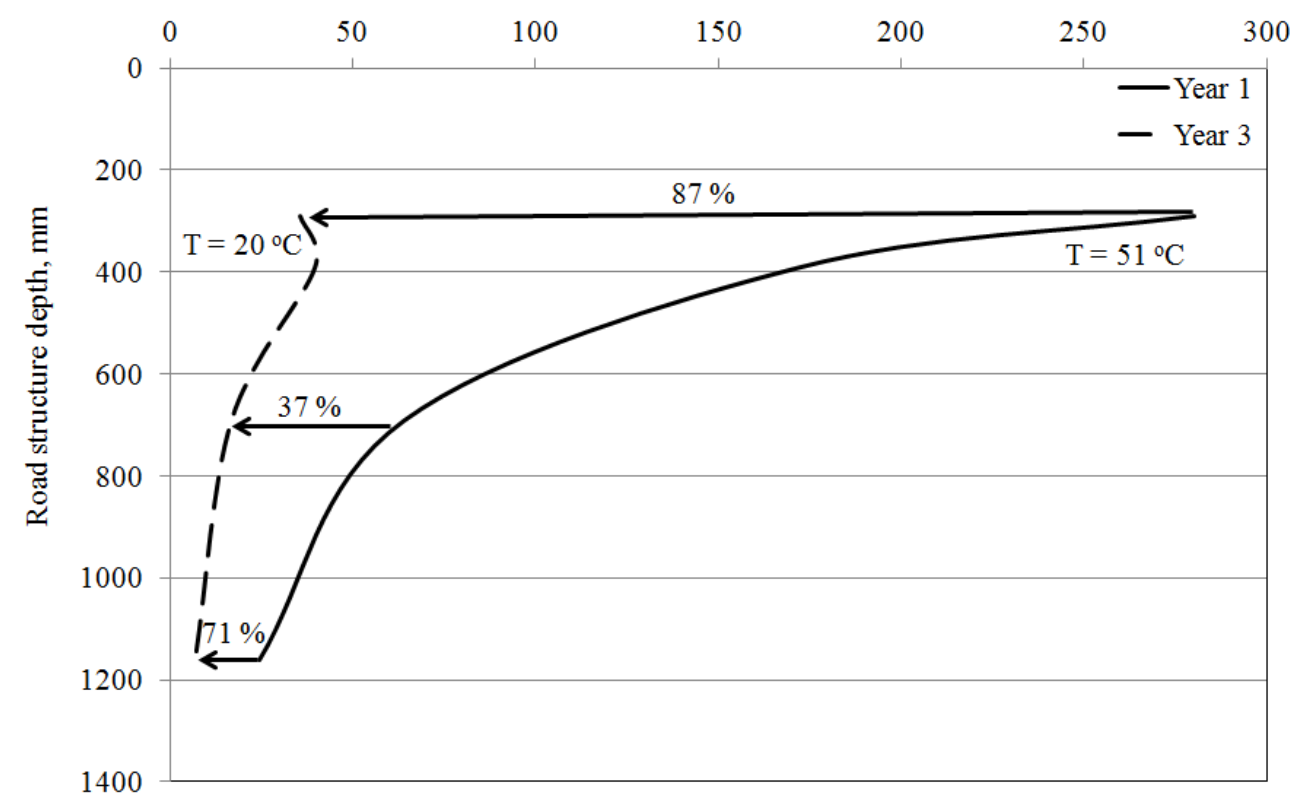

Figure 4.120: Effect of temperature on truck pressure impact profile- Site 2 


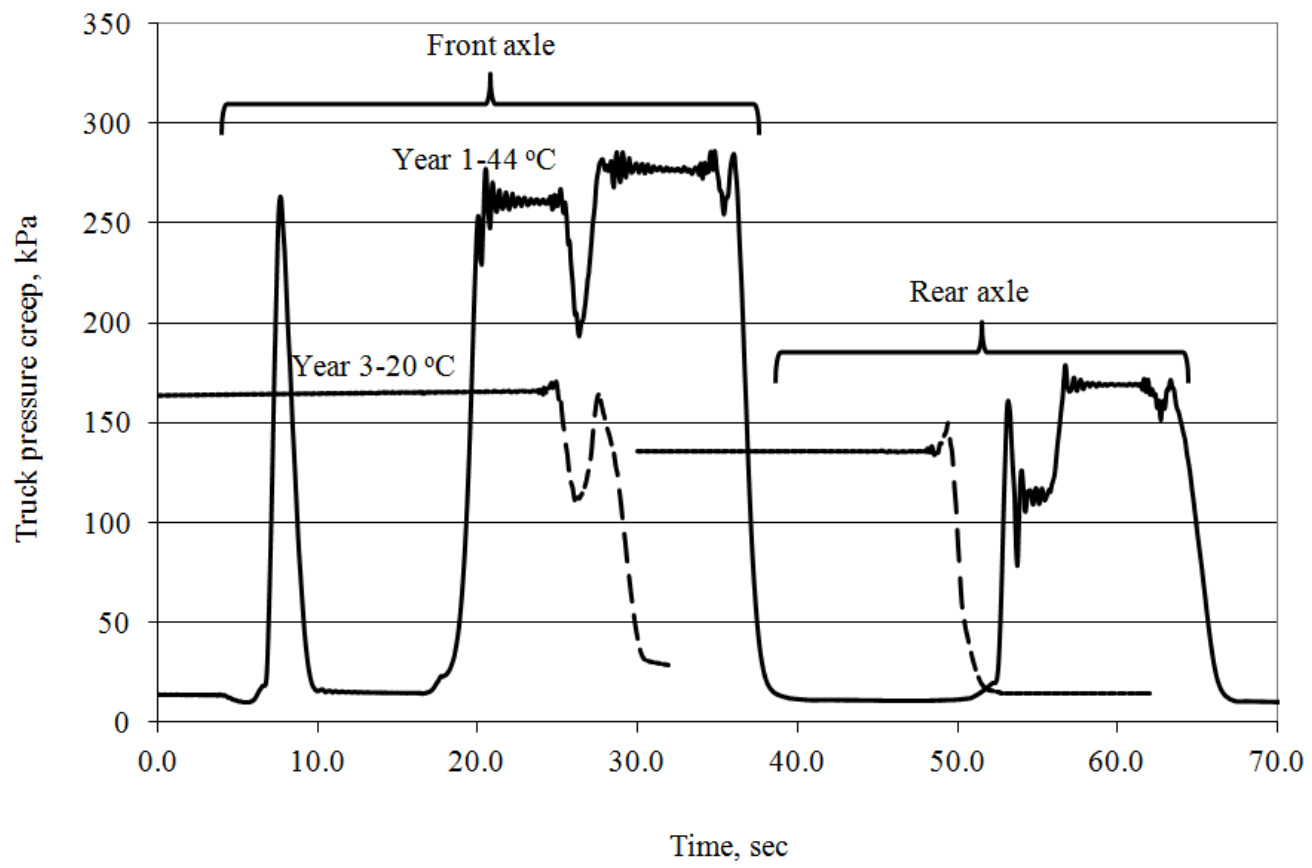

Figure 4.121: Temperature effect on truck pressure creep at a depth of $290 \mathrm{~mm}$ - Site 2

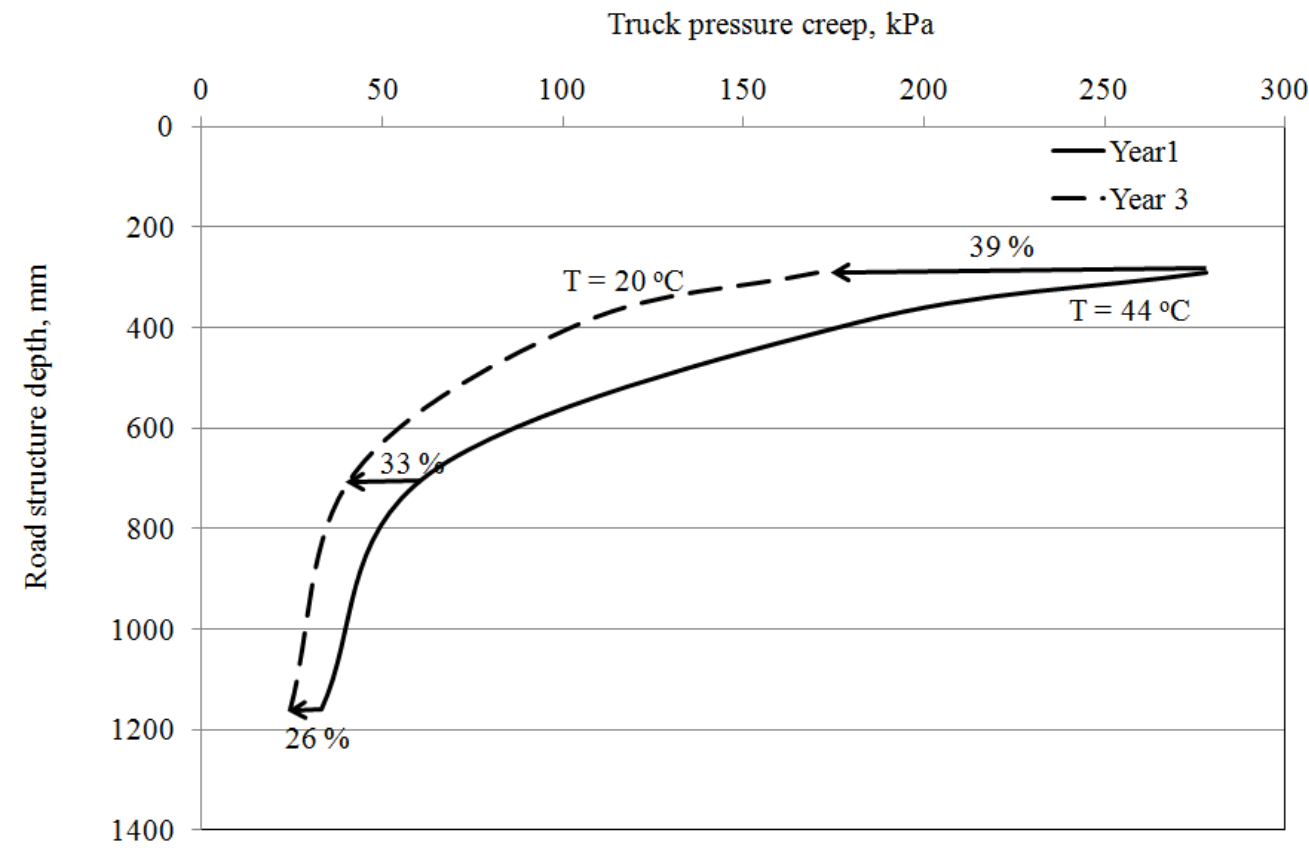

Figure 4.122: Temperature effect on truck pressure creep profile- Site 2 


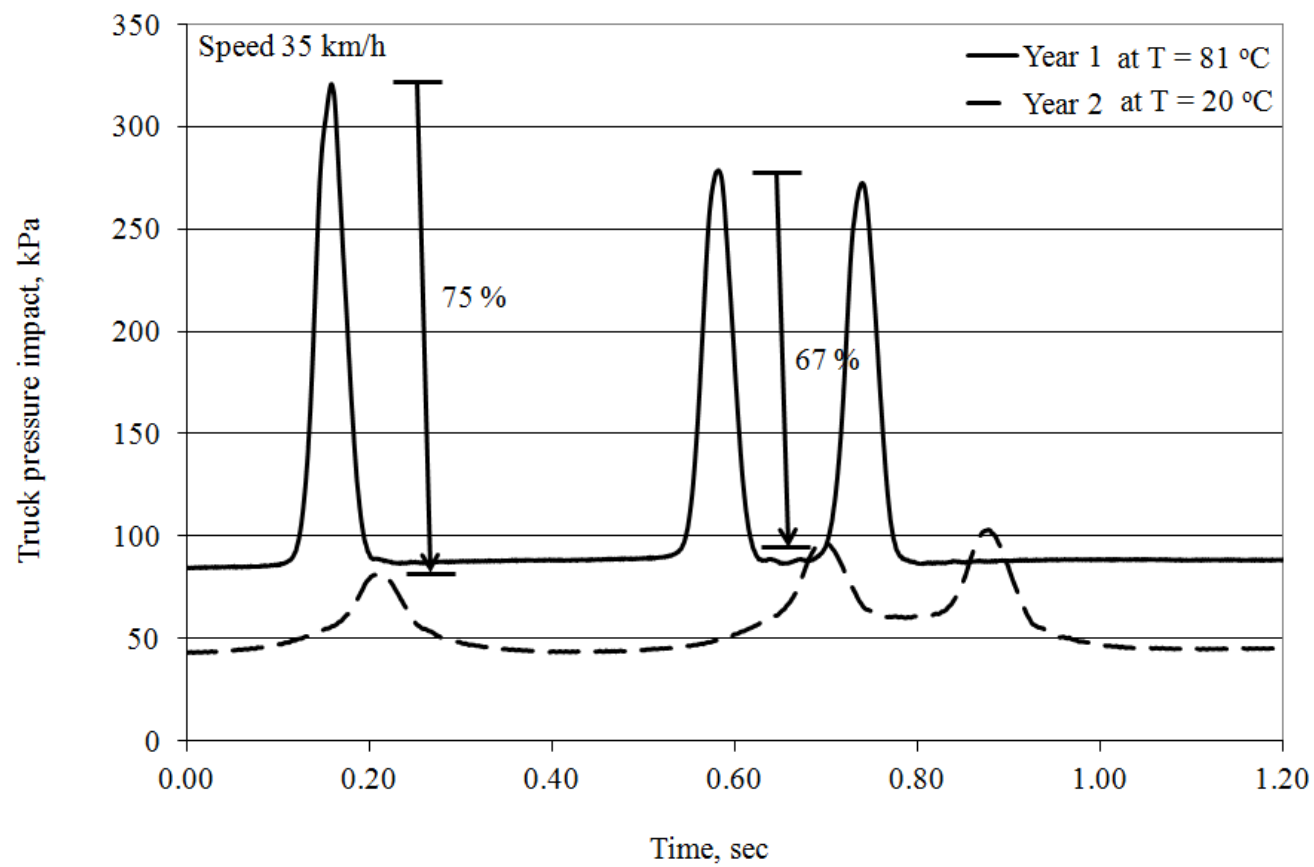

Figure 4.123: Temperature effect on the top pressure cell at a depth of $260 \mathrm{~mm}$ - Site 3 Truck pressure impact, $\mathrm{kPa}$

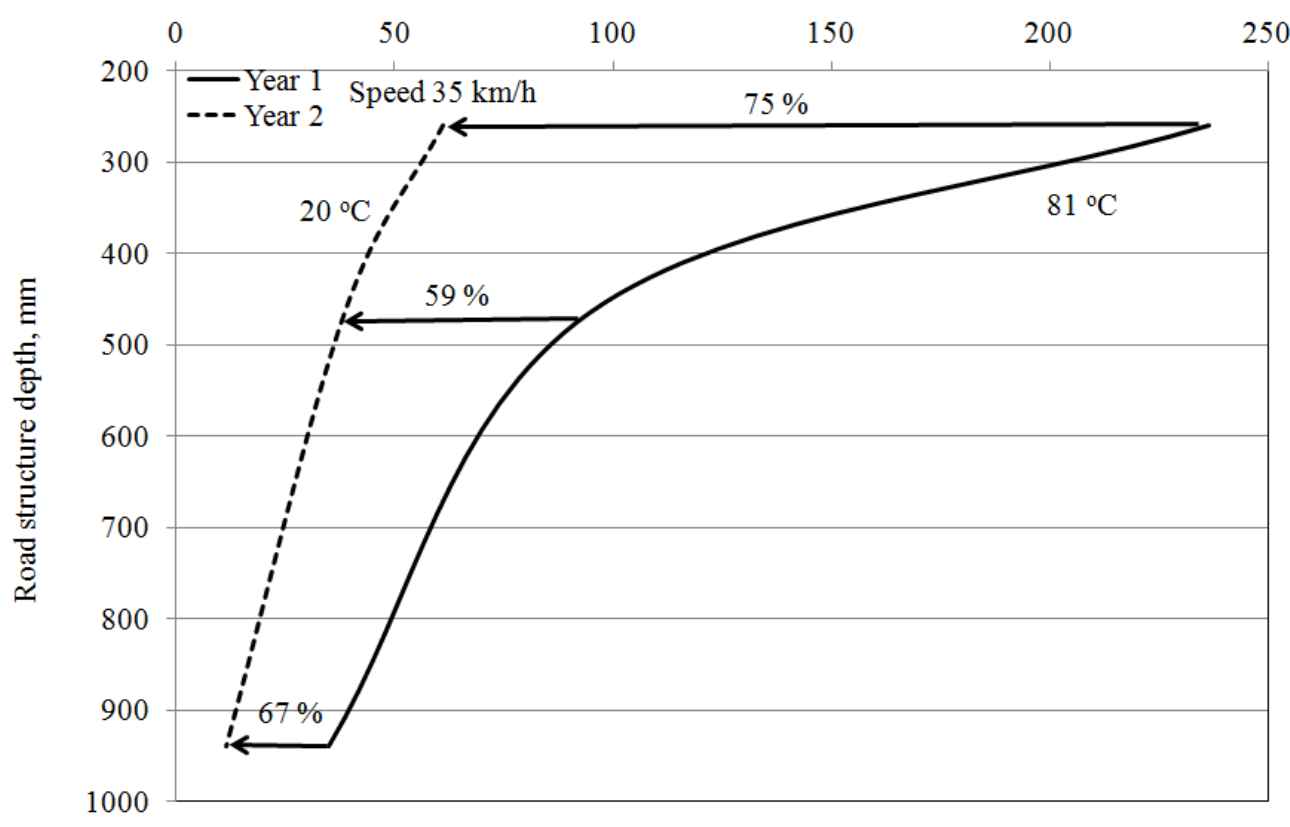

Figure 4.124: Temperature effect on truck pressure impact profiles- Site 3 
Similar to the pressure signal, typical truck strain impact data recorded by the EMU coils at a depth of $390 \mathrm{~mm}$ at site 2 for unbound materials is shown in Figure 4.125. The truck strain impact revealed that when the road was opened to traffic while the asphalt concrete temperature is high $\left(51^{\circ} \mathrm{C}\right)$, the road was susceptible to excessive permanent deformations (settlement and rutting) because of extreme high strains detected in the backfill layers under the action of a moving test truck. Further analysis of the data in Figure 4.125, determined that low stiffness of asphalt concrete at relatively high temperatures $\left(51^{\circ} \mathrm{C}\right)$ was the major contributor to these high strains compared to the strains recorded after 1 year of construction and when the asphalt concrete temperature was $20^{\circ} \mathrm{C}$ (normal operating temperature). The drop in strain for both conditions was 92 $\%$.

Figure 4.126 shows the strain gradient for the unbound materials pavement structure layers. The two strain profiles represent the truck strain impact at the early opening of the road when the asphalt temperature was $51^{\circ} \mathrm{C}$ after the road aged 1 year and where the asphalt temperature was $20^{\circ} \mathrm{C}$. The latter dropped by about $92 \%$ at a depth of $390 \mathrm{~mm}$ and $64 \%$ at depth of $990 \mathrm{~mm}$ below the asphalt concrete surface. It is important to control the excessive deformation occurring as a result of prematurely loading a freshly constructed road.

The truck strain impact on the EMU coil at a depth of $260 \mathrm{~mm}$ for site 3 immediately after construction and after one year of service is shown in Figure 4.127. Figure 4.128 also shows the two profiles of truck impact strain gradients for both road conditions. 


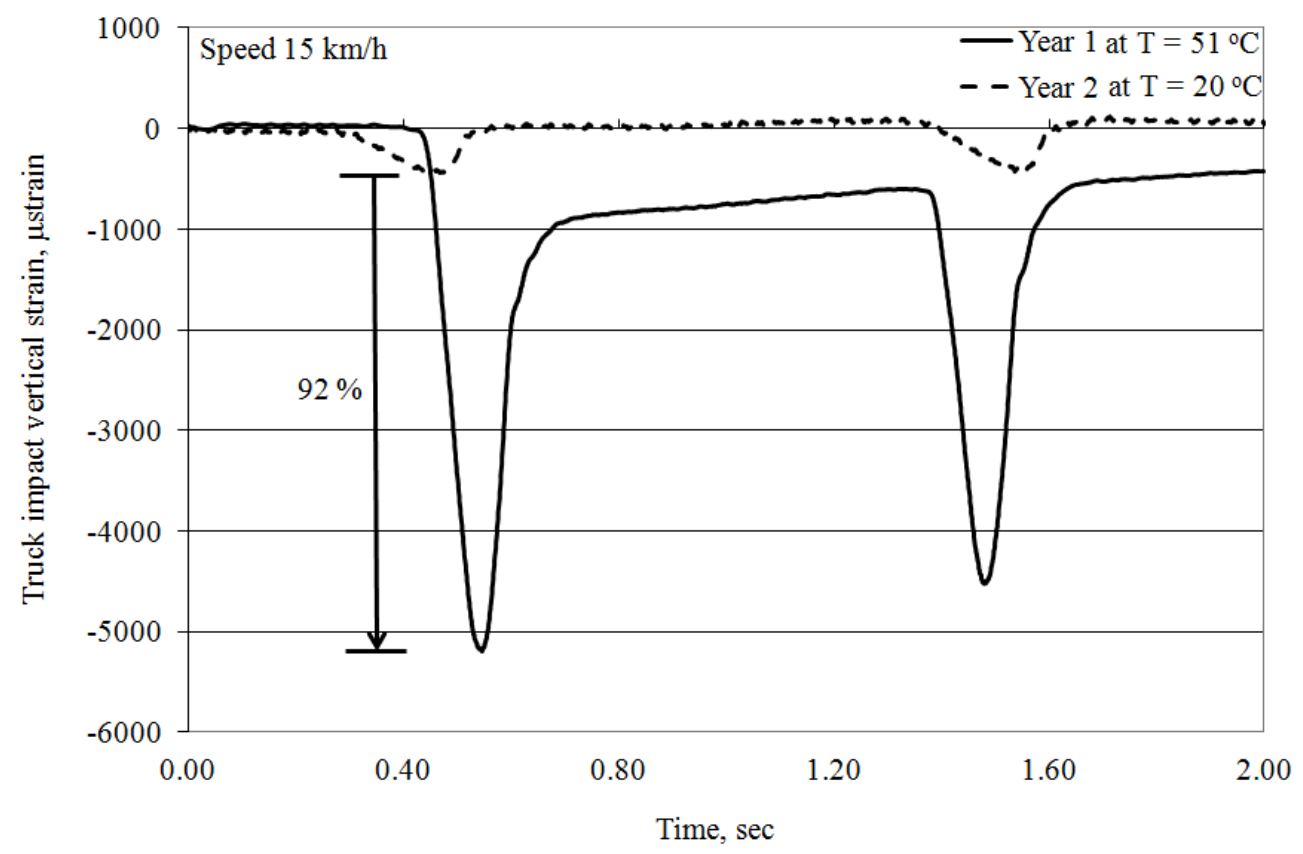

Figure 4.125: Temperature effect on the top EMU coil gauges at a depth of $390 \mathrm{~mm}$ - Site 2

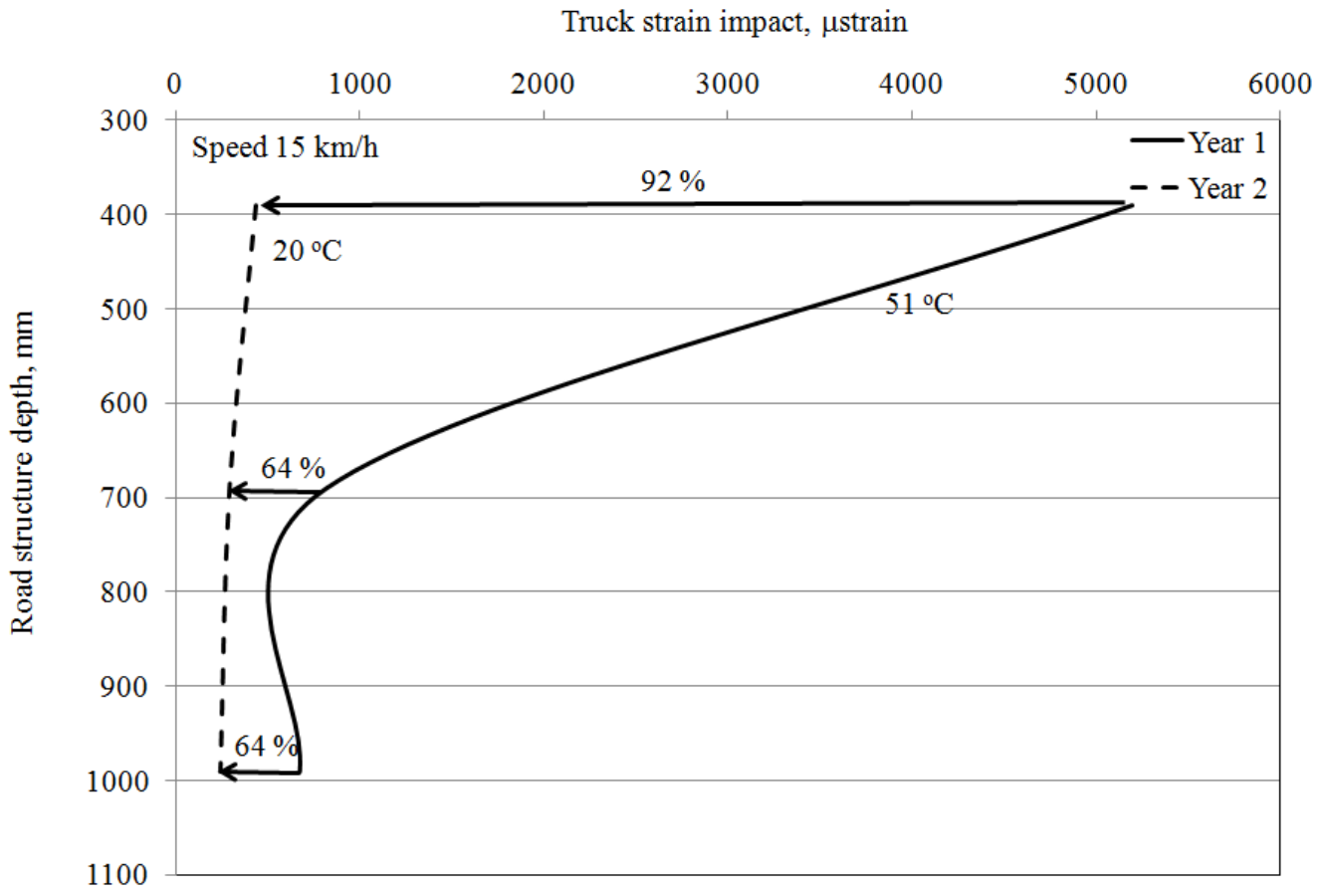

Figure 4.126: Effect of temperature on truck strain impact profile- Site 2 


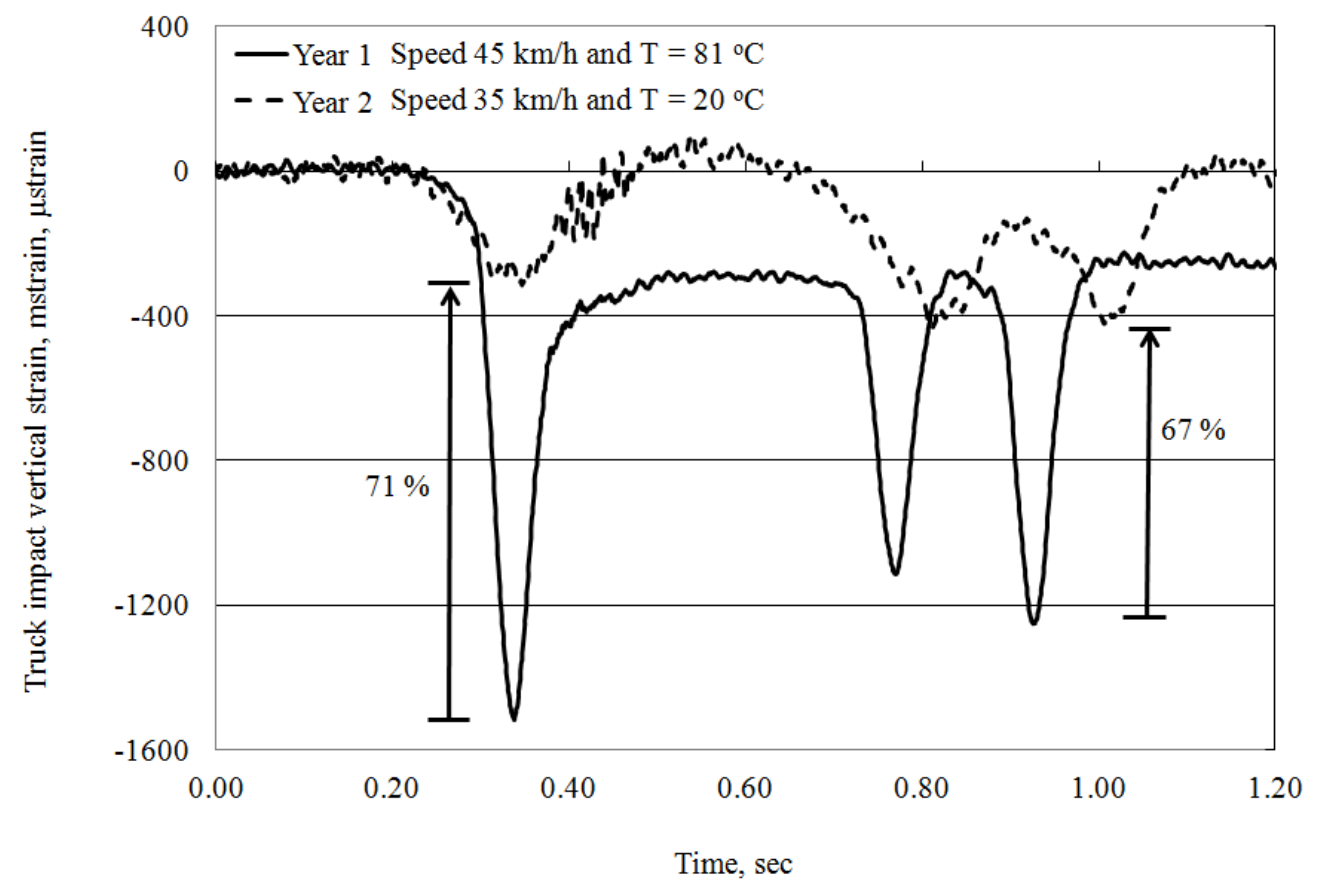

Figure 4.127: Temperature effect on the EMU coil at a depth of $260 \mathrm{~mm}$ - Site 3

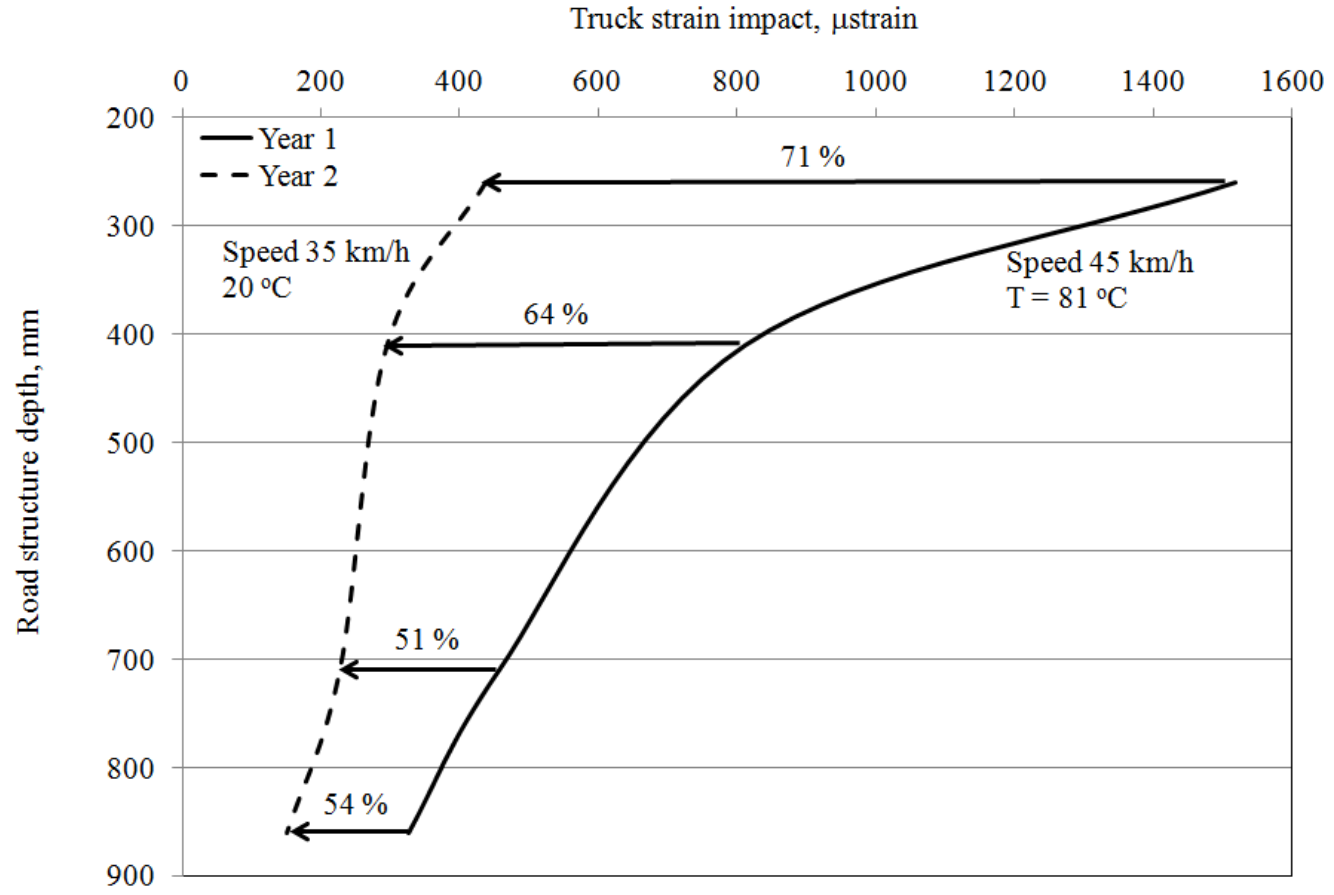

Figure 4.128: Temperature effect on truck strain impact profiles- Site 3 
This study recommends that engineers should prevent the accumulation of excessive deformation during the low asphalt concrete stiffness state associated with high temperatures. Traffic-induced stresses transmitted to the backfill layers beneath the asphalt concrete are directly influenced by the asphalt concrete stiffness. High temperatures result in low asphalt concrete stiffness and, hence, higher stresses are transmitted through the asphalt concrete layer to unbound materials in the road structure.

With damage acquired at this early stage in the service life of road pavement, asphalt concrete performance will be lower than its potential level and deformations will continue at higher than normal rates. Introducing suitable asphalt concrete temperature at which the road may be opened for traffic with less potential for high stress and deformations is needed and should be incorporated in the pavement design guides. 


\section{LABORATORY INVESTIGATION - RESULTS AND ANALYSIS}

\subsection{Introduction}

Monitoring the environmental and structural road behaviour at the three different sites and the response of the different layers forming the pavement structure was one of the elements included in the scope of this study. The temperature and moisture gradient were monitored throughout the road depth at the three sites as discussed earlier. Sites located within regions that experience the build-up of frost were instrumented with a resistivity probe to monitor frost depth. The structural behaviour (stress and strain) at different times was obtained from the three sites in the same manner. Data obtained from environmental and structural fieldwork in this study was used to carry on the laboratory work as intended.

\subsection{Asphalt work}

The complex modulus, creep compliance, indirect tensile strength, binder shear complex modulus and phase angle are the primary input for level 1 of analysis required by the new AASHTO design guide (M-EPDG) for hot mix asphalt.

\subsubsection{Sample preparation}

The Superpave (Superior PERforming Asphalt PAVEments) for $19 \mathrm{~mm}$ maximum size and $12.5 \mathrm{~mm}$ nominal maximum size (SP 12.5) mix were used in this study. The design aggregate structure is selected using control points and a restricted zone on the 0.45 power gradation as shown in Tables 5.1 and 5.2 respectively. The job mix formula in Table 5.3 was used with different materials gradation shown in Table 5.4 to make the Superpave blends of aggregate developed as part of the Hot Mix Asphalt 
(HMA) mix design process and used in the production of HMA that satisfies the requirements of the Ontario Provincial Standard Specification, OPSS 1003 (2013) for the fine and coarse limits as shown in Figure 5.1.

Samples of the SP 12.5 mix, using performance grade PG 58-28 for site 1 and PG 64-22 for sites 2 and 3 were produced. PG 52-22 was also used as another binder to evaluate the sensitivity of the new AASHTO design guide. These mixes were prepared following the requirements of the new AASHTO design guide as detailed below:

$\square \quad$ The superpave mixes were designed according to MTO LS-309 (2013).

$\square \quad$ Mixtures were compacted using a gyratory compactor. The number of gyrations was controlled to produce samples with $100 \mathrm{~mm}$ in height and radius, as specified by AASHTO TP62 (2003) and various air void contents.

$\square \quad$ The physical properties such as bulk specific gravity, maximum specific gravity and air voids content were determined according to AASHTO T166 (2015), T209 (2015) and T269 (2011), respectively.

$\square \quad$ The determined binder content was used to prepare samples for the complex modulus test.

$\square \quad$ The aggregate binder mixtures were prepared using a mechanical mixer and aged in an oven for two hours at the binder's compaction temperature as per the requirements of AASHTO PP2 (2000).

It should be noted that although many agencies may follow the AASHTO grading requirements, some agencies might use different specifications. In most cases, there may be minor modifications to the AASHTO requirements. 
A summary of the SP 12.5 mixes physical properties for PG 52-34, PG 58-28 and PG 64-22 binders is provided in Table 5.5.

Table 5.1: Hot Mix Asphalt requirements for the aggregate control point

\begin{tabular}{|c|c|c|c|c|c|c|c|}
\hline \multicolumn{7}{|c|}{ Nominal max aggregate size - control point } \\
\hline \multicolumn{2}{|c|}{ Sieve Size } & \multicolumn{2}{c|}{$19 \mathrm{~mm}$} & \multicolumn{2}{|c|}{$12.5 \mathrm{~mm}$} & \multicolumn{2}{|r|}{$9.5 \mathrm{~mm}$} \\
\hline $\mathrm{D}, \mathrm{mm}$ & $\mathrm{D}^{\wedge} 0.45$ & Max & Min & Max & Min & Max & Min \\
\hline 25 & 4.26 & & 100 & & & & \\
\hline 19 & 3.76 & 100 & 90 & & 100 & & \\
\hline 12.5 & 3.12 & 90 & & 100 & 90 & & 100 \\
\hline 9.5 & 2.75 & & & 90 & & 100 & 90 \\
\hline 4.75 & 2.02 & & & & & 90 & \\
\hline 2.36 & 1.47 & 49 & 23 & 58 & 28 & 67 & 32 \\
\hline 0.075 & 0.31 & 8 & 2 & 10 & 2 & 10 & 2 \\
\hline
\end{tabular}

Table 5.2: Hot Mix Asphalt requirements for aggregate restricted zones

\begin{tabular}{|c|c|c|c|c|c|c|c|}
\hline \multicolumn{8}{|c|}{ Nominal max aggregate size - restricted zones } \\
\hline \multicolumn{2}{|c|}{ Sieve Size } & \multicolumn{2}{|c|}{$19 \mathrm{~mm}$} & \multicolumn{2}{|c|}{$12.5 \mathrm{~mm}$} & \multicolumn{2}{|c|}{9.5} \\
\hline $\mathrm{mm}$ & $\mathrm{D}^{\wedge} 0.45$ & Max & Min & Max & Min & $\operatorname{Max}$ & Min \\
\hline 4.75 & 2.02 & & & & & & \\
\hline 2.36 & 1.47 & 34.6 & 34.6 & 39.1 & 39.1 & 47.2 & 47.2 \\
\hline 1.18 & 1.08 & 28.3 & 22.3 & 31.6 & 25.6 & 37.6 & 31.6 \\
\hline 0.6 & 0.79 & 20.7 & 16.7 & 23.1 & 19.1 & 27.5 & 23.5 \\
\hline 0.3 & 0.58 & 13.7 & 13.7 & 15.5 & 15.5 & 18.7 & 18.7 \\
\hline
\end{tabular}

Table 5.3: Job mix formula for SP 12.5

\begin{tabular}{|c|c|c|c|c|c|}
\hline \multicolumn{5}{|c|}{ Job mix formula - $12.5 \mathrm{~mm}$ nominal size } \\
\hline CA1 & CA2 & CA3 & F1 & F2 & F3 \\
\hline 0 & 21 & 0 & 74 & 0 & 5 \\
\hline
\end{tabular}


Table 5.4: Aggregate gradation for Hot Mix Asphalt-OPSS

\begin{tabular}{|c|c|c|c|c|c|c|c|c|}
\hline $\begin{array}{c}\text { Sieve Size } \\
\mathrm{D}, \mathrm{mm}\end{array}$ & $\mathrm{D}^{\wedge} 0.45$ & $\mathrm{CA} 1$ & $\mathrm{CA} 2$ & $\mathrm{CA} 3$ & $\mathrm{~F} 1$ & $\mathrm{~F} 2$ & $\mathrm{~F} 3$ & $\begin{array}{c}\text { Mix Design } \\
\text { SP 12.5 }\end{array}$ \\
\hline 25 & 4.257 & 100.0 & 100 & 100 & 100 & 100 & 100 & 100.0 \\
\hline 19 & 3.762 & 86.7 & 100 & 100 & 100 & 100 & 100 & 100.0 \\
\hline 16 & 3.482 & 59.7 & 95.7 & 100 & 100 & 100 & 100 & 99.1 \\
\hline 12.5 & 3.116 & 30.4 & 59.5 & 93.7 & 100 & 100 & 100 & 91.5 \\
\hline 9.5 & 2.754 & 7.3 & 7.9 & 48.3 & 100 & 100 & 100 & 80.7 \\
\hline 4.75 & 2.016 & 2.2 & 3.4 & 2.3 & 90.8 & 99.9 & 100 & 72.9 \\
\hline 2.36 & 1.472 & 1.1 & 2.4 & 0.6 & 61.6 & 98.9 & 100 & 51.1 \\
\hline 1.18 & 1.077 & 0.7 & 2 & 0.6 & 41.3 & 94.4 & 100 & 36.0 \\
\hline 0.6 & 0.795 & 0.5 & 1.7 & 0.5 & 28.3 & 41.5 & 100 & 26.3 \\
\hline 0.3 & 0.582 & 0.4 & 1.3 & 0.5 & 17.6 & 10.5 & 100 & 18.3 \\
\hline 0.15 & 0.426 & 0.3 & 1 & 0.4 & 9.4 & 2.4 & 100 & 12.2 \\
\hline 0.075 & 0.312 & 0.1 & 0.2 & 0.1 & 1.2 & 0.5 & 100 & 5.9 \\
\hline
\end{tabular}

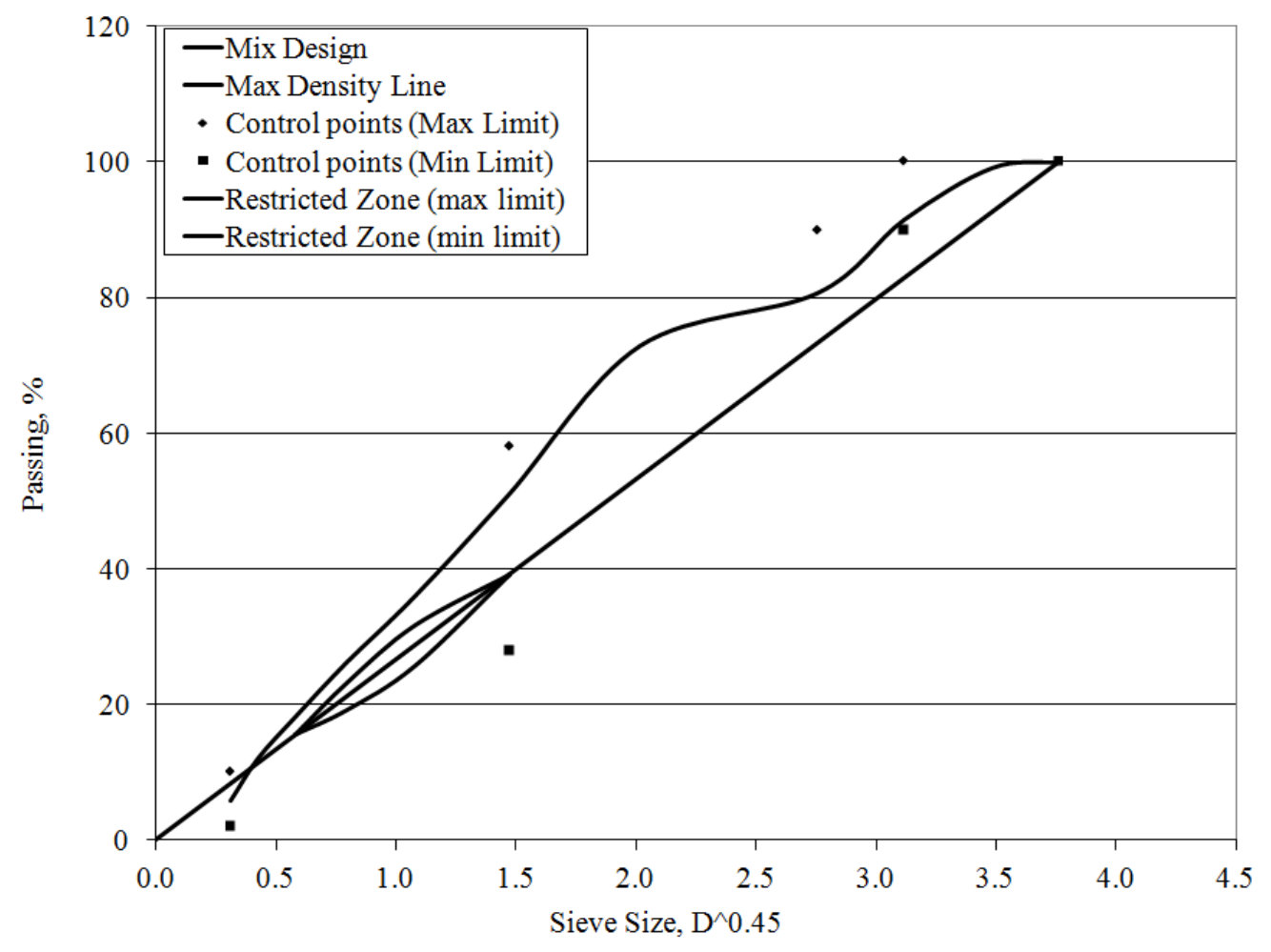

Figure 5.1: Aggregate grain size distributions for SP 12.5 
Table 5.5: Physical properties of Mix SP 12.5

\begin{tabular}{|l|c|c|c|c|}
\hline \multirow{2}{*}{ Properties } & MTO & \multicolumn{3}{c|}{ PG test results } \\
\cline { 3 - 5 } & Requirements & $52-34$ & $58-28$ & $64-22$ \\
\hline Asphalt content, \% & $3 \%-5 \%$ & 4.0 & 4.4 & 4.5 \\
\hline VMA \% & $14 \%(\mathrm{MIN})$ & 12.8 & 14.7 & 14.5 \\
\hline VFA \% & $65 \%-75 \%$ & 70.0 & 73.8 & 73.7 \\
\hline $\mathrm{G}_{\mathrm{mm}}, \% @ \mathrm{~N}_{\text {initial }}$ & 90.0 & 89.0 & 89.0 & 90.5 \\
\hline $\mathrm{G}_{\mathrm{mm}}, \% @ \mathrm{~N}_{\text {design }}$ & 98.0 & 96.5 & 96.7 & 97.0 \\
\hline Dust to Binder Ratio $\left(\mathrm{P}_{0.075} / \mathrm{P}_{\text {be }}\right)$ & $0.6-1.4$ & 1.11 & 1.11 & 1.11 \\
\hline
\end{tabular}

\subsubsection{Dynamic modulus}

The dynamic modulus is the stiffness component of the complex modulus that has been implemented in the M-EPDG. The AASHTO provisional test standard (TP62, 2003) is a strain-controlled version of the complex modulus test and focuses on capturing the viscoelastic response of asphalt concrete (AC) materials. Traffic loading is simulated in the laboratory with a haversine cyclic load applied to the specimen and adjusted so that the specimen is subjected to an axial strain between 50 and 150 microstrain $(\mu \varepsilon)$. The response of the material exhibits a phase lag, (Figure 5.2). The M-EPDG structural response model is based on conducting linear elastic analysis and hence, the phase angle is not being considered in the analysis. Incorporation of the impact of the viscous response in conducting structural analysis should be considered in future designs.

The laboratory test may be conducted under a stress or strain controlled mode. In the stress-controlled mode, the stress applied is given by:

$$
\sigma=\sigma_{0} \sin (\omega . t)
$$

And the corresponding strain is given by:

$$
\varepsilon=\varepsilon_{0} \sin (\text { w.t- } \varnothing)
$$

In the strain-controlled mode, the applied strain is expressed as: 


$$
\varepsilon=\varepsilon_{0} \sin (\omega . \mathrm{t})
$$

And the corresponding stress is given by:

$$
\sigma=\sigma_{0} \sin (\omega . \mathrm{t}+\varnothing)
$$

Where $\sigma_{0}$ is the stress amplitude, $\varepsilon_{0}$ is the strain amplitude (see Figure 5.2) and $\omega$ is the angular velocity related to the frequency $f$ by equation 5.5 :

$$
\omega=2 \pi f
$$

The AASHTO provisional test standard (TP62, 2003) recommended test series consisting of five test temperatures $-10,0,20,30$, and $40{ }^{\circ} \mathrm{C}$ and six loading frequencies $0.1,0.3,1.0,5,10$, and $20 \mathrm{~Hz}$. Each specimen should be tested for the 30 combinations of temperature and frequency starting with the lowest temperature and proceeding to the highest. Testing at a given temperature should begin with the highest frequency of loading and proceed to the lowest. Stresses and strains then can be calculated for the last 3 cycles using equations 5.6 and 5.7.

$$
\sigma_{0}=\frac{\mathrm{F}}{\mathrm{A}}
$$

Where; $\mathrm{A}$ is the cross sectional area of specimen and $\mathrm{F}$ is the recorded axial force

$$
\varepsilon_{\mathrm{o}}=\frac{\Delta \mathrm{h}}{\mathrm{h}}
$$

Where; $\Delta \mathrm{h}$ is the deformation measured by the controlled extensometer, and $\mathrm{h}$ is the gauge length as shown in Figure 5.3.

The angle $\phi$ is the phase lag between the strain and the stress signal (see Figure 5.2). The phase angle is an indicator of the degree of the viscoelastic behaviour of an asphalt concrete mix. The $\phi$ value ranges from 0 to $\pi / 2$. A value of 0 is an indicator of purely elastic behaviour, while a value of $\pi / 2$ is an indicator of purely viscous behaviour. 
Regardless of the test mode used, the ratio of the stress to strain amplitudes defines the absolute value of the complex modulus known as the dynamic modulus and is expressed by equation 5.8 :

$$
\mathrm{E}^{*}=\frac{\sigma_{\mathrm{o}}}{\varepsilon_{\mathrm{o}}}
$$

Stresses and strains are then plotted against time to determine stress amplitude $\left(\sigma_{\mathrm{o}}\right)$ and strain amplitudes $\left(\varepsilon_{\mathrm{o}}\right)$ as shown in Figure 5.2.

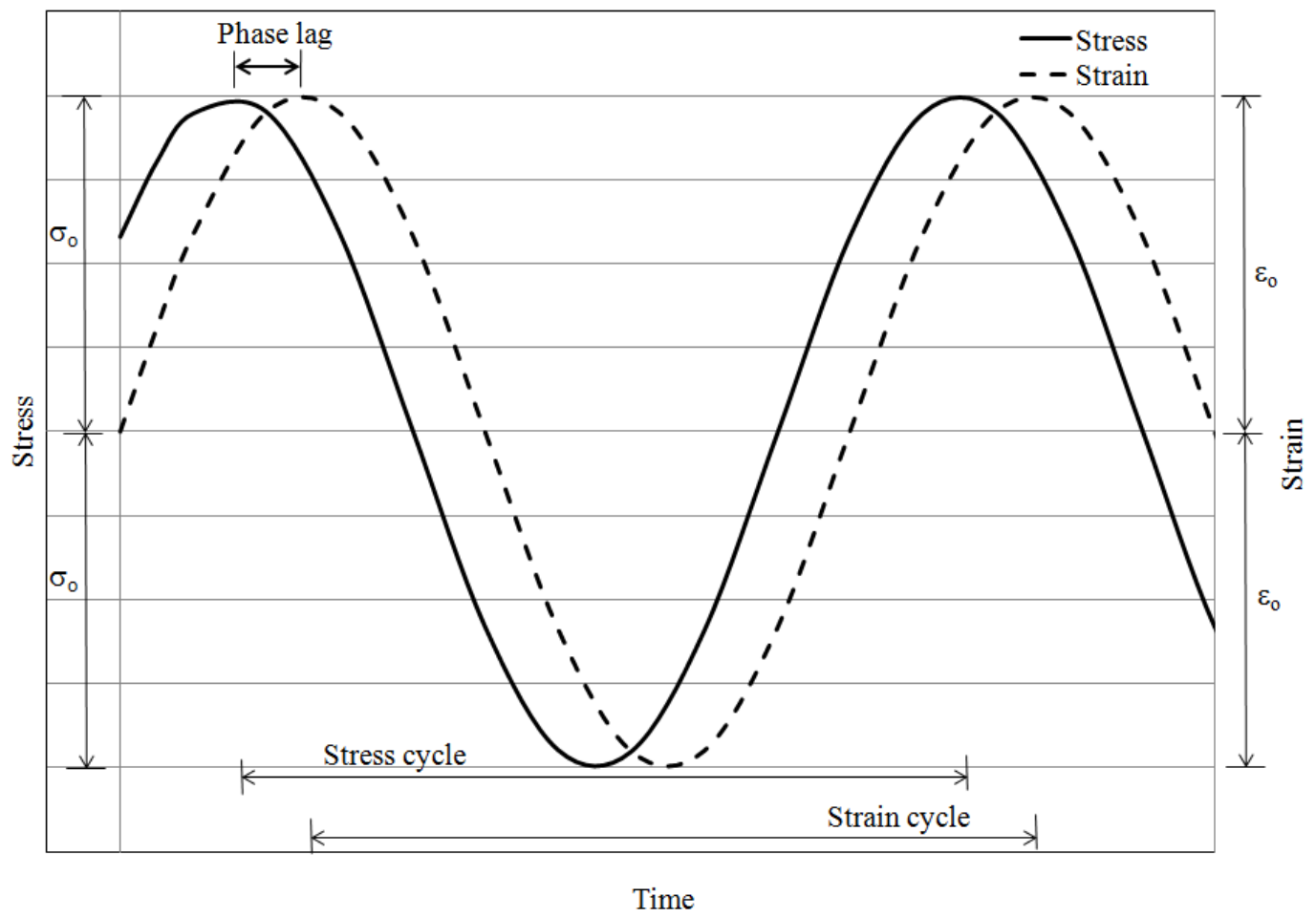

Figure 5.2: Typical viscoelastic response of asphalt concrete. 


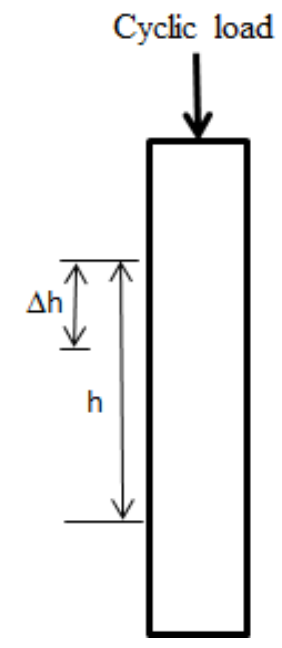

Figure 5.3: Axial deformation measurement set up

Using the data processed, the average time $\left(T_{i}\right)$ lag between the stress peak and the strain peak values determined from Figure 5.2 is used to calculate the phase angle using equation 5.9 .

$$
\varnothing=\frac{\mathrm{T}_{\mathrm{i}}}{\mathrm{T}_{\mathrm{p}}} \times 360^{\circ}
$$

Where; $T_{i}=$ Time lag between the stress and strain cycles $(\mathrm{sec}) ; T_{p}=$ Average time for a stress cycle (sec).

Then calculate the dynamic modulus, $\left|E^{*}\right|$ using equation 5.8 .

The value of the dynamic modulus reflects the stiffness of the mixture and its resistance to deformation at a designated frequency and temperature. It can be used for mix design and analysis of the asphalt concrete layer of a road.

Tables 5.6 to 5.8 show the results of measured dynamic modulus for PS 12.5 mixes. 
Table 5.6: Dynamic modulus results for PG 52-34

\begin{tabular}{|c|c|c|c|c|c|c|}
\hline \multirow{2}{*}{$\mathrm{T},{ }^{\circ} \mathrm{C}$} & \multicolumn{6}{|c|}{$\mathrm{E}^{*}, \mathrm{MPa}$} \\
\cline { 2 - 7 } & \multicolumn{7}{|c|}{ Frequency, Hz } \\
\cline { 2 - 7 } & 0.1 & 0.3 & 1 & 5 & 10 & 20 \\
\hline-12 & 6793 & 8021 & 9575 & 11979 & 13312 & 15140 \\
\hline 5 & 3083 & 4083 & 5350 & 7384 & 8459 & 10025 \\
\hline 20 & 566 & 842 & 1255 & 2054 & 2592 & 3430 \\
\hline 38 & 131 & 171 & 270 & 486 & 656 & 950 \\
\hline 54 & 75 & 96 & 131 & 212 & 291 & 422 \\
\hline
\end{tabular}

Table 5.7: Dynamic modulus results for PG 58-28

\begin{tabular}{|c|c|c|c|c|c|c|}
\hline \multirow{2}{*}{$\mathrm{T},{ }^{\circ} \mathrm{C}$} & \multicolumn{7}{|c|}{$\mathrm{E}^{*}, \mathrm{MPa}$} \\
\cline { 2 - 7 } & \multicolumn{7}{|c|}{ Frequency, Hz } \\
\cline { 2 - 7 } & 0.1 & 0.3 & 1 & 5 & 10 & 20 \\
\hline-12 & 18008 & 19737 & 21496 & 23193 & 24330 & 24957 \\
\hline 5 & 9233 & 11267 & 13612 & 16877 & 18138 & 19716 \\
\hline 20 & 2783 & 4108 & 5617 & 8043 & 9118 & 10288 \\
\hline 38 & 342 & 525 & 874 & 1723 & 2336 & 3176 \\
\hline 54 & 142 & 183 & 294 & 600 & 825 & 1193 \\
\hline
\end{tabular}

Table 5.8: Dynamic modulus results for PG 64-22

\begin{tabular}{|c|c|c|c|c|c|c|}
\hline \multirow{2}{*}{$\mathrm{T}^{\circ}{ }^{\circ} \mathrm{C}$} & \multicolumn{6}{|c|}{$\mathrm{E}^{*}, \mathrm{MPa}$} \\
\cline { 2 - 7 } & \multicolumn{7}{|c|}{ Frequency, Hz } \\
\cline { 2 - 7 } & 0.1 & 0.3 & 1 & 5 & 10 & 20 \\
\hline-12 & 5720 & 6330 & 7040 & 8010 & 8430 & 8710 \\
\hline 5 & 3650 & 4360 & 5190 & 6390 & 6900 & 7400 \\
\hline 20 & 636 & 858 & 1230 & 1940 & 2380 & 2900 \\
\hline 38 & 275 & 359 & 503 & 827 & 1050 & 1350 \\
\hline 54 & 146 & 182 & 242 & 379 & 479 & 625 \\
\hline
\end{tabular}

The dynamic modulus of the asphalt concretes for the three binders are plotted in Figure 5.4 at a frequency of $20 \mathrm{~Hz}$. As expected, the asphalt concrete using the binder PG 58-28 is stiffer than that prepared using the binder PG 52-34. This confirms the intended use of PG 58-28 to minimize rutting and PG 52-34 to minimize thermal cracking, but contradicts the intended use of PG 64-22. 


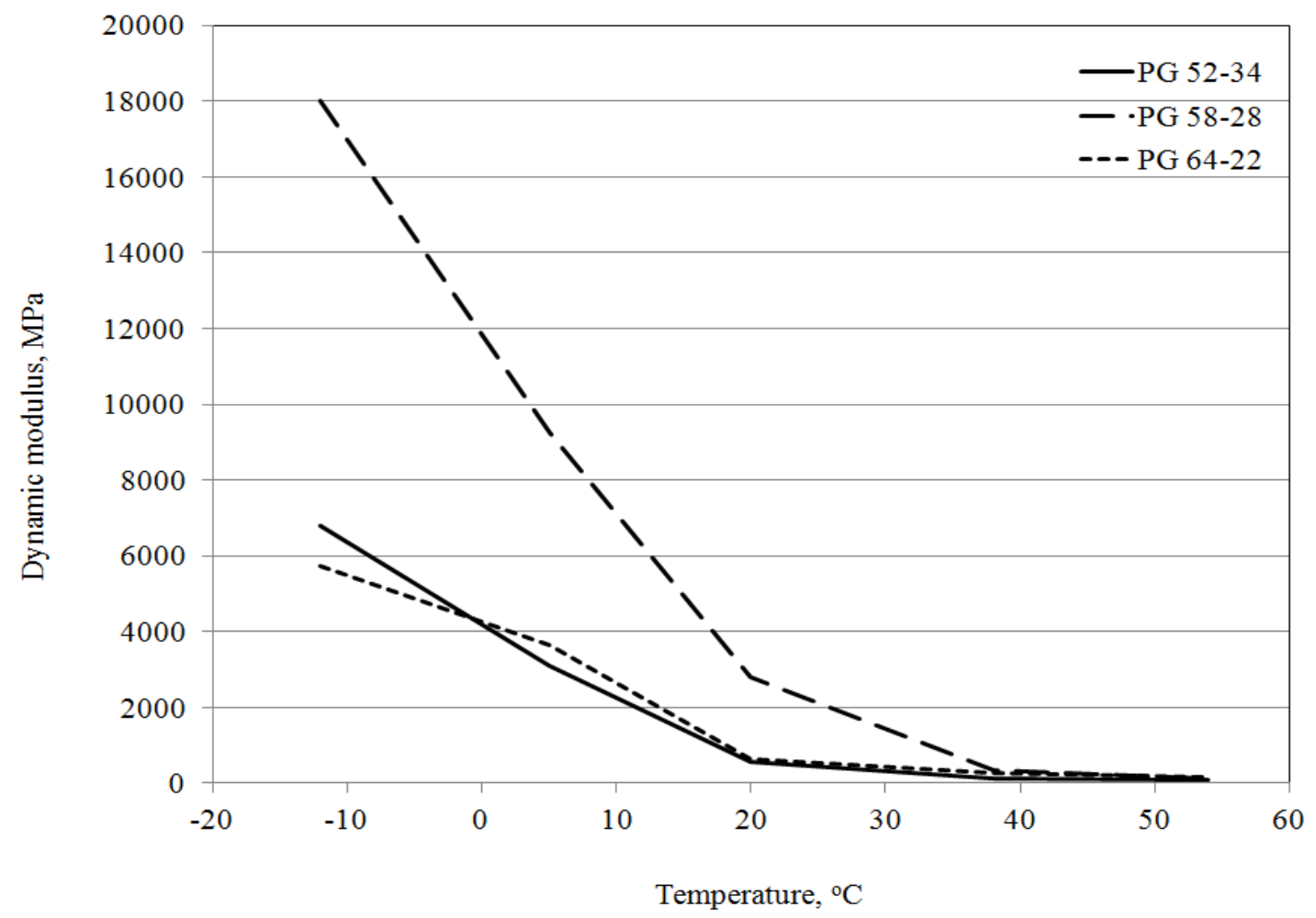

Figure 5.4: Dynamic modulus of SP 12.5 asphalt concrete mixes

\subsubsection{Creep compliance and tensile strength}

The creep compliance and tensile strength were determined following the requirements of AASHTO T322 (2003). The creep compliance was determined by applying a static compressive load of fixed magnitude along the diametric axis of a specimen for duration of 100 seconds. The measured horizontal and vertical deformations from each side and axial load were used to calculate the creep compliance using the series of equations 5.10 to 5.14 .

$$
\begin{gathered}
\mathrm{C}_{\mathrm{CMPL}}=0.6354\left(\frac{\mathrm{X}}{\mathrm{Y}}\right)^{-1}-0.332 \\
0.20 \leq \frac{\mathrm{t}}{\mathrm{D}} \leq 0.65 \\
\mathrm{v}=-0.1+1.480\left(\frac{\mathrm{X}}{\mathrm{Y}}\right)^{2}-0.778\left(\frac{\mathrm{t}}{\mathrm{D}}\right)^{2}\left(\frac{\mathrm{X}}{\mathrm{Y}}\right)^{2}
\end{gathered}
$$




$$
\begin{gathered}
0.05 \leq \mathrm{v} \leq 0.50 \\
\mathrm{D}_{(\mathrm{t})}=\frac{\Delta \mathrm{X}_{(\mathrm{t})} \times \mathrm{D} \times \mathrm{t}}{\mathrm{P} \times \mathrm{GL}} \times \mathrm{C}_{\mathrm{CMPL}}
\end{gathered}
$$

Where; $\mathrm{D}_{(\mathrm{t})}=$ Creep Compliance, $\mathrm{MPa}^{-1} ; \mathrm{X}=$ Horizontal deformation, $\mathrm{mm} ; \mathrm{Y}=$ Vertical deformation, $\mathrm{mm} ; \mathrm{t}=$ Thickness of specimen, $\mathrm{mm} ; \mathrm{D}=$ Diameter of specimen, mm; P = Applied load, N; GL = Gauge length, mm

The average creep compliance of each test series consisted of three test temperatures $\left(-20,-10\right.$ and $\left.0^{\circ} \mathrm{C}\right)$, which are needed as input into the software to calculate low temperature cracking. Tables 5.9 to 5.11 show the measured results of creep compliance of the SP 12.5 mixes for PG 52-34, PG 58-28 and PG 64-22 binders, respectively. The results are plotted in Figure 5.5 which shows that the asphalt concrete prepared using the binder PG 58-28 is stiffer compared to the one prepared using the PG 52-34 and PG 64-22 binders. This suggests that the asphalt concrete prepared using the binder PG 52-34 is more suitable for minimizing cracking due to low temperature.

The indirect tensile strength was measured by applying load on the HMA specimen along its diametric axis at a constant rate of $12.5 \mathrm{~mm} / \mathrm{minute}$ until failure. The test was performed at a temperature of $-10^{\circ} \mathrm{C}$. The indirect tensile strength $\left(\sigma_{t}\right)$ was calculated using equation 5.15 .

$$
\sigma_{t}=\frac{2 P_{f}}{\pi \times t \times D}
$$

Where; $\sigma_{\mathrm{t}}=$ Tensile strength, $\mathrm{MPa} ; \mathrm{P}_{\mathrm{f}}=$ Tensile strength at failure, $\mathrm{N} ; \mathrm{t}=$ specimen thickness, $\mathrm{mm} ; \mathrm{D}=$ specimen diameter, $\mathrm{mm}$ 
The determined tensile strength values were 2.66, 3.73 and $3.59 \mathrm{MPa}$ for the asphalt concrete prepared using the PG 52-34, PG 58-28 and PG 64-22 binders, respectively.

Table 5.9: Creep compliance results for PG 52-34

\begin{tabular}{|c|c|c|c|}
\hline $\begin{array}{c}\text { Loading time, } \\
\text { sec }\end{array}$ & \multicolumn{3}{|c|}{ Creep compliance (1/MPa) } \\
\cline { 2 - 4 } & Low at $-20^{\circ} \mathrm{C}$ & Mid at $-10^{\circ} \mathrm{C}$ & High at $0^{\circ} \mathrm{C}$ \\
\hline 1 & 226 & 387 & 727 \\
\hline 2 & 234 & 421 & 884 \\
\hline 5 & 253 & 467 & 1070 \\
\hline 10 & 267 & 517 & 1279 \\
\hline 20 & 281 & 573 & 1528 \\
\hline 50 & 303 & 667 & 1980 \\
\hline 100 & 323 & 773 & 2424 \\
\hline
\end{tabular}

Table 5.10: Creep compliance results for PG 58-28

\begin{tabular}{|c|c|c|c|}
\hline $\begin{array}{c}\text { Loading time, } \\
\text { sec }\end{array}$ & \multicolumn{3}{|c|}{ Creep compliance (1/MPa) } \\
\cline { 2 - 4 } & Low at $-20^{\circ} \mathrm{C}$ & Mid at $-10^{\circ} \mathrm{C}$ & High at $0^{\circ} \mathrm{C}$ \\
\hline 1 & 114 & 125 & 158 \\
\hline 2 & 120 & 137 & 177 \\
\hline 5 & 125 & 147 & 220 \\
\hline 10 & 129 & 158 & 259 \\
\hline 20 & 133 & 166 & 303 \\
\hline 50 & 142 & 176 & 386 \\
\hline 100 & 149 & 190 & 474 \\
\hline
\end{tabular}


Table 5.11: Creep compliance results for PG 64-34

\begin{tabular}{|c|c|c|c|}
\hline \multirow{2}{*}{$\begin{array}{c}\text { Loading time, } \\
\text { sec }\end{array}$} & \multicolumn{3}{|c|}{ Creep compliance (1/MPa) } \\
\cline { 2 - 4 } & Low at $-20^{\circ} \mathrm{C}$ & Mid at $-10^{\circ} \mathrm{C}$ & High at $0^{\circ} \mathrm{C}$ \\
\hline 1 & 115 & 194 & 374 \\
\hline 2 & 118 & 220 & 455 \\
\hline 5 & 127 & 248 & 583 \\
\hline 10 & 132 & 265 & 675 \\
\hline 20 & 134 & 297 & 797 \\
\hline 50 & 135 & 341 & 1077 \\
\hline 100 & 133 & 384 & 1338 \\
\hline
\end{tabular}

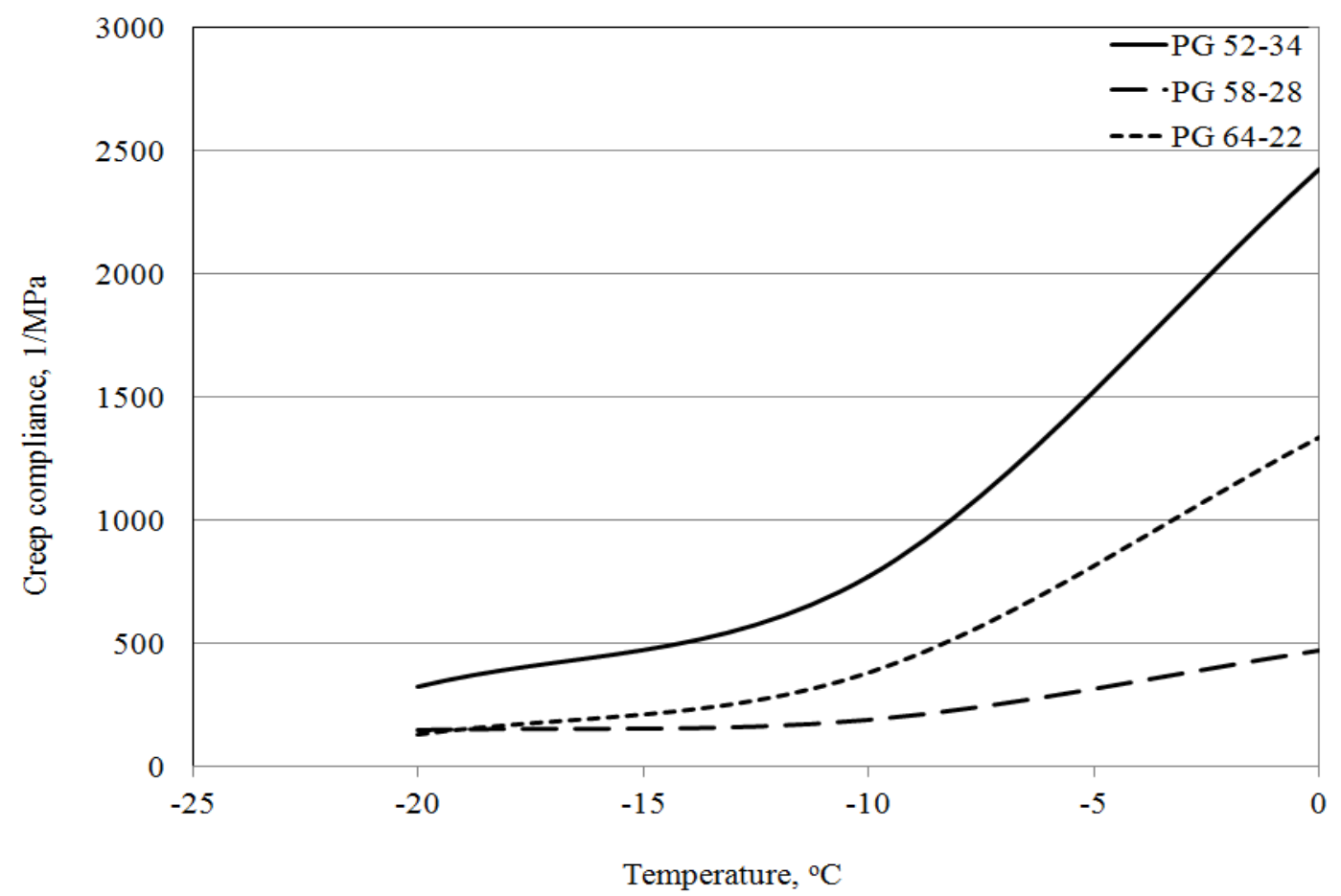

Figure 5.5: Creep compliance for SP 12.5 mixes

\subsubsection{Asphalt binder}

In this study, the complex modulus and phase angle of the asphalt binders PG 52-

34, PG 58-28 and PG 64-22 were calculated using the measured dynamic modulus for the 
SP 12.5 mixes. Equation 5.16 was used to determine the binder complex modulus $\left(G^{*}\right)$ at different temperatures and a loading rate of $1.59 \mathrm{~Hz}(10 \mathrm{rad} / \mathrm{sec})$.

$$
\mathrm{G}^{*}=\frac{\mathrm{E}^{*}}{2(1+\mathrm{V})}
$$

Where; $\mathrm{G}^{*}=$ binder complex shear modulus, Pa; $\mathrm{E}^{*}=$ dynamic modulus; $\mathrm{v}=$ Poisson's ratio

Equations 5.17 and 5.18 were used to determine the binder viscosity and phase angle, respectively.

$$
\log \log \eta=\mathrm{A}+\mathrm{VTS} \log \mathrm{TR}
$$

Where; $\eta=$ viscosity, $\mathrm{cp} ; \mathrm{T}=$ temperature, Rankin; $\mathrm{A}=($ Regression intercept $)$; VTS $=$ regression slope of viscosity temperature

$$
\eta=\frac{G^{*}}{10}\left(\frac{1}{\sin \delta}\right)^{-4.8628}
$$

Where; $\delta=$ binder phase angle

Typical binder values of A and VTS are shown in Table 5.12.

Table 5.12: Recommended A and VTS parameters based on asphalt PG grades

\begin{tabular}{|l|c|c|}
\hline $\begin{array}{l}\text { Binder } \\
\text { grade }\end{array}$ & A & VTS \\
\hline PG 52-34 & 10.707 & -3.602 \\
\hline PG 58-28 & 10.035 & -3.35 \\
\hline PG 64-22 & 9.461 & -3.134 \\
\hline
\end{tabular}

The determined binder complex modulus and phase angle for the SP 12.5 mixes using the PG 52-34, PG 58-28 and PG 64-22 binders are shown in Table 5.13. 
Table 5.13: Binders complex shear modulus and phase angle

\begin{tabular}{|c|c|c|c|c|c|c|}
\hline $\begin{array}{l}\text { PG } \\
\text { Binder }\end{array}$ & \multicolumn{2}{|c|}{$52-34$} & \multicolumn{2}{c|}{$58-28$} & \multicolumn{2}{c|}{$64-22$} \\
\hline $\mathrm{T},{ }^{\circ} \mathrm{C}$ & $\mathrm{G}^{*}, \mathrm{MPa}$ & $\delta$, Degree & $\mathrm{G}^{*}, \mathrm{MPa}$ & $\delta$, Degree & $\mathrm{G}^{*}, \mathrm{MPa}$ & $\delta$, Degree \\
\hline-12 & 3676 & 76 & 8054 & 77 & 2660 & 75 \\
\hline 5 & 2090 & 75 & 5220 & 76 & 1988 & 75 \\
\hline 20 & 505 & 73 & 2213 & 76 & 494 & 74 \\
\hline 38 & 110 & 71 & 370 & 73 & 204 & 71 \\
\hline 54 & 50 & 69 & 126 & 71 & 97 & 69 \\
\hline
\end{tabular}

\subsection{Unbound and sub-grade materials}

The AASHTO Design Guide (2004) has adopted the resilient modulus to characterize the mechanistic response of the unbound and sub-grade materials. The advanced design level recommends using actual laboratory test data of the resilient modulus determined using measured environmental parameters and simulated traffic loading conditions.

The resilient modulus, moisture content, soil density, Atterberg parameters, and sieve analysis are the primary parameters needed for level 3 of analysis.

\subsubsection{Sieve analysis and Atterberg limits}

The sieve analysis for all of the materials used in this study was conducted according to AASHTO T88 (2010) and is given in Tables 5.14, 5.15 and 5.16 for sites 1 , 2 and 3, respectively. The liquid and plastic limits of these materials were determined using ASTM standard test D4318 (1995a) and the values are shown in Table 5.17. 
Table 5.14: Sieve analysis for site 1

\begin{tabular}{|c|c|c|}
\hline \multirow{2}{*}{$\begin{array}{l}\text { Sieve size, } \\
\mathrm{mm}\end{array}$} & \multicolumn{2}{|c|}{ Passing, \% } \\
\cline { 2 - 3 } & Granular Material A & Silty Sand \\
\hline 25 & 100.0 & \\
\hline 19 & 95.5 & \\
\hline 12.5 & 81.2 & \\
\hline 9.5 & 66.6 & 100.0 \\
\hline 4.75 & 43.8 & 99.9 \\
\hline 2.36 & 27.9 & 90.4 \\
\hline 1.18 & 17.4 & 74.4 \\
\hline 0.6 & 11.5 & 50.4 \\
\hline 0.425 & & \\
\hline 0.3 & 8.1 & 23.9 \\
\hline 0.18 & & \\
\hline 0.075 & 4.8 & 2.2 \\
\hline
\end{tabular}

Table 5.15: Sieve analysis for site 2

\begin{tabular}{|c|c|c|}
\hline \multirow{2}{*}{ Sieve size, $\mathrm{mm}$} & \multicolumn{2}{|c|}{ Accumulative passing, \% } \\
\cline { 2 - 3 } & Granular base (CABII) & Select granular backfill material \\
\hline 37.5 & 100.0 & \\
\hline 25 & 99.4 & \\
\hline 19 & 96.8 & 100.0 \\
\hline 12.5 & 90.0 & 99.9 \\
\hline 9.5 & 83.0 & 99.7 \\
\hline 4.75 & 57.0 & 91.0 \\
\hline 2 & 35.8 & 73.3 \\
\hline 0.6 & 22.0 & 20.8 \\
\hline 0.425 & 18.4 & \\
\hline 0.075 & 10.0 & \\
\hline & & \\
\hline
\end{tabular}


Table 5.16: Sieve analysis for site 3

\begin{tabular}{|c|c|c|c|}
\hline \multirow{2}{*}{ Sieve size, mm } & \multicolumn{3}{|c|}{ Accumulative passing, \% } \\
\hline & Dense Granular Aggregate Base Course & Sand & Clay \\
\hline 37.5 & 98.5 & & \\
\hline 25 & 97.2 & & \\
\hline 19 & 95.9 & & \\
\hline 12.5 & 93.5 & & \\
\hline 9.5 & 91.6 & 100.0 & \\
\hline 4.75 & 87.2 & 99.9 & \\
\hline 2.36 & & 90.4 & \\
\hline 2 & 82.5 & & \\
\hline 1.18 & & 74.4 & \\
\hline 0.6 & & 50.3 & \\
\hline 0.425 & 67.2 & & \\
\hline 0.3 & & 23.8 & \\
\hline 0.18 & 42.3 & & \\
\hline 0.075 & 22.4 & 2.2 & 100.0 \\
\hline 0.02 & & & 45.3 \\
\hline 0.002 & & & 27.5 \\
\hline 0.001 & & & 22.9 \\
\hline
\end{tabular}

Table 5.17: Plasticity properties for all materials

\begin{tabular}{|c|l|c|c|}
\hline $\begin{array}{c}\text { Site } \\
\text { number }\end{array}$ & Soil type & Liquid limit, LL & $\begin{array}{c}\text { Plasticity } \\
\text { Index, PI }\end{array}$ \\
\hline \multirow{2}{*}{1} & Granular material A & 28.7 & 8.4 \\
\cline { 2 - 4 } & Silty Sand & 28.7 & 8.4 \\
\hline \multirow{2}{*}{2} & Granular base (CABII) & 0.0 & 0.0 \\
\cline { 2 - 4 } & Select Granular Backfill Material & 16.4 & 16.4 \\
\cline { 2 - 4 } & Silty Clay & 40.0 & 25.0 \\
\hline \multirow{2}{*}{3} & Dense Granular Aggregate & 28.7 & 8.4 \\
\cline { 2 - 4 } & Sand & 20.0 & 20.0 \\
\cline { 2 - 4 } & Clay & 100.0 & 55.0 \\
\hline
\end{tabular}

\subsubsection{Density}

AASHTO T99 (2015) was used to determine the relation between the moisture content and density of soils compacted in a mold of 101.6 or $152.4 \mathrm{~mm}$ diameter with a $2.5 \mathrm{~kg}$ rammer dropped from a height of $305 \mathrm{~mm}$. The results are shown in Table 5.18. 
Table 5.18 shows that a 2 to $6 \%$ decrease from optimum moisture content (dry of optimum) of soils leads to a decrease of 6 to $9 \%$ in dry density, respectively. Further analysis of the results in Table 5.18 indicates that a 1 to $3 \%$ increase of moisture content above the optimum (wet of optimum) leads to decrease of 6 to $18 \%$ in the dry density respectively. These findings clearly indicate and confirm that deviations from optimum conditions lead to a reduction in the dry density. This deviation is more significant on the side wet of optimum conditions.

Table 5.18: Unbound material physical properties

\begin{tabular}{|c|c|c|c|c|c|}
\hline $\begin{array}{l}\text { Site } \\
\text { Number }\end{array}$ & Material & $\begin{array}{c}\text { Soil } \\
\text { condition }\end{array}$ & $\begin{array}{c}\text { Moisture } \\
\text { content, \% }\end{array}$ & $\begin{array}{l}\mathrm{M}_{\mathrm{R}} \\
\mathrm{MPa}\end{array}$ & $\begin{array}{c}\text { Density, } \\
\mathrm{kN} / \mathrm{m} 3\end{array}$ \\
\hline \multirow[t]{6}{*}{1} & \multirow{3}{*}{ Granular Material A } & Dry & 3.4 & 169 & 21 \\
\hline & & $\mathrm{OPC}$ & 5.2 & 148 & 22 \\
\hline & & Wet & 5.9 & 131 & 21 \\
\hline & \multirow{3}{*}{ Silty Sand } & Dry & 3.6 & 105 & 18 \\
\hline & & $\overline{\mathrm{OPC}}$ & 11.1 & 70 & 19 \\
\hline & & Wet & 13.9 & 64 & 17 \\
\hline \multirow[t]{9}{*}{2} & \multirow{3}{*}{$\begin{array}{l}\text { Granular base } \\
\text { (CABII) }\end{array}$} & Dry & 4.5 & 126 & 20 \\
\hline & & OPC & 6.1 & 120 & 22 \\
\hline & & Wet & 6.6 & 116 & 21 \\
\hline & \multirow{3}{*}{$\begin{array}{l}\text { Select Granular } \\
\text { Backfill Material }\end{array}$} & Dry & 6.1 & 96 & 17 \\
\hline & & OPC & 9.1 & 91 & 18 \\
\hline & & Wet & 10 & 76 & 16 \\
\hline & \multirow[t]{3}{*}{ Silty Clay } & Dry & 11.3 & 82 & 16 \\
\hline & & OPC & 16.7 & 65 & 17 \\
\hline & & Wet & 20.2 & 55 & 14 \\
\hline \multirow[t]{9}{*}{3} & \multirow{3}{*}{$\begin{array}{l}\text { Dense Granular } \\
\text { Aggregate }\end{array}$} & Dry & 2.6 & 837 & 19 \\
\hline & & OPC & 5.6 & 383 & 21 \\
\hline & & Wet & 5.9 & 345 & 20 \\
\hline & \multirow[t]{3}{*}{ Sand } & Dry & 6.4 & 373 & 14 \\
\hline & & $\mathrm{OPC}$ & 11.1 & 105 & 16 \\
\hline & & Wet & 13.9 & 99 & 13 \\
\hline & \multirow[t]{3}{*}{ Clay } & Dry & 5.9 & 130 & 22 \\
\hline & & $\mathrm{OPC}$ & 6.3 & 94 & 23 \\
\hline & & Wet & 7.2 & 59 & 21 \\
\hline
\end{tabular}




\subsubsection{Resilient Modulus}

The resilient modulus was determined using the AASHTO 307 (2003) procedure for representative material samples (Sites 1,2 and 3). The resilient modulus test $\left(M_{R}\right)$ was determined for a number of load applications following the sequences shown in the testing procedure. Each cycle has two load segments: the first segment lasts for 0.1 seconds and the second segment and lasts for 0.90 seconds. Figure 5.6 shows a maximum deviator load being applied for duration of .05 seconds throughout the segment number one. Then, the load was released for another 0.05 seconds. The rest of the cycle occurs over a period of 0.9 seconds. The average of the last few points of the last segment is then taken to calculate the resilient modulus. The results are given in Table 5.18.

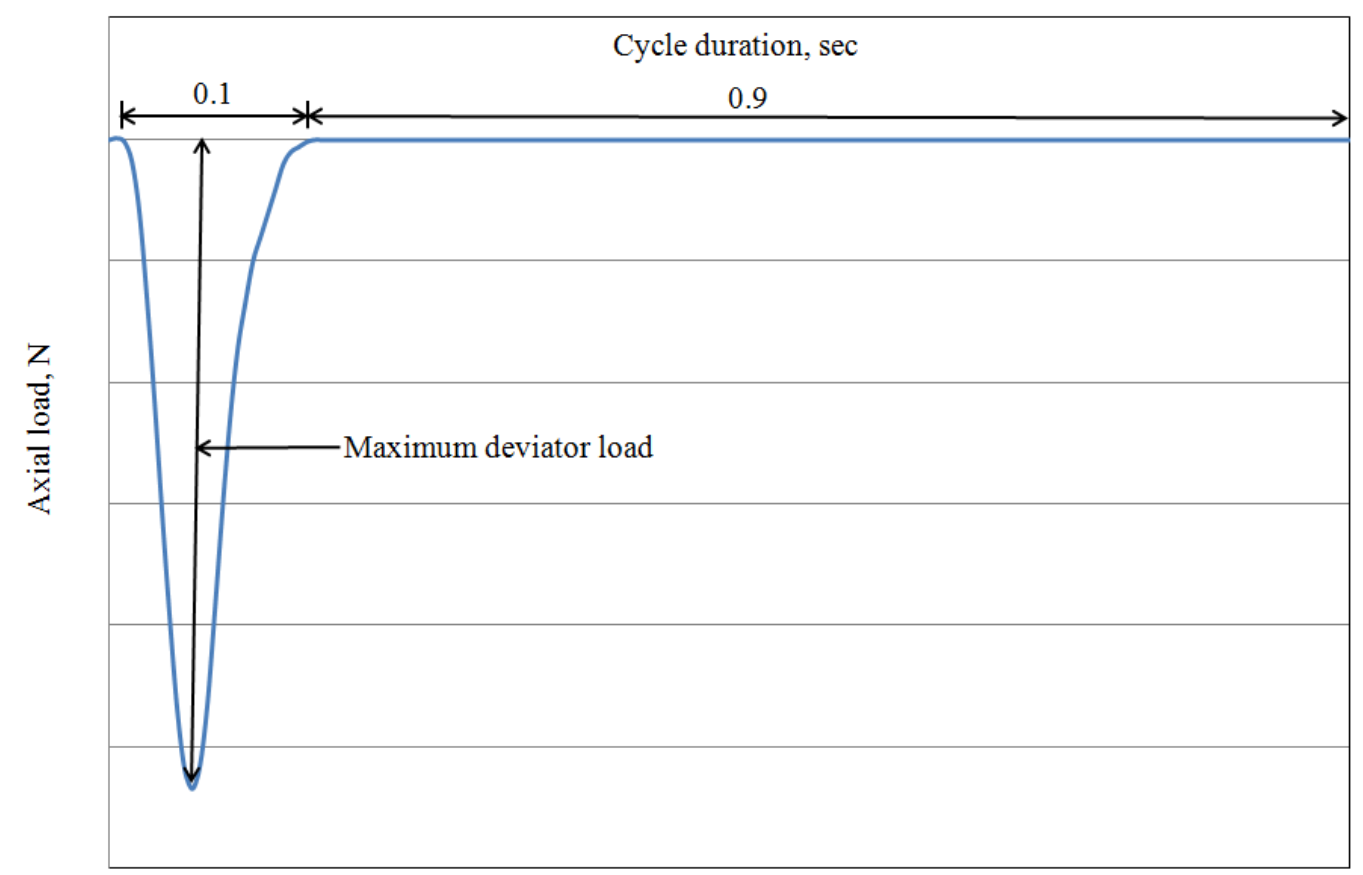

Figure 5.6: Axial load per cycle

The resilient modulus values given in Table 5.18 indicate that at lower moisture content the resilient modulus tends to increase. The resilient modulus decreases at higher moisture contents. Decreasing the water content below the optimum moisture content by 
$2 \%$ increases the resilient modulus by $15 \%$. However, increasing the water content above the optimum moisture content with $1 \%$ decreases the resilient modulus by $11 \%$. 


\section{THICKNESS DESIGN OF FLEXIBLE PAVEMENT}

\subsection{Introduction}

Pavement engineers are still using the existing 1993 AASHTO design guide to effectively determine the thickness of road structure layers. Since the existing design guide has no performance indicators, the performance of the determined thickness will be evaluated using the new M-EPDG. The new M-EPDG is a tool to evaluate the performance of the given pavement structural layers only, and it is not meant to design pavement.

The three constructed sites were chosen for this study based on their different structure, unique traffic patterns and weather conditions as explained earlier. Based on the mechanical materials laboratory testing $\left(\mathrm{M}_{\mathrm{R}}\right)$ conducted in this study, the built thicknesses for the three sites will be evaluated in terms of the initial year of traffic capacity as well as the 20 year design life. Table 6.1 contains the construction details of the three sites. 
Table 6.1: Field sites road structure layers detail

\begin{tabular}{|c|l|l|c|c|}
\hline $\begin{array}{c}\text { Site } \\
\text { Number }\end{array}$ & Classification & Material & $\begin{array}{c}\mathrm{M}_{\mathrm{R}}, \\
\mathrm{MPa}\end{array}$ & $\begin{array}{c}\text { As built plan } \\
\text { Thickness, mm }\end{array}$ \\
\hline \multirow{4}{*}{1} & Asphalt concrete & Asphalt concrete & & 200 \\
\cline { 2 - 5 } & Base & Granular Material A & 148 & 2370 \\
\cline { 2 - 5 } & Sub-grade & Silty Sand & 70 & \\
\hline \multirow{2}{*}{2} & Asphalt concrete & Asphalt concrete & & 230 \\
\cline { 2 - 5 } & Base & $\begin{array}{l}\text { Granular base } \\
\text { (CABII) }\end{array}$ & 120 & 110 \\
\cline { 2 - 5 } & Sub-base & $\begin{array}{l}\text { Select Granular } \\
\text { backfill material }\end{array}$ & 91 & 870 \\
\cline { 2 - 6 } & Sub-grade & Silty Clay & 65 & \\
\hline \multirow{2}{*}{3} & Asphalt concrete & Asphalt concrete & & 240 \\
\cline { 2 - 5 } & Base & $\begin{array}{l}\text { Dense granular } \\
\text { aggregate }\end{array}$ & 383 & 225 \\
\cline { 2 - 5 } & Sub-base & Sand & 105 & 900 \\
\cline { 2 - 5 } & Sub-grade & Clay & 94 & \\
\hline
\end{tabular}

\subsection{Computation of the design ESAL}

It is a normal practice to assign $50 \%$ flow of the traffic to each direction but in some situations uneven splits can occur. The AASHTO design guide (1993) recommended that based on the number of lanes, the \% ESAL in the design lane varies from 100 to $50 \%$ in the case of 1 to 4 lanes respectively.

The AASHTO design guide (1993) summarized the basic computation steps for the design of traffic loading for highway pavement as: estimation of expected initial year traffic volume, estimation of expected annual traffic growth, estimation of traffic stream composition, computation of traffic loads, estimation of directional split of design traffic loads, as well as estimation of design lane traffic loads. Table 6.2 below shows the traffic characteristics of the three constructed sites. 
Table 6.2: Traffic characteristics

\begin{tabular}{|l|l|l|l|l|l|}
\hline $\begin{array}{l}\text { Site } \\
\text { number }\end{array}$ & AADT & \multirow{2}{*}{$\begin{array}{l}\text { Number } \\
\text { of lanes }\end{array}$} & & \multirow{2}{*}{$\begin{array}{l}\text { \% of } \\
\text { trucks }\end{array}$} & \multicolumn{2}{|c|}{1993 AASHTO design guide factors } \\
\cline { 5 - 6 } & & & & $\begin{array}{l}\text { Lane use distribution } \\
\text { factor, } \mathrm{f}_{\mathrm{L}}\end{array}$ & $\begin{array}{l}\text { Directional split } \\
\text { factor, } \mathrm{f}_{\mathrm{D}}\end{array}$ \\
\hline 1 & 7000 & 2 & 15 & 1 & 0.55 \\
\hline 2 & 2000 & 4 & 15 & 0.75 & 0.55 \\
\hline 3 & 33000 & 2 & 15 & 1 & 0.55 \\
\hline
\end{tabular}

The current AASHTO design guide (1993) is based on an $80 \mathrm{kN}$ single axle load. The single axle load of $80 \mathrm{kN}$ was arbitrarily chosen in the AASHTO road test as the standard axle with a unity damaging effect. The combined loading effects of the repetitive application of different axle types on pavements have been converted using equivalency factors to equivalent passes of an $80 \mathrm{kN}$ single axle load (ESAL). Equation 2.10 can be used to compute the loading of the design lane for the design life of a roadway for the three constructed sites using parameters in Table 6.2. Table 6.3 shows the computed initial ESAL, design ESAL for ESAL factors $($ Truck $=0.73$ and passenger car $=0.002)$, number of axles (truck $=3$ and passenger car $=2), 4.5$ annual growth rates and a 20 year design life.

Table 6.3: ESAL traffic loadings

\begin{tabular}{|l|l|l|l|l|}
\hline \multirow{2}{*}{$\begin{array}{l}\text { Site } \\
\text { number }\end{array}$} & \multicolumn{2}{|c|}{ Initial ESAL } & \multicolumn{2}{c|}{ ESAL } \\
\cline { 2 - 5 } & Trucks & Passenger cars & Initial & Design (20 years) \\
\hline 1 & 461625 & 4778 & 466402 & 14631709 \\
\hline 2 & 98920 & 1024 & 99943 & 3135366 \\
\hline 3 & 2176230 & 22524 & 2198755 & 68978058 \\
\hline
\end{tabular}




\subsection{Computation of pavement structure layer thicknesses}

The thicknesses of individual layers are determined by means of the layer analysis concept. Knowing ESAL, serviceability index, reliability, standard deviation, unbound resilient modulus and asphalt concrete elastic modulus, the structural number can be measured using the AASHTO monographs. The AASHTO design guide (1993) defines pavement performance in terms of the present serviceability index (PSI), which varies from 0 to 5. The PSI for newly constructed flexible pavements was found to be 4.2. A serviceability index of 2.5 for a highway is considered terminal or the end of road life. The difference between them represents the road serviceability loss $(\Delta \mathrm{PSI}=1.7)$. The AASHTO guide incorporates the reliability factor of $95 \%$ to account for uncertainties in traffic prediction and pavement performance with overall standard deviations of 0.45 for flexible pavements.

The structural numbers required in each layer of the road structure at the three sites as shown previously in Table 6.1 will be determined from the monograph AASHTO 1993 design guide (see Figure 6.1). By knowing the elastic modulus at $25^{\circ} \mathrm{C}$, then asphalt structural layer coefficient $\left(a_{1}\right)$ can be determined from the chart used by the AASHTO design guide (1993). The coefficient of the materials base $\left(a_{2}\right)$ and sub-base $\left(a_{3}\right)$ can be determined using the correlations given in equation 2.8 .

Once the values of resilient modulus are obtained, the structural layer coefficients will be computed using equation 2.8. With the assumption that drainage of the layers will be excellent, a drainage coefficient of $\mathrm{m}_{1}=\mathrm{m}_{2}=1.3$ are assumed. The layer thicknesses can later be found by substituting the values of SN, structural coefficient and drainage 
coefficients in the equations 6.1 to 6.3 . The calculated different road structure layer thicknesses are summarized in Table 6.4 below.

$$
\begin{gathered}
\mathrm{D}_{1}=\frac{\mathrm{SN}_{1}}{\mathrm{a}_{1}} \\
\mathrm{D}_{2}=\frac{\mathrm{SN}_{2}-\mathrm{SN}_{1}}{\mathrm{a}_{2} \times \mathrm{m}_{2}} \\
\mathrm{D}_{3}=\frac{\mathrm{SN}_{3}-\left(\mathrm{SN}_{1}+\mathrm{SN}_{2}\right)}{\mathrm{a}_{3} \times \mathrm{m}_{3}}
\end{gathered}
$$

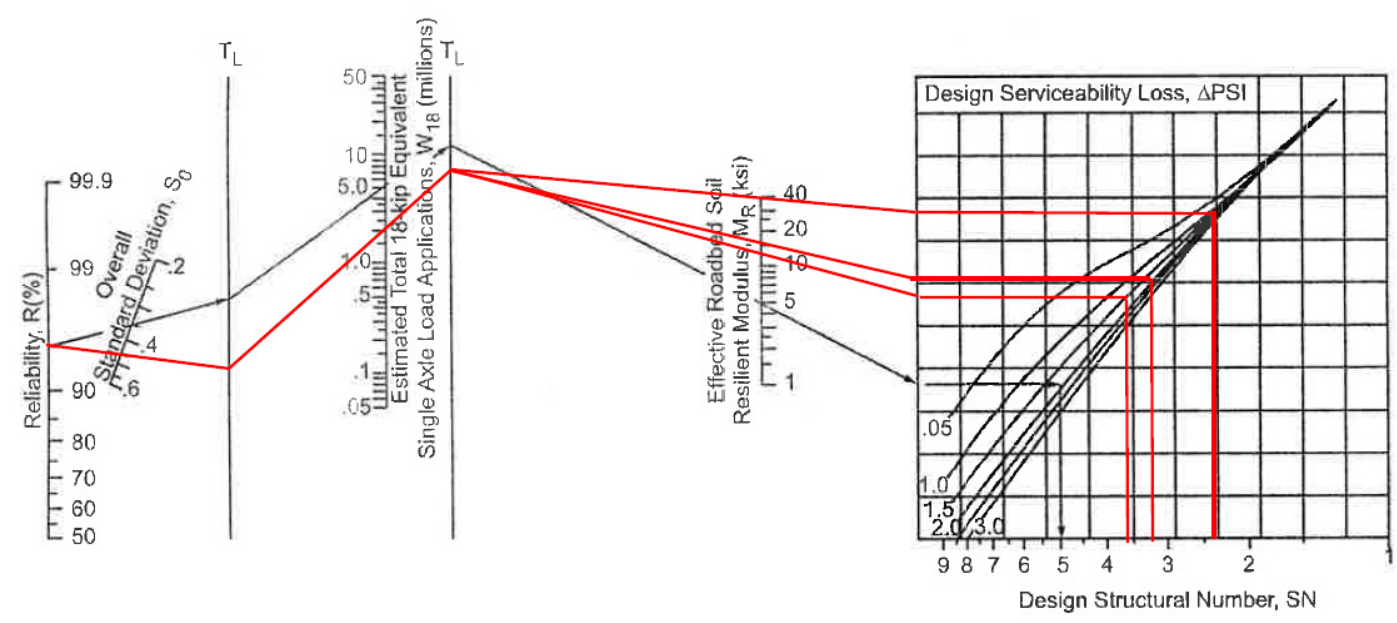

FIGURE 62.6 AASHTO design chart for flexible highway pavements. (Source: AASHTO Guides for Design of Pavement Structures, American Association of State Highway and Transportation Officials, Washington, D.C., 1993. With permission.)

\begin{tabular}{|c|c|c|c|c|c|c|c|c|c|c|}
\hline \multirow{3}{*}{$\begin{array}{l}\text { Site } \\
\text { number }\end{array}$} & \multirow[t]{3}{*}{ ESAL } & \multicolumn{3}{|c|}{$\begin{array}{l}\text { Structural } \\
\text { coefficient }\end{array}$} & \multicolumn{3}{|c|}{ Structural number } & \multicolumn{3}{|c|}{ Thickness, mm } \\
\hline & & $\mathrm{AC}$ & Base & $\begin{array}{l}\text { Sub- } \\
\text { base }\end{array}$ & $\mathrm{AC}$ & Base & $\begin{array}{l}\text { Sub- } \\
\text { base }\end{array}$ & $\mathrm{AC}$ & Base & $\begin{array}{l}\text { Sub- } \\
\text { base }\end{array}$ \\
\hline & & $a_{1}$ & $a_{2}$ & $\mathrm{a}_{3}$ & $\mathrm{SN}_{1}$ & $\mathrm{SN}_{2}$ & $\mathrm{SN}_{3}$ & D1 & $\mathrm{D} 2$ & D3 \\
\hline \multirow[t]{2}{*}{1} & Initial & \multirow[t]{2}{*}{0.4} & \multirow[t]{2}{*}{0.104} & \multirow[t]{2}{*}{0.147} & 2.1 & 2.1 & 2.9 & 133 & 162 & 162 \\
\hline & Design & & & & 3.5 & 3.5 & 4.8 & 222 & 264 & 264 \\
\hline \multirow[t]{2}{*}{2} & Initial & \multirow[t]{2}{*}{0.4} & \multirow[t]{2}{*}{0.079} & \multirow[t]{2}{*}{0.096} & 1.8 & 2 & 2.3 & 114 & 54 & 66 \\
\hline & Design & & & & 3.3 & 3.7 & 4 & 210 & 107 & 66 \\
\hline \multirow[t]{2}{*}{3} & Initial & \multirow[t]{2}{*}{0.4} & \multirow[t]{2}{*}{0.204} & \multirow[t]{2}{*}{0.110} & 2.2 & 3.2 & 3.4 & 140 & 104 & 38 \\
\hline & Design & & & & 3.8 & 4.8 & 5.1 & 241 & 104 & 57 \\
\hline
\end{tabular}

Figure 6.1: AASHTO design guide chart for flexible pavement

Table 6.4: Calculated road structure layer parameters for sites 1 to 3 
Table 6.5 below shows the minimum thickness requirements for asphalt concrete and base layers as recommended by the AASHTO 1993 design guide based on traffic considerations. The calculated road structure layers in Table 6.4 are compared with AASHTO minimum requirements. The calculated required thickness for the base layer at both sites 2 and 3 are below the minimum thickness requirements of AASHTO 1993 in Table 6.5. Thus the minimum recommended thickness of 100 and $150 \mathrm{~mm}$ are selected for initial design ESAL for site 2 and $150 \mathrm{~mm}$ for the base material including both traffic loadings at site 3. The adjusted thicknesses for the three sites are shown in Table 6.6.

Table 6.5: AASHTO recommended minimum thickness of highway layers

\begin{tabular}{|c|c|c|}
\hline \multicolumn{3}{|c|}{ Minimum Thickness ( mm) } \\
\hline $\begin{array}{c}\text { Traffic Loading } \\
\text { (ESAL) }\end{array}$ & $\begin{array}{c}\text { Asphalt Concrete } \\
\text { Surfacing }\end{array}$ & $\begin{array}{c}\text { Aggregate } \\
\text { Base }\end{array}$ \\
\hline$<50000$ & $\begin{array}{c}25, \text { OR } \\
\text { surface treatment }\end{array}$ & 100 \\
\hline $50001-150000$ & 50 & 100 \\
\hline $150001-500000$ & 62.5 & 100 \\
\hline $500001-2000000$ & 75 & 150 \\
\hline $2000001-7000000$ & 87.5 & 150 \\
\hline$>7000000$ & 100 & 150 \\
\hline
\end{tabular}


Table 6.6: Calculated, designed and constructed road structure layers for sites 1 to 3

\begin{tabular}{|c|c|c|c|c|c|c|}
\hline \multirow[t]{2}{*}{$\begin{array}{l}\text { Site } \\
\text { number }\end{array}$} & \multirow[t]{2}{*}{$\begin{array}{c}\text { Layer } \\
\text { classification }\end{array}$} & \multicolumn{2}{|c|}{$\begin{array}{l}\text { Calculated thickness } \\
\text { based on ESAL, } \\
\text { mm }\end{array}$} & \multicolumn{2}{|c|}{$\begin{array}{l}\text { Designed thickness } \\
\text { based on minimum } \\
\text { requirement, mm }\end{array}$} & \multirow[t]{2}{*}{$\begin{array}{l}\text { Constructed } \\
\text { thickness, } \\
\text { mm }\end{array}$} \\
\hline & & Initial & Design & Initial & Design & \\
\hline \multirow[t]{3}{*}{1} & $\mathrm{AC}$ & 133 & 222 & 133 & 222 & 200 \\
\hline & Base & 162 & 264 & 162 & 264 & 1185 \\
\hline & Sub-base & 162 & 264 & 162 & 264 & 1185 \\
\hline \multirow[t]{3}{*}{2} & $\mathrm{AC}$ & 114 & 210 & 114 & 210 & 230 \\
\hline & Base & 54 & 107 & 100 & 150 & 110 \\
\hline & Sub-base & 66 & 66 & 66 & 66 & 870 \\
\hline \multirow[t]{3}{*}{3} & $\mathrm{AC}$ & 140 & 241 & 140 & 241 & 240 \\
\hline & Base & 104 & 104 & 150 & 150 & 225 \\
\hline & Sub-base & 38 & 57 & 38 & 57 & 900 \\
\hline
\end{tabular}

\subsection{Comparison and discussion}

As noted above, the thicknesses of the individual layers are determined by means of the layer analysis concept. Analysis of the obtained results and the constructed pavement structure indicate that the initial structural design based on the initial traffic loading is insufficient to withstand the imposed traffic load for long periods as traffic volume increases over the years. Figure 6.2 shows the asphalt concrete layers for the three sites based on initial design ESALs for the 20-year design period in comparison with constructed layers. The AASHTO 1993 design method yielded comparable values for the thicknesses of the asphalt concrete layers for all sites. Differences in the base and sub-base values are considerable for the three sites. For the base course, sites 1 and 2 were over constructed by about 87 and $33 \%$ respectively, and site 3 was under constructed by about $36 \%$ as shown in Figure 6.3. Figure 6.4 shows thickness results for the sub-base material layers. It is noted that for the three sites, the sub-base layers were over constructed by about 87,92 and $94 \%$ for sites 1,2 and 3, respectively. It is 
understandable for site 2 that an over constructed sub-base (i.e. increase the thickness of the under layers) was a choice of the contractor or original engineer as a replacement for expensive base materials.

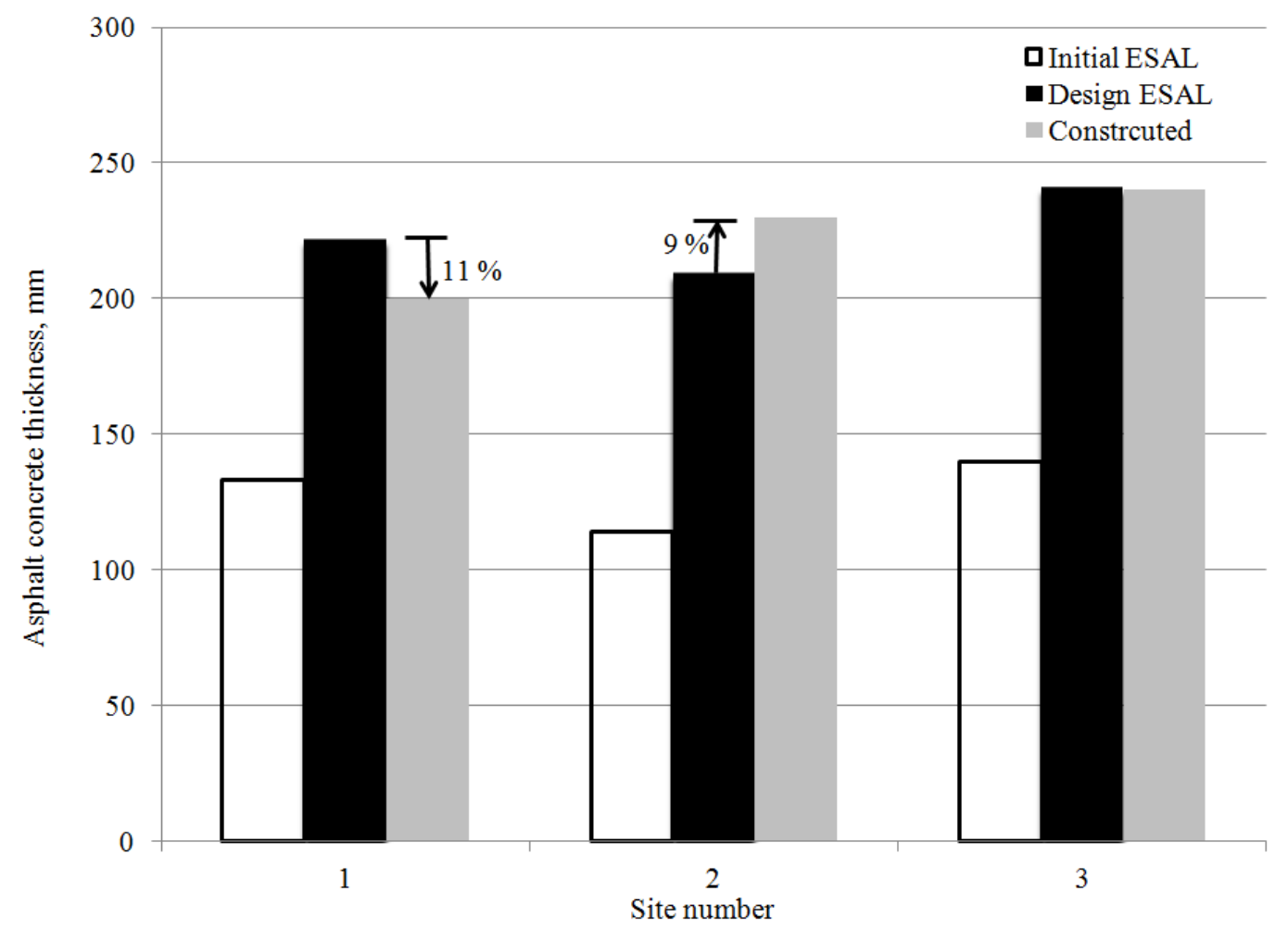

Figure 6.2: Comparison of asphalt concrete layers- ESALs versus constructed 


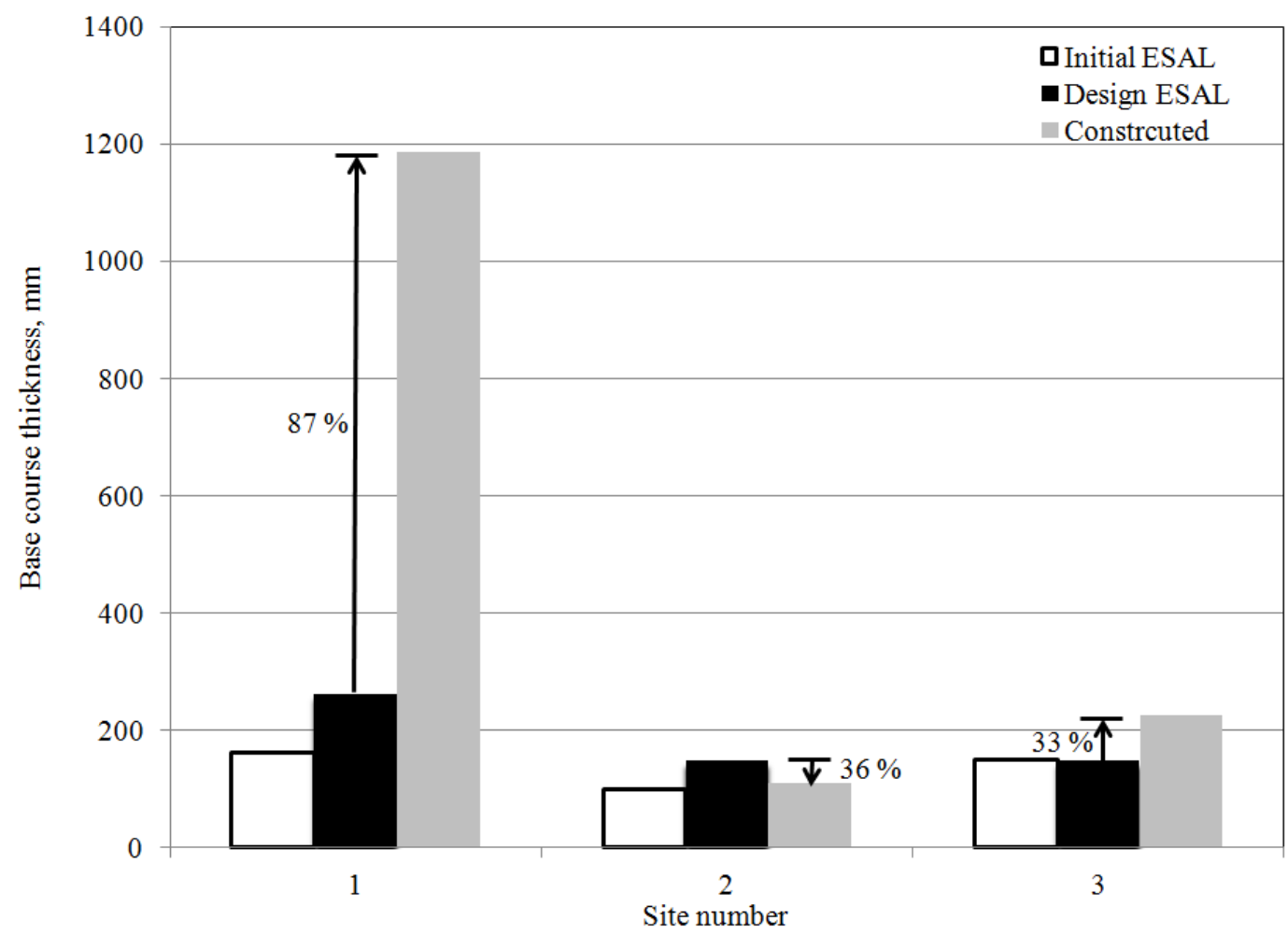

Figure 6.3: Comparison of base course layers- ESALs versus constructed

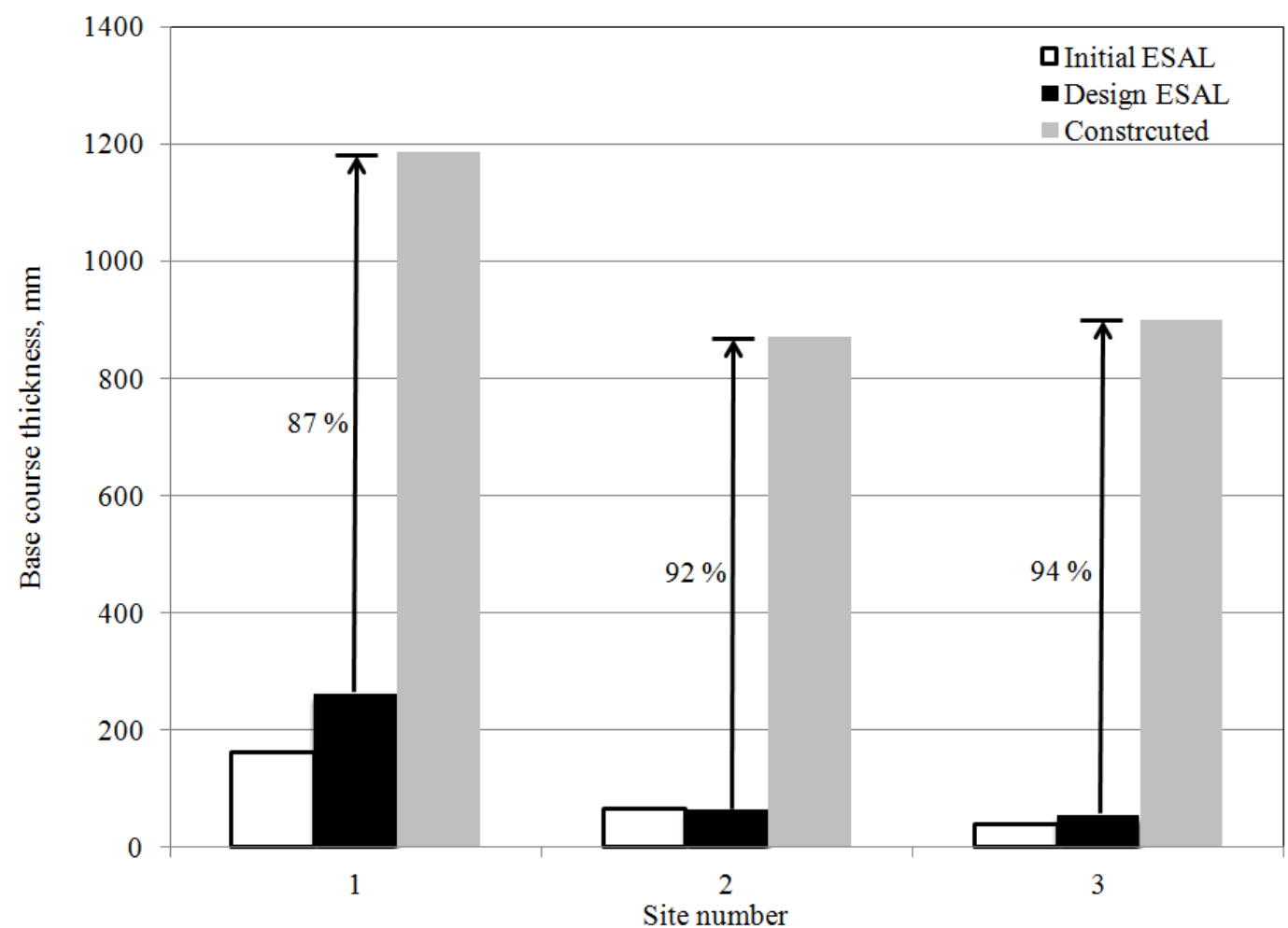

Figure 6.4: Comparison of sub-base course layers- ESALs versus constructed 
It can be concluded that the thickness method of flexible pavement design using the 1993 AASHTO design guide is subject to the following limitations:

$\square \quad$ Assumptions in converting traffic loading to ESAL, based on the $80 \mathrm{kN}$ single axle load can be problematic. The single axle load of $80 \mathrm{kN}$ was arbitrarily chosen in the AASHTO road test as the standard axle with a unity damaging effect. The concept of the relative damage is not quantifiable and is based on empirical results of the 1950 ASSHTO road test.

$\square \quad$ Young modulus "E" to characterize asphalt pavement structures, assuming the pavement as an elastic material is not entirely accurate. This characterization does not account for the fact that asphalt concrete materials do not behave purely in elastic manner, when in fact they are actually viscoelastic.

$\square$ Temperature is a significant factor and it is not considered in the existing design guide. It influences the performance of pavement, especially asphalt concrete. The stiffness of $\mathrm{AC}$ is lessened at higher temperatures, making it susceptible to deformations. Low temperatures make the AC layer extremely brittle and the surface becomes susceptible to cracking.

$\square \quad$ There is only one value of unbound material resilient modulus.

$\square \quad$ Using experimental correlations to estimate drainage and structural coefficient related to the type of material being used in each layer did not represent the actual behaviour.

$\square \quad$ The AASHTO design guide chart is outdated, and high values of ESAL $L_{T}$ and $M_{R}$ were off the chart. 
$\square \quad$ Inaccurate conversion of structural numbers to thickness of various layers of flexible pavement due to its lack of scientific basis and accuracy.

$\square \quad$ It does not provide any reliable indicators for the long term performance of the designed pavement.

The three constructed sites were assessed based on road structure pavement layers using the existing 1993 AASHTO design guide. Calculations regarding pavement thickness are critical to a cost-effective project. If pavements are thicker than required, then unnecessary money is spent on materials and labor that could be better spent elsewhere. If pavements are too thin to support actual traffic, then pavements fail before their anticipated useful life is over. Unfortunately using the existing design guide, the sites from this study cannot be evaluated based on their performance. This is the main reason pavement engineers and practitioners are trying to use the new M-EPDG. In this study the sensitivity of the M-EPDG will be discussed at a later point. The three sites will be used to evaluate their performance compared to the field data. 


\section{EVALUATION OF THE M-EPDG}

In view of the substantial cost needed for their maintenance and rehabilitation, roads are expected to perform without major distresses over a wide range of structural and environmental conditions. Nonetheless, it is not uncommon to see pavement failures after only three to five years of service. Thus, it is necessary to understand the behaviour of the roads in the short, medium and long term with a view of incorporating improvements that help mitigate premature failures. One such improvement may be to link the pavement structure response as being influenced by environmental, operating and service requirements, as well as traffic loading in order to quantify performance according to specific criteria.

Currently, pavement analysis, including that of the proposed MechanisticEmpirical Pavement Design Guide (M-EPDG), is based primarily on multilayered linear elastic analysis. Mechanistic characterization techniques of road materials represent one of the major improvements introduced in the M-EPDG model.

The existing thickness design of flexible pavements in the 1993 AASHTO design guide is a complex engineering process involving a large number of variables. Most structural flexible pavement design approaches are empirical in nature. These approaches use some established relationships to estimate the strength of different materials. However, limitations of the empirical approach are becoming increasingly obvious with developments in the transportation system and increased knowledge in the fields of pavement mechanics and material science. Despite efforts by researchers in the last few decades to enhance the mechanistic part of the design, the mechanistic aspects are not yet fully satisfactory. 
Model runs were performed using the field work and laboratory work conducted at three different sites in this study as input data files. These included design levels of the M-EPDG model to determine the degree of precision achieved by using the advanced design level 1 for asphalt concrete and level 3 for the analysis for unbound materials.

Premature failures of flexible pavement occur at an early stage (within one year after construction) in the service life (Abd El Halim, A.O., 1985), which necessitates the need for a more comprehensive design tool that will incorporate both the mechanistic and empirical behaviour of the structural materials that comprise the road structure.

The output of the current empirical pavement design guide is in the form of structural numbers as explained previously. Thus, the output lacks the performance measures. M-EPDG is therefore in the process of being used within the existing approach.

Currently, pavement analysis, including the M-EPDG model, is based primarily on multilayered linear elastic analysis. Mechanistic characterization techniques of road materials represent one of the major improvements introduced in the M-EPDG model.

\subsection{Sensitivity analysis}

Runs were performed to examine the ability of the new design guide software to capture the impact of different structural and environmental variables and to predict performance of the asphalt. Rutting, fatigue cracking (top down cracking, and bottom up cracking), thermal cracking and international roughness index (IRI) accumulated throughout the 20 year design life were used to measure changes in the behaviour and characteristics of the pavement and the unbound materials that occur with site specific conditions over the design period. 
The new AASHTO design guide provides three levels of input depending on the importance of the project and the availability of the project design inputs. The climate database incorporated in the new design guide and site related cities were selected.

Following the recommendation of the design guide, laboratory and fieldwork was performed as explained in previous chapters and the results were used as input for level 1 for asphalt concrete and level 3 for unbound materials. The details of the unbound material runs used in this analysis are shown in Table 7.1 for site 1 only (see Figure 3.14 ) and details of traffic data input file used are shown in Table 7.2.

Table 7.1: Details of M-EPDG runs site 1

\begin{tabular}{|c|c|c|c|c|}
\hline \multirow{2}{*}{$\begin{array}{l}\text { Code } \\
\text { Classification }\end{array}$} & \multirow{2}{*}{$\begin{array}{l}\text { Soil } \\
\text { condition }\end{array}$} & \multirow{2}{*}{$\begin{array}{l}\text { Run } \\
\text { number }\end{array}$} & \multicolumn{2}{|c|}{ Layer thickness, mm } \\
\hline & & & Constructed & Maximum MEPDG \\
\hline $\mathrm{AC}$ & & R1/R2/R3 & 200 & 200 \\
\hline \multirow{3}{*}{$\begin{array}{l}\text { Base } \\
\text { (GA) }\end{array}$} & Dry & $\mathrm{R} 1$ & \multirow[t]{3}{*}{940} & \multirow[t]{3}{*}{940} \\
\hline & $\mathrm{OPC}$ & R2 & & \\
\hline & Wet & R3 & & \\
\hline \multirow{3}{*}{$\begin{array}{l}\text { Sub-grade } \\
\text { (GA) }\end{array}$} & Dry & $\mathrm{R} 1$ & \multirow[t]{3}{*}{1420} & \multirow[t]{3}{*}{1300} \\
\hline & OPC & R2 & & \\
\hline & Wet & R3 & & \\
\hline \multirow{3}{*}{$\begin{array}{l}\text { Sub-grade } \\
\text { (Silty sand) }\end{array}$} & Dry & $\mathrm{R} 1$ & \multirow[t]{3}{*}{ Last } & \multirow[t]{3}{*}{ Last } \\
\hline & $\mathrm{OPC}$ & R2 & & \\
\hline & Wet & R3 & & \\
\hline
\end{tabular}

Table 7.2: Traffic input data

\begin{tabular}{|l|l|}
\hline Input description & Site 1 \\
\hline Design life (years) & 20 \\
\hline Number of lanes in design direction & 2 \\
\hline Percentage of trucks in design direction & 50 \\
\hline Percentage of trucks in design lane & 95 \\
\hline Operated speed, $\mathrm{km} / \mathrm{h}(\mathrm{mph})$ & $75(45)$ \\
\hline Tire pressure, $\mathrm{kPa}(\mathrm{psi})$ & $827(120)$ \\
\hline Traffic, AADT & 1000 \\
\hline Traffic growth, $\%$ & 4.5 \\
\hline
\end{tabular}




\subsubsection{Effect of M-EPDG layer thickness limitation on permanent deformation}

Due to the limitation in the thickness of road layers that can be used in the new design guide, this study considered a variation of the in-situ conditions. Figure 7.1 shows the difference between the actual road structure materials layer thickness in Site 1 and the maximum allowable thickness of road layers imposed by the new design guide software.

\begin{tabular}{|c|c|c|c|}
\hline Asphalt concrete (AC) & $300 \mathrm{~mm}$ & Asphalt concrete (AC) & $300 \mathrm{~mm}$ \\
\hline \multirow[b]{2}{*}{$\begin{array}{l}\text { Base-Granular material A } \\
\text { (GA) }\end{array}$} & \multirow[b]{2}{*}{$2360 \mathrm{~mm}$} & $\begin{array}{c}\text { Base-Granular material A } \\
\text { (GA) }\end{array}$ & $940 \mathrm{~mm}$ \\
\hline & & $\begin{array}{l}\text { Sub-grade-Granular material A } \\
\text { (GA) }\end{array}$ & $1300 \mathrm{~mm}$ \\
\hline Sub-grade-Silty Sand (SM) & $\frac{1}{1}$ & $\begin{array}{c}\text { Sub-grade-Silty Sand (SM) } \\
\text { Last }\end{array}$ & \\
\hline
\end{tabular}

Fig 7.1a: Actual layers thickness

Fig 7.1b: Software limitation of layers thickness

Figure 7.1: Pavement road structure layers

As previously mentioned, the new design guide software includes an upper limit thickness of $940 \mathrm{~mm}$ for the base layer and $1300 \mathrm{~mm}$ for the sub-base layer. This forced division of the thick base course materials to base and sub-grade materials is shown in Figure 7.1.

These limitations of the M-EPDG warranted examining the effect of dividing an unbound layer into two layers in terms of performance. This was achieved by comparing the two sections shown in Figure 7.2 where the base layer of $940 \mathrm{~mm}$ was divided into two sections; a $432 \mathrm{~mm}$ thick base layer and a $508 \mathrm{~mm}$ thick sub-grade composed of the 
same material (Granular A). The comparison focused on the optimum condition state of this material (see Table 7.2) and PG 58-28 binder.

\begin{tabular}{c}
\hline Asphalt concrete (AC) \\
Base-Granular material A \\
(GA) \\
Sub-grade-Silty Sand (SM) \\
Last
\end{tabular}

Figure 7.2a: Section 1

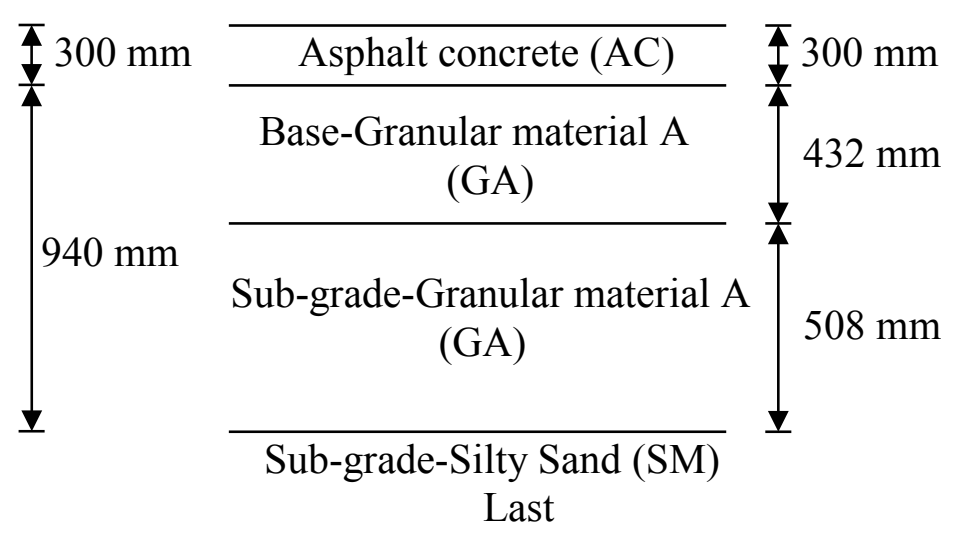

Figure 7.2b: Section 2

Figure 7.2: Sections considered investigating thickness limitation in the MEPDG

The total permanent deformation for both bound and unbound materials for the two sections considered is shown in Figure 7.3. It is clear that dividing an unbound layer into two layers of the same material does not affect the performance. 


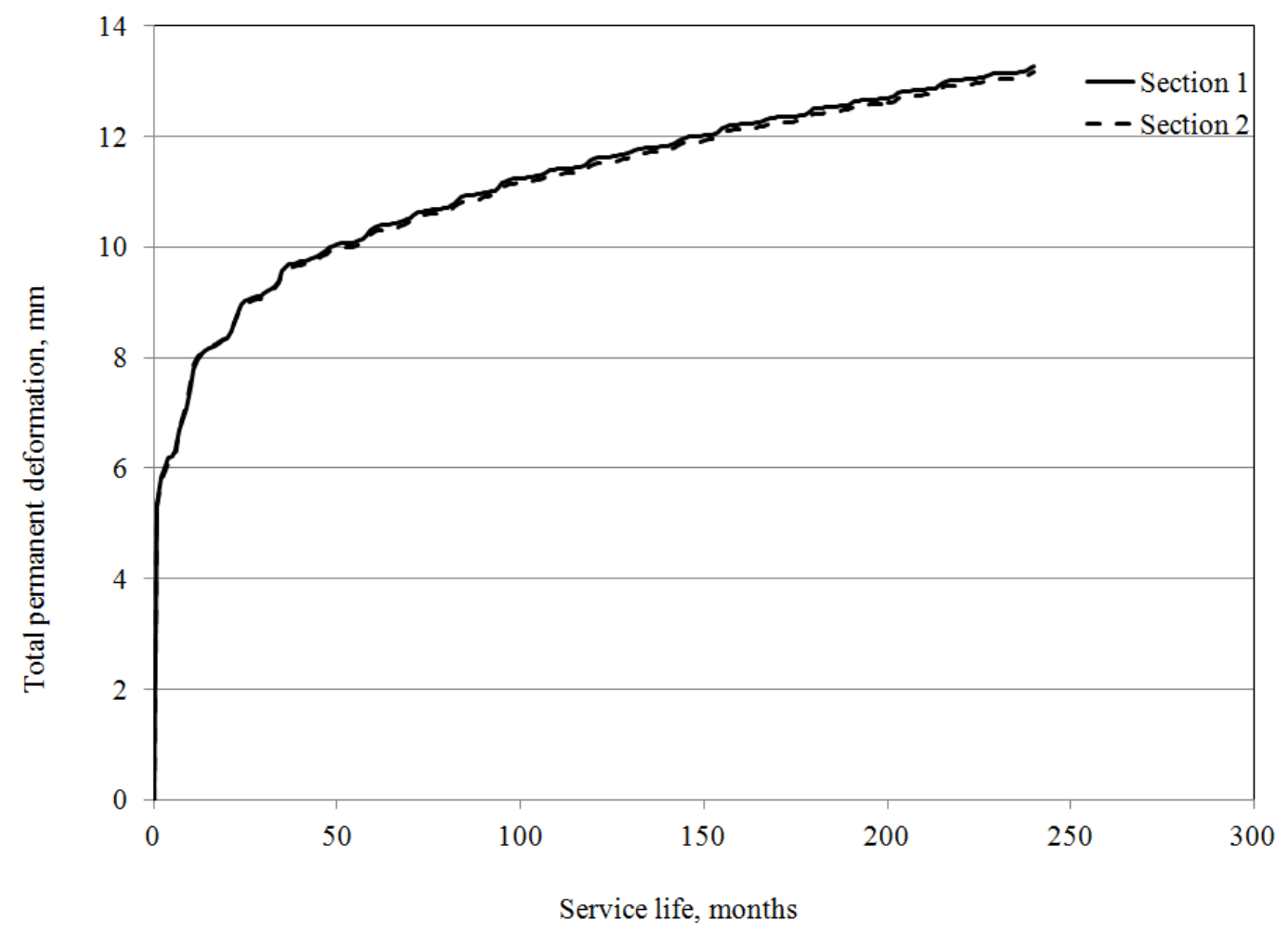

Figure 7.3: Effect of software upper limit on permanent deformation

\subsubsection{Effect of climate on M-EPDG model performances}

Model runs to examine the effect of temperature on asphalt concrete rutting were carried out using two climatic files with different mean annual air temperatures (MAAT) of $20^{\circ} \mathrm{C}$ (Long Beach, California) and $10^{\circ} \mathrm{C}$ (New York). Rutting accumulated throughout the 20 years design life was evaluated using the optimum conditions for the unbound materials and PG 58-28 binder.

\subsubsection{Permanent deformation}

Rutting accumulated throughout the 20 year design life was evaluated using the optimum conditions for the unbound materials of site 1 (see Table 7.1) and PG 58-28. The results are given in Figure 7.4. It is clear that rutting predictions for the warm region (Long Beach, California) were about $51 \%$ higher than for the relatively cold region 
(New York). The M-EPDG model exhibited good sensitivity to different climatic zones regardless of the small output values compared to the design limit, which was due to the use of a low level of AADT (1000).

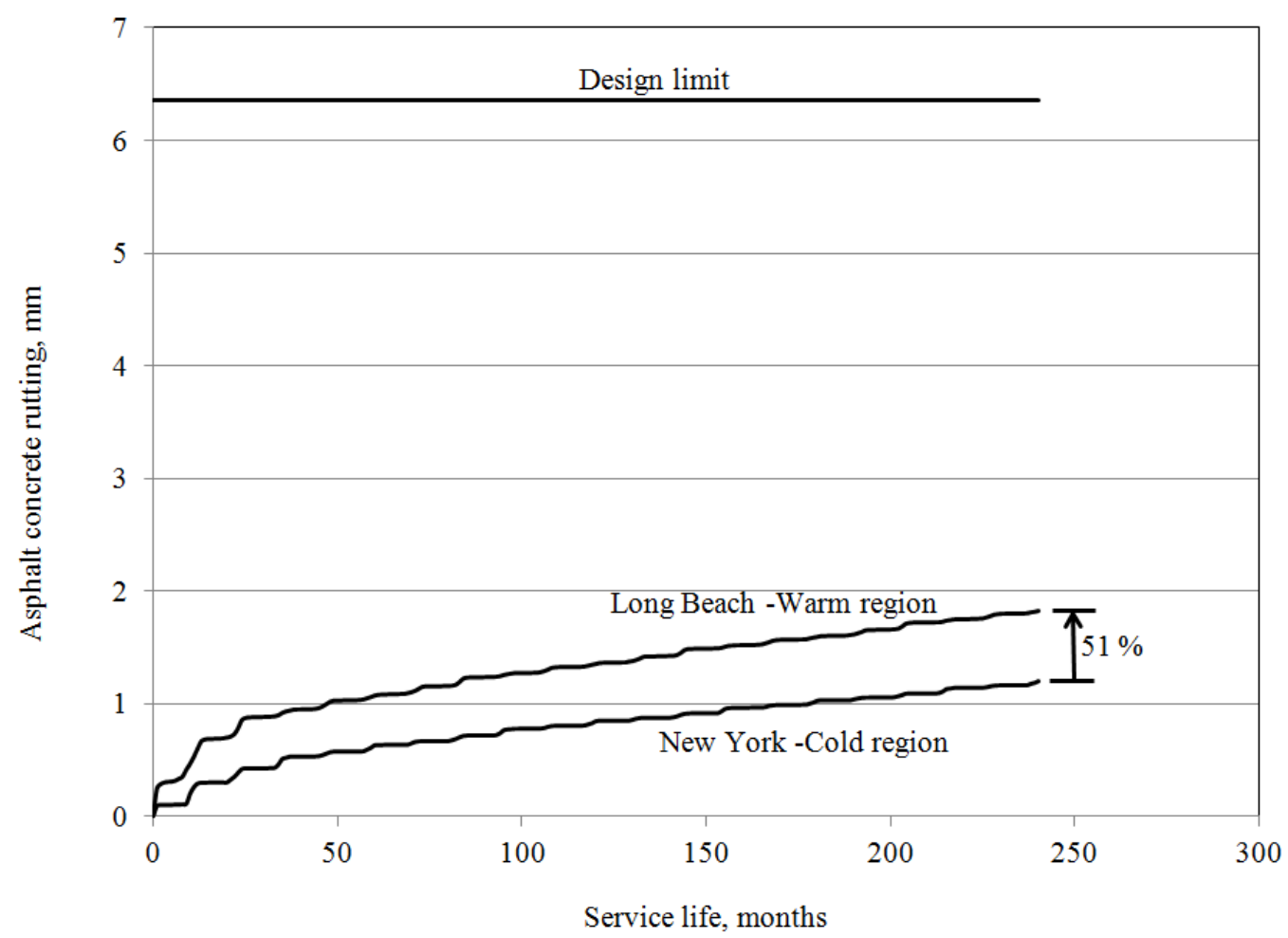

Figure 7.4: Effect of environment on asphalt concrete rutting

\subsubsection{Surface down fatigue (longitudinal) cracking}

Results of the runs are plotted in Figure 7.5. The results show that longitudinal cracks increased by about $22 \%$ in the warm region compared to the cold region. The AADT used in this study was small (1000). The AADT has an impact on the total longitudinal cracking compared to the design limit. However, the M-EPDG model exhibited good sensitivity to different climatic zones. 


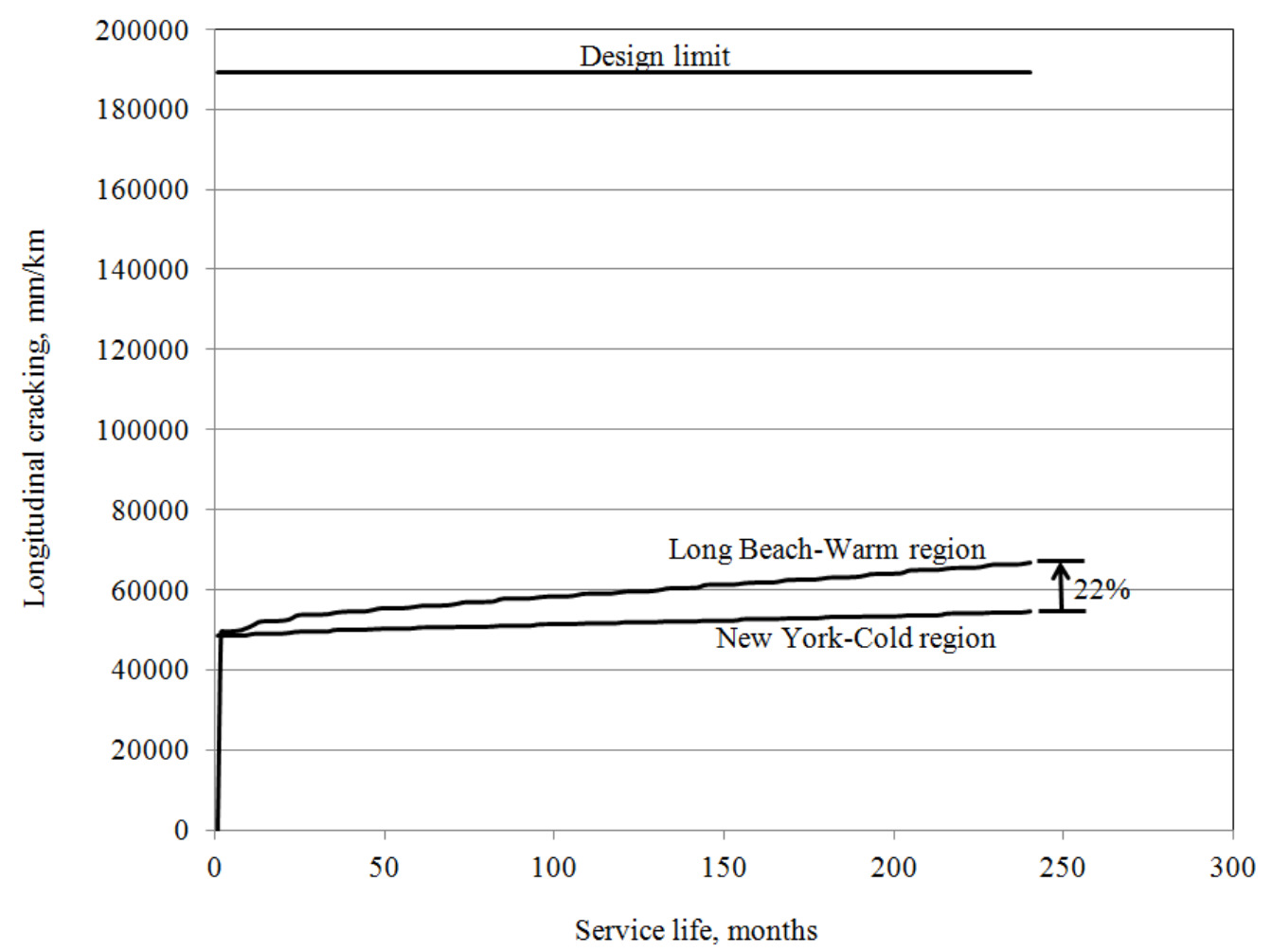

Figure 7.5: Effect of environment on longitudinal cracking

\subsubsection{Bottom up fatigue (alligator) cracking}

Fatigue cracking in the relatively warm climate increases with the temperature of the asphalt concrete layer. Thus the stiffness increases, making the pavement more vulnerable to alligator cracking. The results shown in Figure 7.6 are not in agreement with the impact of temperature on the AC layer stiffness where alligator cracking in cold region is higher than warm region by $6 \%$. This small margin could be considered within the margin of errors given that the evaluation was done at 1000 AADT. 


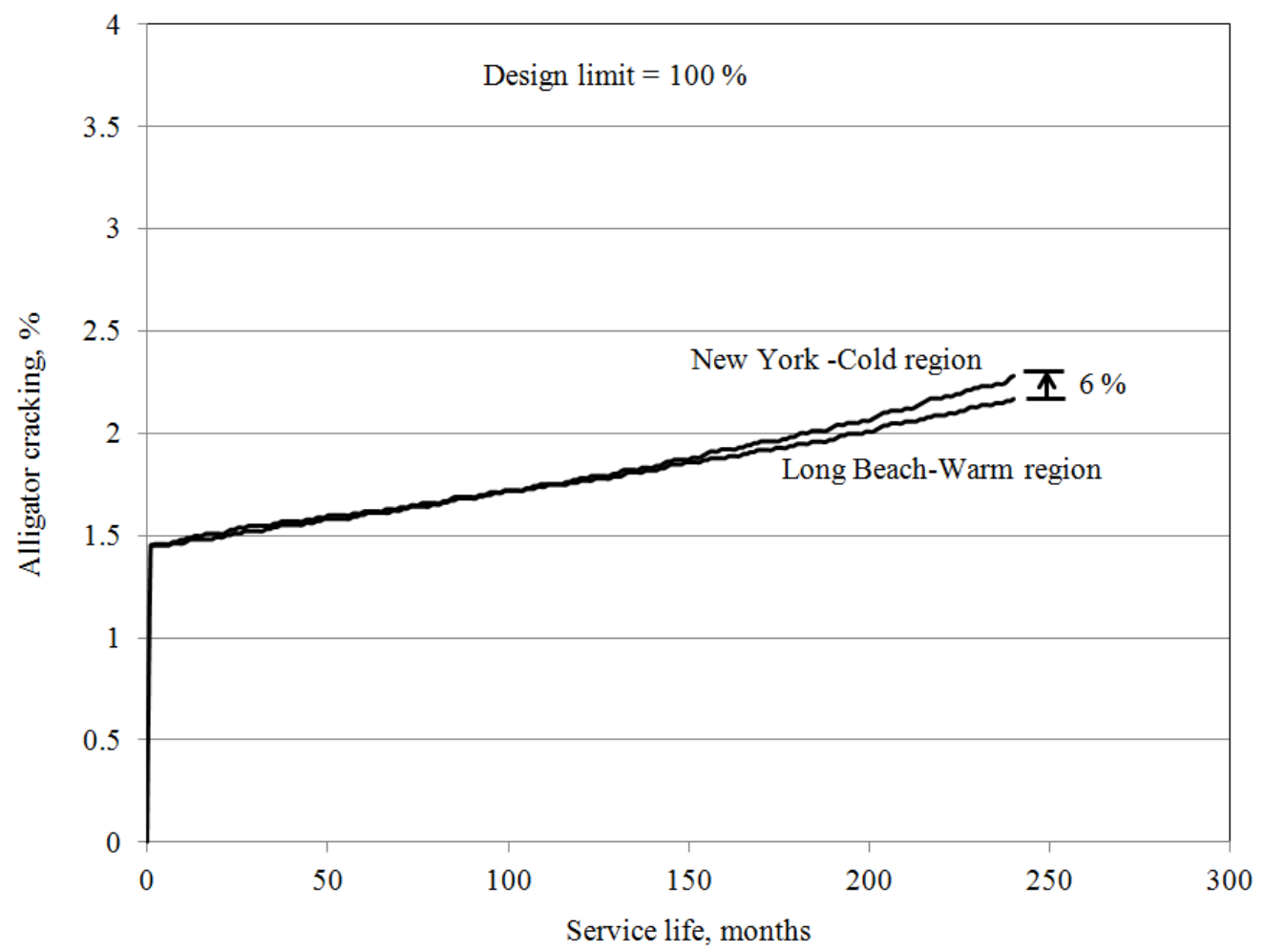

Figure 7.6: Effect of environment on alligator cracking

\subsubsection{Thermal cracking}

One of the most important conclusions of this research is the fact that the predictions of the M-EPDG of the occurrence of thermal cracking reliable or accurate. Typical results are shown in Figure 7.7. 


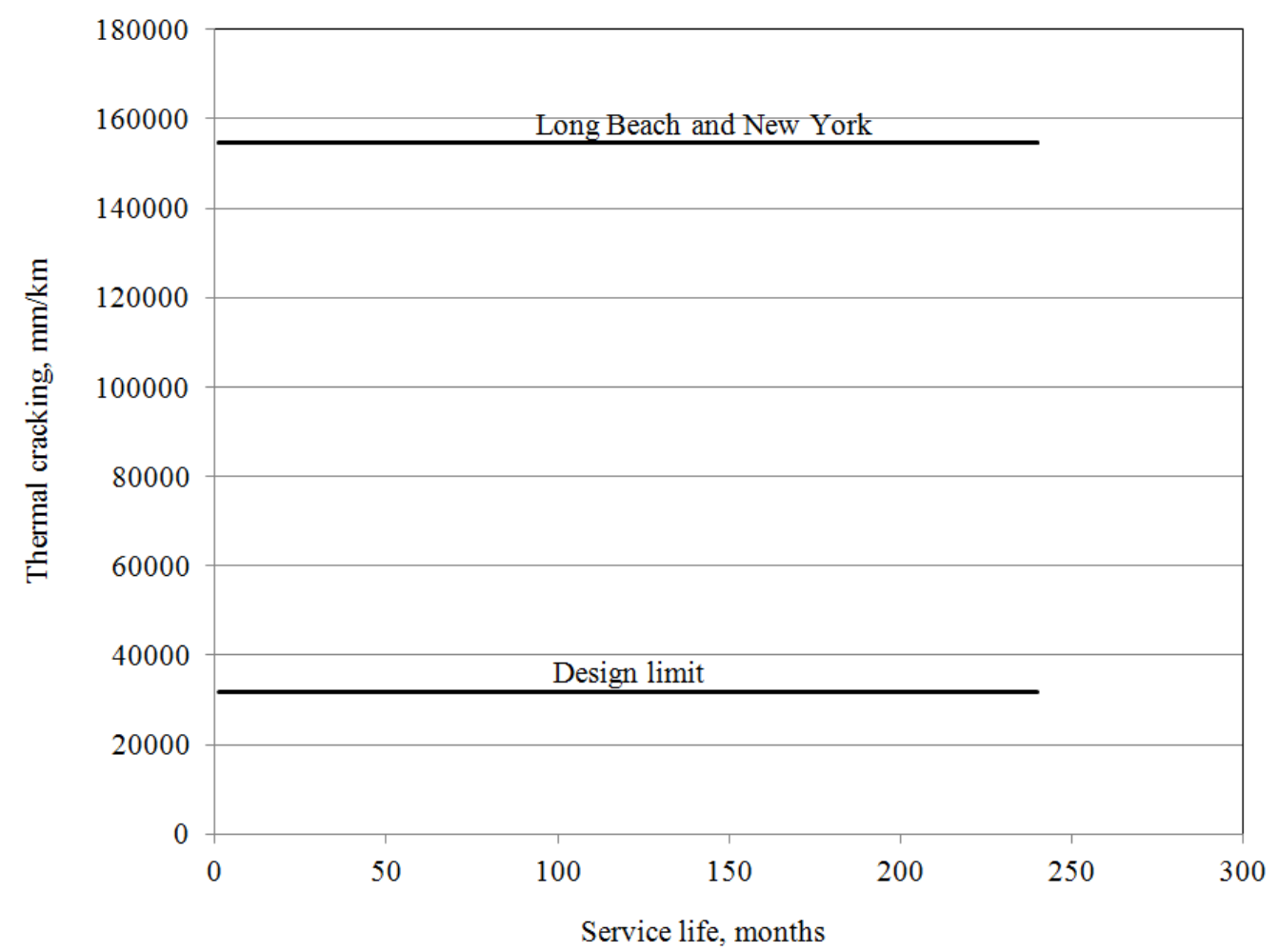

Figure 7.7: Effect of environment on thermal cracking

\subsubsection{International Roughness Index (IRI)}

The M-EPDG uses the international roughness index (IRI) as a measure for smoothness. The M-EPDG predicted smoothness performance for mix of SP 12.5 using PG 58-28 as shown in Figure 7.8. All types of performance distress are supposed to contribute to the loss of pavement smoothness as discussed earlier. The rutting and longitudinal performances for cold regions are lower than for the warm regions but the IRI trend shown in Figure 7.8 shows the opposite behaviour where the cold region IRI is higher than the warm region by $13 \%$. 


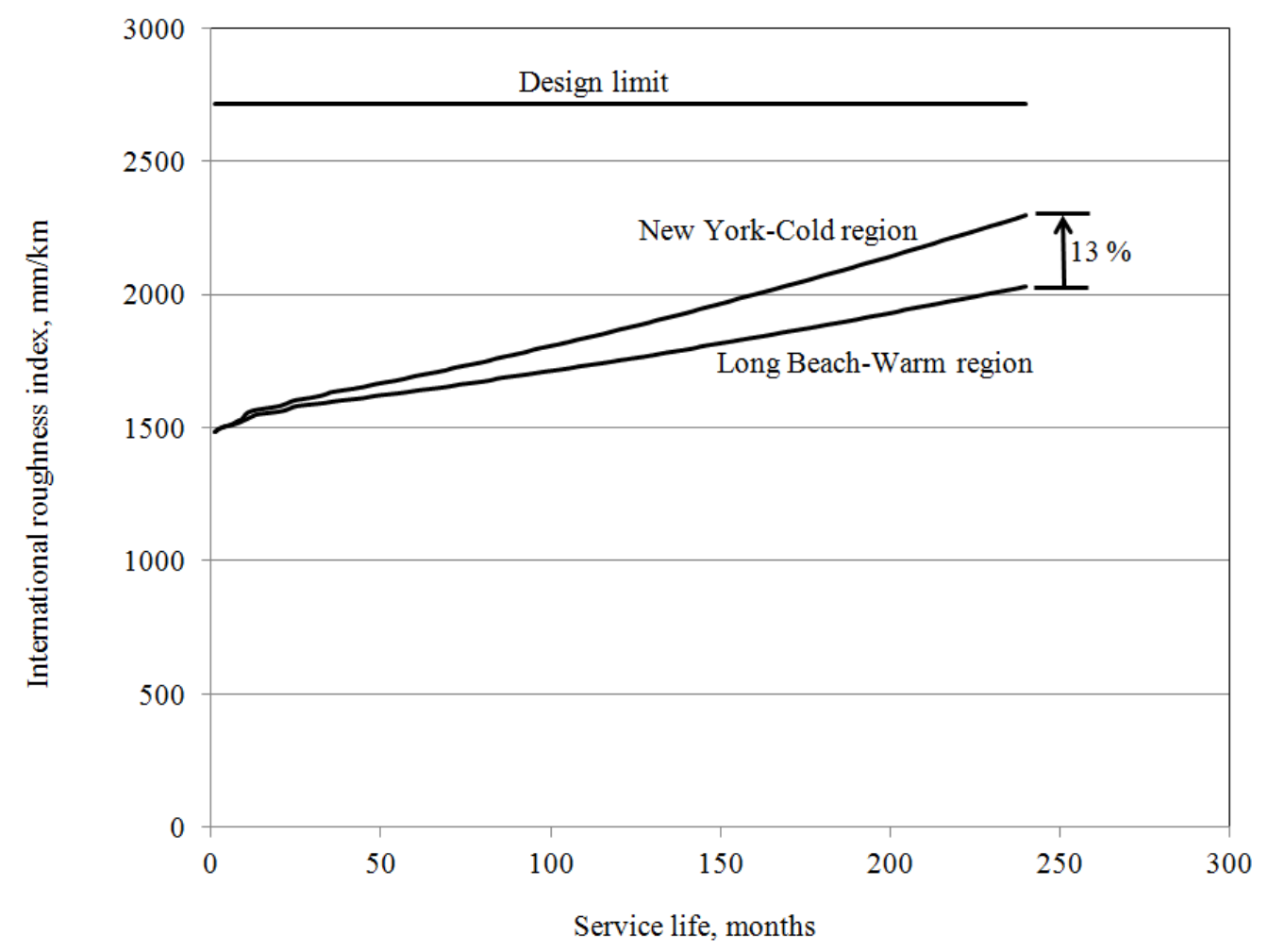

Figure 7.8: Effect of environment on IRI

\subsubsection{Effect of binder type and soil condition on M-EPDG model performances}

Three mix types, namely PG 52-34, PG 58-28 and PG 64-22 were used to evaluate the sensitivity of the model to different binder grades and three levels of soil conditions on the road structure layers of site 1 (see Table 7.1).

\subsubsection{Asphalt concrete permanent deformation}

The permanent deformation of the asphalt concrete layer using these binders for different moisture conditions of the unbound layer is shown in Figure 7.9. The effect of the soil condition on the asphalt concrete permanent deformation for all binders varies with change of 3 to $6 \%$. Figure 7.10 shows asphalt concrete rutting at optimum soil conditions. The asphalt concrete rutting for soft binder PG 52-34 resulted in an increase of $167 \%$ compared to that for binder PG 58-28. Predicted rutting performance is in 
agreement with the laboratory results of dynamic modulus which indicated that PG 58-28 produced stiffer mixes than PG 52-34. Rutting performance results using PG 64-22 showed an increase of about $132 \%$ compared to the stiff binder PG 58-28. This contradicts the purpose of using a high temperature asphalt grade for improving rutting performance. This finding is in good agreement with the measured dynamic modulus values obtained in this study and plotted in Figure 5.4, comparing the three binders.

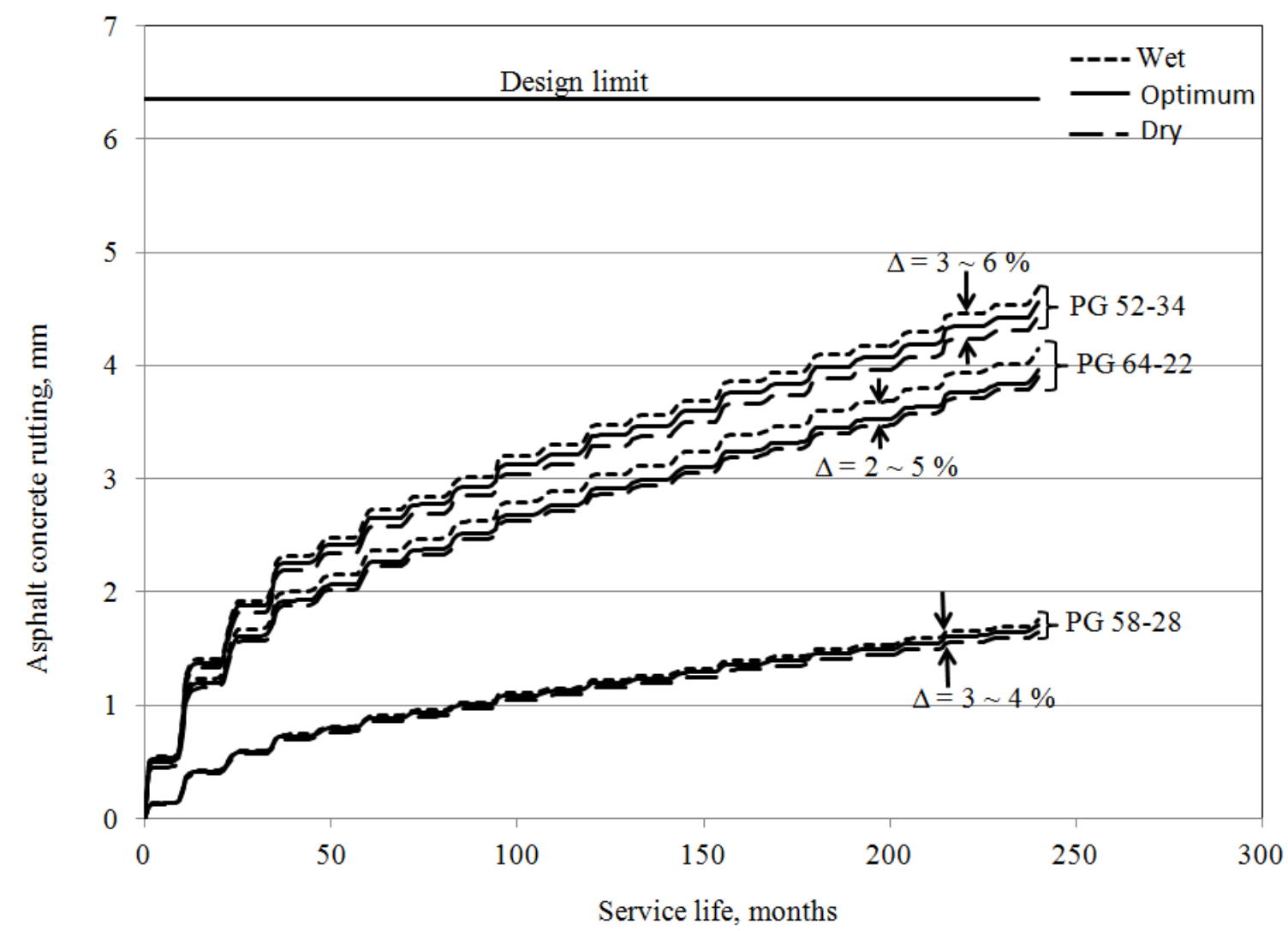

Figure 7.9: Permanent deformation of HMA binders 


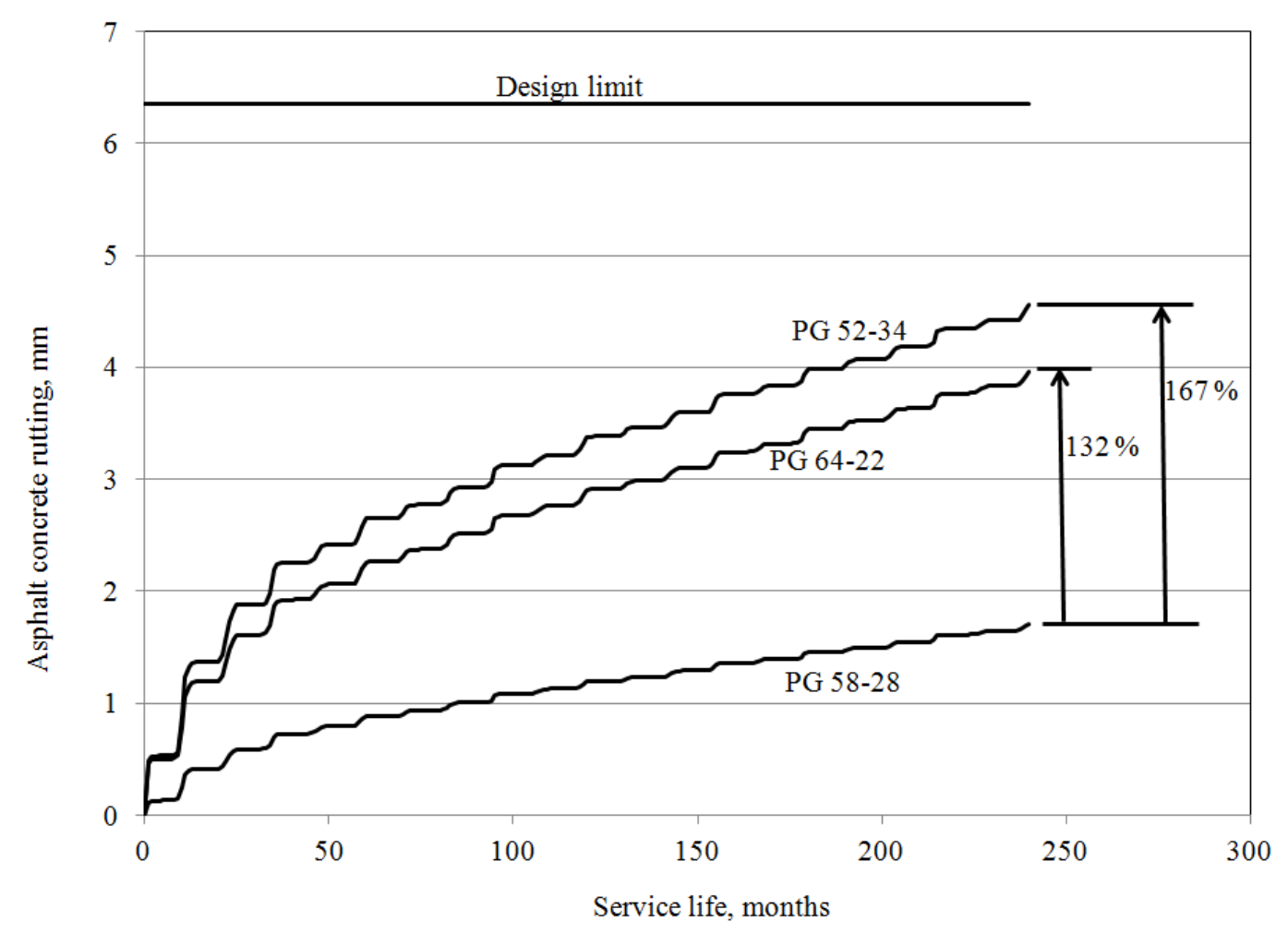

Figure 7.10: Permanent deformation of HMA binders at optimum

\subsubsection{Unbound material permanent deformation}

To investigate the sensitivity of the M-EPDG level 3 to capture the impact of the moisture state of the soil conditions (dry, optimum and wet) in terms of resilient modulus and density of unbound materials, the model runs were performed using PG 52-34, PG 58-28 and PG 64-22 binder grades.

The total permanent deformation of the asphalt concrete, base and sub-grade materials were examined, and the results of model runs performed using PG 52-34, PG 58-28 and PG 64-22 binder grades are shown in Figure 7.11. Regardless of the binder grade used, the total permanent deformation curves of the dry, optimum and wet conditions showed a change between 2 to $6 \%$. In fact, at 20 years of service, the accumulated permanent deformation at these moisture conditions did not differ by more 
than $1 \mathrm{~mm}$ within the same binder and not more than $6 \mathrm{~mm}$ between different binders.

These differences are within the calculation margin of error, which suggests that the level 3 analysis is not sensitive enough to the unbound material conditions. However, Figure 7.12 shows the total rutting at optimum soil condition. The total rutting of the soft binders PG 52-34 and PG 64-22 are higher than the stiff binder PG 58-28 by about 50 and $47 \%$ respectively.

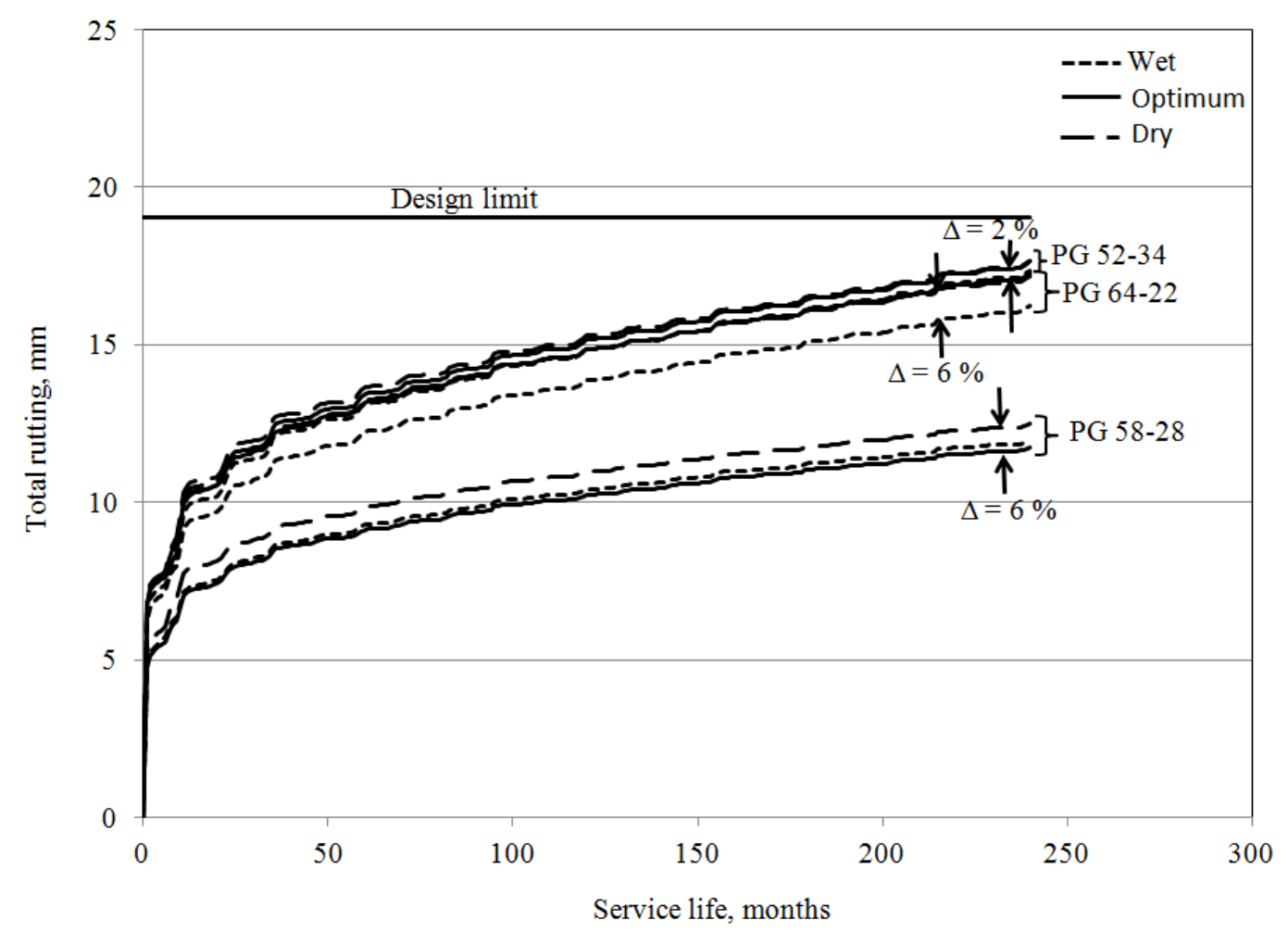

Figure 7.11: Total permanent deformation for bound and unbound material 


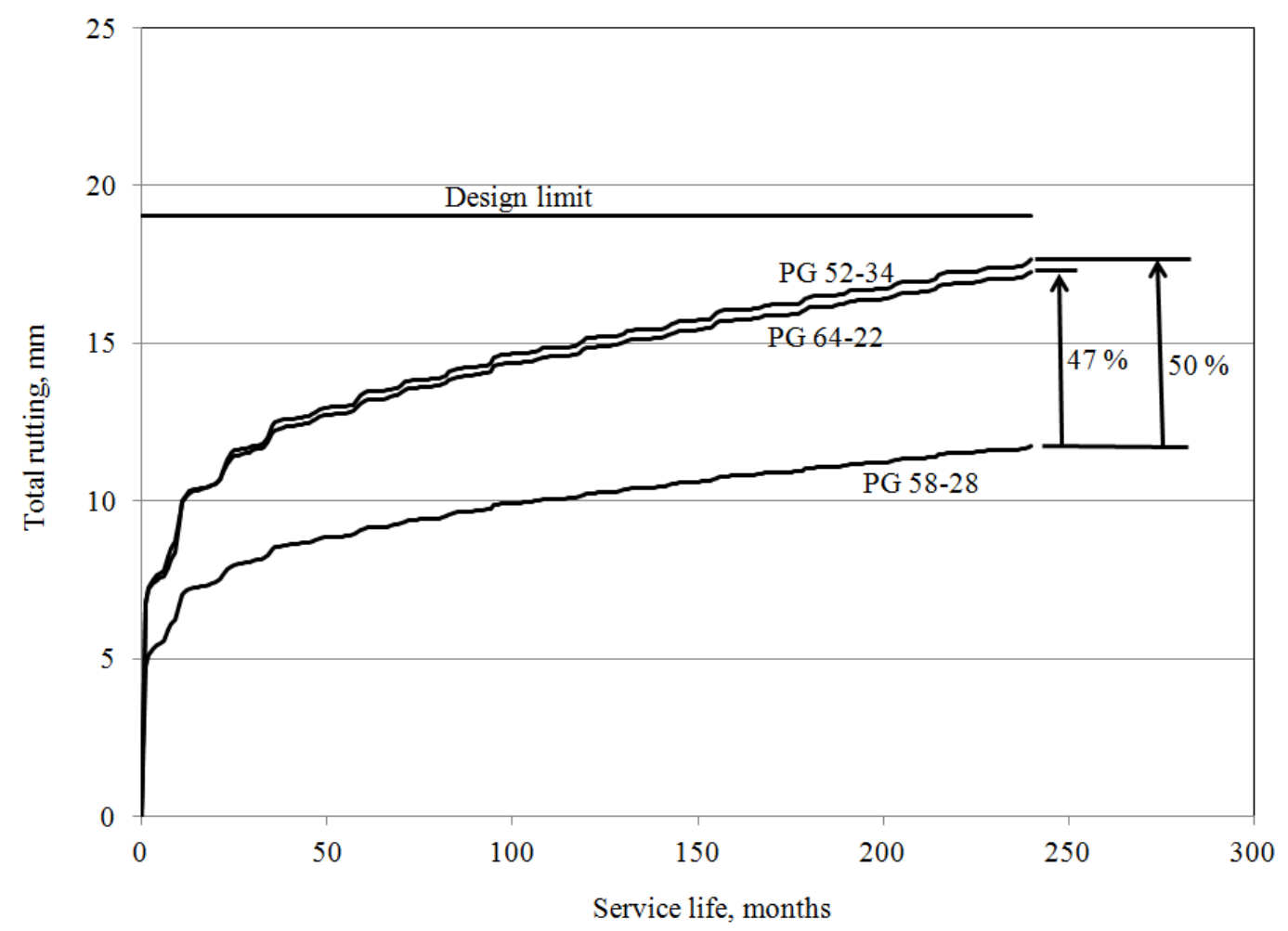

Figure 7.12: Total permanent deformation for bound and unbound material at optimum

\subsubsection{Surface down fatigue (longitudinal) cracking}

The results plotted in Figure 5.4 for the measured laboratory dynamic modulus of the SP 12.5 mix using PG 52-34, PG 58-28 and PG 64-22, are in good agreement with MEPDG predicted longitudinal cracking shown in Figures 7.13, 7.14 and 7.15, for dry, optimum and wet soil conditions, respectively. The use of the softer binder, PG 52-34, increased the longitudinal cracking, and the stiffer binder, PG 58-28 decreased longitudinal cracking. It is noted that the rate formation of the predicted longitudinal cracks is very high in case of softer binders. Figure 7.13 for dry soil condition showed that PG 52-34 longitudinal cracks increased by about $187 \%$ compared to PG 58-28. However, using PG 64-22 binder resulted in a $209 \%$ increase on longitudinal cracking compared to PG 58-28. 
Similarly, Figure 7.14 shows an increase of about 107 and $112 \%$ of longitudinal cracks for PG 52-34 and PG 64-22 respectively in the case of the optimum soil condition. The increase is about 93 and $147 \%$ in the density of longitudinal cracks for PG 52-34 and PG 64-22 respectively in the case of wet soil condition (Figure 7.15). The technical specification and the purpose of using PG 64-22 is the assumption that it must produce stiffer mixes than the other binders. However, the M-EPDG predicted performance in a good agreement with laboratory measured dynamic modulus which indicates that mixes prepared using PG 58-28 was stiffer than binders PG 52-34 and PG 64-22.

Further analysis of the data in Figures 7.13 to 7.15 revealed that the soil condition effect on longitudinal cracks is minimal in the case of the stiffer binder PG 58-28 and very high for the other two softer binders PG 52-34 and PG 64-22. The dry soil condition has a tendency to produce more longitudinal cracks. The impact of the optimum and wet soil conditions on longitudinal cracks is lowered by about 7 to $8 \%$ than the dry soil condition in the case of PG 58-28. It is lowered by approximately 33 and $38 \%$ in the case of PG 52-34 and about 36 and $27 \%$ in the case of PG64 -22 as shown in Figure 7.16.

Further analysis of the data in Figure 7.16 revealed that the pavement design life for both soft binders PG 52-34 and PG 64-22 is 19 and 17 years respectively compared to the design life of 20 years. 


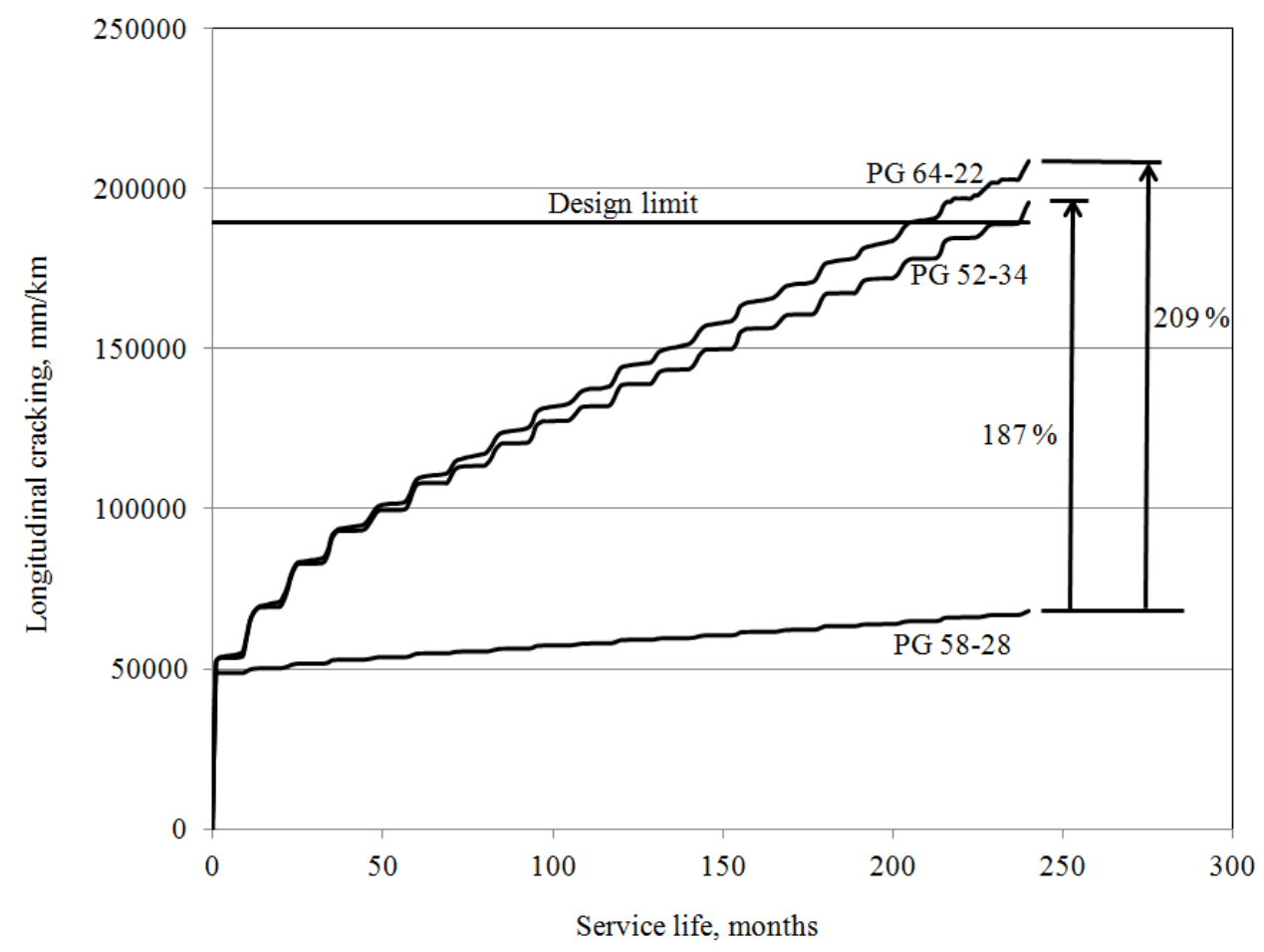

Figure 7.13: Super grade binders effect on longitudinal cracking for the dry soil condition

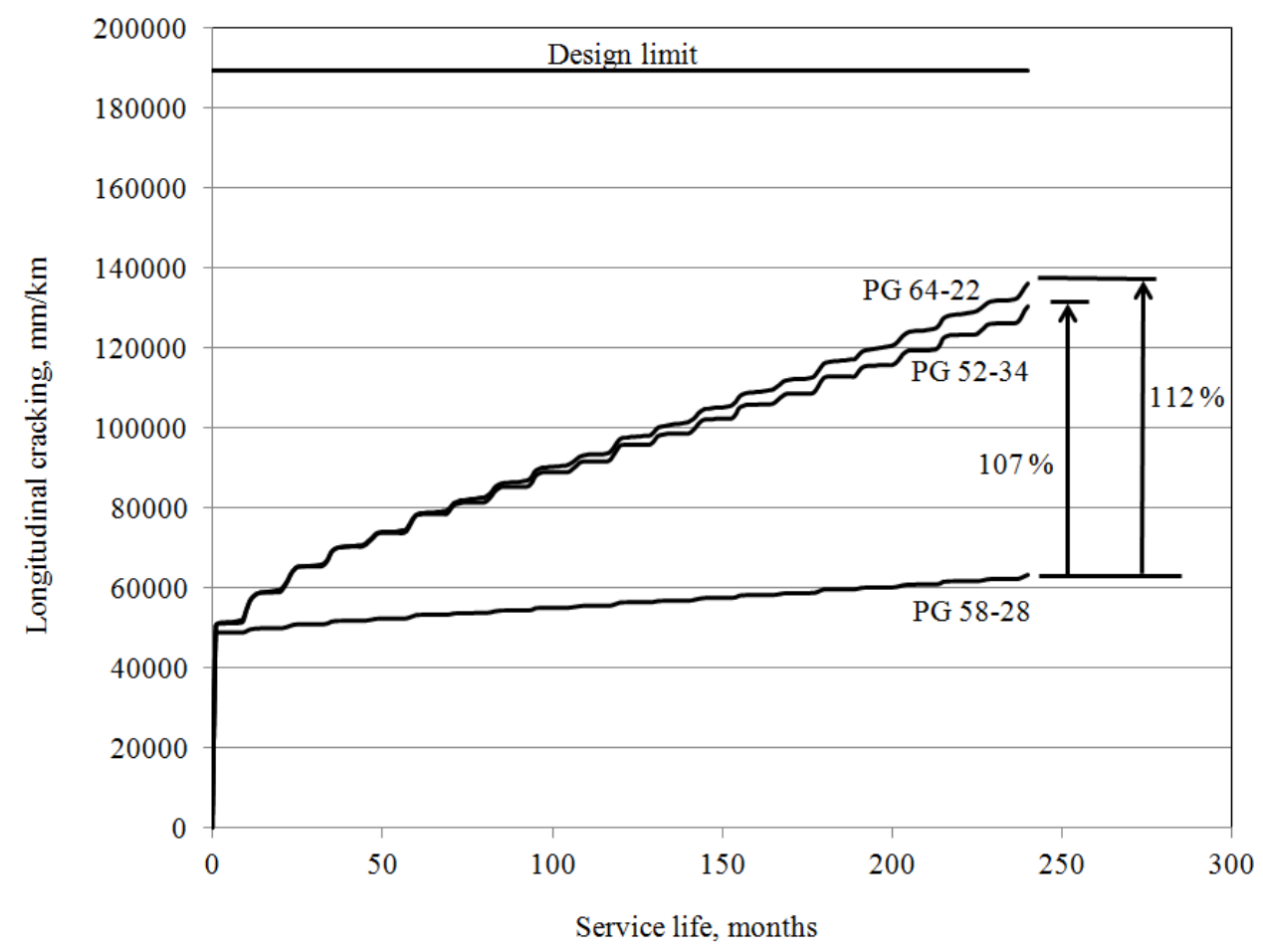

Figure 7.14: Super grade binders' effect on longitudinal cracking for the optimum soil condition 


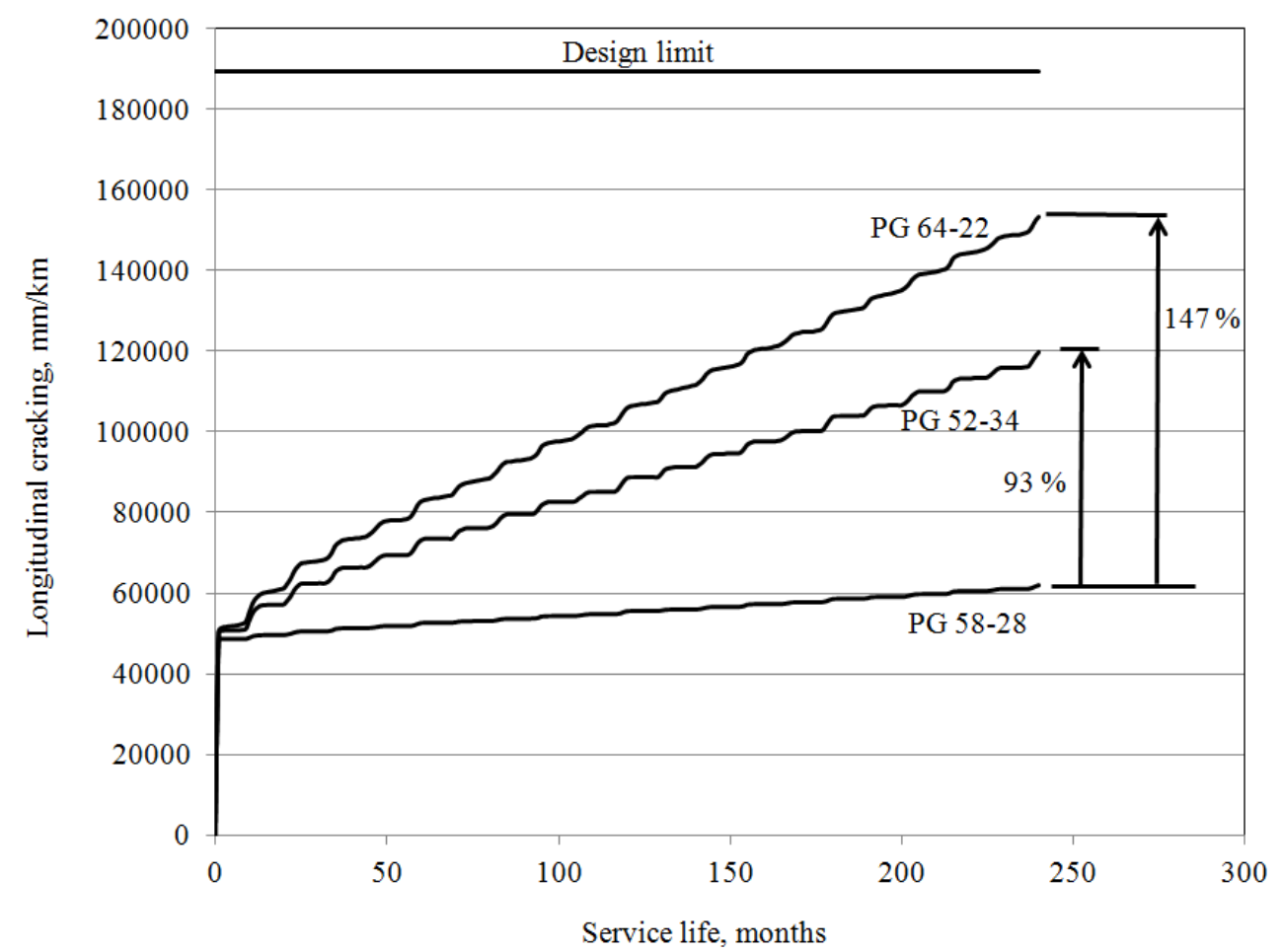

Figure 7.15: Super grade binders' effect on longitudinal cracking for the wet soil condition

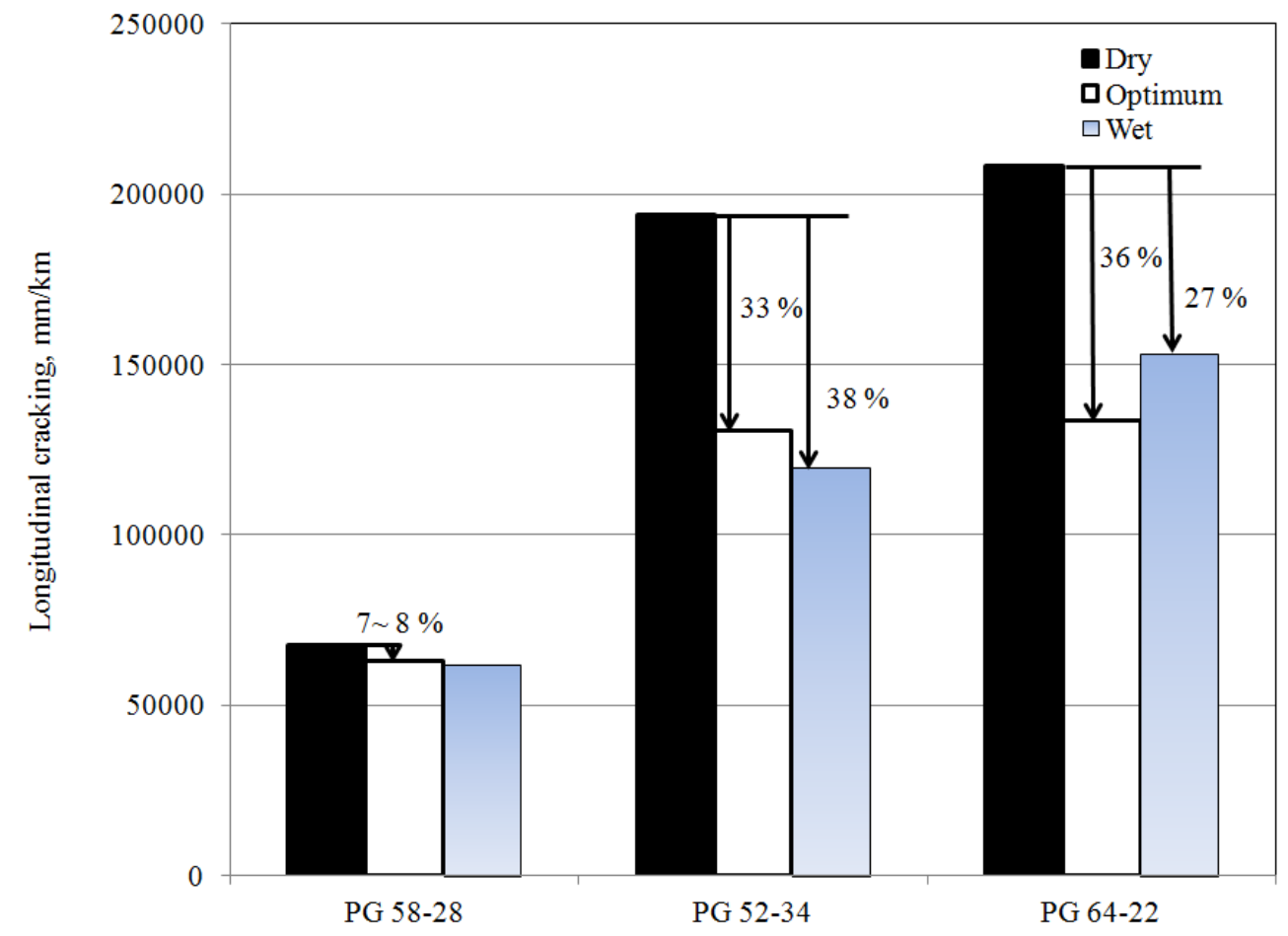

Figure 7.16: Effect of soil condition on the behaviour of super grade binders 


\subsubsection{Bottom up fatigue (alligator) cracking}

Different binders at different soil conditions were used to investigate the model sensitivity to bottom up fatigue cracking. Fatigue cracks are believed to form underside of the hot mix asphalt layer.

The predicted percentages of fatigue cracking for mix SP 12.5 of PG 52-34, PG 58-28 and PG 64-22 are shown Figure 7.17. The model predictions are also in agreement with the measured laboratory dynamic modulus plotted in Figure 5.4. Stiffer binder PG 58-28 shows a negligible amount of alligator cracking compared to the other soft binders. The results plotted in Figure 7.17 revealed that there is little increase of alligator cracking $(17 \%)$ in the case of dry soil condition compared to the wet soil condition for soft binders (PG 52-34 and PG 64-22) whereas the soil condition state has no impact in the case of PG 58-28.

Figure 7.18 shows the effect of different binders at the optimum soil condition on the formation of alligator cracks. The increases in crack density are 739 and $833 \%$ in the case of PG 52-34 and PG 64-22 respectively compared to the stiff binder PG 58-28. However, all binders show that the amount of alligator cracking is well below the design limit. 


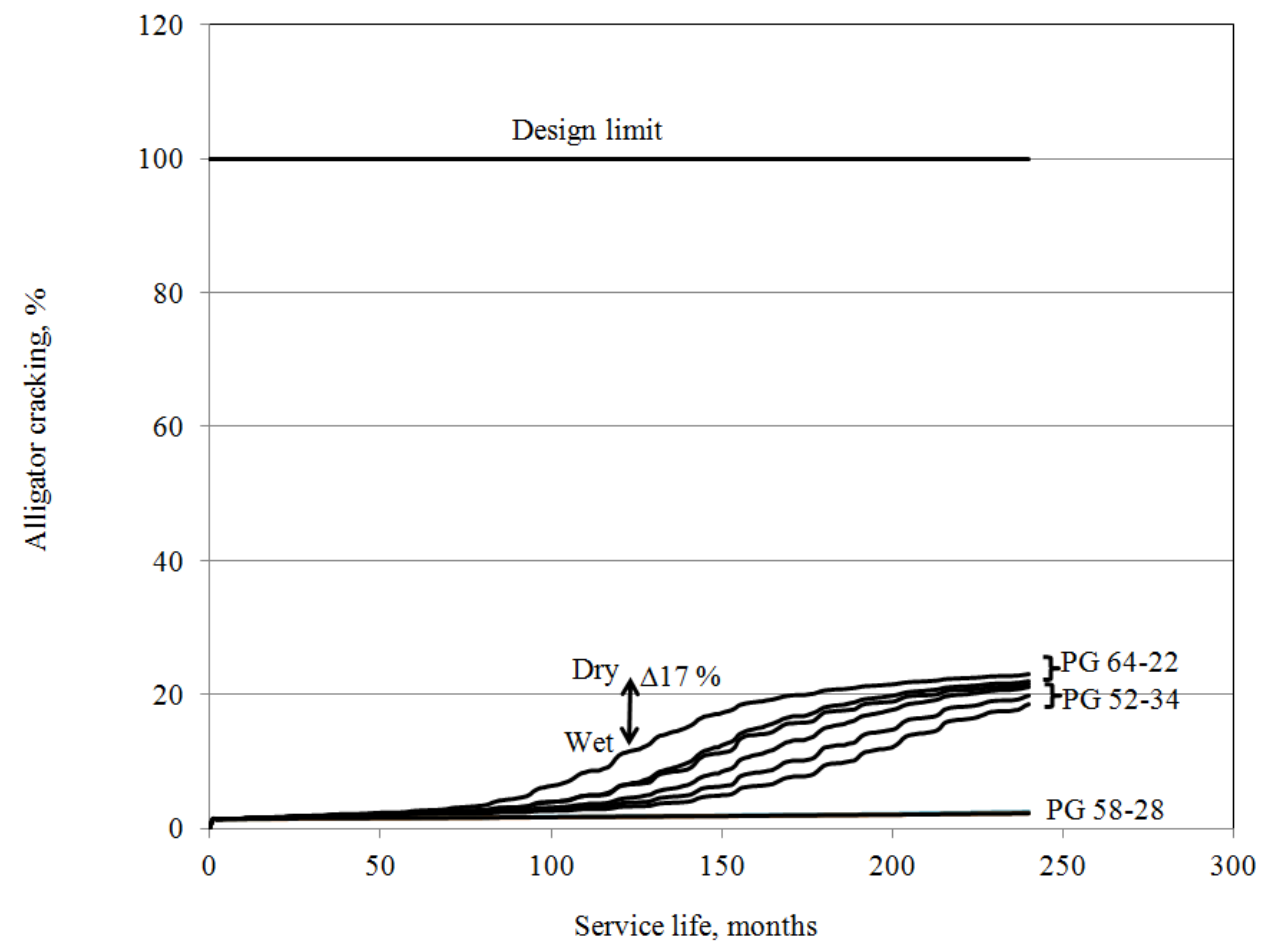

Figure 7.17: Super grade binder effect and soil condition on alligator cracking

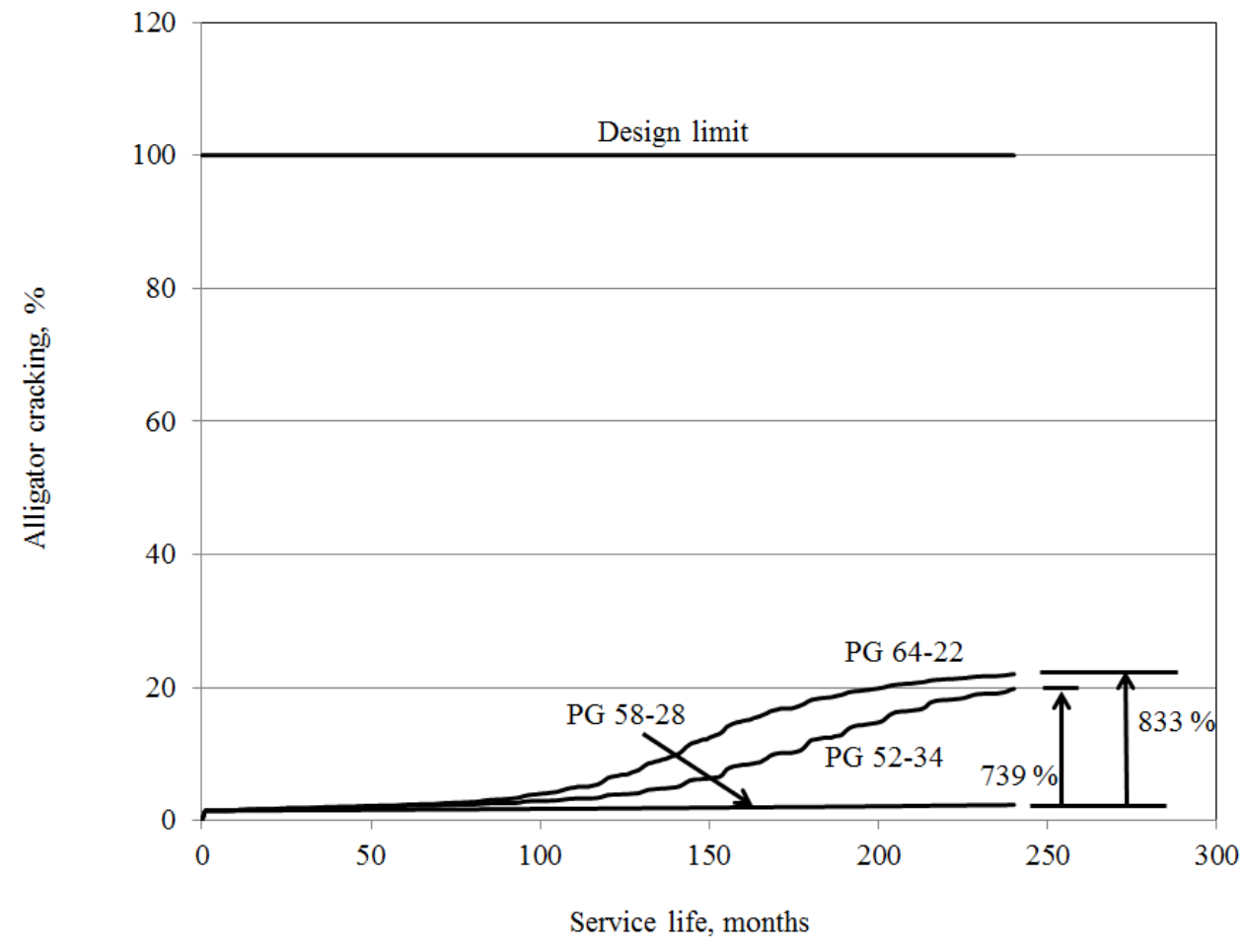

Figure 7.18: Super grade binder effect on alligator cracking for the optimum soil condition 


\subsubsection{International Roughness Index (IRI)}

The M-EPDG uses the international roughness index (IRI) as a measure of smoothness. The M-EPDG predicted smoothness performance for mix SP 12.5 using PG 52-34, PG 58-28 and PG 64-22 as shown in Figure 7.19. All types of performance distress contribute to the loss of pavement smoothness. The IRI values for the soft binders PG 52-34 and PG 64-22 are very similar and higher than IRI values for the stiff binder PG $58-28$ by about $7 \%$. The impact of soil condition is negligible.

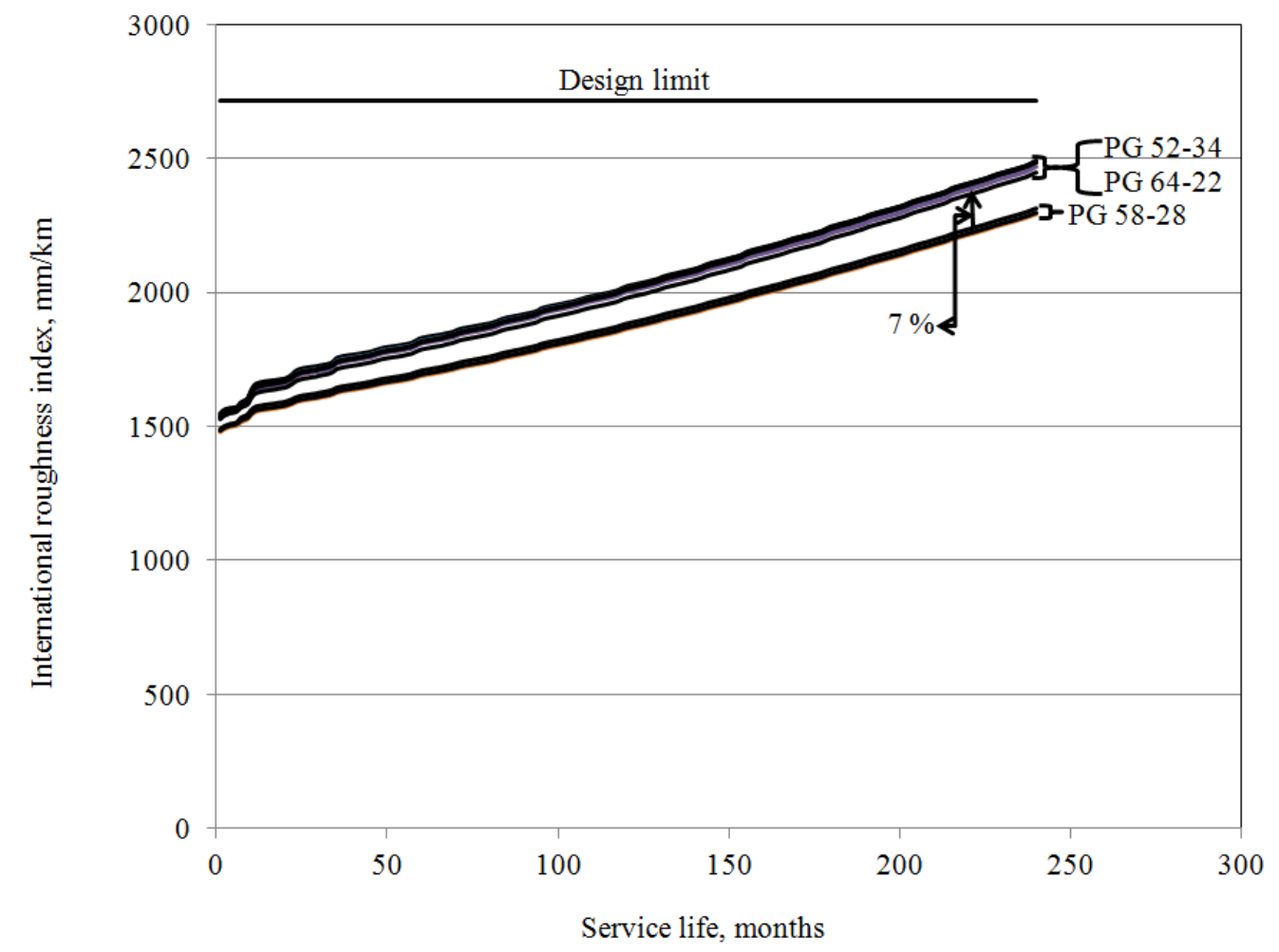

Figure 7.19: Effect of binders and soil condition on IRI

\subsubsection{Effect of traffic speed on M-EPDG model performances}

The effect of speed on the sensitivity of M-EPDG will be analyzed at $0,5,35,75$ and $100 \mathrm{~km} / \mathrm{h}$ to determine its effect on the performance. 


\subsubsection{Permanent deformation}

Figure 7.20 shows the relationship between the age of the pavement and the rutting of the asphaltic concrete layer at the state of creep condition $(0 \mathrm{~km} / \mathrm{h})$. The MEPDG asphalt concrete rutting output is about $2724 \%$ higher than the asphalt concrete rutting at speed of $5 \mathrm{~km} / \mathrm{h}$. Based on this finding and comparing it with the field results (explained in chapter 4), the change of the truck pressure impact from speed of $3 \mathrm{~km} / \mathrm{h}$ to creep state at speed of $0 \mathrm{~km} / \mathrm{h}$ is increased by $60 \%$ (see Figure 4.115 ). A comparison of field results to the M-EPDG output at the creep state confirms that the M-EPDG design guide is not operable at speeds lower than $3 \mathrm{~km} / \mathrm{h}$. It is important to know the effect of creep on pavement performance problems at locations with frequent bus stops and areas close to traffic signals. This finding highlights the importance of considering the creep state in future work.

It can be seen that the asphalt concrete rutting and total rutting (bound and unbound materials) decreases with increasing the speed. Figures 7.21 and 7.22 show that when the speed increases from 5 to $35 \mathrm{~km} / \mathrm{h}$ the amount of rutting decreases by $50 \%$ for the asphalt concrete and the total rutting decreases by the same amount. The amount of rutting decreases by about $60 \%$ as the speed increases from 5 to $75-100 \mathrm{~km} / \mathrm{h}$. Further analysis of the data in 7.21 and 7.22 revealed that there are two speed effect categories, i.e. below and above speed of $35 \mathrm{~km} / \mathrm{h}$. The lower speed category is considered the most critical speed in terms of the amount of damage that can be caused. Additionally, the impact of speed on rutting of asphalt concrete and unbound materials is similar.

The findings of the fieldwork results explained in chapter 4 are in agreement with the M-EPDG speed evaluation results. Figure 4.112 indicated a drop in truck impact dynamic strain by about $37 \%$ when the speed increased from 15 to $35 \mathrm{~km} / \mathrm{h}$ when strain 
was measured at a depth of $390 \mathrm{~mm}$. Similarly, the truck pressure impact decreased $43 \%$ as shown in Figure 4.114 when the speed increased from 3 to $25 \mathrm{~km} / \mathrm{h}$.

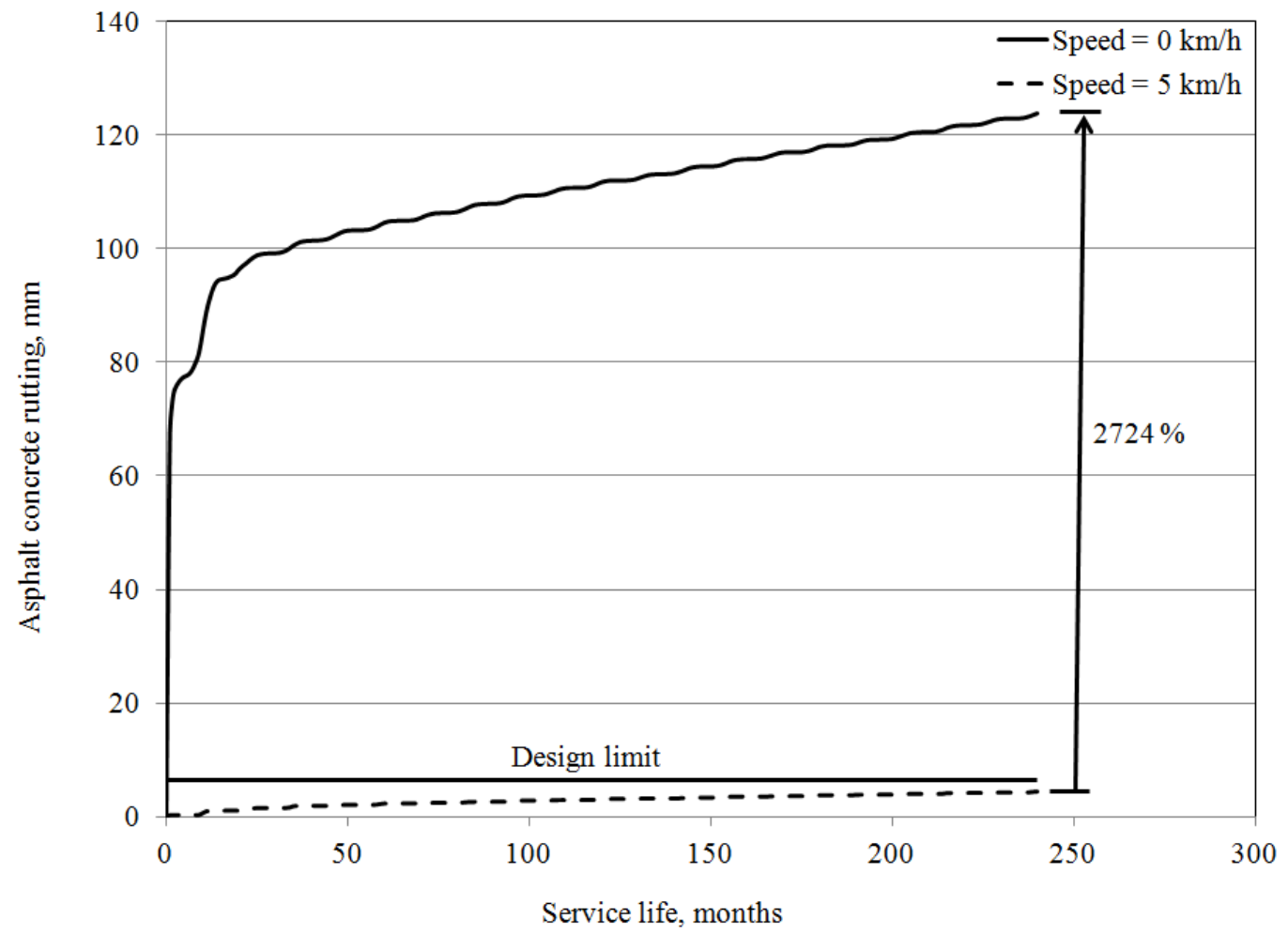

Figure 7.20: Asphalt concrete rutting at creep condition 


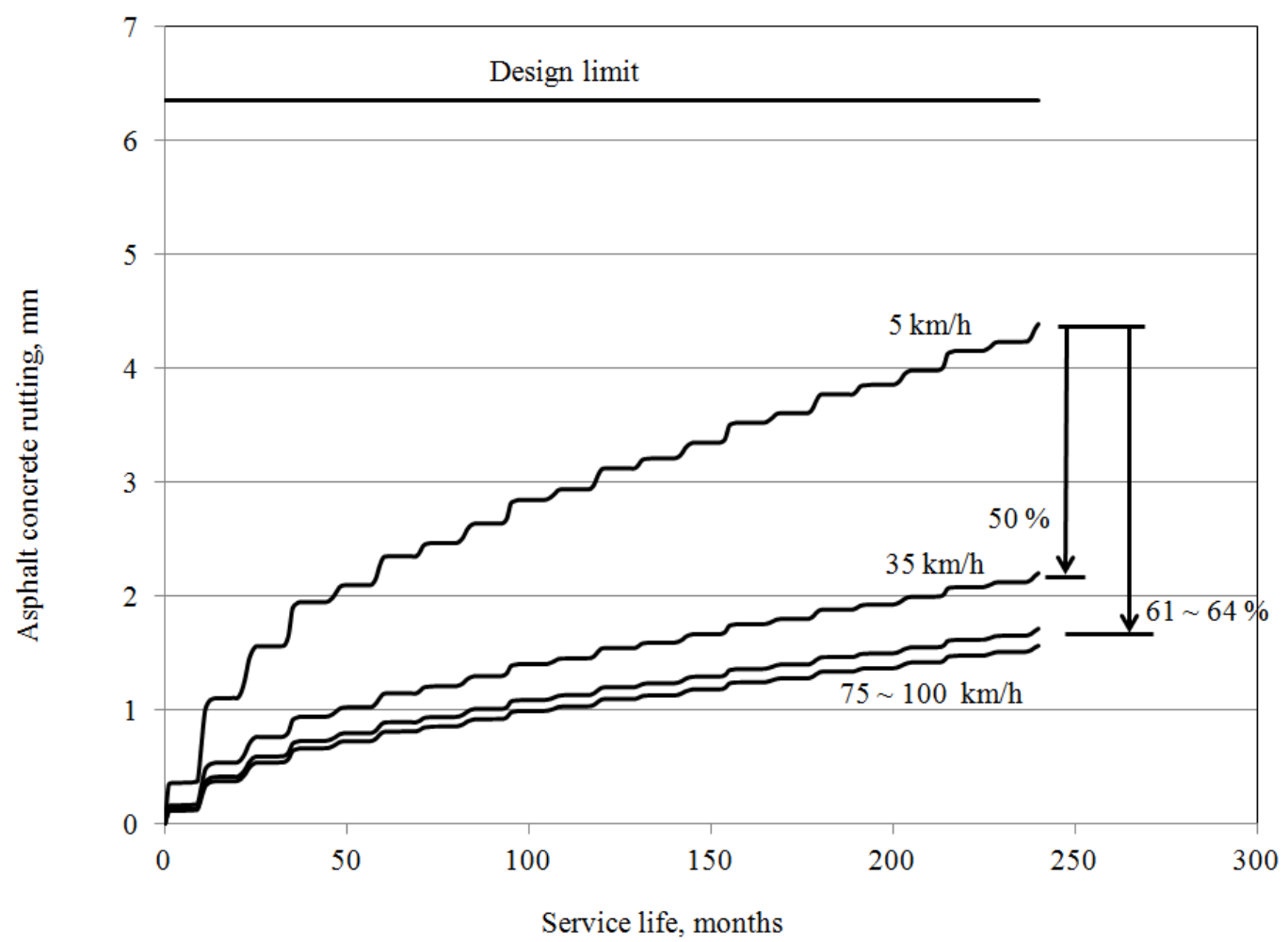

Figure 7.21: Asphalt concrete rutting at different speed

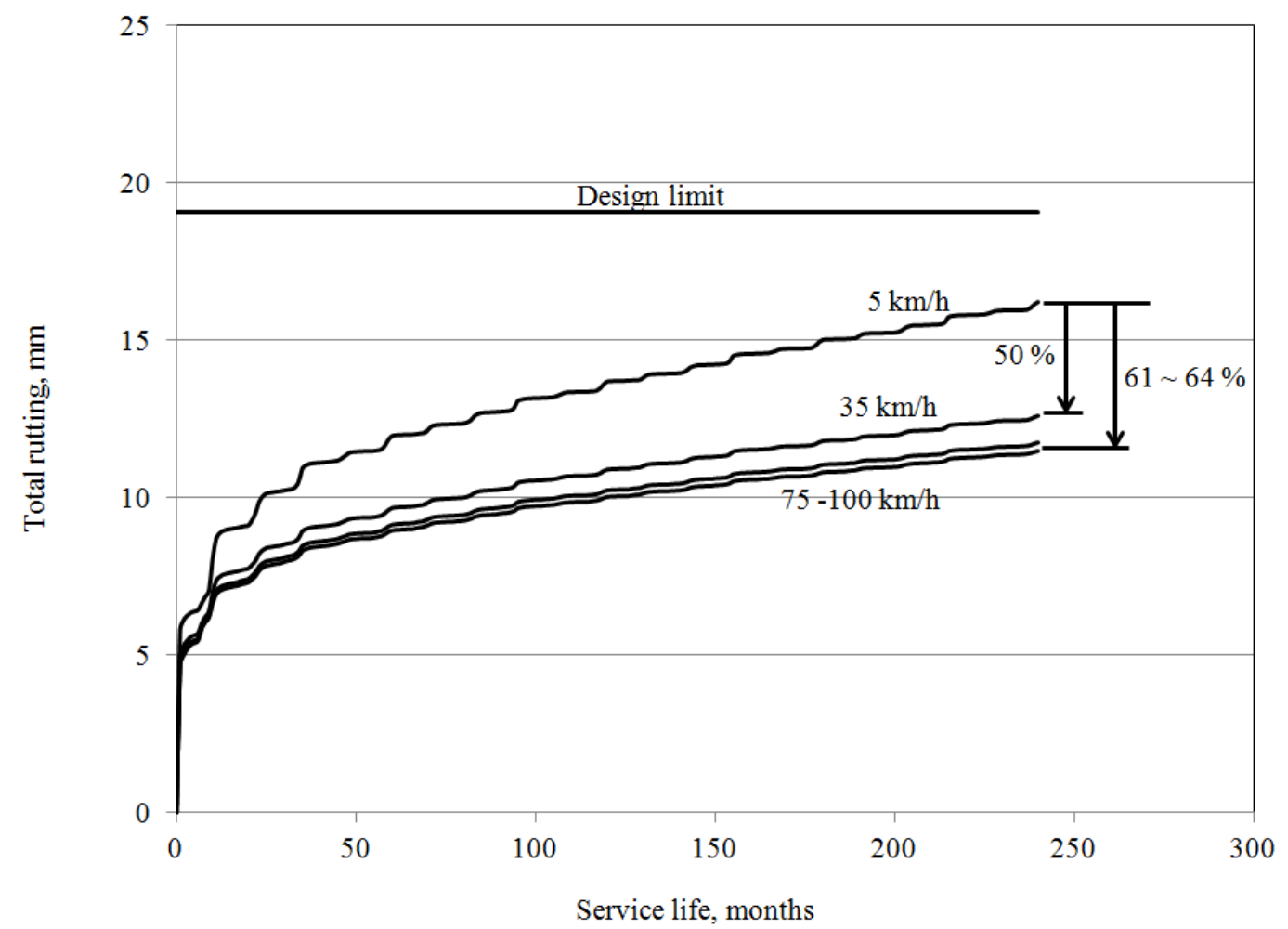

Figure 7.22: Total rutting at different speed 


\subsubsection{Surface down fatigue (longitudinal) cracking}

The M-EPDG predicted performance at a speed of $0 \mathrm{~km} / \mathrm{h}$ (creep) and $5 \mathrm{~km} / \mathrm{h}$ are shown in Figure 7.23. The creep impact increases the longitudinal cracks by $1280 \%$ higher than the design limit, whereas the cracks are only $31 \%$ lower than the design limit when the speed is increased to $5 \mathrm{~km} / \mathrm{h}$. Based on this finding and comparing it with the field results presented in chapter 4 , the change of the truck pressure impact from a speed of $3 \mathrm{~km} / \mathrm{h}$ to the creep state at a speed of $0 \mathrm{~km} / \mathrm{h}$ is an increase of $60 \%$ (see Figure 4.115 ). It is concluded again that longitudinal crack performance is absent below a speed of 5 $\mathrm{km} / \mathrm{h}$. This is similar to the finding of the speed impact on the M-EPDG predicted rutting performance.

The M-EPDG predicted longitudinal cracking decreases with increasing the speed. Figure 7.24 shows that when the speed increases from 5 to $35 \mathrm{~km} / \mathrm{h}$ the amount of longitudinal cracks decreases by $43 \%$. Further, the amount of longitudinal cracking decreases to $52-54 \%$ when the speed increases from 5 to $75-100 \mathrm{~km} / \mathrm{h}$. All the predicted longitudinal cracks for the speed above $5 \mathrm{~km} / \mathrm{h}$ are within the M-EPDG design limit.

Further analysis of the data in Figures 7.24 revealed the longitudinal crack performance has two speed effect categories below and above the speed of $35 \mathrm{~km} / \mathrm{h}$. The lower speed category is considered to be the most critical speed in terms of the amount of damage that can be caused. This was similar to the M-EPDG rutting performance. 


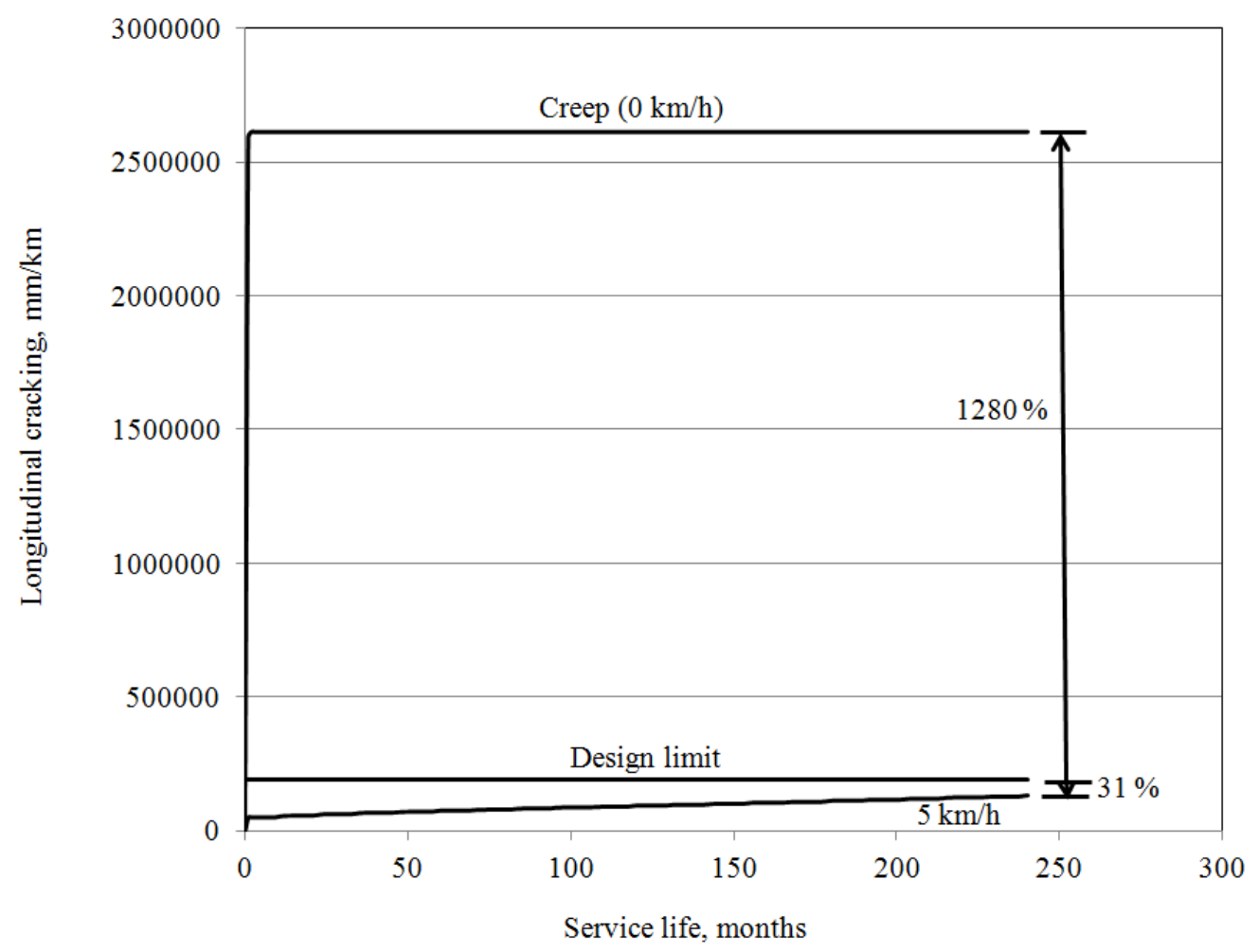

Figure 7.23: Longitudinal cracking at creep condition

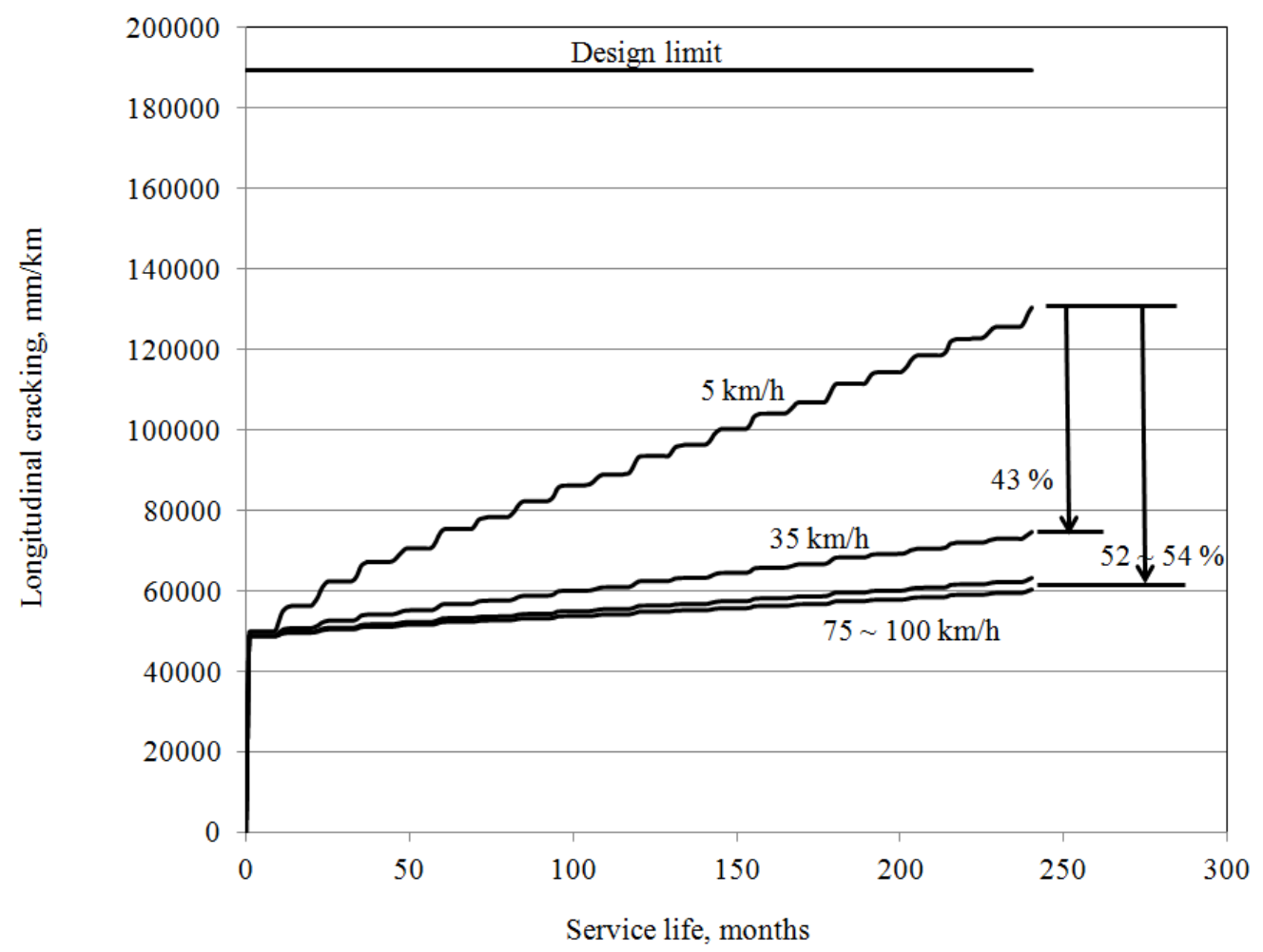

Figure 7.24: Speed effect on longitudinal cracking 


\subsubsection{Bottom up fatigue (alligator) cracking}

Different speeds were used to investigate the model sensitivity to bottom up (known as alligator) fatigue cracking. The M-EPDG predicted that alligator crack performance does not work at a speed of $0 \mathrm{~km} / \mathrm{h}$ as shown in Figure 7.25.

The predicted percentages of alligator cracking for mix SP 12.5 of PG 58-28 is shown in Figure 7.25. The results plotted in Figure 7.25 revealed that speed below 35 $\mathrm{km} / \mathrm{h}$ has impact on alligator cracking whereas above $35 \mathrm{~km} / \mathrm{h}$, the M-EPDG prediction of alligator cracking performance is the same. A speed in the range of $5 \mathrm{~km} / \mathrm{h}$ to $35 \mathrm{~km} / \mathrm{h}$ and above resulted in an increase of $82 \%$ alligator cracking. The M-EPDG predicted alligator cracking performances are very small compared to the M-EPDG design limit.

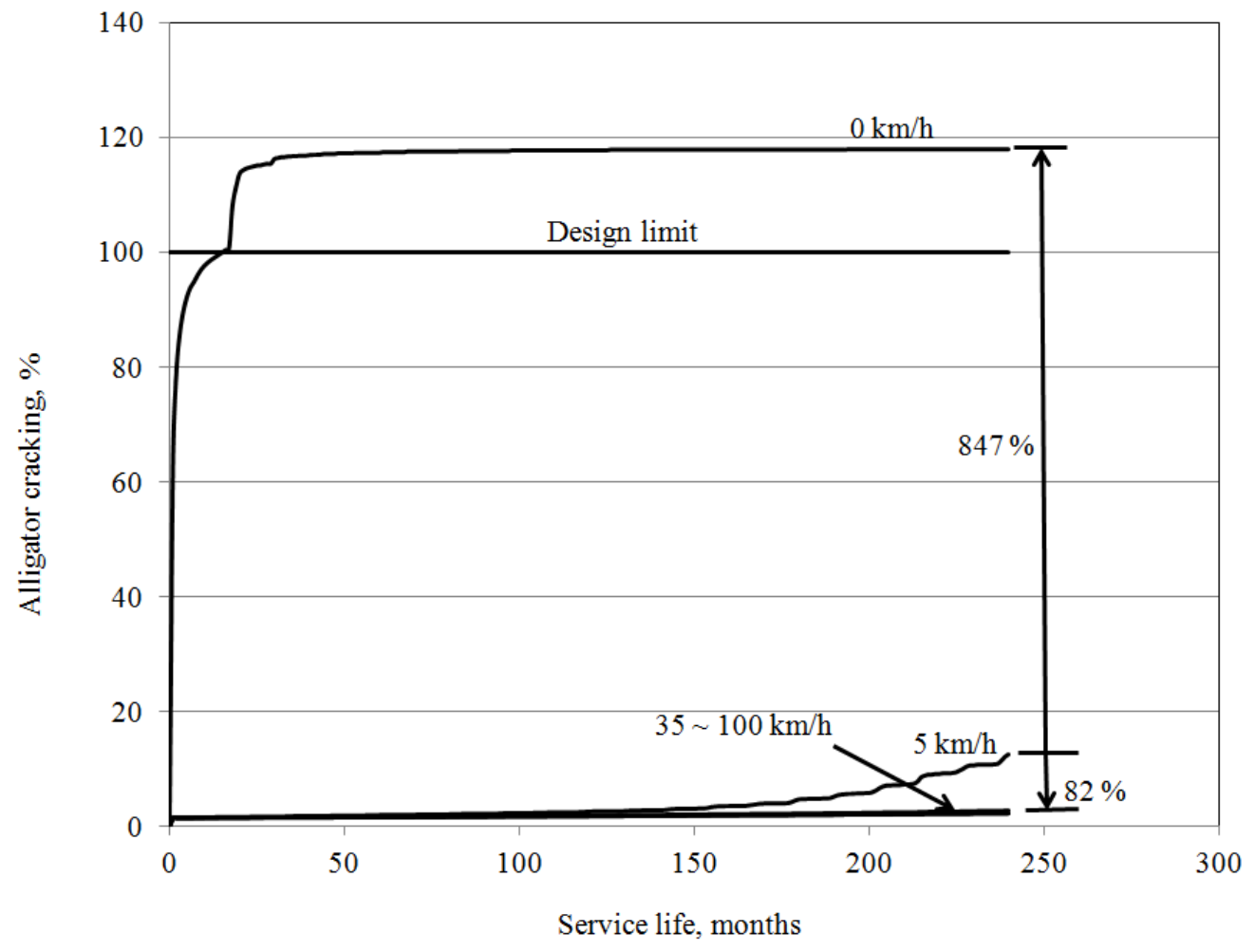

Figure 7.25: Speed effect on alligator cracking 


\subsubsection{International Roughness Index (IRI)}

The M-EPDG predicted smoothness performance for mix SP 12.5 using PG 58-28 is shown in Figure 7.26. All types of performance distress contribute to the loss of pavement smoothness. The predicted M-EPDG values of IRI trends from 5 to $100 \mathrm{~km} / \mathrm{h}$ are within the design limit as shown in Figure 7.26. Increases in speed from $5 \mathrm{~km} / \mathrm{h}$ to a speed of $35 \mathrm{~km} / \mathrm{h}$ and above resulted in a decrease of about $6 \%$.

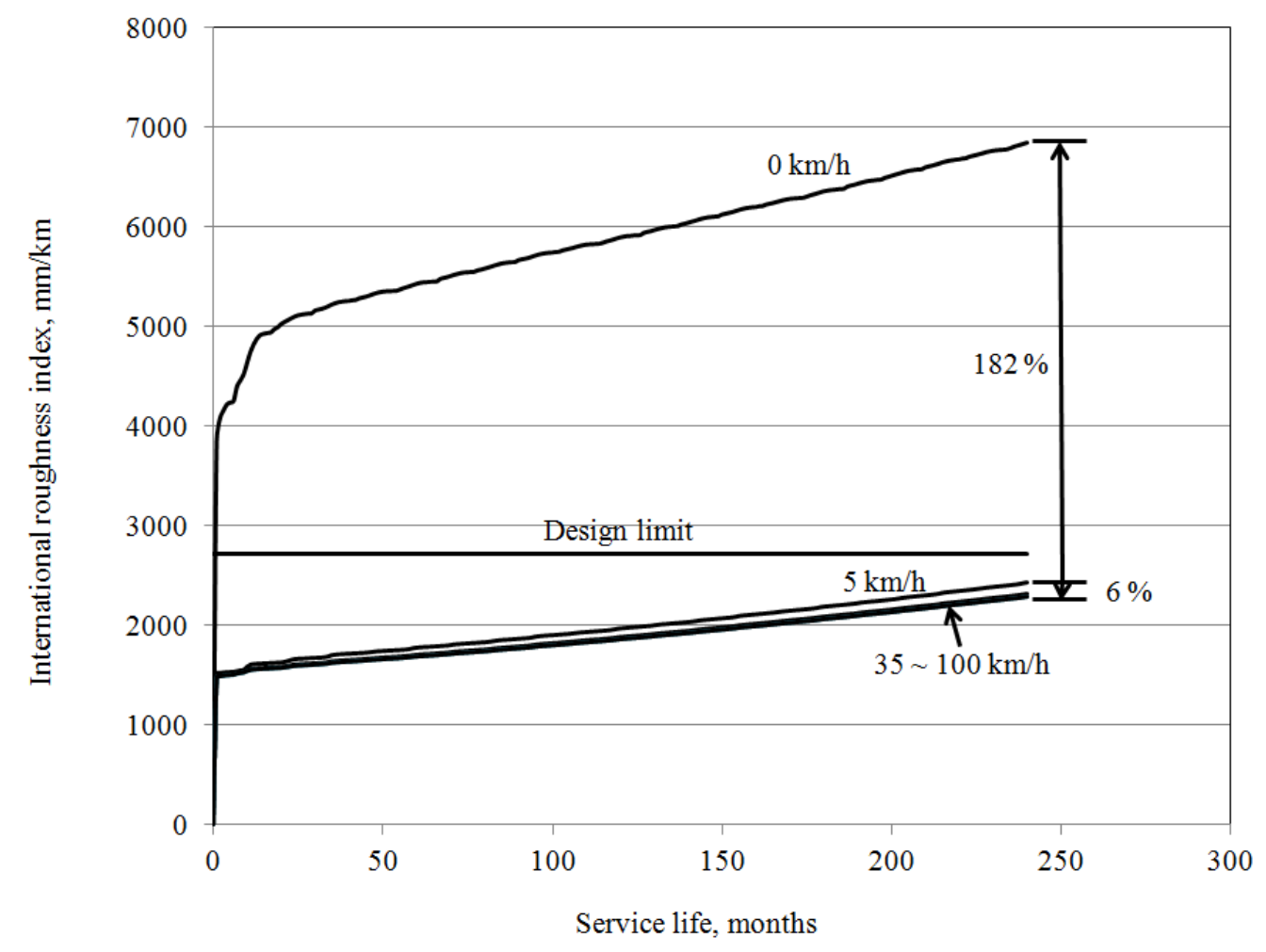

Figure 7.26: Speed effect on IRI

\subsubsection{Effect of traffic capacity on M-EPDG model performances}

The effect of different Annual Average Daily Traffic (AADT) at 1000, 2000 and 4000 on the sensitivity of the M-EPDG design guide will be analyzed to determine its effect on the performance. 


\subsubsection{Permanent deformation}

It is clear that the rutting increases by increasing AADT and pavement service life as shown in Figures 7.27 and 7.28. The results in Figure 7.27 showed an increase of rutting of $39 \%$ and $94 \%$ for AADT values of 2000 and 4000 respectively compared to a value of 1000 AADT. Figure 7.28 shows an increase of total rutting (bound and unbound materials) of 14 and $30 \%$ in the case of 2000 and 4000 AADT respectively compared to 1000 AADT.

Further analysis of the data in both Figures 7.27 and 7.28 reveal that traffic capacity impacts the asphalt concrete layers more than the unbound materials due to the flexible nature of asphalt concrete, which will absorb most of the impact energy represented by depressions at the locations of the wheel paths of a vehicle.

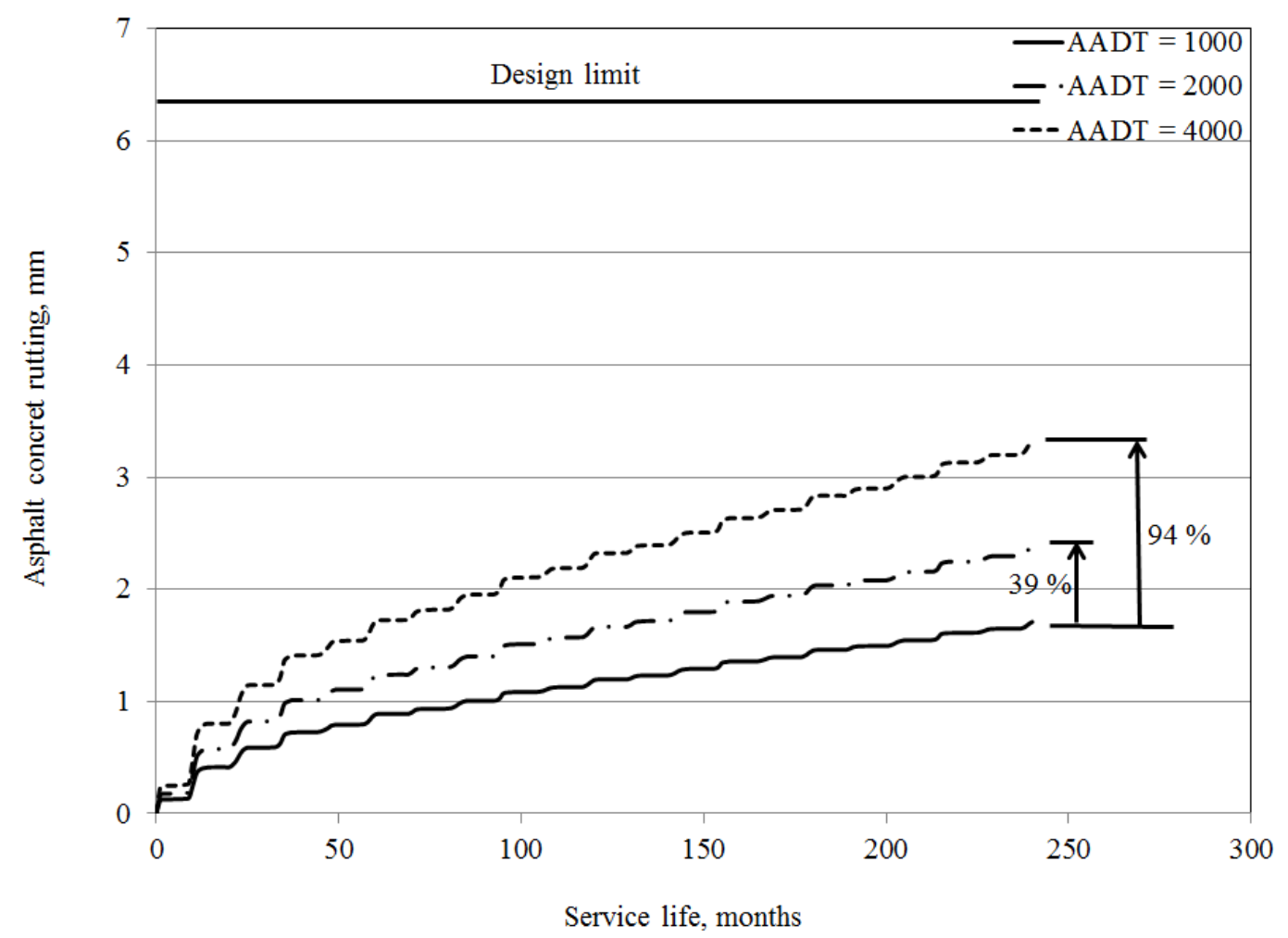

Figure 7.27: Asphalt concrete rutting at different traffic capacity 


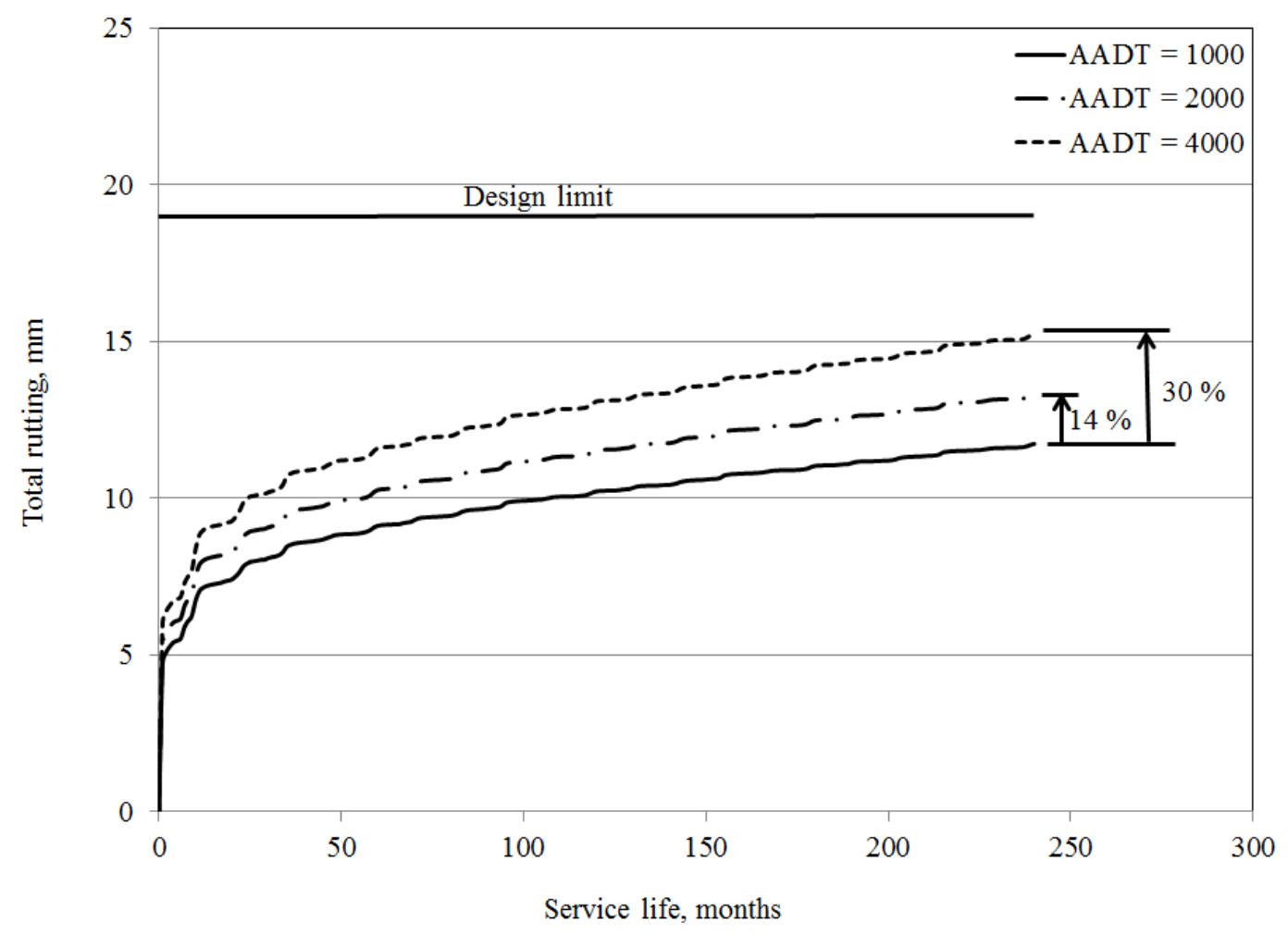

Figure 7.28: Total rutting at different traffic capacity

7.1.5.2 Surface down fatigue (longitudinal) cracking

Traffic capacities of 1000,2000 and 4000 AADT were used to investigate the model sensitivity of mix PS 12.5 for PG 58-28 at the optimum soil condition. The predicted M-EPDG longitudinal cracking performances for different traffic capacities are shown in Figure 7.29. Results showed a 20 and $57 \%$ increase in longitudinal cracking when the traffic increases from 1000 to 2000 and 4000 AADT respectively. 


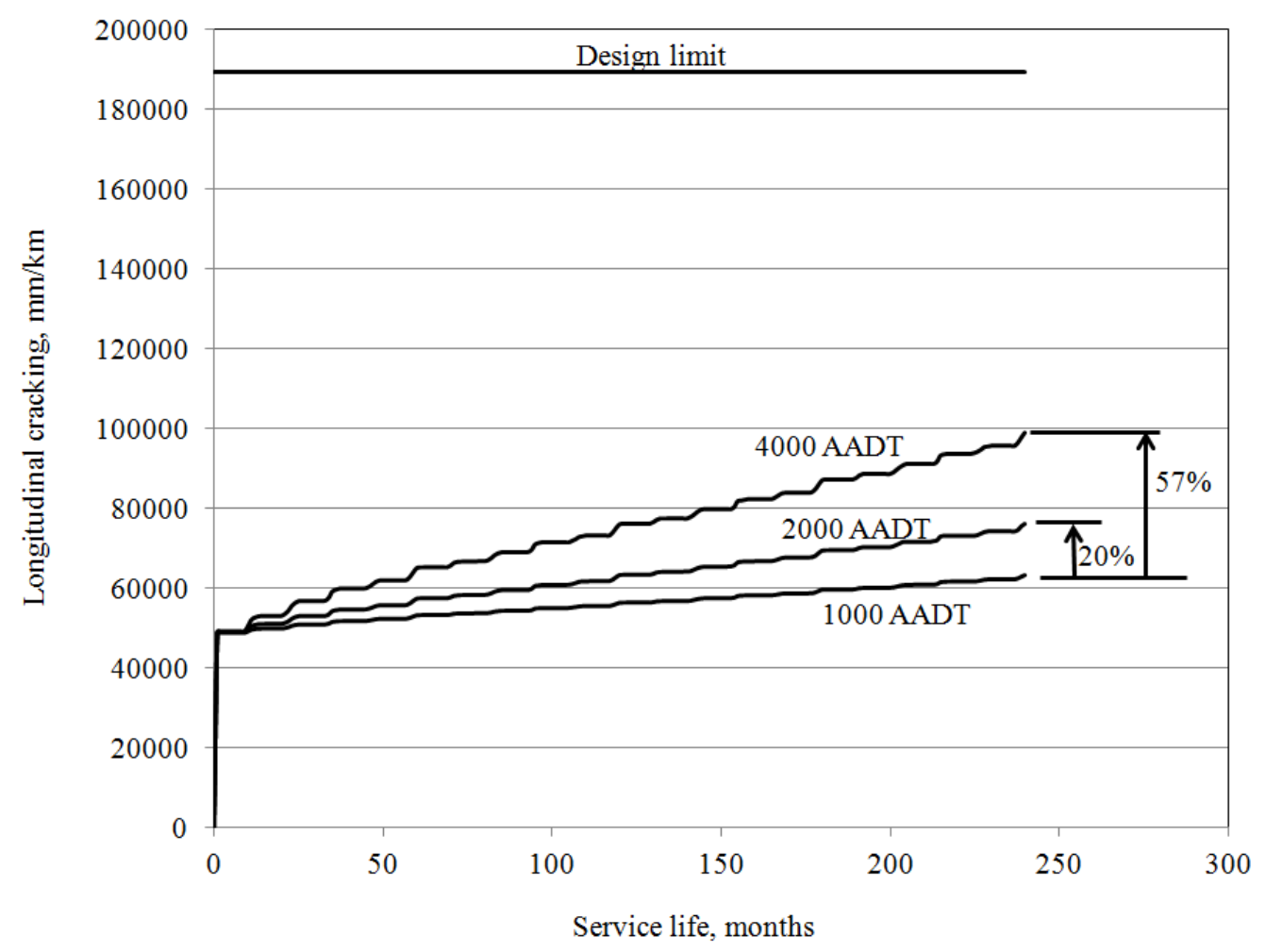

Figure 7.29: Traffic effect on longitudinal cracking

\subsubsection{Bottom up fatigue (alligator) cracking}

Different traffic values were used to investigate the model sensitivity to alligator cracking. The predicted percentages of fatigue cracking for mix SP 12.5 of PG 58-28 at optimum soil condition are shown in Figure 7.30. The results plotted in Figure 7.30 reveal that there is an increase of 178 and $803 \%$ at traffic capacity of 2000 and 4000 AADT respectively compared to 1000 AADT. The M-EPDG predicted alligator cracking performance is very small at range of 1000 to 4000 AADT compared to the M-EPDG design limit. 


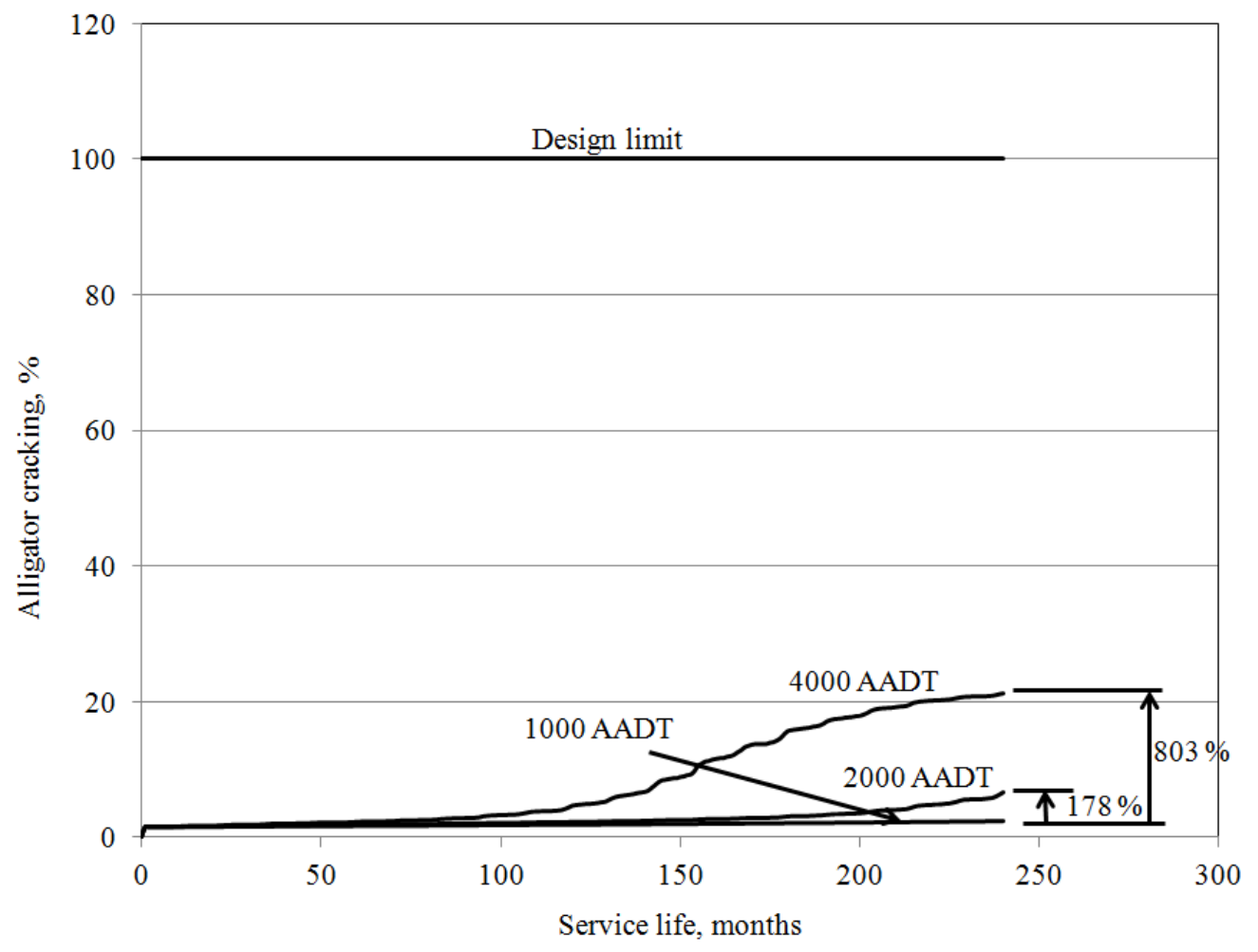

Figure 7.30: Effect of traffic on alligator cracking

\subsubsection{International Roughness Index (IRI)}

The M-EPDG predicted smoothness performance for mix SP 12.5 using PG 58-28 at the optimum soil conditions as shown in Figure 7.31. The IRI values are within the design limit predicted by the M-EPDG are also shown in Figure 7.31. There is an increase of about 2 and $6 \%$ for 2000 and 4000 AADT compared to 1000 AADT. 


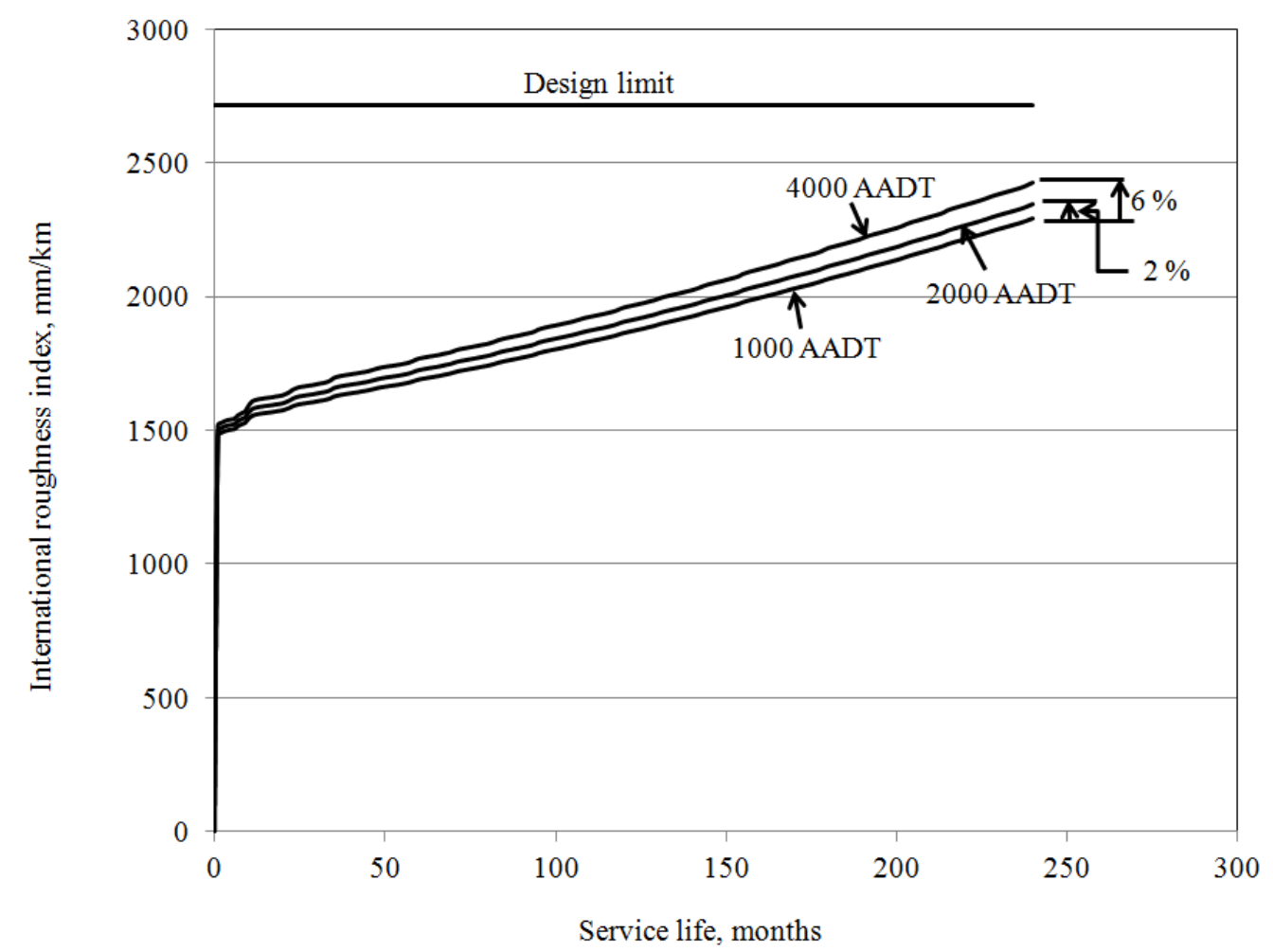

Figure 7.31: Effect of traffic on IRI

\subsubsection{Effect of tire pressure}

The effect of tire pressure 655 (95), 724 (105) and $827 \mathrm{kPa}(120 \mathrm{psi})$, on the sensitivity of M-EPDG will be analyzed to determine its effect on the performance.

\subsubsection{Permanent deformation}

The traffic mix involves vehicles with different tire pressures. Measured pavement response to given vehicle type pressures was determined using the M-EPDG model. The effect of different tire pressures in the asphalt concrete layer is illustrated in Figure 7.32. The results indicate that an 11 and $26 \%$ increase in tire pressure resulted in an increase of 15 and $37 \%$ of rutting respectively for the asphalt concrete layers. The same increase in the tire pressure had a relatively small influence on the total rutting (bound and unbound material) as shown in Figure 7.33. 


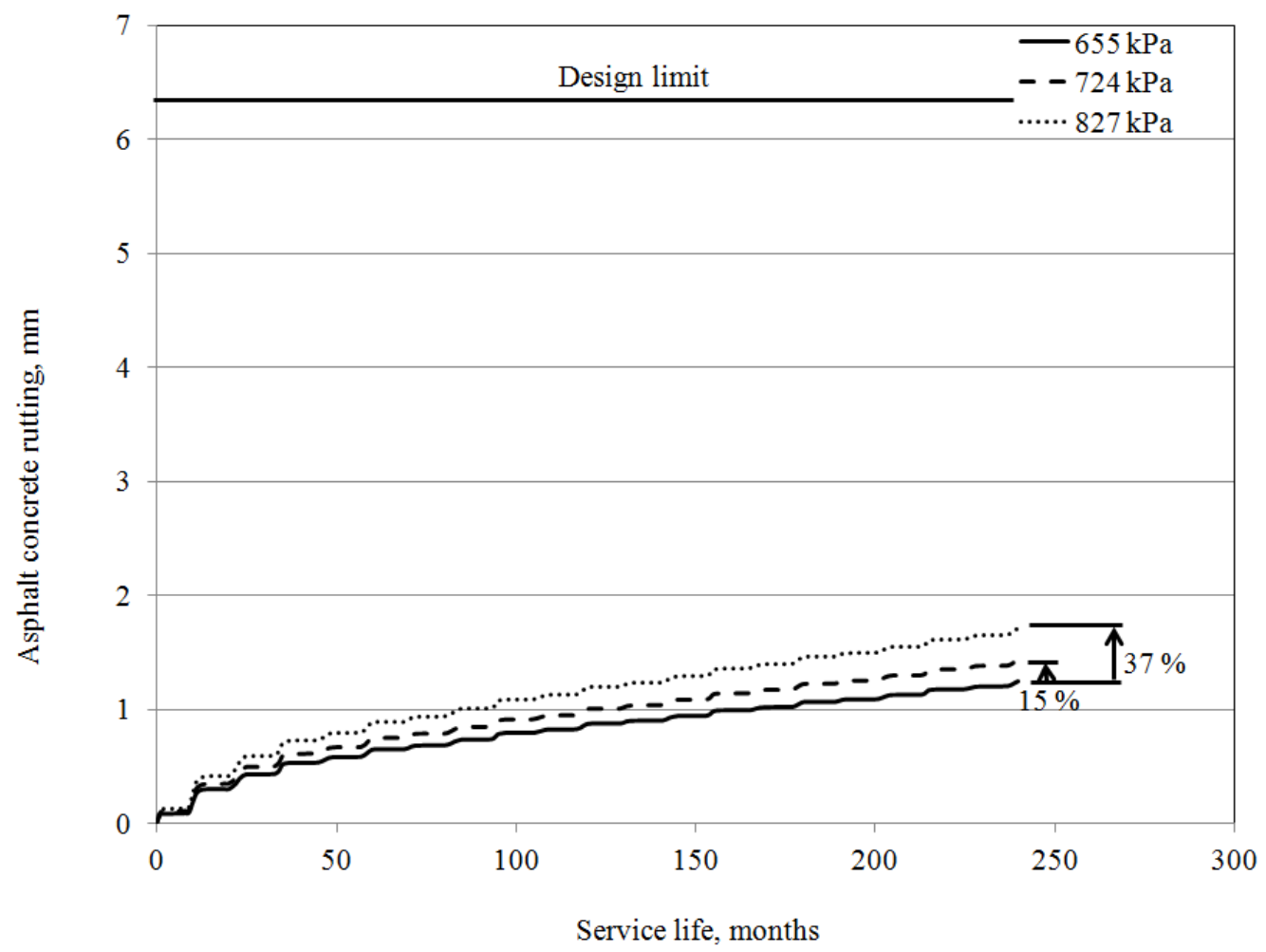

Figure 7.32: Asphalt concrete rutting at different tire pressures

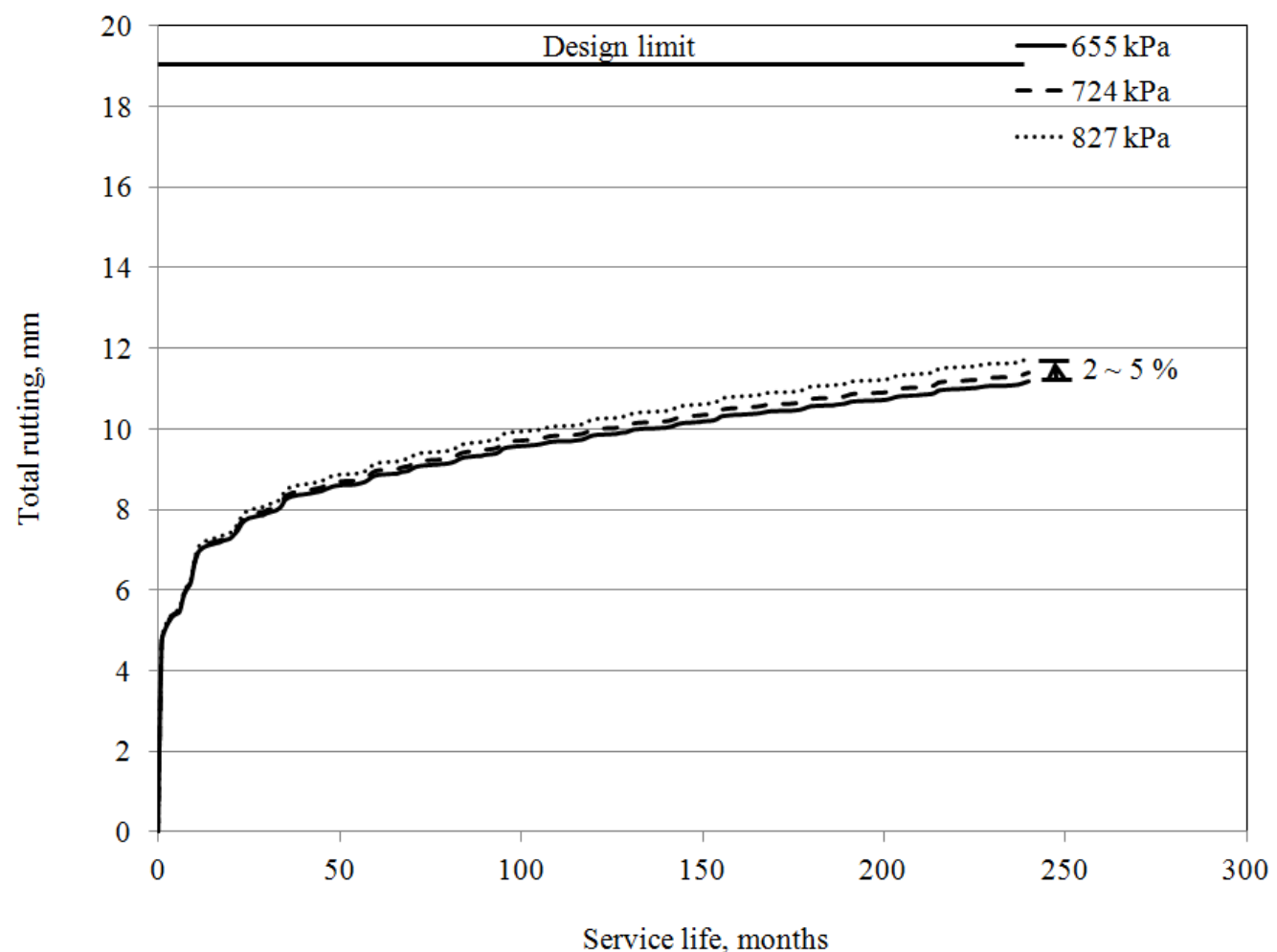

Figure 7.33: Total rutting at different tire pressures 
The M-EPDG has imposed a tire pressure limit up to $827 \mathrm{kPa}$ (120 psi). However, with the growth of traffic and heavy industry, the range of tire pressures used for the majority of the trucks are in the range of $827(120)$ to $1655 \mathrm{kPa}(240 \mathrm{psi})$ and for some heavy trucks the tire pressure can reach $5668 \mathrm{kPa}(822 \mathrm{psi})$. Since the relationship established from the output of the M-EPDG model is linear, a relationship between asphalt concrete rutting and tire pressure at 1000 AADT was established. Using the established equation 7.1 the rutting performance for the asphalt concrete layer can be determined as shown in Figure 7.34.

$$
\text { AC rutting }=0.0027 \times \mathrm{t}_{\mathrm{p}}-0.5219
$$

Where; AC rutting, $\mathrm{mm}$ and $\mathrm{t}_{\mathrm{p}}=$ tire pressure, $\mathrm{kPa}$

Further analysis of Figure 7.34 revealed that the asphalt concrete rutting increases with increasing tire pressure. The increases were 37, 82, 216 and $1085 \%$ as the tire pressure increased from $655 \mathrm{kPa}(95 \mathrm{psi})$ to 1034 (150), 1655 (240) and $5668 \mathrm{kPa}(822$ psi), respectively. 


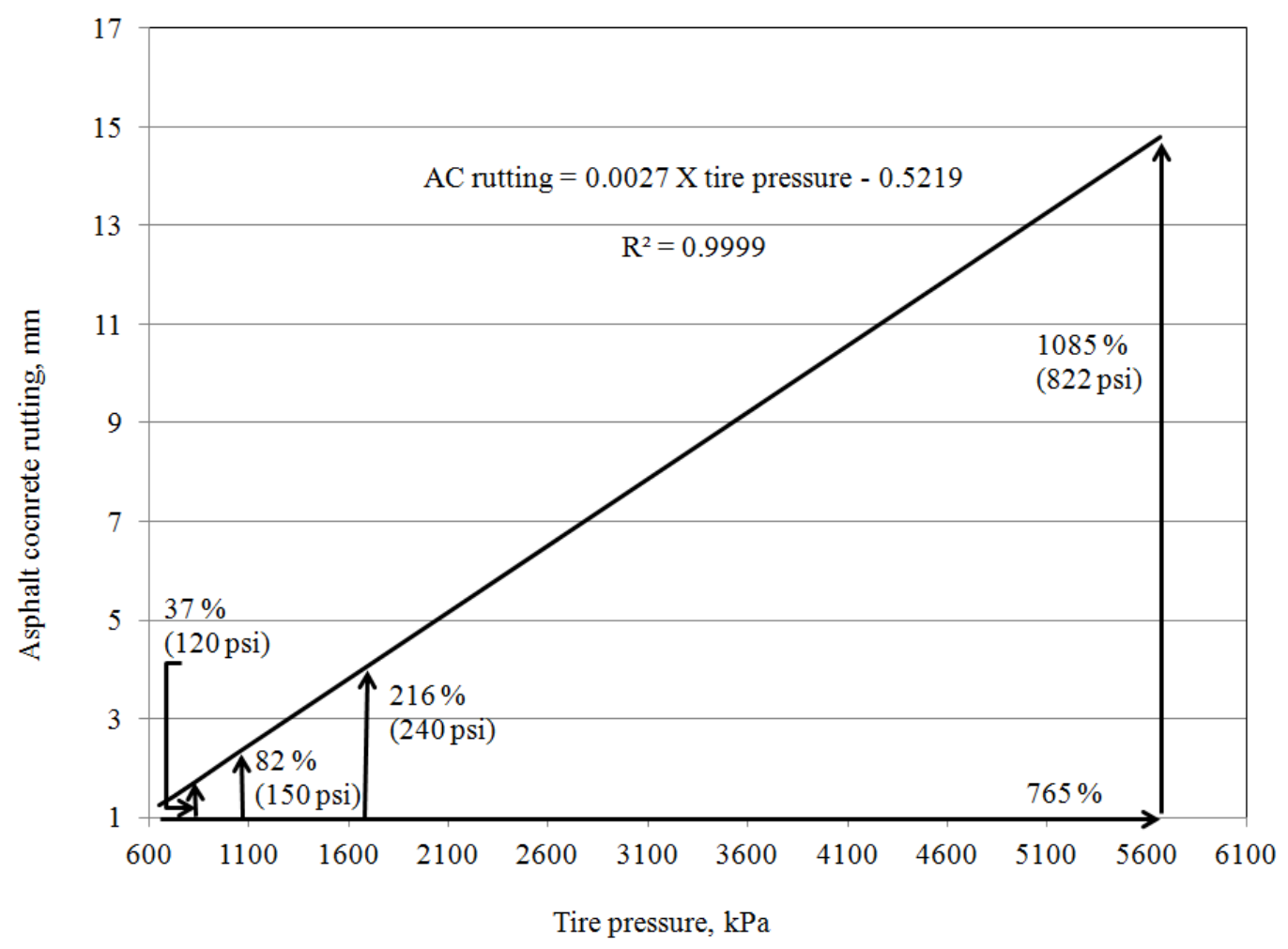

Figure 7.34: Determined asphalt concrete rutting versus tire pressure

\subsubsection{Surface down fatigue (longitudinal) cracking}

The M-EPDG model predictions of longitudinal cracking performances for

different tire pressures are shown in Figure 7.35. The impact of different tire pressures on longitudinal cracking M-EPDG performance trends is shown in Figure 7.35; it is similar for all tire pressures.

It can be concluded that the impact of tire pressure is very small compared to the design limit. Since the relationship established from the output of M-EPDG is linear, in this study a relationship between longitudinal cracking and tire pressure at 1000 AADT was established as shown in Figure 7.36 and is presented by equation 7.2.

$$
\text { Longitudinal cracking }=5.1628\left(\mathrm{t}_{\mathrm{p}}\right)+58870
$$

Where; Longitudinal cracking, $\mathrm{mm} / \mathrm{km}$ and $\mathrm{t}_{\mathrm{p}}=$ tire pressure, $\mathrm{kPa}$ 
Further analysis of the data in Figure 7.36 revealed that longitudinal cracking performance increases by $42 \%$ when the tire pressure increases significantly from 655 to $5668 \mathrm{kPa}(765 \%)$. However the assumptions that all traffic has high tire pressures are still considered very low compared to the design limit. Tire pressure impact is therefore very minimal compared to other form of distresses.

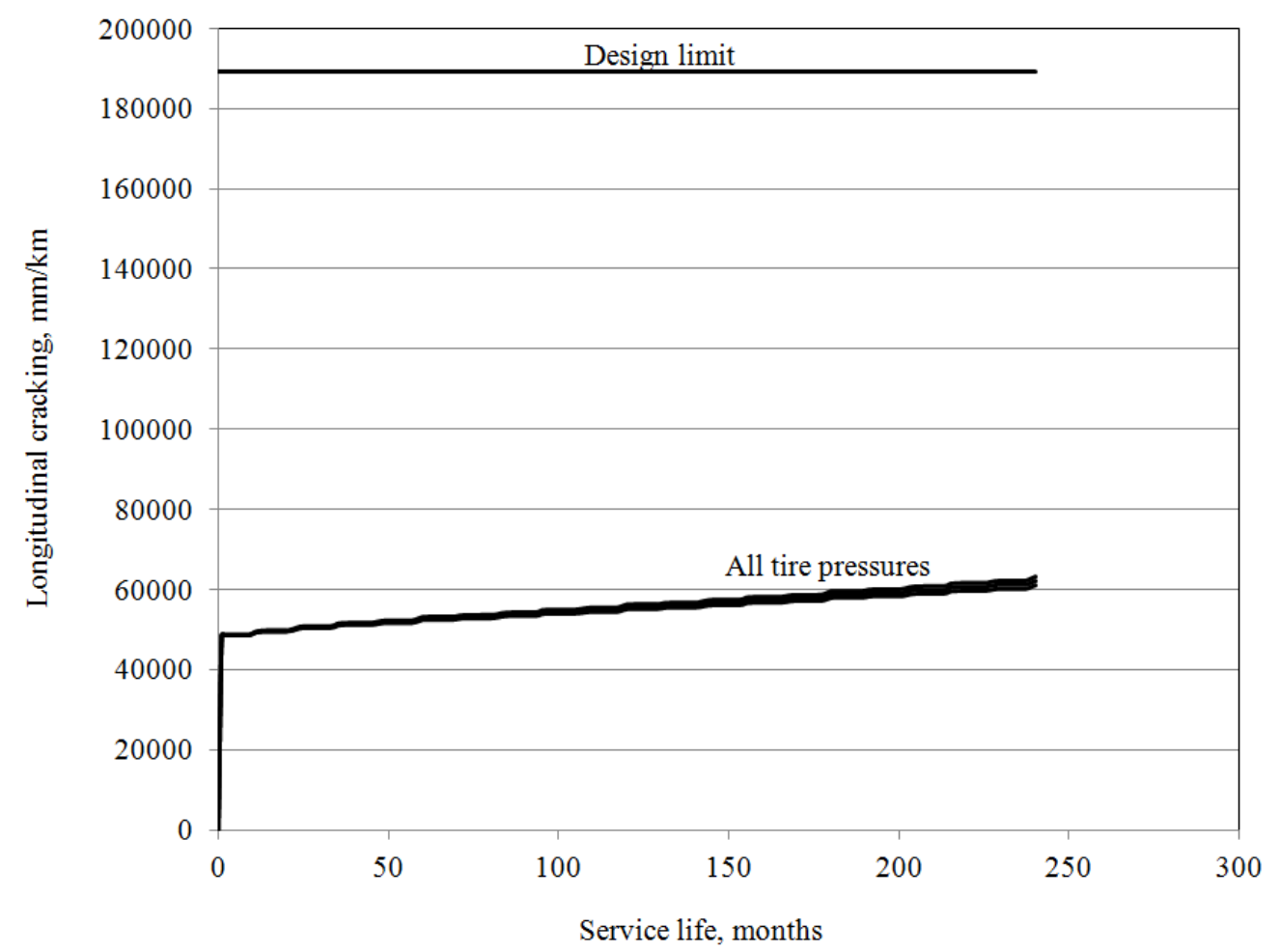

Figure 7.35: Effect of tire pressures on longitudinal cracking 


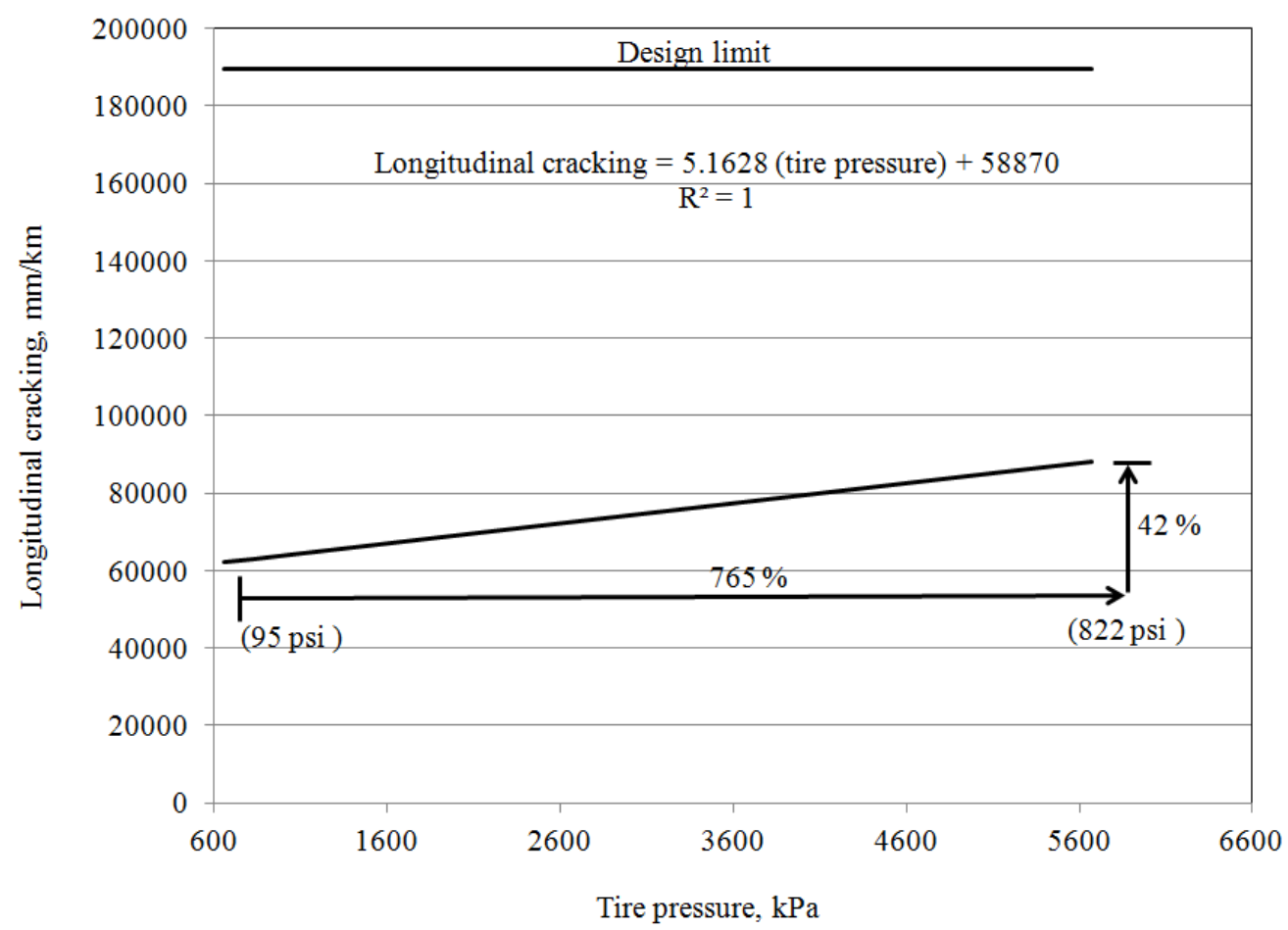

Figure 7.36: Tire pressures effect on pavement service life using longitudinal crack

\subsubsection{Bottom up fatigue (alligator) cracking}

Different tire pressures were used to investigate the model sensitivity to alligator cracking. The predicted percentages of fatigue cracking for mix SP 12.5 of PG 58-28 at the optimum soil condition is shown in Figure 7.37. The results plotted in Figure 7.37 revealed that the effect of tire pressure on alligator cracking is very small and showed an increase of $4 \%$ when the pressure increased to 724 and $827 \mathrm{kPa}$. 


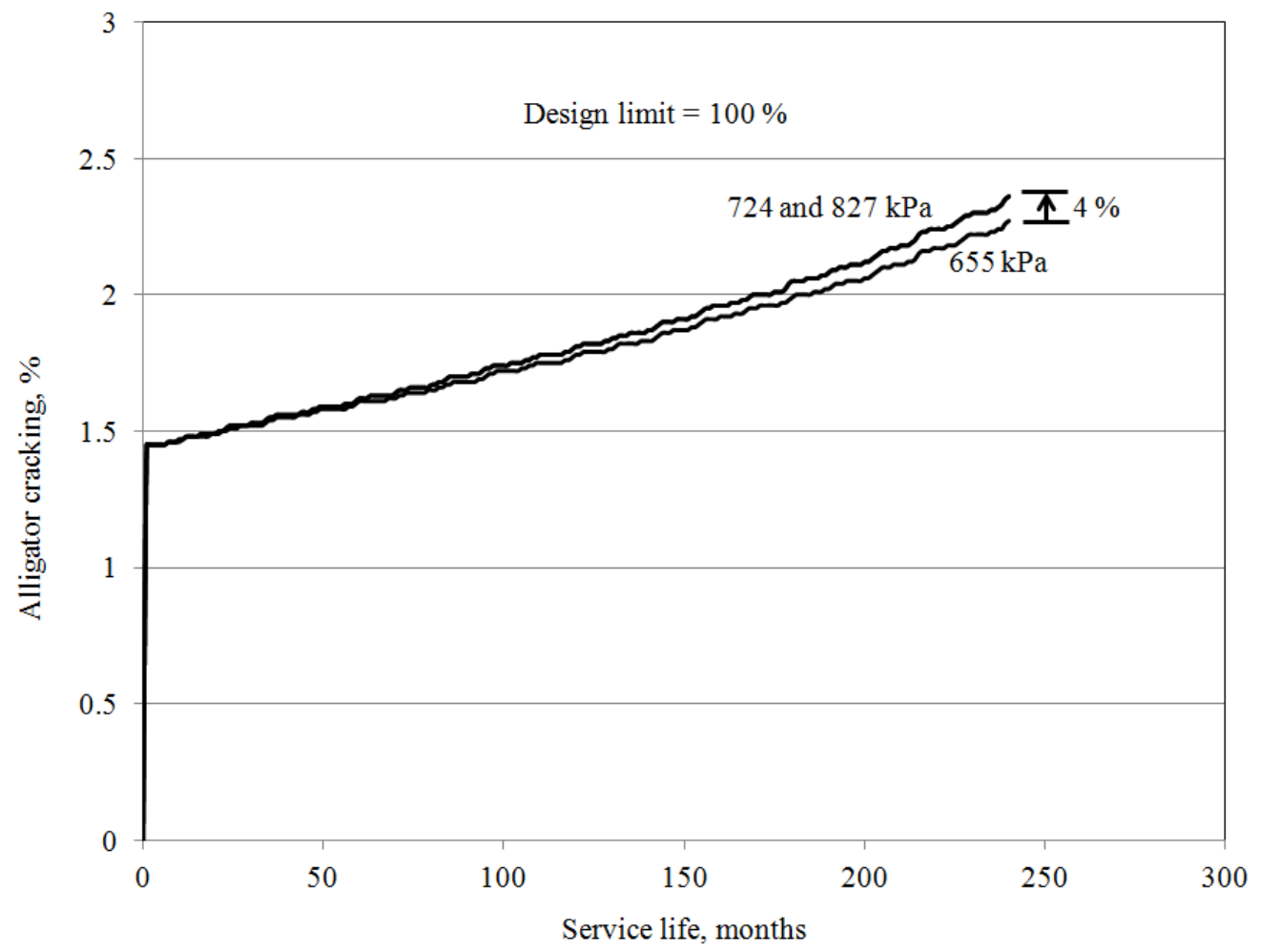

Figure 7.37: Effect of tire pressures on alligator cracking

\subsubsection{International Roughness Index (IRI)}

The M-EPDG predicted smoothness performance for mix SP 12.5 using PG 58-28 at the optimum soil condition is shown in Figure 7.38. The M-EPDG predictions of IRI for all the tire pressures are within the design limit as shown in Figure 7.38. A very similar IRI trend for all of the different tire pressures was obtained. 


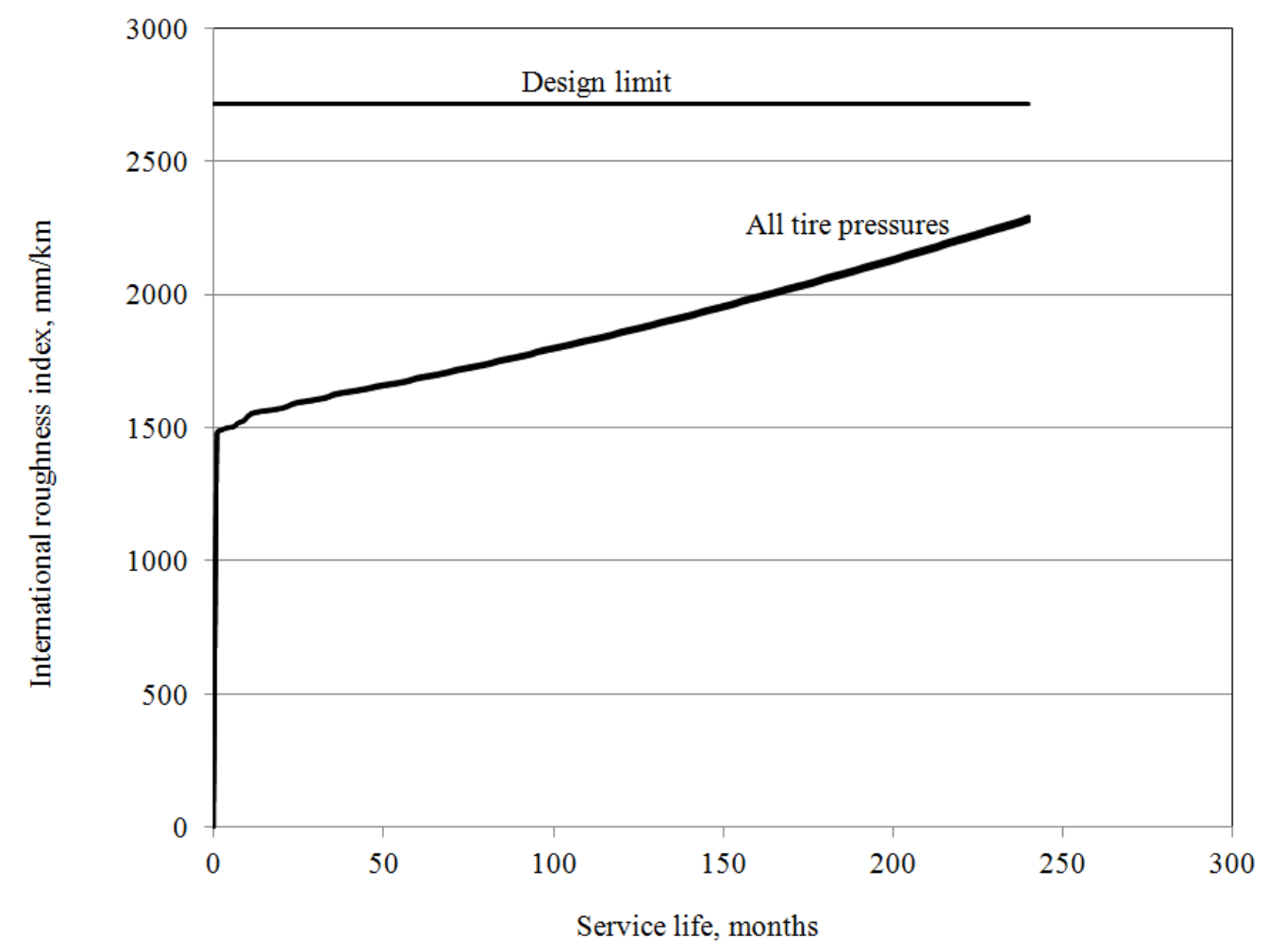

Figure 7.38: Effect of tire pressures on IRI

\subsection{Pavement management system}

The range of traffic volumes have increased tremendously beyond the road design life with the growth of traffic and heavy industry. In response to this, the Ministry of Transportation Ontario (MTO, 2013) developed a Pavement Management System (PMS) to help monitor and evaluate pavement condition. A PMS can be used to monitor the effect of traffic growth on key performance parameters such as rutting, longitudinal cracking and alligator cracking to assist road engineers and practitioners to make decisions in determining the end of service life and the need for rehabilitation or reconstruction. The following is the application of such pavement management system to site 1. 


\subsubsection{Rutting key performance}

The effect of traffic volume on rutting is a key performance indicator. The output of rutting performance based on the M-EPDG was used to establish the traffic effect on pavement service life as shown in Figures 7.39 and 7.40 for asphalt concrete and bound and unbound material (total rutting). Relationships between asphalt concrete rutting and total rutting (bound and unbound material) with respect to traffic were established and are represented in equations 7.3 and 7.4 , respectively.

$$
\begin{aligned}
& \text { AC rutting }=0.0005(\mathrm{AADT})+1.2408 \\
& \text { Total rutting }=0.0011(\mathrm{AADT})+10.776
\end{aligned}
$$

Where; $\mathrm{AC}$ rutting and Total rutting in, $\mathrm{mm}$ and $\mathrm{AADT}=$ Annual Average Daily Traffic

Establishing the rutting performance behaviour as shown in Figures 7.39 and 7.40 will assist engineers and road practitioners in determining the end of service life at which point rehabilitation or reconstruction is required. In this particular case, using the PS 12.5 mix with a stiff binder of PG 58-28 at the optimum moisture content, the AADT failure limit can be determined. The failure limit was found to be 10218 and 7522 in case of asphalt concrete rutting or total rutting respectively, and the governing value of AADT failure limit is the lower one and usually the one found using the total rutting parameter. For instance, when the traffic grows beyond the failure limit the road design life will be affected accordingly. The greater the increase in the traffic beyond this point, the less the design life of the road will be. Using both trends for asphalt concrete rutting or total rutting, the determined end of the road design life at AADT values beyond the limit $12000,16000,20000$ and 24000, will be expected at 16, 13, 12 and 10 years. 


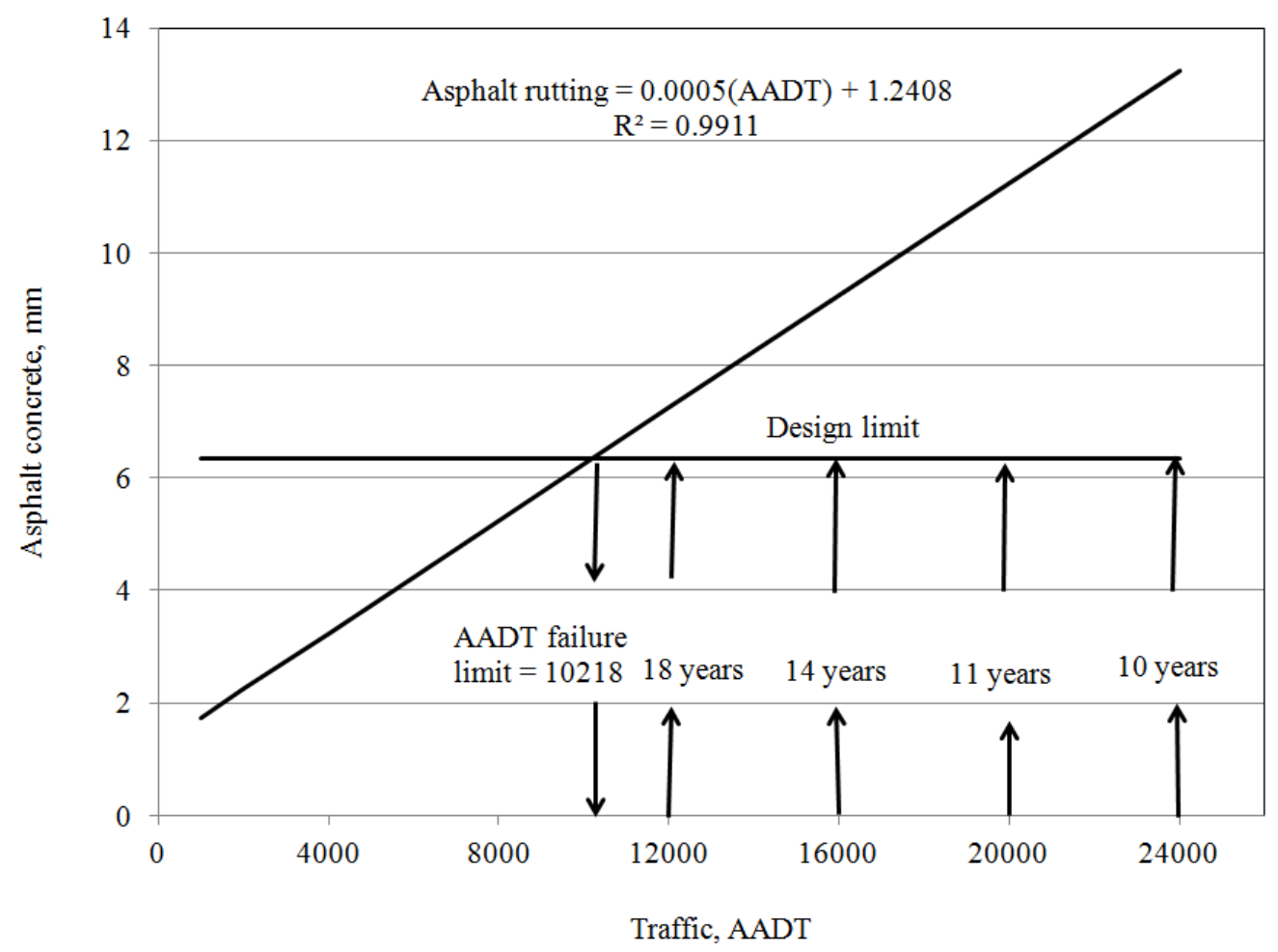

Figure 7.39: Traffic effect on pavement service life using asphalt concrete rutting

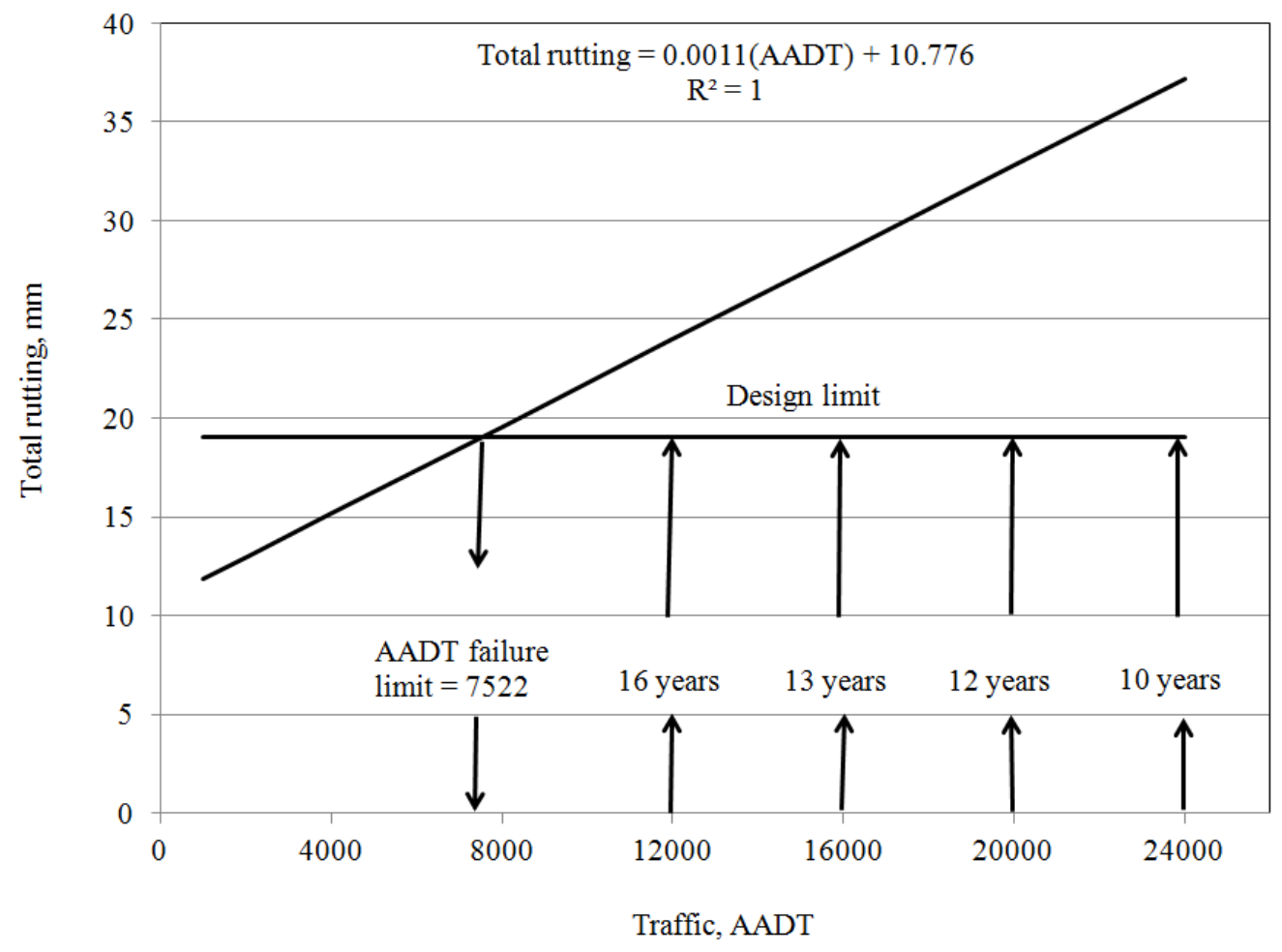

Figure 7.40: Traffic effect on pavement service life using total rutting 


\subsubsection{Longitudinal cracking key performance}

The growth of traffic volume has the same impact as the rutting. The effect of traffic capacity on longitudinal cracking is another key performance indicator and since the relationship established from the output of the M-EPDG model is very sensitive to traffic and linear as shown in Figure 7.41. In this study, a relationship between asphalt concrete longitudinal cracking with respect to traffic is established and represented by equation 7.5.

$$
\text { Longitudinal cracking=11.851 (AADT)+51657 }
$$

Where; Longitudinal cracking in, $\mathrm{mm} / \mathrm{km}$ and AADT = Annual Average Daily Traffic

Establishing the longitudinal cracking performance behaviour as shown in Figure 7.41 will provide engineers and road practitioners with a second tool for determining the end of service life at which point rehabilitation or reconstruction is required. In this particular case using PS 12.5 mix with stiff binder of PG 58-28 at the optimum moisture content, the AADT failure limit can be determined. It was found to be 11622 . The growth of traffic should be below the determined AADT failure limit. Unexpected growth beyond the AADT will limit the road design life. It will be affected and reduced as shown in Figure 7.41. Traffic beyond the AADT failure limit (e.g. 16000, 20000 and 24000) will decrease the road design life to 16,13 and 11 years respectively. 


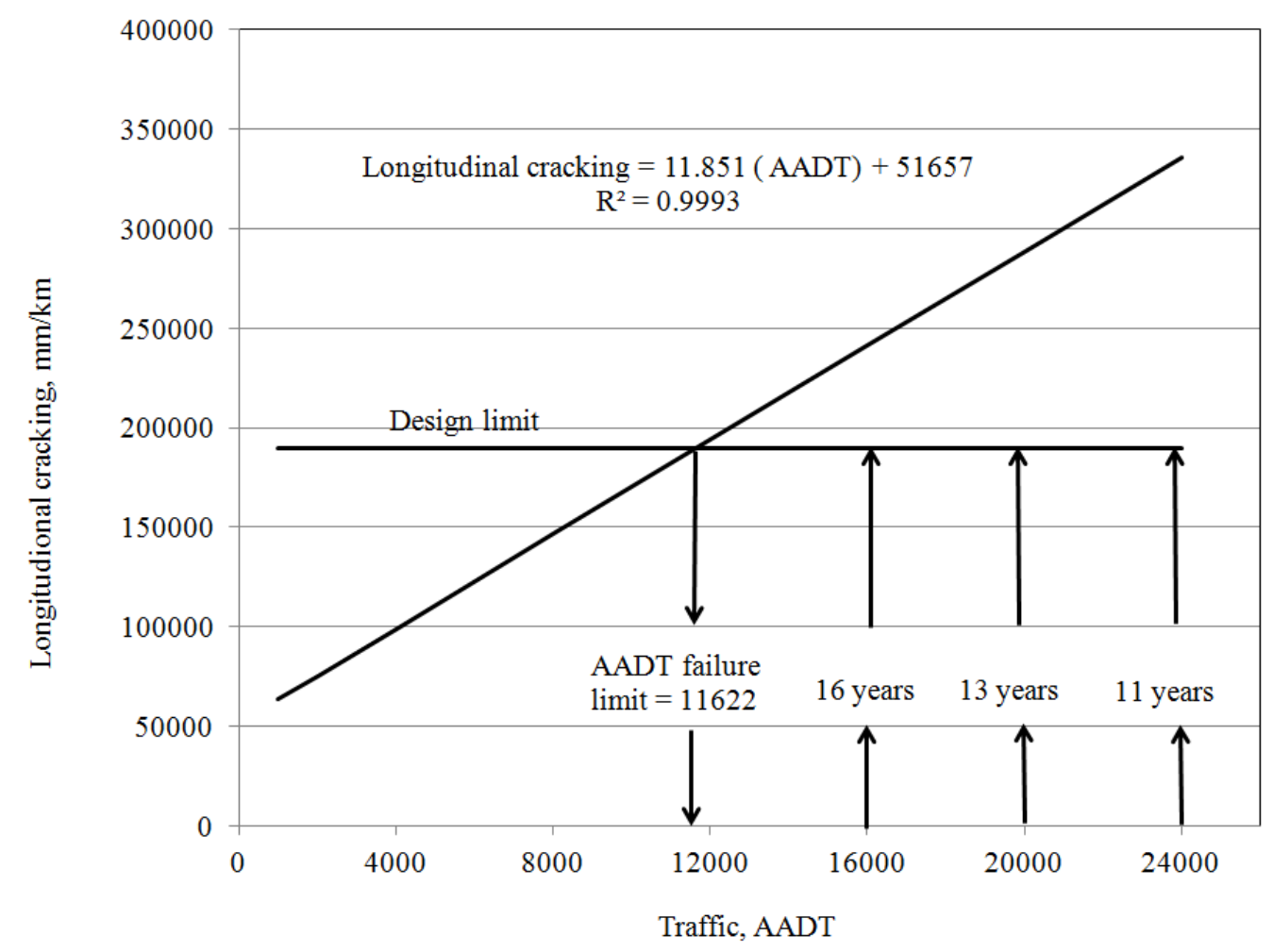

Figure 7.41: Traffic effect on pavement service life using longitudinal crack

\subsubsection{Alligator cracking key performance}

Alligator cracking is another key performance indicator that can provide road engineers and road practitioners with a tool to assist defining the service life of the road.

The traffic input in the M-EPDG is the initial AADT. Assuming traffic growth one can wonder if this will be sufficient. A relationship was established between alligator cracking and the traffic to determine this input. The relationship is illustrated in the Figure 7.42 and is represented by equation 7.6.

Alligator cracking $=0.0065$ (AADT) -5.015

Where; Alligator cracking, $\%$ and AADT = Annual Average Daily Traffic 
The relationship established in this study as shown in Figure 7.42 will assist engineers and road practitioners as another tool for determining the end of service life at which point rehabilitation or reconstruction is required. In this case the PS 12.5 mix with stiff binder of PG 58-28 at optimum moisture content was used. The AADT failure limit can be determined and was found to be 16156 . The growth of traffic should be below the determined AADT failure limit. Exceeding the AADT limit will reduce the road design life as shown in Figure 7.42. At AADT values of 20000 and 24000 the road design life will be 16 and 13 years respectively.

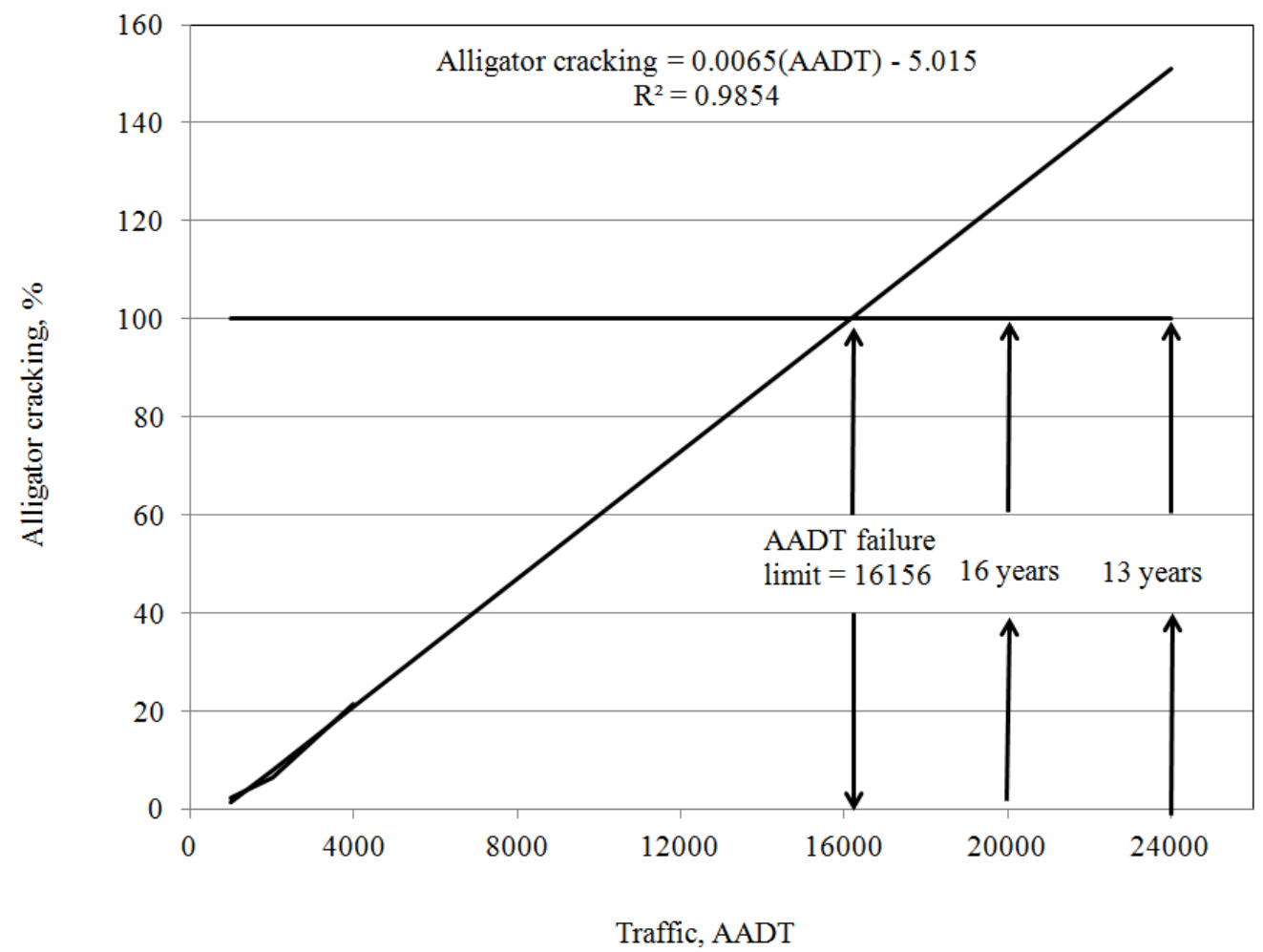

Figure 7.42: Traffic effect on pavement service life using alligator cracking as key parameters

From the discussion above, one can conclude that the total rutting is most important performance indicator for determining the end of the pavement design life as 
shown below in Figure 7.43. Further analysis of the data in Figures 7.39 to 7.42 reveals that the differences between the key performances indicators are small at AADT 20000 or more due to the nature of the unbound materials that are densified due to traffic at an early stage in the service-life (see Figure 7.44).

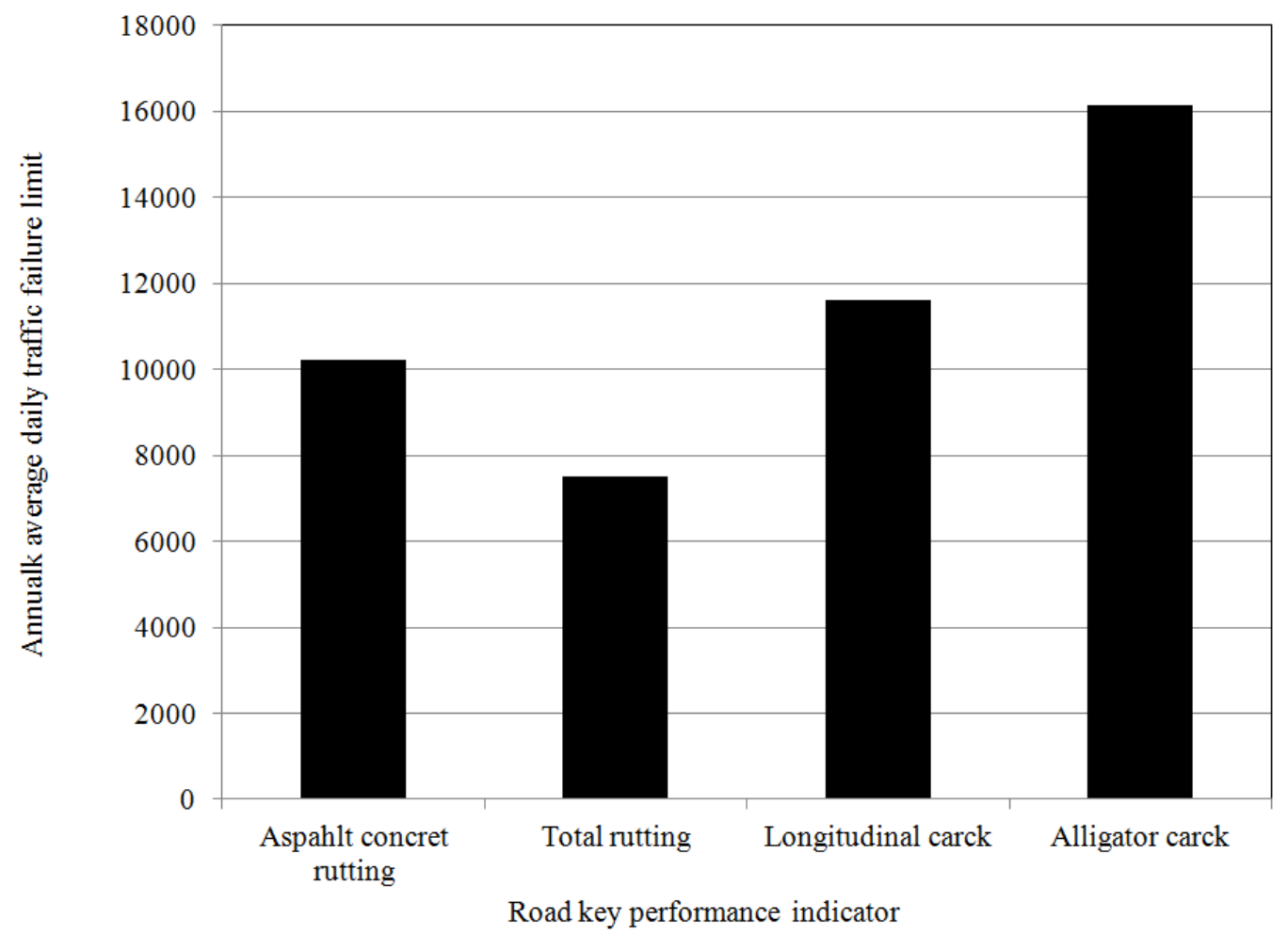

Figure 7.43: AADT failure limit of road key performance indicators 


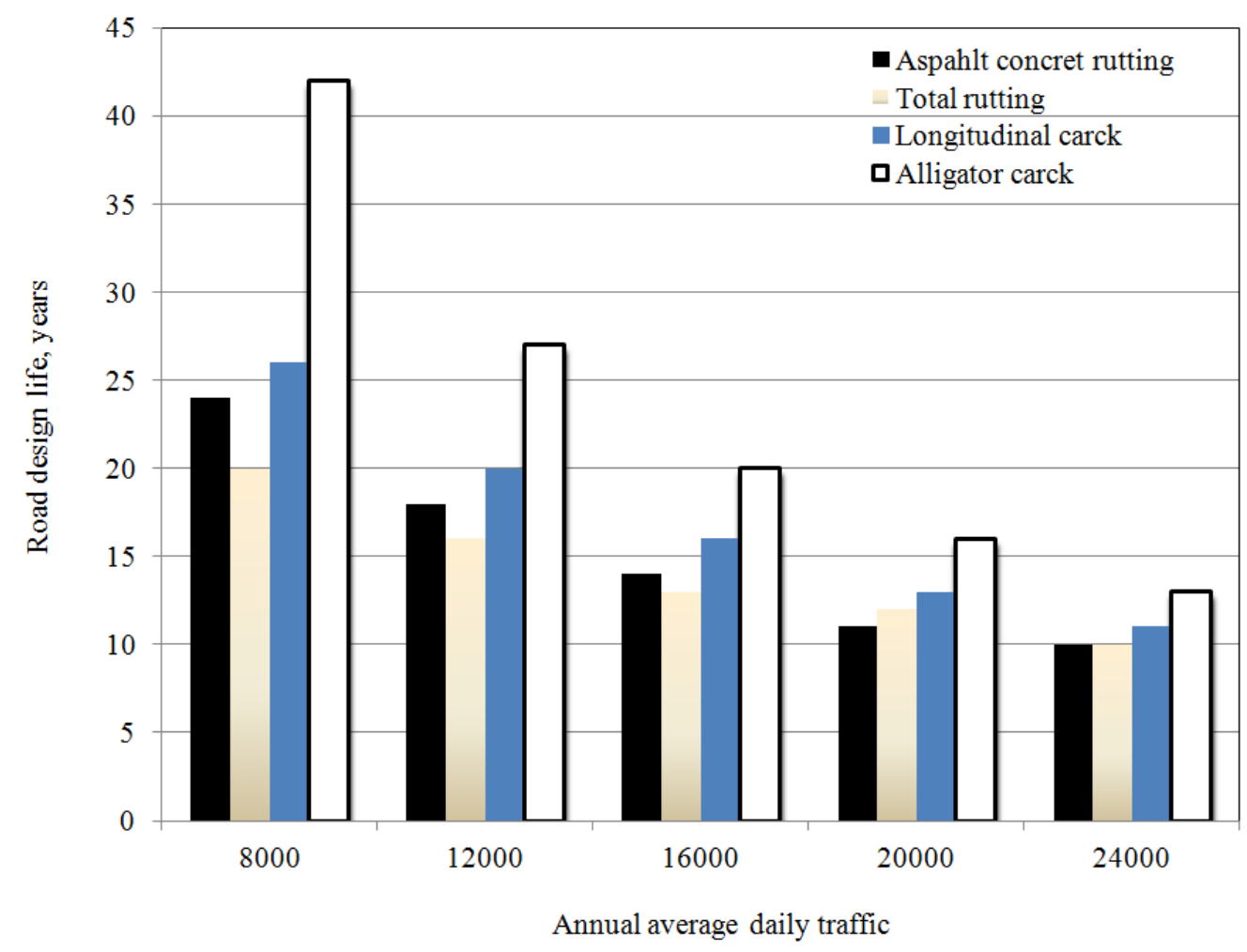

Figure 7.44: Comparison of road design life key performance indicators

\subsection{Field evaluation and comparison}

\subsubsection{Introduction}

The M-EPDG model is a comprehensive pavement analysis tool that can predict the performance of a given pavement section. The sensitivity and accuracy as discussed previously was proven to be acceptable in this study.

The evaluation of the M-EPDG guide usually requires field road investigation under a controlled environment. For this study, three constructed sites were chosen based on their different structure, unique traffic patterns and weather conditions as detailed in chapter 3. A laboratory investigation on all the materials used to construct the three roads was undertaken. Input files were prepared for this study as required by M-EPDG level 1.

Model runs were performed using the field and laboratory work completed at each of the three test sites in this study as input data files. Design levels of the AASHTO 2004 
design guide were used to determine the degree of precision achieved by using the advance design level 1 for asphalt concrete and level 3 of analysis for unbound materials. A SP 12.5 mix, using performance grade binders PG 58-28, PG 64-22 and PG 52-22 were used for all sites. The binder in use for site 1 was PG 58-28 and for sites 2 and 3 was PG 64-22.

The actual annual average daily traffic for each site with rutting measured from the fieldwork was compared to the rutting (asphalt concrete and total) performance indicator of the M-EPDG with a high reliability level for the three sites.

\subsubsection{Input files}

The AASHTO design guide provides three levels of input depending on the importance of the project and the availability of the project design inputs. The climate database incorporated the new design guide and site related cities were selected. Following the recommendation of the design guide, laboratory and fieldwork was performed and the results were used as input level 1 for asphalt concrete and level 3 for unbound materials. The details of the runs are shown in Tables 7.3, 7.4 and 7.5 for sites 1, 2 and 3 respectively. Details of the traffic data input file used are shown in Table 7.6. 
Table 7.3: Details of M-EPDG runs site 1

\begin{tabular}{|c|c|c|c|c|}
\hline \multirow{2}{*}{$\begin{array}{l}\text { Code } \\
\text { Classification }\end{array}$} & \multirow{2}{*}{$\begin{array}{l}\text { Soil } \\
\text { condition }\end{array}$} & \multirow{2}{*}{$\begin{array}{l}\text { Run } \\
\text { number }\end{array}$} & \multicolumn{2}{|c|}{ Layer thickness, mm } \\
\hline & & & Constructed & Maximum MEPDG \\
\hline $\mathrm{AC}$ & & $\mathrm{R} 1 / \mathrm{R} 2 / \mathrm{R} 3$ & 200 & 200 \\
\hline \multirow{3}{*}{$\begin{array}{l}\text { Base } \\
\text { (GA) }\end{array}$} & Dry & R1 & \multirow[t]{3}{*}{940} & \multirow[t]{3}{*}{940} \\
\hline & $\mathrm{OPC}$ & $\mathrm{R} 2$ & & \\
\hline & Wet & R3 & & \\
\hline \multirow{3}{*}{$\begin{array}{l}\text { Sub-grade } \\
\text { (GA) }\end{array}$} & Dry & R1 & \multirow[t]{3}{*}{1420} & \multirow[t]{3}{*}{1300} \\
\hline & $\mathrm{OPC}$ & $\mathrm{R} 2$ & & \\
\hline & Wet & R3 & & \\
\hline \multirow{3}{*}{$\begin{array}{l}\text { Sub-grade } \\
\text { (Silty sand) }\end{array}$} & Dry & R1 & \multirow[t]{3}{*}{ Last } & \multirow[t]{3}{*}{ Last } \\
\hline & $\mathrm{OPC}$ & $\mathrm{R} 2$ & & \\
\hline & Wet & R3 & & \\
\hline
\end{tabular}

Table 7.4: Details of M-EPDG runs site 2

\begin{tabular}{|c|c|c|c|c|}
\hline \multirow{2}{*}{$\begin{array}{l}\text { Code } \\
\text { Classification }\end{array}$} & \multirow{2}{*}{$\begin{array}{l}\text { Soil } \\
\text { condition }\end{array}$} & \multirow{2}{*}{$\begin{array}{l}\text { Run } \\
\text { number }\end{array}$} & \multicolumn{2}{|c|}{ Layer thickness, mm } \\
\hline & & & Constructed & Maximum MEPDG \\
\hline $\mathrm{AC}$ & & R1/R2/R3 & 230 & 230 \\
\hline \multirow{3}{*}{$\begin{array}{l}\text { Base } \\
\text { (CAB II) }\end{array}$} & Dry & $\mathrm{R} 1$ & \multirow[t]{3}{*}{110} & \multirow[t]{3}{*}{110} \\
\hline & $\mathrm{OPC}$ & $\mathrm{R} 2$ & & \\
\hline & Wet & R3 & & \\
\hline \multirow{3}{*}{$\begin{array}{l}\text { Sub-base } \\
(\mathrm{SGBM})\end{array}$} & Dry & R1 & \multirow[t]{3}{*}{870} & \multirow[t]{3}{*}{870} \\
\hline & $\mathrm{OPC}$ & $\mathrm{R} 2$ & & \\
\hline & Wet & R3 & & \\
\hline \multirow{3}{*}{$\begin{array}{l}\text { Sub-grade } \\
\text { (Silty clay) }\end{array}$} & Dry & R1 & \multirow[t]{3}{*}{ Last } & \multirow[t]{3}{*}{ Last } \\
\hline & $\mathrm{OPC}$ & $\mathrm{R} 2$ & & \\
\hline & Wet & R3 & & \\
\hline
\end{tabular}


Table 7.5: Details of M-EPDG runs site 3

\begin{tabular}{|l|l|l|l|l|}
\hline $\begin{array}{l}\text { Code } \\
\text { Classification }\end{array}$ & $\begin{array}{l}\text { Soil } \\
\text { condition }\end{array}$ & $\begin{array}{l}\text { Run } \\
\text { number }\end{array}$ & \multicolumn{2}{|c|}{ Layer thickness, mm } \\
\hline AC & & R1/R2/R3 & 240 & 240 \\
\hline \multirow{2}{*}{$\begin{array}{l}\text { Base } \\
\text { (DGABC) }\end{array}$} & Dry & R1 & 225 & 225 \\
\cline { 2 - 3 } & OPC & R2 & & \\
\cline { 2 - 3 } & Wet & R3 & & \\
\hline \multirow{2}{*}{$\begin{array}{l}\text { Sub-base } \\
\text { (Sand) }\end{array}$} & Dry & R1 & \multirow{2}{*}{900} & 900 \\
\cline { 2 - 3 } & OPC & R2 & & \\
\cline { 2 - 3 } & Wet & R3 & & \\
\hline \multirow{2}{*}{$\begin{array}{l}\text { Sub-grade } \\
\text { (Clay) }\end{array}$} & Dry & R1 & Last & Last \\
\cline { 2 - 3 } & OPC & R2 & & \\
\cline { 2 - 3 } & Wet & R3 & & \\
\hline
\end{tabular}

Table 7.6: Traffic input data

\begin{tabular}{|l|l|l|l|}
\hline Input description & Site 1 & Site 2 & Site 3 \\
\hline Design life (years) & 20 & \multicolumn{2}{|l|}{} \\
\hline Number of lanes in design direction & 2 & 4 & 2 \\
\hline Percentage of trucks in design direction & 50 & \multicolumn{3}{|l|}{} \\
\hline Percentage of trucks in design lane & 95 & $70(45)$ \\
\hline Operated speed, km/h (mph) & $827(120)$ \\
\hline Tire pressure, $\mathrm{kPa}(\mathrm{psi})$ & 7000 & 2000 & 33000 \\
\hline Traffic, AADT & 4.5 & \\
\hline Traffic growth, \% & \multicolumn{3}{|l}{} \\
\hline
\end{tabular}

\subsubsection{Site 1}

The M-EPDG model predicted performance in terms of asphalt concrete rutting throughout the 20 years design life as shown in Figure 7.45. Irrespective of the binder grade used, the asphalt concrete rutting at different soil conditions (dry, optimum and wet) showed a change between 2 to $6 \%$. The effect of the soil condition and all binders in this field study confirms the same results. The sensitivity analysis of the binder effect was shown previously in Figures 7.9 and 7.10. Predicted rutting performance is also in 
agreement with the laboratory results (see Figure 5.4) of dynamic modulus, which indicated that PG 58-28 produced stiffer mixes than PG 52-34.

However, Figure 7.46 shows that for the asphalt concrete rutting at the optimum soil condition, the total rutting values of the soft binders PG 52-34 and PG 64-22 are higher than the stiff binder PG 58-28 by about 132 and $167 \%$ respectively further confirming the previous finding for the sensitivity of the type of binder used as illustrated in Figure 7.10.

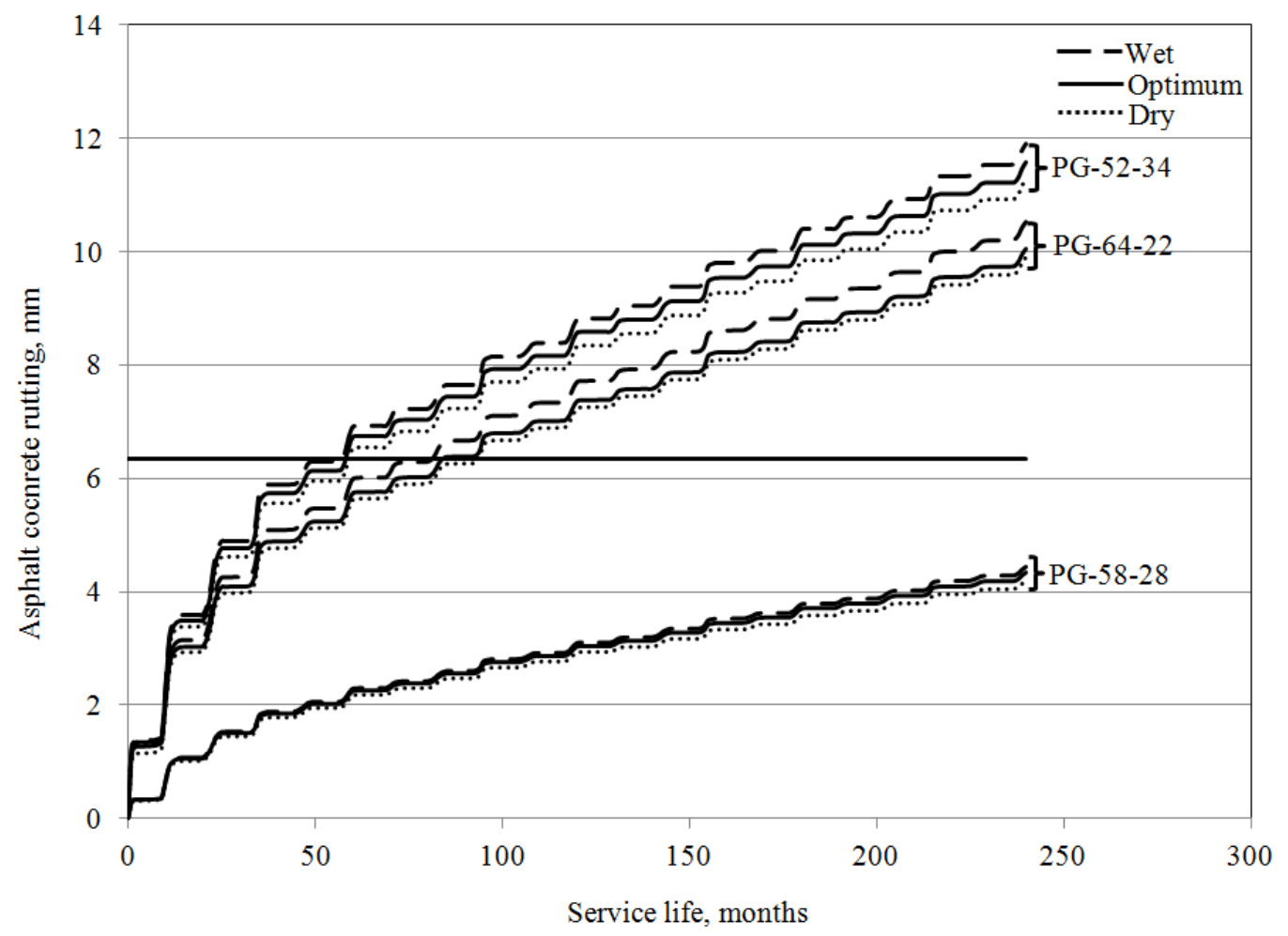

Figure 7.45: Asphalt concrete rutting - Site 1 


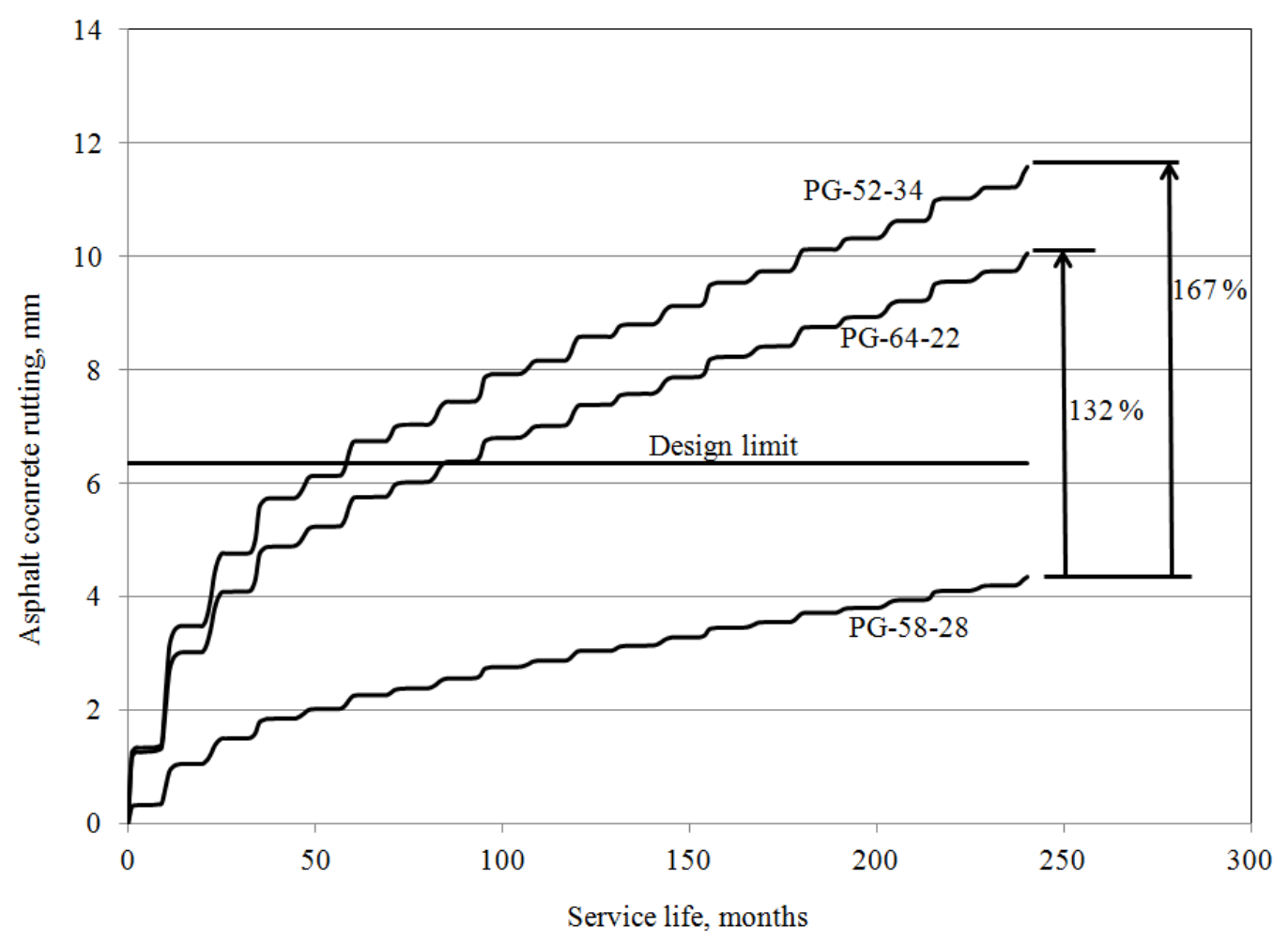

Figure 7.46: Asphalt concrete rutting at the optimum soil condition - Site 1

Regardless of the binder grade used, the total rutting trends for the dry, optimum and wet conditions showed a change of between 2 to $5 \%$ (see Figure 7.47). These differences are within the calculated margin of error, which suggests that the level 3 analysis is not sensitive enough to conclude that there are any differences between the unbound material conditions. However, Figure 7.48 shows that for total rutting at the optimum soil condition, the soft binders PG 52-34 and PG 64-22 have higher values than the stiff binder PG 58-28 by about 61 and $70 \%$ respectively. 


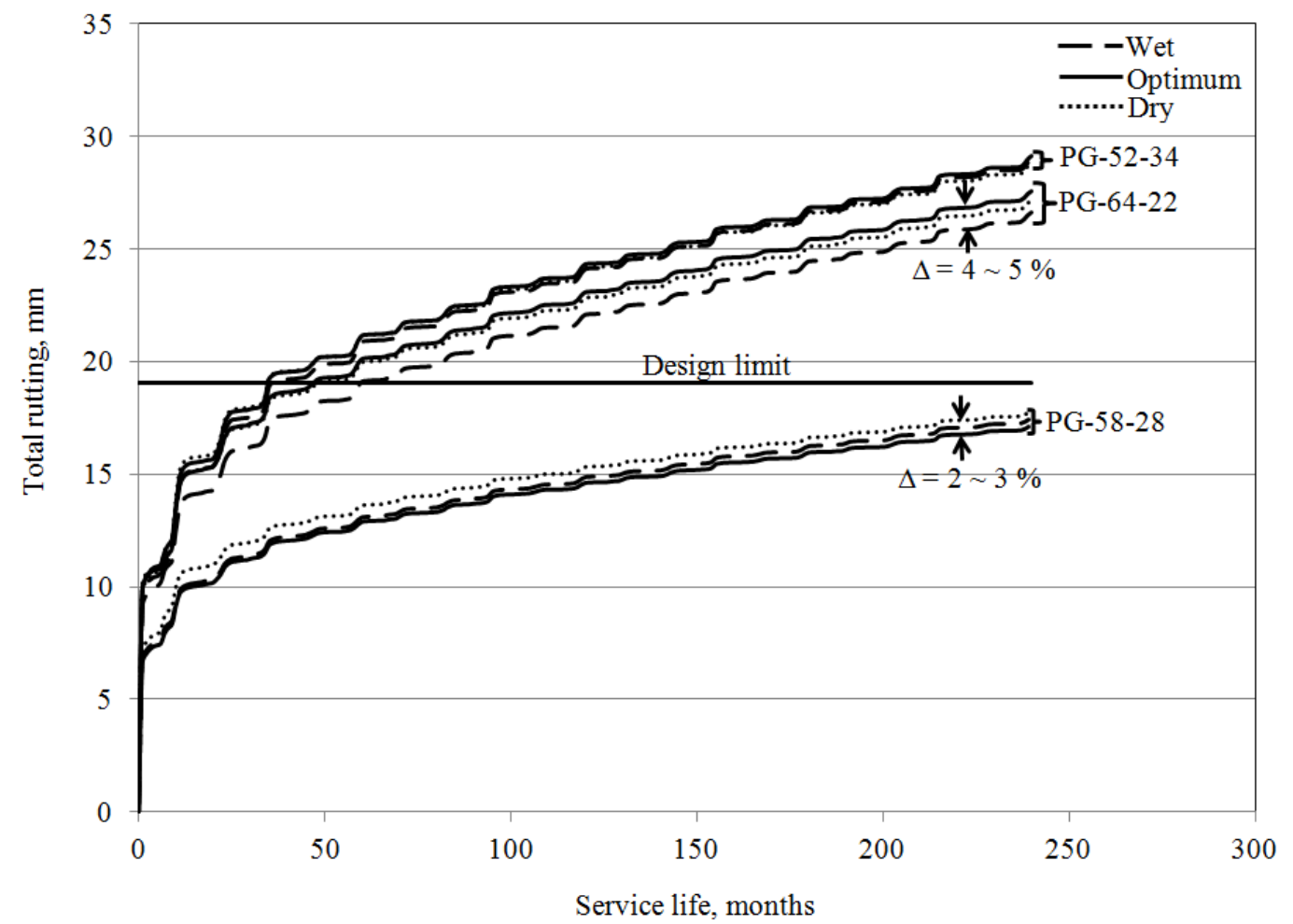

Figure 7.47: Total rutting-Site 1

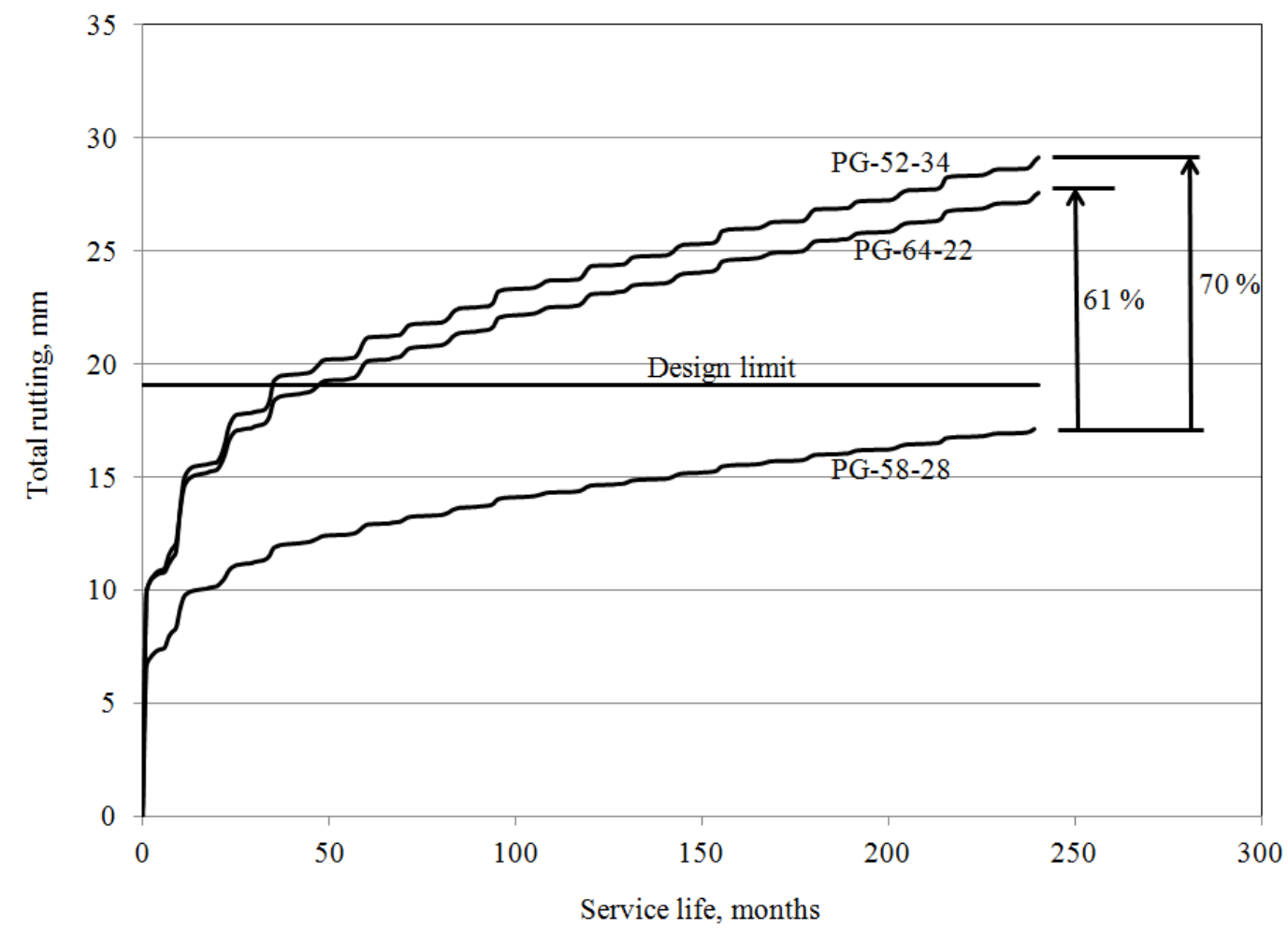

Figure 7.48: Total rutting at optimum soil condition - Site 1 
Further analysis of the data in Figures 7.45 and 7.47 reveal that the use of binder PG 58-28 on site 1 conformed to its intended use and that the trend of the rutting curves is below the design limit throughout the 20 year design life for all of the different soil conditions. The performance of the other two binders PG 52-34 and PG 64-22 in terms of the effect of asphalt concrete rutting and total rutting on road service life is shown in Figures 7.49 and 7.50 respectively. It can be concluded that the total rutting is the key performance indicator as discussed before. The design life of the site 1 road was reduced to 3 years in the case of the use of the PG 52-34 binder and 6 years in case of the PG 6422 binder regardless of the soil condition.

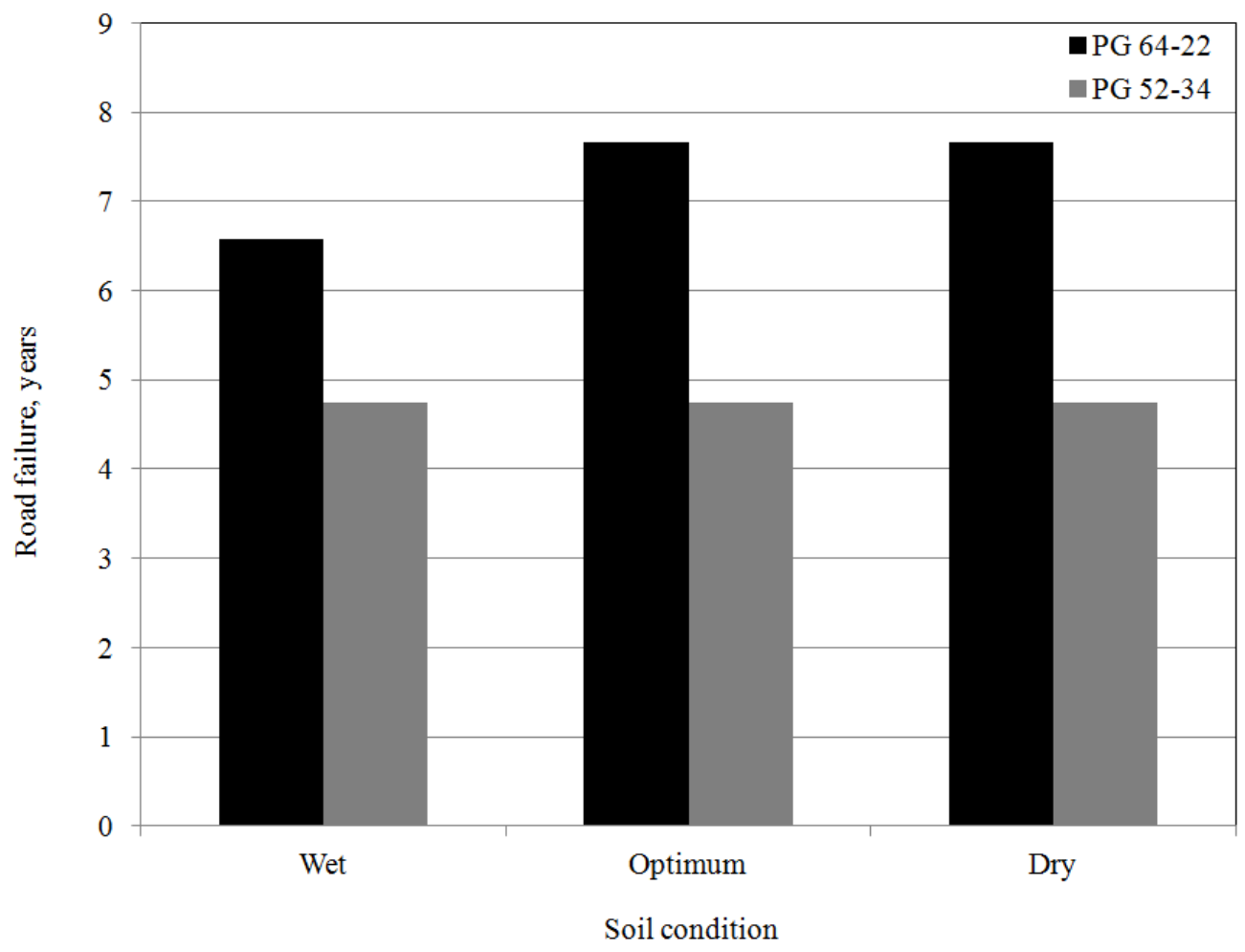

Figure 7.49: Effect of asphalt concrete rutting on road service life - Site 1 


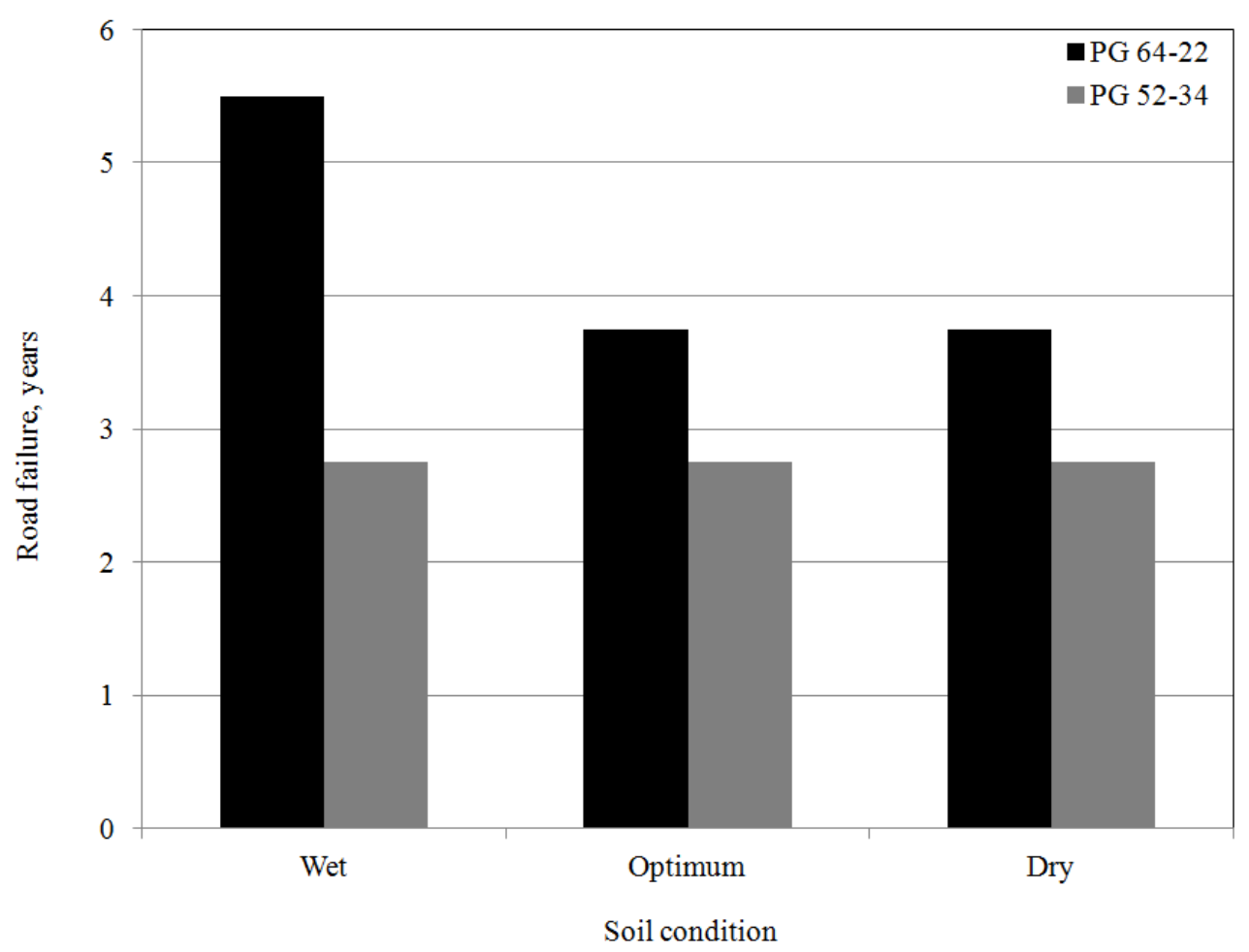

Figure 7.50: Effect of total rutting on road service life - Site 1

The predicted M-EPDG model rutting performance using different soil conditions was small as shown previously in Figures 7.49 and 7.50. This was based on the M-EPDG rutting performance prediction at optimum soil condition. This condition was selected to compare with field measured rutting for both asphalt and total road structure layers.

Figures 7.51 and 7.52, show the M-EPDG model predicted performance rutting (asphalt concrete and total) using the three different binders compared with actual field rutting (asphalt concrete and total) measurements. Comparing the field trend to other predicted trends, it was noted that the highest rate of deformation occurred within the first 8 months followed by a smaller rate for the rest of the design life, supporting observations documented in the literature. This suggests that the majority of poor performance incidents occur at an early stage in the service life. Whereas the M-EPDG predicted trends showed little effect within the first months (first stage) reaching a 
densification initial limit stage (plateau) from 1 to 9 months followed by the last two permanent deformation stages (secondary and tertiary).

The magnitude of permanent deformations shown in Figures 7.51 and 7.52 reflects the sensitivity of the model to variations in the dynamic modulus of the mix (different binders). Permanent deformation varied considerably depending on the binder type used.

The calculated difference with respect to the field asphalt concrete rutting ranged from $47 \%$ lower than the field binder using PG 58-28 and higher by 38 and $61 \%$ for binders PG 64-22 and PG 52-34 respectively (as shown in Figure 7.51).

Using total rutting as a key performance measure to evaluate the sensitivity of the predicted M-EPDG model total rutting performance shown in Figure 7.52 revealed that model runs using the PG 58-28 binder resulted in a $23 \%$ underestimation of total rutting, whereas there were 21 and $26 \%$ overestimations compared with the field results for PG 64-22 and PG 52-34 respectively.

The M-EPDG model results agreed with the design objectives intended by the producer of the binder and the municipality of site 1. High stability and relatively high temperature resistance offers adequate resistance to permanent deformations as laboratory results from this study confirm. The mix with the PG 58-28 binder decreased substantially the accumulation of permanent deformation in the course of the 20 -year design life and satisfied the design limit involving a maximum tolerance of $19 \mathrm{~mm}$ rutting. 


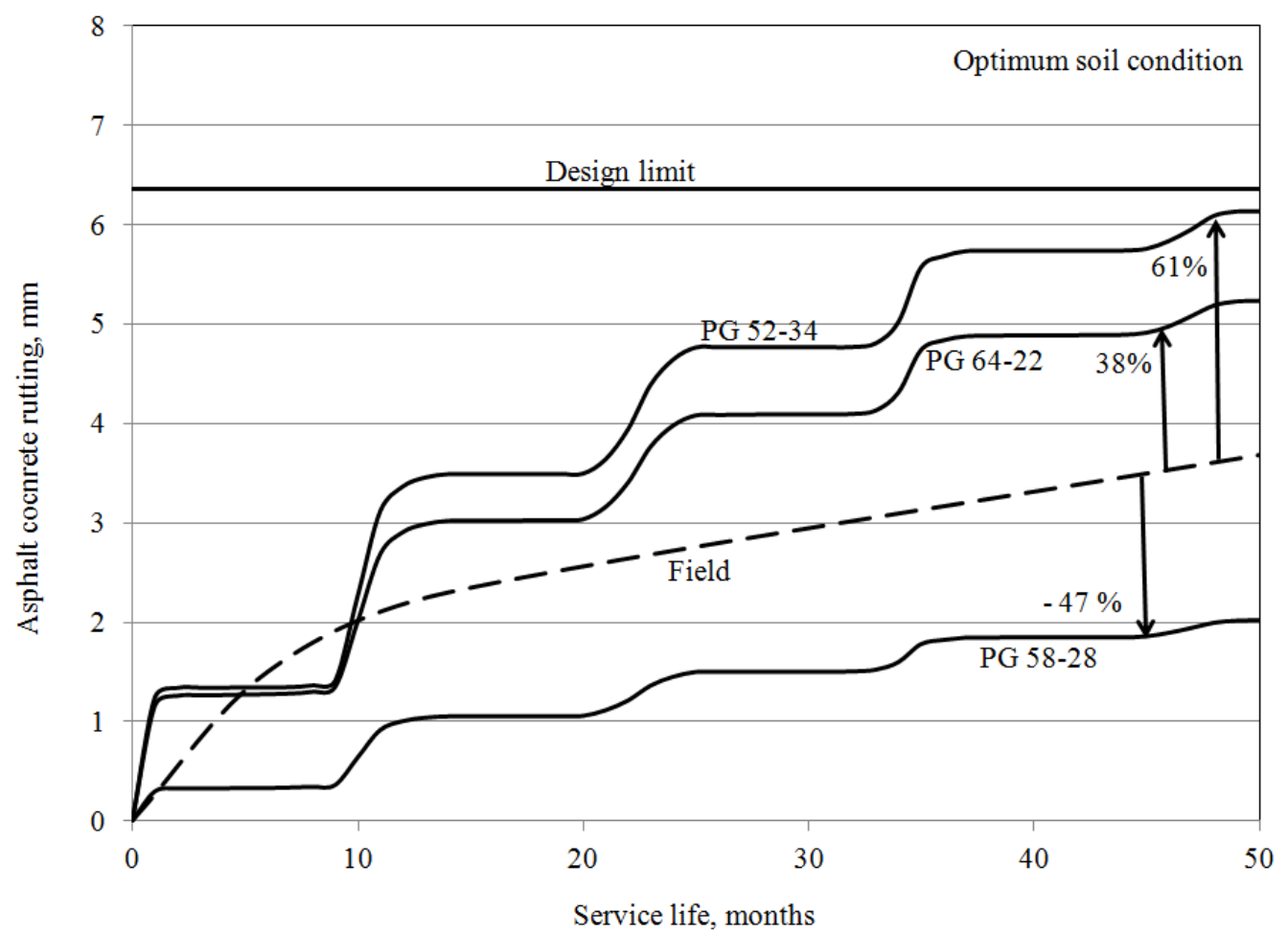

Figure 7.51: Comparison between field and M-EPDG asphalt concrete rutting - site 1

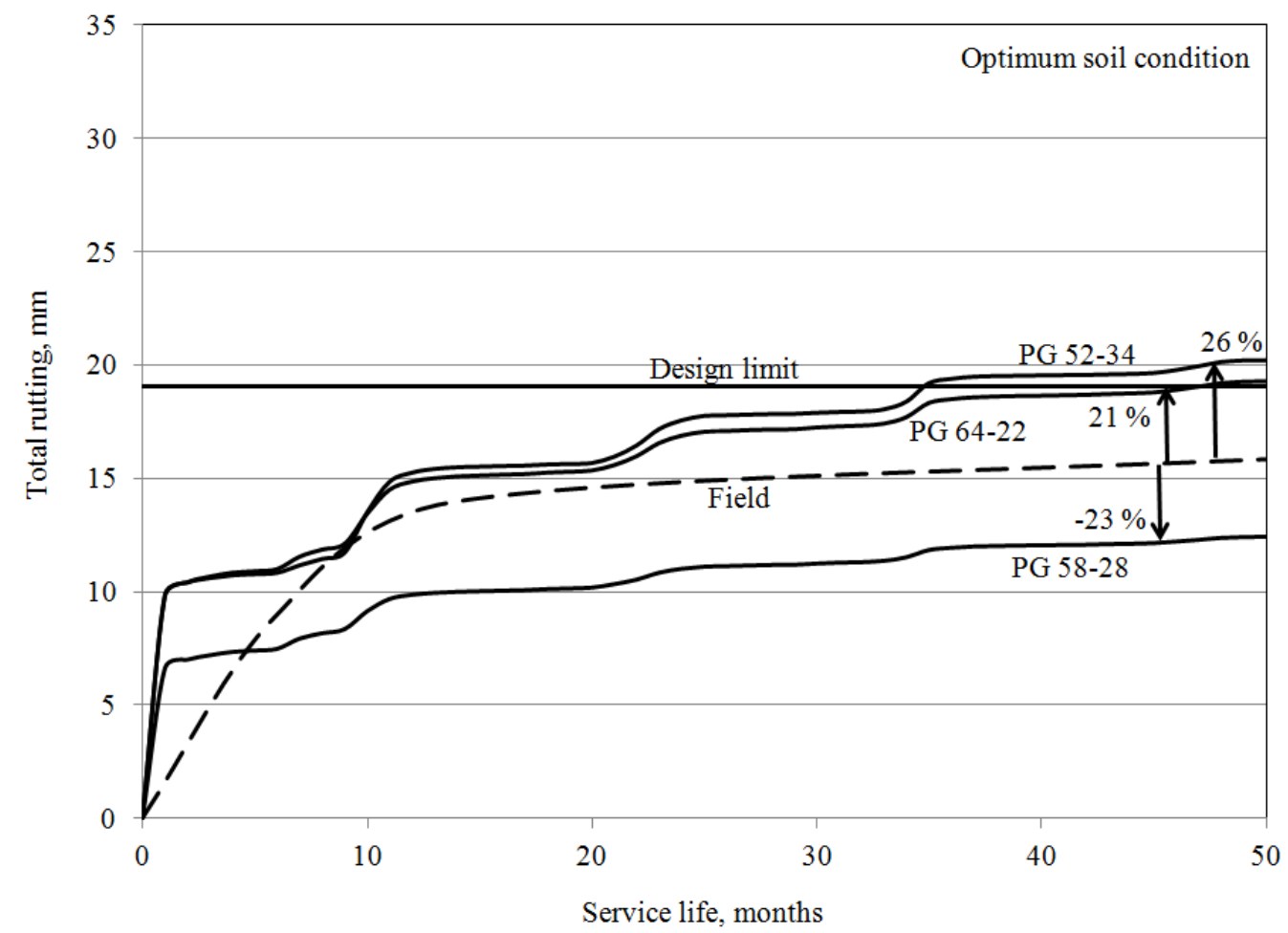

Figure 7.52: Comparison between field and M-EPDG total rutting - site 1 


\subsubsection{Site 2}

The M-EPDG predicted performance based on asphalt concrete rutting throughout the 20 year design life as shown in Figure 7.53. The effects of the soil condition on all binders in site 2 field conditions were small. Predicted rutting performance once again is in agreement with the laboratory results (see Figure 5.4) of dynamic modulus, which indicated that PG 58-28 produced stiffer mixes than PG 52-34 and PG 64- 22.

Figure 7.54 shows the M-EPDG predicted performance for asphalt concrete rutting at the optimum soil condition. The asphalt concrete rutting of the soft binders PG 52-34 and PG 64-22 was higher than that for the stiff binder PG 58-28 by about 155 and $170 \%$ respectively.

All the binders satisfied the design limit involving a maximum tolerance of 6.5 mm rutting.

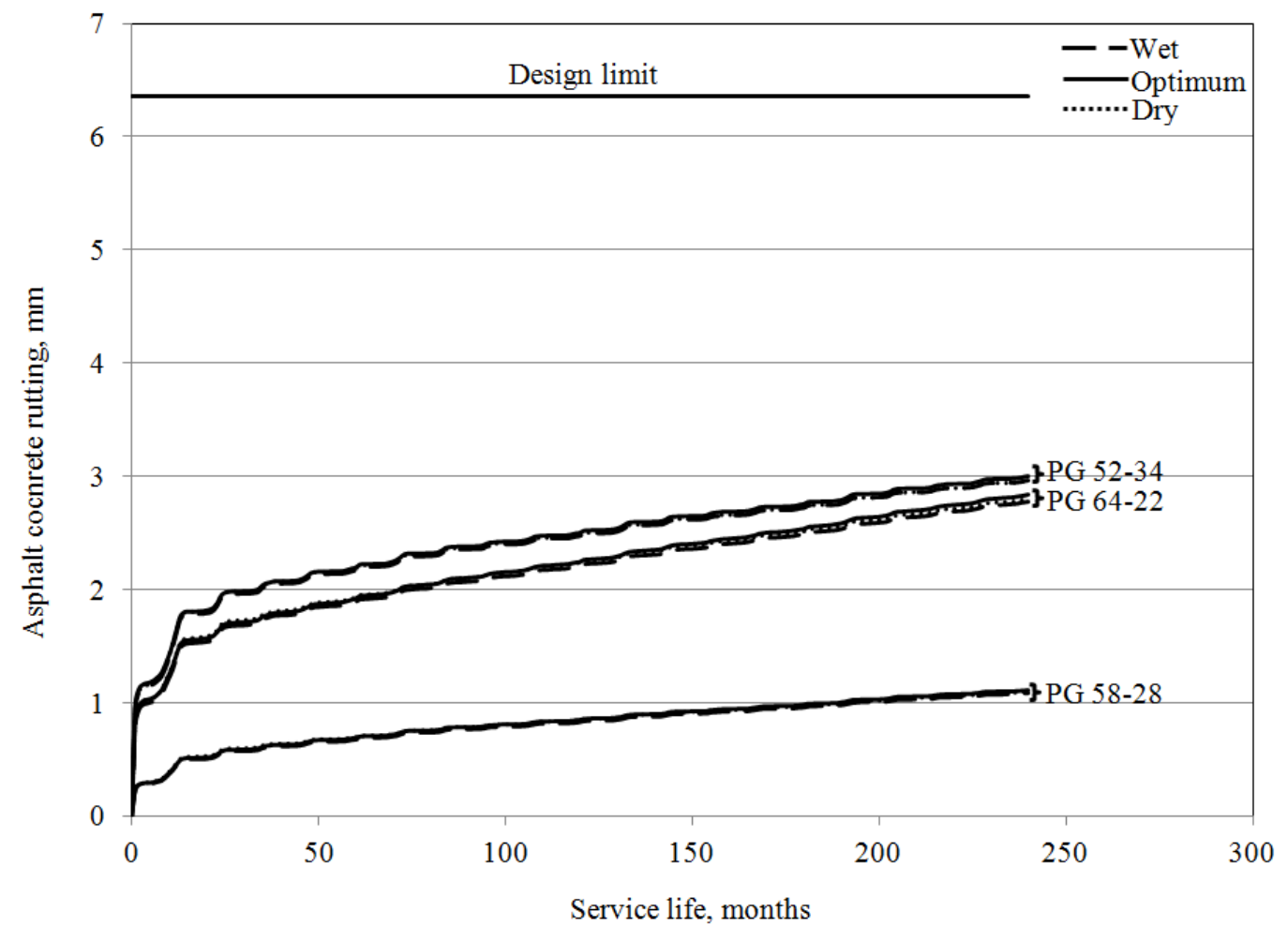

Figure 7.53: Asphalt concrete rutting - Site 2 


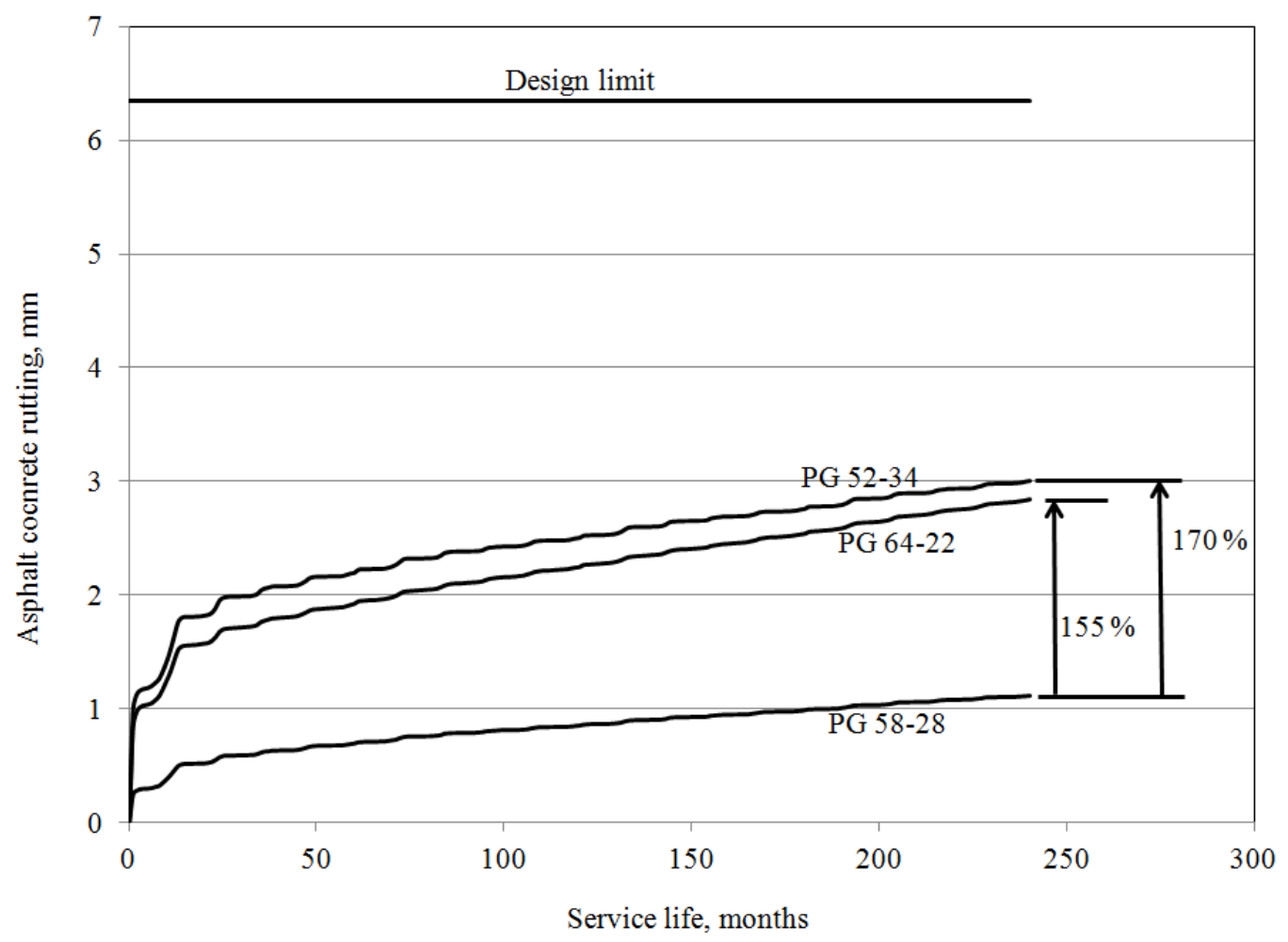

Figure 7.54: Asphalt concrete rutting at optimum soil condition - Site 2

Regardless of the binder grade used, the total rutting trends for the wet and dry condition showed an increase of about 7 and $15 \%$ respectively compared to the total rutting at the optimum soil condition as illustrated in Figure 7.55. However, Figure 7.56 shows the total rutting values at the optimum soil condition of the soft binders PG 52-34 and PG 64-22 are higher than the stiff binder PG 58-28 by about 29 to $31 \%$. 


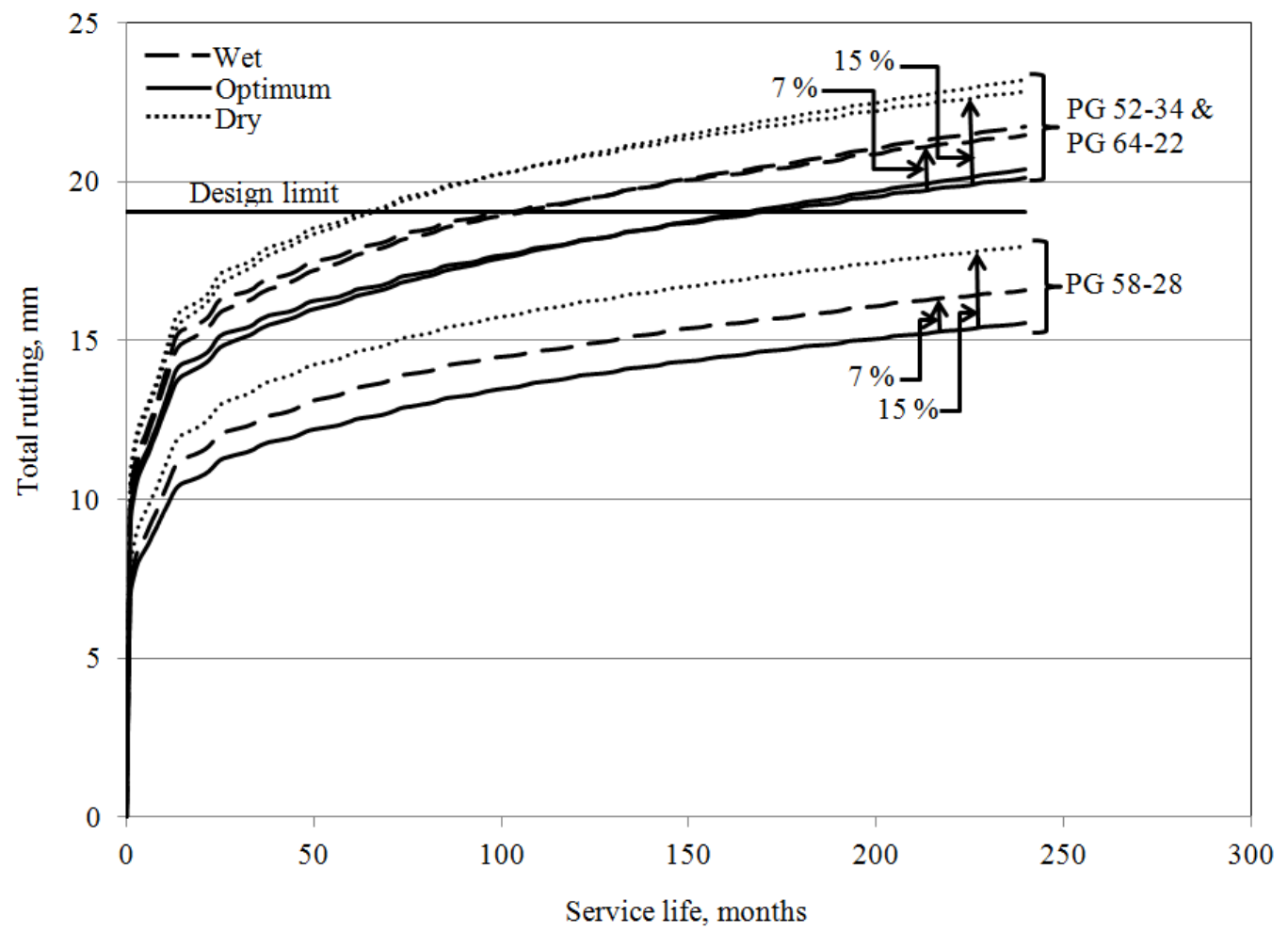

Figure 7.55: Total rutting - Site 2

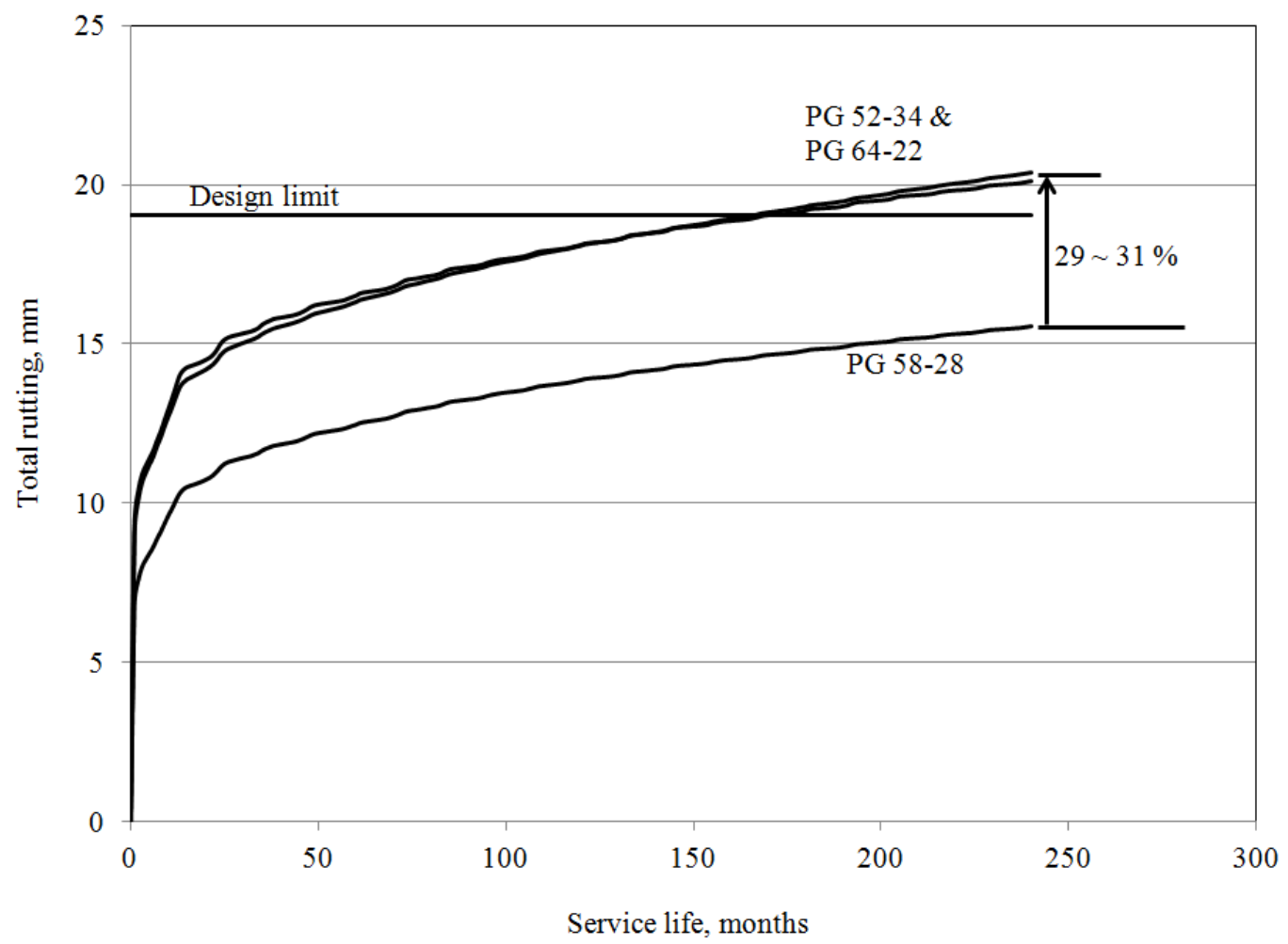

Figure 7.56: Total rutting at the optimum soil condition - Site 2 
Further analysis of the data in Figures 7.56 reveals that the results of using binder PG 58-28 as a substitute for the intended binder (PG 64-22) at site 2 satisfied the design limit or maximum tolerance of total rutting. The design life of the site 2 road based on MEPDG performance using the intended PG 64-22 binder resulted in a reduction to the 20 years design life by 14, 12 and 6 years in the case of dry, wet and optimum soil conditions respectively (see Figure 7.57).

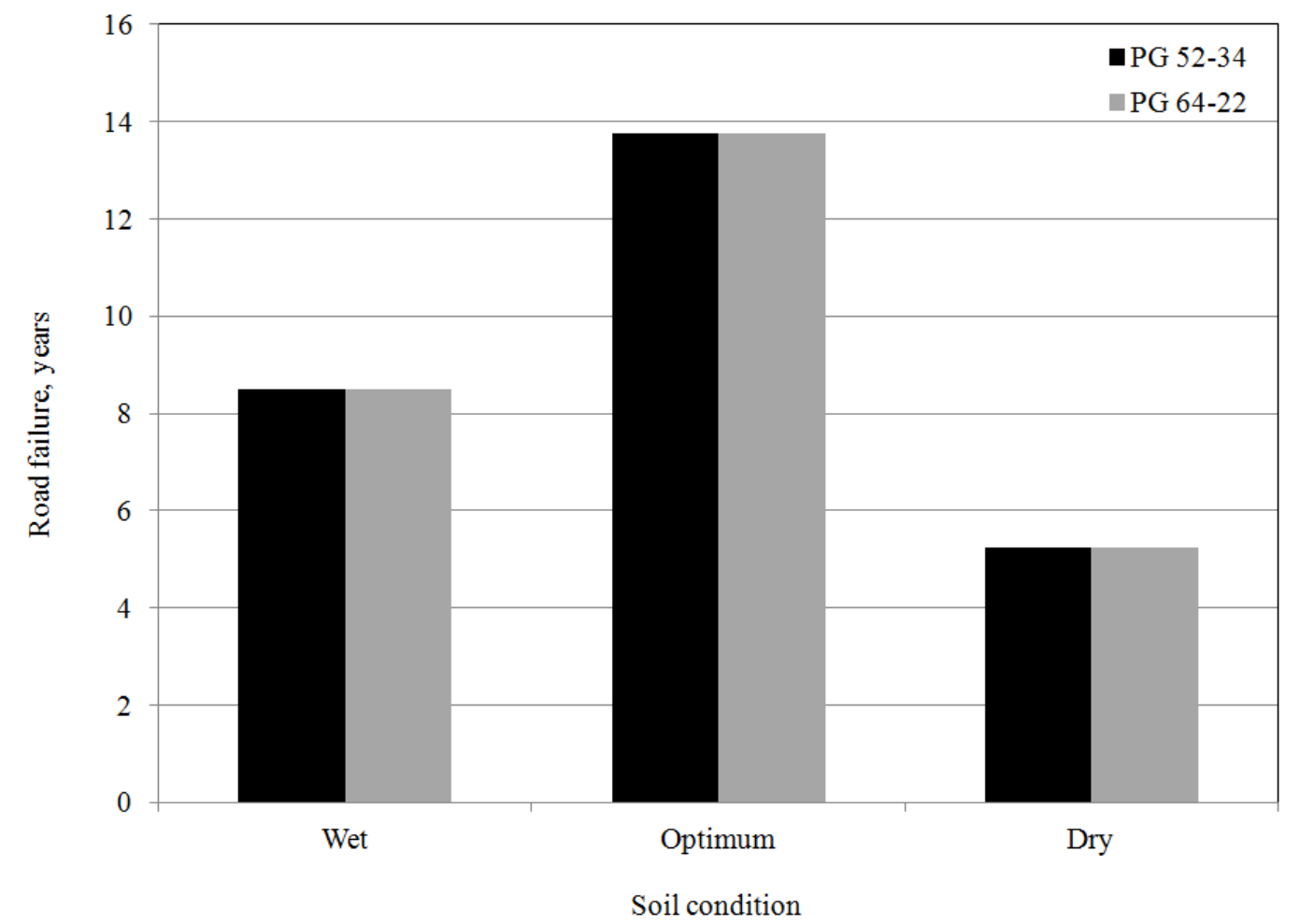

Figure 7.57: Effect of total rutting on road service life - Site 2

The M-EPDG rutting performance predictions at the optimum soil condition are selected for comparison with field measured rutting for both asphalt and total road structure layers.

Figures 7.58 and 7.59, show the M-EPDG predicted performance rutting (asphalt concrete and total) using the three different binders compared with actual field rutting (asphalt concrete and total) measurements. Comparing the field trend to other predicted 
trends it was noted that the highest rate of deformation occurred within the first 18 months followed by smaller rate for the rest of design life, whereas the M-EPDG predicted trends showing a high rate of rutting occurring within the first months due to densification after construction (first stage) followed by the last two permanent deformation stages (secondary and tertiary).

The magnitude of permanent deformations shown in Figures 7.58 and 7.59 are reflective of the sensitivity of the model to variations in the dynamic modulus of the mix (different binders). Permanent deformation varied considerably depending on the binder type used.

The calculated difference with respect to the field asphalt concrete rutting ranged from $52 \%$ lower than the field binder using PG $64-22$ and lower by 45 and $83 \%$ for binders PG 52-34 and PG 58-28 respectively as shown in Figure 7.58.

Using total rutting as a key performance measure to evaluate the sensitivity of the M-EPDG predicted total rutting performance shown in Figure 7.59 revealed that the MEPDG predicted performance total rutting using PG 64-22 and PG 52-34 resulted in a 32 and $34 \%$ overestimation respectively compared to the field rutting measurements. The M-EPDG model predicted performance using PG 58-28 as identical to the field rutting measurements.

The M-EPDG model results disagree with the design objectives intended by the producer of the binder and the municipality of site 2 , where high stability at relatively high temperature resistance offers adequate resistance to permanent deformations confirmed by laboratory results from this study. The mix with the PG 58-28 binder decreased substantially the accumulation of permanent deformation in the course of the 
20-year design life and satisfied the design limit involving a maximum tolerance of 19 $\mathrm{mm}$ rutting. Whereas the intended binder for this site, PG 64-22, showed accumulation of more the design limit after 14 years as shown in Figure 7.57.

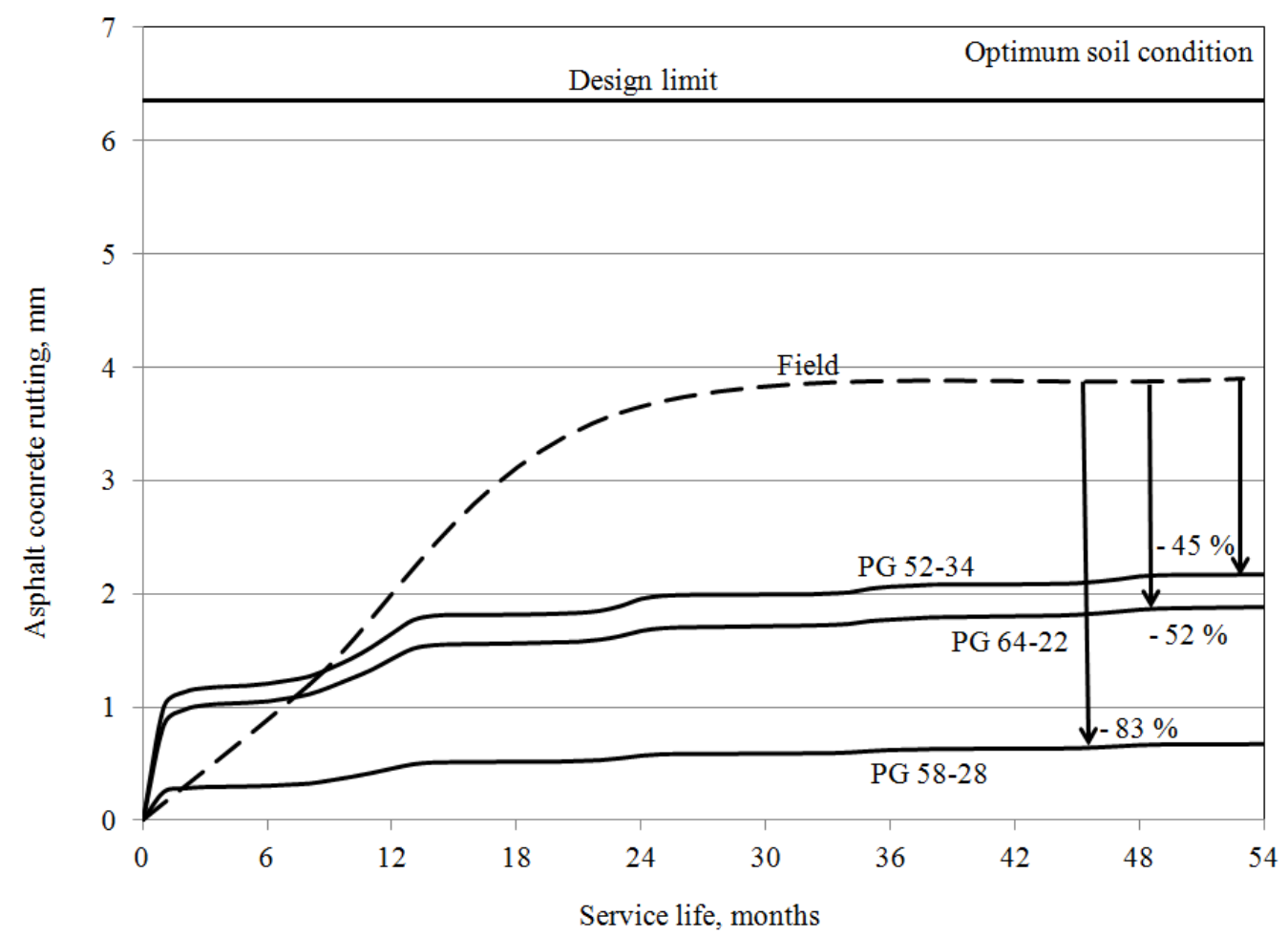

Figure 7.58: Comparison between field and M-EPDG asphalt concrete rutting - Site 2 


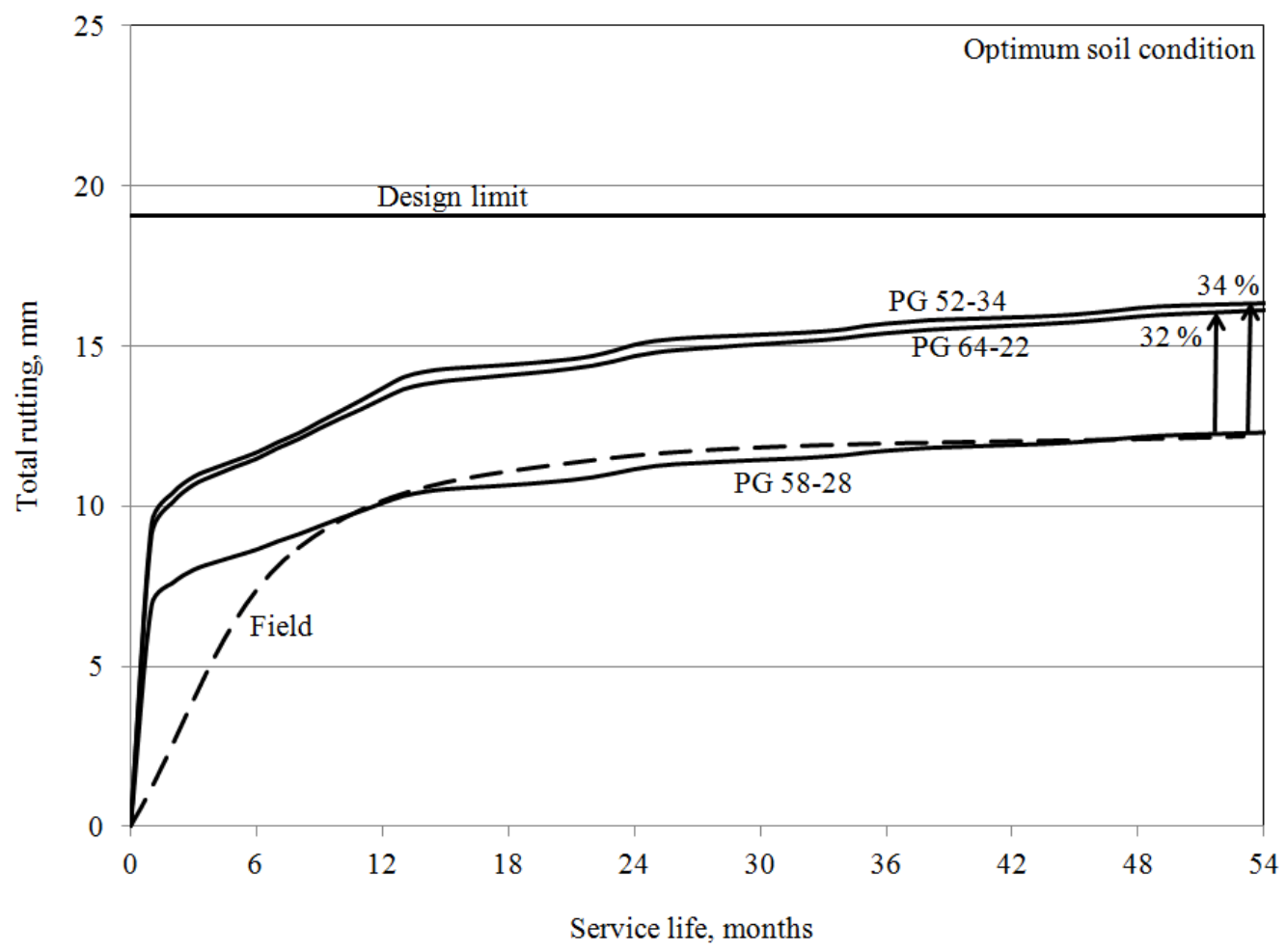

Figure 7.59: Comparison between field and M-EPDG total rutting - Site 2

\subsection{5 $\quad$ Site 3}

The M-EPDG model predicted performance asphalt concrete rutting throughout the 20 year design life is shown in Figure 7.60. The rutting trends for optimum and wet soil condition are almost identical in the case of binders PG 52-34 and PG 58-28, whereas about $7 \%$ deviating from optimum to wet occurred in case of PG 64-22. The M-EPDG model predicted performance asphalt concrete rutting increases by about 15, 24 and $22 \%$ from optimum to dry soil condition for PG 52-34, PG 58-28 and PG 64-22 respectively. Predicted rutting performance once again was in agreement with the laboratory results (see Figure 5.4) of dynamic modulus, which indicated that PG 58-28 produced stiffer mixes than PG 52-34 and PG 64-22.

Figure 7.61 shows M-EPDG predicted performance of asphalt concrete rutting at the optimum soil condition. The asphalt concrete rutting of the soft binders PG 52-34 and 
PG 64-22 was much higher than the stiff binder PG 58-28 by about 229 and $267 \%$ respectively. PG 58-28 was the only binder that satisfied the design limits involving a maximum tolerance of $6.5 \mathrm{~mm}$ rutting.

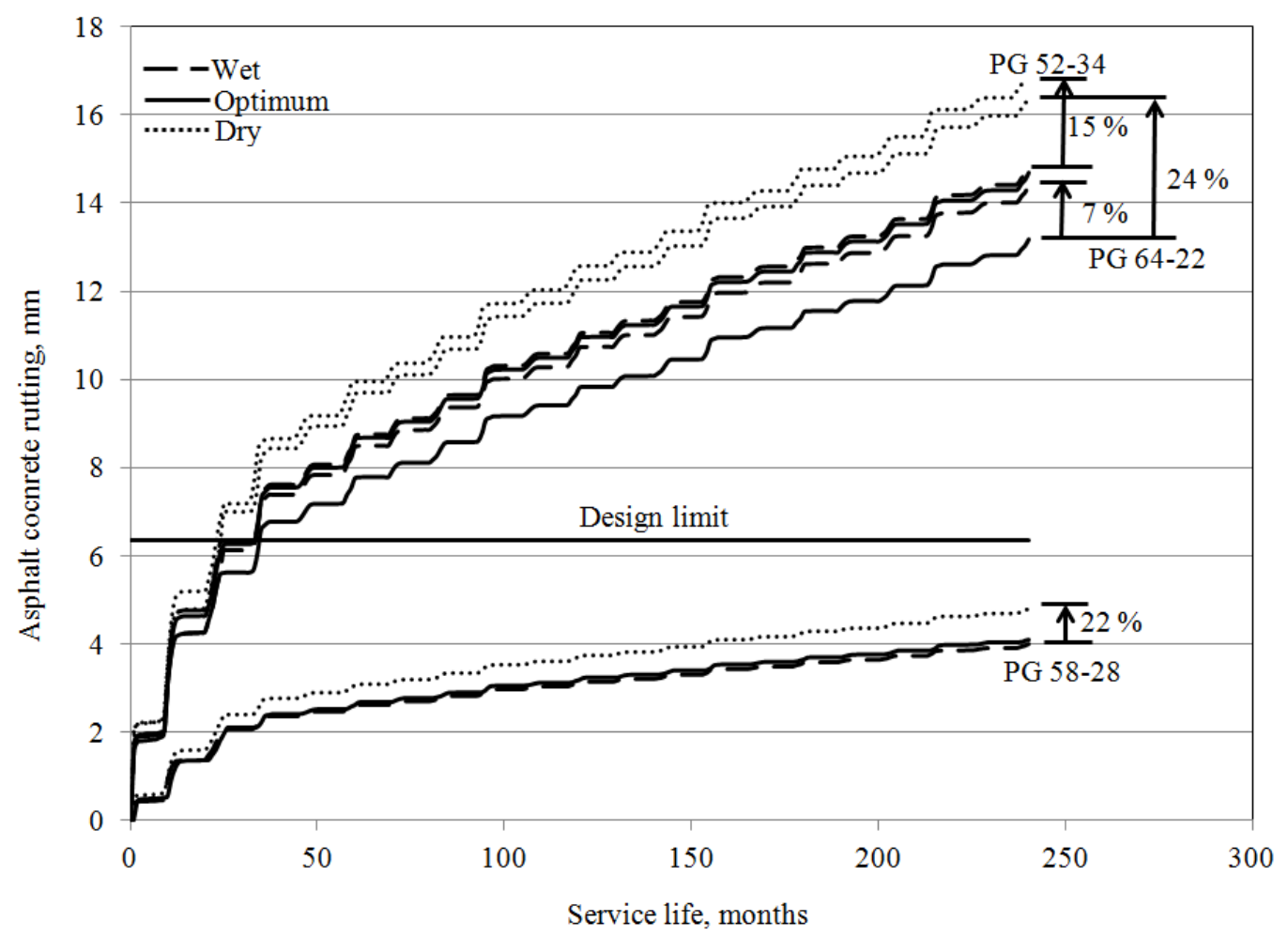

Figure 7.60: Asphalt concrete rutting - Site 3 


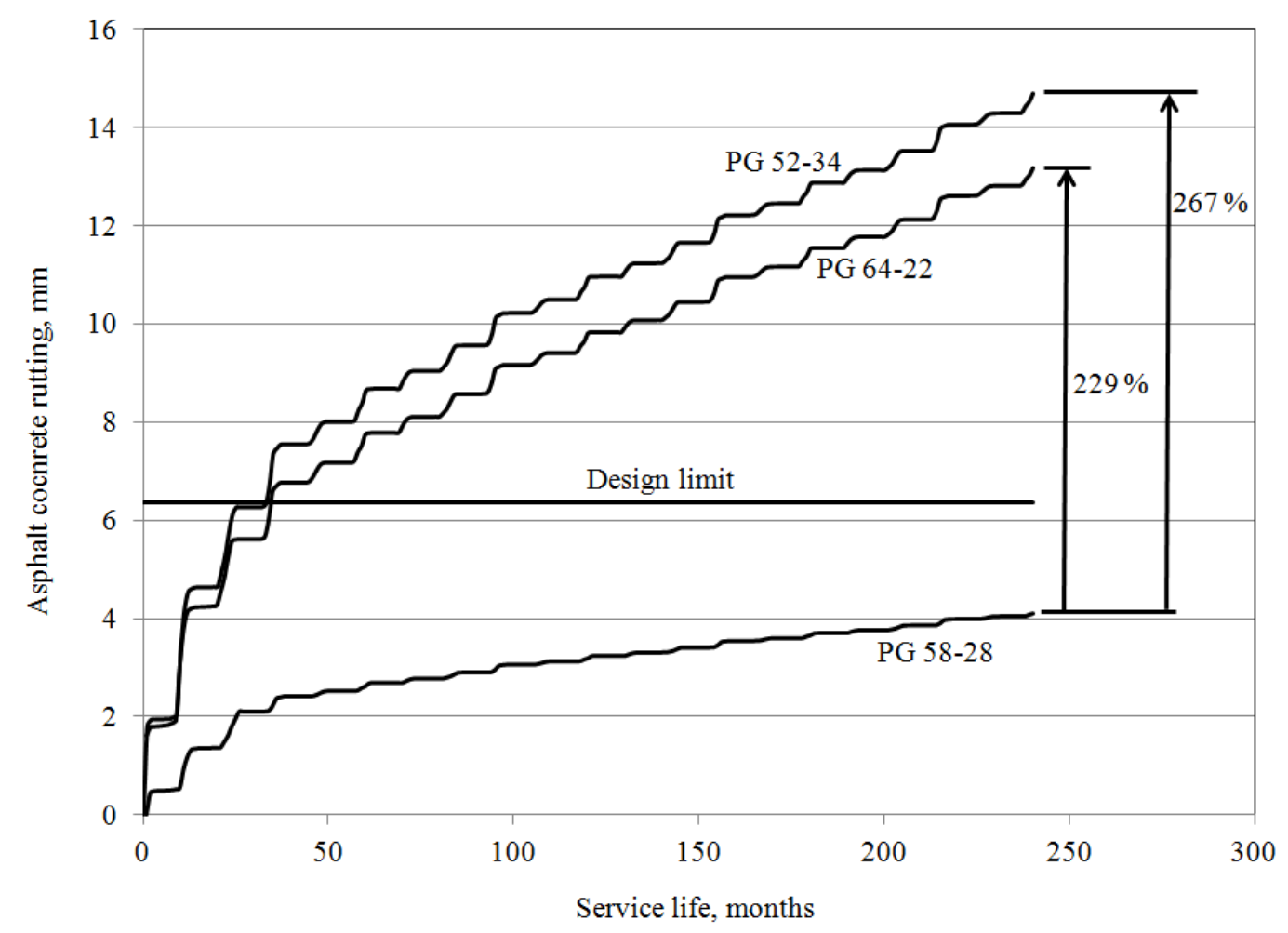

Figure 7.61: Asphalt concrete rutting at optimum - Site 3

Regardless of the binder grade used, the total rutting trends of the dry soil condition showed lower total rutting. The M-EPDG predicted performance of total rutting using PG 58-28 binder at the optimum and wet soil conditions showed increases of about 19 and $67 \%$ compared to dry soil condition. When the PG 64-22 binder was used for the optimum and the wet soil condition, there was an increase about 14 and $56 \%$ compared to dry condition. Similarly, PG 52-34 showed an increase about 16 and $56 \%$ as shown in Figure 7.62. Further analysis of the results revealed that the wet soil condition had a significant impact on the M-EPDG performance due to the type of the unbound soil materials. The wet soil conditions measured in the field was in the range of 3 to $22 \%$ (see Figures 4.5 and 4.6) and the moisture content at wet soil condition was $13.9 \%$. However, Figure 7.63 shows the total rutting at optimum soil condition of the soft binders 
PG 52-34 and PG 64-22 was higher than the stiff binder PG 58-28 in the range of 35 to $38 \%$ respectively.

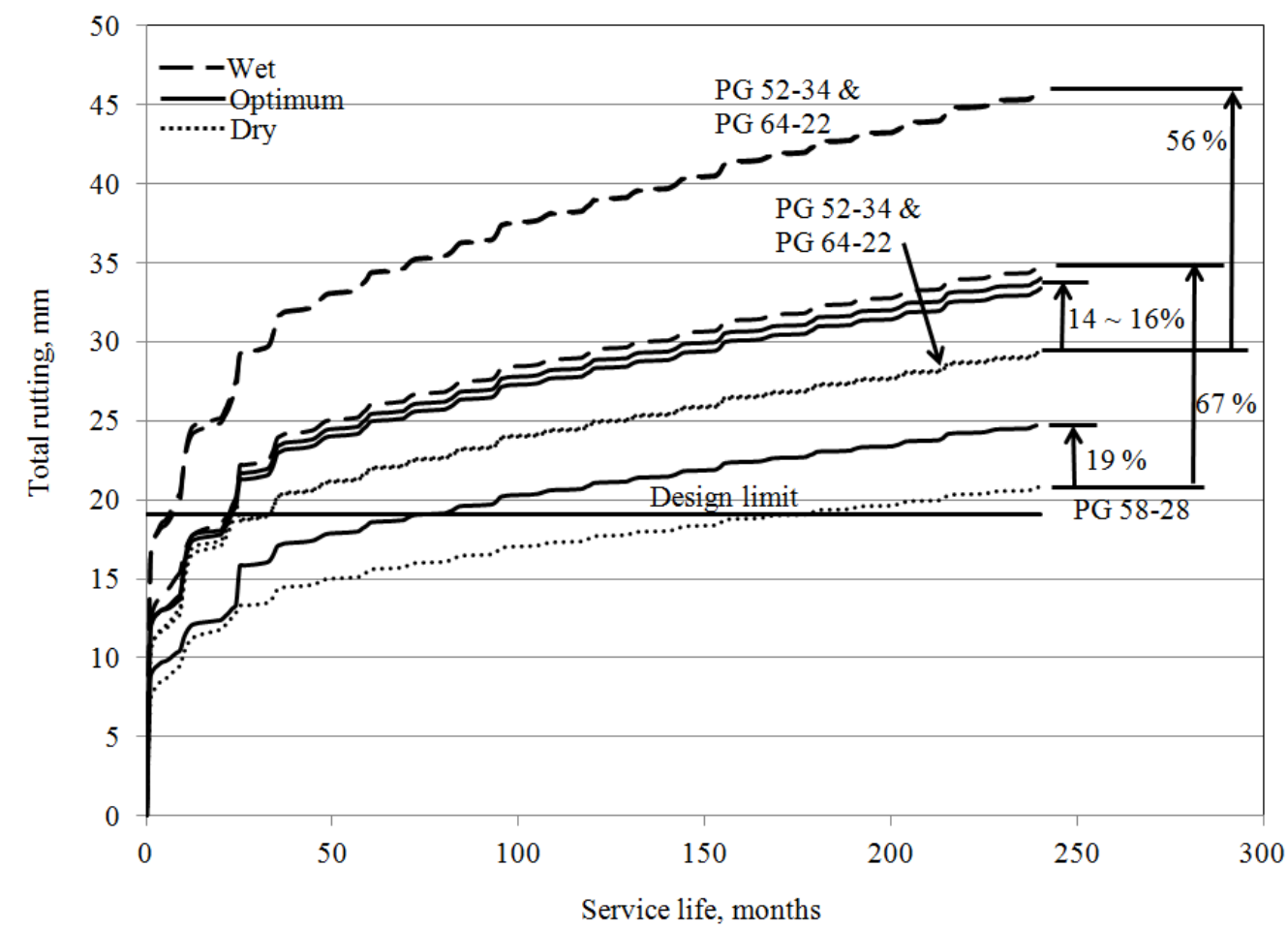

Figure 7.62: Total rutting - Site 3

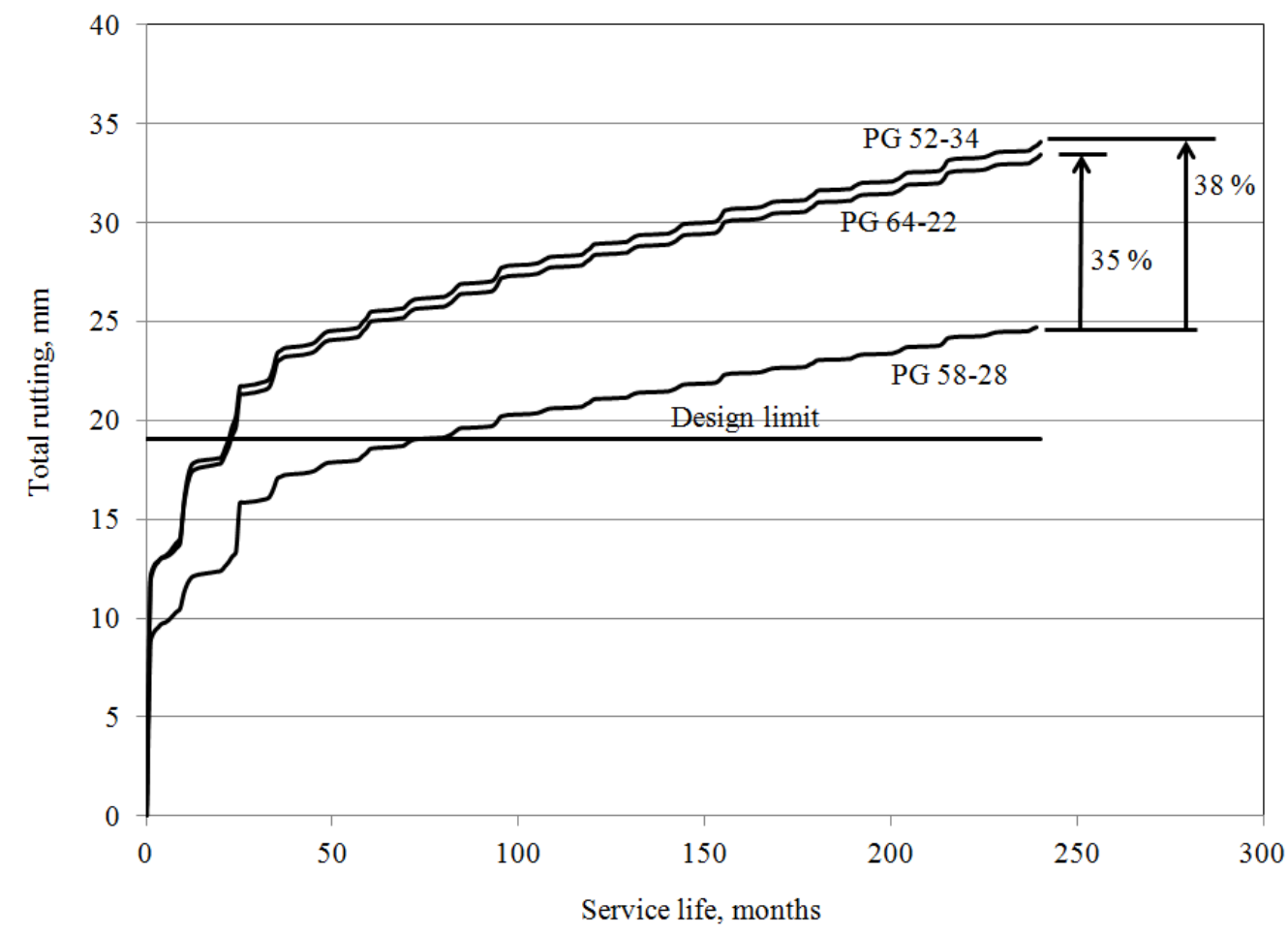

Figure 7.63: Total rutting at optimum soil condition - Site 3 
Figure 7.64 shows the service life of the road based on the M-EPDG model predicted performance of asphalt concrete rutting illustrated previously in Figure 7.60. Results showed that the intended binder PG 64-22 on site 3 is identical to PG 52-34 and both did not satisfy the design limit involving a maximum tolerance of M-EPDG model asphalt concrete rutting $(6.5 \mathrm{~mm})$. However, binder PG $58-28$ as a substitute of intended binder (PG 64-22) on site 3 satisfied the design limit involving a maximum tolerance of asphalt concrete rutting performance. The design life of the site 3 road based on MEPDG model performance using the intended PG 64-22 resulted in a reduction to the 20 years design life by 17 to 18 years regardless of the soil condition status.

Further analysis of the data in Figures 7.62 revealed that the results of using the three different binders did not satisfy the design limit involving a maximum tolerance of M-EPDG model total rutting key performance $(19 \mathrm{~mm})$. This study showed that the key performance indicator to determine the road design life is the total rutting. Using asphalt concrete rutting performance might fail to assess the quality of the road structure layers in use (see Figure 7.60). The design life of the site 3 road based on M-EPDG model total rutting performance using the intended PG 64-22 resulted in a reduction of the 20 years design life by 19, 18 and 17 years in case of wet, optimum and dry soil conditions respectively as shown in Figure 7.65. Using PG 58-28 showed better resistance to rutting and increased the design life of site 3 and the reduction of the 20 years design life is 18 , 14 and 5 years in the case of wet, optimum and dry soil conditions respectively. 


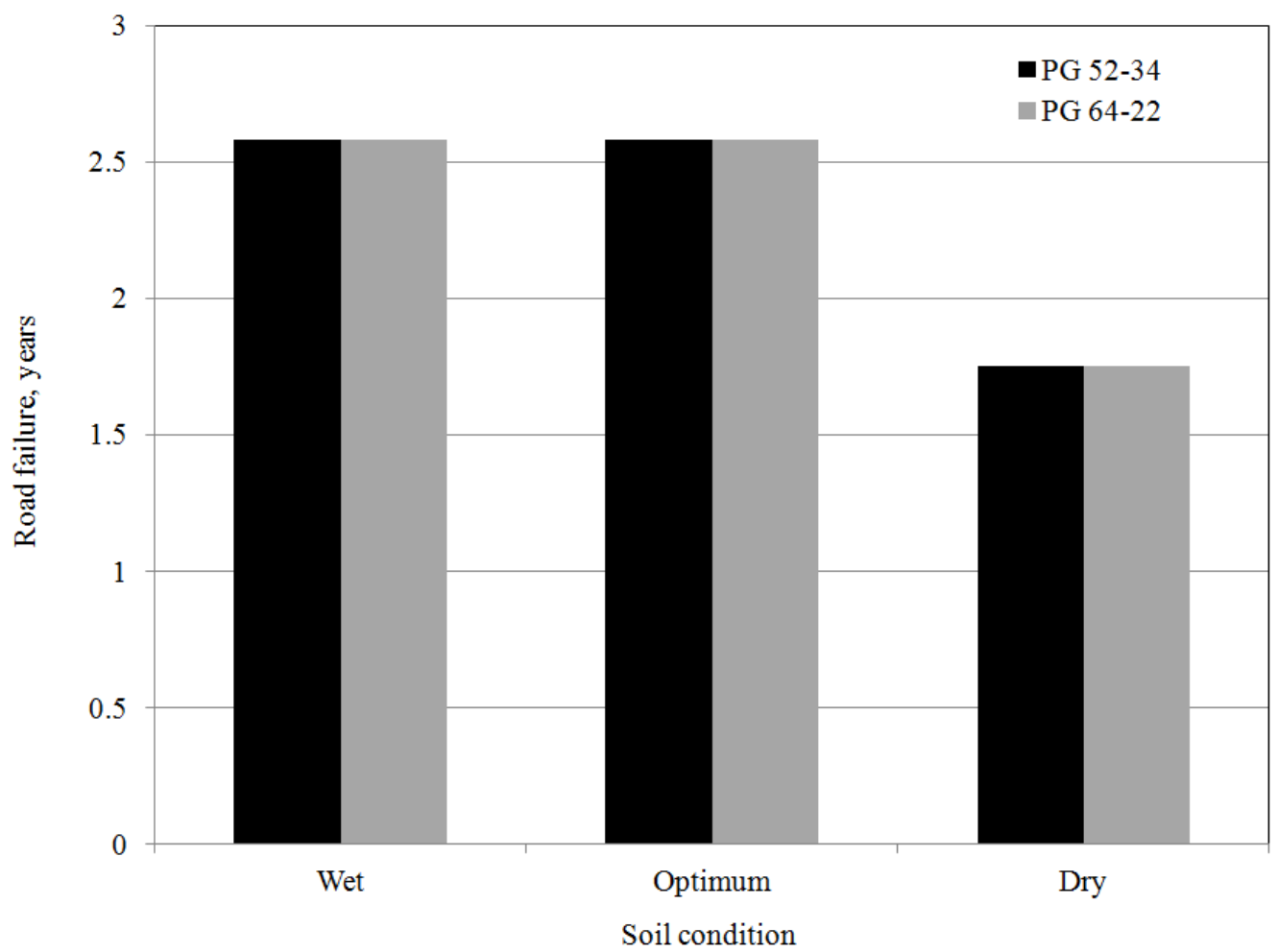

Figure 7.64: Effect of asphalt rutting on road service life - Site 3

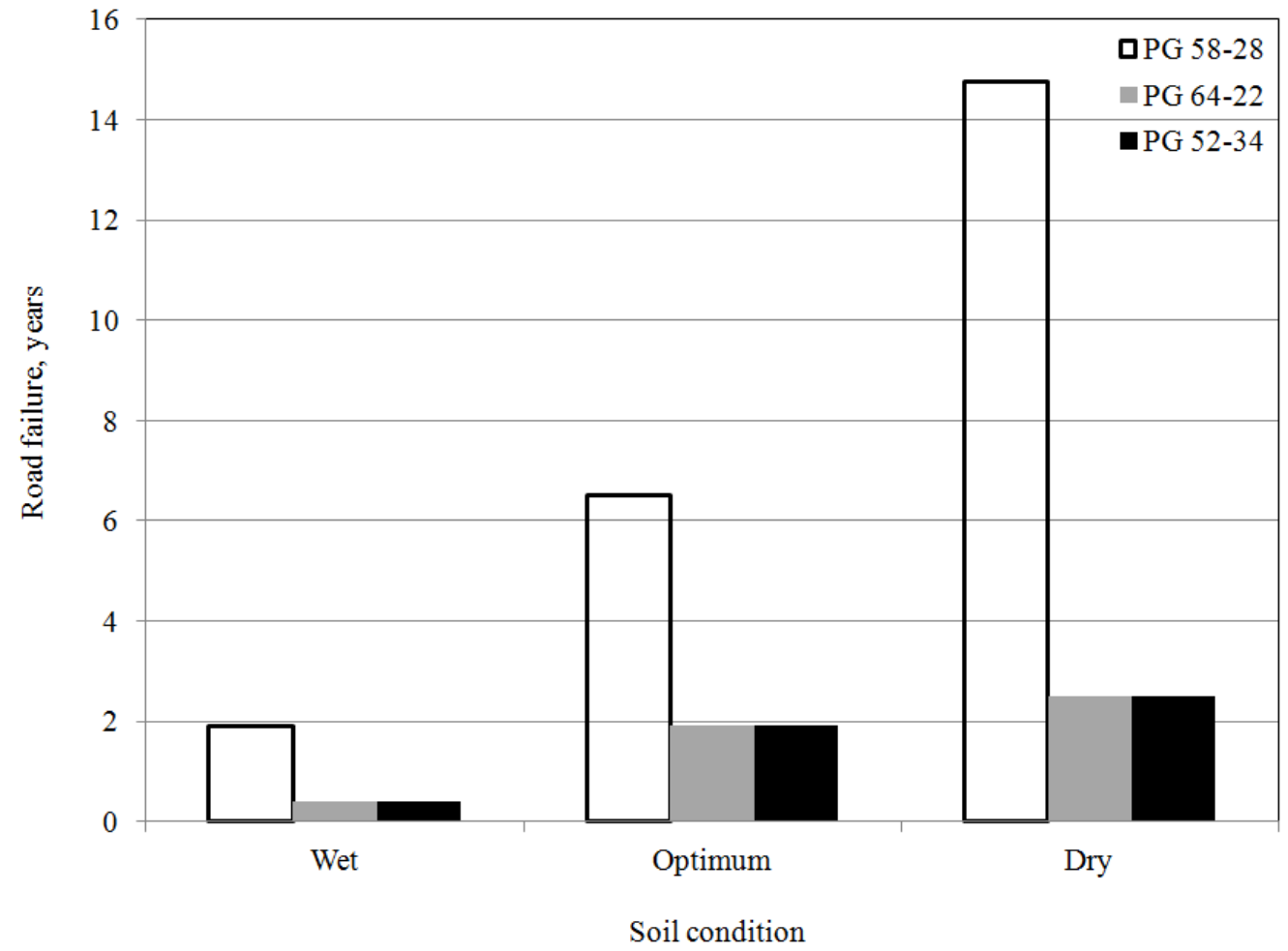

Figure 7.65: Effect of total rutting on road service life - Site 3 
Figures 7.66 and 7.67 show the M-EPDG model predicted performance rutting (asphalt concrete and total) using the three different binders compared with actual field rutting (asphalt concrete and total) measurements. In comparing the field trend to other predicted trends, it is noted that once again the highest rate of deformation occurred within the first 12 months followed by a lower rate for the rest of design life. The MEPDG model predicted trends (cold region area) showing that $30 \%$ of the asphalt rutting happened within the first months due to densification after construction (first stage) densification reaches the initial limit stage (plateau) from 1 to 8 months followed by the last two permanent deformation stages (secondary and tertiary).

Once again at site 3, the magnitude of permanent deformations shown in Figures 7.66 and 7.67 is reflective of the sensitivity of the model to variations in the dynamic modulus of the mix (different binders). Permanent deformation varied considerably depending on the binder type used.

The calculated difference with respect to the field asphalt concrete rutting ranged from $5 \%$ lower than the intended field binder use of PG 64-22 and higher than by 4 and lower than $67 \%$ for binders PG 52-34 and PG 58-28 respectively as shown in Figure 7.66.

Using total rutting as a key performance measure to evaluate the sensitivity of the M-EPDG predicted total rutting performance shown in Figure 7.67 revealed that the MEPDG predicted performance of total rutting using PG 64-22 and PG 52-34 resulted in 18 and $21 \%$ overestimation respectively compared to the field rutting measurements. Whereas M-EPDG predicted performance using PG 58-28 was underestimated by about $20 \%$. 
The M-EPDG results showed good sensitivity compared to the field with the design objectives intended by the producer of the binder and the municipality of site 3 using PG 64-22. The mix with the PG 58-28 binder decreased substantially the accumulation of permanent deformation compared to other binders but the results exceed the design limit involving a maximum tolerance of $19 \mathrm{~mm}$ rutting after 15 years of service whereas the intended binder for this site PG 64-22 showed accumulation of more than the design limit after 3 years as shown in Figure 7.65.

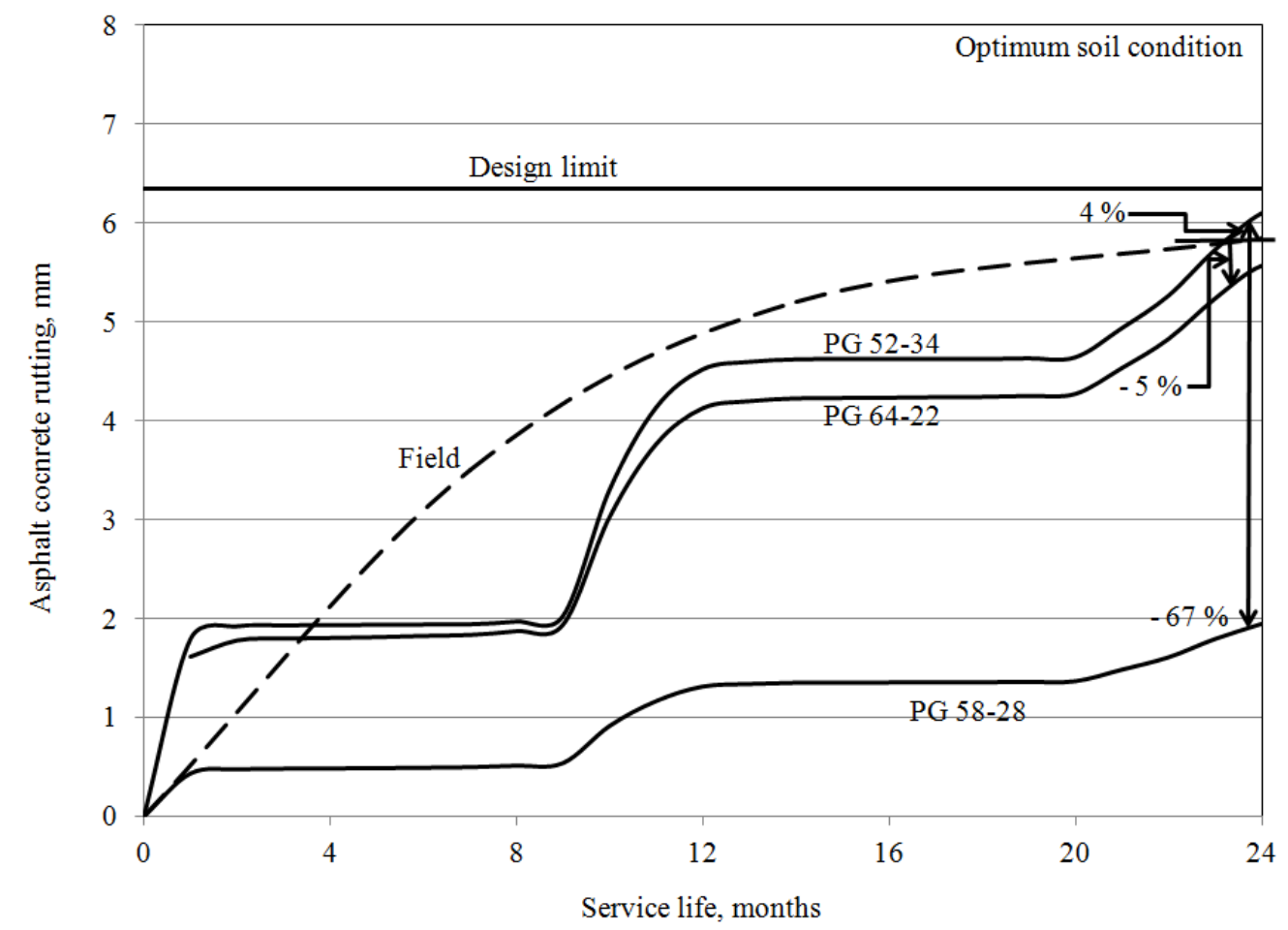

Figure 7.66: Comparison between field and M-EPDG asphalt concrete rutting - Site 3 


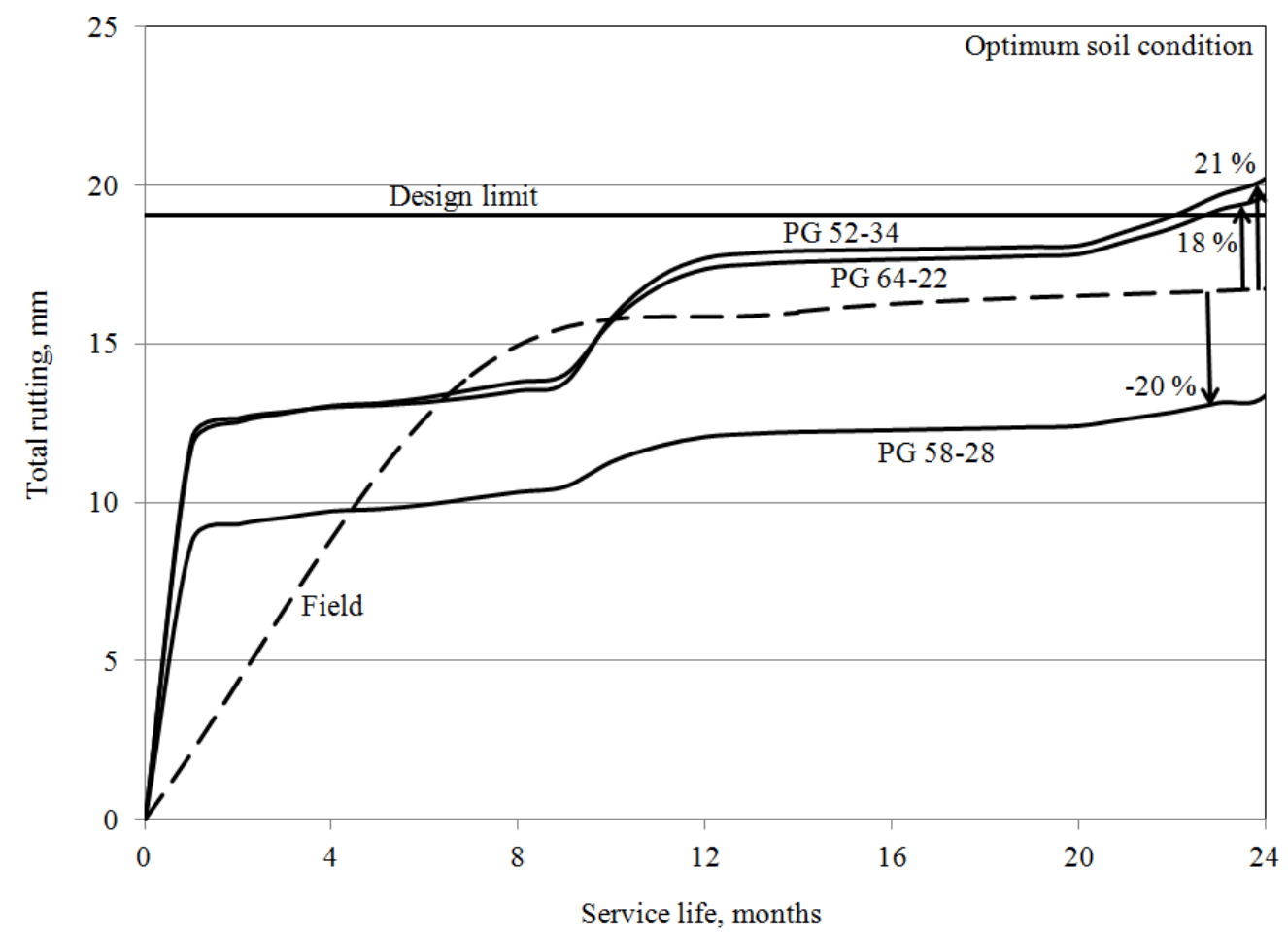

Figure 7.67: Comparison between field and M-EPDG total rutting - Site 3

In summary, the model reflected excellent sensitivity to all the M-EPDG model input files at the different levels with the exception of the thermal cracking model which was non-functional. The sensitivity analysis conducted in this study covered parameters that directly or indirectly influence the material response. These parameters included traffic, different binders, site location and seasonal changes in moisture and temperature.

The M-EPDG model predicted rutting performances reflected sufficient sensitivity compared to the field measurements at the three different sites. The results of the M-EPDG predicted performance model are sensitive enough to site location, bound and unbound materials as well as the trends between model prediction and actual field results. Model predictions and field results are very close, the deviations are within the margin of error, and are caused by unbound material characterization based on the resilient modulus approach, which was implemented in the proposed guide that was 
examined in this study. In the absence of a working module that captures the nonlinear behaviour of the material (currently being redeveloped), only input Levels 2 and 3 were used in this study. 


\section{SUMMARY, CONCLUSIONS AND RECOMMENDATIONS}

This chapter provides the summary of the literature review and provides conclusions and recommendations of this work.

\subsection{Literature review findings}

Based on the literature review of the flexible pavement design guides in this study, the following is the summary of the findings of the literature review of flexible pavement design guides:

\section{$\square \quad$ Empirical nature}

- The current structural design approach to flexible pavement is empirical and based on the results of a limited experimental study conducted more than fifty years ago. The experimental results of the previously discussed Illinois study were used to produce design equations for pavement structures to reflect the observed loss of serviceability to tested pavement thickness and traffic impact.

- Most of the current design methods focus on load repetitions (frequency) to account for the impact of traffic volume on performance. These equivalent load factors mask weight characteristics of different trucks. A simple load factor associated with the design truck does not cover the wide variation in factors such as number of axles and tire contact area.

\section{$\square \quad$ Environmental considerations}

- Temperature is a significant factor in influencing the performance of a pavement, especially in the case of asphalt concrete. The stiffness of AC is less at higher temperature making it susceptible to deformations. Low temperatures make the $\mathrm{AC}$ layer extremely brittle and the surface becomes susceptible to cracking. Additionally, the prevailing temperature condition is a significant factor that influences the rate of 
accumulation of damage in asphalt concrete pavements. However, none of the design standards have considered temperature as a design input.

- Moisture variation was discussed as influencing the resilient modulus. The current AASHTO design guide (1993) uses an equation to estimate the resilient modulus based on the relative damage corresponding to each season. It is noted that the AASHTO design guide (1993) relies on physical properties to characterize pavement structure materials except the native soil (sub grade soil).

\section{$\square \quad$ AASHO road test}

The AASHTO design equations were developed using the specific conditions of road tests. The limitations of these tests and equations can be attributed to:

- The duration of the accelerated test was only two years, rather than the specified expected in-service life of the designed pavement.

- The maximum load used was less than what is experienced in field conditions.

- The distributions of axle load and configuration were simple and did not represent the actual vehicles used today.

- The materials used and construction practice was limited to the 1950 standard.

- It was limited to one climatic condition only.

\section{Mechanistic Empirical design}

- The 2004 AASHTO design guide was aimed at bridging the limitations resulting from the absence of a link between the design and analysis tools and the material properties required for characterization.

- The design guide incorporated the Enhanced Integrated Climatic Model (EICM) to simulate changes in the behaviour and characteristics of pavement and sub-grade materials that concur with climatic conditions over the design period. 
- The continuous development of materials and demands of the road structure have far exceeded the capabilities of the empirical equations.

- The current AASHTO design practice does not accurately account for the speed of the passing traffic. Traffic volume and development of cities across North America resulted in slower traffic speed and stoppage during rush hours. These conditions resulted in high occurrence of rutting damage, more specific during periods of high temperature. This damage can also be the result of using inadequate mix design and roadway usages such as at intersections and bus stops, where greater rutting damage is observed compared to other parts of road structures.

\section{$\square \quad$ Premature failures}

Researchers in the last decade acknowledged premature failure even within a few months and in some cases soon after construction. They have attempted to understand the underlying causes of these failures.

\section{$\square \quad$ Gaps in knowledge}

The efforts of the past 50 years can be summarized as follows: there is a lack of knowledge on how to account for local conditions, materials, construction quality, traffic characteristics and the seasonal variations of moisture and temperature of road layers and their effect on road response.

\subsection{Conclusions:}

\section{Field and laboratory work}

The field and laboratory work that were carried out on the asphalt concrete and unbound materials demonstrated: 
$\square \quad$ The viability of an instrumentation system designed and installed to monitor the environmental and structural behaviour of pavement.

$\square \quad$ The value of a practical pavement instrumentation system that could be used as an effective tool for measuring the response of road layers to a host of applied environmental and traffic loadings.

$\square \quad$ The road authorities may design the pavement monitoring systems to address locally prevailing conditions and existing construction practices that influence the performance of their roads. The maximum load used was less than what is experienced in field conditions.

$\square \quad$ The effectiveness of the system relies on appropriateness of the system design, which includes a selection of hardware components (sensors and data loggers) and the development of effective computer programs that will accurately execute the pavement monitoring plan.

$\square \quad$ The instrumentation system described in this study was simple and may be replicated to produce the local data needed for calibrating critical components of the M-EPDG model and improve its sensitivity to adopted construction practice and in-situ conditions.

$\square \quad$ Positioning sensors in roadway structures is key in advancing knowledge and assisting in developing robust design methods of road structures. With these sensors located in the pavement structure, the road was smarter and provided excellent data, which lead to the development of an effective solution to the road design problem. 
- Data obtained from fieldwork (environmental and structural) in this study can be used to carry on the laboratory work as well to evaluate the M-EPDG predicted performance.

$\square \quad$ Freeze and thaw diagrams obtained using a resistivity probe and adopted thermocouple measurement have similar trends. This provides an opportunity to use practical and inexpensive thermocouple measurements to establish the freeze and thaw diagrams.

$\square \quad$ Permanent and dynamic structural behaviour was successfully monitored for all sites. The field results showed unprecedented high stress and strain levels caused by low asphalt stiffness when the road is opened to traffic while the asphalt mat temperature is above normal operating temperature.

$\square \quad$ The accumulation of excessive deformation during the low asphalt concrete stiffness state is associated with high temperature and can be prevented. Traffic-induced stresses transmitted to the backfill layers beneath the asphalt concrete are directly influenced by the asphalt concrete stiffness. High temperatures result in low asphalt concrete stiffness and hence, higher stresses are transmitted through the asphalt concrete layer to unbound materials of the road structure.

- The speed truck impact test at speeds of 0 (creep) and $25 \mathrm{~km} / \mathrm{h}$ resulted in a very high truck pressure impact. This confirmed that most of pavement performance problems occurred at locations with frequent bus stoppage and areas close to traffic signals. This finding highlighted the importance of traffic speed.

- The dynamic modulus, proposed to characterize asphalt concrete materials, differentiated between different binder performance grades. 
$\square \quad$ The dynamic modulus of the asphalt concretes using the binder PG 58-28 is stiffer than that prepared using the binder PG 52-34. This validates the intended use of PG 58-28 to minimize rutting and PG 52-34 to minimize thermal cracking but does not support the intended use of PG 64-22.

$\square \quad$ The resilient modulus, proposed to characterize unbound materials, is sensitive to the moisture state.

\section{Thickness design of flexible pavement}

The thickness of individual layers at the three sites was determined by means of a layer analysis concept (1993 AASHTO design guide) and compared with the as built plans. It can be concluded that:

$\square \quad$ The initial structural design based on the initial traffic loading is insufficient to withstand the imposed traffic load for a long period as traffic volume increases over the years.

$\square \quad$ The results yielded comparable values for the thickness of the asphalt concrete layers for sites 2 and 3 whereas site 1 constructed asphalt concrete thickness was underestimated by $11 \%$.

$\square \quad$ For base course, sites 1 and 2 were over-constructed and site 3 was underconstructed.

$\square \quad$ For sub-base material layers, the three sites were over-constructed.

\section{Evaluation of the M-EPDG}

\section{$\square \quad$ Sensitivity analysis:}

- The results of the M-EPDG model reflect the differences in material properties. 
- Current evaluation showed that the thickness of different sub-layers has an upper limit:

- The thickness of base and sub-base unbound materials should be not more than 38 in.

- Thickness of sub-grade should be not more than 51 in.

- The thickness limitations included in the M-EPDG does not affect the performance, even when a thick layer is replaced with two layers of the same material.

- The M-EPDG model is sensitive to climatic zones. Rutting and longitudinal cracking performance predictions for the warm region are about 51 and $22 \%$ higher than those for the cold region respectively.

- The M-EPDG model promoted use of enhanced material characterization.

- The M-EPDG model is sensitive to the binder type. The softer binder (PG 52-34) experienced a $167 \%$ increase in asphalt concrete rutting compared to the stiffer binder (PG 58-28). This confirms that the stiffer binder is more suitable to minimize rutting of asphalt concrete layers. Rutting performance results using PG 64-22 showed an increase of about $132 \%$ compared to the stiff binder PG 58-28. This contradicts the purpose of using a high temperature asphalt grade for performance, and this finding is in good agreement with measured dynamic modulus.

- The stiffer asphalt concrete layer induces less stress to the unbound layers and consequently produces a lower level of settlement.

- The rate of rutting of asphalt concrete is much higher than the rate of unbound settlement. 
- The type of asphalt grade affects the asphalt concrete rutting and total rutting.

- The softer binder PG 52-34 increases longitudinal and alligator cracking. The stiffer binder PG 58-28 decreases longitudinal and alligator cracking. The rate of predicted alligator cracks is very high in the case of softer binders.

- A dry soil condition has a tendency to produce more longitudinal cracks than optimum and wet soil conditions.

- The moisture condition of the unbound material does not have significant effect on asphalt concrete rutting and total rutting.

- The resilient modulus of the soil has a significant impact on the asphalt concrete rutting. A low unbound resilient modulus produces low rutting and high unbound settlement.

- All M-EPDG model predicted performances decrease with increasing the speed. Two speed effect categories were identified in this study: below and above $35 \mathrm{~km} / \mathrm{h}$. The lower category is considered the most critical in terms of the amount of damage that can be caused.

- The M-EPDG model predicted performances at the creep state $(0 \mathrm{~km} / \mathrm{h})$ do not work. It was found that the minium accepted speed effect by M-EPDG is $3 \mathrm{~km} / \mathrm{h}$.

- All the M-EPDG predicted performances increase with increasing traffic capacity. Increases in traffic capacity have a significant impact on asphalt concrete rutting and alligator cracking.

- The M-EPDG model predicted performances for asphalt concrete and total rutting increase with increasing tire pressure. The increase is more significant for asphalt 
concrete. The same increase in the tire pressure had a relatively small influence on the longitudinal and alligator cracking. These are both considered very low compared to the M-EPDG model design limit.

- A relationship was established based on the results of the M-EPDG predicted performances of the effect of tire pressure and asphalt concrete rutting and longitudinal cracking at AADT 1000.

- In this study, asphalt concrete rutting, total rutting, longitudinal and alligator cracking and key pavement management performances were established with traffic volumes for the stiff binder PG 58-28. Using established relationships, the impact of unexpected AADT beyond the limit of the road design life can be determined and used to assist engineers and road practitioners in determining the end of service life at which point rehabilitation or reconstruction is required.

$\square \quad$ Field evaluation

- Laboratory results in this study are in good agreement with the M-EPDG model rutting and total rutting key performances and with the design objectives intended by the producer of the binder and the municipality of site 1 city (PG 58-28). They are in disagreement with sites 2 and 3 cities and municipalities with the use of PG 64-22, where high stability at relatively high temperatures offers adequate resistance to permanent deformations.

- The design life of the site 1 based on M-EPDG model performance and field data are within the 20 years design life asphalt concrete rutting and total rutting limit. Site 2 design life was determined to be 6,8 and 14 years for dry, wet and optimum soil 
conditions respectively. However site 3 had an accumulation greater than the design limit after 3 years of operation.

- It is strongly suggested that PG 58-28 binder in a hot and cold area replaces the one in use (PG 64-22) due to decreasing substantially the permanent deformation. This recommendation is based on laboratory work and fieldwork as well as M-EPDG model predicted performance.

- The predicted M-EPDG model rutting performances reflected sufficient sensitivity compared to the field measurements at the three different sites. The results of the MEPDG model predicted performance model are sensitive enough to site location, bound and unbound materials. The trends between model prediction and actual field results are very close and the deviations are within the margin of error. The deviations are due to the absence of a working module that captures the non-linear behaviour of the unbound material characterization.

\subsection{Recommendations:}

This study recommends the following:

1. Introducing non-linear analytical methods to improve model sensitivity, since the current model employs linear elastic analysis with permanent deformation prediction depending on empirical models.

2. Locally calibrating the transfer function by applying appropriate parameters that enable the predicted distress to match field observations. Such a process will be needed in the calibration of the proposed guide before it can be used with confidence. 
3. The M-EPDG creep compliance model as a measure of thermal cracking needs to be improved. Low temperature of asphalt concrete continues to be a prevalent cause of permanent deterioration in asphalt pavement in cold regions. The model was found not to be functioning in this study. Further refinement of the M-EPDG creep compliance model is necessary. 


\section{REFERENCES}

1. AASHO design guide, 1961. AASHO Interim Guide for the Design of Flexible Pavements. American association of state highway and transportation officials, Washington, D.C.

2. AASHO design guide, 1962. AASHO Interim Guide for the Design of Rigid Pavements. American association of state highway and transportation officials, Washington, D.C.

3. AASHTO Interim guide, 1972. AASHTO Interim guide for design of pavement structures. American Association of State Highway and Transportation Officials, Washington, D.C.

4. AASHTO guide for design pavement structures 1986. American association of state highway and transportation officials, Washington, D.C.

5. AASHTO guide for design pavement structures 1993. American association of state highway and transportation officials, Washington, D.C.

6. AASHTO guide for design pavement structures 1983. American association of state highway and transportation officials, Washington, D.C.

7. AASHTO standard test designation T-294, 1992. Resilient modulus of unbound granular base and sub base materials and sub grade soils. SHRP protocol P 46, American Association of State Highway and Transportation Officials.

8. AASHTO T307, 2003. Standard method of test for determining the resilient modulus of soils and aggregate materials, Washington, D.C.

9. AASHTO TP62, 2003. Standard method of test for determining dynamic modulus of hot-mix asphalt concrete mixtures. American association of state highway and transportation officials, Washington, D.C.

10. AASHTO T322, 2003. Standard method of test for determining the creep compliance and strength of hot-mix asphalt using the indirect tensile test device.

11. AASHTO T99, 2015. Standard method of test for moisture density relations of soils using A $2.5 \mathrm{~kg}(5.5 \mathrm{lb})$ rammer and A $305 \mathrm{~mm}$ (12 in.) drop. American association of state highway and transportation officials, Washington, D.C.

12. AASHTO T166, 2015. Standard method of test for bulk specific gravity of compacted asphalt mixtures using saturated surface dry. American association of state highway and transportation officials, Washington, D.C.

13. AASHTO T209, 2015. Standard method of test for theoretical maximum specific gravity and density of hot mix asphalt. American association of state highway and transportation officials, Washington, D.C. 
14. AASHTO T269, 2011. Standard method of test for percent air voids in compacted dense and open asphalt mixtures. American association of state highway and transportation officials, Washington, D.C.

15. AASHTO PP2, 2000. Standard practice for mixture conditioning of hot mix asphalt. American association of state highway and transportation officials, Washington, D.C.

16. AASHTO T88, 2010. Standard method of test for particle size analysis of soils. American association of state highway and transportation officials, Washington, D.C.

17. Abd El Halim, A. O., 1985. Influence of relative rigidity on the problem of reflection cracking, Transportation Research Record No. 1007.

18. Akram, T.T.; Scullion, R.E. Smith and Fernando, E. G., 1992. Estimating damage effects of dual vs. wide base tire with multi depth reflectometers. Transportation research record 1355. Transportation research board. Washington D. C.

19. Amini, F., 2003. Potential applications of dynamic and static cone penetrometers in MDOT pavement design and construction. Final report for Mississippi department of transportation, Jackson State University, Jackson, Miss.

20. Asphalt institute, 1991. Thickness design asphalt pavements for highways and streets annual series No. 1, Lexington, KY.

21. ASTM D4123, 1999. Standard test method for indirect tension test for resilient modulus of bituminous mixtures (ASTM), 100 Barr Harbor Drive, PA 19428-2959, USA.

22. Barksdale, R.D., 1972. Laboratory evaluation of rutting in base course materials. Proc., $3^{\text {rd }}$ international conference on asphalt pavements, University of Michigan, Ann Arbor, pp. 161-174.

23. Brown, S.F., 1974. Repeated load testing of a granular material. Journal of the geotechnical engineering division, Vol. 100, No. 7, pp. 825-841.

24. Brown, S.F., 1996. Soil mechanics in pavement engineering, geotechnique, Vol. 46, No. 3, pp. 383-426.

25. Brown, S. F., 1977. Development in highway pavement engineering: Chapter 2Material characterization for analytical pavement design, pp, 41-92.

26. Choubane, B. and R.L. McNamara, 2000. Flexible pavement embankment moduli using falling weight deflectometer (FWD) data, research report FL/DOT/SMO/00442, state materials office, Florida department of transportation, Tallahassee.

27. Clyne, T., R.; Li, X.; Marasteanu, M., O.; Skok, E., L., 2003. Dynamic and resilient modulus of MN/DOT asphalt mixtures, technical report. Minnesota department of transportation, office of research services, $p p 78$.

28. Dawson, A. R., 1994. The EMU system users manual. Second edition university of Nottingham. 
29. Dawson, A.R., Janoo, V., Irwin, L., Knuth, K. and Eaton, R., 1999. Use of inductive coils to measure dynamic and permanent pavement strains. Proceedings of the accelerated pavement testing conference, Reno, Nevada.

30. Di Benedetto, H. and De La Roche, C. 1998. State of the art on stiffness modulus and fatigue of bituminous mixtures. RILEM Report 17. Taylor and Francis, London, UK. Pp. 69-118.

31. Drumm, E. C., Reeves, J. S., Madget, M. R. and Trolinger, W. D., 1997. Sub-grade resilient modulus correction for saturation effects. Journal of geotechnical engineering, ASCE, 123(7), 603-670.

32. ElHussein, H. Mohamed; Zeghal, M. and Khogali, W.E.I., 2006. Pavement material database- a tool to facilitate implementation of the new mechanistic empirical pavement design guide. Annual conference of the transportation association of Canada Charlottetown, Prince Edward Island.

33. ElHussein, H. Mohamed, Nofal, M., 1997. Mechanistic approach to pavement analysis. Advanced technologies in asphalt pavement engineering, Chun Chon, Korea, August 29, pp. 21-49.

34. Gancalves, F. P.; Ceratti, J. A. P. and Bica, A. V. D., 2003. The use of embedded stress cells for monitoring pavement performance. Geotechnical Testing Journal, Vol. 26, No.4.

35. Hajek, J. J., 1994. General axle load equivalency factors. The transportation research record No. 1482, pp. 67-78

36. Heck, J.V.; Piau, J. M.; Gramsammer, J. C.; Kerzreho, J. P. and Odeon; H., 1998. Thermo-visco-elastic modeling of pavements behaviour and comparison with experimental data from LCPC test

37. Heukelom, W., and Klomp, A.J.G., 1964. Road design and dynamic loading. Journal of the association of asphalt paving technologists, Vol. 33.

38. Heydinger, A. G., 2003. Evaluation of seasonal effects on sub-grade soils. Transportation Research Record 1821.

39. Hopman, P. C., 1996. VEROAD: A viscoelastic multilayer computer program. 75 th TRB meeting, Transportation Research Record 1539, Washington D.C. USA, pp. 7280.

40. Huang, Y.H., 1993. Pavement analysis and design. Prentice Hall, Inc., EnglewoodCliffs, N.J.

41. Johanneck, L. and Khazanovich, L., 2010. Comprehensive evaluation of effect of climate in Mechanistic-Empirical Pavement Design Guide predictions. Journal of transportation research board, No. 2170, Transportation research board of the national academies, Washington, D.C., pp, 45-55.

42. Johanneck, L.; Tompkins, D.; Clyne, T. and Khazanovich, L., 2011. Minnesota road research data for evaluation and local calibration of the Mechanistic-Empirical Pavement Design Guid'e Enhanced Integrated Climatic Model. Journal of 
transportation research board, No. 2226, Transportation research board of the national academies, Washington, D.C., pp, 30-40.

43. Kim, Y. R. and Daniel, J. S., 1997. Development of a mechanistic fatigue prediction model for aging asphalt-aggregate mixtures. Final report submitted to Western Research Institute.

44. Kim, Y. R. and Little, D. N., 1990. One dimensional constitutive modeling of asphalt concrete. Journal of engineering mechanics, ASCE, 11694), 751-772.

45. Knuth, K., 2001. Resistivity probe operation work instruction. USA cold regions research and engineering laboratory, Hanover, N. H.

46. Lee, H. J., 1996. Uniaxial constitutive modeling of asphalt concrete using viscoelasticity and continuum damage theory. Ph.D. Dissertation, North Carolina State University, Raleigh, NC.

47. Lee, H.J. and Kim, Y.R., 1997. A viscoelastic constitutive model of asphalt concrete under cyclic loading. Journal of engineering mechanics, ASCE.

48. Lee, H. J. and Kim, Y. R., 1998. Viscoelastic constitutive model for asphalt concrete under cyclic loading. ASCE Journal of engineering mechanics, Vol. 124, No. 11, pp. 1224-1232.

49. Lu, Y. and Wright, P., 1998. Numerical approach of viscoelasoplastic analysis for asphalt mixtures. Comp. and Struct., 69(2), 139-147

50. Maadani, O.; Abd El Halim, A. and Mostafa, N., 2014. Instrumentation for monitoring pavement performance in cold regions. Journal of cold regions engineering. 10.1061/(ASCE)CR. 1943-5459.000087, 04014017. American Society of Civil Engineers

51. Martin, H. S. and Qingli, D., 2005. A comparison of micro-mechanical modeling of asphalt materials using finite elements and doublet mechanics. Mechanics of Materials 37, 641-662.

52. Ministry of Transportation of Ontario laboratory testing manual, MTO LS 309, 2013. Practice for superpave mix design.

53. Ministry of Transportation of Ontario, MTO, 2013. Pavement design and rehabilitation manual, Ontario.

54. Monismith, C. L. and Finn, F. N., 1977. Flexible pavement design: State of the art1975. Journal of transportation engineering. V. 103, No1, pp, 1-53.

55. Monismith, C.L., 1992. Part 1, TRB distinguished lecture. Transportation research record 1354, TRB, National Research Council, Washington DC.

56. NCHRP. 2004. Guide for mechanistic-empirical design of new and rehabilitated pavement structures (MEPDG). Project 1-37A. Transportation Research Board, national Research Council, Washington, D.C.

57. NCHRP, 1997. Laboratory determination of resilient modulus for flexible pavement design. Final report, NCHRP project 1-28, USA. 
58. Neiber, J.L. and Baker, J.M., 1989. In-situ measurement of soil water content in the presence of freezing/thawing conditions. State of the art of pavement response monitoring systems for roads and airfields, Spec. Rep. 89-23, Janoo, V. and Eaton, R. eds. USA Cold Regions Research and Engineering Laboratory, Hanover, N.H.

59. Ontario Provincial Standard Specification, OPSS, 2013. Material specification for aggregate hot mix asphalt.

60. Perl, M.; Uzan, J. and Sides, A., 1983. Viscoelastoplastic constitutive law for a bituminous mixture under repeated loading. Transportation research record 911, TRB, National Research Council, Washington, D.C., pp.20-27.

61. Robin, M. A. and Wei, Z., 1997. Construction instrumentation and load testing of the Danish road testing. National Research Council U. S. Transportation Research Board, Meeting, 76. Washington D. C.

62. Salgado, R. and Yoon, S., 2002. Dynamic cone penetration test for sub-grade assessment, Research report FHWA/IN/JTRP-30, Purdue University, West Lafayette, Ind.

63. Sayegh, G., 1967. Viscoelastic properties of bituminous mixtures. Proceedings of the $2^{\text {nd }}$ international conference on structural design of asphalt pavement, pp. 743-755. Held at Rackham Lecture Hall, University of Michigan, Ann Arbor, USA.

64. Schapery, R.A. 1984. Correspondence principles and a generalized J-integral for large deformation and fracture analysis of viscoelastic media. International Journal of fracture mechanics, 25, 195-223.

65. Schapery, R. A. and Park, S. W., 1999. Methods of interconversion between linear visco-elastic material functions. Part II-an approximate analytical method." International Journal of solids and structures, Vol. 36, pp.1677-1699.

66. Sides, A.; Uzan, J. and Perl, M., 1985. A comprehensive viscoelastic-plastic characterization of sand-asphalt compressive and tensile cycling loading. J. Testing and evaluation, 13(1), pp49-59

67. Statistics Canada agency, 2003. Local government financial management statisticscapital expenditures. Index 1733.

68. Tarefde, R.A and Zaman, M., 2003. Correlating asphalt concrete modulus with rut potential. Proc. third international symp. on maintenance and rehabilitation of pavements and technological control, Portugal, Vol. 1, pp. 207-217.

69. Uzan, J., 1985. Characterization of granular material. In transportation research record 1022, TRB, National Research Council, Washington, D.C., pp. 52-59.

70. Uzan, J., 1996. Asphalt concrete characterization for pavement performance prediction. Journal asphalt paving technology, AAPT, Volume 65, pp573-607.

71. Van Til, C.J., McCullough, B.F., Vallerga, B.A., and Hicks, R.G., 1972. Evaluation of AASTHO Interim Guides for Design of Pavement Structures. NCHRP Report 128. Highway Research Board, Washington, D.C. 
72. Witczak, M. W. and Fonseca, O. A., 1996. Revised predictive model for dynamic (complex) modulus of asphalt mixtures. Transportation research record, 1540: 15-23.

73. Wright, P. and Zheng, L., 1994. Visco-elasto-plastic behaviour of a hot rolled asphalt mixture under repeated loading and the effects of temperature. $4^{\text {th }}$ international conference, bearing capacity of roads and airfields, Minneapolis, MN, pp 1035-1065.

74. Zeghal, Morched; Adam, Yassin; Ali, Osman and Mohamed, ElHussein, 2005. Review of the new mechanistic-empirical pavement design guide-a material characterization perspective. Annual conference of the Transportation Association of Canada, Calgary, Alberta.

75. Zeghal, Morched and ElHussein H., Mohamed, 2008. Assessment of analytical tools used to estimate the stiffness of asphalt concrete. Ca. J. Civ. Eng. 35: 268-275. 